DEPARTAMENTO DE INGENIERÍA DE ORGANIZACIÓN, ADMINISTRACIÓN DE EMPRESAS Y ESTADÍSTICA

ESCUELA TÉCNICA SUPERIOR DE INGENIEROS INDUSTRIALES

\title{
Metodología del Marco Lógico con Enfoque de Gestión de Riesgos para mejorar la eficacia de los Proyectos de Cooperación al Desarrollo
}

\author{
Tesis Doctoral
}

\author{
Autora: Rocío Rodríguez Rivero \\ Ingeniera Industrial por la Universidad Politécnica de Madrid
}

Directora: Isabel Ortiz Marcos

Doctora Ingeniera Industrial por la Universidad Politécnica de Madrid 

Tribunal nombrado por el Magfco. y Excmo. Sr. Rector de la Universidad Politécnica de Madrid, el día de de 2019.

Presidente:

Vocal:

Vocal:

Vocal:

Secretario:

Suplente:

Suplente:

Realizado el acto de defensa y lectura de la tesis el día ....... de de 2019 en la E.T.S. Ingenieros Industriales de la Universidad Politécnica de Madrid.

CALIFICACIÓN:

EL PRESIDENTE

LOS VOCALES

EL SECRETARIO 

Hoy día está de moda hablar de los pobres.

Por desgracia no lo está hablarles a ellos.

Teresa de Calcuta. 



\section{Agradecimientos}

Al concluir este documento me acuerdo con mucho cariño y agradecimiento de todas las personas que me han acompañado en este camino y han contribuido de una $u$ otra manera a la elaboración de esta tesis.

En primer lugar, quiero dar las gracias a Isabel Ortiz, mi directora de tesis y, por encima de todo, mi amiga. Gracias por tu altísima calidad humana, por tu compromiso y por tu sensibilidad. Gracias por ser como eres y por estar a mi lado en todo momento transmitiéndome la confianza y el cariño para poder afrontar cualquier reto. Gracias por cada una de las oportunidades que me has ofrecido. Sin ti esto nunca habría empezado.

En segundo lugar, quiero agradecer a todas las instituciones que han hecho más fácil el camino del doctorado y, principalmente, a todas las personas que hacen grandes a esas instituciones.

Gracias a la Dirección de Cooperación al Desarrollo de la Universidad Politécnica de Madrid por su ayuda económica para los viajes a Colombia, así como por su interés en la evaluación de los proyectos. Gracias especialmente a Manuel Sierra y Elena López por su dedicación y cercanía, y por la noble labor que hacen en esta universidad.

Gracias al Consejo Social por su ayuda económica para la estancia en la Universidad de Sussex, especialmente a Carlos Pérez por su apoyo en la tramitación.

Gracias a la Escuela Técnica Superior de Ingenieros Industriales por volverme a acoger con más ganas que nunca. Gracias por su ayuda económica para la estancia de investigación en Colombia y por la flexibilidad prestada en su compromiso con la formación y la internacionalización. Gracias al Doctorado de Ingeniería de Organización por su labor encomiable de apoyo y supervisión constante, especialmente a María Jesús Sánchez, a quien agradezco además su apoyo personal y su involucración en esta investigación, a Ruth Carrasco y a Teresa Sánchez. Gracias también a la Biblioteca de Industriales por su profesionalidad y disponibilidad. Gracias, por supuesto, al Departamento de Ingeniería de Organización, Administración de Empresas y Estadística por apoyar todas las peticiones de estancias que he solicitado, especialmente a Camino González por sus consejos, su cariño, y sus ganas de siempre escuchar, y a Miguel Ortega. Y gracias, como no, a mis compañeros y compañeras de Proyectos por apoyarme en mis aventuras y darme flexibilidad con ellas.

Gracias también a esas instituciones que me han acogido fuera. A Unicomfacauca por ser una gran familia que trabaja desde la humildad para ser un poquito más grandes cada día. Especialmente por su cálida acogida agradezco a Victoria Patiño y Pablo López, quienes me abrieron sus puertas y su corazón. Agradezco también a Sergio A. Lozano por su manera generosa de compartir y enseñar, y por haberme introducido en el apasionante mundo de la prospectiva. 
Gracias a la Universidad de Sussex por permitirme enriquecer mis conocimientos sobre sostenibilidad. Especialmente a Andy Stirling por sus motivadoras charlas y sus consejos, pero, sobre todo, por hacerme sentir un miembro más de su familia.

En tercer lugar, me gustaría agradecer a todas aquellas personas que han colaborado de manera directa en los resultados de esta investigación.

Gracias a los responsables de los proyectos de cooperación de la universidad por vuestras respuestas, pero, sobre todo, por seguir dedicando tiempo y esfuerzo a estos proyectos. Gracias a todos aquellos profesionales anónimos de la cooperación que habéis contestado el cuestionario del Marco Lógico. Gracias a Xavier Palau por su tiempo, amabilidad y buenos consejos. Gracias a Mónica Salazar por su dedicación, amistad y por transmitirme la pasión por su trabajo. Gracias a Pablo Pérez por el interés en esta investigación y por implicar en ella a la Gobernación del Cauca.

Gracias a los directores y directoras de los proyectos en el Cauca, por las facilidades prestadas para el estudio de los proyectos y la realización de los talleres. Gracias Sergio, Paulo, Mari Sol, Yanet y Mónica porque sin vuestra ayuda y la de vuestros equipos esto no hubiera sido posible. Gracias también a Comfacauca por su buena disposición a ayudar en todas las gestiones, especialmente a Mari Sol Velasco, Héctor Leonardo Morales y Juan Camilo Rosero.

Gracias también a los ocho profesionales que han dedicado su tiempo a leer la metodología propuesta y a hacerla más útil y valiosa con sus aportaciones. Gracias Xavier, Julia, David, Pablo, Gabriel, Javier, Mónica y Álvaro.

Gracias a Javier Romero por su ayuda y supervisión con la metodología difusa y por el cariño con el que me ha tratado.

Gracias a Virginia Díaz por apostar por mí y por esta tesis en sus comienzos. Gracias por todas las oportunidades de crecimiento que me has dado y por compartir tu experiencia en Cauca conmigo.

En cuarto lugar, tengo que agradecer por su paciencia y amor a todas aquellas personas que con su amistad me acompañan cada día y han sufrido más que nadie mi ocupación.

Gracias a las personas de la Escuela que me quieren y me cuidan. Aunque sé que son muchas y ya he citado a unas cuantas, no me quiero olvidar de destacar la confianza y generosidad que han mostrado conmigo y las oportunidades que me han abierto Suso, Andrés y Cándido.

Gracias a mis anteriores compañeros y compañeras de Empresarios Agrupados por apoyarme en mi decisión y seguir la evolución de este trabajo con vuestro sincero cariño.

Gracias Luis por abrirme tantas puertas dentro y fuera de la Escuela, por cuidarme y por quererme como haces, gracias por ser mi hermano del alma y mi compañero de muchas 
aventuras. Gracias Cristina por ser mi otra hermana, que también me cuida y siempre está ahí. Gracias a los dos por todas las emociones que sacáis en mí. Gracias tito Ángel por cuidarnos a Luis y a mí, y velar porque nuestro camino sea lo más llevadero posible. Gracias José Ramón por iniciar tú el camino.

Gracias Irene por tu apoyo incondicional y tu ejemplo, por ser también hermana de vida y porque estoy segura de que con nuestros viajes se empezó a cuajar el cambio (creo que Cova sonríe). Gracias a ti y a tu familia por confiar en mí y quererme tanto.

Gracias Nuria por compartir conmigo los años en Ecuador y el resto de las aventuras que sin duda me hicieron pensar, sentir y vivir de otra manera. Gracias Vicenta por vivirlo con nosotras. Gracias Maite por tu apoyo y guía. Gracias a la Comunidad de Vizcaya por enseñarme a estar. Gracias a los amigos y amigas de Acción Verapaz por introducirme en todo esto.

Gracias Elvira por apoyarme tantos y tantos años en cada decisión y estar siempre disponible cuando lo he necesitado. Gracias Esther por anteponer siempre los valores y por querer siempre lo mejor para mí.

Gracias Anabella por confiar tanto en mí, hasta el punto de hacerme madrina de Aitana. Gracias Bea y Pablo por todo vuestro cariño y apoyo, especialmente en estos años de tesis.

Gracias Olga, Henar e Isabel por estar ahí y engrandecer cada paso que doy. Gracias Ruth por ser tan inspiradora e involucrarme en tantas aventuras. Gracias Blanquita, Sara, Ro y Crispu por transmitirme tanta pasión y apoyar y difundir todas mis ideas. Gracias Itxas por tu siempre disponibilidad y tus constantes ánimos.

Por último, y por supuesto no menos importante, tengo que agradecer a mi familia su apoyo incondicional en todas mis decisiones. A mis padres por haberme enseñado siempre a ser y no a tener, y por haberme demostrado que la generosidad puede no tener límites. A vosotros os debo la extensión de este apartado por inculcarme que ser agradecida es de bien nacida. Gracias y siempre gracias por vuestro ejemplo. A mi hermana por su ejemplo, por su generosidad y por ser una constante fuente de conocimiento e inspiración. Gracias a ti y a Kitty por vuestra cálida acogida durante mi estancia en Brighton, y por vuestra valiosa ayuda con las revisiones del inglés.

Gracias también a mis abuelos que, aunque no estén ya aquí, sus consejos me acompañan día a día.

Me gustaría acabar dándole las gracias a la vida y a sus oportunidades, por haberme puesto delante un camino por el que fluyo feliz, y a mí misma, por haber sido valiente y elegirlo.

GRACIAS. 



\section{ÍNDICE}

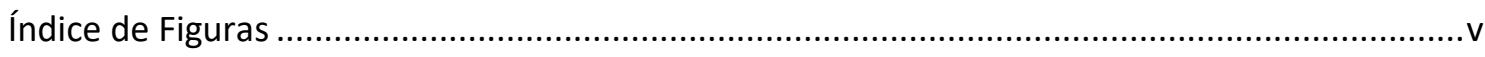

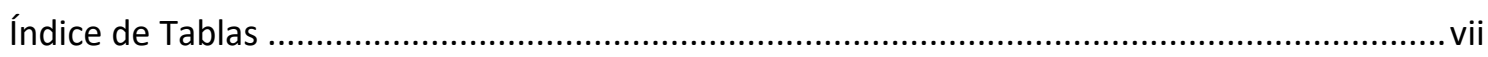

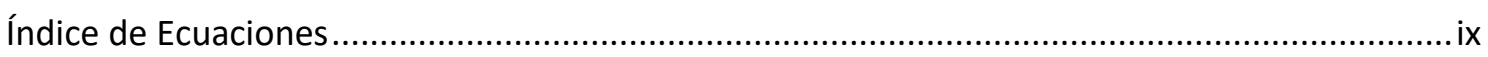

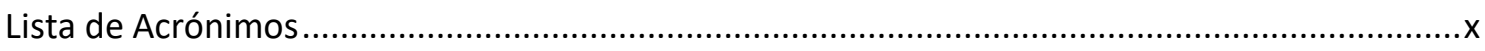

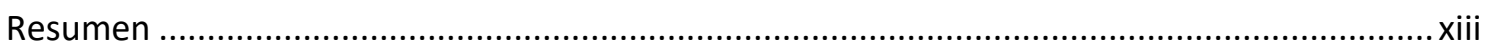

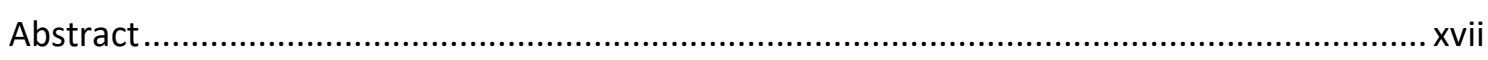

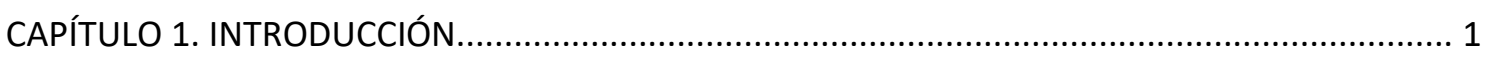

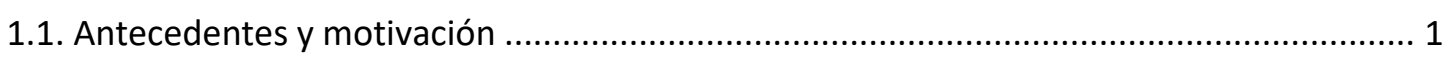

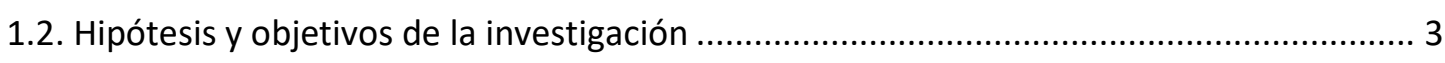

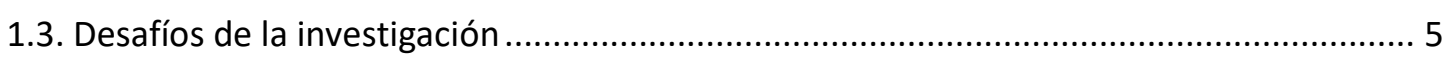

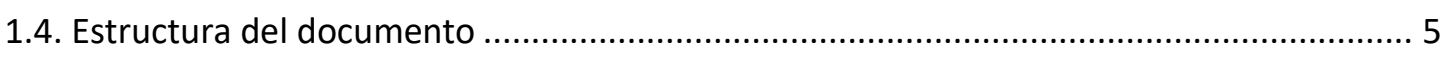

CAPÍTULO 2. LOS PROYECTOS DE COOPERACIÓN AL DESARROLLO ............................................ 7

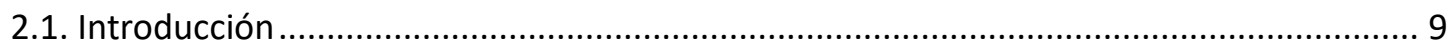

2.2. Los retos de la cooperación internacional al desarrollo ................................................ 9

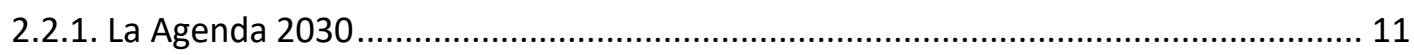

2.2.2. Renovación de los actores: nuevos países donantes y nuevas asociaciones ........... 14

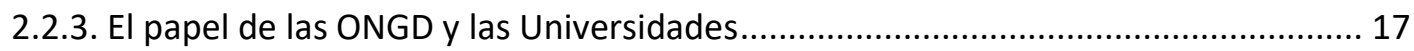

2.3. Particularidades de los proyectos de cooperación al desarrollo ..................................... 18

2.3.1. Evolución de los proyectos de cooperación al desarrollo......................................... 20

2.4. La dirección de proyectos en la cooperación al desarrollo............................................. 22

2.4.1. Herramientas y guías de dirección de proyectos en cooperación.............................. 24

2.4.2. Competencias del director de proyectos en intervenciones de desarrollo ............... 25

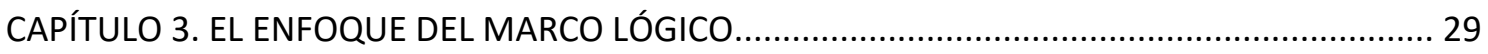

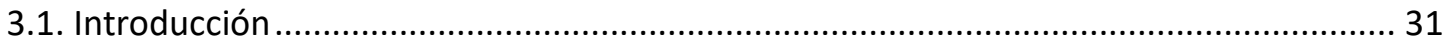

3.2. Origen y evolución del Marco Lógico.......................................................................... 31

3.3. Características del Marco Lógico: limitaciones y fortalezas ............................................ 37

3.4. Propuestas de nuevas versiones en torno al Marco Lógico............................................. 39

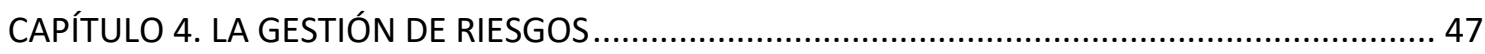

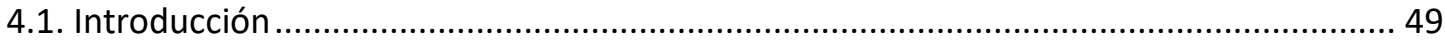

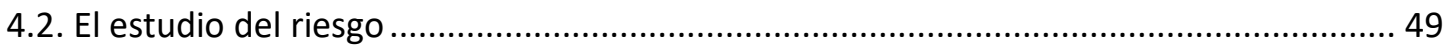

4.2.1. El riesgo en la dirección de proyectos................................................................. 50

4.2.2. Relación entre los riesgos y el éxito del proyecto................................................... 53

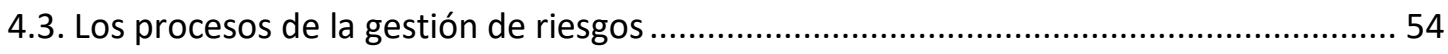




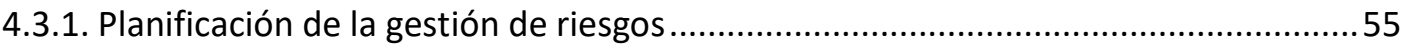

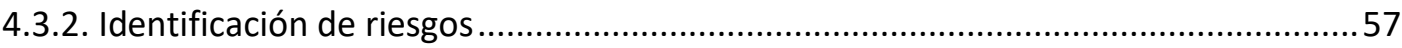

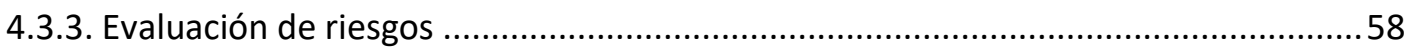

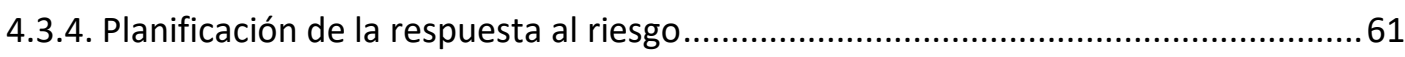

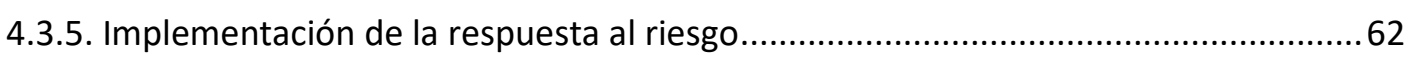

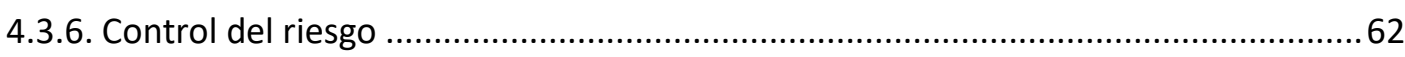

4.4. Gestión de riesgos en los proyectos de cooperación al desarrollo ...................................63

4.4.1. La importancia de los factores culturales...............................................................64

4.4.2. La gestión de riesgos en contextos de incertidumbre.............................................67

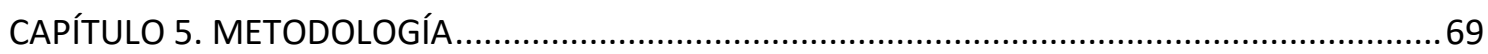

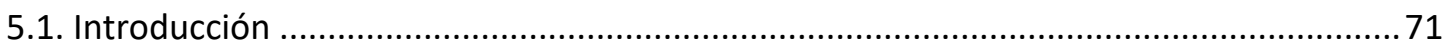

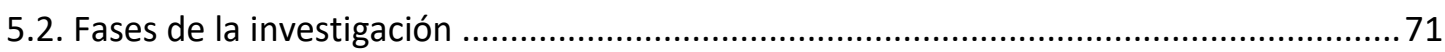

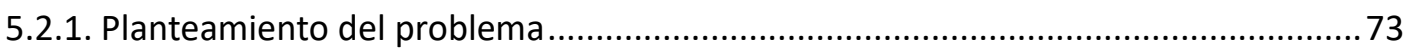

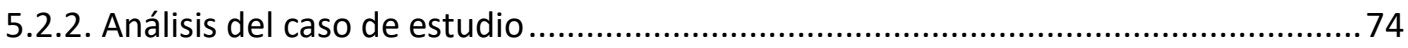

5.2.3. Diseño de la metodología propuesta .................................................................. 76

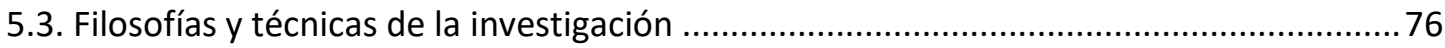

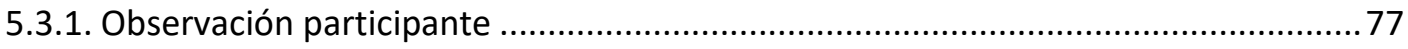

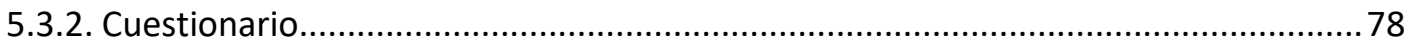

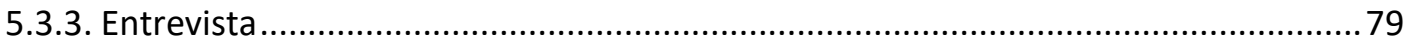

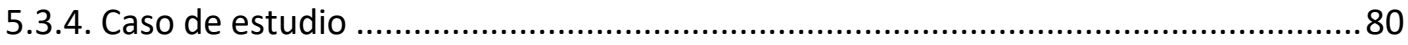

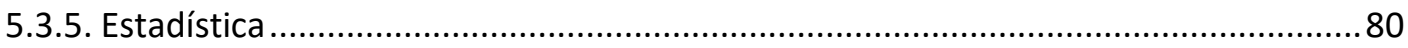

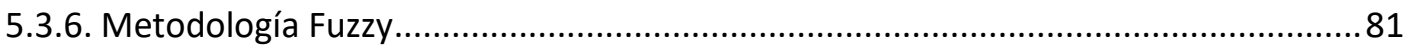

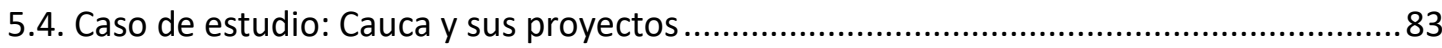

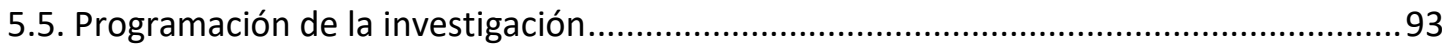

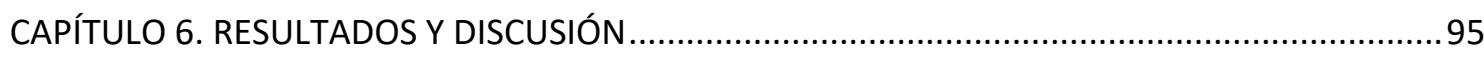

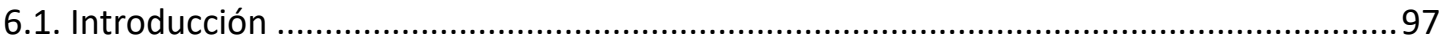

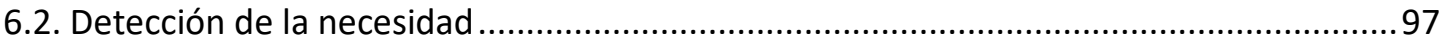

6.2.1. Caso de estudio Universidad Politécnica de Madrid ...............................................97

6.2.2. Análisis del cuestionario del Marco Lógico con profesionales .................................104

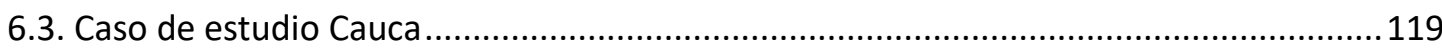

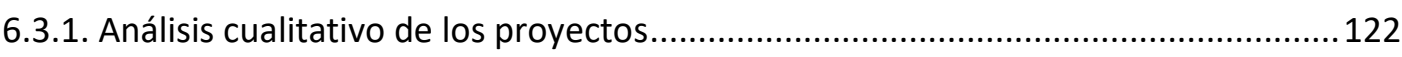

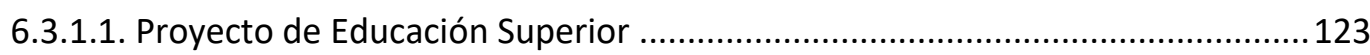

6.3.1.2. Proyecto de creación y fortalecimiento de industrias culturales ......................129

6.3.1.3. Proyecto de emprendimiento con población desplazada .................................134

6.3.1.4. Proyecto de empoderamiento de las mujeres rurales ....................................138 
6.3.1.5. Proyectos en Espacios Territoriales de Capacitación y Reinserción (ETCR)..... 143

6.3.1.6. Reflexiones conjuntas 148

6.3.2. Análisis a través de la metodología fuzzy 151

6.3.2.1. Representatividad de la muestra 151

6.3.2.2. Elección de las variables 151

6.3.2.3. Preparación de las variables 154

6.3.2.4. Análisis de las condiciones necesarias 155

6.3.2.5. Análisis de las condiciones suficientes. 158

6.3.2.6. Resumen de resultados y validación 171

6.4. Registro de riesgos 173

6.5. Diseño de la Metodología del Marco Lógico con Enfoque de Gestión de Riesgos... 176

6.5.1. La metodología del MLEGR en el ámbito de la propia organización . 177

6.5.2. La metodología MLEGR en el ámbito de la dirección de $P C D$. 178

6.5.2.1. Gestión de Riesgos en los pasos del Marco Lógico 179

6.5.2.2. EI MLEGR como proceso participativo 183

6.5.2.3. Definir e implementar la respuesta a los riesgos 184

6.5.2.4. El control y la monitorización del registro de riesgos. 185

6.5.2.5. La asociación de los riesgos a las etapas del ciclo de vida del proyecto........... 185

6.5.3. Contraste de la Metodología del MLEGR ................................................................ 186

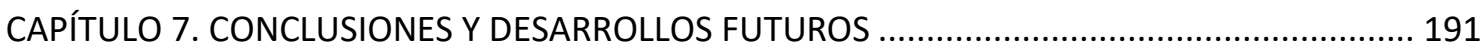

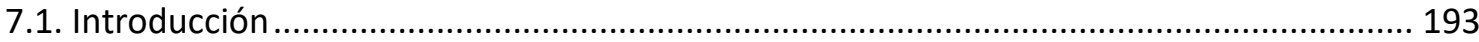

7.2. Sobre la Metodología del Marco Lógico con Enfoque de Gestión Riesgos.................... 194

7.3. Sobre la actualidad de la cooperación al desarrollo y la necesidad de eficacia ............. 196

7.3.1. Las lecciones aprendidas y los riesgos de los PCD de la UPM (OE1) ...................... 197

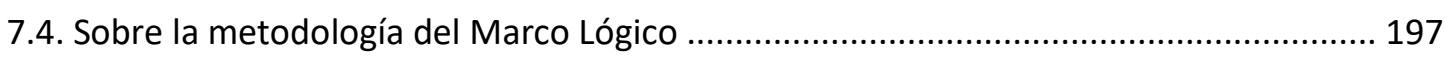

7.4.1. Fortalezas y debilidades de la metodología del Marco Lógico (OE2) .................... 197

7.5. Sobre la necesidad de incluir la gestión de riesgos........................................................ 199

7.5.1. Riesgos en el caso de estudio y vínculos con el éxito del proyecto (OE3 y OE4).... 199

7.6. Sobre la contribución de la metodología a la eficacia .................................................... 201

7.6.1. Contraste de la metodología con profesionales del sector (OE5) .......................... 201

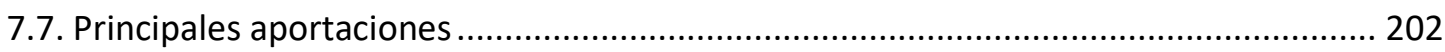

7.8. Principales dificultades y limitaciones ...................................................................... 205

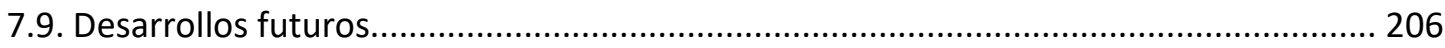

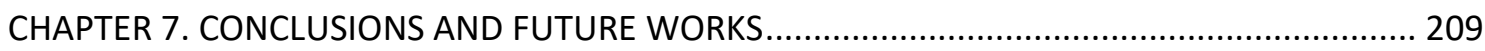

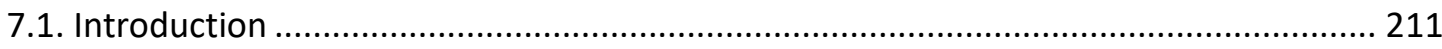


7.2. About the Logical Framework with a Risk Management Approach ..............................212

7.3. About the current situation of int. development and the need for effectiveness.........214

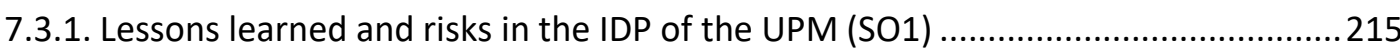

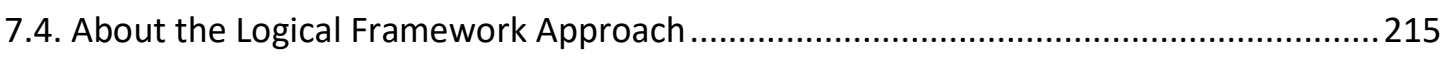

7.4.1. Strengths and weaknesses of the Logical Framework Approach (SO2) ..................215

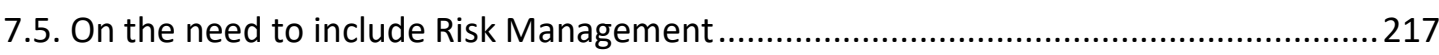

7.5.1. Risks in the case study and their links with the sucess of the project ( $\mathrm{SO} 3$ \& SO4) 217

7.6. About the contribution of the methodology to the effectiveness .................................219

7.6.1. The contrast of the methodology with professionals of the sector (SO5) ..............219

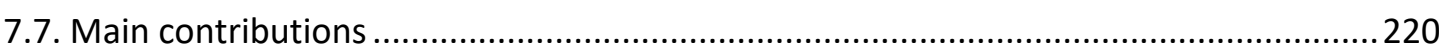

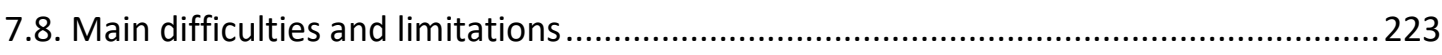

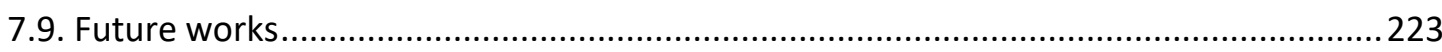

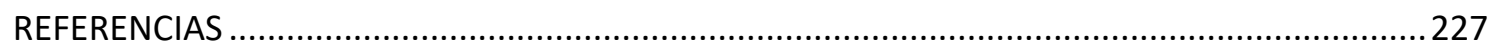

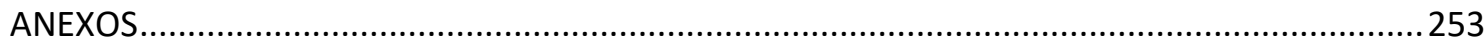

Anexo I: Plantilla de la Matriz del Marco Lógico para solicitud de proyectos europeos ......255

Anexo II: Cuestionario de evaluación de riesgos en los PCD de la UPM ...............................256

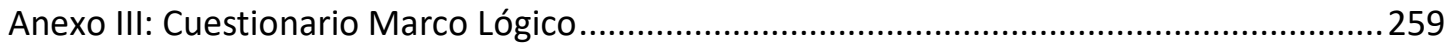

Anexo IV: Cuestionario Riesgos y Éxito para los proyectos del Cauca ..................................262

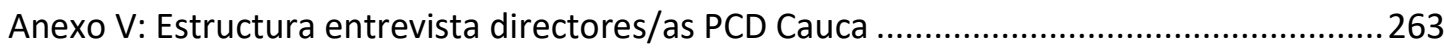

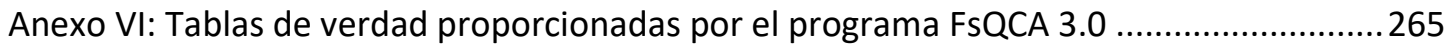

Anexo VII: Soluciones complejas proporcionadas por el programa FsQCA3.0 ......................269 


\section{Índice de Figuras}

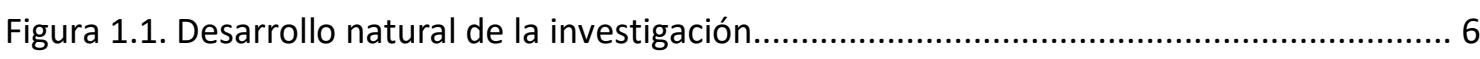

Figura 2.1. Los proyectos de cooperación al desarrollo. ....................................................... 7

Figura 2.2. Evolución de los conceptos ligados a desarrollo en las webs de investigación........ 14

Figura 2.3. Evolución de los Proyectos de Cooperación al Desarrollo....................................... 21

Figura 2.4. Los cuatro pilares de los proyectos de desarrollo de capacidades............................ 22

Figura 2.5. Las competencias más destacadas del director de un PCD ................................... 27

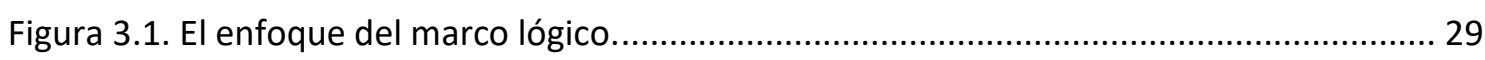

Figura 3.2. Planificación por objetivos vs planificación por actividades................................... 33

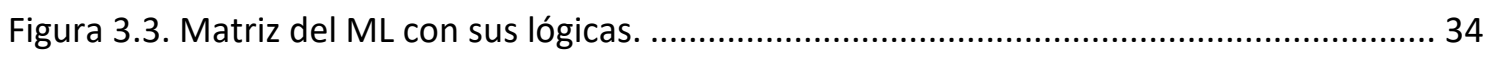

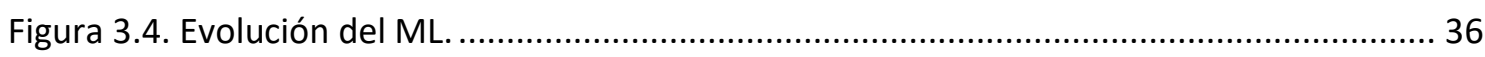

Figura 3.5. Propuesta de matriz del Marco Lógico modificada por Ika y Lytvynov. ................... 40

Figura 3.6. Propuesta de matriz del Marco Lógico del Milenio. ................................................. 40

Figura 3.7. Tres vistas de la propuesta de matriz del Marco Lógico-3D. .................................... 42

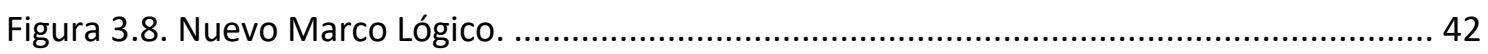

Figura 3.9. Matriz del Marco Lógico para proyectos con financiación de EuropeAid. ............... 43

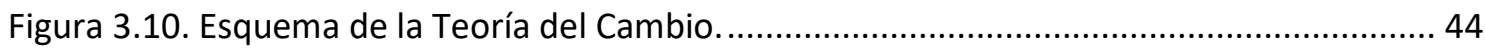

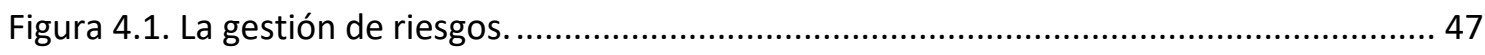

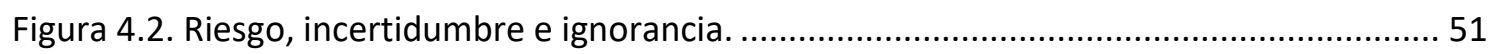

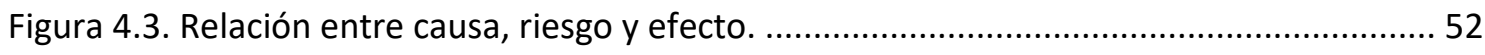

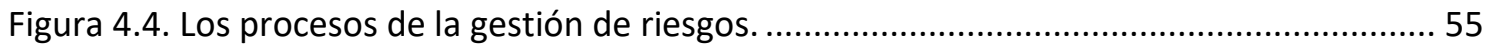

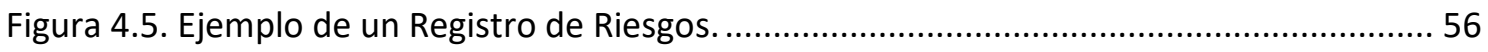

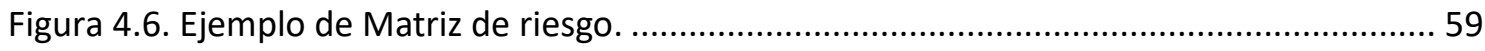

Figura 4.7. Diagrama Proximidad-Detectabilidad-Impacto de los riesgos...................................6 60

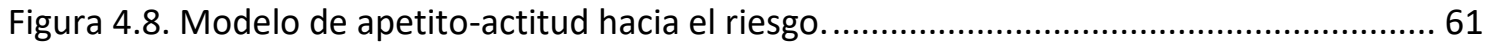

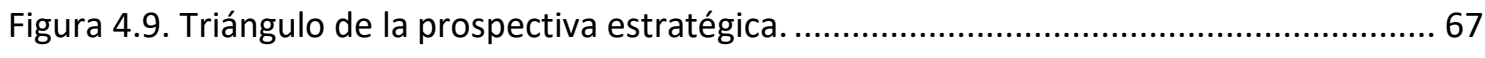

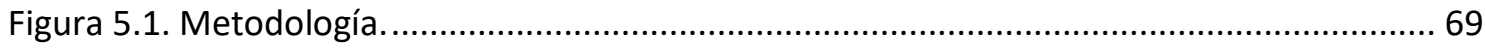

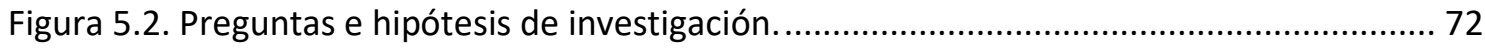

Figura 5.3. Esquema de la metodología de investigación............................................................ 72

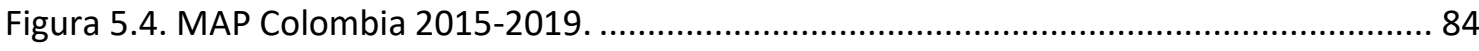

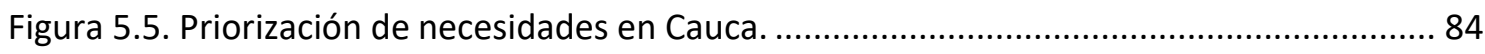

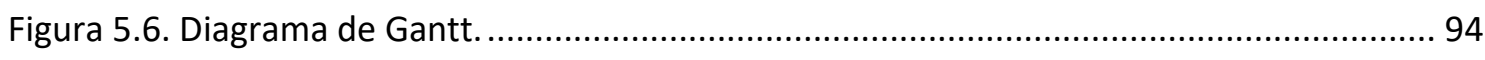

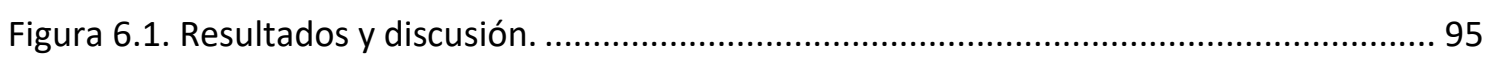

Figura 6.2. Sector de desarrollo de los PCD realizados por la UPM......................................... 98 
Figura 6.3. Porcentaje de los PCD realizados por la UPM en cada área geográfica....................99

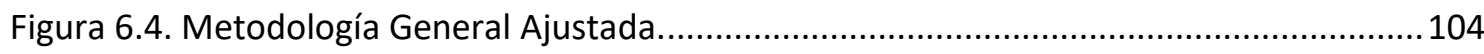

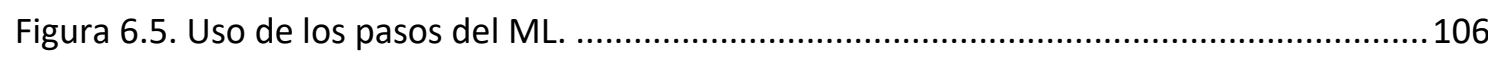

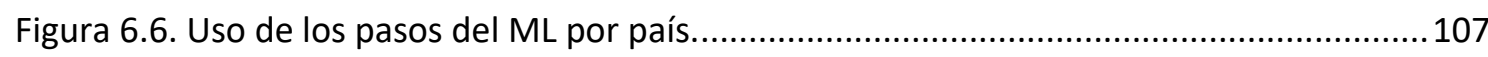

Figura 6.7. Estadística descriptiva sobre las 15 variables del cuestionario del ML..................... 109

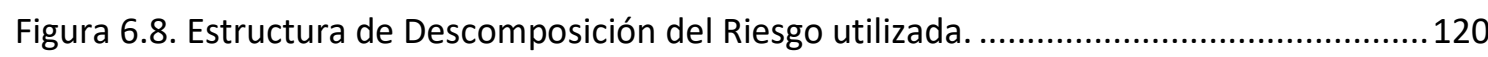

Figura 6.9. Matriz probabilidad impacto utilizada para el caso de estudio. ...............................123

Figura 6.10. Casos, condiciones y resultados utilizados en el estudio Fuzzy. ............................ 152

Figura 6.11. Posibles condiciones necesarias para alcanzar los resultados. .............................. 156

Figura 6.12. Relación entre las condiciones necesarias, suficientes y resultados.......................158

Figura 6.13. Selección de las condiciones causales para contribuir al resultado de Impacto....161

Figura 6.14. Condiciones suficientes, principales y contribuyentes: impacto ...........................163

Figura 6.15. Condiciones suficientes, principales y contribuyentes: ausencia de impacto. ......166

Figura 6.16. Condiciones suficientes, principales y contribuyentes: dirección de proyectos...169

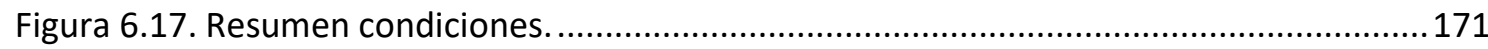

Figura 6.18. Análisis TTT para riesgos en la organización.........................................................177

Figura 6.19. Metodología del MLEGR aplicada a los pasos del ML. ......................................179

Figura 6.20. Ejemplo de cambios en la interrelación de las personas con la intervención........180

Figura 6.21. Ejemplo de matriz poder-interés..................................................................... 180

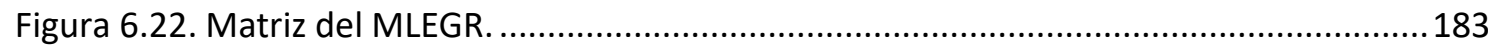

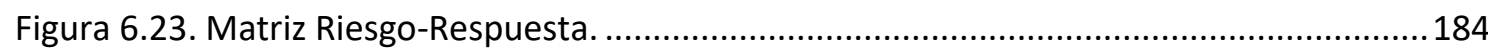

Figura 6.24. Asociación de riesgos a cada fase del ciclo de vida del PCD .................................186

Figura 6.25. Panel multiactor seleccionado para el contraste de la metodología.....................187

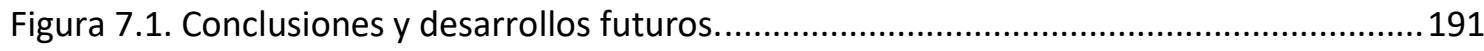

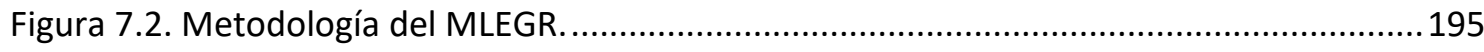

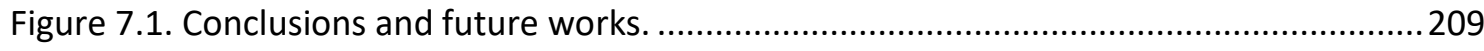

Figure 7.2. LFRMA 


\section{Índice de Tablas}

Tabla 2.1. Objetivos de Desarrollo Sostenible vs Objetivos de Desarrollo del Milenio............... 12

Tabla 2.2. Particularidades de los proyectos de cooperación al desarrollo. ............................... 19

Tabla 3.1. Algunos ejemplos de guías de uso del Marco Lógico................................................... 32

Tabla 4.1. Los procesos de la gestión de riesgos según las principales guías de DP. ................. 54

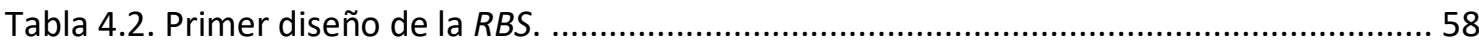

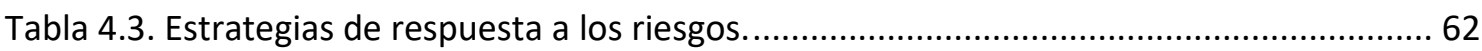

Tabla 4.4. Dimensiones culturales de los principales estudios sobre la cultura nacional. .......... 65

Tabla 5.1. Alternativas para el rediseño de las investigaciones sociales................................... 82

Tabla 5.2. Proyectos en ejecución o previstos para el Cauca.................................................. 85

Tabla 5.3. Ficha: acceso y permanencia a la educación superior en el Norte del Cauca............. 87

Tabla 5.4. Ficha: creación y fortalecimiento de industrias culturales en el Norte del Cauca..... 88

Tabla 5.5. Ficha: emprendimiento con población desplazada..................................................... 89

Tabla 5.6. Ficha: empoderamiento mujeres rurales................................................................. 90

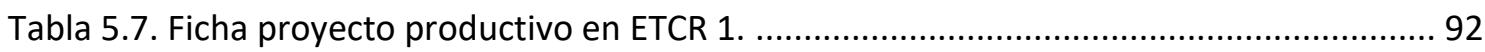

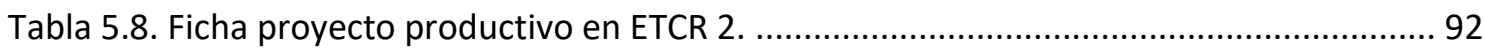

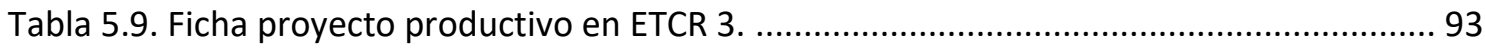

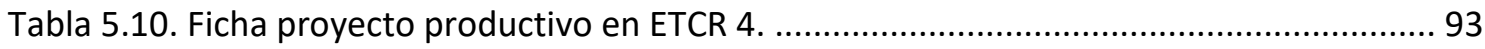

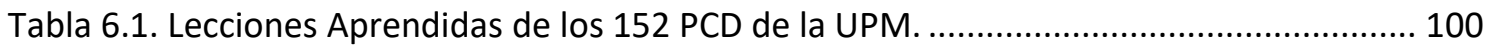

Tabla 6.2. Identificación de riesgos por Áreas Geográficas......................................................... 101

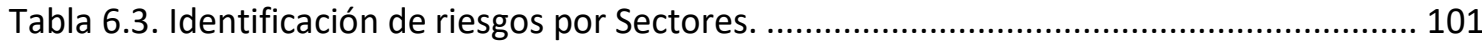

Tabla 6.4. Evaluación de riesgos por Áreas Geográficas para los 152 PCD de la UPM............ 102

Tabla 6.5. Evaluación de riesgos por Sectores para los 152 PCD de la UPM.......................... 103

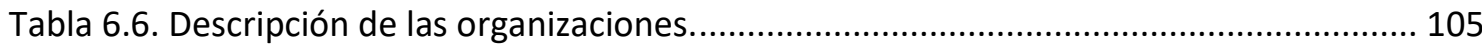

Tabla 6.7. Descripción actividad directores/as de Proyecto en los últimos cinco años. ........... 105

Tabla 6.8. Frecuencias del grado de conformidad sobre afirmaciones ML. ............................. 108

Tabla 6.9. Análisis de las correlaciones entre las variables del cuestionario del ML................ 112

Tabla 6.10. Medias para los grupos de España y Colombia........................................................ 114

Tabla 6.11. Prueba t de igualdad de medias para muestras independientes........................... 115

Tabla 6.12. p-valor del análisis de igualdad de medias............................................................ 117

Tabla 6.13. Medias para los subgrupos significativamente diferentes................................... 118

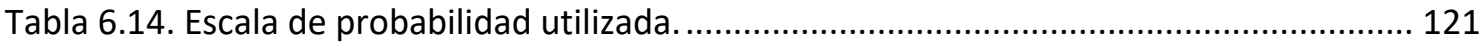

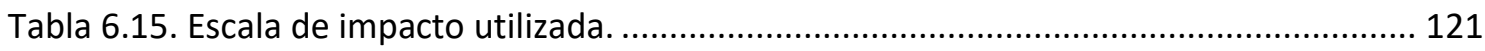

Tabla 6.16. Fases del ciclo de vida del proyecto utilizadas en el análisis. ............................... 122 
Tabla 6.17. Riesgos identificados y categorizados para proyecto de Educación Superior.........125

Tabla 6.18. Evaluación de riesgos para el proyecto de Educación Superior. ...............................127

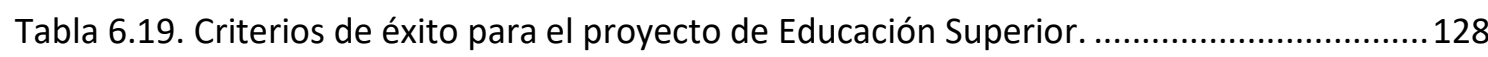

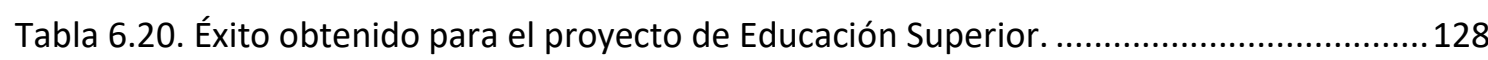

Tabla 6.21. Identificación de riesgos para el proyecto de Industrias Culturales.........................129

Tabla 6.22. Evaluación de riesgos para el proyecto de Industrias Culturales. ............................132

Tabla 6.23. Criterios de éxito para el proyecto de Industrias Culturales. ..................................133

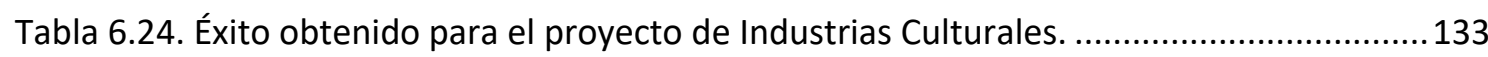

Tabla 6.25. Identificación de riesgos para el proyecto Emprendimiento con Desplazados.......134

Tabla 6.26. Evaluación de riesgos para el proyecto Emprendimiento con Desplazados. ..........136

Tabla 6.27. Criterios y niveles de éxito para el proyecto Emprendimiento con Desplazados. . 137

Tabla 6.28. Identificación de riesgos para el proyecto Empoderamiento de Mujeres Rurales.138

Tabla 6.29. Evaluación de riesgos para el proyecto Empoderamiento de Mujeres Rurales.....141

Tabla 6.30. Criterios de éxito para el proyecto Empoderamiento de las Mujeres Rurales........142

Tabla 6.31. Éxito obtenido para el proyecto Empoderamiento de Mujeres Rurales.................143

Tabla 6.32. Identificación de riesgos para los proyectos productivos en los ETCR....................144

Tabla 6.33. Evaluación de riesgos para los proyectos productivos en los ETCR. ......................147

Tabla 6.34. Criterios de éxito para los proyectos productivos en los ETCR. .............................148

Tabla 6.35. Éxito obtenido para para los proyectos productivos en los ETCR. .......................... 148

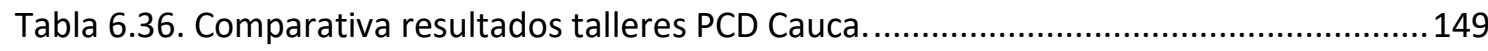

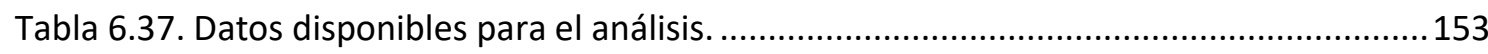

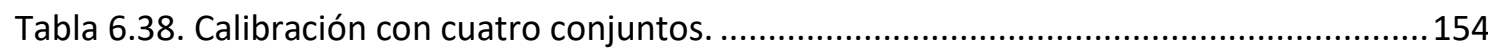

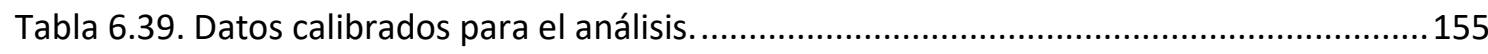

Tabla 6.40. Condiciones necesarias para los cuatro resultados................................................. 158

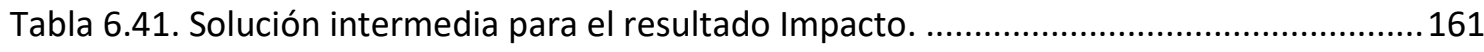

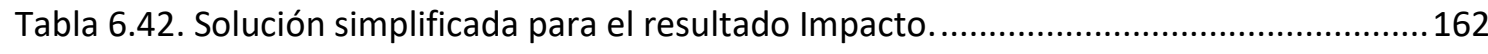

Tabla 6.43. Análisis opciones de la solución intermedia más representativa para Impacto. . 164

Tabla 6.44. Solución intermedia para el resultado de ausencia de impacto............................... 165

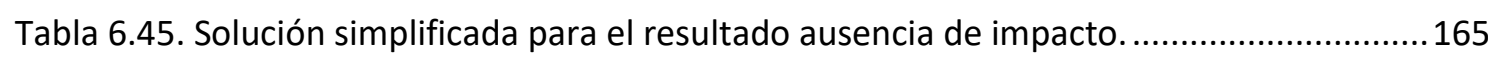

Tabla 6.46. Solución intermedia para el resultado de dirección de proyectos.......................... 167

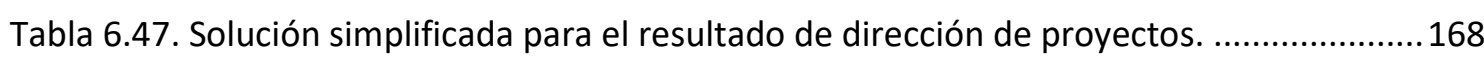

Tabla 6.48. Solución intermedia para el resultado de ausencia de éxito en la DP.....................170

Tabla 6.49. Solución simplificada para el resultado de ausencia de éxito en la DP ...................170

Tabla 6.50. Registro de riesgos por categorías para PCD en Cauca (Colombia)........................174

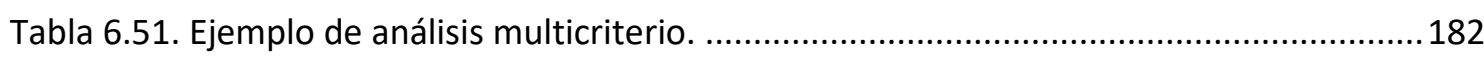




\section{Índice de Ecuaciones}

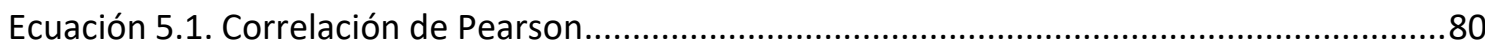

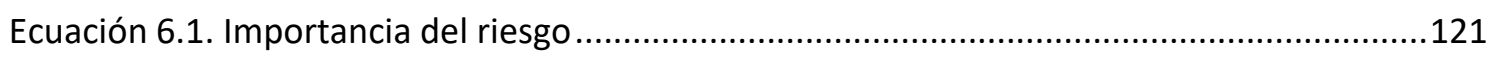

Ecuación 6.2. Importancia del riesgo con prioridad impacto en el alcance ...............................124

Ecuación 6.3. Importancia del riesgo con prioridad impacto en el tiempo ...............................144 


\section{Lista de Acrónimos}

AAAA

ADEVA

AECID

AG

AOD

AOTDS

AusAID

BID

BRICS

CAS

CEPAL

CIDA

CMAD

CMNUCC

CNUCD

COMFACAUCA

CSS

DANIDA

DNP

DP

E

EDP

EDR (RBS)

EpD

ETyT

ETCR

FAO

FARC
Agenda de Acción de Addis Abeba

Análisis de la Varianza

Agencia Española de Cooperación Internacional para el Desarrollo

Área Geográfica

Ayuda Oficial al Desarrollo

Apoyo Oficial Total para el Desarrollo Sostenible

Agencia de Cooperación Australiana

Banco Iberoamericano de Desarrollo

Asociación de los países Brasil, Rusia, India, China y Suráfrica

Sistemas Complejos Adaptativos

Comisión Económica para América Latina y el Caribe

Agencia de Cooperación Canadiense

Comisión de Medio Ambiente y Desarrollo

Convención Marco de Naciones Unidas sobre el Cambio Climático

Conferencia de las Naciones Unidas sobre Comercio y Desarrollo

Caja de Compensación Familiar del Cauca

Cooperación Sur Sur

Agencia de Cooperación Danesa

Departamento Nacional de Planeación (Colombia)

Dirección de Proyectos

Experto

Estructura de Descomposición del Proyecto

Estructura de Descomposición del Riesgo (Risk Breakdown Structure)

Educación para el Desarrollo

Educación Técnica y Tecnológica

Espacio Territorial de Capacitación y Reinserción

Organización de las Naciones Unidas para la Alimentación y la Agricultura

Fuerzas Armadas Revolucionarias de Colombia 
FsQCA

GIZ

GpRD

GR

IOV

ISO

LA

MGA

$\mathrm{ML}$

MLEGR

MML

NASA

NBD

NORAD

OCDE

OCHA

ODS

ODM

$\mathrm{OE}$

OIM

ONU

ONGD

PCD

PMI

PNUD

$\mathrm{R}$

S

SENA

SIDA

SPSS
Fuzzy set Qualitative Comparative Analysis

Agencia de Cooperación Alemana

Gestión para Resultados de Desarrollo

Gestión de Riesgos

Indicadores Objetivamente Verificables

International Organization for Standardization

Lección Aprendida

Metodología General Ajustada

Marco Lógico

Marco Lógico con Enfoque de Gestión de Riesgos

Matriz del Marco Lógico

Agencia Espacial Americana

Nuevo Banco de Desarrollo

Agencia de Cooperación Noruega

Organización para la Cooperación y el Desarrollo Económico

Oficina de Naciones Unidas para la Coordinación de Asuntos Humanitarios

Objetivos de Desarrollo Sostenible

Objetivos del Milenio

Objetivo Específico

Organización Internacional para las Migraciones

Organización de las Naciones Unidas

Organización No Gubernamental de Desarrollo

Proyectos de cooperación al desarrollo

Project Management Institute

Programa de las Naciones Unidas para el Desarrollo

Riesgo

Sector

Servicio Nacional de Aprendizaje (Colombia)

Agencia de Cooperación Sueca

Statistical Package for the Social Sciences 
TC

Teoría del Cambio

TICS

Tecnologías de la Información y la Comunicación

Unicomfacauca Corporación Universitaria COMFACAUCA

UNOSSC Oficina de las Naciones Unidas para la Cooperación Sur-Sur

UPM

Universidad Politécnica de Madrid

USAID

Agencia de Cooperación de los Estados Unidos de América 


\section{Resumen}

Inspirada por cuestiones éticas y de justicia social, esta Tesis Doctoral quiere contribuir a mejorar la eficacia de los Proyectos de Cooperación al Desarrollo.

Para ello, en la parte de revisión de la literatura, analiza, en primer lugar, las particularidades y la complejidad de los proyectos de cooperación al desarrollo. En segundo lugar, y con el reconocimiento que merecen sus 50 años de utilización en la gestión de estos proyectos, se revisa la metodología del Marco Lógico. Y, por último, el marco teórico se cierra con la revisión de la Gestión de Riesgos, un área habitual en otro tipo de proyectos y, sin embargo, muy poco abordada en el ámbito de la cooperación al desarrollo.

Con la visión más amplia que permite el profundo análisis de la literatura en los temas citados y atendiendo a la necesidad de buscar la máxima eficacia de los proyectos de cooperación al desarrollo, imprescindible para alcanzar las metas de la Agenda 2030, esta tesis se reafirma en su objetivo de desarrollar una metodología para la gestión de estos proyectos con una gestión de riesgos integrada. Con ella, se busca contribuir a incrementar la tasa de éxito de los proyectos de cooperación al desarrollo, entendida en su doble vertiente de impacto en la comunidad y de dirección del proyecto.

Para ayudar a conseguir este objetivo, el trabajo de investigación desarrollado en la Tesis Doctoral se apoya en las preguntas básicas ¿qué?, ¿para qué? y ¿cómo?, que dan lugar a las hipótesis de investigación.

Qué: mejorar el Marco Lógico por ser la metodología más utilizada en la cooperación al desarrollo. Hipótesis uno: El Marco Lógico necesita ser mejorado.

Para qué: para mejorar la eficacia de los proyectos de cooperación al desarrollo, representada en sus niveles de éxito. Hipótesis dos: El éxito de los proyectos de cooperación al desarrollo depende la buena gestión de los riesgos.

Cómo: a través de la metodología del Marco Lógico con Enfoque de Gestión de Riesgos. Hipótesis tres: El Marco Lógico con Enfoque de Gestión de Riesgos puede mejorar la eficacia de los proyectos de cooperación al desarrollo.

La metodología que permite afrontar este trabajo parte de sentar unas bases sólidas fundamentadas en trabajos anteriores. Para ello, además de más de 150 artículos científicos, se estudian 152 proyectos de cooperación al desarrollo realizados por la Universidad Politécnica de Madrid y se pregunta a sus responsables por los riesgos que sufrieron. A partir de estos primeros pasos, se consulta con 77 profesionales de la cooperación (españoles y colombianos) sobre el Marco Lógico y se demuestra que, pese a que sus fortalezas son más valoradas que las debilidades, esta metodología necesita 
ser mejorada, y que la propuesta mejor valorada para ello, es introducir la gestión de riesgos.

Los siguientes pasos se dan en terreno, en Cauca, un Departamento de Colombia que destaca por la vulnerabilidad de su población y por su riqueza étnica y cultural. Por ello, Cauca es el caso de estudio elegido para estudiar los proyectos de cooperación al desarrollo que se realizaron allí, para conocer a qué riesgos se enfrentaron y qué niveles de éxito consiguieron.

El estudio de ocho proyectos y el trabajo con sus equipos ha permitido identificar y evaluar un conjunto de riesgos, entre los que destacan por su importancia y por ser comunes a todos los proyectos, los asociados a las categorías: económica, cultural y política. A partir del estudio de los riesgos de estos proyectos, se ha elaborado un registro de riesgos de valor para futuros proyectos en la zona y que puede orientar también a otros proyectos de cooperación al desarrollo en otros lugares.

El análisis de los niveles de éxito de los proyectos estudiados permite descubrir que los valores obtenidos en la dirección del proyecto son superiores a los del impacto del proyecto, pese a buscar en todo momento alcanzar el máximo impacto en la comunidad beneficiaria.

El uso de la metodología fuzzy para el análisis cuantitativo de los datos obtenidos del trabajo en campo, ha facilitado encontrar los vínculos entre las categorías de riesgos y el éxito del proyecto, demostrando, por ejemplo, que los riesgos asociados a las diferencias culturales tienen una relación directa y biunívoca con el impacto de los proyectos en la comunidad beneficiaria.

El estudio documental previo, así como conocer la opinión de los profesionales sobre el Marco Lógico, y demostrar las relaciones entre los riesgos y el éxito del proyecto, ha permitido diseñar la metodología del Marco Lógico con Enfoque de Gestión de Riesgos.

La metodología del Marco Lógico con Enfoque de Gestión de Riesgos es la principal aportación de esta Tesis Doctoral. Está dotada de un carácter integral que implica a la organización en la cultura de gestión de riesgos para alcanzar mayor repercusión con las acciones y que éstas puedan documentarse de un proyecto a otro. Su uso puede hacerse a través de sencillas herramientas y con escasos recursos adicionales. Su integración en los cinco pasos de la metodología del Marco Lógico es una apuesta por repensar y reutilizar esta metodología aprovechando su reconocimiento.

Esta metodología, en su búsqueda de ser participativa desde su concepción, ha contado con el contraste multiactor de ocho profesionales de la cooperación al desarrollo, tanto españoles como colombianos, pertenecientes a diferentes ámbitos. Los profesionales consultados han destacado la sencillez y aplicabilidad de la metodología para introducir 
la gestión de riesgos en los proyectos de cooperación al desarrollo, aspecto fundamental por estar rodeados de incertidumbres $y$, sin embargo, escasamente incorporado hasta ahora. Con ella, confirman, se contribuirá a la mejora de los niveles de éxito de estos proyectos y, por tanto, a la eficacia buscada. 


\section{Abstract}

Inspired by ethical issues and social justice, the aim of this Doctoral Thesis is to contribute to improve the effectiveness of International Development Projects.

In order to achieve this, the literature review section analyzes in the first place, the particularities and complexity of international development projects. In the second place, due to the respect owed to a methodology that has been used for five decades in the management of these projects, the Logical Framework Approach is reviewed. Finally, the theoretical framework closes with a review of Risk Management literature. Risk management is a common area in other types of projects and, however, very little addressed in the field of international development.

With the broadest vision that allows an extensive review of the literature, and looking for the maximum effectiveness of the international development projects, as essential to achieve the goals of the 2030 Agenda, this thesis is reaffirmed in its objective of developing a methodology for the management of international development projects with integrated risk management. This goal seeks to contribute to increasing the success rate of these projects. The success rate is understood in its double aspect of impact on the community and project management.

To help achieve this goal, the research work developed in the Doctoral Thesis is based on the simple questions, what? why? and how? which give rise to research hypotheses.

What: improving the Logical Framework since it is the most common methodology in international development. Hypothesis one: The Logical Framework Approach needs to be improved.

Why: to improve the effectiveness of international development projects, increasing their levels of success. Hypothesis two: The success of international development projects depends on proper risk management.

How: through the methodology of the Logical Framework with Risk Management Approach. Hypothesis three: The Logical Framework with a Risk Management Approach can improve the effectiveness of international development projects.

The methodology that allows facing this work starts from laying solid foundations based on previous works. To this end, in addition to more than 150 indexed articles, 152 international development projects carried out by the Universidad Politécnica de Madrid were studied and their managers were asked about their risks.

From these first steps, 77 international development professionals (Spanish and Colombian) were consulted about the Logical Framework Approach. It was proven that, 
although the strengths of the Logical Framework Approach were more valued than the weaknesses, this methodology needs to be improved. The best-valued proposal for this is to introduce risk management.

The following steps were taken in the field, in Cauca, a Department of Colombia that stands out for the vulnerability of its population and for its ethnic and cultural richness. The case study of Cauca allowed analyzing eight international development projects, to know what risks they faced and what levels of success they achieved.

The study of these eight projects and the workshop with their teams made possible to identify and evaluate a set of risks, among which those associated with the categories economic, cultural and political, stand out for their relevance and as a common denominator to all projects. Based on the study of the risks of these projects, a valuable risk register has been prepared for future projects in the area. It could also guide risk identification in other international development projects executed in different places.

The analysis of the levels of success of the projects studied makes it possible to discover that the values obtained in project management are superior to those of the impact of the project, despite the team's effort to reach the maximum impact in the beneficiary community.

The use of the fuzzy logic for the quantitative analysis of the data has facilitated finding the links between the risk categories and the success of the project, demonstrating, for example, that the risks associated with cultural differences have a direct relationship with the impact of the projects in the beneficiary community.

The previous documentary study, as well as knowing the opinion of the professionals on the Logical Framework and demonstrating the relationship between the risks and the success of the project, have allowed designing the methodology of the Logical Framework with a Risk Management Approach.

The methodology of the Logical Framework with a Risk Management Approach is the main contribution of this Doctoral Thesis. It is endowed with an integral character that involves the organization in the culture of risk management to achieve greater impact with the actions, and that these can be documented from one project to another. Its use can be applied through simple tools and with few additional resources. Its integration into the five steps of the Logical Framework Approach is a commitment to rethink and reuse this methodology taking advantage of its recognition.

The Logical Framework with a Risk Management Approach, in its quest to be participatory since its conception, has counted for its elaboration with the multi-actor contrast of eight professionals of international development, both Spanish and Colombian, belonging to different fields. The professionals consulted have highlighted 
the simplicity and applicability of the methodology for introducing risk management in international development projects. Integrating risk management has been proven to be a fundamental aspect, since these projects are surrounded by uncertainties and, however, poorly incorporated so far. This methodology, according to the professionals' opinion, will contribute to the improvement of the levels of success of the international development projects and, therefore, to the efficiency sought. 


\section{CAPÍTULO 1. INTRODUCCIÓN}

En el presente capítulo se recoge la problemática planteada y la motivación para desarrollar esta Tesis Doctoral, así como los objetivos de la misma. Se incluye también la descripción de la estructura del documento.

\subsection{Antecedentes y motivación}

Inspirada por cuestiones éticas y de justicia social, esta Tesis Doctoral quiere contribuir a mejorar la eficacia, la sostenibilidad y el impacto de los Proyectos de Cooperación al Desarrollo (PCD).

Con una inversión en ayuda al desarrollo cifrada por la Organización para la Cooperación y el Desarrollo Económico (OCDE) (2018) en \$144,16 billones en el año 2017, y unos niveles de hambre en el mundo que continúan subiendo por tercer año consecutivo y afectan ya a 821 millones de personas (una de cada nueve) (FAO, 2018), ser eficaz en la gestión de los PCD no es solo un compromiso marcado por la Declaración de París (OCDE, 2005), o un reto para alcanzar las metas marcadas por la Organización de las Naciones Unidas (ONU) en la Agenda 2030 (ONU, 2015a), sino una responsabilidad de todas aquellas personas que participan, de una u otra manera, en alguno de estos proyectos.

De acuerdo con el Informe de Resultados y desempeño del Banco Mundial 2017 (Banco Mundial, 2018), sobre un total de 713 proyectos finalizados durante los años fiscales 2014 y 2016 por el grupo del Banco Mundial, solo el 73\% alcanzan el éxito ${ }^{1}$ de una manera moderadamente satisfactoria ${ }^{2}$ o superior. Este nivel es ligeramente inferior al marcado como objetivo por el grupo (75\%). Si se habla en términos de volumen, en esa misma franja temporal, las tasas de éxito moderadamente satisfactorio o superior alcanzan el $84 \%$, sobre un volumen de $\$ 70$ billones (el objetivo del grupo era el $80 \%$ ). Al medir en términos de volumen de inversión, se están considerando al mismo nivel los resultados de pocos proyectos con una altísima inversión, que pueden distorsionar los resultados de la mayoría de los proyectos. Por ejemplo, si se eliminan los 28 proyectos con un volumen superior a los $\$ 800$ millones, las tasas de éxito decrecen al $76 \%$ (por debajo del $80 \%$ marcado). Si se realiza un análisis por zonas, en cambio, solo los proyectos llevados a cabo en el sur de Asia (cuatro proyectos) o en Europa y Asia Central (17), superan el $75 \%$ de nivel de éxito moderadamente satisfactorio. Con niveles para África (20) o Asia del este (10) del 50\%.

\footnotetext{
${ }^{1}$ Estas tasas de éxito están medidas atendiendo a la calidad de la supervisión, a la trayectoria del líder del equipo, a la incorporación de lecciones aprendidas y de trabajo analítico, a la calidad de la cadena de resultados, a la calidad del diseño del proyecto y a la amplitud y colaboración con los participantes locales. 2 Escala de seis niveles, del más bajo al más alto: altamente insatisfactorio, insatisfactorio, moderadamente insatisfactorio, moderadamente satisfactorio, satisfactorio y altamente satisfactorio.
} 
Sin querer entrar en mayor detalle en estas cifras, queda ya constancia de que aproximadamente uno de cada cuatro proyectos de cooperación no alcanza un éxito ni si quiera moderado. Si lo que se busca es tener un éxito altamente satisfactorio, las cifras se ven muy reducidas, en torno al 3\%, esto es, aproximadamente 21 proyectos de los 713 analizados en el periodo 2014-2016.

Anteriormente, ya otros informes y autores habían destapado el bajo nivel de efectividad de los PCD (Golini, Kalchschmidt y Landoni, 2015; Hekala, 2012; Ika, 2012). Por ejemplo, el informe McKinsey-Devex (Lovegrove et al., 2011), llevado a cabo con motivo del IV Foro de Alto Nivel sobre la Efectividad de la Ayuda de Busan (2011), lanzaba ya la alarmante cifra de que solo el $36 \%$ de los proyectos financiados con la ayuda al desarrollo se podían considerar exitosos, en el sentido de alcanzar el impacto buscado.

Entre las causas posibles de los bajos niveles de éxito, el Banco Mundial señalaba en informes anteriores directamente a los riesgos residuales ${ }^{3}$ de los proyectos. Por eso, en el Informe de Resultados y desempeño del Banco Mundial 2017 (Banco Mundial, 2018), se realizó por primera vez un análisis que trataba de relacionar las tasas de riesgos de los proyectos con las tasas de éxito de los mismos. El resultado fue que mientras que no existe correlación significativa entre los riesgos iniciales del proyecto y sus tasas de éxito, sí existe una correlación significativa entre las altas tasas de riesgos residuales y las bajas tasas de éxito de los proyectos (Banco Mundial, 2018). Estos resultados apoyan la idea de que una gestión de riesgos adecuada en los proyectos para reducir y mitigar los riesgos es necesaria para obtener un proyecto eficaz, especialmente en aquellos proyectos de alto riesgo.

Hekala (2012) apuntó también a los riesgos inherentes a los PCD como causantes de los bajos niveles de impacto de los mismos, señalando que, si bien convivir con estos riesgos es inevitable, se podrían controlar mejor con una mejor planificación del proyecto y con mejores habilidades del director del proyecto que, en la mayoría de los casos, es un director de proyecto accidental, sin formación específica en dirección de proyectos.

Así, son muy pocos autores los que hacen referencia a cómo mejorar la gestión de riesgos en los $P C D$, enfocándola, en todo caso, a la inclusión de los riesgos en la matriz de planificación del Marco Lógico 4 (Couillard, Garon y Riznic, 2009; Ika y Lytvynov, 2011). Esto resulta llamativo cuando en otro tipo de proyectos, la gestión de riesgos forma parte de las áreas de gestión de la dirección de proyectos de manera indiscutible.

\footnotetext{
${ }^{3}$ Riesgo residual es aquel que perdura después de aplicar las medidas de mitigación del riesgo

${ }^{4}$ El Marco Lógico es la herramienta más utilizada en los proyectos de cooperación desde hace 50 años. En esta tesis se dedicará el Capítulo 3 a abordarlo con detalle.
} 
El éxito en los proyectos se puede entender en una doble vertiente: el éxito en la dirección del proyecto y el éxito en el impacto del proyecto. Estas dos interpretaciones del éxito pueden darse de manera independiente. Tradicionalmente, en la literatura relacionada con la dirección de proyectos, el éxito en la dirección de proyectos se vincula a la eficiencia, principalmente en el entorno del conocido triángulo de oro (alcance, coste y tiempo); siendo la efectividad ligada en mayor medida a la satisfacción del cliente (Berssaneti y Carvalho, 2015).

En los PCD, aunque el éxito en la dirección del proyecto es también importante, cobra un papel fundamental el éxito en el impacto del proyecto sobre la comunidad beneficiaria, por el objetivo intrínseco de los mismos de mejorar la calidad de vida de las personas. Bien es cierto que para que se pueda dar impacto en la población, se deben cumplir una serie de condicionantes. Un proyecto con impacto positivo en la comunidad beneficiaria tiene que ser primero eficaz y sostenible. Se considera eficaz cuando ha cumplido los objetivos para los que fue creado de una manera altamente satisfactoria. Si a ello se añaden unas condiciones de contexto favorables que pasan, entre otras, por la información y formación a las personas en el ámbito del proyecto para su aceptación y mantenimiento, el proyecto alcanzará el grado de sostenible. De nuevo, si a este proyecto sostenible se le suman unas condiciones favorables de contexto que fomentan su apropiación por parte de la comunidad, se obtendrá el deseado impacto del proyecto.

Esta tesis busca desarrollar una metodología de incorporación de la gestión de riesgos que, aunque se centra en conseguir un proyecto eficaz, propone también la gestión de algunos riesgos asociados al contexto y la cultura que ayudarán a mejorar la aceptación y apropiación del proyecto por parte de la comunidad, facilitando la consecución de un proyecto con impacto.

\subsection{Hipótesis y objetivos de la investigación}

Las hipótesis de investigación se plantean acordes a las tres preguntas básicas que todo investigador debe hacerse ¿qué?, ¿para qué? y ¿cómo?

Qué: mejorar el Marco Lógico. Siendo la metodología más utilizada en la gestión de los PCD, hablar de la gestión de los PCD está ligado a hablar del Marco Lógico, y cualquier mejora de éxito de estos proyectos previsiblemente guarda relación con mejorar esta metodología.

Hipótesis de investigación uno: El Marco Lógico necesita ser mejorado.

Para qué: para mejorar la eficacia de los PCD. Conocidos los niveles mejorables de éxito de este tipo de proyectos, así como puesto el foco en la posible vinculación de este éxito con el nivel de riesgo de los proyectos, el para qué plantea mejorar la eficacia de los PCD a través de una mejor gestión de los riesgos. 
Hipótesis de investigación dos: El éxito de los proyectos de cooperación al desarrollo depende la buena gestión de los riesgos.

Cómo: a través de la metodología del Marco Lógico con Enfoque de Gestión de Riesgos (MLEGR). Teniendo el punto de partida de una metodología que necesita ser mejorada y el horizonte en la mejora de los niveles del éxito de los PCD a través de una disminución de sus niveles de riesgo, el cómo propone incorporar al marco lógico una gestión de riesgos transversal a lo largo de todas sus etapas.

Hipótesis de investigación tres: El Marco Lógico con Enfoque de Gestión de Riesgos puede mejorar la eficacia de los PCD.

El objetivo principal de esta Tesis Doctoral, soportado en la constatación de las tres hipótesis anteriores, es desarrollar una metodología para la gestión de los PCD con una gestión de riesgos integrada, con el fin de mejorar su eficiencia y eficacia, y contribuir a un mayor impacto en la comunidad beneficiaria. Esta metodología tomará los puntos fuertes de la conocida metodología del Marco Lógico, incorporando la gestión de riesgos en cada una de sus etapas, por ello, se propone el nombre de Metodología del Marco Lógico con Enfoque de Gestión de Riesgos.

Para contribuir a este objetivo principal y, partiendo desde la identificación de las particularidades de los PCD y del profundo análisis de su principal metodología de gestión (el Marco Lógico), a través de la revisión de la literatura, se plantean los siguientes objetivos específicos (OE):

OE1. Conocer cómo son los PCD de la Universidad Politécnica de Madrid, cuáles son sus lecciones aprendidas y a qué riesgos se enfrentan.

OE2. Analizar las fortalezas y debilidades de la metodología del Marco Lógico para proponer las mejoras más convenientes.

OE3. Identificar y evaluar los riesgos de los proyectos caso de estudio para proponer un registro y categorización de riesgos en el contexto analizado que pudiera servir de modelo para otros contextos.

OE4. Descubrir la relación existente entre los riesgos evaluados y la percepción de éxito de los proyectos caso de estudio para encontrar posibles vinculaciones entre los riesgos y el éxito del proyecto.

OE5. Contrastar con profesionales del ámbito de la cooperación el diseño de la metodología del MLEGR para que sea una metodología útil y realista que tenga aplicación en el sector. 


\subsection{Desafíos de la investigación}

El primer y más importante desafío de esta investigación es no perder de vista el lado humano de la cooperación al desarrollo y la sensibilidad ante los problemas que rodean los contextos donde se desarrollan los PCD, respetando y admirando el trabajo de profesionales y voluntarios, y entendiendo las limitaciones a las que se enfrentan. Así como defendiendo la participación de las comunidades locales en los pasos hacia la mejora de su calidad de vida.

El otro gran desafío ha sido plantear el desarrollo de la tesis en el tiempo acotado. Para implantar una nueva metodología de planificación, ejecutar el proyecto y esperar a ver el impacto que puede tener en la comunidad se requiere un tiempo del que una Tesis Doctoral no dispone. Del mismo modo, idealmente hubiera sido interesante poder comparar las diferencias entre un proyecto realizado bajo la Metodología del Marco Lógico y otro bajo la Metodología del MLEGR, pero cada proyecto es único y, por tanto, las diferencias encontradas podrían no deberse solo a la distinta metodología aplicada. Es por ello por lo que el planteamiento de la investigación ha sido trabajar con proyectos ya realizados, en un mismo contexto, para extraer conclusiones, y, a partir de ahí, y de la mano con profesionales de la cooperación, plantear la metodología.

\subsection{Estructura del documento}

Este documento está formado por siete capítulos, referencias y anexos.

Tras este primer capítulo de Introducción donde se plantea la motivación para realizar esta tesis, así como los objetivos e hipótesis de partida, los capítulos 2, 3 y 4 componen el marco teórico de la investigación.

El capítulo dos presenta los retos que plantea hoy en día la cooperación al desarrollo bajo el paraguas de la Agenda 2030, y muestra las particularidades de los PCD, intentando encontrar un puente entre las herramientas de dirección de proyectos convencionales y las específicas de este sector.

El capítulo tres se centra en el Enfoque del Marco Lógico, para mostrar su evolución en sus 50 años de vida, encontrar sus actuales limitaciones y analizar las propuestas de nuevas versiones que se han realizado.

El capítulo cuatro está dedicado a la gestión del riesgo, prestando especial atención a los contextos de incertidumbre en los que se desarrollan los PCD, así como a la influencia de los factores culturales.

El capítulo quinto, una vez presentado el marco teórico, describe la metodología que ha sido utilizada para obtener los resultados y conclusiones de esta investigación. Este 
quinto capítulo presenta los proyectos casos de estudio analizados y expone las técnicas de investigación utilizadas.

El capítulo sexto presenta los resultados obtenidos tras cuestionarios y entrevistas con profesionales de la cooperación al desarrollo, así como tras el análisis de los casos de estudio, proponiendo la metodología del MLEGR.

El séptimo y último capítulo presenta las principales conclusiones de la investigación, así como sus limitaciones y futuros desarrollos. Las conclusiones obtenidas responden a las preguntas iniciales de investigación.

Finalmente, se incluye la bibliografía utilizada en la elaboración de esta Tesis Doctoral, y los anexos que complementan algunos puntos de la investigación.

El desarrollo natural que muestran estos capítulos se refleja en la Figura 1.1 e irá apareciendo a lo largo del documento, al principio de cada capítulo, para facilitar la contextualización de la lectura. El color verde de la figura representa las condiciones favorables de contexto que han tenido que darse para poder llevar a cabo este desarrollo natural y que no son otras que el apoyo y supervisión por parte de la directora de este trabajo, la colaboración de los profesionales del sector de la cooperación, la buena disposición de las personas que participaron en los proyectos caso de estudio, la cálida acogida en las estancias realizadas y el esfuerzo y cariño de la autora.

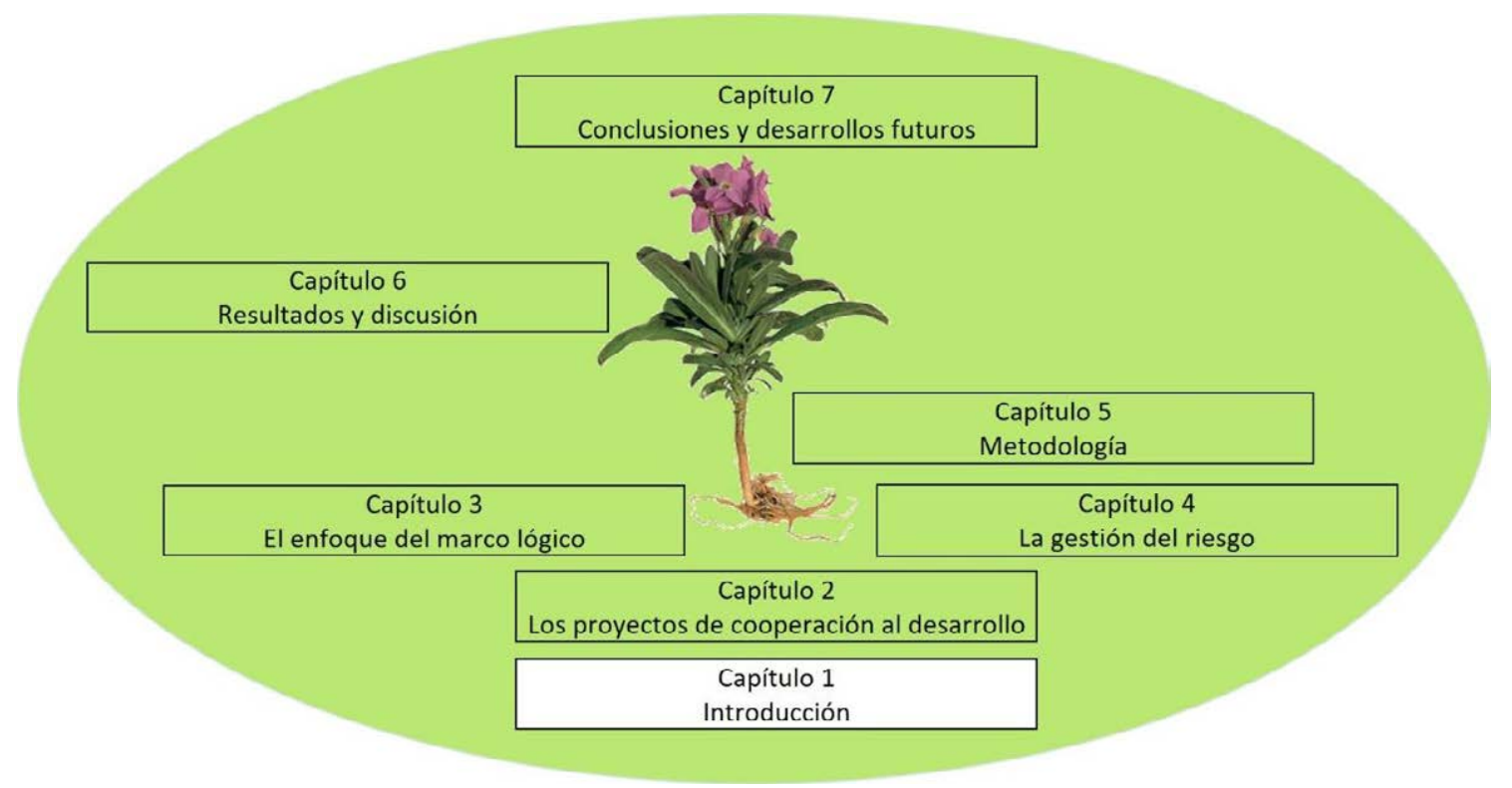

Figura 1.1. Desarrollo natural de la investigación.

Fuente: Elaboración propia. 


\section{CAPÍTULO 2. LOS PROYECTOS DE COOPERACIÓN AL DESARROLLO}

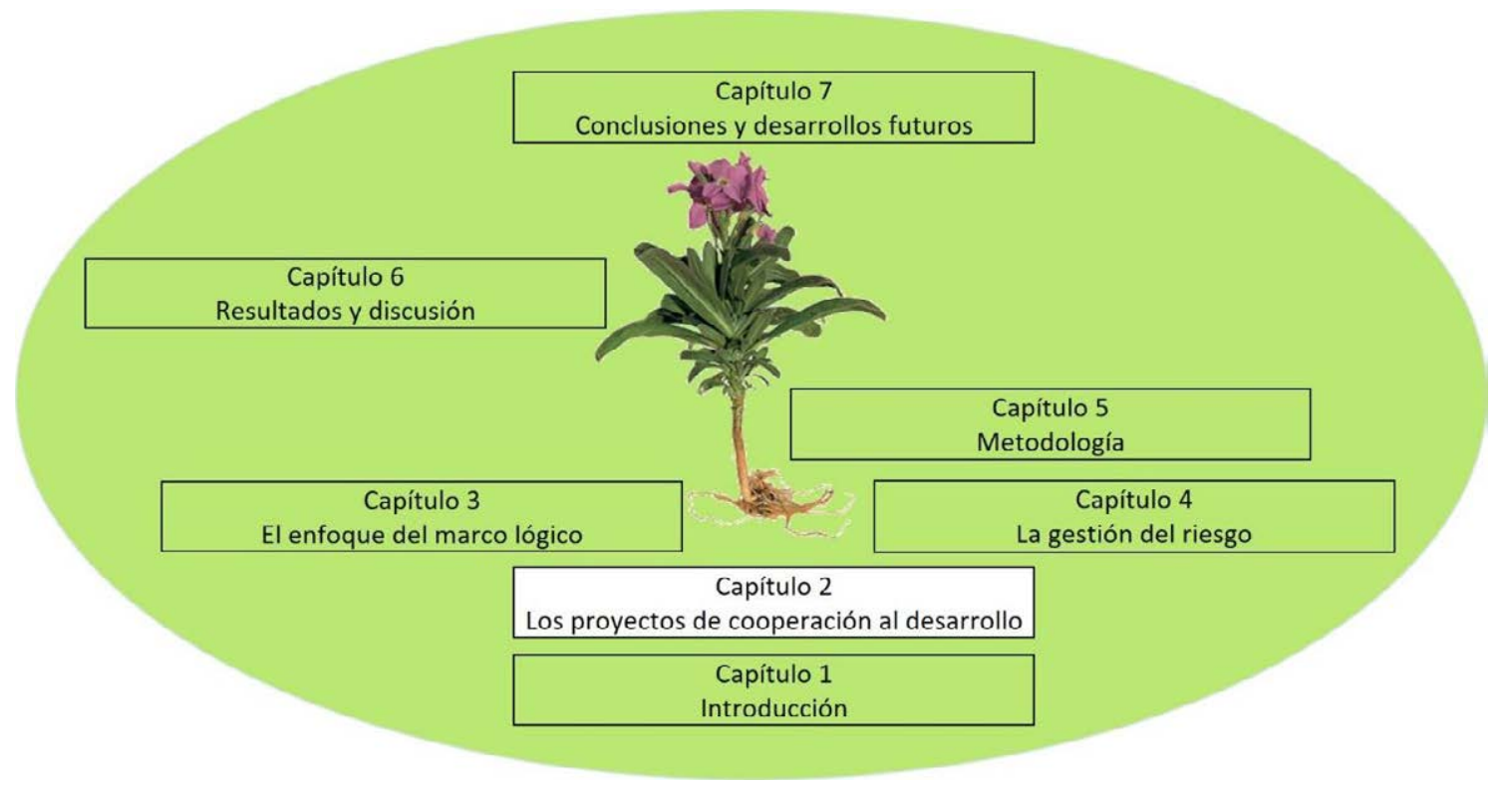

Figura 2.1. Los proyectos de cooperación al desarrollo.

Fuente: Elaboración propia.

"Hay una fuerza motriz más poderosa que el vapor, la electricidad y la energía atómica: la voluntad"

(Atribuída a Albert Einsten, 1879-1955) 


\subsection{Introducción}

Este segundo capítulo, dedicado a los proyectos de cooperación al desarrollo (PCD), se presenta como el primero correspondiente al marco teórico de la investigación.

Como los proyectos son los medios a través de los cuales se realiza la cooperación al desarrollo, previo a conocerlos, se plantean los grandes retos a los que la cooperación al desarrollo se enfrenta en estos días, marcados principalmente por la Agenda 2030 y por la inclusión de nuevos actores.

La introducción de nuevos países donantes, tanto BRICS $^{5}$ como países del Sur, ha sustituido en el ámbito de la cooperación términos como soberanía, para incorporar asociación, participación y apropiación (Mawdsley, 2015; Morvaridi y Hughes, 2018).

Los PCD, en el camino de asumir también estos grandes retos de la cooperación, muestran su evolución a lo largo del tiempo, y son presentados a través de sus características fundamentales, que los diferencian de cualquier otro tipo de proyecto.

A partir de estas particularidades, se plantea la idoneidad de las herramientas de dirección de proyectos específicas para este tipo de proyectos, así como cuáles son las competencias que debería tener la persona encargada de dirigir los PCD.

\subsection{Los retos de la cooperación internacional al desarrollo}

Son muchos los que sitúan el origen de la cooperación internacional al desarrollo tras la segunda guerra mundial, y más concretamente, en el discurso inaugural del segundo mandato del presidente estadounidense Harry Truman (Escobar, 1995; Rist, 2008; Sachs, 1992; Brooks, 2017).

"Debemos embarcarnos en un nuevo y audaz programa para hacer que los beneficios de nuestros avances científicos y el progreso industrial estén disponibles para la mejora y el crecimiento de las zonas subdesarrolladas. El viejo imperialismo - la explotación de los beneficios extranjeros - no tiene cabida en nuestros planes. Lo que contemplamos es un programa de desarrollo basado en el concepto de acuerdos justos y democráticos" (Harry S. Truman, 1949).

A lo largo de estas siete décadas, y atendiendo a los bajos niveles de desarrollo en algunas regiones, principalmente de África, profesionales e investigadores del ámbito de la cooperación al desarrollo se han preguntado si la ayuda internacional funciona (Bourguignon y Platteau; 2017; Cassen, 1986; Svensson, 2003). Mientras que algunos autores creen que funciona y genera desarrollo en el largo plazo (Arndt, Jones y Tarp, 2015; Juselius, Møller y Tarp, 2014; Sachs, 2005), otros creen que es inefectiva (Bigsten

\footnotetext{
${ }^{5}$ Asociación de países compuesta por Brasil, Rusia, India, China y Suráfrica. Se verá en detalle más adelante.
} 
y Tengstam, 2015; Easterly, 2006) o, incluso peor, que es en sí misma el problema, al estar basada en unos modelos occidentales capitalistas que en lugar de disminuir las diferencias entre los países del norte y los del sur, establecen relaciones de dependencia entre ellos (Brooks, 2017; Moyo, 2009).

Esta última visión más crítica la ofrecen las teorías enmarcadas en el ámbito del postdesarrollo, que cobró fuerza a raíz de la publicación del bestseller de Wolfgang Sachs The development dictionary (1992). Este movimiento entiende que la noción de desarrollo, ligada al crecimiento económico de los mercados, a la productividad y a la satisfacción de necesidades infinitas de bienes materiales, responde a un modelo económico occidental que ignora otras dimensiones posibles de la actividad económica, como la relación con la Madre Tierra, que juega un rol principal en las labores agrícolas, o la idea de suficiencia, o las de solidaridad y comunidad (Ziai, 2017).

El debate sobre la efectividad de la ayuda ha sido mantenido por la comunidad internacional en numerosas ocasiones en los tiempos más recientes, como queda reflejado en la celebración de una serie de conferencias, como los foros de alto nivel de Eficacia de la Ayuda: Roma 2003, París 2005, Accra 2008, Busán 2011 y Méjico 2014 (Bigsten y Tengstam, 2015; Cobo, 2010; Novales y Freres, 2016). Los resultados de estas conferencias, aunque han conseguido mantener los compromisos de calidad de la ayuda, distan de alcanzar el impacto buscado (OCDE/PNUD, 2014). Resultados similares se obtuvieron del análisis del cumplimiento de los Objetivos Del Milenio6 (ODM), que, aunque significativos en algunos casos, fueron muy desiguales (ONU, 2015b). Con estos antecedentes, en 2015 se firmaron tres acuerdos internacionales de gran relevancia para el desarrollo: la Agenda 2030 para el Desarrollo Sostenible (ONU, 2015a), la Agenda de Acción de Addis Abeba (AAAA) (ONU, 2015c) sobre financiación del desarrollo y el Acuerdo de París sobre cambio climático (CMNUCC, 2015).

En la cooperación española, al igual que en el resto de la comunidad internacional, se está tratando de superar la visión clásica de la ayuda oficial al desarrollo (AOD), para dar paso al conocido como Apoyo Oficial Total para el Desarrollo Sostenible (AOTDS) (AECID, 2018). Mientras se lleva a cabo esta modernización de la ayuda, el informe AidWatch 2018 (Concord, 2018) arroja datos muy alejados para la AOD del porcentaje objetivo del 0,7\% del Producto Interior Bruto para casi todos los países miembros de la Unión Europea, que mantienen en cambio el compromiso adquirido con la Agenda 2030 de financiar el desarrollo sostenible.

Esta noción de sostenibilidad, que ha empezado a estar presente de una manera habitual, no solo en la comunidad internacional, sino en la propia sociedad, responde a

\footnotetext{
${ }^{6}$ Los Objetivos del Milenio fueron establecidos en la 55a Asamblea General de la ONU, celebrada en la sede de las Naciones Unidas el 18 de septiembre del año 2000, como parte de la Declaración del Milenio. Aprobada por 189 países, constaba de 8 objetivos y 21 metas, cuantificables a través de 60 indicadores
} 
la demanda de satisfacer unas necesidades respetando el medio ambiente (Kates, 2011). Al introducir esta componente medioambiental, surge la multidireccionalidad de la cooperación, en la que tienen cabida conceptos indígenas del sur como el buen vivir $^{7}$, con el que se quiere recoger el desarrollo comunitario productivo y sostenible, y que ofrece valiosas lecciones para los debates internacionales alrededor del concepto de desarrollo sostenible (Radcliffe, 2018).

Hay muchas definiciones de sostenibilidad, pero quizá la más conocida sea la establecida por Harlem Brundtland en su etapa al frente de la Comisión de Medio Ambiente y Desarrollo de la ONU, y que ha llegado a conocerse como la definición de Brundtland: "el desarrollo sostenible es aquel desarrollo que responde a las necesidades del presente, sin comprometer la capacidad de generaciones futuras para satisfacer sus propias necesidades" (CMAD, 1987).

Reestructurar la cooperación internacional al desarrollo hacia un modelo más eficaz, en términos no solo sociales y económicos, sino también medioambientales, incluyendo a nuevos actores y sin dejar a nadie atrás, responde a uno de los retos más importantes a los que se enfrenta la sociedad en este siglo.

\subsubsection{La Agenda 2030}

La Agenda 2030 es un plan de acción en favor de las personas, el planeta y la prosperidad (ONU, 2015a). Aprobada en la asamblea general de las Naciones Unidas, celebrada en Nueva York el 25 de septiembre de 2015, se compone de 17 Objetivos de Desarrollo Sostenible (ODS) y 169 metas de carácter integrado e indivisible donde se conjugan las tres dimensiones del desarrollo sostenible: económica, social y ambiental (ONU, 2015a).

La elaboración de esta agenda supuso la mayor consulta social a nivel civil de la historia de las Naciones Unidas, contando con una altísima participación y consenso por parte de gobiernos y sociedad de todo el mundo. Los 193 países miembros de este organismo firmaron su compromiso con ella (ONU, 2016).

Los ODS son un ejemplo de las políticas internacionales en cascada, cuyos precedentes más directos serían los ODM, que supusieron por primera vez un marco de asociación explícita hacia el desarrollo entre países desarrollados y países en desarrollo (McArthur, 2014). En la Agenda 2030, no solo los gobiernos están llamados a actuar, sino también se incluyen nuevos agentes de cambio, como las empresas, los gobiernos locales y toda la sociedad civil (Hajer et al., 2015; Kamphof y Melissen, 2018; Zelenev, 2017). Éste es uno de los puntos novedosos que encuadra esta agenda. Otro muy significativo, y que muestra la apuesta de la comunidad internacional por el desarrollo sostenible, es la

\footnotetext{
${ }^{7}$ El Buen Vivir es la traducción del Sumak kawsay kichwa (Ecuador), y del Suma qamaña aymara (Bolivia), es un concepto que hace referencia a la convivencia entre las personas y entre éstas y la naturaleza. Aparece recogido tanto en la constitución de Ecuador de 2008, como en la de Bolivia de 2009.
} 
apertura del ODM7 en objetivos más detallados (agua, energía, cambio climático, ecosistemas marinos y terrestres) (Bebbington y Unerman, 2018), como se muestra en la Tabla 2.1.

Tabla 2.1. Objetivos de Desarrollo Sostenible vs Objetivos de Desarrollo del Milenio. Fuente: elaboración propia.

\begin{tabular}{|c|c|c|c|}
\hline ODS & & ODM & \\
\hline 1 & $\begin{array}{l}\text { Fin de la pobreza } \\
\text { Poner fin de la pobreza en todas sus formas } \\
\text { y en todo el mundo }\end{array}$ & \multirow[b]{2}{*}{1} & \multirow{2}{*}{$\begin{array}{l}\text { Erradicar la pobreza extrema y el } \\
\text { hambre }\end{array}$} \\
\hline 2 & $\begin{array}{l}\text { Hambre cero } \\
\text { Poner fin al hambre, lograr la seguridad } \\
\text { alimentaria y la mejora de la nutrición y } \\
\text { promover la agricultura sostenible }\end{array}$ & & \\
\hline \multirow{3}{*}{3} & \multirow{3}{*}{$\begin{array}{l}\text { Salud y bienestar } \\
\text { Garantizar una vida sana y promover el } \\
\text { bienestar de todos a todas las edades }\end{array}$} & 4 & $\begin{array}{l}\text { Reducir la mortalidad de los niños } \\
\text { menores de } 5 \text { años }\end{array}$ \\
\hline & & 5 & Mejorar la salud materna \\
\hline & & 6 & $\begin{array}{l}\text { Combatir el VIH/SIDA, la malaria y } \\
\text { otras enfermedades }\end{array}$ \\
\hline 4 & $\begin{array}{l}\text { Educación de calidad } \\
\text { Garantizar una educación inclusiva y } \\
\text { equitativa de calidad y promover } \\
\text { oportunidades de aprendizaje permanente } \\
\text { para todos }\end{array}$ & 2 & $\begin{array}{l}\text { Lograr la enseñanza primaria } \\
\text { universal }\end{array}$ \\
\hline 5 & $\begin{array}{l}\text { lgualdad de género } \\
\text { Lograr una igualdad de género y } \\
\text { empoderar a todas las mujeres y las niñas }\end{array}$ & 3 & $\begin{array}{l}\text { Promover la igualdad entre los } \\
\text { sexos y el empoderamiento de la } \\
\text { mujer }\end{array}$ \\
\hline 6 & $\begin{array}{l}\text { Agua limpia y saneamiento } \\
\text { Garantizar la disponibilidad y la gestión } \\
\text { sostenible del agua y el saneamiento para } \\
\text { todos }\end{array}$ & \multirow{2}{*}{7} & \multirow{2}{*}{$\begin{array}{l}\text { Garantizar la sostenibilidad del } \\
\text { medioambiente }\end{array}$} \\
\hline 7 & $\begin{array}{l}\text { Energía asequible no contaminante } \\
\text { Garantizar el acceso a una energía } \\
\text { asequible, fiable, sostenible y moderna } \\
\text { para todos }\end{array}$ & & \\
\hline 8 & $\begin{array}{l}\text { Trabajo decente y crecimiento económico } \\
\text { Promover el crecimiento económico } \\
\text { sostenido, inclusivo y sostenible, el empleo } \\
\text { pleno y productivo y el trabajo decente } \\
\text { para todos }\end{array}$ & & \\
\hline 9 & $\begin{array}{l}\text { Industria, innovación e infraestructura } \\
\text { Construir infraestructuras resilientes, } \\
\text { promover la industrialización inclusiva y } \\
\text { sostenible y fomentar la innovación }\end{array}$ & & \\
\hline
\end{tabular}




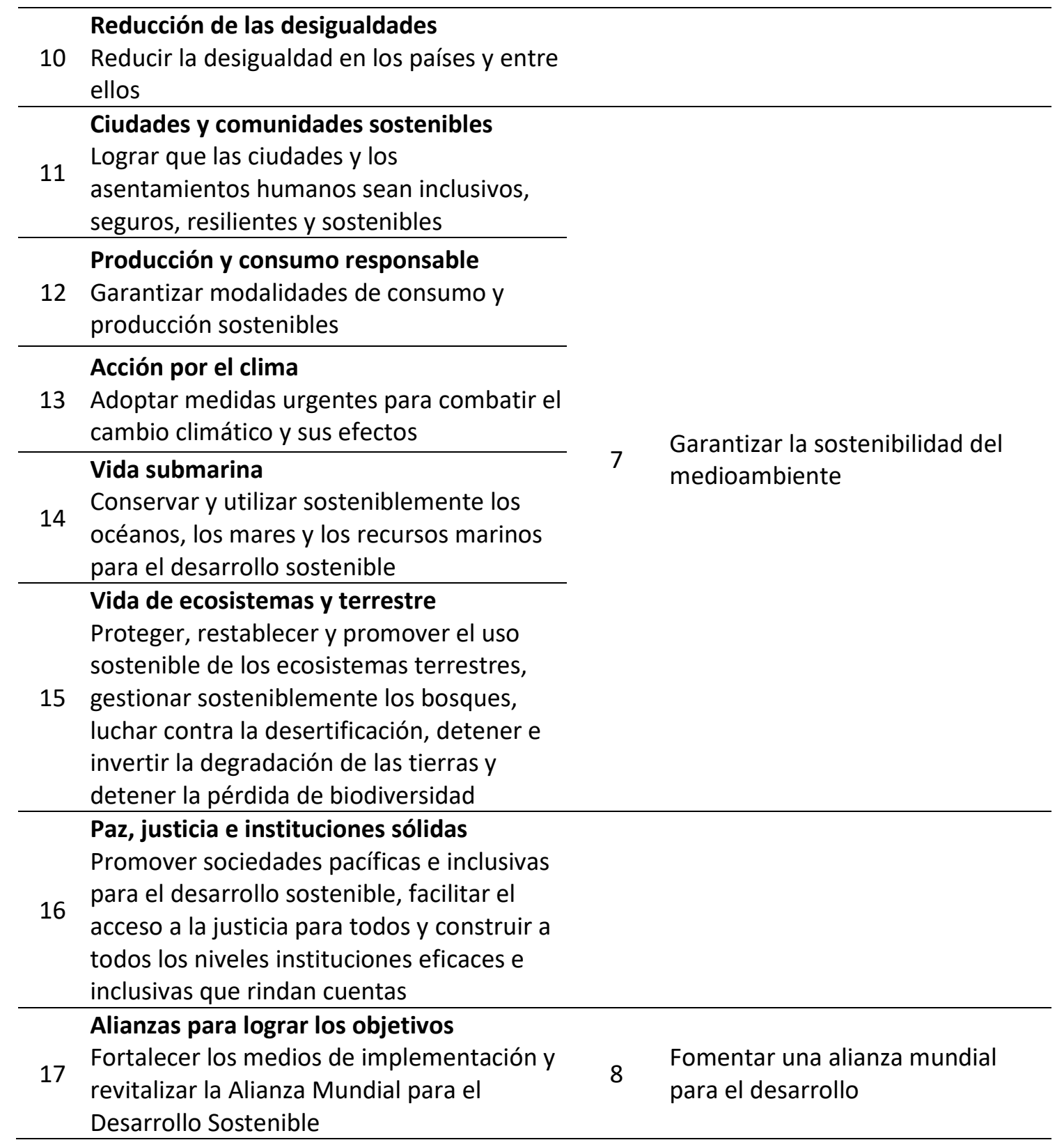

Los ODS muestran así, fuertes conexiones entre ecología y sociedad: igualdad, justicia y paz son los pilares para una existencia en armonía de todas las especies del planeta (Leal Filho et al., 2017).

La Agenda 2030, y los propios ODS han cobrado un papel importante en el mundo académico en los últimos años. La multidisciplinariedad de los objetivos ha hecho que sean muchos los campos de investigación en los que se pueda trabajar (Bebbington y Unerman, 2018). Este creciente interés del mundo académico en torno al desarrollo sostenible puede apreciarse en la Figura 2.2, en la que se han analizado el número de veces que aparecen en el título los conceptos de Cooperación Internacional al Desarrollo, Objetivos de Desarrollo Sostenible y Agenda 2030 en dos de las bases de 
datos más utilizadas, la Web of Science, y Scopus. Se puede observar que ambas revistas siguen la misma tendencia, en la que la investigación relacionada con los ODS está en plena madurez, y ha superado por mucho la investigación exclusivamente centrada en la cooperación internacional al desarrollo, que, aunque inicialmente pudiera esperarse que disminuyera, se mantiene constante.

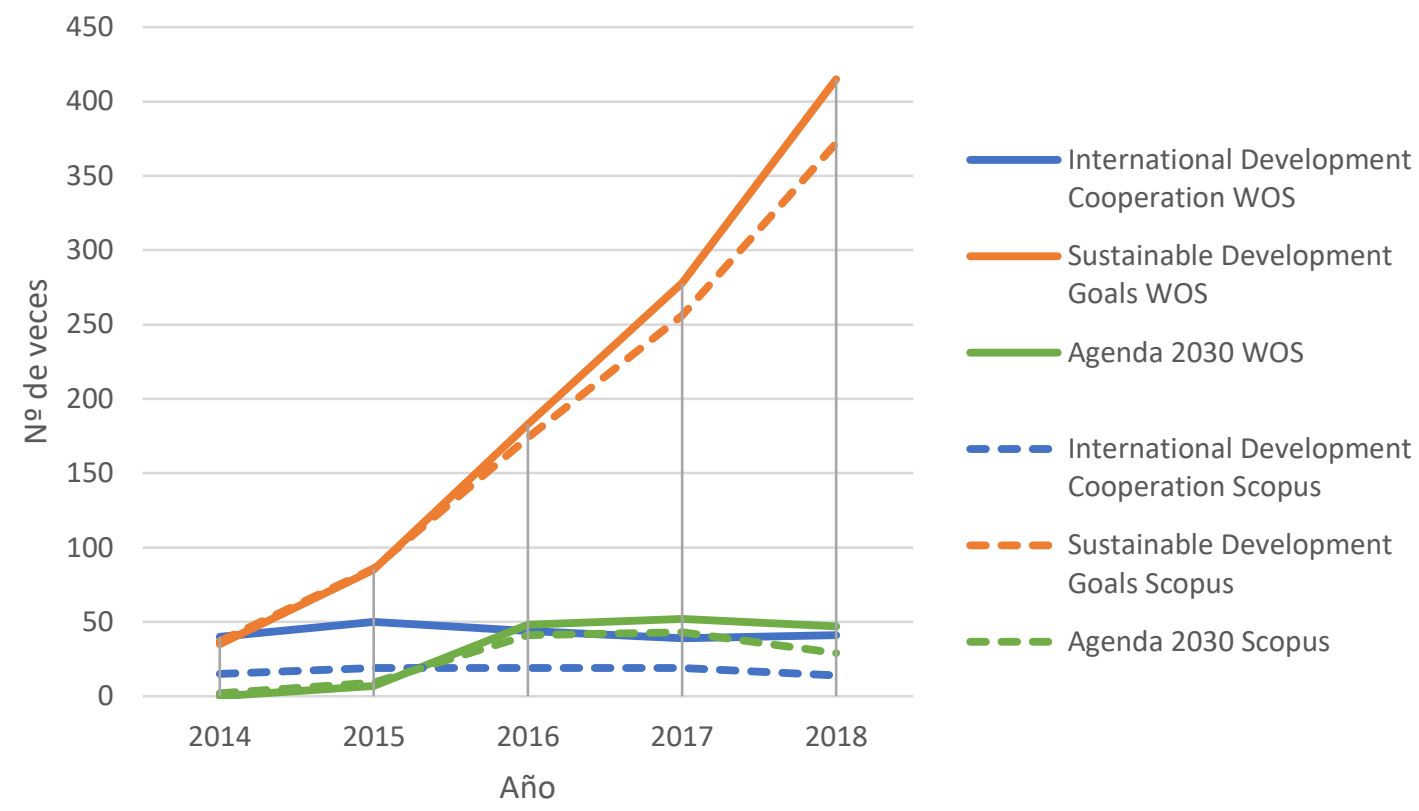

Nota: Los datos de 2019 no se incluyen por no haberse completado el año en la fecha de edición de esta Tesis Doctoral.

Figura 2.2. Evolución de los conceptos ligados a desarrollo en las webs de investigación. Fuente: elaboración propia a partir de datos de la Web of Science y Scopus en marzo de 2019.

En cuanto a las disciplinas, son las revistas de Environmental Sciences Ecology (41,2\%) las que más publicaciones tienen relacionadas con los ODS, seguidas de las categorizadas como de Business Economics (20,9\%). El resto de las disciplinas está muy repartido, demostrando una vez más la versatilidad que ofrecen los ODS.

\subsubsection{Renovación de los actores: nuevos países donantes y nuevas asociaciones}

Los procesos participativos y en los que intervienen múltiples actores están ganando protagonismo a medida que avanza el siglo XXI, dando respuesta a la necesidad que plantean los nuevos esquemas internacionales, marcados por el surgimiento de los BRICS y el auge de los países del Sur. 
El acrónimo BRICS fue precedido inicialmente por el término BRIC, utilizado por primera vez por O'Neill (2001), en su artículo de Goldman Sachs en el que predecía que Brasil, Rusia, India y China, serían los futuros conductores del crecimiento económico a nivel mundial.

Paralelamente a esta asociación económica, e impulsado por el presidente ruso Putin, desde 2003 comenzaron a tener lugar una serie de cumbres entre los jefes de estado de Rusia, India y China. En 2006, Brasil también fue invitado, consolidándose la asociación política de los BRIC en el primer encuentro mantenido en Rusia en 2009. En el segundo encuentro, mantenido en Brasilia en 2010, estos cuatro países decidieron que sería muy oportuno invitar a Suráfrica a unirse a su próximo encuentro. Así, al tercer encuentro, mantenido en China en 2011, asistieron los cinco países, generándose el conocido acrónimo político-económico BRICS (Carey y Li, 2016). La inclusión de estas economías emergentes está alentando al crecimiento económico de regiones de Asia, América Latina y África, ayudando a la reducción de la pobreza, y, sobre todo, a redefinir la economía y la política a nivel mundial (Carey y Li, 2016).

Fruto de la inmersión de los BRICS en la cooperación al desarrollo es, por ejemplo, la creación del Nuevo Banco de Desarrollo (NBD), con sede central en Shanghái, que supone una alternativa al Banco Mundial y al Fondo Monetario Internacional. EI NBD, empezó a dar visibilidad a las acciones colectivas de los BRICS en términos de cooperación al desarrollo (Gu, Shankland y Chenoy, 2018).

El continente africano ha sido uno de los que quizá más ha notado el compromiso de los BRICS con la cooperación el desarrollo, destacando el papel protagonista de China que contrasta con la geolocalización de Sudáfrica en el mismo continente (Carmody, 2012). Sudáfrica parece haberse mantenido como suministrador de servicios, principalmente banca y telefonía, para el resto de los países del África subsahariana (Shaw, Cooper y Chin, 2009). China y Brasil, por otro lado, han influenciado en el desarrollo urbano dentro de las ciudades de numerosos países subsaharianos (Schumaker et al., 2017).

Hasta la llegada de los BRICS, la cooperación internacional estaba inicialmente marcada por una cooperación Norte-Sur, con presencia también en los últimos años de la cooperación Sur-Sur. Con los BRICS comprometidos con los principales acuerdos internacionales hacia el desarrollo sostenible: Agenda 2030, AAAA y Cambio Climático (ONU, 2015a, 2015c; CMNUCC, 2015), la cooperación internacional al desarrollo cobra un nuevo enfoque global.

La Cooperación Sur-Sur (CSS) surgió inicialmente como un movimiento de liberación anti-colonial que se consolidó en la Conferencia de Bandung de 1955 (Harris y Vittorini, 2018; Morvaridi y Hughes, 2018; Soares de Lima, Milani y Muñoz, 2016). 
Desde entonces, la CSS se ha visto apoyada por la comunidad internacional a través de dos instituciones principalmente, la Conferencia de las Naciones Unidas sobre Comercio y Desarrollo (CNUCD), creada en 1964, y el Programa de Naciones Unidas para el Desarrollo (PNUD), fundado en 1965. Precisamente, dentro del PNUD nace en 1974 la Oficina de las Naciones Unidas para la Cooperación Sur-Sur (UNOSSC, de sus siglas en inglés), creada con la intención de coordinar, promover y apoyar la CSS y la cooperación triangular dentro del sistema de las Naciones Unidas. Esta institución define la CSS como "un amplio marco para la colaboración entre países del Sur en aspectos políticos, económicos, sociales, culturales, medioambientales y técnicos. [...] Los países en desarrollo comparten conocimiento, habilidades, experiencia y recursos para encontrar sus objetivos de desarrollo a través de esfuerzos coordinados" (UNOSSC, 2016). En definitiva, como define Tahina Ojeda (2016), es un entramado de relaciones y de intercambio cooperativo y complementario entre actores del Sur.

A pesar de la larga convivencia entre la Cooperación Norte-Sur y la CSS, ésta no ha tomado verdadera relevancia hasta que en el III Foro de Alto Nivel de Accra, mantenido en 2008, fue reconocida como una parte necesaria de la cooperación al desarrollo. En el IV Foro de Alto Nivel de Busan, se reconocía también la complejidad de actores en la cooperación al desarrollo, que incluye a países de renta media (que pueden ser a su vez donantes y receptores), a organismos internacionales, a Organismos No Gubernamentales (ONGD), al sector privado y a la propia sociedad (OCDE-CAD, 2011). Con esta visión, la cooperación oficialmente comienza a dar un cambio hacia el fin de la cooperación controlada por el Norte (Mawdsley, 2012). La cooperación enfocada en comunidades, organizaciones o en el sector privado de manera separada no parece suficiente para dar respuesta a los ODS (Ashley, 2014). Surgen así, por un lado, la cooperación triangular y, por otro, las alianzas multi-actor.

La cooperación triangular "implica alianzas impulsadas por el Sur entre dos o más países en desarrollo, con el apoyo de uno o más países desarrollados, o de organizaciones multilaterales para ejecutar programas y proyectos de cooperación al desarrollo" (PNUD, 2018). De esta definición se puede extraer que la cooperación triangular concibe múltiples asociaciones y en todas ellas, se debe buscar el beneficio de cada socio (winwin-win). Esta modalidad es aún muy reciente y encara importantes retos para su crecimiento, que debe apoyarse, principalmente, en los logros de experiencias exitosas, entre las que destacan los ejemplos de Japón y Alemania (Gómez, Ayllón y Albarrán, 2011).

Las alianzas multi-actor surgen de esta manera como asociaciones necesarias, no solo como respuesta a la Agenda 2030 (Hajer et al., 2015), sino también para mejorar la efectividad del proyecto a nivel local (Khan Mohmand y Loureiro, 2017). Los trabajos de Rein y Stott (2009) ya encontraban especialmente valioso de estas alianzas 
precisamente su habilidad para entregar mejoras tangibles en servicios sociales o bienes económicos, así como en oportunidades, a los núcleos más débiles de una comunidad. Así, aunque la conformación de este tipo de alianzas es un proceso complejo debido a la disparidad de contextos de sus miembros, poseen la capacidad de iniciar y promover soluciones innovadoras ante problemas retorcidos (Mataix et al., 2017).

La inclusión de nuevos países y de nuevos actores, en resumen, ha cambiado la perspectiva vertical de la cooperación internacional al desarrollo por una mirada múltiple, que invita, ante todo, al encuentro.

\subsubsection{El papel de las ONGD y las Universidades}

Entre los actores privados destacan las ONGD por su importante labor, no solo en la canalización de recursos económicos para ayuda humanitaria, sino también como presión política para los estados y como actores de cambio a través de proyectos (Cuesta y Calabuig, 2010). Estas organizaciones han conseguido, junto a otras asociaciones y movimientos sociales, dar voz a la solidaridad de la sociedad civil.

Para hacer frente a los grandes retos que la cooperación al desarrollo presenta, las ONGD, esencialmente formadas por voluntarios y comunidad religiosa, han tenido que ir profesionalizándose (Lewis y Kanji, 2009), y, poco a poco, han ido adoptando un rol casi institucional, participando algunas de ellas (las más grandes e internacionales) en grandes foros mundiales y como "consultoras" ante organismos multilaterales como el propio Banco Mundial (Cuesta y Calabuig, 2010).

Este papel fundamental de las ONGD en la cooperación internacional al desarrollo ha hecho que algunos investigadores vean necesaria conocer y considerar la opinión de estos profesionales para poder acercarse a conceptos como los factores de éxito de un proyecto de cooperación al desarrollo (Ika, 2012; Proulx y Brière, 2014).

En el ámbito público, donde los estados y las administraciones locales y autonómicas y, sobre todo, los organismos multilaterales, son los principales agentes portadores de recursos económicos, aparece la Universidad, poniendo al servicio de la sociedad las capacidades con las que cuenta. Precisamente por tratarse de una entidad transformadora y capaz de generar cambios en la sociedad, no puede eludir la responsabilidad que eso conlleva y debe responder como un actor más en la cooperación para el desarrollo (Gómez y Monzó, 2010; Rodríguez-Rivero et al., 2017).

EI V Plan Director de la Cooperación Española (AECID, 2018), ve en la Universidad a un socio clave en la Agenda 2030, no solo para generar y transmitir conocimiento, sino también por su capacidad de generar competencias transversales en los estudiantes que les inciten a contribuir activa y comprometidamente en la consecución de los ODS. 
La Educación para el Desarrollo (EpD), definida como un "proceso educativo constante, encaminado a través de conocimientos, actitudes y valores, a promover una ciudadanía global generadora de una cultura de la solidaridad comprometida en la lucha contra la pobreza y la exclusión, así como con la promoción del desarrollo humano" (Ortega, 2007, p. 19), ha sido puesta en práctica en los últimos años tanto en la Universidad, como en las ONGDs. En la Universidad, la EpD se desarrolla en el ámbito formal principalmente a través de asignaturas, programas de postgrado y prácticas en proyectos sociales, y en el ámbito extracurricular por medio de actividades de sensibilización (seminarios, jornadas, etc.). Las ONGDs han hecho igualmente uso de las prácticas de Epd, no solo a nivel externo (jornadas o cursos de formación para otras entidades), sino también desde la perspectiva interna en el seno de la organización y en su relación con las contrapartes (Boni y Cerezo, 2008).

La EpD es solo uno de los puntos en común que pueden unir a la comunidad universitaria con las ONGDs. De hecho, estudios como el de Olivier, Hunt y Ridde (2016) revelan los beneficios de la colaboración entre ONGDs e investigadores. Ambos colectivos, como entidades transformadoras y ante los retos que la cooperación internacional propone hoy, cobran un papel fundamental como aliados imprescindibles de toda intervención de desarrollo.

\subsection{Particularidades de los proyectos de cooperación al desarrollo}

La mayor parte de la cooperación internacional al desarrollo se realiza a través de proyectos (Diallo y Thuillier, 2005). Los Proyectos de Cooperación al Desarrollo (PCD) han estado siempre en el núcleo de las actividades de la cooperación al desarrollo, como ya demostró Hirschman en su clásico Development projects observed (1967).

Los PCD se diferencian de los proyectos de emergencia en que mientras que los segundos tienen el objetivo de proporcionar asistencia inmediata a las poblaciones afectadas por guerras o desastres naturales, principalmente; los primeros tienen el objetivo de mejorar las condiciones de vida de las personas de una determinada comunidad, a través de la mejora de la economía, la educación o la salud, entre otros (Golini, Kalchschmidt y Landoni, 2015; Landoni y Corti, 2011).

La ONU, definía PCD como "una empresa planificada que consiste en un conjunto de actividades interrelacionadas y coordinadas para alcanzar objetivos específicos dentro de los límites de un presupuesto y un periodo dados" (ONU, 1984, citado en Cohen y Franco, 2006, pág. 85); en la misma línea, la agencia de cooperación al desarrollo alemana (GIZ), hablaba de ellos como "una tarea innovadora que tiene un objetivo definido, debiendo ser efectuada en un cierto periodo, en una zona geográfica delimitada y para un grupo de beneficiarios; solucionando de esta manera problemas específicos o mejorando una situación" (GTZ, actualmente GIZ, citado en Camacho et 
al., 2001, págs. 14 y 15). Estas definiciones comparten grandes semejanzas con la dada por el Project Management Book of Knowledge (PMBoK), del Project Management Institute (PMI), referencia para los estándares de la Dirección de Proyectos (DP), que indica que un proyecto "es un esfuerzo temporal que se lleva a cabo para crear un producto, servicio o resultado único" (PMI, 2017, pág. 4).

Los PCD, como todos los proyectos, son únicos y temporales, y responden a una necesidad, generando un cambio (Morris, 2013; Shenhar y Dvir, 2007). Lo particular de los PCD es que estos cambios, en la mayoría de los casos, o son difícilmente medibles, o requieren un largo plazo para poder apreciarse, como sería el caso de la mejora de la calidad de vida de una determinada comunidad. Éstas y otras peculiaridades que diferencian a los PCD del resto de proyectos se han recogido en trabajos anteriores y pueden apreciarse en la Tabla 2.2.:

Tabla 2.2. Particularidades de los proyectos de cooperación al desarrollo. Fuente: elaboración propia a partir de la revisión de la literatura.

\begin{tabular}{lll}
\hline \multicolumn{1}{c}{ Particularidades de los PCD } & & \multicolumn{1}{c}{ Referencias } \\
${$\cline { 1 - 2 }$} }$ & & Diallo y Thuillier (2005); Ika (2012) \\
Pertenecen típicamente al sector público & & Ika y Donnelly (2017); Ika, Diallo y \\
& & Thuillier (2010); Ika y Hodgson (2014); \\
& Wirick (2009)
\end{tabular}

Frecuentemente son ejecutados en contextos Grisham (2010); Ika y Donnelly (2017); complicados Ika y Hodgson (2014); Landoni y Corti (2011); Youker (2003)

Implican a muchos grupos de interés diferentes y en Grisham (2010); Hirschman (1967); Ika distintos países (2012); Julian (2016); Khang y Moe (2008); Youker (1999);

El cumplimiento de sus objetivos se aprecia con Crawford y Bryce (2003); Ika y dificultad en el corto plazo Donnelly (2017); Khang y Moe (2008);

No persiguen beneficios económicos

Ahsan y Gunawan (2010); Ika y Donnelly (2017)

El cliente es una comunidad que no financia el proyecto Ahsan y Gunawan (2010); Ika (2012) y pocas veces está incluída en su definición

Las herramientas de dirección de proyectos no son Blunt y Jones (1992); Muriithi y válidas en algunas culturas

Crawford (2003)

El conjunto de estas características hace de este tipo de proyectos un caso extremo de complejidad sociopolítica (Ika y Hodgson, 2014). Fruto de esta complejidad es que los impactos de los proyectos en la comunidad beneficiaria, en muchas ocasiones, no 
alcancen los niveles deseados. Es por ello por lo que, entre la escasa literatura que existe dentro de la DP dedicada a los PCD, son muchos los trabajos que se encuentran dedicados a averiguar los factores que influyen a la hora de alcanzar el éxito en el impacto de estos proyectos, buscando, en definitiva, una mejor eficacia de los mismos (Diallo y Thuillier, 2005; Ika y Donnelly, 2017; Ika, Diallo y Thuillier, 2012; Khang y Moe, 2008; Steinford y Walker, 2007).

Aunque el estudio realizado por Denizer, Kaufmann y Kraay (2013) con datos de 6000 proyectos del Banco Mundial concluye que, a la hora de obtener mejores resultados, influyen más variables relacionadas con el propio proyecto, como su duración y presupuesto, y la supervisión del mismo, que con el contexto del país en el que se desarrollan, son muchos los autores que otorgan especial importancia al contexto en el que se ejecutan los PCD y a la influencia que éste ejerce sobre los impactos del mismo (Grisham, 2010; Ika, 2012; Ika y Donelly, 2017; Ika y Hodgson, 2014; Khang y Moe, 2008). Este contexto es especialmente relevante para proyectos como los que se enfocan en el desarrollo de capacidades (Ahsan y Gunawan 2010; McEvoy, Brady y Munck, 2016), y progresivamente se ha ido teniendo cada vez más en cuenta a medida que la cooperación al desarrollo ha ido evolucionando y, con ella, los PCD.

\subsubsection{Evolución de los proyectos de cooperación al desarrollo}

El nuevo marco de asociaciones entre países en el que la cooperación se ha visto inmersa ha producido un movimiento desde los proyectos particulares a trabajar con proyectos que pertenezcan a un mismo programa y estén alineados en él, pero también con las estrategias de desarrollo locales y, más recientemente, con los ODS (Ika y Lytvynov, 2011; McEvoy, Brady y Munck, 2016).

La misma evolución que ha vivido la cooperación al desarrollo la han vivido sus proyectos, que han pasado de ser meramente asistencialistas, basados en infraestructuras o procesos técnicos (blueprint ${ }^{8}$ ), a buscar el desarrollo de capacidades de las comunidades locales y el entendimiento cultural (Boni, 2010; Ika y Hodgson, 2014; McEvoy, Brady y Munck, 2016).

Esta evolución se puede apreciar en la Figura 2.3 Conviene destacar que, aunque se ha incluido en esta figura una evolución en el tiempo de los $\mathrm{PCD}$, es solo una relación temporal orientativa que liga un periodo con la tendencia predominante hacia un tipo de proyectos. No quiere decir que hoy en día no se estén implementando proyectos de asistencia técnica o de construcción de capacidades, pero sí, que en un momento

\footnotetext{
${ }^{8}$ Blueprint es un anglicismo utilizado en arquitectura e ingeniería para designar un anteproyecto o plano detallado. Su término fue muy utilizado entre los años 1940 y 1950, con el empleo de las primeras máquinas para copiar planos, dado que las copias salían con líneas blancas sobre fondo azul (Taylor, 2004, Blueprint Reading for Machine Trades, Thomson Delmar Learning, Nueva York). Es un término muy utilizado cuando se habla de proyectos de infraestructuras que requieren este tipo de planos de diseño.
} 
liderado por el partenariado y la búsqueda de acuerdos de mutuo beneficio, el desarrollo de capacidades está cobrando un especial protagonismo.

EI PNUD define el desarrollo de capacidades como "el proceso mediante el cual las personas, organizaciones y sociedades obtienen, fortalecen y mantienen las aptitudes necesarias para establecer y alcanzar sus propios objetivos de desarrollo a lo largo del tiempo" (PNUD, 2009, p. 3).

\section{Asistencia Técnica}

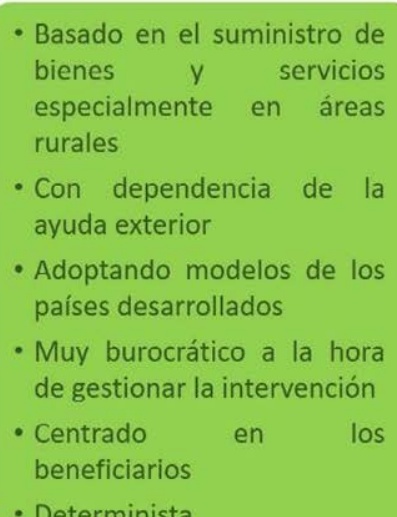

- Determinista

$1950-1980$
Construcción de capacidades

- Basado en reforzar las

habilidades técnicas como

medida para garantizar que

los proyectos perduren

- Fomenta la adquisición de capacidades nuevas

- Apostando por la formación y la salud

- Fijándose en el tipo de gobernanza existente

- Centrado en implementadores

- Abierto
Desarrollo de capacidades

- Basado en sacar lo mejor de

los recursos locales

(capacidades, personas, e instituciones)

- Con visión global de la sociedad y adaptación al cambio

- Sostenible a largo plazo

- Buscando empoderamiento y apropiación

- Centrado en los ciudadanos de una comunidad

- Abierto y complejo

2000 -

Figura 2.3. Evolución de los Proyectos de Cooperación al Desarrollo.

Fuente: elaboración propia a partir de Boni (2010), Ika (2012), Ika y Hodgson (2014), McEvoy, Brady y Munck (2016), y LenCD (2018).

El desarrollo de capacidades se sostiene en cuatro pilares fundamentales, como representa la Figura 2.4. Éstos son: (1) Los arreglos institucionales para permitir el buen funcionamiento de las organizaciones; (2) El liderazgo, para influir y motivar a otros para que logren sus objetivos; (3) El conocimiento, a través de la educación (individual) y de la capacitación (comunitaria) y (4) La rendición de cuentas, por la cual, los titulares de derechos pueden exigir el cumplimiento de las obligaciones adquiridas (PNUD, 2009). 


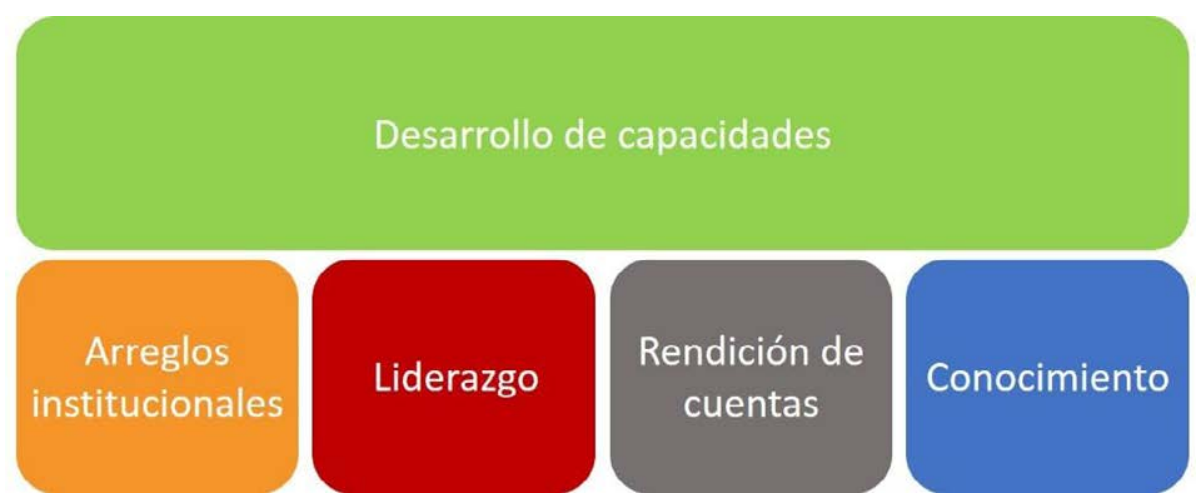

Figura 2.4. Los cuatro pilares de los proyectos de desarrollo de capacidades. Fuente: elaboración propia inspirada en el texto del PNUD (2009).

Con este tipo de proyecto tan centrado en "lo local", aspectos como la cultura cobran un valor fundamental y el concepto de "one-size-fits-all", a menudo utilizado en los proyectos blueprint, deja de tener espacio en la cooperación al desarrollo. Gestionar estos proyectos, tan orientados a las necesidades y características particulares de una comunidad es el reto que tiene actualmente la DP, que se encuentra ante la disyuntiva de si este tipo tan particular de proyectos debe o no ser conducido a través de las herramientas convencionales de la DP.

\subsection{La dirección de proyectos en la cooperación al desarrollo}

La DP es "la aplicación de conocimientos, habilidades, herramientas y técnicas a las actividades del proyecto para cumplir con los requisitos del mismo" (PMI, 2017, p. 10). La DP conlleva cinco grupos de procesos: comienzo, planificación, ejecución, control y cierre, que se ejecutan durante el ciclo de vida del proyecto ${ }^{9}$. El PMBoK (PMI, 2017), referencia a la hora de hablar de DP, identifica diez áreas de conocimiento para la DP: integración, alcance, tiempos, costes, calidad, recursos, comunicaciones, riesgos, adquisiciones y grupos de interés. Estas diez áreas se gestionan a lo largo del ciclo de vida del proyecto. Como esta guía, de origen americano, existen otras parecidas como la elaborada por la Asociación Internacional de Dirección de Proyectos, (IPMA, por sus siglas en inglés), conocida como International Competence Baseline (ICB) (IPMA, 2015), o la realizada por la Asociación para la Dirección de Proyectos inglesa (APM, por sus siglas en inglés), conocida como Body of Knowledge (BoK) (APM, 2012). Todas tienen en común una procedencia occidental, con conceptos que pueden resultar irrelevantes para otras culturas, como la africana, donde los valores están más centrados en la

\footnotetext{
${ }^{9}$ Desde que Baum (1970) introdujo el ciclo de vida del proyecto hace ya casi 50 años, las fases han ido cambiando según la organización que implemente el proyecto. En el ámbito de la cooperación, las agencias, por ejemplo, varían el número de fases desde tres (Agencia de cooperación americana, USAID) hasta siete (Agencia de cooperación canadiense, CIDA). Aunque el número de pasos pueda estar más o menos detallado, el ciclo se mantiene intacto.
} 
cultura y el comportamiento humano que en la racionalidad económica (Muriithi y Crawford, 2003).

Como los PCD ofrecen particularidades que los diferencian de otro tipo de proyectos, algunos autores como Youker (2003), indican que el enfoque para su implementación debe ser diferente al que ofrecen estos estándares de la DP desarrollados por instituciones profesionalizadas. Otros autores ya habían dicho que, para cualquier tipo de proyectos, el entorno de desarrollo es determinante, defendiendo esa adaptación al contexto en la dirección de todo tipo de proyectos (Engwall, 2003).

Aunque no hay una opinión consensuada entre la literatura sobre cómo debería realizarse la dirección de los $P C D$, son muchos los autores que defienden que las herramientas de dirección de proyectos, principalmente las relacionadas con la gestión de riesgos, de costes y de grupos de interés (Yamaswari et al., 2016), ayudarían, y se podrían seguir ciertos estándares como los definidos en el PMBoK, pero adaptándolos al contexto de cada proyecto (Flyvjberg, 2005; Grisham, 2010; Khang y Moe, 2008; Wirick, 2009). Estudios, como el de Golini, Kalchschmidt y Landoni (2015), en el seno de las ONGDs, demuestran que el uso de las herramientas de la DP está relacionado con el éxito y el impacto del proyecto en el largo plazo. Otros, contrarios a que todos los proyectos puedan ser tratados de la misma manera, proponen utilizar metodologías y herramientas específicas (Golini y Landoni, 2014; Ika, Diallo y Thuillier, 2010; Muriithi y Crawford, 2003; Papke-Shields, Beise y Quan, 2010).

En esta línea, surgen algunas guías diseñadas especialmente para los contextos de cooperación al desarrollo, entre las que destacan principalmente PMDPro (2013) y PM4DEV (2015). Las últimas investigaciones tratan de conciliar el uso de estas herramientas al mismo tiempo con las demandas de los beneficiarios (sociedad), con un enfoque más participativo y predictivo, dado que el compromiso de la comunidad con la DP es esencial en los PCD, mientras que, en otro tipo de proyectos, la implicación de los clientes carece de significado (Yalegama, Chileshe y Ma, 2016). Otra diferencia fundamental a la hora de dirigir los PCD frente al resto de proyectos, es que, en los PCD, los directores del proyecto no están normalmente implicados en la planificación del proyecto, sino solo en su implementación en terreno, donde además están también limitados a los deseos de la organización donante en muchos de los casos (Ika y SaintMacary, 2012).

Pese a estas peculiaridades y a que el dinero y los recursos humanos destinados a los PCD ha ido en aumento (OCDE, 2018), en el mundo académico aún son escasas las referencias a la DP en cooperación al desarrollo, centrándose en el uso de sus herramientas, guías y prácticas (Biggs y Smith, 2003; Golini, Kalchschmidt y Landoni, 2015; Hermano et al., 2013; Murithi y Crawford, 2003). Algunos autores han tratado de analizar el estado de la DP en los PCD también a través del estudio de los proyectos 
financiados por bancos de desarrollo o agencias internacionales (Ahsan y Gunawan, 2010; Hermano y Cruz, 2013; Ika, Diallo y Thuillier, 2012), o a través de la evolución de las propias agencias de cooperación (Landoni y Corti, 2011). Y son muchos, los que analizan la dirección de los PCD a través de una de las herramientas más utilizadas en cooperación al desarrollo, el marco lógico (Crawford y Bryce, 2003; Ika y Lytvynov, 2011; Landoni y Corti, 2011; McEvoy et al., 2016; Yamaswari et al., 2016). Esta herramienta será analizada en detalle en el Capítulo 3.

\subsubsection{Herramientas y guías de dirección de proyectos en cooperación}

La gestión del ciclo de vida del proyecto ha sido durante décadas la principal metodología usada por los países donantes y las ONGDs para la gestión y evaluación de las intervenciones de desarrollo (Landoni y Corti, 2011; McEvoy, Brady y Munck, 2016). Dentro de esta metodología se han desarrollado diversas herramientas, pero entre todas, la más conocida es el Marco Lógico. Hasta el nacimiento del Marco Lógico a finales de la década de los 60 , no se conocía ninguna herramienta específica para la DP en el área de la cooperación al desarrollo (Hermano et al., 2013), y aunque en estos años ha recibido algunas críticas, lo cierto es que no hay una única herramienta de DP que pueda incluir todo lo necesario para alcanzar el éxito en un proyecto (Pfeiffer, 2015).

Además del Marco Lógico, que se verá en el Capítulo 3, algunas guías de dirección de proyectos han sido elaboradas para incluir las peculiaridades ya mencionadas de los PCD. Precisamente, una de las primeras fue la Project Management for Post Disaster Reconstruction (PMI, 2005), elaborada por el propio PMI. Esta guía, basada en el PMBoK, nació ante la creencia de que después de un desastre, y ante los altos niveles de altruismo que la sociedad demuestra, trabajar con un enfoque sistemático, ayuda a la pronta recuperación (Sterling, 2008).

La evolución que ha vivido la cooperación al desarrollo, al igual que sus proyectos, ha hecho que las agencias y organizaciones internacionales hayan ido adaptando tanto el ciclo de vida de sus proyectos como el marco lógico que utilizan, y lo mismo ha sucedido con los estándares y metodologías con las que trabajan (Landoni y Corti, 2011).

Desde comienzos del siglo XXI son numerosas las organizaciones internacionales que han desarrollado sus propias guías. Un caso particular es el de la organización LINGOs, que apoyada inicialmente por una beca del PMI, agrupó a profesionales de grandes ONGDs del ámbito internacional con el interés principal de elaborar materiales adecuados y de libre acceso para el aprendizaje de la dirección de proyectos en el sector de la cooperación al desarrollo (Nelson y Cropper, 2016). A partir de estos trabajos nació la guía PMD Pro (PM4NGOS, 2013), cuya primera edición salió en 2010. Para velar por esta guía y los procesos de certificación necesarios en dirección de proyectos de 
cooperación al desarrollo, se conformó simultáneamente la ONGD PM4NGOS ${ }^{10}$. Caso similar ocurre con la guía PM4DEV (2015). Ambas guías fueron comparadas en estudios previos con el PMBoK (Golini y Landoni, 2014; Hermano et al., 2013), destacando que todas las herramientas del PMBoK estaban presentes en ambas guías, que aportaban además dos herramientas muy utilizadas en la cooperación al desarrollo: el marco lógico y el análisis a través de un árbol de problemas/soluciones (Golini, Kalchschmidt y Landoni, 2015).

Estudios más actuales (Quereda, 2018), tras el análisis de 21 guías pertenecientes a organizaciones internacionales dedicadas a la cooperación al desarrollo (ONU, FAO, GIZ, etc. $)^{11}$, entre las que además se encontraban las dos guías citadas anteriormente, $P M D$ Pro 2 ( $2^{a}$ edición) y PM4DEV, concluyen que la guía PMD Pro 2 es el manual más completo en cuanto a técnicas de dirección de proyecto se refiere. De este estudio se extrae además que: (1) el ciclo de vida es una de las herramientas más utilizadas en el contexto de la cooperación; (2) destacan las herramientas participativas y, entre ellas, la Participatory Rural Appraisal, consistente en involucrar siempre a la comunidad en la toma de decisiones; (3) la matriz del marco lógico es la herramienta más explicada.

La introducción de metodologías más participativas cobró fuerza a finales del siglo XX y principios de este siglo (Cornwall, 2006) y encaja con el enfoque de intervenciones de desarrollo de capacidades que buscan tanto la apropiación, como la sostenibilidad. Aprender a trabajar con ellas es solo uno de los retos a los que se enfrentan las personas que se encargan de dirigir este tipo de proyectos.

\subsubsection{Competencias del director de proyectos en intervenciones de desarrollo}

Cuanto más entrenado esté el equipo que participa en el proyecto y mejores capacidades tenga su líder, los resultados mejoran (Ika et al., 2015; Banco Mundial, 2018). En la misma línea, Müller y Turner (2010) ligaban el éxito del proyecto directamente con el estilo de liderazgo y las competencias personales del director del proyecto.

Parry (1998) define las competencias como un conjunto relacionado de conocimientos, habilidades y características personales que tienen influencia en el trabajo individual y colectivo dentro de una organización, estando relacionadas con la obtención de resultados y pudiendo ser mejoradas a través de la formación y la experiencia profesional. EI PMI (2007) divide estas competencias en tres grandes categorías: Técnicas o de conocimiento ("del saber"), funcionales o de ejecución ("del hacer") y

\footnotetext{
${ }^{10}$ PM4NGOS es también una ONGD y todos los pagos relacionados con los exámenes de certificación son dedicados al desarrollo de nuevos materiales didácticos. Actualmente más de 15.000 personas están certificadas bajo este distintivo.

${ }^{11}$ FAO: Food and Agriculture Organization (Organización de las Naciones Unidas para la Alimentación y la Agricultura); GIZ: siglas en alemán para la Agencia de Cooperación Alemana.
} 
personales ("del ser"). Este último tipo de competencias está principalmente ligado al trabajo con personas y a la sensibilidad para detectar sus necesidades y motivarlas, y requiere del dominio de la comunicación (El-Sabaa, 2001). El liderazgo se engloba también dentro de la categoría de competencias personales.

Cuando se estudian los factores críticos de éxito de los PCD, las competencias personales y la experiencia del director de proyecto, así como la del propio equipo de proyecto, siempre ocupan posiciones destacadas (Ika, 2012; Khang y Moe, 2008; Westerveld, 2003). Son pocos los estudios que se han fijado en las competencias de los directores de proyecto de PCD, destacando los de Cobo (2010) y Ortiz-Marcos et al. (2013), que, centrándose en proyectos de ingeniería para el desarrollo, encontraron que el factor crítico de éxito más valorado durante la etapa de ejecución del proyecto estaba relacionado con las competencias del director de proyecto y de su equipo, y con su capacidad para hacer frente a los cambios, riesgos y oportunidades que pudieran surgir durante la implementación del mismo, esto es, capacidad de adaptación. La generación de confianza es otra de las competencias más valoradas para el director de proyecto en los PCD (Diallo y Thuillier, 2005).

La mayoría de los proyectos internacionales, y los PCD esencialmente lo son, fallan más que los proyectos a nivel nacional, debido a la falta de formación en competencias interculturales (Kealey et al., 2005). Muchos PCD en África fallan por la falta de competencias del personal que participa en el equipo del proyecto durante la implementación del mismo y por la falta de consideración hacia los conocimientos y técnicas locales (Agheneza, 2009).

Trabajar con diferentes culturas, como sucede en el caso de los PCD por regla general, conlleva la necesidad de formarse en una serie de competencias, entre las cuales, destaca la capacidad de adaptación del equipo y del director del proyecto al entorno en el que se desarrolla el proyecto (Rodríguez-Rivero et al., 2018). Esta misma capacidad de adaptación fue también la más valorada en el estudio de Ika y Donnelly (2017) con 20 profesionales de la cooperación en cuatro PCD.

La Figura 2.5 resume lo que, a través de la revisión de la literatura, se ha identificado como las competencias personales más importantes del director de un PCD, dando especial importancia a su capacidad de adaptación. Solo liderando el proyecto desde la generación de confianza con la población local, comprendiendo su cultura, se puede pensar en generar apropiación del proyecto por parte de la comunidad. 


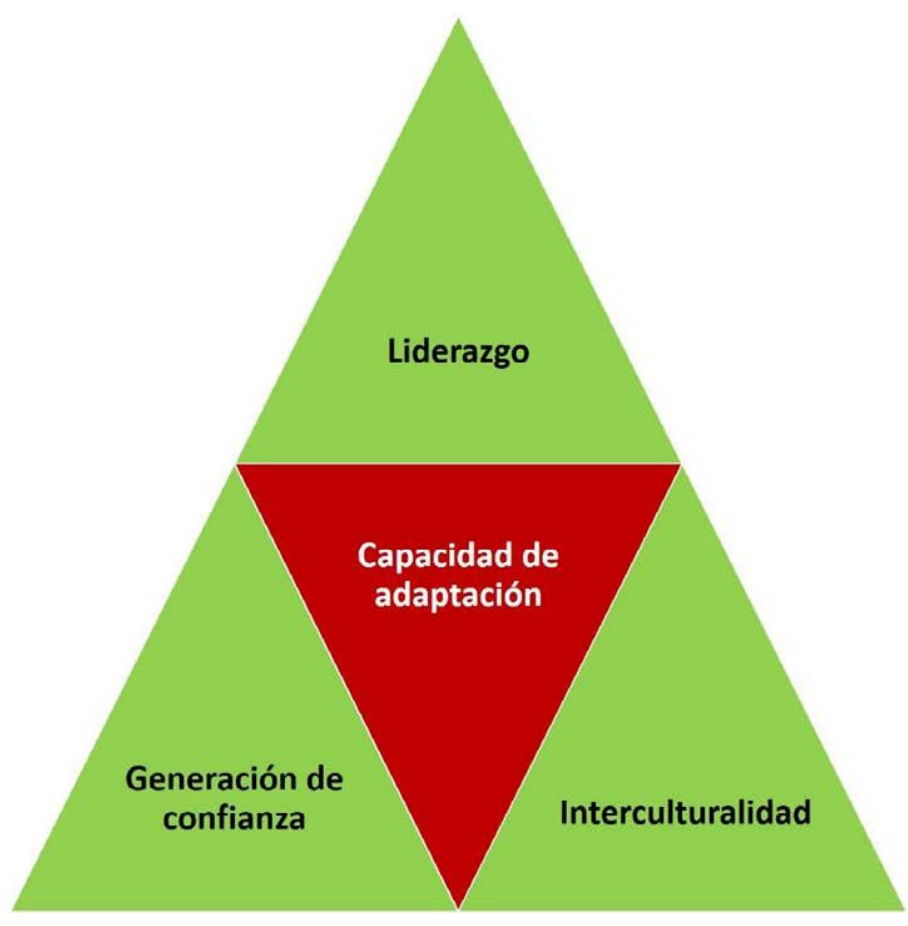

Figura 2.5. Las competencias más destacadas del director de un PCD. Fuente: elaboración propia inspirada en la revisión de la literatura. 


\section{CAPÍTULO 3. EL ENFOQUE DEL MARCO LÓGICO}

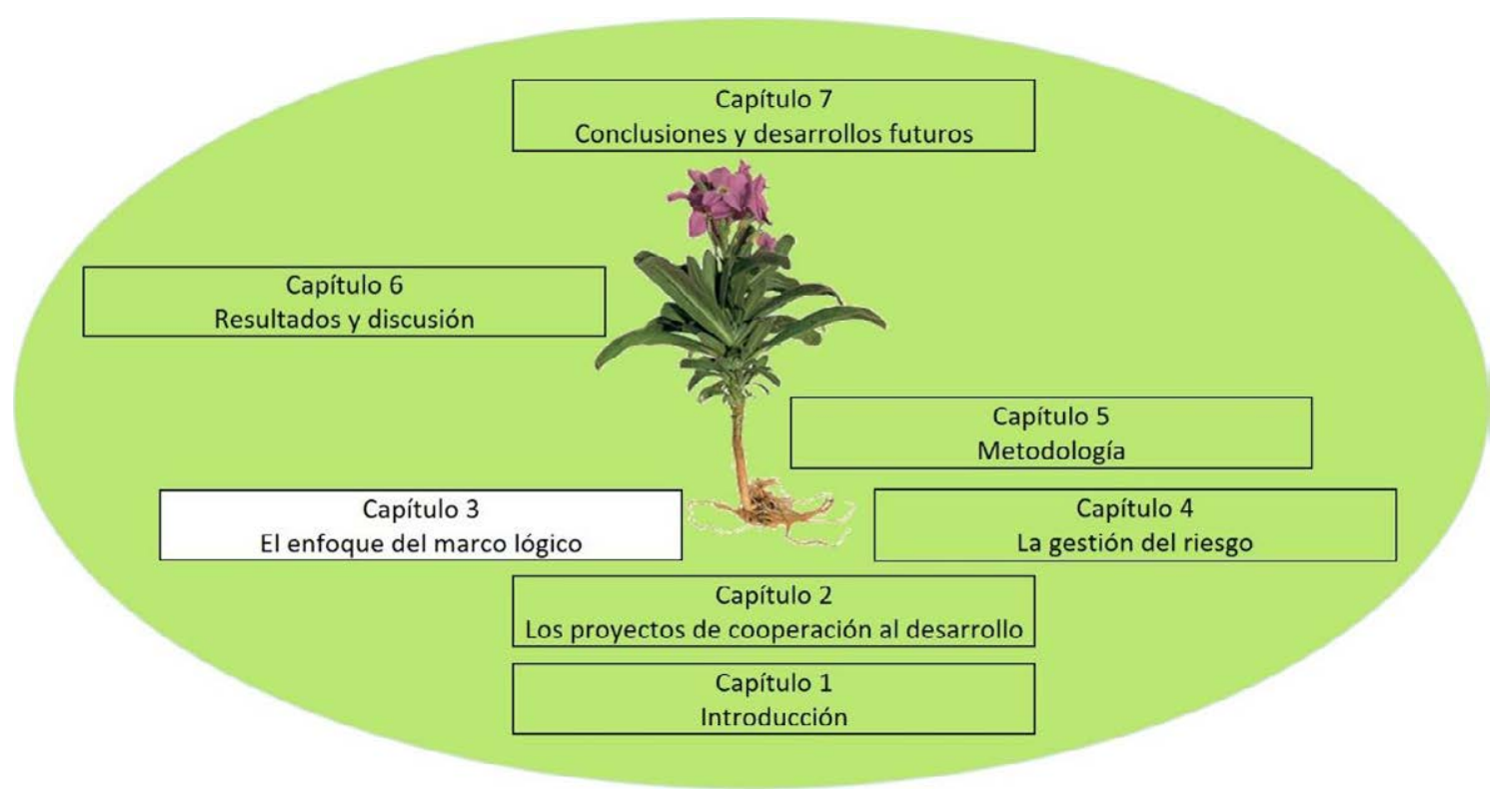

Figura 3.1. El enfoque del marco lógico.

Fuente: elaboración propia.

"No es la más fuerte de las especies la que sobrevive, tampoco es la más inteligente la que sobrevive. Es aquella que se adapta mejor al cambio"

(Atribuida a Charles Darwin, 1809-1882) 


\subsection{Introducción}

El Enfoque del Marco Lógico (EML) nació en 1969 como una metodología específica para los PCD. Desde su aparición, ha sido el método más utilizado por países donantes, agencias de cooperación y ONGDs para la planificación y gestión de estos proyectos (Camacho et al., 2001; Hermano et al., 2013; McEvoy, Brady y Munck, 2016). Hoy, 50 años después de su nacimiento, aunque con algunas evoluciones, esta metodología mantiene intacta su esencia.

Aunque algunos autores como Hummelbrunner (2010) hacen referencia al EML como un proceso más completo que el Marco Lógico ( $\mathrm{ML})$, al que identifica exclusivamente por la Matriz del Marco Lógico (MML), lo cierto es que los fundadores de esta metodología, miembros de la consultora Practical Concepts Incorporated, definían el EML directamente solo como la MML (Practical Concepts Incorporated, 1979). En esta Tesis Doctoral, para evitar confusiones, se utilizará el término del Marco Lógico (ML) para hacer referencia al enfoque o metodología completa, con sus correspondientes pasos. Se recurrirá al término de MML para hacer referencia exclusivamente a la matriz de planificación del marco lógico. Se pretende así no entrar en discusiones sobre un término tan extendido y aceptado por la comunidad internacional en términos de cooperación al desarrollo, sobre el que, como ya establecieron trabajos previos de Bakewell y Garbutt (2005), actualmente hay matices en términos de connotaciones con respecto a qué es en realidad, interpretándose desde una manera de pensar hasta un simple requisito de obligado cumplimiento para obtener financiación.

Así, en este capítulo se realiza un profundo análisis de esta metodología, desde sus orígenes hasta sus versiones más actuales, prestando especial atención tanto a sus fortalezas como a sus debilidades, puesto que solo identificándolas y analizándolas, será posible extraer la máxima eficacia en su utilización y orientar los cambios necesarios que consigan que esta metodología siga siendo útil por muchos años más.

\subsection{Origen y evolución del Marco Lógico}

El ML nació en 1969, cuando la Agencia Americana de Cooperación Internacional (con sus siglas en inglés, USAID), encargó a la consultora Practical Concepts Incorporated analizar su sistema de evaluación de proyectos, del cual destacaron principalmente que la planificación era demasiado indefinida, lo cual impedía no solo la evaluación entre lo planificado y lo realizado, sino también relacionar las actividades con la consecución de los objetivos, así como descubrir la contribución del proyecto en el impacto generado (Practical Concepts Incorporated, 1979). El ML es la solución que ofreció la consultora en respuesta a estos problemas, presentándolo como una metodología para el diseño y la evaluación de los proyectos. 
Los conceptos que usa el ML se basan en gran medida en la experiencia previa que Rosenberg ${ }^{12}$, al que se puede considerar el padre del ML, había adquirido en la gestión interna de proyectos militares, así como en la planificación de los primeros lanzamientos de satélites y los programas espaciales de la Agencia Espacial Americana (con sus siglas en inglés, NASA) (Hailey y Sorgenfrei, 2004; Practical Concepts Incorporated, 1979). Estos orígenes marcaron el fuerte carácter jerárquico y el enfoque hacia la precisa definición de objetivos (Hummelbrunner, 2010).

Entre 1970 y 1971, el ML fue probado en 30 proyectos de cooperación de USAID. La siguiente organización en aplicarlo fue la Agencia de Cooperación Canadiense (con sus siglas en inglés, CIDA), en 1974 (Practical Concepts Incorporated, 1979; Landoni y Corti, 2011). En los años 1980s, empezó a ser utilizada por numerosos organismos internacionales (Hummelbrunner, 2010) y desde comienzos de este siglo, su expansión ha hecho que se trate de un lenguaje común en la cooperación al desarrollo (Banco Mundial, 2005), solicitándose además como un requisito imprescindible para obtener financiación (Golini, Kalchschmidt y Landoni, 2015). En la actualidad, existen gran cantidad de guías (ver Tabla 3.1.) y formaciones específicas relacionadas con su aprendizaje, sin embargo, a veces se recurre al uso de la metodología sin conocer bien cómo aplicarla, utilizándose solo para cumplir con los requisitos del donante, más que como un método para gestionar los PCD.

Tabla 3.1. Algunos ejemplos de guías de uso del Marco Lógico.

Fuente: elaboración propia.

\begin{tabular}{|c|c|c|}
\hline Entidad & Título & Fecha \\
\hline Banco Mundial & The Logframe Handbook & 2005 \\
\hline Gobierno Serbio & Guide to The Logical Framework Approach & 2011 \\
\hline $\begin{array}{l}\text { Agencia de Cooperación Noruega } \\
\text { (con sus siglas en inglés, NORAD) }\end{array}$ & The Logical Framework Approach & 1999 \\
\hline $\begin{array}{l}\text { Comisión Económica para América } \\
\text { Latina y el Caribe (CEPAL) }\end{array}$ & $\begin{array}{l}\text { Metodología del marco lógico para la planificación, el } \\
\text { seguimiento y la evaluación de proyectos y programas }\end{array}$ & 2015 \\
\hline Fundación CIDEAL & El Enfoque del marco lógico: 10 casos prácticos & 2001 \\
\hline $\begin{array}{l}\text { Agencia de Cooperación Sueca (con } \\
\text { sus siglas en inglés, SIDA) }\end{array}$ & $\begin{array}{l}\text { The Logical Framework Approach. A summary of the } \\
\text { theory behind the LFA method }\end{array}$ & 2004 \\
\hline $\begin{array}{l}\text { Agencia de Cooperación Canadiense } \\
\text { (con sus siglas en inglés, CIDA) }\end{array}$ & The logical framework: Making it results-oriented & 1997 \\
\hline $\begin{array}{l}\text { Agencia de Cooperación Australiana } \\
\text { (con sus siglas en inglés, AusAID) }\end{array}$ & AusGUIDE: The Logical Framework Approach & 2003 \\
\hline $\begin{array}{l}\text { Agencia de Cooperación Danesa } \\
\text { para el Desarrollo (con sus siglas en } \\
\text { inglés, DANIDA) }\end{array}$ & $\begin{array}{l}\text { Logical Framework Approach: A flexible tool for } \\
\text { participatory development }\end{array}$ & 1996 \\
\hline
\end{tabular}

12 Leon J. Rosenberg fue también el fundador de Practical Concepts Incorporated, además de ser, junto a L. D. Posner, el principal diseñador del ML dentro de la consultora. 
El ML es una metodología de planificación por objetivos, definida así precisamente para resolver los primeros problemas observados en la evaluación de los PCD de USAID, donde el cumplimiento de actividades derivaba en la consecución de unos objetivos que distaban del objetivo inicial. Con la planificación por objetivos, o también conocida como de arriba abajo, los objetivos de un nivel son los medios para satisfacer los objetivos de su nivel superior (Baccarini, 1999). La principal diferencia entre la planificación por objetivos y la planificación por actividades, se puede apreciar en la Figura 3.2, donde se observa que la planificación de arriba abajo permite responder a la pregunta cómo, permitiendo no perder de vista desde el momento inicial el objetivo final al que quiere contribuir el proyecto. La planificación de abajo arriba, o por actividades, respondería en cambio a la pregunta para qué. Toda planificación por objetivos tiene que partir del análisis de un árbol de problemas, que dé lugar a un árbol de objetivos, que para cumplirse necesite de unas actividades, es decir, antes de planificar las actividades, es necesario realizar el análisis de problemas y objetivos (Ortengren, 2004).

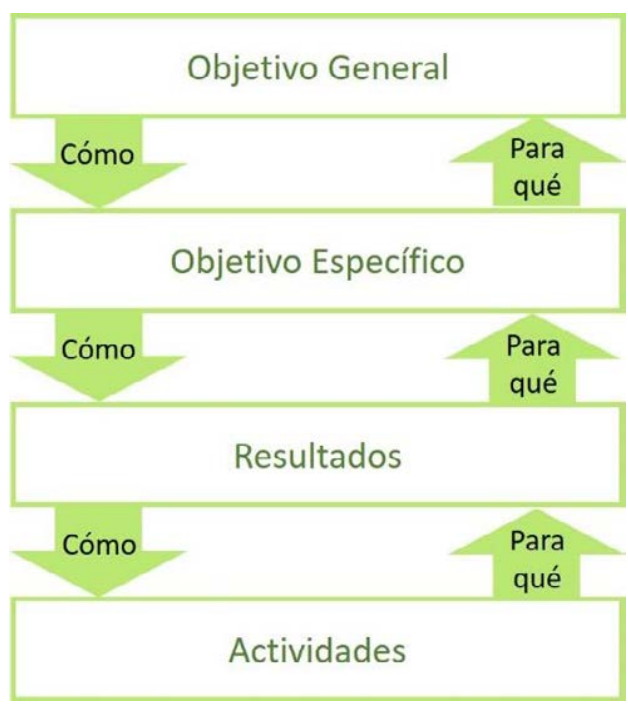

Figura 3.2. Planificación por objetivos vs planificación por actividades. Fuente: adaptación de Baccarini (1999)

El ML diseñado en 1969 constaba de lo que hoy se conoce como la MML, una matriz 4x4 que representa el elemento más conocido del ML (e.g. Camacho et al., 2001; Ortegón, Pacheco, y Prieto, 2015; Practical Concepts Incorporated, 1979). La Figura 3.3 representa la matriz, con sus lógicas Vertical, Horizontal y Mixta.

La Lógica Vertical o jerárquica, se construye de tal manera que se puedan examinar los vínculos causales, así las actividades generan resultados, que permiten obtener el objetivo específico para el cual se realiza el proyecto. Este objetivo específico, 
contribuirá al objetivo general, ya fuera de los límites propios del proyecto (Camacho et al., 2001; Ortegón, Pacheco, y Prieto, 2015).

La Lógica Horizontal presenta el progreso de cada objetivo, resultado o actividad, a través de los Indicadores Objetivamente Verificables (IOV), que son comprobados a través de las Fuentes de Verificación (FV). También existe una lógica más compleja, conocida como Lógica Mixta o Lógica Horizontal Completa (representada a través de flechas rojas en la Figura 3.3), a través de la cual, la MML expresa que si se cumplen unas condiciones previas que permiten realizar unas actividades, éstas al cumplirse junto con unos supuestos, logran dar unos resultados, que igualmente al alcanzarse, y dándose unos supuestos, permiten obtener el objetivo específico, que igualmente siempre que se cumplan unos supuestos, contribuye al objetivo general del proyecto (Camacho et al., 2001; Ortegón, Pacheco, y Prieto, 2015). En esta última lógica, cobran especial importancia los supuestos, o hipótesis, externos al proyecto, que deben ser cumplidos para alcanzar el siguiente nivel de la jerarquía de objetivos. Esta columna de Supuestos ha sido especialmente criticada por no representar la realidad en muchas ocasiones (Yamaswari et al., 2016) y refleja alguna de las limitaciones, como se verá más adelante.

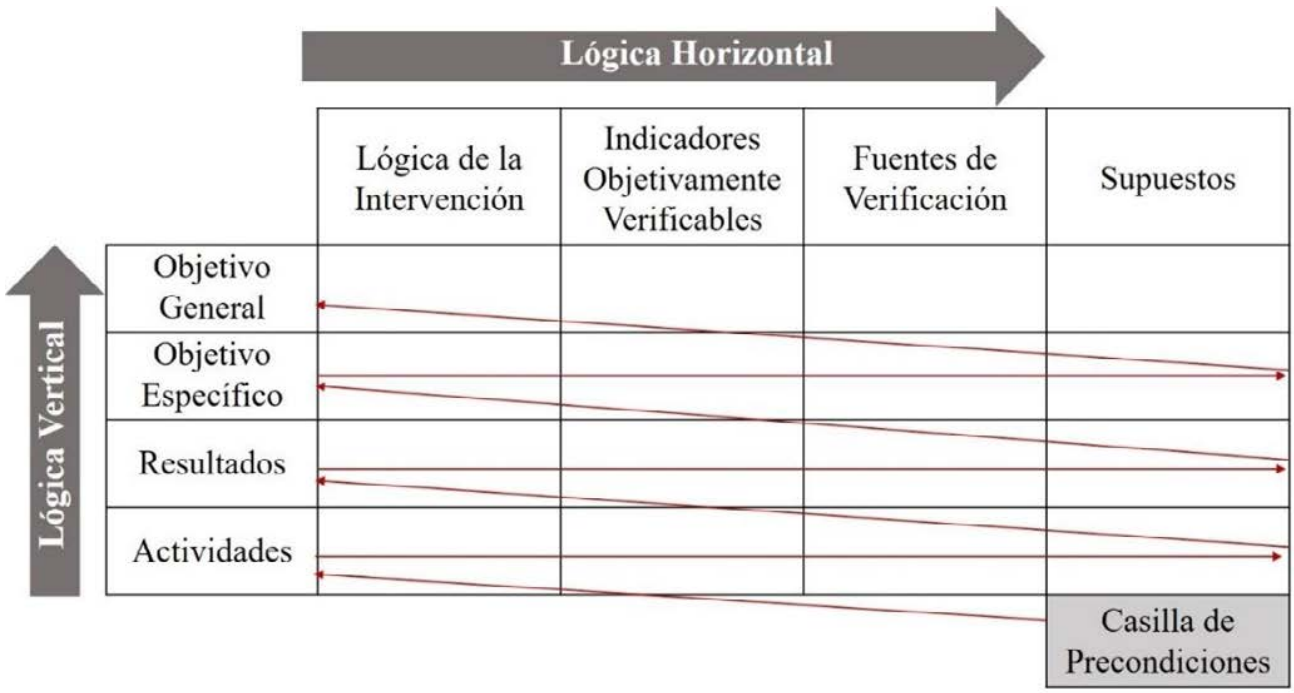

Figura 3.3. Matriz del ML con sus lógicas.

Fuente: elaboración propia a partir de Camacho et al. (2001) y Ortegón, Pacheco y Prieto (2015).

Esta matriz representa lo que se considera la primera generación del ML (Couillard, Garon y Riznic, 2009; Sartorius, 1996), y fue criticada principalmente por su rigidez, por su terminología confusa (principalmente entre objetivo específico y general) y por no mostrar claridad en el proceso, centrándose únicamente en la matriz como resultado y dejando a un lado la implicación de los participantes (Couillard, Garon y Riznic, 2009). 
En los primeros años de la década de los 1980s, la Agencia Alemana de Cooperación (más conocida por sus siglas en alemán, GIZ, anteriormente GTZ), modificó el ML creando una versión extendida más participativa, conocida como Ziel Orientierte Projekt Planung (ZOPP) (GTZ, 1997). Esta metodología que implicaba la realización de talleres en los que se implicaba a los principales grupos de interés del proyecto se componía de los siguientes seis pasos (GTZ, 1997): (1) Análisis de los participantes, (2) análisis de los problemas, identificando el problema principal, (3) análisis de las causas y efectos del problema principal, (4) análisis de los objetivos o de las soluciones, (5) análisis de las alternativas, y (6) la MML. Hoy en día el análisis de los problemas se hace en un solo paso, componiéndose así la metodología de cinco pasos, que representa la segunda generación del ML.

Los cuatro primeros pasos de esta metodología se corresponden con lo que varios autores y guías conocen como fase de análisis, mientras que la MML se enmarca dentro de la fase de planificación (e.g. Gómez y Sainz, 1999; Camacho et al., 2001).

El análisis de los participantes se realiza para tener una visión lo más precisa posible de la realidad social sobre la que se pretende incidir con la intervención, identificando no solo a los beneficiarios directos e indirectos de la misma, sino también a los que resultan excluidos del alcance del proyecto o incluso, perjudicados (Camacho et al., 2001). Al analizar sus intereses se puede potenciar el apoyo de los colectivos con intereses coincidentes o complementarios al proyecto y conseguir el apoyo de los indiferentes o excluidos (Ortegón, Pacheco y Prieto, 2015).

El análisis de los problemas, junto con el análisis de los participantes, es lo que podría llamarse análisis de la situación. Consiste en identificar los problemas que afectan a los colectivos ya priorizados y establecer, a través de diagramas causa-efecto, las relaciones que existen entre estos problemas (e.g. Camacho et al., 2001). Se suele recurrir a un diagrama en forma de árbol para representarlo.

El análisis de los objetivos permite describir la situación futura a la que se desea llegar al resolver los problemas (e.g. Ortegón, Pacheco y Prieto, 2015). Igualmente se representa a través de un diagrama de árbol considerado la copia en positivo del árbol de problemas, pero donde lo que antes eran relaciones causales, ahora son relaciones instrumentales, es decir, los niveles inferiores del árbol son ahora los medios para alcanzar los superiores (Camacho et al., 2001).

El análisis de las alternativas se realiza para seleccionar una entre las alternativas planteadas para alcanzar el objetivo buscado. En esta etapa, la transparencia y la negociación con las comunidades locales cobran un papel fundamental (Camacho et al., 2001). Según la cantidad de trabajo necesario, la estrategia elegida podría traducirse en 
una única intervención a través de un proyecto, o en un programa compuesto de varios proyectos (Ortegón, Pacheco y Prieto, 2015).

La MML es la representación ya planteada en la Figura 3.3. En la segunda generación, todavía se criticaba, con respecto a esta matriz, que los IOV eran difíciles de obtener y que la terminología utilizada continuaba siendo difícilmente entendible (Couillard, Garond y Riznic, 2009).

La tercera generación del ML surge entre la década de los 1990s, y la entrada de los 2000s, debido al interés de muchas agencias de cooperación en su uso. Estas agencias (e.g. AusAID, 2003; CIDA, 1997; NORAD, 1999) empiezan a promover la elaboración de guías que clarifiquen la metodología, permitiendo así su mejor entendimiento y una mayor involucración de todos los participantes. Sin embargo, aunque esta tercera generación promueve la integración con otros procesos y herramientas de la DP, no propone medios para conseguirlo (Couillard, Garond y Riznic, 2009; Hermano et al., 2013).

La Figura 3.4. resume de manera gráfica esta evolución cronológica del ML, indicándose en la parte azul sus principales características, y en la parte roja sus limitaciones.

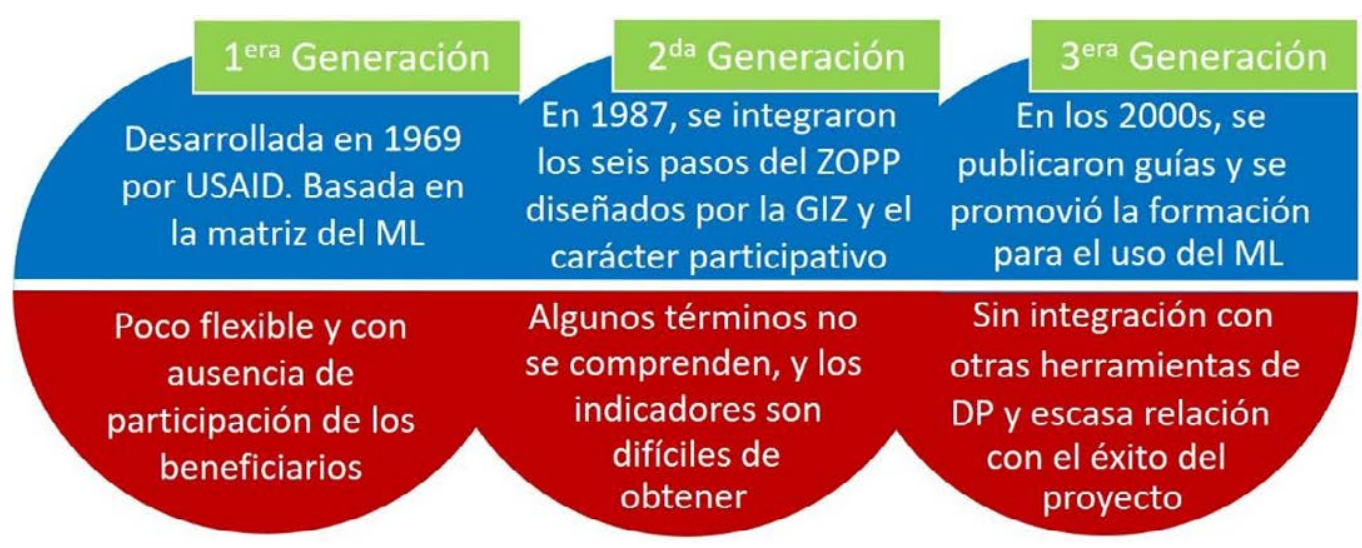

Figura 3.4. Evolución del ML.

Fuente: elaboración propia a partir de Couillard, Garon y Riznic (2009).

Algunos autores como Landoni y Corti (2011), han estudiado esta misma evolución del ML a través de su uso en las agencias de cooperación.

De un modo u otro, la evolución del ML se ha debido precisamente a la fortaleza de su sencillez, que le ha permitido mantenerse al frente de la planificación y evaluación de los PCD a lo largo de ya 50 años, pero también a la existencia de puntos de mejora que hoy en día se siguen encontrando. El siguiente punto tratará de sintetizar las fortalezas 
y debilidades de esta metodología para ver hacia dónde pueden orientarse las nuevas propuestas que continúen con su evolución.

\subsection{Características del Marco Lógico: limitaciones y fortalezas}

EI ML es una herramienta de planificación utilizada mayoritariamente en contextos de países en desarrollo en los que abunda la incertidumbre (Couillard, Garond y Riznic, 2009; Ika y Donelly, 2017; Ika y Hodgson, 2014). En este entorno y con la máxima de Eisenhower ${ }^{13}$ "plans are nothing, planning is everything", la necesidad de cambiar la planificación inicial para hacer frente a los imprevistos parece necesaria para alcanzar el éxito del proyecto (Dvir y Lechler, 2004). Precisamente, el mantenimiento del orden y la causalidad inicial según avanza el proyecto es uno de los aspectos más criticados de esta metodología, tachada de rígida y de estática (Coleman, 1987; Crawford y Bryce, 2003; Gasper, 2000; Hummelbrunner, 2010).

Este estatismo se debe precisamente a la ausencia de la dimensión del tiempo en la herramienta (Crawford y Bryce, 2003; Golini, Landoni y Kalchscmidt, 2017). Yamaswari et al. (2016) culpaban de este estatismo a la vinculación que existe entre el ML y la concesión del proyecto, proponiendo separar el ML del contrato del proyecto para así poder actualizar los documentos derivados del uso de la metodología conforme avanza el proyecto. La falta de temporalidad alimenta otra de las grandes críticas que recibe la metodología, dado que la impide poderse desarrollar a lo largo del ciclo de vida del proyecto (Khang y Moe, 2008), otorgándole utilidad exclusivamente a las etapas de planificación y de monitorización (Gasper, 2000).

Otra de las críticas más frecuentes, debido precisamente a los contextos inciertos ya citados, es que la columna de supuestos o hipótesis no incluye verdaderamente los factores de incertidumbre, recurriéndose a formulaciones muy neutras o positivas de acontecimientos exclusivamente externos que se darán para poder desarrollar el proyecto (Yamaswari et al., 2016). Este planteamiento en positivo, en lugar de valorar posibles riesgos, impide plantear medidas de prevención o corrección.

Es por ello por lo que muchos autores remarcan la necesidad que tiene el $\mathrm{ML}$ de complementarse de otras herramientas de la DP para gestionar de manera completa un proyecto (Coleman, 1987; Couillard, Garond y Riznic, 2009; Hermano et al., 2013). La dificultad de integración del ML con otras herramientas de DP, pese a ser muy citada en el mundo académico (Couillard, Garond y Riznic, 2009; Crawford y Bryce, 2003; Gasper, 1997) no es corroborada curiosamente por directores de proyecto trabajando en ONGDs, como demuestra el estudio de Golini, Landoni y Kalchscmidt (2017), en el que

\footnotetext{
${ }^{13}$ Dwight D. Eisenhower (1890-1969), presidente de Estados Unidos entre los años 1953 y 1961 conocido por citar en uno de sus discursos el principio de Urgencia/Importancia en los proyectos, que refleja a su vez la esencia de realizar cambios continuamente en la planificación.
} 
los profesionales destacan que el ML se integra fácilmente con otras herramientas de DP. En este mismo estudio, el ML demuestra ser una herramienta con efecto positivo en la actuación del proyecto, es decir, con vinculación directa en el éxito del mismo. Este trabajo se opone en estas valoraciones a otros estudios previos más teóricos que establecían que no eran claros los nexos del buen uso del ML con respecto al éxito del proyecto (Couillard, Garond y Riznic, 2009). En cualquier caso, que, tras 50 años de uso de esta herramienta, no exista un claro consenso en el sentido de vincular su uso con el éxito del proyecto, no hace más que demostrar la dificultad de encontrar causas que garanticen el éxito de un PCD. Alguna crítica a la metodología está, precisamente, relacionada con la falta de inclusión de criterios y factores de éxito (Ika y Lytvynov, 2011).

Muy cuestionado está también el hecho de que, al ser, principalmente la matriz, requerida por las instituciones donantes o convocatorias de financiación, en numerosas ocasiones se complementa por cumplir, sin dedicarle la suficiente atención (Gasper, 2000), dando lugar a una inapropiada asignación de IOV (Couillard, Garond y Riznic, 2009; Crawford y Bryce, 2003), o a la formulación de fuentes de verificación no adecuadas (Crawford y Bryce, 2003).

Desde el punto de vista del empoderamiento de las comunidades locales, son muchas las críticas que recibe el ML por la escasa participación de los beneficiarios en su elaboración (Chambers, 2005), pese a ser considerada, por definición, una metodología participativa (e.g. Ortegón, Pacheco y Prieto, 2015; Banco Mundial, 2005).

Son numerosos los estudios que relacionan la metodología del ML con los estándares de la Dirección de Proyectos (Baccarini, 1999; Couillard, Garon y Riznic, 2009; Hermano et al., 2013; Khang y Moe, 2008; Golini, Landoni y Kalchscmidt, 2017; Landoni y Corti, 2011; Yamaswari et al., 2016). De todos ellos se deducen sus limitaciones, ya comentadas, pero al mismo tiempo, su hegemonía como herramienta de dirección de proyectos en contextos de cooperación al desarrollo, y ello es debido, a que, junto a sus debilidades, posee unas fortalezas muy consolidadas a lo largo de estos 50 años de uso.

Precisamente, esta antigüedad de la herramienta hace que represente hoy en día un lenguaje común en las intervenciones de desarrollo (Hummelbrunner, 2010) que facilita la cooperación entre todos los participantes. La amplia aceptación que ha tenido el ML a lo largo de su historia posiblemente se deba a que se trata de una herramienta sencilla y fácil de utilizar (Buttigieg, Gauci y Dey 2016; Camacho et al., 2001; Hummelbrunner, 2010). Esta sencillez, permite que pueda ser explicada y trabajada con prácticamente todas las comunidades, con el único requisito, no banal, de saber leer y escribir. Se han ensayado versiones que facilitan su uso incluso con estos limitantes, aunque plantea problemas de difícil solución (Camacho et al., 2001). 
Además, es muy valorada por ser una herramienta que proporciona una visión holística que permite el entendimiento del proyecto (Couillard, Garon y Riznic, 2009; Practical Concepts Incorporated, 1972). Su orden y su causalidad fomentan una visión completa y las implicaciones de cada una de las actividades a los logros del proyecto.

Partiendo de estas ventajas, algunos han sabido ver su aplicación más allá de los proyectos de cooperación, por ejemplo, el trabajo de Buttigieg, Gauci y Dey (2016), demuestra que su enfoque desde objetivos permite determinar cuáles son los problemas que afectan a una organización, aplicándose para implementar su mejora continua. En Canadá, otros organismos como la Agencia Espacial o la Comisión de Seguridad Nuclear, relacionados con sus orígenes, también están utilizando esta metodología en sus proyectos (Couillard, Garon y Riznic, 2009). En Colombia, el Departamento Nacional de Planificación, diseñó la Metodología General Ajustada, basada en el Marco Lógico, para la gestión de todos los proyectos de financiación pública.

Su expansión a ámbitos diferentes al de la cooperación al desarrollo consolida las fortalezas de esta metodología en la gestión de proyectos. No obstante, en estos 50 años de su existencia, además de la evolución presentada, la detección de debilidades, junto al reconocimiento que merece la metodología, ha llevado a varios autores a plantear nuevas versiones, que, manteniendo esa sencillez e integración, incorporan propuestas de mejora para alguna de las debilidades encontradas.

\subsection{Propuestas de nuevas versiones en torno al Marco Lógico}

Muchas de las nuevas versiones del Marco Lógico propuestas en la literatura tratan de dar respuesta a las limitaciones encontradas anteriormente.

Una de las limitaciones comentadas era la falta de inclusión de aquellos factores internos al propio proyecto que podían condicionar su desarrollo, como podrían ser las relaciones entre los interesados, o las diferencias entre las organizaciones que intervienen. Incluir estos condicionantes internos tanto como supuestos, como riesgos, es la propuesta de Yamaswari et al. (2016), junto con una mayor incidencia en la consideración de los factores externos, que, en muchas ocasiones, criticaban, se hace de una manera muy vaga.

El planteamiento del trabajo de Yamaswari et al. apuesta por una mejor gestión de riesgos (internos y externos) pero mantiene la convivencia de los riesgos junto a los supuestos. Del mismo modo, Ika y Lytvynov (2011), mantienen los supuestos, pero añaden otros factores, que llaman de influencia, entre los que incluyen los criterios de éxito, factores de éxito, supuestos y riesgos, todos en una misma columna. Asimismo, incorporan dos nuevas columnas, la de costes y la de beneficios, como muestra la Figura 3.5. Estas dos últimas columnas plantean que se vayan rellenando según se va 
disponiendo de la información, por tanto, indirectamente, también resuelve el estatismo criticado por otros autores, dado que mantiene viva la matriz a lo largo del proyecto.

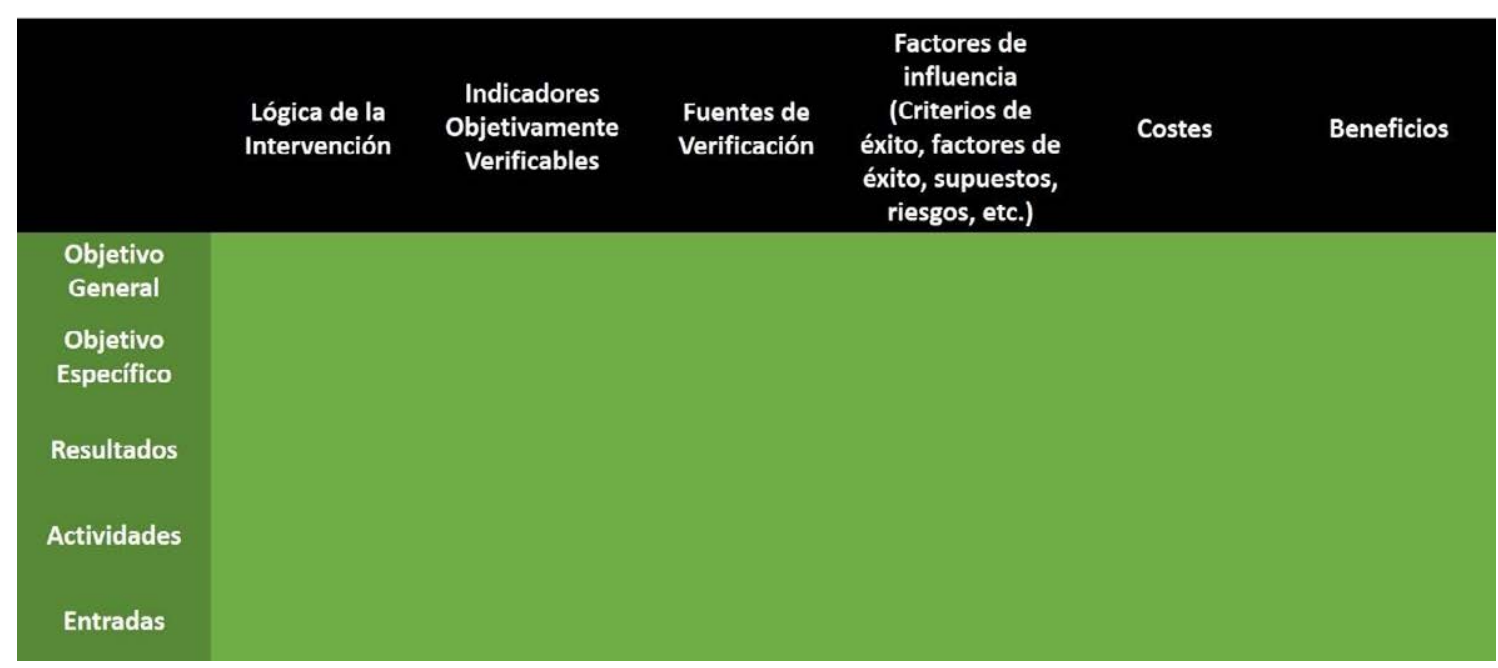

Figura 3.5. Propuesta de matriz del Marco Lógico modificada por lka y Lytvynov.

Fuente: Ika y Lytvynov (2011).

La Figura 3.6. muestra el modelo de matriz propuesto por Couillard, Garond y Riznic (2009), al cual bautizaron como el Enfoque del Marco Lógico del Milenio.

\begin{tabular}{|c|c|c|c|c|c|c|}
\hline \multirow{2}{*}{$\begin{array}{l}\text { Compromisos del } \\
\text { proyecto }\end{array}$} & \multicolumn{2}{|c|}{$\begin{array}{c}\text { Prioridad de las medidas de } \\
\text { éxito }(E, F, A)\end{array}$} & \multirow{2}{*}{$\begin{array}{l}\text { Fuentes de } \\
\text { Verificación }\end{array}$} & \multicolumn{2}{|c|}{ Riesgos (B, M, A) } & \multirow[t]{2}{*}{ Responsable } \\
\hline & Medida & Prioridad & & Riesgo & Nivel & \\
\hline \multicolumn{7}{|l|}{$\begin{array}{l}\text { Valor organizativo } \\
\text { (Misión) }\end{array}$} \\
\hline \multicolumn{7}{|l|}{$\begin{array}{l}\text { Alcance y } \\
\text { entregables }\end{array}$} \\
\hline \multicolumn{7}{|l|}{ Actividades } \\
\hline Recursos & & & & & & \\
\hline
\end{tabular}

Figura 3.6. Propuesta de matriz del Marco Lógico del Milenio. Fuente: Couillard, Garon y Riznic (2009).

Como se puede apreciar, esta versión da un paso más hacia la mejora de la gestión de riesgos, sustituyendo la columna de supuestos por la de riesgos, e introduciendo a su 
vez valores para indicar la importancia del riesgo (B: bajo; M: medio; $A$ : alto). Sustituye también los indicadores por medidas de éxito, otorgándoles igualmente unos niveles de prioridad (E: esencial; F: flexible; A: ajustable), para darlas así más o menos importancia. Además, añade la columna de la persona responsable de cada uno de los compromisos del proyecto. Esta versión establece vínculos con otras herramientas muy utilizadas en la DP, como la Estructura de Descomposición del Proyecto (EDP) y sus entregables, los planes de gestión de recursos humanos, o de riesgos, la matriz de asignación de responsabilidades y el Diagrama de Gantt. El Marco Lógico del Milenio se acerca más así a la integración con otras herramientas convencionales de la DP, dando respuesta a algunas de las debilidades citadas anteriormente. Aunque la dimensión del tiempo no aparece citada explícitamente en esta versión, se encuentra envuelta en el concepto de prioridad.

La versión más compleja y rompedora de la $\mathrm{MML}$ es seguramente la propuesta por Crawford y Bryce (2003), que, en un formato tridimensional de prisma triangular, separa la parte con responsabilidad directa sobre la dirección del proyecto (entradas, actividades y resultados), de la parte que considera de hipótesis de desarrollo (objetivos específico y general). Separa además entre dos puntos de vista, el de la persona encargada de planificar el proyecto, y el de la persona responsable de su dirección. Sobre ambas visiones, siempre presente el transcurso del tiempo y las actualizaciones a lo planificado inicialmente, asignando para ello también a una persona responsable. Esta versión, que promueve el dinamismo de la herramienta y además permite el aprendizaje a través de los históricos, no presta, sin embargo, la atención que prestaban las anteriormente expuestas versiones a los riesgos. Es posible que sea debido a que esta versión es la primera que se desarrolló, en plena etapa de expansión del ML (2003), y la gestión de riesgos no fuera en ese momento una debilidad detectada. Esta versión, con sus tres vistas se puede ver en la Figura 3.7. La base de cada uno de los niveles consta de una tabla donde los IOV y las FV se completan con el cronograma y las variaciones con respecto a lo previsto. Los supuestos, al igual que en la MML original, son los que condicionan la escalada jerárquica, pero solo desde el punto de vista de la DP.

Al igual que Crawford y Bryce dividían entre lo que estaba al alcance de la DP y lo que se consideraban hipótesis de desarrollo, doce años después Pfeiffer (2015), proponía separar igualmente lo que consideraba la parte manejable del proyecto de la parte no gestionable. Justificaba esta división, en que los PCD tienen como objetivo generar cambios a situaciones sociales, y estos cambios no pueden ser tratados como si fueran bienes que se entregan, por lo tanto, no son directamente gestionables dentro del ámbito del proyecto, sino que le trascienden. Las cuatro columnas originales de la MML aplicarían, de esta manera, solo a la parte no gestionable del proyecto. Esta versión de la matriz se muestra en la Figura 3.8 y se conoce como el Nuevo Marco Lógico. 


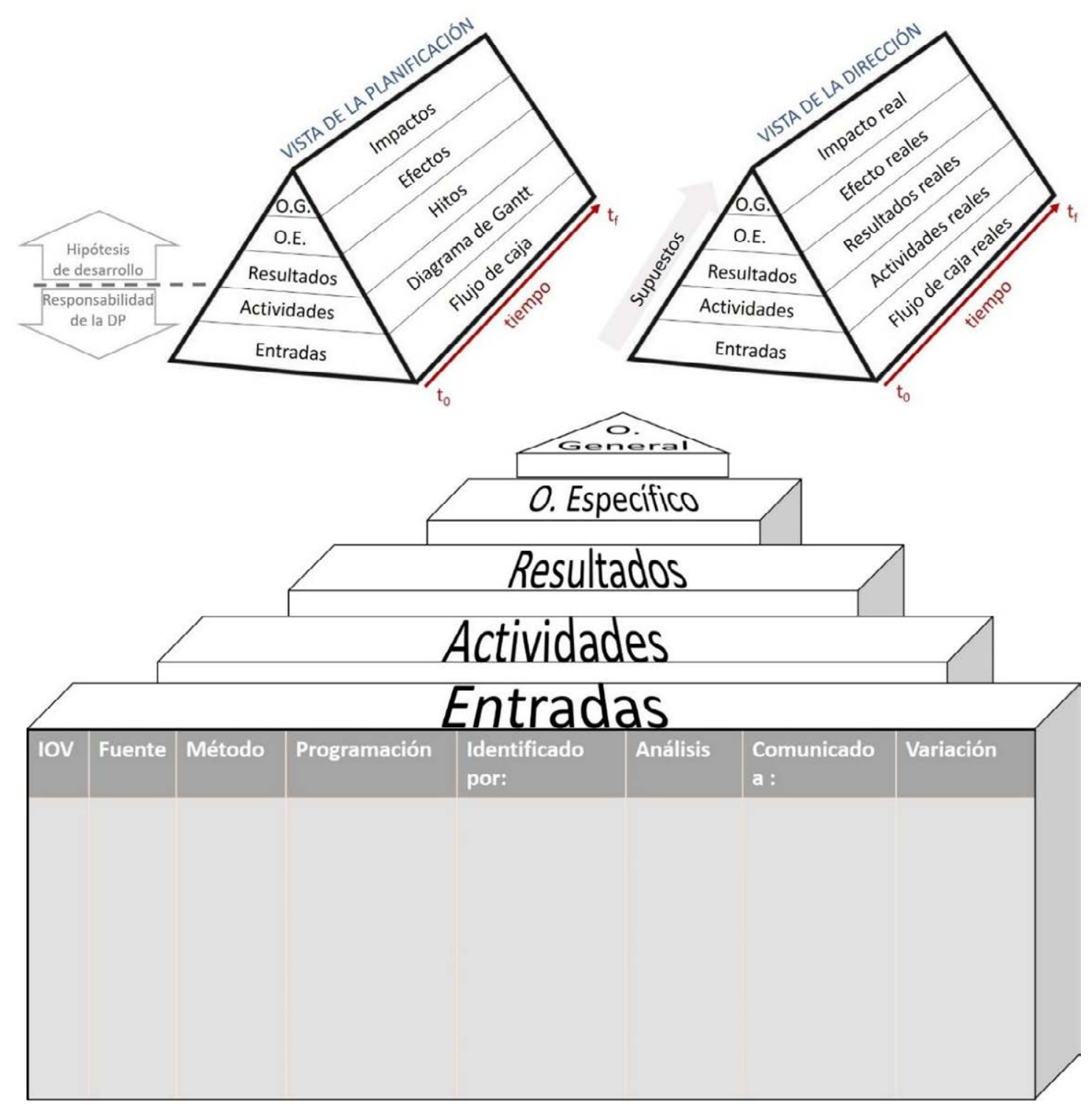

Figura 3.7. Tres vistas de la propuesta de matriz del Marco Lógico-3D.

Fuente: Crawford y Bryce (2003).

\begin{tabular}{|c|c|c|c|}
\hline Lógica de intervención & $\begin{array}{l}\text { Indicadores de } \\
\text { impacto }\end{array}$ & $\begin{array}{l}\text { Fuentes de } \\
\text { comprobación }\end{array}$ & $\begin{array}{l}\text { Suposiciones } \\
\text { importantes }\end{array}$ \\
\hline \multicolumn{4}{|l|}{ Objetivo Superior } \\
\hline \multicolumn{4}{|l|}{ Objetivo del proyecto } \\
\hline \multicolumn{4}{|c|}{ Lógica de producción } \\
\hline $\begin{array}{l}\text { Resultados } \\
\text { esperados }\end{array}$ & $\begin{array}{l}\text { Principales } \\
\text { entregables }\end{array}$ & $\begin{array}{l}\text { Recursos } \\
\text { necesarios }\end{array}$ & Condiciones previas \\
\hline
\end{tabular}

Figura 3.8. Nuevo Marco Lógico.

Fuente: Pfeiffer (2015). 
Todas estas versiones nuevas se refieren en exclusiva a la MML, quizá por ser la parte más conocida y utilizada de la metodología. Algunos organismos internaciones, como la Unión Europea, atendiendo a estas modificaciones que, manteniendo todas las fortalezas reducen las limitaciones encontradas a la $\mathrm{MML}$, propone una matriz ligeramente modificada de la original, que se muestra en la Figura 3.9 y puede verse con más detalle en el Anexo I. Esta plantilla es la que se solicita desde julio de 2015 para todas las convocatorias de financiación de proyectos de cooperación internacional al desarrollo por parte de la Comisión Europea (EuropeAid, 2018). Además, se está fomentando su uso también desde el resto de las convocatorias de las Agencias de Cooperación Internacional europeas.

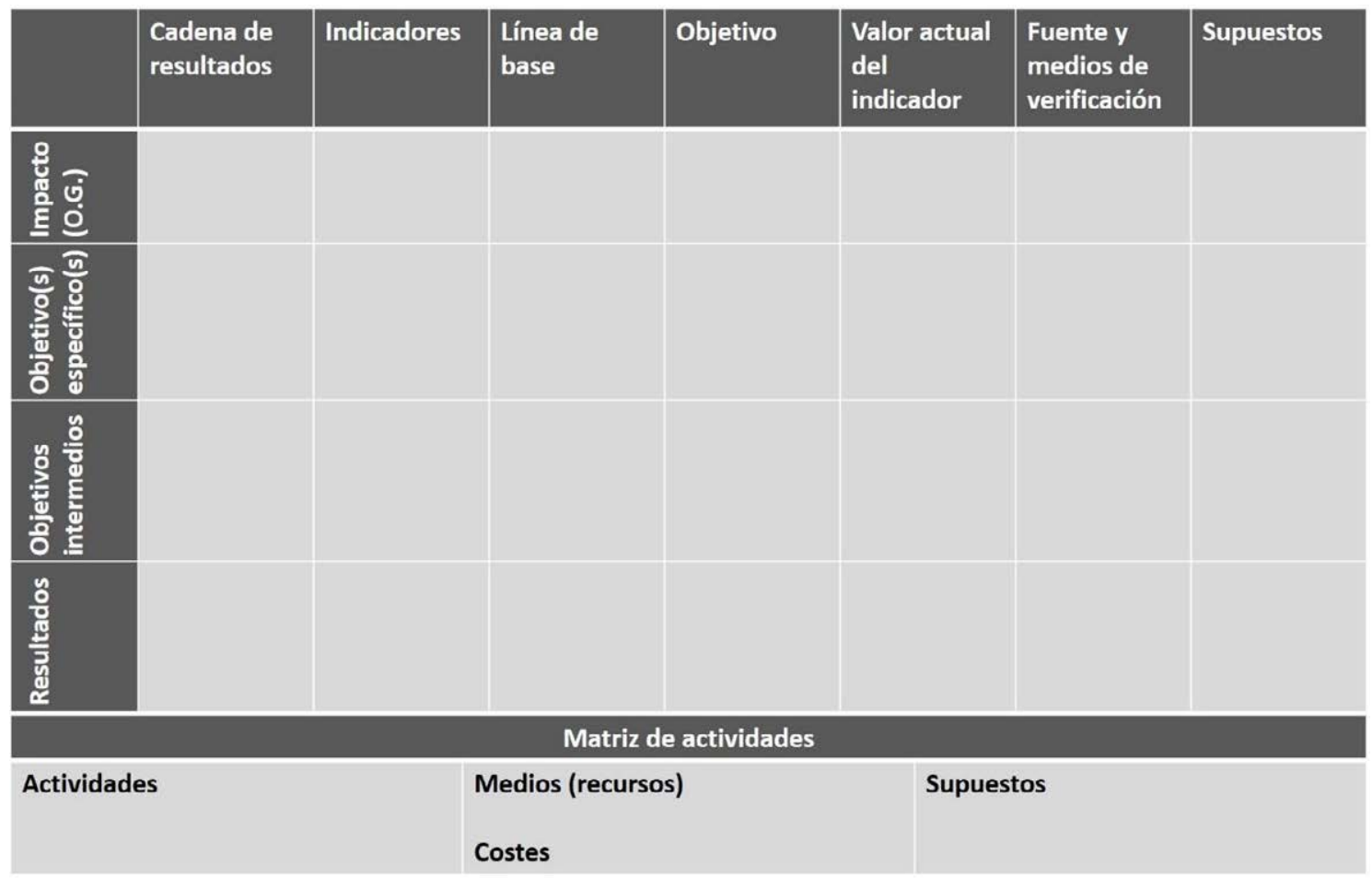

Figura 3.9. Matriz del Marco Lógico para proyectos con financiación de EuropeAid.

Fuente: EuropeAid (2018).

Esta versión de la MML trata de integrar la Teoría del Cambio (TC) y su secuencia lógica de cadenas de resultados con resultados intermedios y línea de base para poder apreciar el cambio. Aunque la matriz trata de sintetizar algunos de los conceptos de la TC, esta teoría no se reduce exclusivamente a la MML, sino a todo el conjunto de los cinco pasos del $\mathrm{ML}$, pues todo el proceso se da en un entorno dinámico y complejo.

La TC se podría definir como un conjunto de supuestos y proyecciones sobre cómo se puede llegar desde una realidad actual hasta una realidad cambiada futura, basándose en un análisis realista del contexto, una autovaloración de las capacidades disponibles durante el proceso y una explicitación crítica de los supuestos considerados (Retolaza, 
2010). La TC otorga un lugar privilegiado a los supuestos o condicionantes del entorno. Vogel (2012) defiende este especial énfasis en hacer las hipótesis o supuestos explícitos, no solo porque éstos reflejan valores y normas existentes en el contexto, sino porque sólo conociéndolos se pueden chequear y debatir sobre ellos.

Existen diversos tipos de cambios, los emergentes, basados en el aprendizaje experimental, los transformativos, basados en el desaprender, y los proyectables, basados en problemas que se pueden resolver a través de acciones planificadas y desde una lógica lineal. En términos generales, la TC se centra en proponer acciones para los cambios transformativos, más complejos, y que exigen una lógica flexible, utilizando el ML para tratar los cambios proyectables (Retolaza, 2010).

La principal diferencia entre el ML y la TC estriba en que la última se fundamenta en la idea de un sistema abierto a múltiples niveles de resultados intermedios que apoyan el proceso de cambio positivo, y en el reconocimiento de la actuación de diversos participantes y factores externos para la consecución del objetivo (Ortiz y Rivero, 2007). Así, mientras que el ML define relaciones lineales entre los diferentes niveles de una intervención, en la TC estas relaciones son dinámicas y representan una cadena de resultados muy afectada por el contexto y los supuestos. La TC propone que la combinación de muchas intervenciones (propias o de otros actores), puede generar un "efecto cadena", produciéndose de forma espontánea vínculos entre los resultados previos y los resultados de nivel superior (Ortiz y Rivero, 2007). Estas relaciones pueden verse en la Figura 3.10.

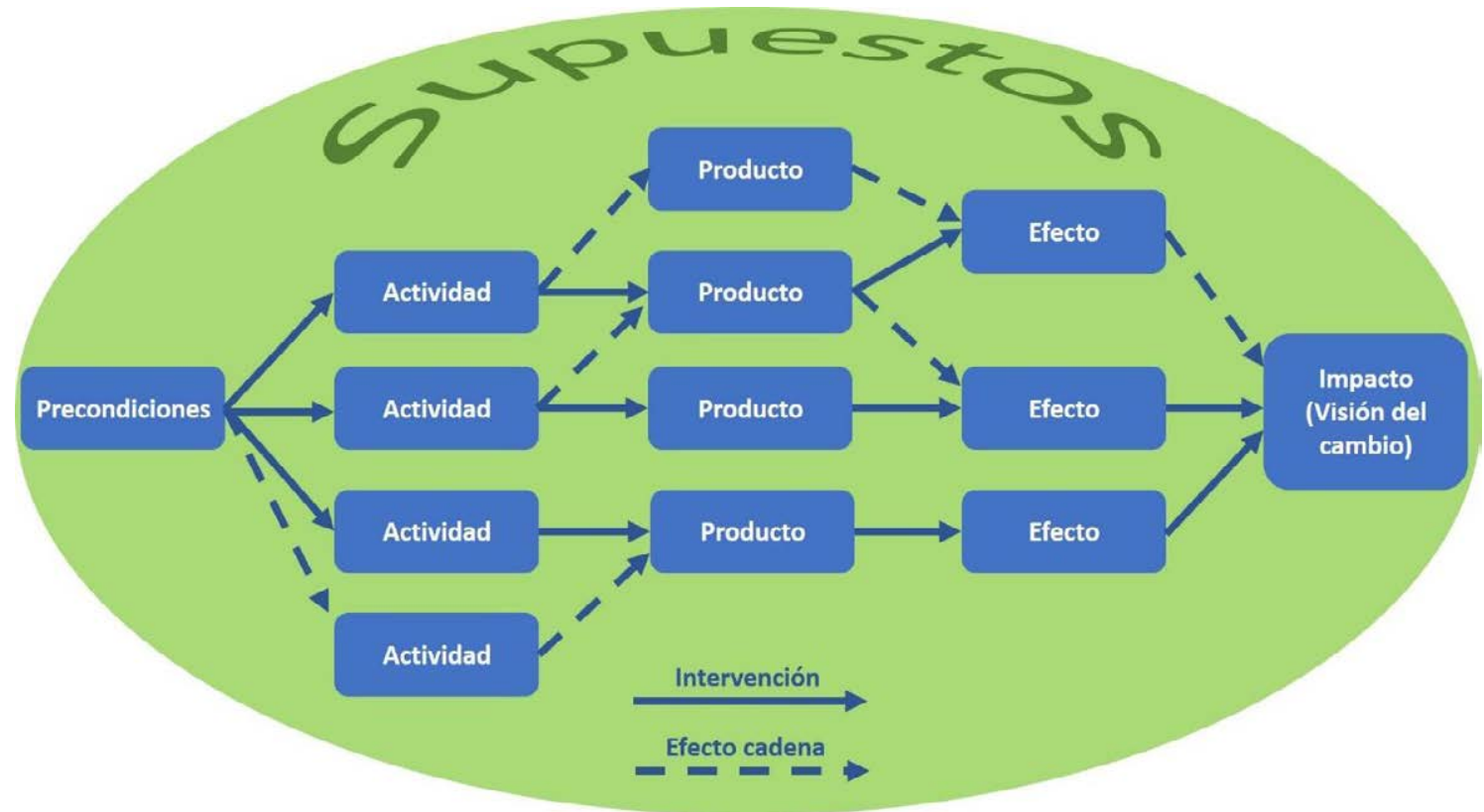

Figura 3.10. Esquema de la Teoría del Cambio.

Fuente: elaboración propia inspirada en Ortiz y Rivero (2007). 
La TC aporta un proceso reflexivo entre los diferentes grupos de interés que intervienen en el proyecto acerca de los supuestos sobre los que el cambio se puede producir y los riesgos que le pueden acechar. Este pensamiento crítico es precisamente el que, apoyado en la secuencia lógica, fortalece esta teoría (Vogel, 2012).

La TC no es un sustituto del ML, sino que puede convivir con él apoyándole principalmente en intervenciones de transformación social (Retolaza, 2010).

McEvoy, Brady y Munck (2016) ya resaltaron la necesidad de utilizar metodologías más complejas para proyectos de desarrollo de capacidades, que pueden representar esa transformación social. En su estudio se recurrió al uso de Sistemas Complejos Adaptativos (con sus siglas en inglés, CAS) para comprender integrada y multidisciplinarmente la realidad social.

Anteriormente, la Gestión para Resultados de Desarrollo (GpRD), en su camino hacia la eficacia, ya se acercaba al concepto de cadena de resultados y reconocía que el proceso de mejorar las condiciones en el mundo, en un país o en una organización, conlleva una gestión del cambio. Después de la Declaración de París (OCDE, 2005) y con el apoyo de la Declaración del Milenio (ONU, 2000), la GpRD cobró un especial protagonismo al establecer que la ayuda puede ser más eficaz mejorando la apropiación por parte del país, alineando la asistencia con las prioridades del país, armonizando las políticas de las agencias de desarrollo, y centrando la atención sistemáticamente en el logro de resultados de desarrollo. Este enfoque de resultados de desarrollo centra su atención en el impacto, reflejado en el desarrollo humano, y en el efecto al que se quiere contribuir, entendido éste como un cambio observable de conducta, institucional y social, en el medio-largo plazo (Ortiz-Marcos y Cobo, 2011).

La GpRD tampoco es un sustituto del ML, de hecho, podría decirse que refuerza la metodología posicionándola en el centro de la GpRD, y vinculándola con indicadores de desempeño que garantizan que el éxito del proyecto está orientado hacia un interés con los deseos del país (Ika y Lytvynov, 2011). El ML se enfoca así en el nivel del proyecto, mientras que la GpRD abarca las relaciones entre las organizaciones a nivel país y cuál es la contribución de cada una al logro de los resultados (Ortiz-Marcos y Cobo, 2011).

La GpRD, al igual que la perspectiva CAS, demuestra la necesidad de un sistema más abierto para los PCD, con un diálogo entre la gestión de programas y la gestión de proyectos. Esta apertura tiene que estar inspirada en un deseo de cambio y sostenida en la interacción con los participantes de la comunidad (beneficiarios). La TC apoya esta idea defendiendo que, además, el contexto, la adaptabilidad y el aprendizaje son de gran valor para lograr el cambio deseado con la intervención.

Es necesario ver estas metodologías como necesarias y complementarias al ML para tener un punto de mira más amplio hacia los beneficios del proyecto y el aprendizaje 
emergente. Además, los vínculos entre ellas han hecho mejorar el ML y contemplar nuevos enfoques en su uso, como el Enfoque de Género y el Enfoque Basado en Derechos Humanos (EBDH). Por ejemplo, a raíz de la institucionalización del ML por parte de los países en las administraciones públicas, con la GpRD, se ha fomentado la inclusión de la perspectiva de género, que se incorpora a los programas presupuestales, al ser la igualdad entre mujeres y hombres un derecho humano inalienable y de aceptación universal reconocido en diversos instrumentos internacionales (INMUJERES, 2014). Algo similar ocurre con el EBDH, que implica asumir distintos roles y fortalecer capacidades de los diferentes actores que intervienen en los PCD, distinguiendo entre los titulares de derechos (todos los seres humanos), los titulares de obligaciones (el estado y la comunidad internacional) y los titulares de responsabilidades (las organizaciones sociales, la comunidad, la familia, etc.). La esencia de este enfoque es que, por primera vez, los miembros de la comunidad beneficiaria del proyecto pasan a ser sujetos de necesidades, para ser sujetos de derechos. Esto conlleva que, junto a ellos, conviven los sujetos de obligaciones y de responsabilidades (ISI Argonauta, 2011).

Las particularidades de ambos enfoques se apoyan en desagregar a la población para poder ver si los problemas afectan de manera diferenciada a los colectivos más vulnerables, y buscar indicadores que reflejen explícitamente el cumplimiento de los objetivos, resultados o actividades para cada colectivo, incluyendo, en su caso, a los titulares de obligaciones y responsabilidades.

La existencia de nuevas versiones y enfoques no hacen sino demostrar la valía de la metodología del ML, base reconocida sobre la cual empezar a construir los matices necesarios para la mejor gestión de los PCD. 


\section{CAPÍTULO 4. LA GESTIÓN DE RIESGOS}

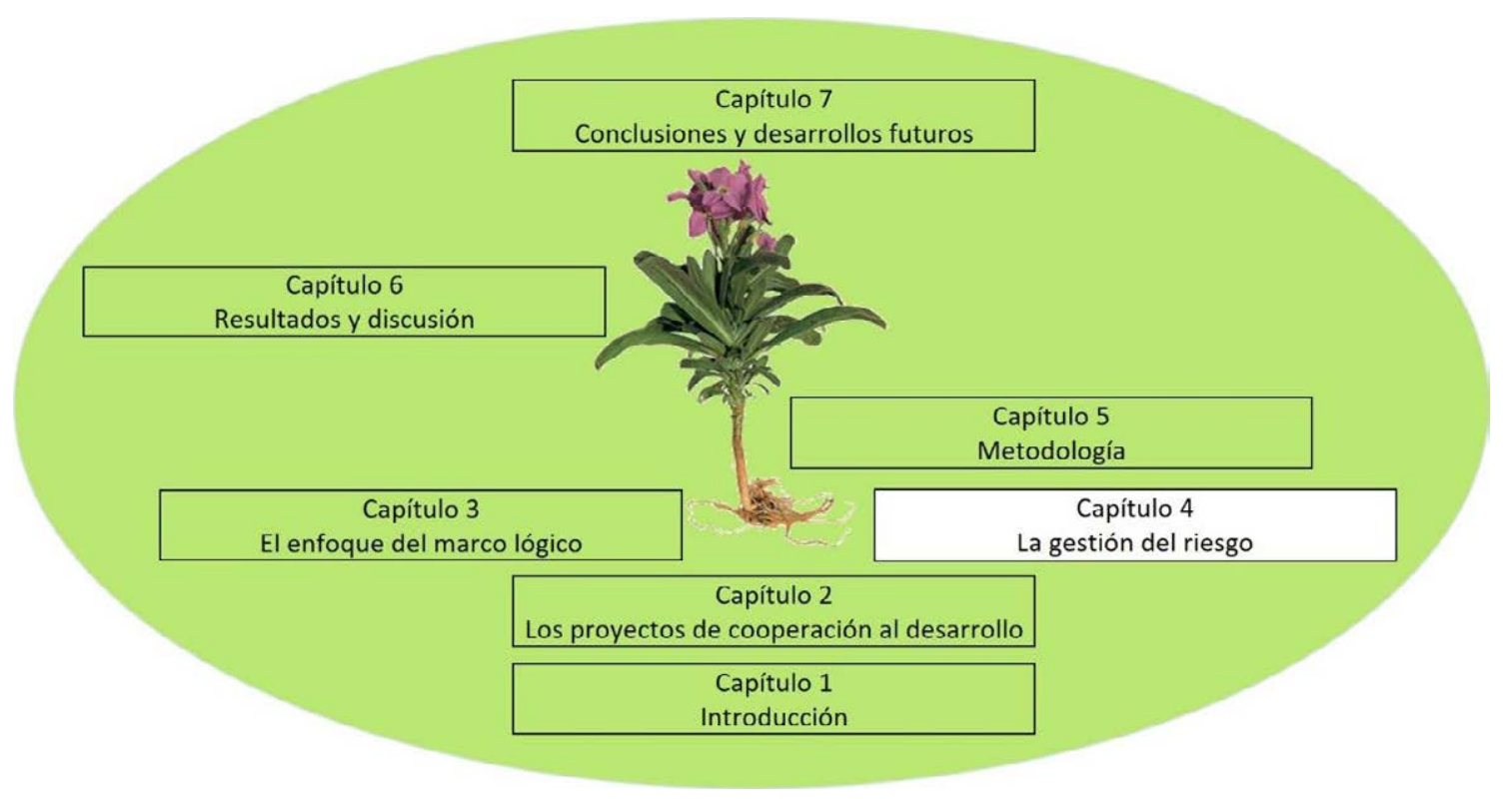

Figura 4.1. La gestión de riesgos.

Fuente: elaboración propia. 


\subsection{Introducción}

La cooperación para el desarrollo, a pesar de que ha ido evolucionando y mejorando en sus estrategias y métodos de intervención, sigue presentando deficiencias en la planificación, implementación y seguimiento de los proyectos, los cuales llevan en ocasiones al fracaso de estos o al logro parcial de sus objetivos.

El éxito que pueda tener un PCD depende de muchos factores, algunos de ellos impredecibles (Hirschman, 1967), dado que la incertidumbre está siempre presente en las acciones humanas y, por lo tanto, los riesgos son inevitables (Wang, Dulaimi y Aguria, 2004). Sin embargo, identificarlos lo más pronto posible y pensar en su respuesta es necesario para minimizar los aspectos negativos que pueda tener y maximizar los positivos.

La Gestión de Riesgos (GR) es el área de conocimiento de la DP que ayuda en este proceso, y actualmente es escasamente utilizada en el ámbito de las intervenciones de cooperación al desarrollo.

A lo largo de este capítulo se ofrecen los pasos y herramientas utilizadas en el proceso de la GR, destacando por qué es de especial necesidad realizar una buena GR para los $P C D$, y qué importancia tiene considerar los riesgos vinculados a las diferencias culturales en este proceso.

\subsection{El estudio del riesgo}

La palabra riesgo parece tener su origen etimológico en la palabra árabe rizq, incluida en el Corán (s. VII) con el significado de divina providencia que protege y guía a los fieles en su tarea de expansión del islam a través de terrenos inhóspitos (Mairal Buil, 2013). El siguiente registro que se tiene de este término aparece en la expresión latina ad meum risicum que aparece documentada en un contrato marítimo realizado en Génova en 1248 (Mairal Buil, 2013). Estos orígenes demuestran cómo el concepto de riesgo supuso un cambio en la historia de la humanidad. Hasta su aparición no había dudas acerca del futuro, puesto que podía ser conocido a través de los dioses, pero desde el momento que las personas son conscientes de su existencia, surge la preocupación por la incertidumbre del futuro al enfrentarse a nuevas misiones (Mairal Buil, 2013).

Mairal Buil (2013) establece que, aunque muchas veces se utiliza el término de la percepción del riesgo, el riesgo tiene intrínsecamente asociada una probabilidad y, por lo tanto, no se puede percibir. Si se puede percibir es un peligro. La confusión entre ambos conceptos posiblemente se fundamente en el hecho de que el término inglés hazard se refiere indistintamente a ambos, peligro y riesgo. 
En el momento en el que la probabilidad empieza a ser estudiada se sientan las bases de muchas de las teorías actuales del riesgo. Daniel Bernoulli (1700-1782) fue un matemático y físico suizo al que primero se le atribuye la evaluación del riesgo en su Commentarii Academiae Scientiarum Imperialis Petropolitanae (Bernoulli, 1738; reeditado en 1954). Posteriormente, en 1944, Neumann y Morgenstern publicaron su Theory of games and economic behavior, que actualmente está considerado la piedra angular de la Teoría de la Utilidad Esperada y que sigue el modelo más reconocido para evaluar el riesgo: el modelo de probabilidad-impacto (Farooq, Thaheem y Arshad, 2018).

También ligada a los orígenes de la evaluación del riesgo se encuentra la Teoría de la Prospectiva o Teoría de las Perspectivas, que, desarrollada por Kahneman y Tversky en 1979, describe cómo las personas evalúan las potenciales pérdidas y ganancias que trae consigo un riesgo, demostrando aversión al riesgo cuando se habla de ganancias, y tolerancia al riesgo cuando se trata de pérdidas (Kahneman y Tversky, 2013). Aunque el ámbito de aplicación de esta teoría es esencialmente financiero, goza también de una amplia repercusión en el estudio de toma de decisiones. Así, estudios recientes demuestran que los comportamientos que establece esta teoría se acentúan cuando la toma de decisiones se hace bajo los efectos del estrés (Cahlikova y Cingl, 2017; Kirchler et al., 2017).

En el ámbito de las ciencias sociales, el estudio del riesgo se liga principalmente a la toma de decisiones, donde se demuestra la existencia de una alta dosis de subjetividad, donde las características individuales de cada persona y sus experiencias vividas les hacen enfrentarse de manera muy diferente a los riesgos que supone la toma de decisiones (Cappelen et al., 2013; Cettolin, Riedl y Tran, 2018; Sword-Daniels et al., 2018).

\subsubsection{El riesgo en la dirección de proyectos}

Si anteriormente se ha mostrado la diferencia entre riesgo y peligro, en el contexto de la DP, los conceptos de incertidumbre y de riesgo se tratan en ocasiones indistintamente.

Sucede además que en los proyectos, incertidumbre y complejidad se entremezclan también en numerosas ocasiones, dado que el constructo de complejidad no ha alcanzado consenso en una definición única (Brady y Davies, 2014; Cooke-Davies, et al., 2007; Padalkar y Gopinath, 2016; Vidal y Marle, 2008), planteando el debate sobre si la incertidumbre es un componente de la complejidad, o la complejidad es un factor de incertidumbre en los proyectos (Padalkar y Gopinath, 2016). Sin querer entrar en esta discusión, lo cierto es que ambos términos, junto a la propia gestión de riesgos, están siendo considerados cada vez más en los estudios de dirección de proyectos, así como en las propias guías de esta materia. 
Los riesgos y la incertidumbre son inherentes a los proyectos a lo largo de todo su ciclo de vida, ya que, por definición son únicos, complejos y ejecutados por personas, (APM, 2012; Carvalho y Rabechini, 2015; Kerzner, 2017). La diferencia entre ambos términos ha sido muy discutida en trabajos previos (Perminova, Gustafsson y Wikström, 2008; Stirling, 1999; Ward y Chapman, 2003). Osipova y Eriksson (2013) establecían que los riesgos quedan en el ámbito de los known-unknown ${ }^{14}$, mientras que la incertidumbre queda en el de los unknown-unknown. Stirling (1999) establecía gráficamente esta misma diferencia (ver Figura 4.2), abriendo paso además a nuevas técnicas como las metodologías difusas y la prospectiva, que se verán con más detalle en el Apartado 4.4.2. EI PMBoK (PMI, 2017) recomienda para los riesgos desconocidos, la posibilidad de asignarles una reserva de gestión para imprevistos, gestionándolos así de manera proactiva. Contar también con lecciones aprendidas de proyectos anteriores resulta de gran valor (Stirling, 2010).

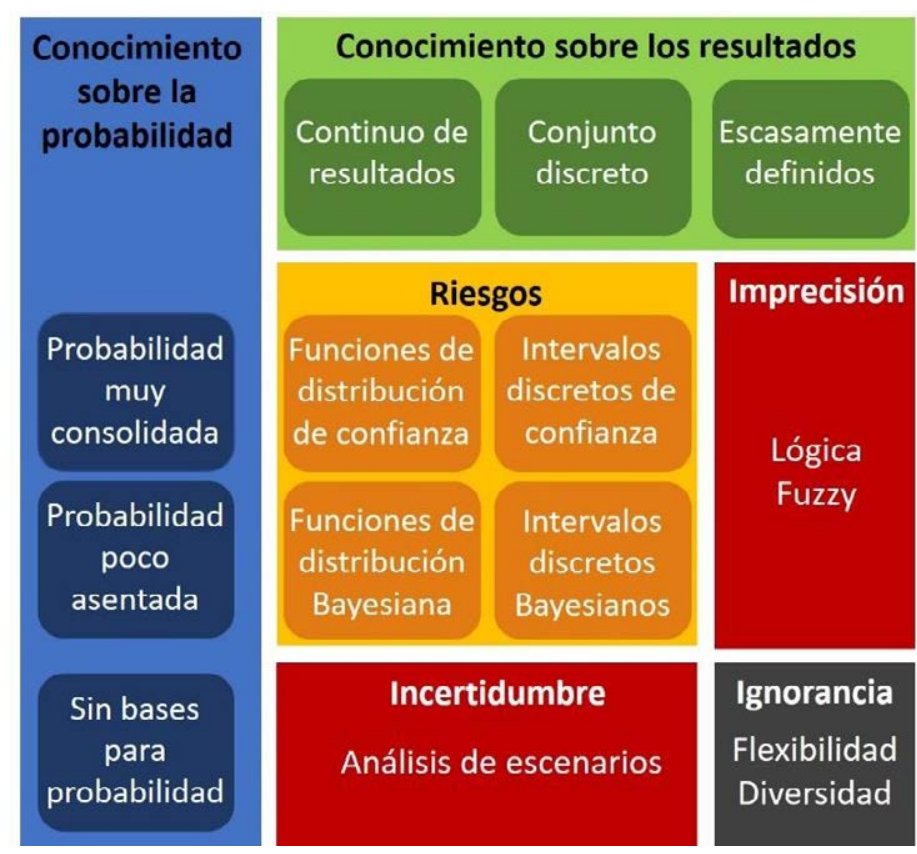

Figura 4.2. Riesgo, incertidumbre e ignorancia.

Fuente: Stirling (1999).

Kerzner (2017) establece la diferencia entre incertidumbre y riesgo en que un riesgo tiene intrínsecamente asociada una probabilidad, mientras que asignar una probabilidad a una incertidumbre no es posible por definición. De manera semejante,

\footnotetext{
${ }^{14}$ Donald Rumsfeld, siendo Secretario de Estado para la Defensa de Estados Unidos, declaró en una sesión informativa del Departamento de Defensa en febrero de 2002: "Hay conocidos conocidos. Hay cosas que sabemos que sabemos. Hay incógnitas conocidas. Es decir, hay cosas que ahora sabemos que no sabemos. Pero también hay incógnitas desconocidas. Hay cosas que no sabemos que no sabemos".
} 
David Hillson, conocido en el ámbito de la DP como Doctor Riesgo, opina que el riesgo es un tipo de incertidumbre. La clave reside en que el riesgo está definido en relación con los objetivos, así puede decirse que es "una incertidumbre que importa", e importa porque puede afectar a uno o más objetivos (Hillson, 2018). Así, Essinger y Rosen (1991) definían el riesgo como una medida anticipada de la diferencia entre las expectativas (objetivos planificados) y lo realizado (objetivos alcanzados).

Esta misma línea sigue la norma ISO 31.000:2018 de Gestión de Riesgos, que define riesgo como "los efectos de la incertidumbre sobre unos objetivos" (ISO, 2018). Debe destacarse que como indica la propia norma, un efecto es una desviación sobre lo esperado, y puede ser positivo (oportunidad) o negativo (amenaza).

La guía de referencia en la DP, el $P M B o K$, igualmente define el riesgo de un proyecto como "un evento o condición incierta que, de producirse, tiene un efecto positivo o negativo en uno o más objetivos del proyecto" (PMI, 2017, p. 310).

Todo riesgo o evento incierto, para que ocurra, tiene intrínsecamente asociada una o varias causas (ver Figura 4.3), que podrían definirse como un conjunto de circunstancias o hechos pertenecientes al proyecto o a su entorno que elevan los niveles de incertidumbre, como, por ejemplo, ejecutar el proyecto en un país en vías de desarrollo (Hillson, 2002a).
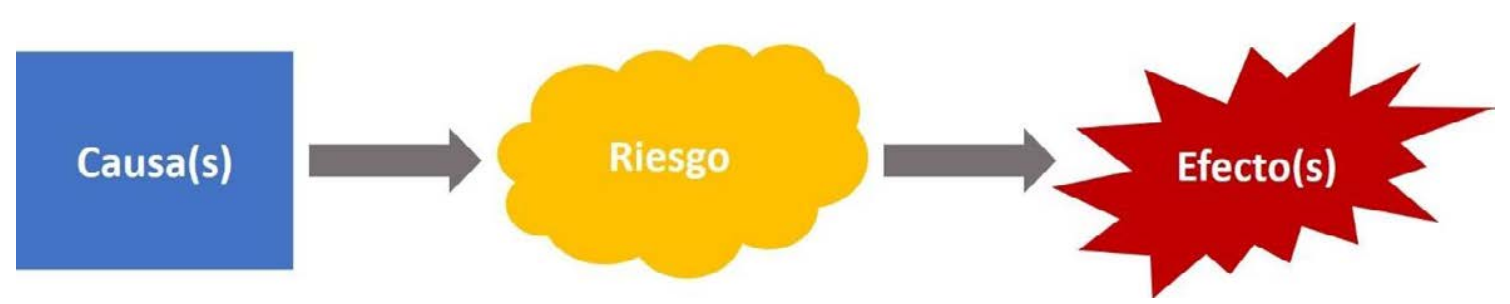

Figura 4.3. Relación entre causa, riesgo y efecto.

Fuente: e.g. Hillson (2002a).

Aunque la tendencia a considerar las dos caras del riesgo, positivo y negativo, van en aumento, son aún pocos los que contemplan la posibilidad de que el riesgo sea positivo (Hillson, 2002b; PMI, 2017; Rafindadi et al., 2014; Ward y Chapman, 2003; Zou, Zhang y Wang, 2007). Hillson (2002b) considera que esto es debido a que mientras que la necesidad de neutralizar o minimizar los riesgos negativos es evidente, la idea de gestionar las oportunidades, solo se contempla actualmente como una carga de trabajo adicional. 
La gestión de riesgos se define así como el área de la DP que aborda los riesgos de un proyecto (APM, 2012; Kerzner, 2017; PMI, 2017). Debe ser mucho más que una práctica analítica, incorporando valores éticos y responsabilidades (Power, 2004).

Aunque está reconocida como una de las áreas de conocimiento de la DP (Kerzner, 2017; PMI, 2017), se ha investigado sobre ella de una manera muy limitada si se compara con otros ámbitos en los que se lleva estudiando el riesgo mucho más tiempo, como las finanzas (Farooq, Thaheem y Arshad, 2018; Mikes, 2011). La investigación sobre la gestión de riesgos en los proyectos es un área de estudio relativamente joven, de no más de 40 años, cuyo desarrollo ha ido a la par que el de la Sociedad de Análisis de Riesgo (SRS, por sus siglas en inglés), fundada en 1980 y editora de la revista Risk Analysis, la mejor posicionada en la materia.

En el campo de la DP, el tipo de proyectos en los que más se ha investigado sobre la gestión de riesgos pertenecen al ámbito de la construcción (Chan et al, 2011; Farooq, Thaheem y Arshad, 2018; Rafindadi et al. 2014; Wang, Dulaimi y Aguria, 2004; Zou, Zhang y Wang, 2007). Pese a su reconocida importancia, algunos autores han resaltado en sus estudios lo escasamente implantada que está en muchas organizaciones (Kutsch y Hall, 2009, 2010; Papke-Shields, Beise y Quan, 2010).

Actualmente, el uso del paquete de software Entreprise Risk Management (ERM) por muchas empresas, está haciendo que aumenten las investigaciones en relación a la influencia que tiene la incorporación de la gestión de riesgos dentro de las actividades estratégicas de una empresa para mejorar los riesgos de sus proyectos (Ahmad, Ng y McManus, 2014; Farrel y Gallagher, 2019).

\subsubsection{Relación entre los riesgos y el éxito del proyecto}

La gestión de riesgos, según Kerzner (2017), es la manera de afrontar proactiva y positivamente los riesgos de un proyecto, de tal manera que se puedan incrementar las posibilidades de su éxito. Así, la gestión de riesgos cada vez es más entendida como el proceso para mejorar la probabilidad de éxito de un proyecto (Olechowski et al., 2016).

El estudio de Zwikael y Ahn (2011) sobre 700 directores de proyecto, revelaba que había una correlación negativa entre los riesgos y el éxito del proyecto, y que la aplicación efectiva de la gestión de riesgos moderaba el efecto negativo de esos riesgos.

Otros autores han tratado también de vincular la gestión de riesgos con el éxito del proyecto (De Bakker, Boonstra y Wortmann, 2010; Carvalho y Rabechini, 2015; Mishra, Das y Murray, 2016), principalmente en proyectos relacionados con las tecnologías de la información.

Conviene aquí hacer una reflexión sobre qué se entiende por el éxito del proyecto en estas investigaciones. Para ello es importante destacar la doble concepción del concepto 
de éxito en un proyecto, dado que por un lado está el éxito en su dirección y en el cumplimiento de, entre otras, las tradicionales dimensiones del triángulo de hierro de la DP (alcance, tiempo y coste), y por otro lado está el éxito del proyecto en el sentido de la utilidad para dar respuesta a la necesidad por la que fue diseñado (Cooke-Davis, 2002; Pinto y Slevin, 1988; Shenhar y Dvir, 2007).

Hasta ahora todos los estudios se han enfocado principalmente en la primera concepción del éxito, atendiendo solo al cumplimiento de los objetivos marcados dentro de la DP. Incluso esta concepción del éxito es discutida por centrarse en tiempos y costes, y no dando respuesta a la verdadera complejidad del éxito de la dirección de un proyecto (Papke-Shields, Beise y Quan, 2010).

\subsection{Los procesos de la gestión de riesgos}

La gestión de riesgos debe ir más allá de la identificación de potenciales riesgos. El proceso debe incluir una planificación formal de las actividades, un análisis para estimar la probabilidad y predecir el impacto sobre el proyecto de los objetivos identificados, una estrategia para responder a estos riesgos y la capacidad de controlar su progreso (Kerzner, 2017; PMI, 2017).

Aunque dependiendo de la guía que se tome o de la organización, el número de procesos o el nombre que se les asigne puede variar ligeramente, lo cierto es que todos ellos deben contener, al menos una planificación, una identificación, un análisis o evaluación de los riesgos, un diseño de respuestas, implementación y el correspondiente control, tanto de los riesgos, como de las respuestas. La Tabla 4.1. muestra los distintos procesos con los que trabajan las guías más relevantes en DP.

Tabla 4.1. Los procesos de la gestión de riesgos según las principales guías de DP. Fuente: elaboración propia.

\begin{tabular}{|c|c|c|c|}
\hline PMBoK (PMI, 2017) & $\begin{array}{l}\text { BoK (APM, 2012) y } \\
\text { PRAM (APM, 2004) }\end{array}$ & Kerzner (2017) & $\begin{array}{l}\text { PMDPro } \\
\text { (PM4NGOS, 2013)* }\end{array}$ \\
\hline Planificar & Iniciar & Planificar & \\
\hline Identificar & Identificar & Identificar & Identificar \\
\hline Evaluar cualitativamente & Evaluar & Evaluar & Evaluar \\
\hline \multicolumn{4}{|l|}{ Evaluar cuantitativamente } \\
\hline Planificar respuesta & Planificar respuesta & Planificar respuesta & Planificar respuesta \\
\hline Implementar respuesta & Implementar respuesta & & \\
\hline Controlar riesgos & & Controlar riesgos & Controlar riesgos \\
\hline
\end{tabular}

*Se incluye para su comparación, aunque se trata de una guía específica de DP para PCD. 
Estos procesos se agrupan para su mejor explicación en los siguientes: Planificar, Identificar, Evaluar, Planificar la respuesta, Implementar la respuesta y Controlar los riesgos, como puede verse en la Figura 4.4.
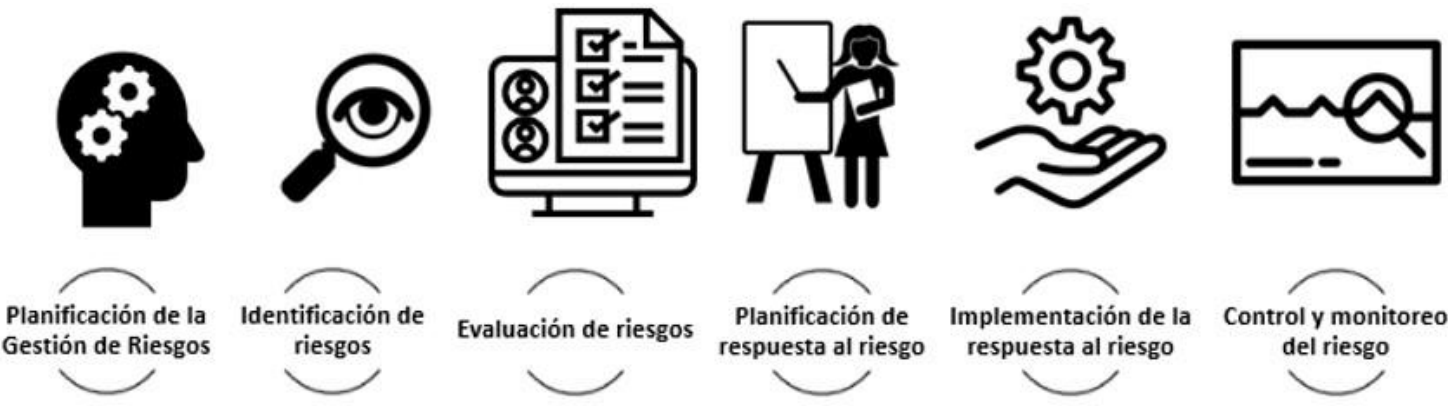
riesgos
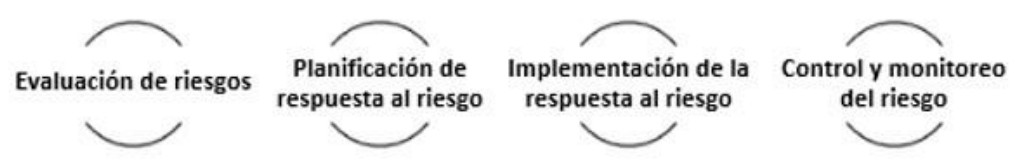

Figura 4.4. Los procesos de la gestión de riesgos.

Fuente: PMI (2017).

\subsubsection{Planificación de la gestión de riesgos}

"Planificar la gestión de los riesgos es el proceso de definir cómo realizar las actividades de gestión de riesgos de un proyecto" (PMI, 2017, p. 401). Aunque es cierto que la gestión de riesgos es necesaria para cualquier tipo de proyecto, su nivel de detalle puede variar de un proyecto a otro, cobrando especial importancia en aquellos proyectos que tengan que enfrentarse a mayores incertidumbres (Kerzner, 2017). Este nivel de detalle es el que se define en la planificación de la gestión de riesgos.

La planificación de la gestión de riesgos, aunque sea realizada de una manera muy esquemática, reduce los efectos negativos de los riesgos en el proyecto (De Bakker, Boonstra y Wortmann, 2010; Zwikael y Ahn, 2011). Esta planificación debe comenzar en la misma concepción del proyecto y estar vigente durante toda su duración, siendo además un proceso iterativo que incluye el resto de los procesos presentes en la gestión de riesgos (Kerzner, 2017). Así, el Plan de Gestión de Riesgos es el documento dentro del Plan de Dirección del Proyecto en el que se describe cómo se realizarán las actividades previstas para la gestión de riesgos (Kerzner, 2017; PMI, 2017). Este plan debería incluir la definición de los conceptos y las escalas con las que se va a trabajar en la evaluación, las categorías de riesgo, la metodología y las herramientas que se van a utilizar con sus formatos correspondientes, los roles y responsabilidades de todos los participantes, el presupuesto y el calendario dedicados a los procesos de Gestión de Riesgos (Kerzner, 2017; PMI, 2017).

Aunque el formato del Registro de Riesgos con el que se trabaje variará de una organización a otra, se muestra en la Figura 4.5 un ejemplo en el que se incluye la información más común utilizada en estos registros. 


\begin{tabular}{|c|c|c|c|c|c|c|c|c|c|c|c|}
\hline \multirow{2}{*}{$\begin{array}{l}\text { Categoría } \\
\text { del riesgo }\end{array}$} & \multicolumn{3}{|c|}{ Riesgo } & \multirow{2}{*}{$\begin{array}{l}\text { Probabilidad } \\
\text { (P) }\end{array}$} & \multirow{2}{*}{$\begin{array}{l}\text { Impacto } \\
\text { (I) }\end{array}$} & \multirow{2}{*}{$\begin{array}{l}\text { Importancia } \\
\text { (Pxl) }\end{array}$} & \multirow{2}{*}{$\begin{array}{c}\text { Estrategia } \\
\text { de } \\
\text { respuesta }\end{array}$} & \multirow{2}{*}{ Respuesta } & \multirow{2}{*}{ Coste } & \multirow{2}{*}{ Responsable } & \multirow{2}{*}{$\begin{array}{c}\text { Fase de } \\
\text { ciclo de } \\
\text { vida }\end{array}$} \\
\hline & Causa & Evento & Efecto & & & & & & & & \\
\hline & & & & & & & & & & & \\
\hline & & & & & & & & & & & \\
\hline & & & & & & & & & & & \\
\hline & & & & & & & & & & & \\
\hline & & & & & & & & & & & \\
\hline & & & & & & & & & & & \\
\hline & & & & & & & & & & & \\
\hline & & & & & & & & & & & \\
\hline & & & & & & & & & & & \\
\hline & & & & & & & & & & & \\
\hline
\end{tabular}

Figura 4.5. Ejemplo de un Registro de Riesgos.

Fuente: elaboración propia 


\subsubsection{Identificación de riesgos}

Identificar los riesgos abarca más allá de la identificación de los riesgos individuales del proyecto, debe también identificar las fuentes de riesgo general del proyecto y documentar sus características (PMI, 2017). Este proceso debe llevarse a cabo no solo en la planificación y diseño del proyecto, sino a lo largo de todo el ciclo de vida del proyecto, dado que según evoluciona el proyecto pueden aparecer nuevas fuentes de riesgo.

La identificación de riesgos es el proceso más importante para una buena gestión de riesgos (De Bakker, Boonstra y Wortmann, 2012; Reeves et al. 2013). Además, es la etapa más creativa, dado que depende esencialmente de la capacidad de las personas de imaginar futuros alternativos al presente, más que querer predecir el futuro en términos cuantitativos (Power, 2004). En la identificación se suelen utilizar técnicas participativas, como las lluvias de ideas, los focus group o la planificación de escenarios, así como entrevistas con expertos. El histórico de riesgos acontecidos en otros proyectos realizados en la organización también resulta de gran apoyo.

Dado que los riesgos pueden ser tanto negativos, como positivos (oportunidades), Hillson (2018) recomienda utilizar técnicas y herramientas específicas para la identificación de cada tipo de riesgos, como, por ejemplo, apoyarse en el análisis DAFO $^{15}$.

Además de su carácter positivo o negativo, los riesgos son inherentemente multidimensionales $\mathrm{y}$, por ello, el proceso de su identificación debe tener en cuenta diversas categorías, como la ecológica, tecnológica, económica, etc. (Guntzburger et al., 2018).

Aunque algunos autores como Carter et al. (1996) y estándares como la australiana AS/NZS 4360 (1999) habían defendido con anterioridad la necesidad de presentar los riesgos del proyecto de una manera estructurada y organizada para facilitar su comprensión, lo cierto es que se le atribuye a David Hillson el desarrollo de la Risk Breakdown Structure (RBS, por sus siglas en inglés) (Hillson, 2002b; Hillson, 2019). Con una estructura muy similar a la Work Breakdown Structure (WBS), es la herramienta por excelencia para la categorización de riesgos. La propuesta original de Hillson (2002c) puede verse en la Tabla 4.2.

\footnotetext{
${ }^{15}$ Análisis de las Debilidades, Amenazas, Fortalezas y Oportunidades a las que se enfrenta un proyecto. También conocido como FODA, o SWOT (por sus siglas en inglés).
} 
Tabla 4.2. Primer diseño de la RBS.

Fuente: Hillson (2002c).

\begin{tabular}{|c|c|c|c|}
\hline Nivel 0 & Nivel 1 & Nivel 2 & Nivel 3 \\
\hline \multirow{28}{*}{$\begin{array}{l}\text { Riesgo del } \\
\text { proyecto }\end{array}$} & \multirow{8}{*}{ De gestión } & \multirow{4}{*}{ Corporativos } & Historia/experiencia \\
\hline & & & Estabilidad \\
\hline & & & Financiero \\
\hline & & & Etc. \\
\hline & & \multirow{4}{*}{$\begin{array}{l}\text { De clientes y } \\
\text { participantes }\end{array}$} & Historia/experiencia \\
\hline & & & Contrato \\
\hline & & & Definición de los requisitos \\
\hline & & & Etc. \\
\hline & \multirow{10}{*}{ Externos } & \multirow{3}{*}{ Medioambientales } & Entorno físico \\
\hline & & & Localización \\
\hline & & & Etc. \\
\hline & & \multirow{4}{*}{ Culturales } & Políticos \\
\hline & & & Legales \\
\hline & & & Participantes \\
\hline & & & Etc. \\
\hline & & \multirow{3}{*}{ Económicos } & Mercado laboral \\
\hline & & & Mercado financiero \\
\hline & & & Etc. \\
\hline & \multirow{10}{*}{ Tecnológicos } & \multirow{3}{*}{ De requisitos } & Incertidumbre en el alcance \\
\hline & & & Complejidad \\
\hline & & & Etc. \\
\hline & & \multirow{3}{*}{ De ejecución } & Madurez de la tecnología \\
\hline & & & Limitaciones de la tecnología \\
\hline & & & Etc. \\
\hline & & \multirow{4}{*}{ De aplicacion } & Experiencia de la organización \\
\hline & & & Competencias de la plantilla \\
\hline & & & Recursos físicos \\
\hline & & & Etc. \\
\hline
\end{tabular}

\subsubsection{Evaluación de riesgos}

La evaluación de los riesgos es el proceso sistemático para estimar el nivel de los riesgos identificados (Kerzner, 2017). Como toda evaluación, ésta puede ser cualitativa o cuantitativa. La evaluación cualitativa se apoya en el análisis de probabilidad e impacto y su representación en la matriz de probabilidad-impacto. Los enfoques cuantitativos se basan en simulaciones y en estimaciones de los costes asociados, principalmente.

El uso del modelo de probabilidad-impacto es el más utilizado y está asociado a escalas numéricas para cada valor de probabilidad e impacto o severidad, que permiten a través de su producto ser ordenadas de acuerdo a su importancia (Ale, Burnap y Slater, 2015; Chan et al., 2011; Cox, 2008). Las matrices probabilidad-impacto o también Ilamadas matrices de riesgo, o mapas de riesgos, son percibidas como la manera preferida de 
simplificar la complejidad de la percepción de los riesgos (Ale, Burnap y Slater, 2015). La Figura 4.6 muestra un ejemplo de matriz de riesgo.

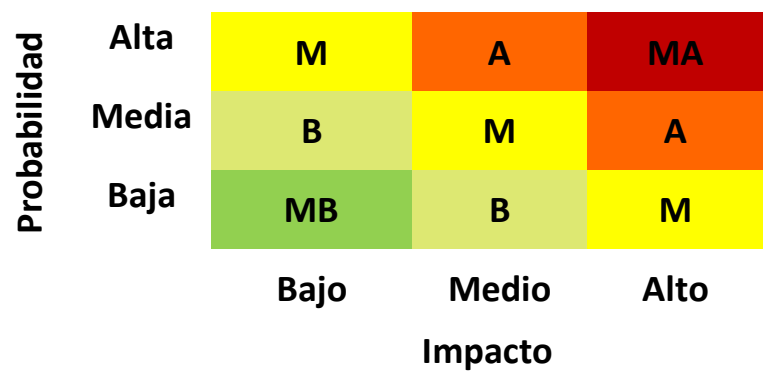

Figura 4.6. Ejemplo de Matriz de riesgo.

Fuente: e.g. PM4NGOS (2013).

Duijm (2015) y Bao, Li y Wu (2016) establecían que las matrices de riesgo podían ser vistas como una colección de conjuntos difusos, abriendo el camino hacia las metodologías difusas en la gestión de riesgos, como ya había anticipado Stirling (1999).

Tanto la probabilidad de ocurrencia, como el impacto, requieren de una métrica que debe ser definida en el Plan de Riesgos. Frecuentemente, el impacto es medido en varios niveles, como tiempo, coste o alcance, principalmente, debido a su relación con el triángulo de oro de la DP, pero dependiendo de la organización, se pueden incorporar otros niveles como seguridad, calidad o medio ambiente (El-Karim, Nawawy y AbdelAlim, 2015). Posiblemente, el más medido sea el impacto sobre el coste, de hecho, Ale, Burnap y Slater (2015) definían la gestión de riesgos como el proceso de mantener los riesgos dentro de los límites definidos por el coste del proyecto.

Como ya se ha comentado antes, los riesgos también pueden ser positivos, y Hillson (2018) propone que el proceso de análisis para ellos, aunque idéntico, sea independiente, utilizando así una matriz de riesgo para cada tipo de riesgo (positivo o negativo).

El PMBoK en su 6ạ edición (PMI, 2017), propone, además de medir la probabilidad y el impacto, la posibilidad de incorporar la detectabilidad del riesgo y la proximidad del riesgo. Haciendo uso de los conocidos diagramas de burbujas, representar tres dimensiones es posible, así, en uno de los ejes se podría medir la proximidad y en otro la detectabilidad, representando el tamaño de las burbujas, el impacto de los riesgos (ver Figura 4.7), o cualquier otra combinación de tres de las cuatro dimensiones. 


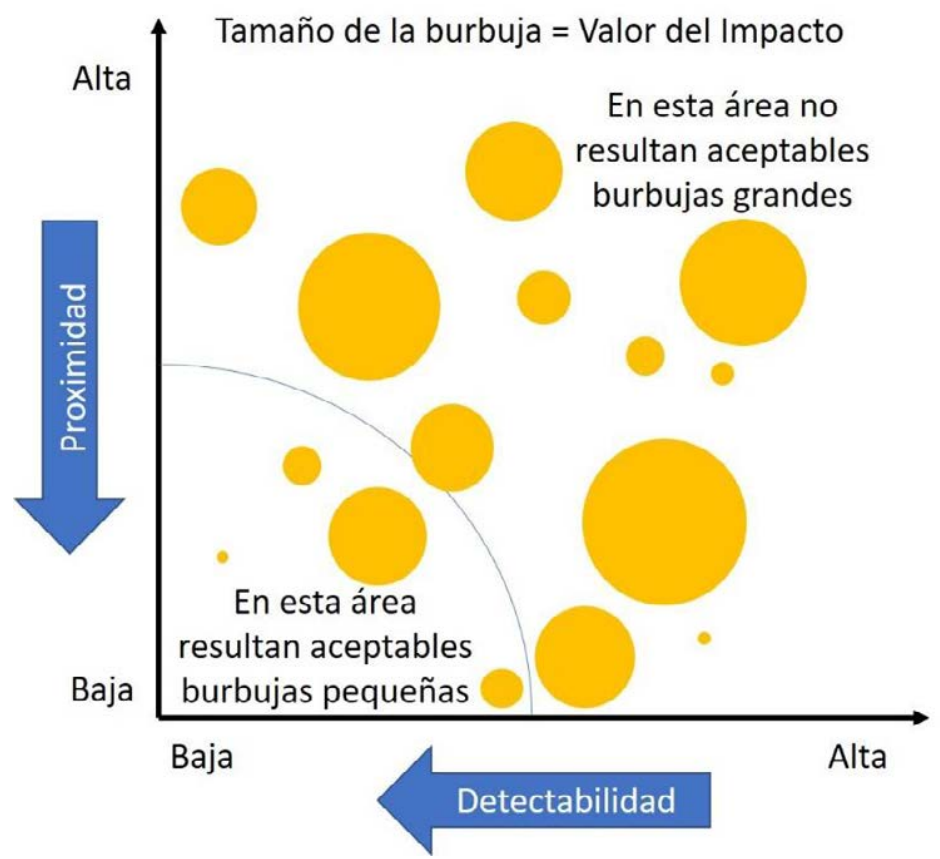

Figura 4.7. Diagrama Proximidad-Detectabilidad-Impacto de los riesgos.

Fuente: PMI (2017).

La evaluación de los riesgos, por toda la subjetividad que implica, es el proceso más complejo de la gestión de riesgos (Otway, 1975). Esta subjetividad se basa en la propensión o aversión al riesgo de cada persona, así como de sus experiencias previas. Mientras que estos conceptos se usan a nivel individual, al hablar de organizaciones se suelen utilizar los conceptos de apetito de riesgo y actitud hacia el riesgo. El término apetito de riesgo, entendido como el nivel de aceptación de riesgo por parte de una organización, comenzó a extenderse a principios de este siglo, y ha sido recogido en los más reconocidos estándares, como ISO31000:2009 (ISO, 2009) o BS 31100:2008 (BSI, 2008). El término actitud hacia el riesgo condicionará las respuestas dadas a los riesgos (Hillson, 2012). La Figura 4.8 representa el modelo de apetito-actitud hacia el riesgo (RARA, por sus siglas en inglés) diseñado por Hillson (2012).

La subjetividad que existe en el proceso de evaluación de riesgos debe ir acompañada de la ética, que no solo resulta imprescindible, sino cada vez más demandada, sobre todo en los ámbitos de la salud y el medio ambiente (Checker, 2007; Cotton, 2009).

Algunos autores, como Power (2004), opinan que la evaluación de riesgos debería estar caracterizada por la experiencia y los aprendizajes obtenidos en otros proyectos, más que por un proceso estrictamente estructurado. Así, realizar una evaluación cooperativa entre técnicos especialistas y profesionales de un ámbito más social, ayudaría a identificar los valores y supuestos de los que parte cada organización para la evaluación de riesgos (Wendling, 2014). 


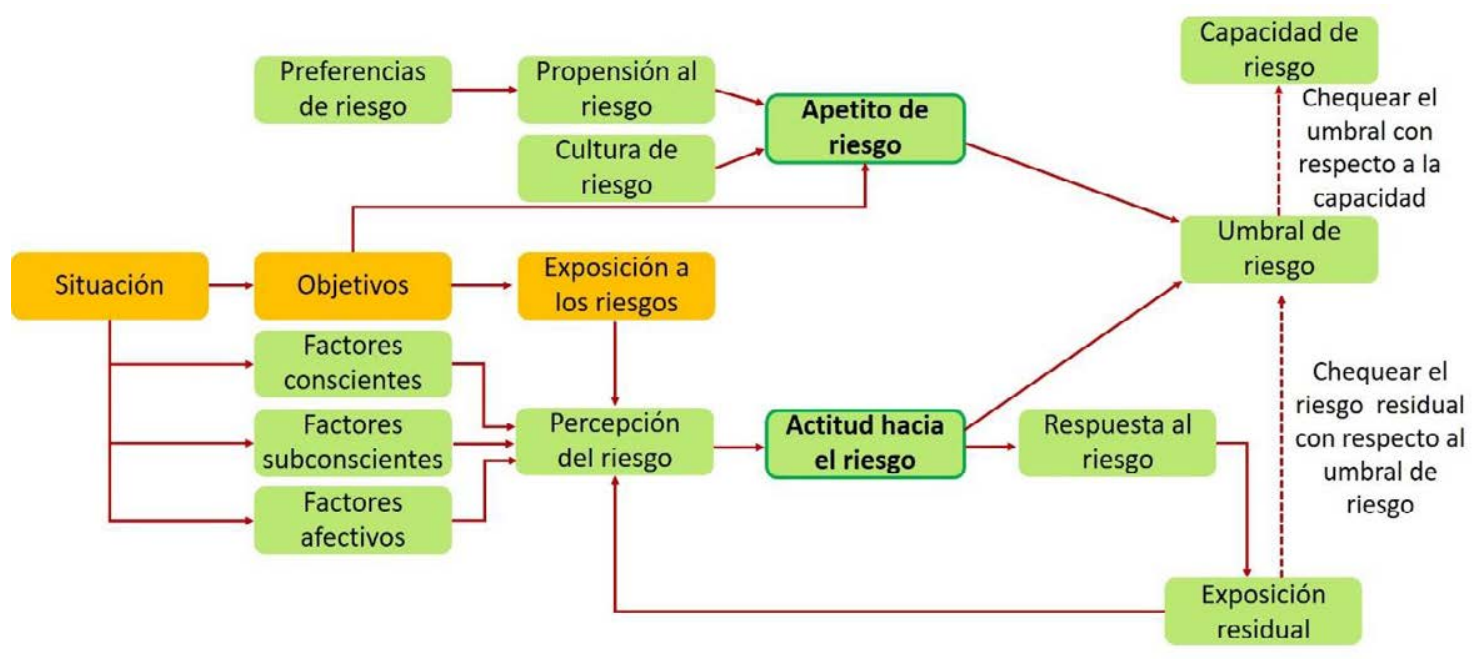

Figura 4.8. Modelo de apetito-actitud hacia el riesgo.

Fuente: Hillson (2012).

\subsubsection{Planificación de la respuesta al riesgo}

Planificar la respuesta a los riesgos es el proceso de desarrollar opciones, seleccionar estrategias y acordar acciones para abordar los riesgos del proyecto (PMI, 2017). Esta actividad debe incorporarse al presupuesto del proyecto, por ello, las respuestas a los riesgos deben adecuarse a la importancia de los mismos, y deben ser eficaces y realistas. El principal objetivo de este proceso no es entonces eliminar todos los riesgos, sino reducir, tanto como sea posible, el potencial impacto de los riesgos, especialmente de los más críticos, de la manera más efectiva y aumentar el nivel de control sobre los mismos (Chapman y Ward, 2004; Wang, Dulaimi y Aguria, 2004).

Muy pocos autores han investigado sobre las respuestas a los riesgos, más allá de describir las posibilidades que existen (Hillson, 2002b). Una notable excepción es el trabajo de Wang, Dulaimi y Aguria (2004) sobre la eficacia de las medidas de mitigación de riesgos en los proyectos de construcción en China.

A la hora de definir las diferentes estrategias para responder ante un riesgo, todas las referencias coinciden en proponer respuestas tanto para los riesgos positivos como para los negativos. Al mismo tiempo, estas respuestas son compartidas por todas las guías de DP, como puede verse en la Tabla 4.3. El PMBoK añade como novedad en su última edición la estrategia de escalar los riesgos, tanto los positivos como los negativos, al nivel del programa u otra parte relevante de la organización, cuando se trata de riesgos fuera del alcance del propio proyecto (PMI, 2017). Destaca el hecho de que la guía más relevante entre las específicas para cooperación al desarrollo, PMDPro (PM4NGOS, 2013) no mencione los riesgos positivos, haciendo hincapié además en que los riesgos 
(negativos) no se pueden ignorar, concepto que si utilizaba Hillson (2002b) para los riesgos positivos, haciendo referencia a no tomar ninguna acción.

Tabla 4.3. Estrategias de respuesta a los riesgos. Fuente: elaboración propia.

\begin{tabular}{|c|c|c|c|c|c|}
\hline & $\begin{array}{l}\text { PMBoK } \\
\text { (PMI, 2017) }\end{array}$ & $\begin{array}{l}\text { BoK (APM, 2012) y } \\
\text { PRAM (APM, 2004) }\end{array}$ & $\begin{array}{l}\text { Kerzner } \\
\text { (2017) }\end{array}$ & $\begin{array}{l}\text { Hillson } \\
\text { (2002b) }\end{array}$ & $\begin{array}{l}\text { PMDPro } \\
\text { (PM4NGOS, } \\
\text { 2013)* }\end{array}$ \\
\hline $\begin{array}{l}\text { Riesgos } \\
\text { negativos } \\
\text { (amenazas) }\end{array}$ & $\begin{array}{l}\text { Escalar } \\
\text { Evitar } \\
\text { Mitigar } \\
\text { Transferir } \\
\text { Aceptar }\end{array}$ & $\begin{array}{l}\text { Evitar } \\
\text { Reducir } \\
\text { Transferir } \\
\text { Aceptar }\end{array}$ & $\begin{array}{l}\text { Evitar } \\
\text { Mitigar } \\
\text { Transferir } \\
\text { Aceptar }\end{array}$ & $\begin{array}{l}\text { Evitar } \\
\text { Mitigar } \\
\text { Transferir } \\
\text { Aceptar }\end{array}$ & $\begin{array}{l}\text { Evitar } \\
\text { Mitigar } \\
\text { Transferir } \\
\text { Aceptar }\end{array}$ \\
\hline $\begin{array}{l}\text { Riesgos } \\
\text { positivos } \\
\text { (oportunidades) }\end{array}$ & $\begin{array}{l}\text { Escalar } \\
\text { Explotar } \\
\text { Mejorar } \\
\text { Compartir } \\
\text { Aceptar }\end{array}$ & $\begin{array}{l}\text { Explotar } \\
\text { Mejorar } \\
\text { Compartir } \\
\text { Aceptar }\end{array}$ & $\begin{array}{l}\text { Explotar } \\
\text { Mejorar } \\
\text { Compartir } \\
\text { Aceptar }\end{array}$ & $\begin{array}{l}\text { Explotar } \\
\text { Mejorar } \\
\text { Compartir } \\
\text { Ignorar }\end{array}$ & \\
\hline
\end{tabular}

*Se incluye para su comparación, aunque se trata de una guía específica de DP para PCD.

\subsubsection{Implementación de la respuesta al riesgo}

Implementar la respuesta a los riesgos es el proceso de ejecutar los planes acordados de respuesta a los riesgos (PMI, 2017). Este proceso no era contemplado inicialmente, pero la evidencia de que las organizaciones no tomaban medidas para gestionar los riesgos de acuerdo a las estrategias identificadas previamente ha hecho necesaria su inclusión (APM, 2004; PMI, 2017).

Manteniendo un control documentado de cómo se están acometiendo las respuestas por parte de los responsables de cada riesgo, se podrán gestionar de forma proactiva los riesgos que afectan al proyecto (PMI, 2017).

\subsubsection{Control del riesgo}

El control de los riesgos es el proceso de monitorear la implementación de los planes de respuesta acordados, hacer el seguimiento de la evolución de los riesgos identificados, e identificar y analizar los nuevos riesgos que van surgiendo a lo largo del ciclo de vida del proyecto (Kerzner, 2017; PMI, 2017).

El estado de los riesgos, así como las propias medidas correctoras que se les asignaron debe revisarse periódicamente a lo largo del ciclo de vida del proyecto, dado que los riesgos evolucionan con el propio proyecto (Hillson, 2002b). Debido precisamente a que los riesgos cambian durante la ejecución del proyecto, la flexibilidad debe ser una parte esencial en este proceso (Osipova y Eriksson, 2013). 
Son muchas las organizaciones que fallan al no revisar la evolución de los riesgos ni el estado de sus riesgos residuales (Hillson, 2002b). Los riesgos residuales son aquellos que quedan una vez se ha actuado sobre ellos, e igualmente deben ser controlados en la siguiente evaluación de riesgos (Green, 2015).

La gestión de riesgos es un proceso iterativo, por lo tanto, todos sus procesos deberían hacerse periódicamente para comprobar que todos los riesgos permanecen en los niveles aceptables para el proyecto.

\subsection{Gestión de riesgos en los proyectos de cooperación al desarrollo}

Principalmente, las investigaciones sobre gestión de riesgos se han realizado en contextos de países desarrollados, como denuncia Hartono et al. (2014), siendo muy escasos los estudios que se han llevado a cabo en países en vía de desarrollo, centrándose, principalmente, en Asia (Munns, Aloquili y Ramsay, 2000; Wang, Dulaimi y Aguria, 2004; Yamaswari et al., 2016). Sin embargo, de acuerdo con la investigación de Wang, Dulaimi y Aguria (2004), los riesgos a nivel país son los que más afectan a un proyecto.

Frecuentemente y de una manera muy sencilla, los riesgos se dividen en internos (al propio proyecto) y externos. Mientras que los riesgos internos son relevantes para todos los proyectos, independientemente de si el proyecto se desarrolla a nivel local o internacional, los proyectos internacionales están sujetos a una mayor exposición a riesgos externos (Wang, Dulaimi y Aguria, 2004). Hillson (2002c) encontraba como una causa directa de riesgo el mero hecho de ejecutarlo en un país en vías de desarrollo.

En el Capítulo 2 ya se vieron las características que hacen de los PCD un caso muy particular de alta complejidad sociopolítica dentro de los proyectos internacionales (Ika y Hodgson, 2014, p. 1186). Sin embargo, y aunque la guía PMD Pro (PM4NGOS, 2013) dedica un capítulo a la Gestión de Riesgos, la escasa literatura dedicada a la DP en PCD a penas le presta atención, con la excepción de Couillard et al. (2009) e Ika y Lytvynov (2011) que proponen añadir los riesgos en la MML. Esta ausencia ha sido reclamada por el Banco Mundial, quien considera la gestión de los riesgos algo imperativo en la dirección de estos proyectos que tienen como último fin el desarrollo económico y la erradicación de la pobreza (Enyinda, 2017).

En estos proyectos, el contexto y los eventos inciertos que los rodean, cobran un papel fundamental (Ika y Donelly, 2017; Syrett y Devine, 2012). Quizá el estudio más conocido sobre la incidencia de la incertidumbre en los PCD ha sido el de Albert Hirschman (1967), quien con su teoría de la Hidding Hand, a afirma que muchas veces los esquemas mentales de los directores de estos proyectos, además inexpertos en la dirección de proyectos en la mayoría de los casos, impiden percibir el riesgo. 
Además del propio contexto, "la incertidumbre y los riesgos son dos conceptos inherentes al ML" (Yamaswari et al., 2016, p. 117). Esto es debido a que el propio PCD está lleno de incertidumbres internas, más allá de las que rodean a las actividades que se vayan a desarrollar, dado que el comportamiento de los diferentes participantes en el proyecto es impredecible (Petit, 2009). Otros autores ya habían establecido que los participantes de un proyecto son la mayor fuente de incertidumbre en todas las etapas de un proyecto (Rafindadi et al., 2014; Ward y Chapman, 2008).

Atender y entender a los participantes del proyecto, supone conocer su cultura. Son muchos los autores que encuentran los factores relacionados con la cultura como determinantes a la hora de ejecutar un proyecto internacional (Hofstede, 1984; Sluyts et al., 2011; Zwikael y Ahn, 2009; Meyer, 2015). Hartono et al. (2014) destacan que estos factores son especialmente relevantes para los PCD.

\subsubsection{La importancia de los factores culturales}

Una efectiva gestión de riesgos debe considerar tanto el comportamiento humano, como los factores culturales (ISO, 2018). Es curioso que, aunque la ISO 31000:2018 así lo reconoce, el PMBoK no trata esta dimensión en el capítulo dedicado a la gestión de riesgos, tratándolo sin embargo en otros capítulos como Adquisiciones, Participantes o Comunicación. Kerzner ${ }^{16}$ (2017) tampoco incluye estos factores. Más llamativo resulta aún que la guía diseñada específicamente para la dirección de los PCD, PMDPro (PM4NGOS, 2013), tampoco los incluya.

Entre todos los modelos existentes para el estudio de los factores culturales, el presentado por Hofstede $(2001 ; 2010)$ ha sido reconocido como efectivo y ampliamente aceptado en el ámbito de la dirección de proyectos (Bredillet, Yatim y Ruiz, 2010; Liu, Meng y Fellows, 2015; Rees-Caldwell y Pinnington, 2013; Shore y Cross, 2005).

Aunque el modelo de Hofstede será explicado con más detalle, en la Tabla 4.4. se muestran también resumidos los resultados de los principales estudios realizados sobre la cultura nacional. Todos ellos realizaron estudios comparativos de estas dimensiones en numerosos países, permitiendo diferenciar las culturas nacionales de cada uno de ellos. Como se puede apreciar, muchas de las dimensiones establecidas son parecidas.

Erin Meyer cuenta en su libro The Culture Map (2015), cómo el holandés Geert Hofstede (1928- ), formado en ingeniería mecánica, viajó a Indonesia por trabajo y quedó impresionado por las diferencias culturales que existían entre las personas indonesias y sus compañeros de trabajo holandeses. A partir de ahí, durante los años 1960 y 1970 comenzó una labor de investigación sobre las diferencias culturales a través de los

\footnotetext{
${ }^{16}$ Kerzner (2017) hace en su capítulo de gestión de riesgos referencia a las culturas organizativas, es decir, a las maneras de trabajar propias de cada organización. Pero en este apartado nos estamos refiriendo en todo momento a lo que Hofstede considera Cultura Nacional.
} 
empleados de la multinacional IBM (con sede en numerosos países). Los primeros resultados de este trabajo fueron publicados en su libro Culture's Consequences (1981, reeditado en 2001), en el que definía inicialmente cuatro de sus dimensiones, y que lo convirtió en precursor de la investigación intercultural comparativa.

Tabla 4.4. Dimensiones culturales de los principales estudios sobre la cultura nacional. Fuente: elaboración propia.

\begin{tabular}{|c|c|c|c|c|}
\hline Hofstede (2010) & Schwartz (2014) & $\begin{array}{l}\text { Trompenaars y } \\
\text { Hampden-Turner } \\
\text { (2011) }\end{array}$ & $\begin{array}{l}\text { GLOBE Project } \\
\text { (House et al., } \\
\text { 2002) }\end{array}$ & Meyer (2015) \\
\hline $\begin{array}{l}\text { Distancia al } \\
\text { poder }\end{array}$ & Integración & Universalismo & $\begin{array}{l}\text { Orientación al } \\
\text { desempeño }\end{array}$ & Comunicación \\
\hline Individualismo & Jerarquía & Individualismo & $\begin{array}{l}\text { Colectivismo } \\
\text { institucional }\end{array}$ & Evaluación \\
\hline Masculinidad & Maestría & Específico & $\begin{array}{l}\text { Igualdad de } \\
\text { género }\end{array}$ & Liderazgo \\
\hline $\begin{array}{l}\text { Evasión a la } \\
\text { incertidumbre }\end{array}$ & $\begin{array}{l}\text { Autonomía } \\
\text { afectiva }\end{array}$ & Neutral & $\begin{array}{l}\text { Evasión a la } \\
\text { incertidumbre }\end{array}$ & Decisión \\
\hline $\begin{array}{l}\text { Orientación a } \\
\text { largo plazo }\end{array}$ & $\begin{array}{l}\text { Autonomía } \\
\text { intelectual }\end{array}$ & Logros & $\begin{array}{l}\text { Colectivismo en } \\
\text { el grupo }\end{array}$ & Confianza \\
\hline \multirow[t]{4}{*}{ Indulgencia } & Igualitarismo & Secuencia & $\begin{array}{l}\text { Orientación a } \\
\text { futuro }\end{array}$ & Desacuerdo \\
\hline & Harmonía & Control interno & $\begin{array}{l}\text { Orientación al ser } \\
\text { humano }\end{array}$ & Programación \\
\hline & & & Asertividad & Persuasión \\
\hline & & & $\begin{array}{l}\text { Distancia al } \\
\text { poder }\end{array}$ & \\
\hline
\end{tabular}

Nota: Se incluyen las referencias de sus últimas ediciones, aunque los primeros trabajos son muy anteriores.

Para el diseño de las dimensiones de la cultura nacional, Hofstede se apoyó también en otros estudios previos, como el de Kluckhohn y Strodtbeck (1961) o el de Hall (1976). Kluckhohn (1953) fue el primero en afirmar que las culturas podían ser clasificadas a través de categorías universales, mientras que Edward Y. Hall está considerado como el padre de la comunicación intercultural (Arasaratnam y Doerfel, 2005). Ellos, junto a su primera investigación, le permitieron desarrollar inicialmente sus cuatro dimensiones culturales:

- Distancia al poder: representa la medida en la que las personas en una sociedad esperan y aceptan que el poder no se distribuya de manera igualitaria. Hofstede 
se basó para definir esta dimensión en el análisis de los sistemas políticos de cada país.

- Individualismo vs Colectivismo: refleja la tendencia de las personas de una sociedad a preocuparse por sí mismas y por su familia directa, o, por el contrario, a establecer fuertes vínculos con el resto de las personas del grupo o grupos a los que pertenece. Hofstede estableció aquí correlaciones con el Producto Interior Bruto (PIB).

- Masculinidad vs Feminidad: relaciona la tendencia hacia valores predominantemente competitivos y el culto al éxito frente a la empatía, la cooperación y el gusto por la calidad de vida en una sociedad. Hofstede se apoyó para esta dimensión en la parte de los ingresos nacionales que estaban dedicados a la ayuda al desarrollo.

- Aversión a la incertidumbre: representa el grado de angustia que sienten las personas en una sociedad ante situaciones desconocidas. Hofstede lo correlacionó con una de las dimensiones establecidas en el estudio de salud mental realizado por Lynn y Hampson (1975).

Posteriormente, una quinta dimensión fue incluida, basada en la investigación sobre el Lejano Este que llevaron a cabo Hofstede y Bond (1988) que demostró la necesidad de incorporar el pensamiento Confucionista.

- Orientación a largo plazo: manifiesta la propensión de las personas de una sociedad hacia el ideal de recompensas futuras (ahorro, perseverancia, etc.).

La sexta y última dimensión fue incluida en 2010 gracias a los trabajos de Michael Minkov (Hofstede, Hofstede y Minkov, 2010).

- Indulgencia vs represión: representa el grado de libertad con el que las personas en una sociedad muestran o reprimen sus deseos.

El trabajo continuo con estas dimensiones, incorporando nuevos países y actualizando periódicamente los resultados, ha permitido diseñar un mapa cultural que bajo el título de Cultures and Organizations, software of the mind (Hofstede, Hofstede y Minkov, 2010), no solo ha inspirado a otros autores (Kirkman, Lowe y Gibson, 2006; Lewis, 2010; Meyer, 2015; Müller y Turner, 2004), sino que ha conseguido consolidarse como el modelo más reconocido entre todos los estudios interculturales.

Atender a las diferencias culturales que puedan existir entre los diferentes países que participan en una intervención al desarrollo se convierte así en un factor a tener en cuenta, puesto que, como Hofstede (2001) destacaba, las técnicas de DP que son adecuadas para una cultura no tienen por qué ser las adecuadas para otra. 


\subsubsection{La gestión de riesgos en contextos de incertidumbre}

Considerando entonces la importancia del contexto en los PCD (Ika y Donelly, 2017) y las dificultades que supone enfrentarse a una intervención donde abundan los unknown-unknown, resulta evidente el difícil reto al que se enfrentan los directores de estos proyectos (Syrett y Devine, 2012).

En estos entornos en los que el conocimiento de probabilidades se convierte en incierto, es necesario realizar deliberaciones participativas y planteamiento de nuevos escenarios, desde alcances adaptativos y resilientes (Stirling, 2010). Son esos eventos que ni se imaginaba que pudieran suceder, aquellos que la gestión de riesgos tiene que anticipar. Para ello, la prospectiva y su diseño de escenarios, como adelantaba Stirling (1999), puede ser una buena aliada.

El filósofo francés Gaston Berger es considerado el padre de la prospectiva con su publicación Human Science and Forecasting (1957). Ben R. Martin (1996) presentó el término anglosajón foresight aproximándolo por primera vez a la francesa prospectiva. Aunque comparten la idea de que no existe un único futuro, sino muchos posibles, el énfasis de la foresight está puesto en la tecnología, mientras que el de la prospectiva está puesto en los participantes (Ortega-San Martín, 2017). Así, la prospectiva enseña que no es necesario sufrir por el futuro, sino construirlo a través de la anticipación (Godet, 1986). La Figura 4.9 muestra la relación que existe entre la anticipación, la acción y la apropiación de los proyectos.

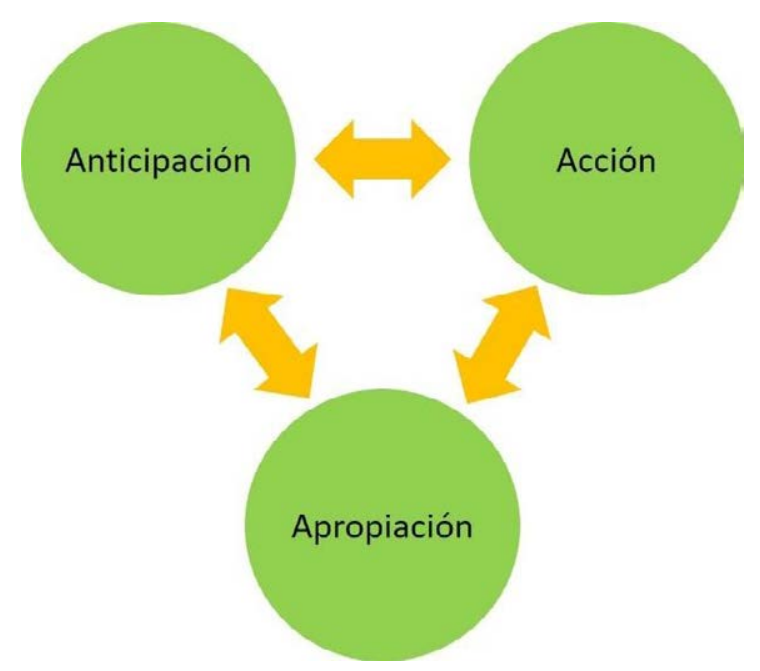

Figura 4.9. Triángulo de la prospectiva estratégica. Fuente: Godet (1986).

El mundo académico ha reconocido a la prospectiva como la teoría que debe liderar la toma de decisiones en contextos de incertidumbre (Starmer, 2000; Wakker, 2010). 
Así, aunque nadie puede prever lo impredecible, la prospectiva, apoyada en los procesos participativos con los que suelen contar las intervenciones de desarrollo, puede acercarse a imaginar el impacto deseado del proyecto e identificar todo aquello que pudiera afectarle, contribuyendo a la mejora en la consecución de sus objetivos. 


\section{CAPÍTULO 5. METODOLOGÍA}

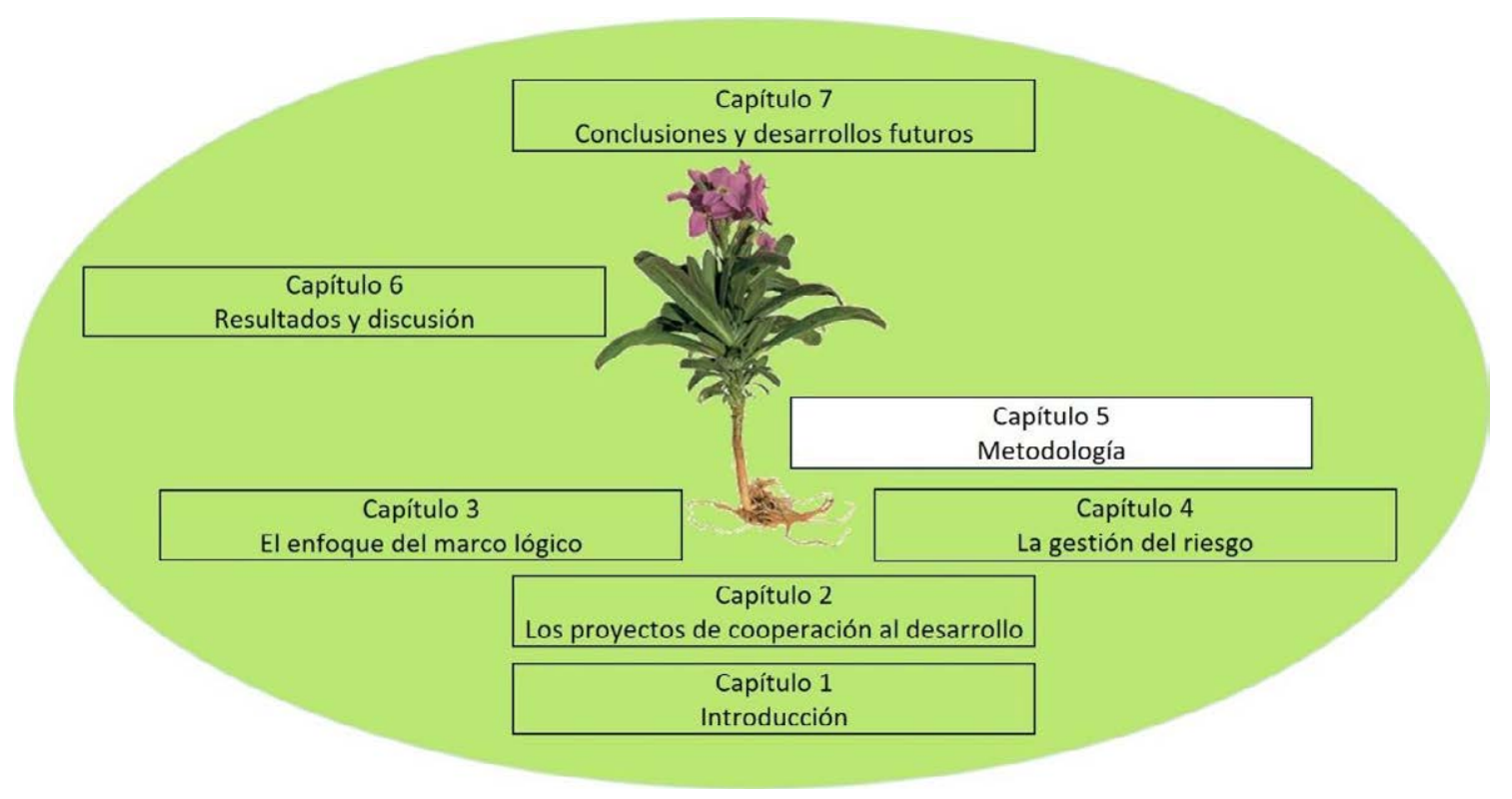

Figura 5.1. Metodología.

Fuente: elaboración propia.

"El que ha llegado tan lejos que ya no se confunde, ha dejado también de trabajar"

(Atribuida a Max Planck, 1858-1947) 


\subsection{Introducción}

Para que una investigación pueda considerarse como tal es necesario un planteamiento del problema, una recogida sistemática de información con el claro propósito de resolver el problema y, por último, una interpretación de los datos (Walliman, 2017; Saunders, Lewis y Thornhill, 2016).

En este capítulo se presenta, a través de sus fases y técnicas, la metodología de investigación seguida, tanto a nivel documental y analítico, como en campo, donde se realizó, a través de metodologías participativas, la recogida de información de los proyectos del Cauca (Colombia), zona elegida para seleccionar los casos de estudio. Las fichas resumen correspondientes a estos proyectos se incluyen también en este capítulo, mostrando la descripción de sus principales características.

\subsection{Fases de la investigación}

Las principales guías sobre métodos de investigación recomiendan que previamente a iniciar cualquier estudio es necesario identificar qué se quiere conocer (Robson y McCartan, 2016; Saunders, Lewis y Thornhill, 2016). Esto requiere de un acercamiento a la problemática a través de la literatura existente, así como de todas aquellas fuentes de información fiables al alcance (profesionales del sector, académicos, familiares, etc.) (Sekaran y Bougie, 2016).

Partiendo de esa premisa, y con un enfoque top-down que permita no perder de vista el principal objetivo de este trabajo, la propuesta de esta investigación es dar respuesta a si es posible mejorar la eficacia de los PCD. Como los datos conocidos demuestran que estos proyectos no alcanzan los niveles deseados de éxito y, existe además el compromiso marcado por la Agenda 2030 que exige mejorar en las intervenciones de desarrollo, la respuesta a esta pregunta resulta afirmativa. La siguiente pregunta que se plantea es entonces cómo se podría mejorar la eficacia de estos proyectos. El abanico de respuestas a esta pregunta es cuanto menos variado. Por ello se pone el foco en la propuesta de mejora más relevante, la introducción de la GR, por ser un hecho contrastado que estos proyectos se desarrollan en diferentes entornos que tienen en común la incertidumbre que les rodea y por ser novedosa su consideración en estos contextos. Al ser la GR un área de conocimiento de la dirección de proyectos, la última pregunta pone el foco en la metodología más utilizada para la dirección de estos proyectos, el Marco Lógico, para cuestionar si podría ser mejorada a través de la introducción de la GR.

Estas preguntas dan lugar a tres hipótesis que ya se plantearon en el Capítulo 1:

H1: El Marco Lógico necesita ser mejorado. 
H2: El éxito de los PCD depende de la buena Gestión de Riesgos.

H3: El Marco Lógico con Enfoque de Gestión de Riesgos puede mejorar la eficacia de los PCD.

Estas hipótesis, se muestran desde un enfoque bottom-up debido a que este proceso es el recomendado cuando se trabaja de una manera participativa, contrastando con los principales actores (Stirling, 2008). La Figura 5.2 muestra ambos enfoques para las preguntas e hipótesis de investigación.

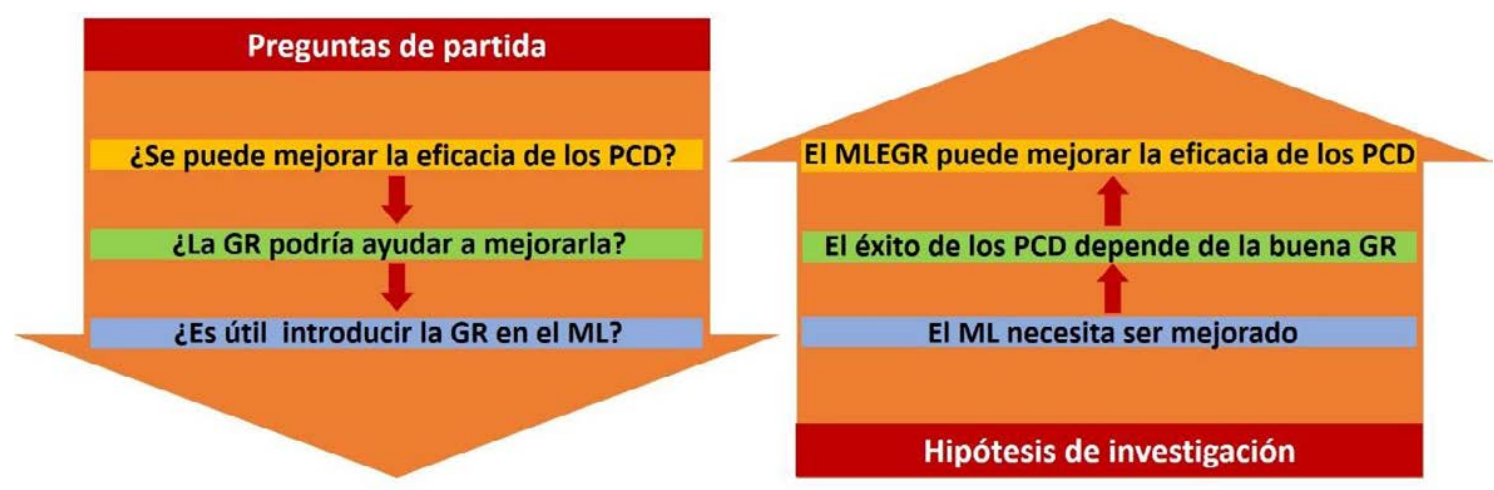

Figura 5.2. Preguntas e hipótesis de investigación.

Fuente: elaboración propia.

Para dar respuesta a las preguntas enunciadas y contrastar las hipótesis, la investigación se ha dividido en fases, como se muestra en la Figura 5.3. Los resultados que se mostrarán en el Capítulo 6 presentarán los contrastes de estas hipótesis.

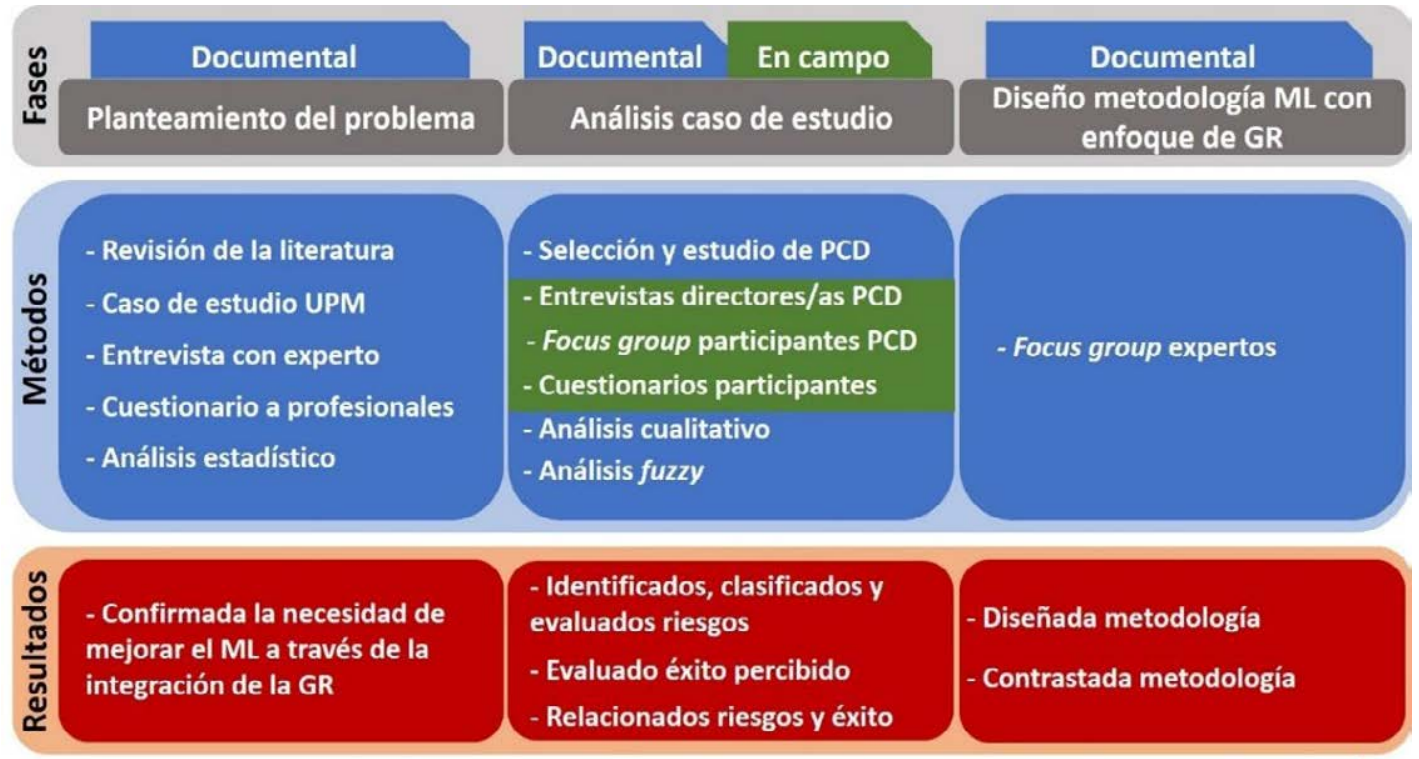

Linea temporal

Figura 5.3. Esquema de la metodología de investigación.

Fuente: elaboración propia. 


\subsubsection{Planteamiento del problema}

Para llegar a identificar el problema sobre el cual se quería investigar, en primer lugar, se revisó una extensa colección de documentos, entre los que destacan más de 150 artículos de revistas indexadas, relacionadas, en la mayoría de los casos, con la Dirección de Proyectos y extraídos de la Web of Science; informes de los principales organismos internacionales (Banco Mundial, Naciones Unidas, etc), así como de las Agencias de Cooperación Internacional; libros, tanto del ámbito de la dirección de proyectos, como del área del desarrollo sostenible. Esta etapa de revisión de la literatura se ha prolongado prácticamente durante todo el desarrollo de la Tesis Doctoral, para mantener actualizada la información.

En segundo lugar, para tener un conocimiento de qué se estaba haciendo en los PCD dentro de la propia Universidad Politécnica de Madrid (UPM) y qué necesidades y lecciones aprendidas se podían extraer, así como a qué riesgos se enfrentaban estos proyectos, se realizó el estudio de un total de 152 PCD financiados en las convocatorias de cooperación de la UPM entre los años 2004 y 2014, y se pidió a sus responsables que evaluaran los riesgos (ver Anexo II).

El conocimiento adquirido tras estas dos primeras etapas permitió plantear las preguntas y las hipótesis ya señaladas. Se diseñó un cuestionario para contrastar con profesionales del sector de la cooperación al desarrollo en España, las fortalezas y debilidades detectadas (a través de la revisión de la literatura) del Marco Lógico. Este planteamiento inicial, tanto de las hipótesis como del cuestionario fue contrastado en una entrevista de $2 \mathrm{~h}$ de duración mantenida con el responsable de Cooperación Internacional de Oxfam Intermón.

El cuestionario, diseñado en Google Forms y cuya estructura se puede ver en el Anexo III, consistió en una primera sección dedicada a conocer la organización para la que trabajaban los profesionales (tres preguntas); una segunda sección para conocer la experiencia de la persona encuestada en PCD (cuatro preguntas); y una tercera sección diseñada para conocer el uso de los pasos de la metodología y su opinión sobre el Marco Lógico. Esta tercera sección constaba de dos bloques diferenciados. El primero estaba dedicado a conocer qué pasos utilizaban de los que propone la metodología del ML e incluía una pregunta abierta sobre si no se utilizaba la matriz tradicional del ML qué columna, fila o casilla era la que se cambiaba. El segundo constaba de 15 afirmaciones sobre las que se medía el grado de conformidad en una escala 1-4 (completamente en desacuerdo, en desacuerdo, de acuerdo y completamente de acuerdo), con una posibilidad también para No sabe/No contesta. Esta escala se escogió apoyándose en la 
conocida escala Likert $^{17}$, pero sin incluir el valor central, para eliminar así la tendencia a situarse en este valor, de acuerdo con recomendaciones estadísticas (AEVAL, 2014) y como ya contemplan algunos autores (Cohen, Manion y Morrison, 2011; Smith y Albaum, 2005). De las 15 afirmaciones, las ocho primeras representaban características (fortalezas y debilidades) el ML extraídas de la literatura; las seis siguientes exponían las propuestas de cambio a introducir en el ML para su mejora. La última afirmación de esta serie resumía el bloque buscando el grado de conformidad respecto a la necesidad de mejorar la metodología.

Además, se incluía una pregunta final abierta para que las personas participantes pudieran incluir su opinión acerca del ML y de sus campos de mejora.

Los datos de este cuestionario se estudiaron a través de estadística descriptiva en primera estancia, para continuar analizando las correlaciones entre las 15 afirmaciones y finalizar realizando un análisis de la varianza (ADEVA, o ANOVA, por sus siglas en inglés).

Para realizar el estudio ADEVA se formaron grupos atendiendo a las diferentes características de las personas encuestadas (por ejemplo, tipo, tamaño y experiencia de la organización), y se comprobaron las diferencias entre las medias para cada uno de los grupos, con un intervalo de confianza de un $95 \%$.

El análisis de estos datos se muestra en el Capítulo de resultados, pero se resume aquí que demostró la necesidad de introducir la GR en el ML, dando pie a seguir enfocando la investigación desde este punto de vista.

\subsubsection{Análisis del caso de estudio}

Como caso de estudio se escogió el Departamento del Cauca (Colombia), tras haber tenido la oportunidad de participar en un PCD desarrollado en la zona ${ }^{18}$ durante el primer año de la investigación, y haber podido apreciar que Colombia atraviesa un momento coyuntural muy complejo, y que la población del Cauca presentaba un alto nivel de vulnerabilidad, juntamente con una gran riqueza étnica y cultural. Este contexto era muy adecuado para el estudio que se quería llevar a cabo. Por ello, se comenzaron a entablar contactos a partir de ese primer viaje para recopilar información de PCD desarrollados en la zona, o en ejecución.

\footnotetext{
${ }^{17}$ Escala de cinco puntos diseñada por el americano Rensis Likert (1903-1981), muy utilizada en el ámbito social para medir el grado de conformidad según: "Totalmente en desacuerdo"; "En desacuerdo"; "Ni de acuerdo, ni en desacuerdo (neutral)"; "De acuerdo"; "Totalmente de acuerdo".

18 Proyecto Clúster social y productivo de café en el corregimiento de La Venta de Cajibío (CaucaColombia). Fase II. Liderado por Virginia Díaz Barcos, con una duración total de un año y una financiación de $12.000 €$. La estancia en terreno fue de 12 días.
} 
Se recopiló y se analizó la información facilitada por los coordinadores de nueve PCD en Cauca. Finalmente, por imposibilidad de realizar talleres con todos en el tiempo convenido, se trabajó solo con ocho de estos proyectos en terreno ${ }^{19}$. Para cada uno de ellos se realizaron grupos focales con las personas que intervinieron en los proyectos, con quienes se trabajó en la identificación y evaluación de los riesgos, así como en la percepción del éxito de las intervenciones. Se realizaron además entrevistas con los coordinadores/as de estos proyectos para contrastar los resultados obtenidos con el trabajo de los grupos focales y para conocer de primera mano cómo fue la dirección de los proyectos y su gestión de riesgos, con qué dificultades se encontraron y qué cambiarían para futuros proyectos.

Los grupos focales con los participantes se celebraron en terreno, en sesiones con una duración media de tres horas, en los que inicialmente se exponía lo que se iba a hacer y en qué consistía tanto la GR, como las dos diferentes perspectivas del éxito del proyecto, la del impacto sobre la comunidad, y la de la propia dirección del proyecto en el cumplimiento de objetivos.

Tras ello, los participantes definían individualmente en qué consistía el éxito del proyecto, pudiendo utilizar hasta tres definiciones por persona, escritas cada una en un post-it. Estas definiciones eran agrupadas posteriormente por todos los participantes de manera consensuada en un máximo de tres factores.

A continuación, y siguiendo la misma dinámica, cada participante definía los objetivos del proyecto de manera individual, para luego, en grupo, priorizarlos.

Después, en conjunto, los participantes eran preguntados qué habrían hecho de otra manera si el proyecto volviera a empezar y qué herramientas hubieran utilizado. Se buscaba aquí conocer las lecciones aprendidas con cada proyecto.

Tras un breve descanso, se continuaba la sesión con la identificación de riesgos. Tras unos ejemplos previos y llegados al acuerdo de trabajar con la Estructura de Descomposición del Riesgo (RBS, por sus siglas en inglés) propuesta, conjuntamente se identificaban los riesgos que afectaron o pudieron haber afectado al proyecto, y se incluían en la categoría correspondiente. En cada categoría se identificaron algunos riesgos previamente por parte de la autora de esta Tesis, los cuales fueron propuestos a los participantes y, aceptándose la mayoría de ellos, se complementaron con otros identificados tras el trabajo en grupo. Al trabajar en papel, estos riesgos nuevos se incluyeron directamente en el cuestionario para su posterior evaluación.

\footnotetext{
${ }^{19}$ Las entrevistas y los grupos focales se desarrollaron en terreno en un periodo de 35 días.
} 
La evaluación, tanto de los riesgos, como de los diferentes puntos de vista de éxito identificados, se realizó de manera individual por cada uno de los participantes, rellenando un cuestionario en papel que seguía el formato presentado en el Anexo IV.

Los resultados obtenidos se contrastaron con los coordinadores/as de los proyectos, que también habían tomado parte en el grupo focal. Las entrevistas realizadas con los ocho coordinadores/as de estos proyectos tuvieron una duración media de $1 \mathrm{~h}$ y 30 minutos y consistieron en dos bloques de preguntas abiertas, el primero dedicado a la planificación del proyecto, y el segundo relacionado con su ejecución. Previamente, se incluyó también información sobre la experiencia de la persona entrevistada en la coordinación de este tipo de proyectos. El guion de estas entrevistas se puede ver en el Anexo V. Con anterioridad a la entrevista, se envió a cada coordinador/a una ficha resumen con los datos del proyecto para su validación.

Los resultados de estos talleres fueron analizados cualitativamente en primer lugar, y en segundo lugar a través de la metodología fuzzy, que se explicará en el Apartado 5.3.6.

\subsubsection{Diseño de la metodología propuesta}

Atendiendo al estudio realizado y a los resultados obtenidos, que se presentarán en el Capítulo 6, se diseña una metodología participativa basada en la incorporación de la GR en cada uno de los cinco pasos del ML (puede verse en el Apartado 6.5).

Esta metodología es contrastada con ocho profesionales del sector, que, en los contactos previos realizados para evaluar el ML, manifestaron su deseo de participar en futuros trabajos relacionados con esta investigación y con la mejora de la gestión de riesgos en los PCD. De entre las 29 personas dispuestas a participar, se seleccionaron estas ocho para poder disponer de puntos de vista multidisciplinares y heterogéneos, tratando de cubrir todos los actores posibles implicados en las intervenciones de cooperación.

\subsection{Filosofías y técnicas de la investigación}

La combinación de estrategias y técnicas que se han llevado a cabo durante la investigación responde, en primer lugar, a una investigación documental y una investigación en campo.

La investigación documental se realizó a través de recursos principalmente bibliográficos, de referencia (guías) y de estudio (libros, manuales y Tesis doctorales) y mayoritariamente de publicaciones periódicas de carácter científico.

La investigación en terreno se apoya en la teoría filosófica del construccionismo, donde la verdad es subjetiva y el contexto es determinante, resultando necesario utilizar métodos cualitativos (Sekaran y Bougie, 2016). El construccionismo se aleja por tanto 
de la única y objetiva verdad que plantea el positivismo y sus metodologías cuantitativas. Aunque Europa ha enfocado tradicionalmente sus investigaciones en el ámbito de la gestión hacia metodologías cualitativas, una nueva tendencia fomentada por el núcleo positivista norteamericano está introduciendo cada vez más las metodologías cuantitativas en este tipo de investigaciones (Saunders y Bezzina, 2015). Contrario a este movimiento está el surgimiento de las teorías críticas, como el realismo crítico, que establece en dos pasos el proceso del conocimiento de la verdad, primero lo que se percibe y segundo lo que, tras un proceso mental influenciado por la realidad conocida, se percibe (Saunders, Lewis y Thornhill, 2016). Construccionismo, positivismo y realismo crítico son, según Alvesson y Sköldberg (2009), las tres corrientes de referencia en el ámbito de la investigación científica.

En esta investigación se utilizan estrategias cualitativas para la obtención de datos, dado que no solo gozan de completo reconocimiento en las ciencias sociales, sino que además son las técnicas de investigación predominantes (Denzin y Lincoln, 2011; Saunders, Lewis y Thornhill, 2016).

Para la investigación cualitativa la presencia en terreno del investigador cobra un papel fundamental, así las entrevistas, las conversaciones y los trabajos realizados en campo permiten estudiar los casos en su auténtica naturaleza, ayudando a interpretar los fenómenos de acuerdo con cómo la población local los vive (Denzin y Lincoln, 2011).

Esta investigación en terreno utiliza también la técnica de investigación-acción (Lewin, 1946), dado que explora conjuntamente teoría y práctica, enfatizando en el conocimiento adquirido a través de la aplicación de la teoría con los actores participantes (Eden y Ackermann, 2018).

Las técnicas de investigación utilizadas han sido la observación participante, el cuestionario, la entrevista y el caso de estudio. Estas técnicas se complementaron con metodologías estadísticas y difusas para construir nuevas hipótesis a partir de los datos obtenidos.

\subsubsection{Observación participante}

La observación participante es una de las más valiosas metodologías utilizadas para entender la cultura y la estructura de las comunidades (Fine, 2015). De hecho, aunque hay muchas metodologías para realizar el trabajo de campo, se suele utilizar ese concepto cuando realmente se habla de la observación participante.

Aunque se considera esencial el uso de esta técnica en investigaciones in situ, acompañarla de cuestionarios o entrevistas es muy recomendado para enriquecer la recogida de datos (Fine, 2015). 
La observación participante se ha llevado a cabo durante las dos estancias en terreno de la autora de la Tesis en Cauca.

\subsubsection{Cuestionario}

Los cuestionarios son una de las técnicas más utilizadas y de mayor expansión en los últimos años en investigaciones sociales, dado que permiten obtener información a través de un amplio número de respuestas, sin la necesidad de estar presente la persona que realiza la investigación (Saunders, Lewis y Thornhill, 2016).

Dado que la persona investigadora no está presente, es necesario cuidar el diseño del cuestionario, haciéndolo comprensible por las personas que lo van a realizar.

Los cuestionarios suelen componerse de preguntas cerradas y/o abiertas.

En esta investigación se realizaron dos tipos de cuestionarios, unos enviados a través de internet, y otro en papel. Los enviados por internet se utilizaron en la primera fase para conocer, por un lado, la evaluación de los riesgos de los PCD de la UPM, y por otro, la opinión de los profesionales sobre el Marco Lógico. El otro cuestionario fue usado en la segunda fase para conocer la opinión de los participantes sobre los riesgos y el éxito alcanzado en cada proyecto de los estudiados en el Cauca.

El cuestionario relacionado con los PCD de la UPM y sus riesgos fue enviado por correo electrónico a los 87 responsables aún en activo, dado que, de los 152 proyectos, algunos habían sido dirigidos por las mismas personas, existiendo un total de 112 directores o directoras de Proyecto y, de estos, tres habían fallecido a fecha del estudio y otros 22 no pertenecían ya a la UPM. Debido a la alta ocupación de muchas de ellas, y a la lejanía temporal, en muchos casos, del proyecto dirigido, solo 40 personas respondieron al cuestionario.

El cuestionario sobre el ML se envió inicialmente a través de la coordinadora nacional de ONGDs de España, a las 17 coordinadoras autonómicas, quienes se encargaron de distribuirlo. Merece la pena destacar que aquellas coordinadoras como la aragonesa, la riojana o la navarra, que pidieron que se contactara directamente con las organizaciones asociadas, facilitando sus correos, permitieron alcanzar un número mayor de respuestas. Igualmente, se debe comentar que, aunque la coordinadora nacional representa a 400 organizaciones, más de la mitad de ellas no formulan directamente proyectos y, por lo tanto, no contaban con personal experimentado en el uso del ML. El cuestionario obtuvo inicialmente 46 respuestas obtenidas a través de este medio. Además, se pidió expresamente a 11 profesionales españoles experimentados en el uso de la metodología en universidades, empresas y administraciones públicas que contestaran el cuestionario. 
Este mismo cuestionario se pasó también a profesionales que trabajan con el $\mathrm{ML}$ en Colombia. En esta ocasión, se envió a 20 personas específicas con extenso conocimiento de la metodología y su aplicación en el ámbito de la cooperación al desarrollo, dado que en Colombia el ML es utilizado para la formulación de todos los proyectos de financiación pública.

En total se ha trabajado con las respuestas de 77 personas.

El cuestionario, como se ha visto en el Apartado 5.2.1, está compuesto de preguntas cerradas, salvo una última cuestión abierta.

El segundo cuestionario, dedicado a evaluar riesgos y éxito de los PCD, se entregó en papel a los participantes de los focus group. En ese papel, donde venían identificados algunos riesgos a modo de ejemplos, se fueron completando con más riesgos durante el desarrollo de la sesión. Las preguntas eran cerradas y consistían en asignar una probabilidad a los riesgos, y un impacto de los mismos, atendiendo a cuatro parámetros: tiempo, coste, alcance y seguridad. Ambas variables, probabilidad e impacto, se midieron con una escala de cinco niveles: Muy alta/o, alta/o, media/o, baja/o y muy baja/o, por ser la más habitual en los estudios de gestión de riesgos (Cox, 2008; El-Karim, Nawawy y Abdel-Alim, 2015). Las dimensiones del éxito del PCD fueron introducidas en las casillas designadas para ello en el cuestionario, de acuerdo con lo decidido por el grupo, y fueron consiguientemente evaluadas del 1 al 10.

\subsubsection{Entrevista}

Desde el principio de los tiempos el ser humano ha utilizado las conversaciones como la herramienta esencial para conocer información de otros ${ }^{20}$, y pese a las críticas sobre su subjetividad, Brinkmann (2013) las considera el método más objetivo para investigar sobre aspectos relacionados con experiencias humanas.

En esta investigación se han realizado diferentes tipos de entrevista. La mayoría (9) han sido presenciales, salvo una última telefónica para contrastar con la Gobernación del Cauca los resultados del análisis con las metodologías fuzzy. Todas ellas han constado de preguntas abiertas, pero mientras que las realizadas a las personas responsables de dirigir los proyectos fueron estructuradas, la realizada para contrastar los resultados fue semiestructurada y la dedicada inicialmente a contrastar el cuestionario sobre el marco lógico no mantuvo ningún guion.

\footnotetext{
${ }^{20}$ La primera entrevista para prensa fue realizada a mitad del siglo XIX. La primera vez que se utilizaron las entrevista para fines de investigación fue entrado ya el siglo XX y se le atribuye a Sigmund Freud en torno al año 1900.
} 


\subsubsection{Caso de estudio}

El caso de estudio es un método de investigación flexible y puede ser utilizado dentro de diferentes paradigmas filosóficos, incluyendo positivismo, construccionismo y teorías críticas (Cavaye, 1996). El caso de estudio es definido como una herramienta de investigación empírica sobre un fenómeno dentro de su contexto real (Yin, 2014; Farquhar, 2012).

Dentro de esta técnica se puede trabajar con un solo caso de estudio o con múltiples casos (Dul y Hak, 2008).

Trabajar con un solo caso requiere que éste disponga de características singulares y puede ser utilizado como estudio piloto, mientras que trabajar con múltiples casos permite comparar resultados (Darke y Shanks, 2002).

En esta investigación se ha trabajado con el caso de estudio de Cauca (Colombia) por su singularidad y riqueza cultural, pudiéndose luego replicar el estudio en otras localizaciones. Dentro de este caso de estudio, se ha trabajado con ocho PCD que serían a su vez los casos de estudio sobre los cuales se pueden interpretar los datos desde diferentes puntos de vista, comparándolos entre sí. Estos ocho proyectos se describen en el Apartado 5.4.

\subsubsection{Estadística}

Para el análisis cuantitativo de la investigación se han utilizado las técnicas estadísticas siguientes, apoyadas en el software de IBM SPSS ${ }^{\circledR}$ :

- Estadística descriptiva, con el estudio de las medias, mediana y desviación estándar. Este análisis estadístico permite entender, describir y comparar cuantitativamente los datos obtenidos en la investigación (Saunders, Lewis y Thornhill, 2016).

- Análisis de la correlación, donde se estudia la relación entre las variables. EI coeficiente de correlación de Pearson, $r$, viene definido de la siguiente manera:

$$
r=\frac{\operatorname{cov}_{x y}}{s_{x} s_{y}}=\frac{\sum\left(x_{i}-\bar{x}\right)\left(y_{i}-\bar{y}\right)}{(n-1) s_{x} s_{y}}
$$

[Ecuación 5.1. Correlación de Pearson]

Donde $s_{x}$ y $s_{y}$ son las desviaciones estándar, y $\operatorname{cov}_{x y}$ o $\operatorname{cov}(x, y)$ es la covarianza, esto es la media de las diferencias combinadas (Field, 2003; Wherry, 1984). 
Este coeficiente $r$ debe estar entre -1 y 1 , cuanto más cercano al valor unitario, más relacionadas estarán las variables, positiva o negativamente. Un valor de correlación $(r)$ igual a 0,55 indica que las variables explican la varianza de una sobre la otra en un $30,25 \%\left(0,55^{2}\right)$. Para las correlaciones, un valor de significancia con una $p=0,05$, esto es, la probabilidad de que esa correlación no exista es de un $5 \%$ o menor, es generalmente aceptado en investigaciones sociales (Sekaran y Bougie, 2016).

- Análisis ADEVA, para ver si existían diferencias en la opinión atendiendo a los diferentes grupos a los que pertenecían los encuestados (Saunders, Lewis y Thornhill, 2016). Para ello, se trabajó con el modelo $y_{i j}=\mu_{i}+u_{i j}$, donde $y_{i j}$ son las observaciones, $\mu_{i}$ las medias de las observaciones para el grupo $\mathrm{i}, \mathrm{y} \mathrm{u}_{\mathrm{ij}}$, son los errores residuales normalmente distribuidos, $u_{i j} \sim N\left(0, \theta^{2}\right)$. El test de normalidad fue previamente comprobado para garantizar la fiabilidad del análisis (Box, Hunter y Hunter, 1978). Este análisis estadístico permitió comprobar cuál de las hipótesis se cumplía:

$H_{0}$ : Todas las medias son iguales para los diferentes grupos $\left(\mu_{1}=\mu_{2}=\ldots=\mu_{n}\right)$.

$\mathrm{H}_{1}$ : Alguna de las medias es diferente con respecto al resto.

\subsubsection{Metodología Fuzzy}

Inicialmente, la lógica difusa o Fuzzy se aplicó exclusivamente en el ámbito de las ciencias formales (e.g. matemáticas, estadística o lógica), de hecho, en los primeros trabajos que se conocen con esta técnica, realizados por Zadeh (1965), se la consideraba una teoría matemática utilizada bajo la lógica polivalente. Lo cierto es que en los últimos años se han publicado muchos trabajos aplicados a diferentes sectores, como la identificación de los grupos de interés (Gil-Lafuente y Paula, 2013), el transporte (Paula y Silva Marins, 2018; Romero Ruiz, 2017), la energía (Yu, Huang y Huarng, 2016), o los efectos del cambio climático (Jones y Cheung, 2017), entre otros. Su uso cobra especial interés en entornos de incertidumbre (Blanco-Mesa, Merigó y Gil-Lafuente, 2016; Jones y Cheung, 2017; Paula y Silva Marins, 2018; Zadeh, 1965), dado que a la hora de clasificar la pertenencia a una categoría, no se usa exclusivamente el todo o nada, sino que la lógica difusa permite pertenecer más o menos a uno u otro conjunto, permitiendo una escala gradual muy pertinente cuando se trata de percepciones, como en este caso, del riesgo que afecta a un proyecto o del éxito que logra.

En esta investigación se utiliza la metodología difusa a través del programa FsQCA $3.0^{21}$ (Fuzzy set Qualitative Comparative Analysis). Este software utiliza lógica combinatoria,

${ }^{21}$ El programa fsQCA 3.0, así como el manual elaborado para facilitar su uso User's guide to FuzzySet/Qualitative Comparative Analysis (Ragin y Davey, 2017), se han obtenido gratuitamente de http://www.socsci.uci.edu/ cragin/fsQCA/. 
la teoría de conjuntos de la lógica difusa y la minimización booleana para averiguar qué combinación de características pueden ser necesarias o suficientes para dar un resultado (Kent y Olsen, 2008). FsQCA permite identificar cuáles son las condiciones necesarias y cómo influyen a la hora de alcanzar el resultado o variable salida. Este método permite también identificar la condición suficiente (combinación a su vez de condiciones) para alcanzar el resultado (Ragin, 2008).

Este tipo de análisis, basado en la lógica difusa, permite comprender la complejidad de las relaciones causales entre las condiciones necesarias y las suficientes para obtener un resultado determinado, mientras que los métodos convencionales solo analizan los efectos netos (Huarng, Rey-Martí y Miquel-Romero, 2018). La Tabla 5.1, muestra las diferencias conceptuales entre las denominadas técnicas tradicionales y la metodología difusa. El uso de las técnicas fuzzy exige un conocimiento mayor por parte de la persona que realiza la investigación sobre el fenómeno estudiado y las relaciones entre las condiciones o variables, dado que tiene que otorgar una calibración adecuada a las variables y, además, saber interpretar la solución obtenida (Romero Ruíz, 2017).

Tabla 5.1. Alternativas para el rediseño de las investigaciones sociales.

Fuente: Ragin, 2008.

\begin{tabular}{|c|c|c|}
\hline $\begin{array}{l}\text { Investigaciones } \\
\quad \text { sociales } \\
\text { convencionales }\end{array}$ & $\begin{array}{l}\text { Investigaciones } \\
\text { sociales } \\
\text { rediseñadas }\end{array}$ & Ventajas \\
\hline Variables & Conjuntos & $\begin{array}{l}\text { El uso de un conjunto en lugar de una variable está más } \\
\text { orientado al caso, implicando la consideración de un } \\
\text { número de miembros y consecuencias en la clasificación. }\end{array}$ \\
\hline Medidas & Calibraciones & $\begin{array}{l}\text { Tomando medidas calibradas se elimina la relatividad entre } \\
\text { las medidas (algo es más o menos que otro de la propia } \\
\text { muestra). La calibración permite relativizar con estándares } \\
\text { externos. }\end{array}$ \\
\hline $\begin{array}{l}\text { Variables } \\
\text { dependientes }\end{array}$ & $\begin{array}{l}\text { Resultados } \\
\text { cualitativos }\end{array}$ & $\begin{array}{l}\text { El problema con estudiar la variación de la variable } \\
\text { dependiente es que esta variación no suele estar calibrada. } \\
\text { Los resultados permiten en cambio explicar un cambio } \\
\text { observable y, con gran conocimiento de los casos, se puede } \\
\text { establecer un criterio para ver cuáles pertenecen al } \\
\text { resultado. Los resultados deben ser también calibrados. }\end{array}$ \\
\hline $\begin{array}{l}\text { Poblaciones } \\
\text { dadas }\end{array}$ & $\begin{array}{l}\text { Poblaciones } \\
\text { construidas }\end{array}$ & $\begin{array}{l}\text { Al usar poblaciones construidas se evita incluir casos } \\
\text { irrelevantes. }\end{array}$ \\
\hline Correlaciones & $\begin{array}{l}\text { Conjunto de } \\
\text { relaciones } \\
\text { teóricas }\end{array}$ & $\begin{array}{l}\text { El cálculo de las correlaciones es totalmente simétrico, se } \\
\text { usa tanto para relaciones de causa efecto, como para } \\
\text { relaciones de ausencia de causa y ausencia de efecto. En los } \\
\text { estudios sociales esta simetría no se cumple, y los estudios } \\
\text { cualitativos están basados en conjuntos de relaciones } \\
\text { teóricas, dado que las propias relaciones son conjuntos } \\
\text { teóricos en sí mismos. Las relaciones de necesidad y de } \\
\text { suficiencia son asimétricas en la vida real y solo se pueden } \\
\text { interpretar a través de estos conjuntos de relaciones. }\end{array}$ \\
\hline
\end{tabular}




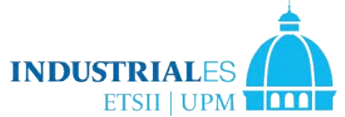

\begin{tabular}{lll}
\hline $\begin{array}{l}\text { Matriz de } \\
\text { correlaciones }\end{array}$ & $\begin{array}{l}\text { Tabla de verdad } \\
\text { Efectos netos }\end{array}$ & $\begin{array}{l}\text { Las correlaciones evalúan dos series de valores entre sí, } \\
\text { pero no considera cómo los casos encajan entre sí dentro } \\
\text { de los otros casos. La tabla de verdad en cambio agrupa los } \\
\text { casos con el mismo perfil en las condiciones causales. }\end{array}$ \\
\hline causales & $\begin{array}{l}\text { Los efectos netos de cada variable y su participación para } \\
\text { explicar la variación de la variable resultado implican aislar } \\
\text { las variables causales, cuando en los estudios sociales se } \\
\text { sabe que ninguna condición tiene efectos independientes } \\
\text { sobre un resultado. Por eso las fórmulas causales presentan } \\
\text { una combinación de condiciones mucho más orientada al } \\
\text { caso. }\end{array}$ \\
\hline $\begin{array}{lll}\text { Estimación de la la } \\
\text { hipótesis de } \\
\text { contraste }\end{array}$ & $\begin{array}{l}\text { Análisis de la } \\
\text { hipótesis de } \\
\text { contraste }\end{array}$ & $\begin{array}{l}\text { El análisis de la hipótesis de contraste está ligado con la } \\
\text { noción de diversidad limitada, que suele darse cuando no se } \\
\text { trabaja con datos experimentales. }\end{array}$ \\
\hline
\end{tabular}

\subsection{Caso de estudio: Cauca y sus proyectos}

Cauca es uno de los Departamentos más castigados por el conflicto armado en Colombia y es una de las zonas con las tasas de pobreza extrema más alta del país, con un $21,8 \%$ de la población afectada, cuando en el resto de Colombia esta cifra se reduce al 7,4\% (DANE, 2017). Cauca destaca, además, por su alto nivel de población indígena y de población rural. Su nivel de formación en educación superior es igualmente más bajo que en el resto del país (Ministerio de Educación de Colombia, 2018).

La situación de este Departamento es apreciada por la comunidad internacional y son numerosos los PCD que se desarrollan en la zona. Por ejemplo, actualmente, la Agencia Española de Cooperación Internacional y Desarrollo (AECID), para quien Cauca es una de las regiones prioritarias en su Marco Asociación País (MAP) 2015-2019 (AECID, 2015), está desarrollando diez proyectos en Cauca, con una aportación total de 8.263.434€. Todos se centran en el emprendimiento de mujeres a través de diversos cultivos. La Figura 5.4 muestra el mapa de Colombia con las regiones prioritarias de actuación para la AECID.

La Oficina de Naciones Unidas para la Coordinación de Asuntos Humanitarios (OCHA), también considera el Cauca una zona de actuación prioritaria, definiendo la mayoría de sus municipios como de necesidad muy alta (ver Figura 5.5). 


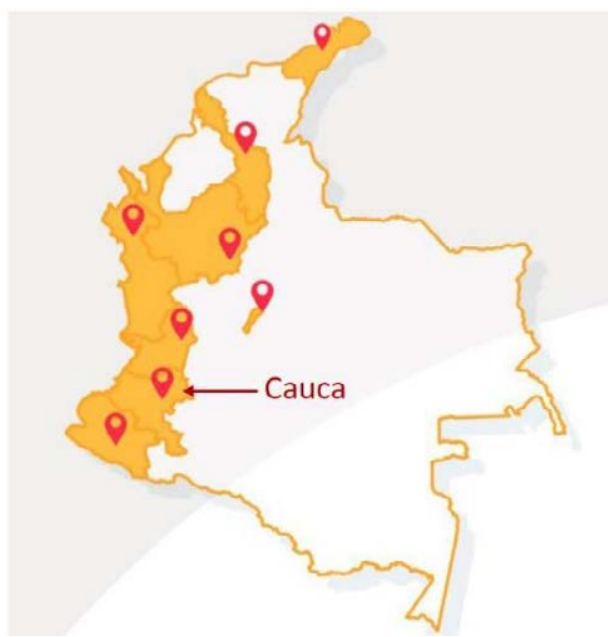

Figura 5.4. MAP Colombia 2015-2019.

Fuente: AECID (2015).

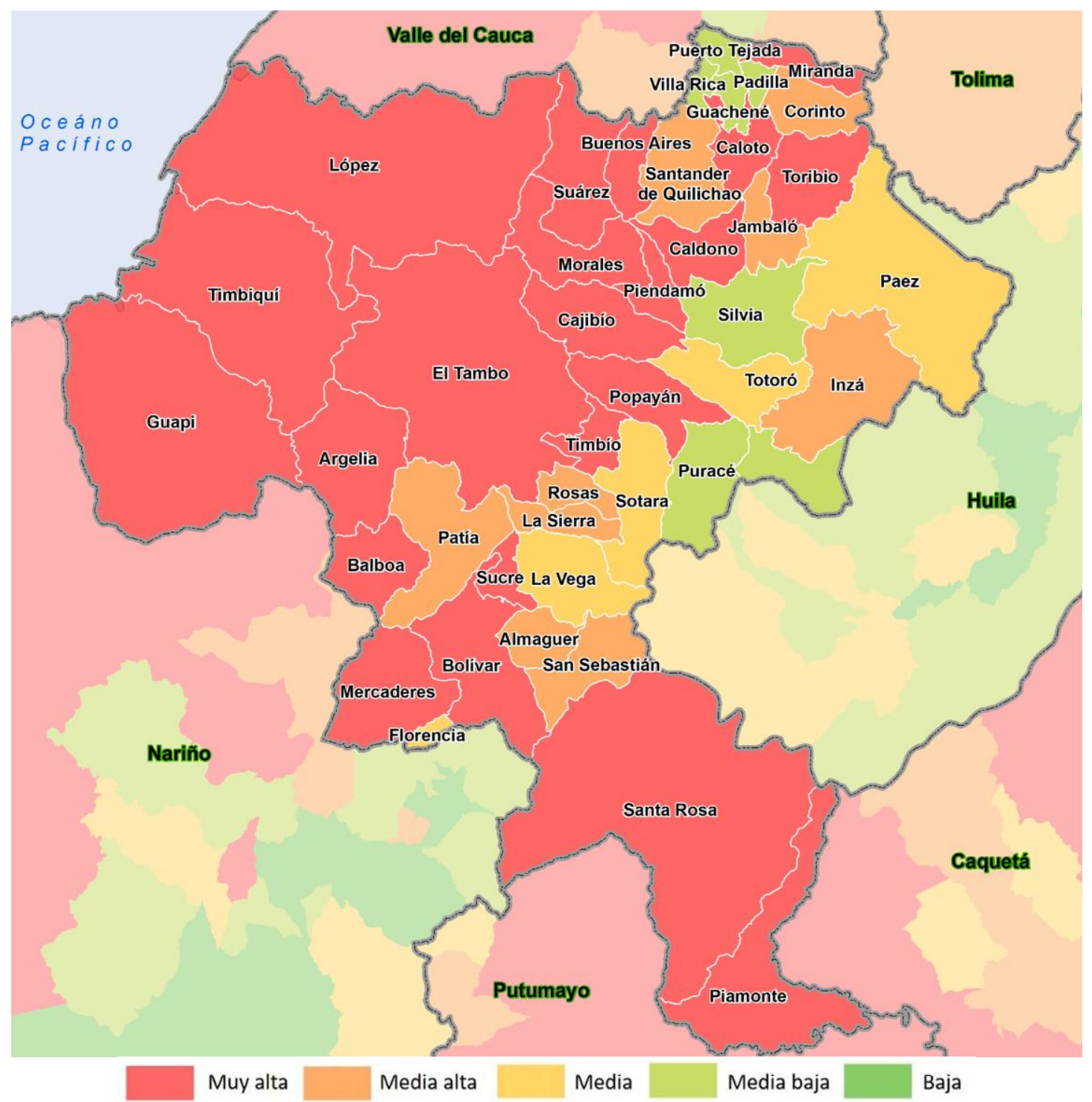

Figura 5.5. Priorización de necesidades en Cauca.

Fuente: OCHA (2014). 
Los ocho proyectos que se presentan a continuación han sido todos ejecutados o están en ejecución en Cauca. Se escogen ocho proyectos para mantener un equilibrio entre una buena representación de los PCD en la zona y un estudio exhaustivo de los mismos.

La verificación de la representatividad de los proyectos de cooperación para la zona del Cauca se realiza a través de varias etapas. En primer lugar, consultando a los profesionales de las organizaciones internacionales que trabajan en terreno. En segundo lugar, con un minucioso estudio de las financiaciones de instituciones internacionales otorgadas a proyectos en el Cauca, cuyo resumen se puede ver en la Tabla 5.2. Y, por último, los proyectos encontrados se validan con el Director de Cooperación de la Gobernación del Cauca, en una entrevista mantenida telefónicamente el 10 de diciembre de 2018. Aunque la Gobernación del Cauca no exige a las organizaciones registrar los proyectos, las organizaciones suelen tramitar en esta institución la certificación de sus proyectos para obtener los beneficios correspondientes en el pago de impuestos, es por eso que se considera una fuente válida para comprobar los proyectos realizados o previstos en el Cauca entre esos años.

Tabla 5.2. Proyectos en ejecución o previstos para el Cauca.

Fuente: elaboración propia.

\begin{tabular}{|c|c|}
\hline Organización/es & Breve descripción \\
\hline AECID & $\begin{array}{l}\text { A finales de } 2018 \text { se han financiado } 10 \text { proyectos en el Cauca con } \\
\text { una aportación total de } 8.263 .434 € \text {. Estos proyectos se centran en } \\
\text { el emprendimiento de mujeres a través de diversos cultivos. En } \\
\text { ellos también colaboran el PNUD, ONU MUJERES, el Programa } \\
\text { Mundial de Alimentos y FAO. }\end{array}$ \\
\hline USAID & $\begin{array}{l}\text { Ahora mismo hay } 11 \text { proyectos de cooperación internacional en el } \\
\text { Cauca con USAID, con el fin de consolidar un Cauca, Territorio de } \\
\text { Paz, bajo el programa Territorio de Oportunidad, que busca } \\
\text { sustituir cultivos ilícitos de coca en cinco municipios del Cauca, con } \\
\text { una duración de cinco años. }\end{array}$ \\
\hline $\begin{array}{l}\text { ONU, PNUD, AECID, UE, } \\
\text { Embajada de Suecia, } \\
\text { Embajada de Noruega y } \\
\text { otros organismos } \\
\text { colombianos. }\end{array}$ & $\begin{array}{l}\text { Proyecto de Alianzas Territoriales para la Paz y el Desarrollo, con } \\
\text { una duración de tres años, afectando a varios departamentos, } \\
\text { entre ellos el Cauca. }\end{array}$ \\
\hline Unión Europea (UE) & $\begin{array}{l}\text { Proyecto Paz Adentro, de inversión para la paz en el Cauca, con los } \\
\text { municipios de oriente, financiado con } 11 \text { millones de euros, } \\
\text { fomenta la educación participativa y el desarrollo rural, con } \\
\text { acuerdos, por ejemplo, de exportación de café a Alemania. }\end{array}$ \\
\hline Embajada francesa & $\begin{array}{l}\text { Asesorías en programas de ciencia, tecnología y educación, en el } \\
\text { municipio de Caldono (Cauca), con un presupuesto de } \\
500.000 .000 \operatorname{COP}(140.940 €)^{*} \text {. }\end{array}$ \\
\hline $\begin{array}{l}\text { Agencia de cooperación } \\
\text { suiza }\end{array}$ & $\begin{array}{l}\text { Proyecto ASIR SABA "agua y saneamiento integral en áreas } \\
\text { rurales", con } 3.400 \text { millones de pesos colombianos ( } 958.392 €)^{*} \text {, } \\
\text { en Santander de Quilichao (Cauca). }\end{array}$ \\
\hline
\end{tabular}




\begin{tabular}{|c|c|}
\hline Fundación CODESPA & $\begin{array}{l}\text { Apoyo a las Mujeres indígenas artesanas del Nororiente Caucano } \\
\text { para la producción y comercialización de productos fabricados con } \\
\text { tejidos étnicos ancestrales, en los municipios de Jambaló, Silvia y } \\
\text { Caldono (Cauca) con } 74 \text { mujeres indígenas beneficiarias, con } \\
13.200 € \text { y una duración de } 9 \text { meses. }\end{array}$ \\
\hline Gobierno de Holanda & $\begin{array}{l}\text { Proyecto CLED, "proyecto de desarrollo económico local del } \\
\text { Cauca", con 500.000€, para los municipios de Silvia, Caldono y } \\
\text { Totoró (Cauca) para desarrollo inclusivo sensible al conflicto. }\end{array}$ \\
\hline $\begin{array}{l}\text { Agencia de Cooperación } \\
\text { alemana }\end{array}$ & $\begin{array}{l}\text { Fortalecimiento de capacidades organizacionales y humanas en la } \\
\text { región de Las Hermosas (Cauca), con ocho municipios del Cauca } \\
\text { como participantes, y una financiación de } 700.000 € \text {. }\end{array}$ \\
\hline $\begin{array}{l}\text { Organización } \\
\text { Internacional de las } \\
\text { Migraciones (OIM) y } \\
\text { Gobierno de Canadá }\end{array}$ & $\begin{array}{l}\text { Proyecto Progresa DRET. Segunda fase del proyecto DRET } \\
\text { (Desarrollo Rural con Enfoque Territorial) financiado por el } \\
\text { gobierno de Canadá con una cuantía superior a los dos millones de } \\
\text { dólares canadienses }(1.319 .533 €)^{* *} \text {. }\end{array}$ \\
\hline Polus Center & $\begin{array}{l}\text { Atención a víctimas del terrorismo por minas antipersona, con } 60 \\
\text { personas beneficiarias sobre las cuales se trabaja en prótesis, en } \\
\text { generación de ingresos y en lazos de soporte familiares, con } \\
700.000 .000 \text { COP }(197.316 €)^{*}\end{array}$ \\
\hline
\end{tabular}

Los proyectos con los que se ha trabajado en Cauca se presentan a continuación en tablas a modo fichas con la información principal relativa a cada uno de ellos (ver Tablas $5.3,5.4,5.5$ y 5.6$)$. 
Tabla 5.3. Ficha: acceso y permanencia a la educación superior en el Norte del Cauca.

Fuente: elaboración propia.

Título Implementación de un modelo innovador de acceso y permanencia en educación técnica profesional y tecnológica y empleabilidad en el Norte del Cauca.

Solicitante Gobernación del Cauca (contratante); Institución Universitaria Tecnológica de Comfacauca ITC (contratista).

Convocatoria Sistema General de Regalías, Plan Nacional de Desarrollo. Plan de Desarrollo del Departamental 2012-2015: Cauca: Todas las Oportunidades dentro del Eje Social en su componente de Pertinencia e innovación al educar.

Objetivo General Contribuir al acceso y permanencia en la educación superior, a la generación de empleo y a la disminución de la pobreza a través de la formación académica, generando capacidades técnicas y tecnológicas a 1.035 jóvenes en situación de vulnerabilidad de 13 municipios ubicados en la zona Norte del departamento del Cauca.

Objetivo(s) Específico(s)

1. Articular 27 instituciones de enseñanza media en sus Proyectos Educativos Institucionales (PEIs) a la formación técnica profesional.

2. Mejorar la preparación académica para el acceso y la permanencia en la educación superior, de 1.035 jóvenes en condiciones de vulnerabilidad.

3. Incrementar la capacidad para permanecer en el sistema educativo, de 1.035 jóvenes, mediante estrategias de retención y permanencia en la educación superior.

4. Incrementar las opciones de empleabilidad de los técnicos y tecnólogos mediante estrategias de inserción al mundo laboral y apoyo al emprendimiento.

5. Ajustar los currículos de los programas técnicos profesionales y tecnológicos con los requerimientos del sector productivo.

6. Incrementar el acceso a la educación técnica y tecnológica de jóvenes en condiciones de vulnerabilidad o provenientes de etnias afrodescendientes e indígenas de los 13 municipios del norte del Cauca.

Presupuesto 6.322.298.896 COP $(1.754 .062 €)^{22}$ es el presupuesto total, del cual 3.633.047.446 COP $(1.024 .085 €)^{6}$ es el presupuesto asignado a Unicomfacauca.

Plazo 36 meses

Localización Puerto Tejada, Guachené, Villa Rica, Padilla, Santander de Quilichao, Caloto, Buenos Aires, Suarez, Miranda, Corinto, Caldono, Jambaló y Toribio.

Comunidad beneficiaria 1035 jóvenes, hombres y mujeres en situación de vulnerabilidad de los 13 municipios del Norte del Cauca.

Equipo de proyecto Dos coordinadores académicos, uno en la sede de Santander de Quilichao y otro en la sede de Puerto Tejada y Miranda, con un equipo cada uno integrado por una persona de bienestar, una auxiliar académica, un decano y una persona de emprendimiento.

Cada decano a su vez tenía entre 12 a 15 docentes también participando.

Dificultades

- El desconocimiento del manejo de recursos públicos, por ser la gestión del primer PCD.

- La situación económica de los jóvenes estudiantes, que se desmayaban por hambre

- Retrasos con los pagos y la parte administrativa de la Gobernación Lecciones aprendidas

- El subsidio de transporte, en caso de darse, no debe enfatizarse. Algunos estudiantes se apuntaron solo para ver qué beneficio podían sacarle al subsidio.

- Incluir directamente en el proyecto la estructura para su seguimiento.

${ }^{22}$ Conversión realizada el 19 de abril de 2019 (Fuente: Expansión) 
Tabla 5.4. Ficha: creación y fortalecimiento de industrias culturales en el Norte del Cauca. Fuente: elaboración propia.

Título Creación y fortalecimiento de las industrias culturales ${ }^{23}$ para el desarrollo socioeconómico de Popayán y el norte del Cauca a través del aprovechamiento de su patrimonio histórico y cultural

Solicitante Caja de Compensación Familiar del Cauca - COMFACAUCA

Convocatoria Banco Iberoamericano de Desarrollo (BID)-Fondo Multilateral de Inversiones $(\text { FOMIN })^{24}$

Objetivo General Contribuir al desarrollo socio económico del departamento del Cauca, posicionando a las industrias culturales y al patrimonio cultural como fuente de desarrollo y oportunidades

Objetivo(s) Específico(s) Promover la oferta y la demanda turística-Cultural en la ciudad de Popayán y en el Norte del Cauca, a través de un modelo de articulación público-privado focalizado en el desarrollo de nuevas empresas y el fortalecimiento de las existentes

\begin{tabular}{l}
\hline Presupuesto 1.255.627 US\$ $(1.125 .214 €)^{23}$ \\
\hline Plazo 36 meses \\
\hline Localización Departamento del Cauca \\
Comunidad beneficiaria Emprendimientos iniciales con alto potencial, las empresas formales \\
del área de influencia que estén activas en el Departamento del Cauca \\
\hline Equipo de proyecto 10-12 personas, dependiendo del momento \\
\hline Dificultades \\
- La gestión de las contrapartidas, que pese a estar previamente firmadas, las instituciones \\
públicas decían que no les correspondían. Esto es porque los proyectos se conceden con \\
cartas de intención, y al no haber obligación legal a través de un Certificado de Disposición \\
Presupuestal, no se puede reservar la partida \\
- El cambio de administración \\
- Articulación institucional, dado que este proyecto tenía a muchas instituciones \\
participando: Ministerio de cultura, gobernación, varias alcaldías, cámara de comercio... \\
\hline Lecciones aprendidas \\
- El término “industria” no gusta, dado que se considera anti-cultura \\
- Mejor priorizar un sector cultural o una zona territorial que dejarlo tan abierto \\
- Necesidad de dar difusión a las actividades que se hacen \\
- En términos de actividades culturales o artesanales, los emprendedores sienten \\
verdadera vocación
\end{tabular}

\footnotetext{
${ }^{23}$ Las industrias culturales son aquellas que producen, reproducen, difunden y comercializan bienes y servicios de base cultural a escala industrial, de acuerdo a criterios económicos de rentabilidad y siguiendo una estrategia comercial de crecimiento.

${ }^{24}$ El Banco Interamericano de Desarrollo (BID) fue fundado en 1959 con la misión de mejorar vidas. El Fondo Multilateral de Inversiones (FOMIN), creado a principios de la década de los 90 para apoyar el desarrollo del sector privado en América Latina y el Caribe, es administrado por el BID. Desde su creación, el FOMIN ha canalizado más de 2.000 millones de dólares para financiar unas 2.000 operaciones, convirtiéndose en la mayor fuente de donaciones con asesoría técnica para pequeños proyectos impulsados por empresas, fundaciones y ONGs. El FOMIN fue pionero en el apoyo a las microfinanzas.
} 
Tabla 5.5. Ficha: emprendimiento con población desplazada.

Fuente: elaboración propia.

Título Fortalecimiento de microempresas asociativas de producción y servicios que integra población desplazada y vulnerable en los municipios de Corinto, Popayán, Timbio, Sotará, Puracé, Balboa, La Vega y Almaguer

Solicitante Caja de Compensación Familiar del Cauca - COMFACAUCA

Convocatoria Ministerio de Comercio, Industria y Turismo y las Entidades Territoriales de Colombia junto con la Organización Internacional para las Migraciones (OIM)

Objetivo General Generar condiciones de organización, constitución, asesorías y comercialización de las microempresas creadas y de los nuevos emprendimientos identificados de población desplazada y vulnerable que incluyan la asociatividad y la sostenibilidad mediante procesos técnicos de acompañamiento profesional para la consolidación de las unidades productivas y de servicios que las articulen al mercado regional

Objetivo(s) Específico(s)

1. Contribuir al desarrollo productivo del departamento del Cauca y de sus diferentes regiones, a través del fomento y/o apoyo institucional a iniciativas de los campesinos, microempresarios del sector urbano, organizaciones comunitarias, indígenas y afrodescendientes, de economía solidaria, en fin, de diferentes formas de organización y en los diferentes sectores y actividades productivas del departamento

2. Coordinar las acciones de diversas instituciones que a nivel regional desarrollan programas y proyectos orientados al desarrollo del aparato productivo del departamento, en especial el sector primario de la economía: actividades agropecuaria, forestal, pesca, agroindustria y minería

Presupuesto 599.528.989 COP $(168.995 €)^{23}$.

Plazo 12 meses

Localización Municipios de Corinto, Popayán, Timbio, Sotará, Puracé, Balboa, La Vega y

Almaguer (Cauca, Colombia)

Comunidad beneficiaria 19 Microempresas de los municipios seleccionados y 246 personas creadoras de empresas (123 hombres y 123 mujeres de los mismos municipios). En total 285 familias como beneficiarias directas

Equipo de proyecto 16 personas en el equipo y seis personas haciendo las capacitaciones

Dificultades

- Miedo a la asociación y a la formalización de la sociedad

- Cambio en la legislación sobre los impuestos de asociación

- Falta de aplicación de buenas prácticas en relación con la seguridad alimentaria Lecciones aprendidas

- Trabajar sobre la experiencia de las personas. Se atendió la petición de que las personas querían aprender un oficio nuevo, distinto al que ejercían antes, pero no tenían conocimientos

- Estudiar la parte legal y tributaria

- Los riesgos se deben identificar desde el inicio del planteamiento del proyecto 
Tabla 5.6. Ficha: empoderamiento mujeres rurales.

Fuente: elaboración propia.

Título Empoderamiento económico y social de mujeres rurales de la región del Alto Patía, sur del departamento del Cauca, como apuesta a la construcción de Paz y Desarrollo Territorial Solicitante Fundación Alpina

Convocatoria EuropeAid

Objetivo General Empoderar económica y socialmente a 400 mujeres rurales de cinco municipios del sur del Departamento del Cauca (Argelia, Balboa, Mercaderes, Florencia y Sucre) a través de la puesta en marcha y fortalecimiento de los agro-negocios individuales y asociativos

Objetivo(s) Específico(s)

3. Caracterización inicial de la actividad técnica, productiva, social, empresarial y organizativa de 400 mujeres rurales en 5 municipios de la región del Alto Patía

4. Empoderamiento económico, social y de inclusión de la mujer rural con enfoque de género

5. Tecnificación de la producción primaria en el área agrícola y/o pecuaria

6. Fortalecimiento de las organizaciones de base

7. Incremento de los canales de comercialización y acceso a nuevos mercados

8. Medición y evaluación de los indicadores que reflejen los resultados

Presupuesto 2.664.300.000 COP $(751.080 €)^{23}$

Plazo 24 meses

Localización Argelia, Balboa, Mercaderes, Florencia y Sucre (Sur de Cauca)

Comunidad beneficiaria 400 mujeres del departamento del Cauca como beneficiarias directas. Los habitantes de los 5 municipios como beneficiarios indirectos

Equipo de proyecto 18 personas

Dificultades

- Encontrar alianzas en el territorio, de hecho, el proyecto inicialmente se quería haber realizado con más municipios, pero solo se pudo enfocar en esos porque fueron con los que se consiguió establecer alianzas con las municipalidades locales

- Influencias políticas a la hora de seleccionar a las mujeres beneficiarias

- Desconfianza de las mujeres hacia el proyecto, dado que se les exigía acudir a formaciones y ellas estaban acostumbradas a recibir en lugar de a capacitarse

- Las mujeres no estaban acostumbradas a trabajar unidas y con un objetivo común, cada una trabajaba antes una línea productiva diferente, hubo que plantear entonces distintas líneas de producción

Lecciones aprendidas

- Las sociedades acostumbradas a trabajar con cultivos ilícitos son tremendamente violentas, naturalizan la violencia

- Es necesario considerar las diferencias culturales

- Los riesgos se deben identificar desde el inicio del planteamiento del proyecto

Se presentan a continuación los cuatro proyectos estudiados en los Espacios Territoriales de Capacitación y Reinserción (ETCR) financiados con 12.000\$ (en el momento 38 millones de pesos colombianos) por parte del Gobierno de Suecia. Fue este gobierno quien decidió, tras una visita, donar el dinero a estos cuatro espacios para los proyectos que se decidiesen en el PNUD en consenso con los exguerrilleros. Debido a 
que era necesario, de acuerdo con los términos de la financiación, ejecutarlos en el mismo año, estos proyectos fueron denominados proyectos de implementación rápida. Su estudio pareció muy interesante debido a la necesidad social inminente de trabajar en la reinserción de los excombatientes en Colombia, que se refleja actualmente en la mayoría de las convocatorias de cooperación, así como por presentar un nuevo modelo de implementación en el que se presumía que los riesgos estarían más presentes.

Conviene destacar que en estos ETCR hay exguerrilleros reconocidos en las listas del Gobierno colombiano, cobrando un subsidio por ello, y otros, principalmente mujeres, que no están reconocidos en ninguna lista y, por lo tanto, no cobran nada.

Los cuatro ETCR donde se desarrollaron estos proyectos están localizados en el Cauca y debido a que toda información relativa a estos espacios se considera muy sensible, se Ilamará a cada uno de los ETCR por la numeración del 1 al 4. Cada uno de estos espacios tiene características muy diferentes que afectaron al desarrollo de los proyectos. Por ejemplo, en el ETCR 1 estaban los principales directivos y líderes de las FARC (Fuerzas Armadas Revolucionarias de Colombia), y estaban muy bien organizados, incluso legalmente constituidos, contando con un fuerte liderazgo. En cambio, en el ETCR 2, había muchas personas de base sin ningún tipo de formación (no sabían leer, ni escribir) y con absoluta falta de liderazgo. Un caso particular fue el del ETCR 3, en el que había un fuerte liderazgo a través de muchos líderes indígenas de distintas comunidades, lo cual dificultó mucho el consenso. En el ETCR 4 estaban inicialmente muchos líderes de las FARC y tenía una estructura muy organizada, similar a la del ETCR 1, pero los principales líderes fueron desplazados a Bogotá y surgió un estado de inestabilidad en la organización.

Todos los proyectos tienen el Objetivo General de generar procesos productivos que permitan la reinserción de las personas habitantes de los ETCR y su integración con las comunidades rurales circundantes. Debido a la urgencia de la implementación, todos los proyectos están relacionados con procesos productivos sobre los que las personas participantes tenían previa experiencia.

Todos los proyectos cuentan también con las mismas implicaciones de personal del PNUD y del SENA (Servicio Nacional de Aprendizaje) para las capacitaciones y con el mismo presupuesto.

Pese a la urgencia, se detecta como muy positivo el hecho de estas experiencias piloto para identificar oportunidades y acercarse a esta población que de otra manera hubiera sido muy difícil.

Las Tablas 5.7, 5.8, 5.9 y 5.10 muestran las fichas resumen de cada uno de los proyectos. La Tabla 5.7 se presenta más completa, no incluyendo en las restantes la información 
relativa a Convocatoria, Objetivo General, Presupuesto, Plazo y Equipo de Proyecto, por ser iguales al proyecto presentado en la citada Tabla 5.7.

Tabla 5.7. Ficha proyecto productivo en ETCR 1.

Fuente: elaboración propia.

\begin{tabular}{l}
\hline Título Granja Integral de Autoabastecimiento \\
\hline Solicitante CECOESPE (Cooperativa de excombatientes de la Esperanza) \\
\hline Convocatoria Gobierno de Suecia \\
\hline Objetivo General Generar procesos productivos que permitan la reinserción de las personas \\
habitantes de los ETCR y su integración con las comunidades rurales circundantes \\
\hline $\begin{array}{l}\text { Objetivo(s) Específico(s) Consolidar una granja integral de autoabastecimiento para los } \\
\text { excombatientes adscritos al ETCR }\end{array}$ \\
\hline Presupuesto 9.500.000 COP (2.678 $€)^{23}$ \\
\hline Plazo 9 meses \\
\hline Localización ETCR 1 y veredas vecinas \\
\hline Comunidad beneficiaria Los miembros de la cooperativa CECOESPE \\
\hline Equipo de proyecto Cinco personas, dos del PNUD, dos del SENA y un profesor de la \\
Universidad del Cauca \\
\hline Dificultades \\
- Sacar el registro ICA ${ }^{25}$ para movilizar y tener los cerdos en la finca \\
Lecciones aprendidas \\
- Cuando se pide confianza para la autogestión del proyecto, siendo un grupo organizado, \\
$\quad$ hay que otorgarla, eso permite estrechar la confianza y consolidar otras iniciativas \\
\hline
\end{tabular}

Tabla 5.8. Ficha proyecto productivo en ETCR 2.

Fuente: elaboración propia.

\begin{tabular}{l}
\hline Título Granja Avícola Monterredondo Huevo Feliz \\
\hline Solicitante ETCR 2 y PNUD \\
\hline Objetivo(s) Específico(s) Generar opciones de autoabastecimiento con la obtención de \\
huevos a partir de la crianza de 500 gallinas ponedoras \\
\hline Localización ETCR 2 y veredas vecinas \\
\hline Comunidad beneficiaria 15 personas sin subsidios pertenecientes al ETCR 2 \\
\hline Dificultades \\
- Falta de organización, de liderazgo, de formación y de humanidad en el espacio \\
- Falta de interés en el proyecto \\
- Problemas de inseguridad en el espacio que conllevan una alta itinerancia \\
- Pese a ser el espacio legalmente arrendado, no se les permite a los excombatientes \\
realizar tareas de siembra
\end{tabular}

\footnotetext{
25 Instituto Colombiano Agropecuario (ICA). Este organismo estableció los requisitos sanitarios para la movilización de carne porcina y de animales de la especie porcina, desde o hacia zonas libres de peste porcina clásica o en proceso de declaración dentro del territorio nacional, a través de la Resolución 2421 del 4 de abril de 2017. Por lo tanto, era necesario el correspondiente registro y certificación.
} 


\section{Lecciones aprendidas}

- Cuando las personas no tienen ningún tipo de formación y han vivido además en entornos carentes de humanidad no cuentan con la confianza para poder participar en las reuniones, se requiere un trabajo psicológico de sensibilidad previo

- No subestimar el potencial de las personas, que fueron creciendo en autoestima y liderazgo según avanzaba el proyecto

Tabla 5.9. Ficha proyecto productivo en ETCR 3.

Fuente: elaboración propia.

Título Cultivo de tomate de árbol en asocio con hortalizas

Solicitante ETCR 3 y PNUD

Objetivo(s) Específico(s) Consolidar una iniciativa productiva entorno al cultivo de tomate de árbol en asocio a verduras ETCR

Localización ETCR 3 y veredas vecinas

Comunidad beneficiaria 40 personas pertenecientes al ETCR 3

\section{Dificultades}

- Problemas administrativos para la compra de instrumental de riego para el cultivo

- Dificultades en la comunicación debido a la estructura vertical de los excombatientes Lecciones aprendidas

- Establecer alianzas estratégicas para alcanzar metas y generar confianza

Tabla 5.10. Ficha proyecto productivo en ETCR 4.

Fuente: elaboración propia.

Título Levante de pollos de engorde y establecimiento de cultivos agrícolas

Solicitante Cooperativa Senda Paz (COOPSENDAPAZ)

Objetivo(s) Específico(s) Consolidar una iniciativa productiva entorno al levante de pollos de engorde y cultivos agrícolas mixtos.

Localización ETCR 4 y veredas vecinas

Comunidad beneficiaria 25 personas pertenecientes a COOPSENDAPAZ

Dificultades

- Retrasos en la implementación del proyecto debido a que las personas del espacio provienen de otro espacio y estaban resolviendo sus problemas de vivienda y de servicios básicos

- No disponían de agua, ni de luz el espacio

Lecciones aprendidas

- En este espacio hay muy buena apertura al trabajo con otras instituciones y cooperantes

\subsection{Programación de la investigación}

La Figura 5.6 presenta la programación de la investigación a través del Diagrama de Gantt, mostrando en color rojo aquellas actividades que forman parte del camino crítico. 


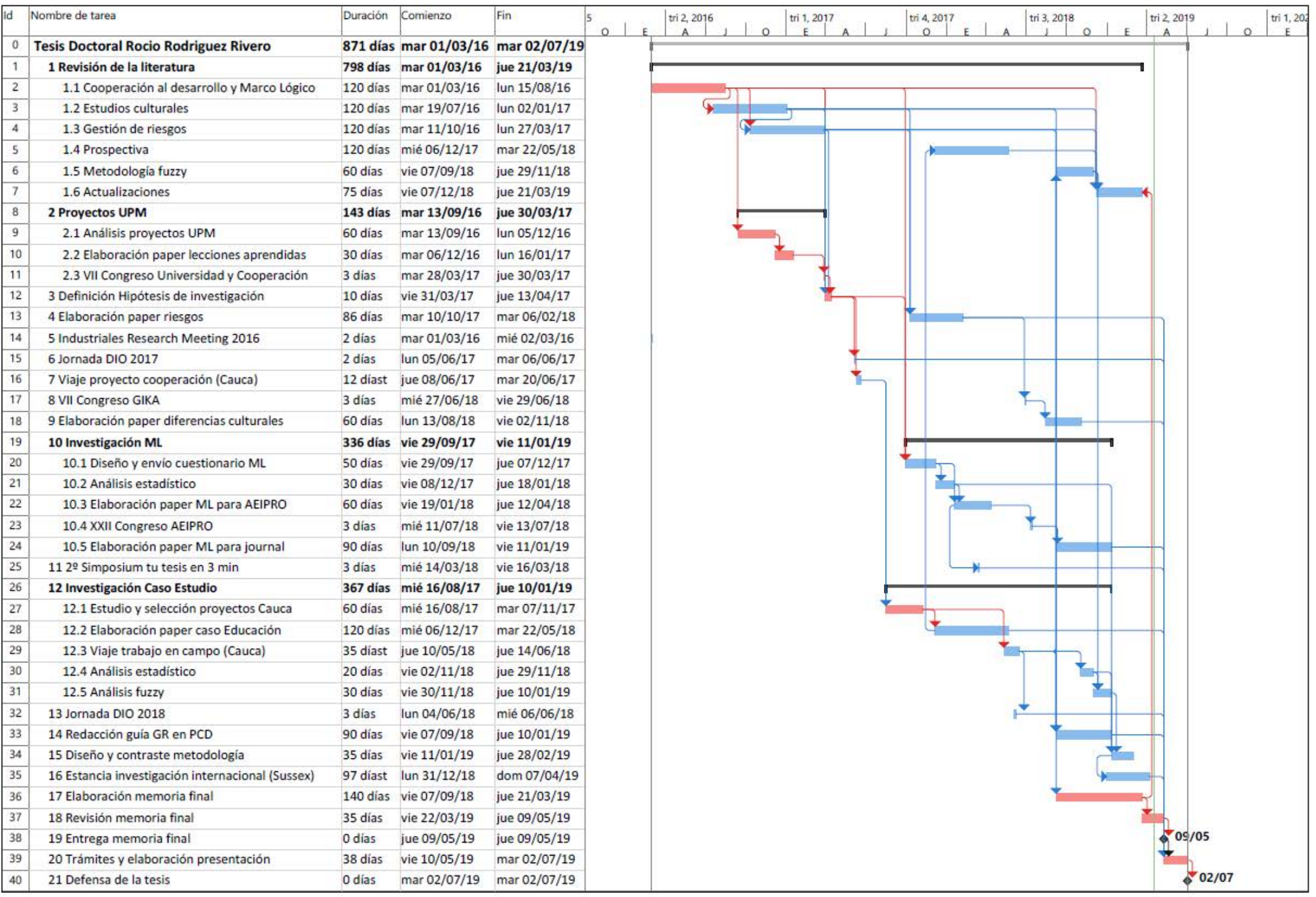

Figura 5.6. Diagrama de Gantt.

Fuente: elaboración propia. 


\section{CAPÍTULO 6. RESULTADOS Y DISCUSIÓN}

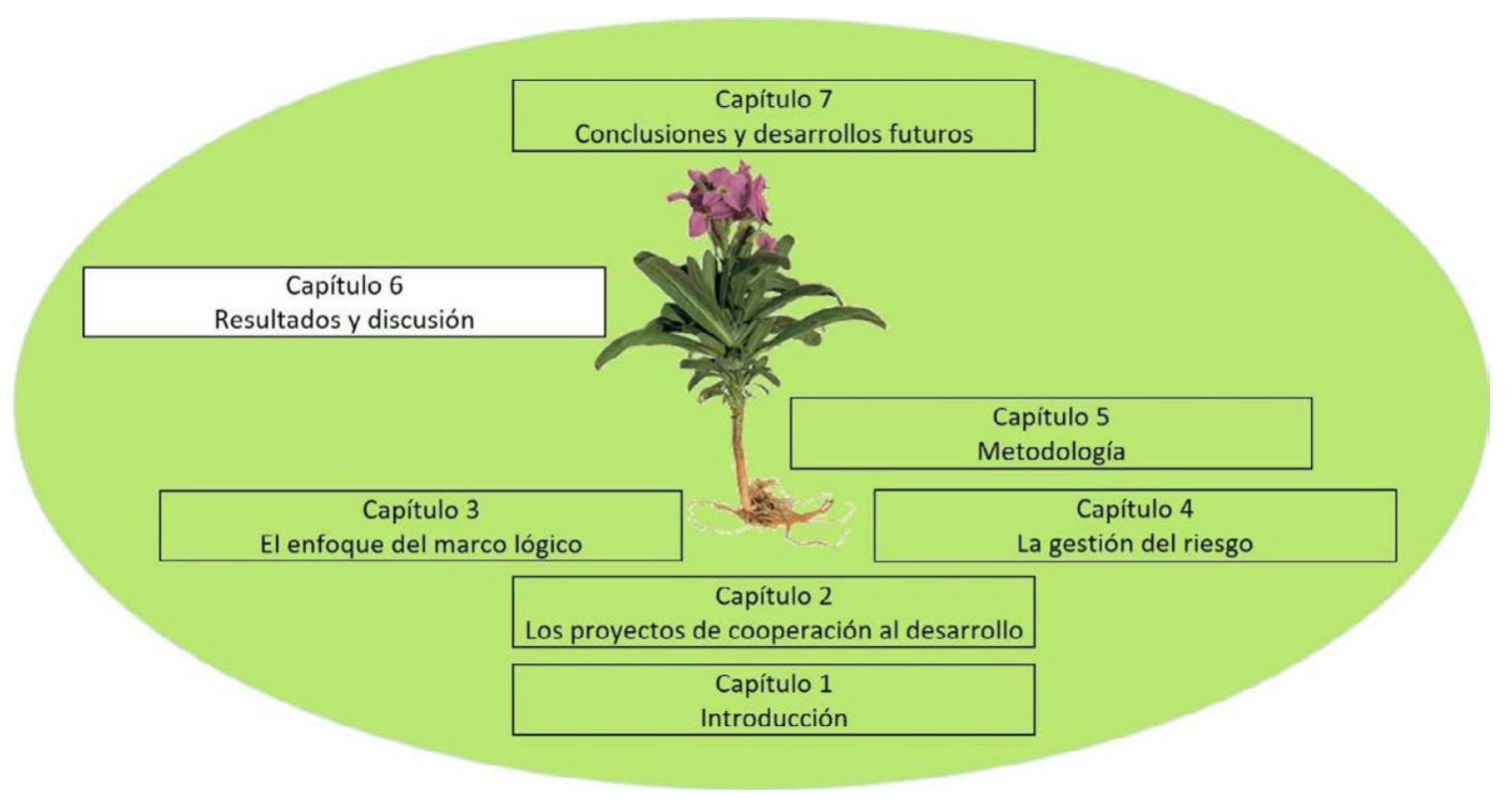

Figura 6.1. Resultados y discusión.

Fuente: elaboración propia.

"Quien no ve la mano que realiza la escritura, supone que el resultado procede del movimiento de la pluma"

(Atribuida al poeta sufí Rumi, 1207-1273) 


\subsection{Introducción}

Este capítulo presenta el conjunto de resultados obtenidos a lo largo de la investigación. Estos resultados son discutidos a lo largo de su presentación, facilitando así su interpretación.

En una primera parte (Apartado 6.2) se presentan los resultados iniciales que sirvieron para apoyar y dar valor a la investigación, como el estudio de 152 PCD realizados en la Universidad Politécnica de Madrid (UPM), y la investigación con profesionales de la cooperación sobre su uso y opinión del ML.

En la segunda parte (Apartado 6.3) se presentan los proyectos estudiados en el caso de estudio del Departamento del Cauca, mostrando la identificación y evaluación de sus riesgos, así como valorando los niveles de éxito alcanzados. Este estudio se realiza cualitativamente y a través de la lógica difusa. Derivado de este trabajo se incluye además un Registro de Riesgos para PCD en el Cauca (Apartado 6.4), que puede ser de utilidad, no solo para intervenciones en este territorio, sino para inspirar en la identificación de riesgos en PCD realizados en cualquier otro lugar.

La última parte (Apartado 6.5) presenta la metodología del Marco Lógico con Enfoque de Gestión de Riesgos (MLEGR), diseñada por la autora de esta Tesis, a partir de todo el trabajo previo realizado, para incrementar el número de intervenciones útiles y realistas en el ámbito de la cooperación y así aumentar el impacto en la comunidad beneficiaria y la eficacia de los proyectos. Esta metodología, fundamentada en su propio espíritu participativo e integrador, ha sido contrastada con ocho profesionales de diversos sectores de la cooperación para su mejor aceptación y posterior utilización.

\subsection{Detección de la necesidad}

Tras una extensa revisión de la literatura dirigida en buena parte hacia la Gestión de Riesgos y hacia la gestión de PCD, representada principalmente por el ML, los primeros pasos que se dan hacia la detección de la necesidad de la investigación se encaminan hacia el conocimiento de la planificación, ejecución y resultados de los PCD financiados por la UPM y hacia el conocimiento la metodología del ML.

\subsubsection{Caso de estudio Universidad Politécnica de Madrid}

Atendiendo a que la inmersión de la Universidad en la cooperación al desarrollo es un reto ineludible en nuestros días, como punto de partida, se realiza el análisis de los 152 PCD financiados en las convocatorias de cooperación de la UPM y realizados por sus 29 grupos de cooperación. Con esto se quiere tener una idea de qué se está haciendo dentro de esta universidad, dónde y en qué se está trabajando, el alineamiento de estos proyectos con los antiguos ODM y con los actuales ODS, qué lecciones aprendidas se 
pueden extraer y con qué riesgos se enfrentaron estos proyectos para poder repercutir acertadamente en el desarrollo de las comunidades beneficiarias.

El análisis consistió en dos etapas. La primera etapa fue documental, en la que se estudiaron los informes finales de los 152 proyectos y toda la documentación adicional facilitada por las personas que dirigían estos proyectos. Toda esta información fue facilitada por la Dirección de Cooperación de la UPM y su estudio ha sido difundido y publicado (Rodríguez-Rivero, Ortiz-Marcos y Sierra-Castañer, 2017). A partir de este estudio, para extraer más información relacionada con la gestión de riesgos, comenzó una etapa analítica en la que se procedió a extraer los riesgos más comunes a todos los proyectos y a evaluarlos por las personas que los habían dirigido a través de sencillos cuestionarios basados en la matriz de riesgos probabilidad-impacto, con una escala del 1 al 5, tanto para probabilidad, como para impacto.

Las Figuras 6.2 y 6.3 muestran una fotografía inicial de en qué sectores y en qué lugares se trabaja en temas de cooperación al desarrollo en la UPM. Destacando sobre todo el sector de las Tecnologías de la Información y Comunicación (TICS), seguido de agua y saneamiento y los proyectos de construcción, relacionados principalmente con habitabilidad básica. En cuanto a las áreas geográficas, más del $50 \%$ de los proyectos se realizan en América Latina, ejecutándose otro porcentaje destacado (30\%) en África. Este resultado está muy en línea con las directrices marcadas por AECID en sus planes directores, y guarda relación también con el resultado que se mostrará en el Apartado 6.2.2.

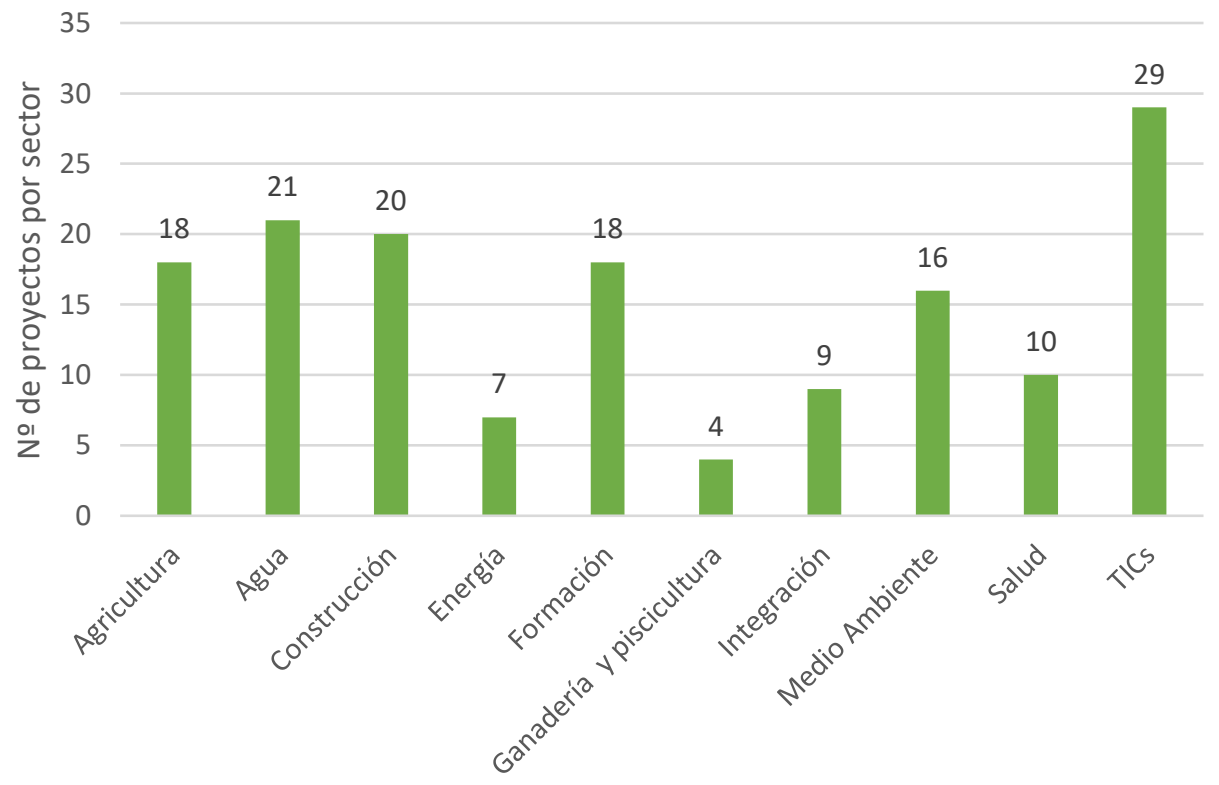

Figura 6.2. Sector de desarrollo de los PCD realizados por la UPM.

Fuente: elaboración propia. 


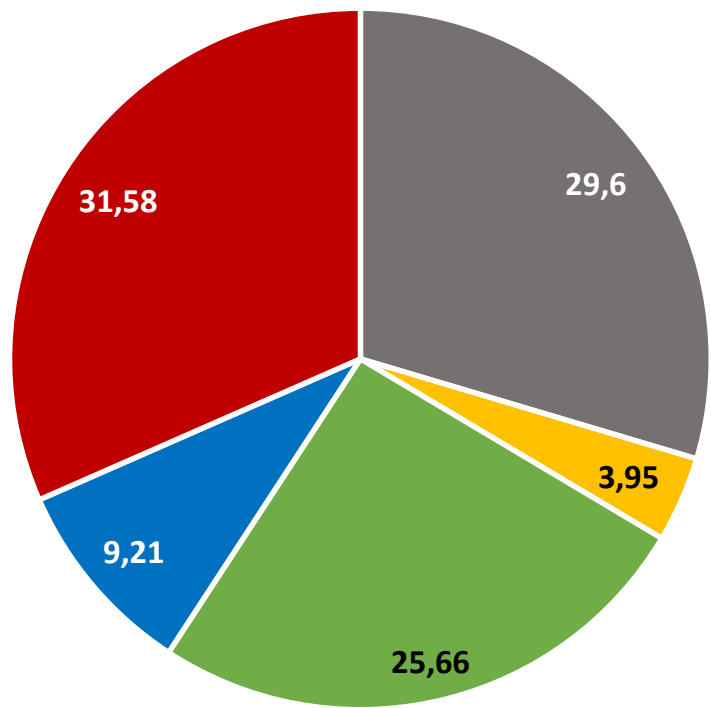

- África - Asia - Centroamérica y Caribe - España - Suramérica

Figura 6.3. Porcentaje de los PCD realizados por la UPM en cada área geográfica. Fuente: elaboración propia.

Estos proyectos, que contaban con una duración media de entre 12 y 18 meses y un presupuesto medio de 26.541€, estaban alineados principalmente con el ODS 17, "Alianzas para lograr objetivos" (13,82\%), el ODS 9, "Industria, innovación e infraestructura" (13,82\%) y el ODS 6, "Agua limpia y saneamiento" $(11,18 \%)$. Apreciando estos porcentajes principales, queda claro que el vínculo con los ODS ha sido muy repartido, estando el $92,8 \%$ de los PCD relacionados directamente con algún ODS. Igualmente, todos los ODS, a excepción del ODS 1, "Fin de la pobreza", han sido tratados de manera directa en los PCD, siendo este ODS 1 tratado de manera indirecta al combatir estos proyectos desigualdades y aportar oportunidades para el fin de la pobreza. Aunque en el periodo estudiado los ODS aún no habían sido definidos, el estudio se ligó con los ODS dado que eran más amplios (que los ODM vigentes en el momento de realizar estos proyectos) y cubrían todos los sectores, además de permitir futuros contrastes.

El estudio de estos proyectos permitió además encontrar una serie de lecciones aprendidas, que se exponen en la Tabla 6.1 a modo de recomendaciones. De todas ellas, salvo las tres últimas que se enmarcan en el contexto de las universidades, podrían ser de aplicación a cualquier organización, y destacando aquellas que tienen que ver la necesidad de conocer en profundidad el contexto político y cultural en el que se ubica la comunidad beneficiaria. 
Tabla 6.1. Lecciones Aprendidas (LA) de los 152 PCD de la UPM.

Fuente: elaboración propia a partir de los informes de evaluación facilitados por la Dirección de Cooperación de la UPM.

\section{Id. Lección aprendida}

LA 1 Convivir previamente con la comunidad en la que se va a trabajar para tener en cuenta aspectos como accesos, recursos materiales disponibles y mano de obra capacitada disponible, teniendo en cuenta la posibilidad de migraciones de los pobladores jóvenes

LA 2 Averiguar si las políticas actuales del lugar de destino son asistencialistas y limitan una asociación autosostenible

LA 3 No invertir en proyectos en países con altas inestabilidades políticas, dado que se pone en peligro su desarrollo

LA 4 Conocer el marco legal y las políticas que existen entorno a las instituciones donde se trabaja, aunque se suele considerar, la recogida de esta información no es una labor fácil

LA 5 Conocer el contexto cultural de la zona de desarrollo del proyecto para evitar situaciones de conflicto (necesidad de prever procesos de mediación de conflictos)

LA 6 Contar con las diferencias culturales existentes en la concepción del tiempo

LA 7 Conocer la climatología de la zona (época de lluvias)

LA 8 Prever los posibles traspasos de personal en la contraparte que afectan al desarrollo del programa

LA 9 Buscar sinergias con otros actores y actividades

LA 10 No desembolsar en un solo pago toda la ayuda económica a la contraparte, para asegurar un mayor compromiso

LA 11 Hay que considerar que la sincronización con otros proyectos puede acarrear mayores retrasos, sobre todo si son de otras entidades

LA 12 Contar con que el desarrollo de una actividad puede necesitar de la mejora/aumento/disminución de otra

LA 13 Difundir las experiencias piloto exitosas para conseguir mayores niveles de implicación en la zona

LA 14 Contemplar una segunda fase posterior para los proyectos que se dediquen a realizar una metodología o una guía, para disponer de tiempo y recursos necesarios para implementarla adecuadamente

LA 15 Aumentar la documentación sobre el proyecto para aumentar la transferencia de conocimiento entre miembros del grupo

LA 16 Publicar libros, realizar cursos y encuentros informativos al terminar un proyecto

LA 17 Garantizar programas de voluntarios en la Universidad que generen una masa crítica capaz de atender a los numerosos proyectos que surgen

LA 18 Asociar trabajos fin de grado, máster o tesis, a los proyectos de cooperación

Estas lecciones aprendidas, junto al contenido de los informes y un estudio en profundidad del contexto donde se realizaron estos proyectos (Perea, 2017) dieron lugar, en primer lugar, a la identificación de 13 riesgos por parte de la autora de esta Tesis Doctoral (ver Tabla 6.2), ligados con el lugar geográfico en el que se desarrollaron los proyectos. Posteriormente, por ver si además del contexto en el que se realizaban, influía el sector en el que se desarrollaban, se identificaron también 11 riesgos ligados a esta variable (ver Tabla 6.3). Todos estos riesgos fueron después evaluados por los 
directores y directoras de los PCD. En esta primera fase exploratoria se optó por la sencillez y el menor número de riesgos facilitando así la participación.

Tabla 6.2. Identificación de riesgos por Áreas Geográficas (AG).

Fuente: elaboración propia a partir de los informes de evaluación facilitados por la Dirección de Cooperación de la UPM.

\begin{tabular}{|c|c|}
\hline Id. & Riesgo \\
\hline AG_R1 & $\begin{array}{l}\text { Las personas beneficiarias del proyecto no expresan su opinión al equipo del } \\
\text { proyecto }\end{array}$ \\
\hline AG_R2 & Falta de entendimiento por no hablar el mismo idioma \\
\hline AG_R3 & Corrupción del estado y falta de implicación de los líderes locales \\
\hline AG_R4 & Inestabilidad política y existencia de revueltas sociales \\
\hline AG_R5 & Desastres naturales y climatología adversa \\
\hline AG_R6 & Conflictos entre grupos de interés o con las indefiniciones de alcance del proyecto \\
\hline AG_R7 & Falta de orientación a largo plazo por la comunidad beneficiaria \\
\hline AG_R8 & $\begin{array}{l}\text { Falta de formación por parte de la mano de obra local o de las personas enviadas } \\
\text { para la ejecución del proyecto }\end{array}$ \\
\hline AG_R9 & Escasez de mano de obra local joven \\
\hline AG_R10 & Problemas de suministro eléctrico o de conexión a internet \\
\hline AG_R11 & Dificultades en el transporte por bloqueo o mal estado de las vías de comunicación \\
\hline AG_R12 & Variaciones en el coste total del proyecto por fluctuaciones en la moneda \\
\hline AG_R13 & Escepticismo ante el proyecto por parte de la comunidad beneficiaria \\
\hline
\end{tabular}

Tabla 6.3. Identificación de riesgos por Sectores (S).

Fuente: elaboración propia a partir de los informes de evaluación facilitados por la Dirección de Cooperación de la UPM.

\begin{tabular}{cl}
\hline Id. & Riesgo \\
\hline S_R1 & Falta de infraestructura, equipamiento o manuales de operación necesarios \\
S_R2 & Mala programación de las etapas del proyecto y falta de capacidad de reacción \\
S_R3 & $\begin{array}{l}\text { Incidencia de plagas y enfermedades } \\
\text { S_R4 }\end{array}$ \\
S_R5 & $\begin{array}{l}\text { Mala calidad del servicio del agua o mala disponibilidad del agua } \\
\text { de formación }\end{array}$ \\
S_R6 & $\begin{array}{l}\text { Falta de indicadores para evaluar la conducta y el progreso durante el proceso } \\
\text { formativo }\end{array}$ \\
S_R7 & $\begin{array}{l}\text { Inclemencias meteorológicas } \\
\text { S_R8 }\end{array}$ \\
Cambios legislativos y falta de apoyo de las instituciones locales \\
S_R9 & $\begin{array}{l}\text { Mal acceso a la comunidad beneficiaria } \\
\text { S_R10 }\end{array}$ \\
$\begin{array}{l}\text { Alto coste de mantenimiento y operación de la nueva tecnología } \\
\text { Dificultades en el aprendizaje sin la guía de una persona física y dificultades con la } \\
\text { lengua inglesa de manuales y programas }\end{array}$ \\
\hline
\end{tabular}

Los riesgos presentados en la Tabla 6.2 podían darse en distintos lugares, al igual que los riesgos de la Tabla 6.3 podían coincidir en diversos sectores. Pero al evaluarlos, se ha 
identificado en qué áreas geográficas y en qué sectores son más importantes, y en cuáles podrían ser comunes.

Para la evaluación de los riesgos se contactó con los responsables de cada uno de los proyectos, como se describió en el apartado 5.3.2. Este cuestionario, aparte de evaluar los riesgos, también sirvió para conocer que tan solo un $34 \%$ de los proyectos ejecutados habían contado con una evaluación de riesgos previa. Entre las respuestas por áreas geográficas, dado que solo se contó con un número de respuestas mínimo (fijado por la autora de esta Tesis Doctoral en cinco) para África (9 respuestas), América del Sur (18) y América Central y Caribe (5), el análisis se enfocó en estas tres áreas, que, por otro lado, eran las mayoritarias, representando casi al $87 \%$ de las zonas geográficas. Para el análisis por sectores, se contó con el número mínimo de cinco respuestas para cinco de los sectores, Agua y saneamiento (5 respuestas), Construcción (5), Agricultura (14), Formación (6) y TICS (11). Estos sectores también eran los que contaban con más proyectos, suponiendo el $69,7 \%$ del total. Los cinco riesgos más importantes para cada una de las evaluaciones pueden verse en las Tablas 6.4 y 6.5 .

Tabla 6.4. Evaluación de riesgos por Áreas Geográficas para los 152 PCD de la UPM. Fuente: elaboración propia a partir de los informes de evaluación facilitados por la Dirección de Cooperación de la UPM.

\begin{tabular}{llllll}
\hline \multicolumn{2}{r}{ África subsahariana } & \multicolumn{2}{c}{ América del sur } & \multicolumn{2}{c}{ América Central y Caribe } \\
\hline Id. & $\begin{array}{l}\text { Importancia } \\
\text { del riesgo* }\end{array}$ & Id. & $\begin{array}{l}\text { Importancia } \\
\text { del riesgo }\end{array}$ & Id. & $\begin{array}{l}\text { Importancia } \\
\text { del riesgo }\end{array}$ \\
\hline AG_R2 & 13,3 & AG_R10 & 16,3 & AG_R4 & 12,6 \\
AG_R8 & 13 & AG_R11 & 12,6 & AG_R5 & 11,2 \\
AG_R7 & 12,3 & AG_R7 & 11,6 & AG_R3 & 11,2 \\
AG_R10 & 11,6 & AG_R8 & 11,6 & AG_R6 & 10,2 \\
AG_R1 & 11,4 & AG_R9 & 11 & AG_R11 & 9,8 \\
\hline
\end{tabular}

*Valores obtenidos con escalas del 1 al 5 para probabilidad e impacto, siendo la importancia el producto de ambas medidas.

La primera valoración que se puede hacer de este análisis es que los niveles de riesgo, medidos a través de las puntuaciones obtenidas de su importancia, son muy parecidos para las tres zonas. De este análisis destacan también los riesgos comunes entre las regiones de África subsahariana y América del Sur, falta de orientación a largo plazo (AG_R7), que se podría asociar a una categoría cultural de riesgos, falta de formación (AG_R8), que podría encuadrarse dentro de los riesgos organizativos, y problemas de suministro eléctrico o de conexión a internet (AG_R10), que encajaría con los riesgos tecnológicos. La presencia del riesgo AG_R10 era de esperar, dado que ya se había visto que principalmente los proyectos estaban dedicados a las TICs, agua y saneamiento y construcción, mostrando así una componente técnica muy fuerte, propia, por otro lado, 
a la Universidad caso de estudio. Resalta también el hecho de que haya más semejanzas entre los riesgos encontrados entre África Subsahariana y América del Sur, en lugar de entre América del Sur y América Central y Caribe, que solo comparten el riesgo de dificultades en el transporte.

Tabla 6.5. Evaluación de riesgos por Sectores para los 152 PCD de la UPM.

Fuente: elaboración propia a partir de los informes de evaluación facilitados por la Dirección de Cooperación de la UPM.

\begin{tabular}{lllllllllll}
\hline \multicolumn{2}{c}{$\begin{array}{c}\text { Agua y } \\
\text { saneamiento }\end{array}$} & \multicolumn{2}{c}{ Construcción } & \multicolumn{2}{c}{ Agricultura } & \multicolumn{2}{c}{ Formación } & \multicolumn{2}{c}{ TICs } \\
\hline Id. & $\begin{array}{l}\text { Imp. del } \\
\text { riesgo* }\end{array}$ & Id. & $\begin{array}{l}\text { Imp. del } \\
\text { riesgo }\end{array}$ & Id. & $\begin{array}{l}\text { Imp. del } \\
\text { riesgo }\end{array}$ & Id. & $\begin{array}{l}\text { Imp. del } \\
\text { riesgo }\end{array}$ & Id. & $\begin{array}{l}\text { Imp. del } \\
\text { riesgo }\end{array}$ \\
\hline S_R4 & 15,8 & S_R4 & 10,6 & S_R6 & 16 & S_R1 & 9 & S_R10 & 19,6 \\
S_R11 & 15,3 & S_R6 & 10 & S_R1 & 12 & S_R9 & 9 & S_R1 & 18,5 \\
S_R7 & 11,8 & S_R7 & 9 & S_R8 & 12 & S_R5 & 7,5 & S_R11 & 17,7 \\
S_R10 & 11,5 & S_R5 & 8 & S_R9 & 9 & S_R4 & 6,8 & S_R5 & 16,4 \\
S_R5 & 11,3 & S_R1 & 6,8 & S_R2 & 8 & S_R7 & 6 & S_R9 & 12 \\
\hline \\
*Valores obtenidos con escalas del 1 al 5 para probabilidad e impacto, siendo la importancia el producto \\
\multicolumn{2}{l}{ de ambas medidas. }
\end{tabular}

Entre los riesgos que aparecen, destacan sobre todo aquellos que se dan en casi todos los sectores, como S_R1, mal acceso a la comunidad beneficiaria, y S_R5, falta de conocimiento sobre los temas de interés para formación en la comunidad, que obtienen además valores muy altos.

El sector de la agricultura es aquél que menos riesgos tiene en común con los demás, y el sector de formación es aquél que presenta los niveles de importancia de riesgo más bajos de entre los sectores estudiados, frente al de las TICs que alcanza los valores más altos, encabezados por el riesgo de alto coste de mantenimiento y operación de la nueva tecnología (S_R10).

El análisis del caso de estudio de la UPM ha permitido conocer los PCD desarrollados por su personal y obtener unas lecciones aprendidas muy valiosas para futuros proyectos. Además, se ha demostrado que ni siquiera una institución académica, conocedora de los beneficios de la Gestión de Riesgos, la aplica de manera sistemática en sus PCD. La identificación y evaluación de riesgos ha permitido disponer de un registro de riesgos por área geográfica y por sector, que además cuenta con la priorización de los riesgos más importantes, que, aunque nunca puede ser directamente extrapolable, dado que cada proyecto es único, puede servir de referencia para futuras evaluaciones. Además, el descubrimiento de algunos riesgos comunes a casi todas las áreas y sectores orienta hacia la búsqueda de sencillas medidas correctoras para dichos riesgos directamente en las futuras formulaciones. 


\subsubsection{Análisis del cuestionario del Marco Lógico con profesionales}

Las 77 personas que respondieron el cuestionario sobre el ML (Anexo II) han facilitado el estudio de esta metodología, identificando qué fortalezas y debilidades son observadas desde el punto de vista de los profesionales que trabajan a diario con la misma. Su colaboración ha permitido también guiar los futuros pasos para la mejora de la metodología, reforzando la importancia de introducir la GR en esta metodología.

La muestra de profesionales que han participado en la investigación se puede ver en la Tabla 6.6, atendiendo a las organizaciones en las que trabajan, y en la Tabla 6.7, atendiendo a su propia experiencia en el uso y aplicación de la metodología para la gestión de PCD. Como se puede apreciar, el $60 \%$ de los profesionales cuentan con una experiencia de más de diez años en la gestión de este tipo de proyectos.

Junto a los 57 profesionales españoles, se ha querido contrastar también con 20 profesionales colombianos. En Colombia, el Departamento Nacional de Planeación (DNP), organismo que diseña el Plan Nacional de Desarrollo, implantó la Metodología General Ajustada (MGA) para el diseño y formulación de proyectos de inversión pública. Como se puede apreciar en la Figura 6.4, la MGA está basada en la metodología del ML. Para comprobar si este hecho de tener una mayor aplicación ofrecía un punto de vista diferente del cual se pudieran extraer conclusiones complementarias, se incluyeron en el análisis los resultados obtenidos por los profesionales en Colombia.

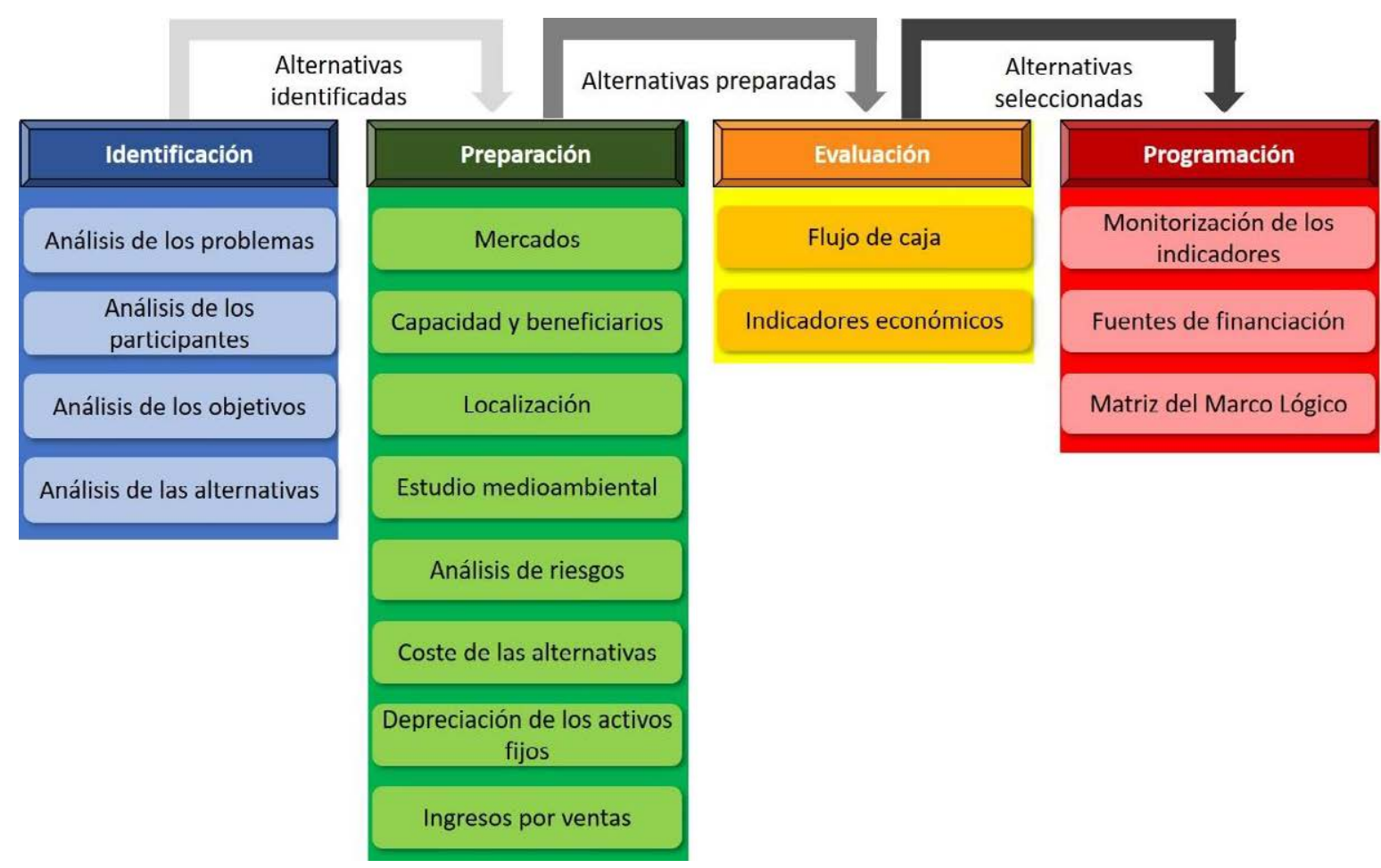

Figura 6.4. Metodología General Ajustada. Fuente: elaboración propia basada en DNP. 
Tabla 6.6. Descripción de las organizaciones.

Fuente: elaboración propia.

\begin{tabular}{lll}
\hline País & N & $\%$ \\
\hline España & 57 & 74 \\
Colombia & 20 & 26 \\
\hline Total & 77 & 100 \\
\hline
\end{tabular}

\begin{tabular}{lll}
\hline Tipo & $\mathrm{N}$ & $\%$ \\
\hline ONGD & 48 & 62,3 \\
Empresa & 6 & 7,8 \\
Universidad & 16 & 20,8 \\
Administración pública & 7 & 9,1 \\
\hline Total & 77 & 100 \\
\hline
\end{tabular}

\begin{tabular}{lll}
\hline N.o empleados & N & $\%$ \\
\hline$<10$ & 29 & 37,6 \\
$10-100$ & 25 & 32,5 \\
$>100$ & 23 & 29,9 \\
\hline Total & 77 & 100 \\
\hline
\end{tabular}

\begin{tabular}{lll}
\hline N.o proyectos al año & $\mathrm{N}$ & $\%$ \\
\hline$<5$ & 19 & 24,6 \\
$5-10$ & 17 & 22,18 \\
$10-50$ & 23 & 29,9 \\
$>50$ & 18 & 23,4 \\
\hline Total & 77 & 100 \\
\hline
\end{tabular}

Tabla 6.7. Descripción actividad directores/as de Proyecto en los últimos cinco años.

Fuente: elaboración propia.

\begin{tabular}{|c|c|c|c|c|c|c|c|c|c|c|c|}
\hline $\begin{array}{l}\text { Proyectos } \\
\text { dirigidos }\end{array}$ & $\mathrm{N}$ & $\%$ & $\begin{array}{l}\text { Lugar de } \\
\text { ejecución }\end{array}$ & $\mathrm{N}$ & $\%$ & $\begin{array}{l}\text { Duración } \\
\text { media }\end{array}$ & $\mathrm{N}$ & $\%$ & $\begin{array}{l}\text { Presupuesto } \\
\text { medio }(€)\end{array}$ & $\mathrm{N}$ & $\%$ \\
\hline$<5$ & 20 & 26 & Europa & 19 & 12,3 & $<1$ año & 20 & 26 & $<100.000$ & 26 & 46.4 \\
\hline $5-10$ & 11 & 14,3 & África & 38 & 24,5 & 1-3 años & 50 & 64,9 & $100.000-200.000$ & 8 & 14.3 \\
\hline \multirow[t]{2}{*}{$>10$} & 46 & 59,7 & Sur América & 84 & 54,2 & >3 años & 7 & 9,1 & $200.000-500.000$ & 16 & 28.6 \\
\hline & & & Asia & 14 & 9 & & & & $>500.000$ & 6 & 10.7 \\
\hline
\end{tabular}

Aunque la mayoría de las personas encuestadas pertenecen a ONGDs, dado que inicialmente se planteó el cuestionario para este colectivo. Al querer abordar el problema desde un punto de vista multiactor, en línea con el camino marcado por la Agenda 2030, se incluyó a participantes de otros ámbitos (empresa privada, administraciones públicas y organismos internacionales y universidad) en el análisis, tanto en España, como en Colombia. Todos estos participantes externos al ámbito de las ONGDs fueron contactados personalmente por su experiencia en la metodología del marco lógico y aceptaron participar en su evaluación.

En relación con los lugares de ejecución de los proyectos, conviene destacar que las 20 personas de Colombia trabajaban exclusivamente en PCD ejecutados en América del Sur, América Central y Caribe, lo que distorsiona ligeramente el resultado final. Pese a ello, en esta región trabaja el 49,2\% de las personas encuestadas de España. Por ser en 
cualquier caso la región principal, no se considera negativa esta posible distorsión de los resultados.

En cuanto al uso de la metodología, la Figura 6.5 representa la utilización de cada uno de los pasos de la metodología, pudiendo cada profesional hacer uso de algunos pasos, o de todos. La gran mayoría, utiliza la MML, siendo un escaso porcentaje de profesionales los que hacen uso exclusivo de ella (13\%). En general, es combinada siempre con otras metodologías, pero llama la atención que los cinco pasos sólo son seguidos por el $39 \%$ de las personas encuestadas. Igualmente, y como muestra la misma Figura 6.5 , resulta muy llamativo que solo el $53,2 \%$ de los profesionales realice el análisis de los participantes.

A la pregunta abierta de qué cambiaban en caso de no utilizar la MML tradicional, las pocas personas que no utilizaban esta matriz (9\%), destacaban la dependencia de los requerimientos del financiador a la hora de utilizar una u otra matriz. Entre los cambios más mencionados está el de sustituir la columna de Supuestos por la de Riesgos.

El uso de la casilla de precondiciones en la MML es utilizado por el $48 \%$ de las personas encuestadas, usándose más en España (52,6\%) que en Colombia (35\%).

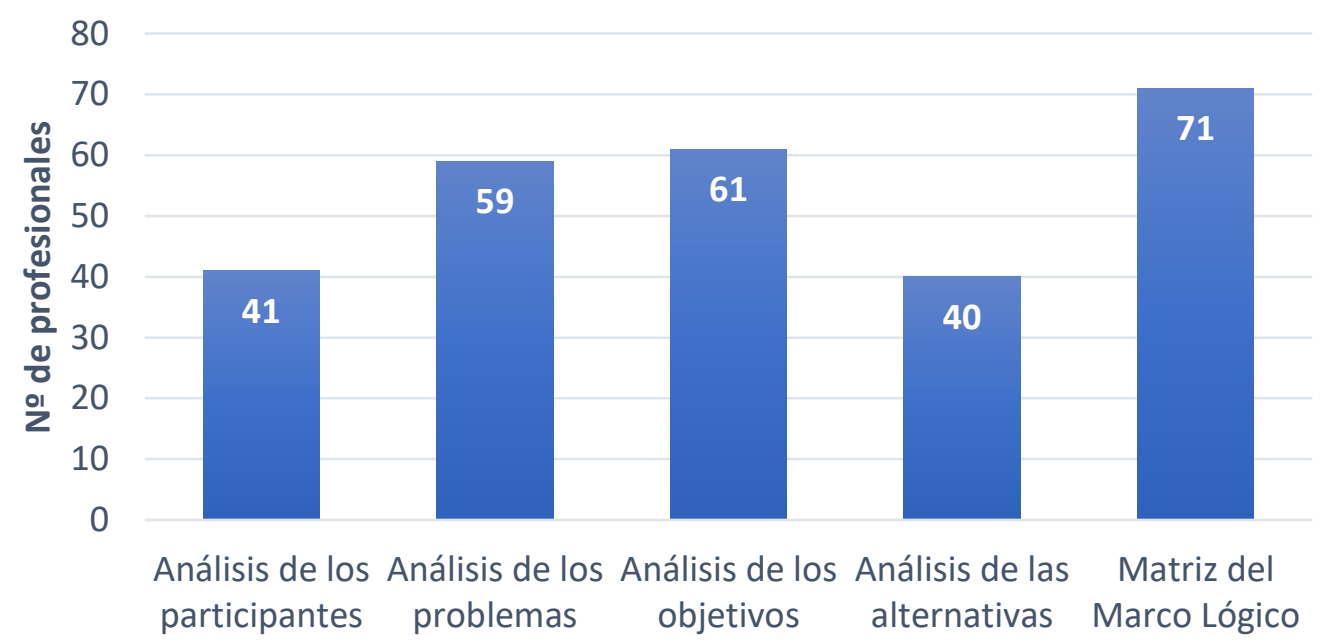

Figura 6.5. Uso de los pasos del ML.

Fuente: elaboración propia.

Haciendo el análisis separado entre España y Colombia, por si pudieran encontrarse diferencias, y pasado todo a porcentajes con respecto a la muestra analizada por países, se puede ver en la Figura 6.6 que existen diferencias en el uso de los diferentes pasos que plantea la metodología. Estas diferencias son más notables principalmente en el uso del análisis de alternativas y de la $M M L$, destacando que, en Colombia, se utiliza más el análisis de los objetivos que la MML. La explicación puede deberse que al estar tan integrada esta metodología en los proyectos públicos, y ser la MML el último paso, es 
un paso que solo se da cuando se han analizado muy bien los pasos previos y las alternativas. Destaca también en ambos casos, el escaso análisis de los participantes que se realiza.

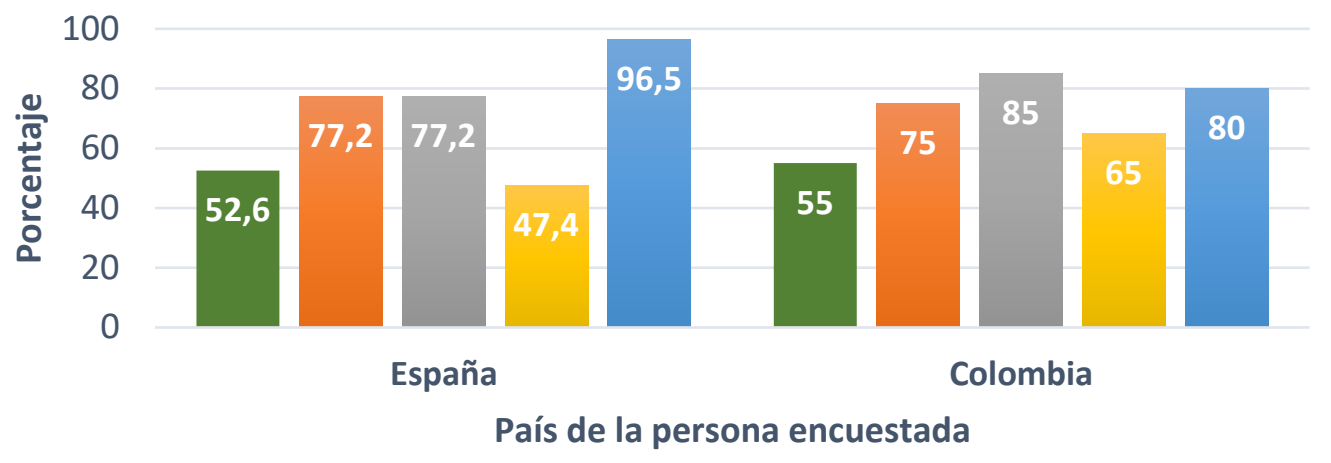

Análisis de los participantes
Análisis de los objetivos
Matriz del Marco Lógico

Análisis de los problemas

Análisis de las alternativas

Figura 6.6. Uso de los pasos del ML por país.

Fuente: elaboración propia.

Para las 15 afirmaciones utilizadas para conocer el grado de conformidad por los participantes, se utilizaron descripciones obtenidas de la literatura, donde se muestran las debilidades de la metodología, como su rigidez (Crawford y Bryce, 2003; Hummelbrunner, 2010), su terminología confusa (Couillard, Garon y Riznic, 2009), su escasa relación con el éxito del proyecto (Couillard, Garon y Riznic, 2009; Ika y Lytvynov, 2011) y su dificultad de integración con otras herramientas de DP (Gasper, 1997; Hermano et al., 2013). Igualmente, las fortalezas que han permitido el prolongado uso de esta metodología, como su visión completa del proyecto (Couillard, Garon y Riznic, 2009), su vinculación con la obtención de financiación en cualquier tipo de convocatoria (Golini, Kalchschmidt y Landoni, 2015) y su utilidad a lo largo del ciclo de vida del proyecto (Gasper, 2000; Khang y Moe, 2008) y buen uso de la columna de supuestos (Yamaswari et al., 2016). Estas dos últimas fortalezas han sido discutidas con anterioridad por los autores indicados. Se recurrió también a valorar las propuestas de mejora inspiradas en trabajos previos, como la sustitución de la columna de supuestos por la de riesgos (Couillard, Garon y Riznic, 2009), la introducción de gestión de riesgos (Couillard, Garon y Riznic, 2009), la inclusión de una columna para costes y beneficios (Ika y Lytvynov, 2011), la inclusión de la dimensión temporal (Crawford y Bryce, 2003), la mejor definición y asignación de IOV y FV (Couillard, Garond y Riznic, 2009; Crawford y Bryce, 2003) o la necesidad de enfocarse solo en la parte manejable del proyecto (Pfeiffer, 2015). 
La Tabla 6.8 muestra las frecuencias obtenidas en las respuestas sobre las afirmaciones encontradas en la literatura a cerca del ML. El grado de conformidad se midió en una escala Likert con los valores de Completamente en Desacuerdo (CED), En Desacuerdo (ED), De Acuerdo (DA) y Completamente De Acuerdo (CDA). Adicionalmente se incluyó también la opción de No Sabe/No Contesta (NS/NC) para no contaminar los resultados cuando las personas encuestadas no se sentían confiadas en su respuesta.

Tabla 6.8. Frecuencias del grado de conformidad sobre afirmaciones ML. Fuente: elaboración propia.

\begin{tabular}{|c|c|c|c|c|c|c|c|c|c|c|}
\hline \multirow{2}{*}{ El Marco Lógico... } & \multicolumn{2}{|c|}{ CED } & \multicolumn{2}{|c|}{ ED } & \multicolumn{2}{|c|}{ DA } & \multicolumn{2}{|c|}{ CDA } & \multicolumn{2}{|c|}{ NS/NC } \\
\hline & $\mathbf{N}$ & $\%$ & $\mathbf{N}$ & $\%$ & $\mathbf{N}$ & $\%$ & $\mathbf{N}$ & $\%$ & $\mathbf{N}$ & $\%$ \\
\hline ...es una metodología rígida & 3 & 3,9 & 25 & 32,5 & 38 & 49,4 & 10 & 13 & 1 & 1,3 \\
\hline ...usa una terminología confusa & 12 & 15,6 & 43 & 55,8 & 17 & 22,1 & 4 & 5,2 & 1 & 1,3 \\
\hline $\begin{array}{l}\text {...tiene escasa relación con el éxito del } \\
\text { proyecto }\end{array}$ & 10 & 13 & 44 & 57,1 & 18 & 23,4 & 5 & 6,5 & - & - \\
\hline $\begin{array}{l}\text {...no tiene integración con otras } \\
\text { herramientas de DP }\end{array}$ & 6 & 7,8 & 44 & 57,1 & 22 & 28,6 & 2 & 2,6 & 3 & 3,9 \\
\hline $\begin{array}{l}\text {...proporciona una visión completa } \\
\text { del proyecto }\end{array}$ & 2 & 2,6 & 17 & 22,1 & 32 & 41,6 & 25 & 32,5 & 1 & 1,3 \\
\hline $\begin{array}{l}\text {...es imprescindible a la hora de } \\
\text { solicitar subvenciones }\end{array}$ & 1 & 1,3 & 17 & 22,1 & 24 & 31,2 & 29 & 37,7 & 6 & 7,8 \\
\hline $\begin{array}{l}\text {...no es solo útil en las fases de } \\
\text { planificación y ejecución, sino } \\
\text { también para control y evaluación }\end{array}$ & - & - & 13 & 16,9 & 42 & 54,5 & 19 & 24,7 & 3 & 3,9 \\
\hline $\begin{array}{l}\text {...considera adecuadamente los } \\
\text { riesgos en la columna de Supuestos }\end{array}$ & 5 & 6,5 & 40 & 51,9 & 22 & 28,6 & 7 & 9,1 & 3 & 3,9 \\
\hline $\begin{array}{l}\text {...debería cambiar la columna de } \\
\text { Supuestos por la de Riesgos }\end{array}$ & 2 & 2,6 & 14 & 18,2 & 36 & 46,8 & 10 & 13 & 15 & 19,5 \\
\hline $\begin{array}{l}\text {...debería integrar la gestión de } \\
\text { riesgos en todo el proceso }\end{array}$ & - & - & 10 & 13 & 45 & 58,4 & 16 & 20,8 & 6 & 7,8 \\
\hline $\begin{array}{l}\text {... debería añadir la columna de Costes } \\
\text { y Beneficios }\end{array}$ & 6 & 7,8 & 25 & 32,5 & 29 & 37,7 & 8 & 10,4 & 9 & 11,7 \\
\hline $\begin{array}{l}\text {...debería incluir la dimensión del } \\
\text { tiempo }\end{array}$ & - & - & 18 & 23,4 & 42 & 54,5 & 11 & 14,3 & 6 & 7,8 \\
\hline ...debería definir mejor IOV y FV & 2 & 2,6 & 14 & 18,2 & 40 & 51,9 & 15 & 19,5 & 6 & 7,8 \\
\hline $\begin{array}{l}\text {...debería enfocarse únicamente en la } \\
\text { parte manejable del proyecto } \\
\text { (actividades y resultados) }\end{array}$ & 11 & 14,3 & 36 & 46,8 & 22 & 28,6 & 4 & 5,2 & 4 & 5,2 \\
\hline ...necesita ser mejorado & - & - & 9 & 11,7 & 36 & 46,8 & 23 & 29,9 & 9 & 11,7 \\
\hline
\end{tabular}

A partir de la Tabla 6.8 se hizo la traducción numérica del grado de conformidad (CED=1; $\mathrm{ED}=2$; $\mathrm{DA}=3$; $\mathrm{CDA}=4$ ) para trabajar los datos con SPSS.La Figura 6.7 muestra los principales valores del análisis descriptivo de la muestra. 


\begin{tabular}{|c|c|c|c|c|c|c|c|c|c|c|c|c|c|c|c|c|}
\hline & $\begin{array}{l}\frac{\pi}{0} \\
\frac{0}{0} \\
\frac{\pi}{00} \\
\frac{0}{0} \\
\frac{0}{0} \\
\frac{0}{0} \\
\frac{0}{2}\end{array}$ & 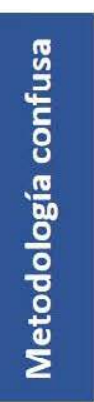 & 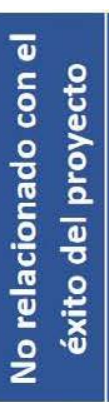 & 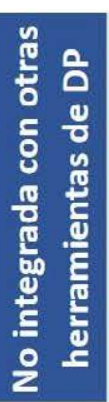 & 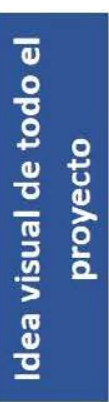 & 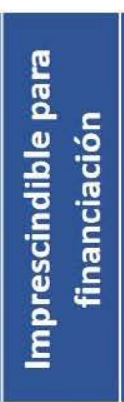 & 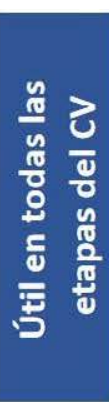 & 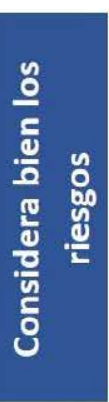 & 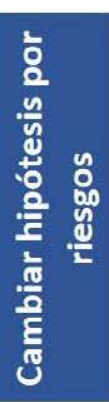 & 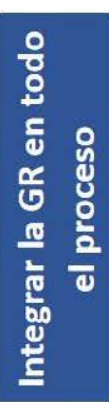 & 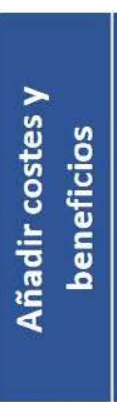 & 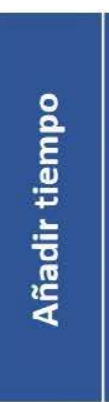 & 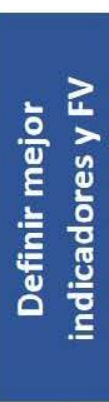 & 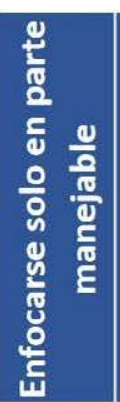 & 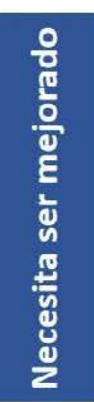 \\
\hline \multirow[t]{2}{*}{ N } & Válido & 76 & 76 & 77 & 74 & 76 & 71 & 74 & 74 & 62 & 71 & 68 & 71 & 71 & 73 & 68 \\
\hline & Perdidos & 1 & 1 & 0 & 3 & 1 & 6 & 3 & 3 & 15 & 6 & 9 & 6 & 6 & 4 & 0 \\
\hline \multicolumn{2}{|l|}{ Media } & 2,72 & 2,17 & 2,23 & 2,27 & 3,05 & 3,14 & 3,08 & 2,42 & 2,87 & 3,08 & 2,57 & 2,90 & 2,96 & 2,26 & 3,21 \\
\hline \multicolumn{2}{|c|}{ Error estándar de la media } &, 085 & 087 & , 087 & ,075 & ,093 & ,099 & ,076 & ,088 & ,090 &, 072 & ,099 & 075 & ,086 & ,092 & 080 \\
\hline \multicolumn{2}{|l|}{ Mediana } & 3,00 & 2,00 & 2,00 & 2,00 & 3,00 & 3,00 & 3,00 & 2,00 & 3,00 & 3,00 & 3,00 & 3,00 & 3,00 & 2,00 & 3,00 \\
\hline \multicolumn{2}{|l|}{ Moda } & 3 & 2 & 2 & 2 & 3 & 4 & 3 & 2 & 3 & 3 & 3 & 3 & 3 & 2 & 3 \\
\hline \multicolumn{2}{|c|}{ Desviación estándar } & 741 & ,755 & ,759 & ,647 & ,815 & 833 & ,657 & ,759 & ,713 & ,603 & ,816 & ,636 & ,726 & ,782 & 659 \\
\hline \multicolumn{2}{|c|}{ Asimetría } &,- 109 & ,466 & ,504 & ,297 &,- 402 &,- 425 &,- 085 & ,476 &,- 369 &,- 034 &,- 074 & ,082 &,- 397 & ,218 &,- 246 \\
\hline \multicolumn{2}{|c|}{ Error estándar de asimetria } & ,276 & ,276 & ,274 & ,279 & ,276 & ,285 & ,279 & 279 & ,304 & , 285 & ,291 & ,285 & ,285 & ,281 & ,291 \\
\hline \multicolumn{2}{|l|}{ Curtosis } &,- 247 & ,224 & ,230 & ,259 &,- 616 & $-1,014$ &,- 629 &,- 085 & ,273 &,- 190 &,- 433 &,- 477 & 169 &,- 260 &,- 698 \\
\hline \multicolumn{2}{|c|}{ Error estándar de curtosis } &, 545 & ,545 &, 541 & ,552 & ,545 & ,563 &, 552 & ,552 & ,599 & ,563 &, 574 & ,563 & ,563 &, 555 &, 574 \\
\hline \multicolumn{2}{|c|}{ Mínimo } & 1 & 1 & 1 & 1 & 1 & 1 & 2 & 1 & 1 & 2 & 1 & 2 & 1 & 1 & 2 \\
\hline \multicolumn{2}{|l|}{ Máximo } & 4 & 4 & 4 & 4 & 4 & 4 & 4 & 4 & 4 & 4 & 4 & 4 & 4 & 4 & 4 \\
\hline \multirow[t]{3}{*}{ Percentiles } & 25 & 2,00 & 2,00 & 2,00 & 2,00 & 2,25 & 2,00 & 3,00 & 2,00 & 2,00 & 3,00 & 2,00 & 2,00 & 3,00 & 2,00 & 3,00 \\
\hline & 50 & 3,00 & 2,00 & 2,00 & 2,00 & 3,00 & 3,00 & 3,00 & 2,00 & 3,00 & 3,00 & 3,00 & 3,00 & 3,00 & 2,00 & 3,00 \\
\hline & 75 & 3,00 & 3,00 & 3,00 & 3,00 & 4,00 & 4,00 & 4,00 & 3,00 & 3,00 & 3,00 & 3,00 & 3,00 & 3,00 & 3,00 & 4,00 \\
\hline
\end{tabular}

Figura 6.7. Estadística descriptiva sobre las 15 variables del cuestionario del ML.

Fuente: elaboración propia a partir de tratamiento de datos con SP 
El análisis permite comprobar que para los profesionales la metodología es poco flexible, pero no confusa, y sí que tiene relación con el éxito de los proyectos e integración con otras herramientas. Destaca así, entre las debilidades la rigidez (2,72 sobre 4$)$.

Entre las fortalezas, lo más valorado es que su uso es imprescindible para obtener financiación (3,14 sobre 4), así como que presenta una idea visual completa de todo el proyecto (3,05 sobre 4). Destaca que, contrariamente a lo que otros autores establecían sobre su uso exclusivo en las etapas de planificación y monitorización (Gasper, 2000; Khang y Moe, 2008), las personas encuestadas encuentran esta metodología útil en todas las etapas del ciclo de vida del proyecto (3,08 sobre 4). En cambio, la correcta consideración de los riesgos en la columna de Supuestos no está muy bien valorada, pero aun así sorprende por su alto valor (2,42 sobre 4) con respecto a lo esperado atendiendo a la literatura (Yamaswari et al., 2016).

Queda demostrado aquí que, de acuerdo con los profesionales, la metodología del ML tiene unas fortalezas más valoradas que sus debilidades, hecho que permite explicar que, pese a las críticas, siga siendo la metodología por excelencia a la hora de gestionar PCD. De nuevo, tal y como sucedía en el estudio de Golini, Landoni y Kalchschmidt (2017), cuando se pregunta a profesionales, la visión del ML es más positiva que lo que se percibe a través de estudios académicos.

Entre las propuestas de mejora, la más valorada es la de introducir la Gestión de Riesgos en todo el proceso (3,08 sobre 4), destacando además la menor variabilidad en esta respuesta, que se puede apreciar en el valor más bajo de la desviación estándar. La siguiente propuesta mejor valorada es la de definir mejor los Indicadores Objetivamente Verificables y las Medidas de Verificación (2,96 sobre 4). Esta medida se trataría de una mejora sobre lo ya existente, frente a la de introducir la GR en todo el proceso, que sería una innovación. La siguiente medida considerada como innovadora, mejor valorada sería la de introducir la dimensión del tiempo (2,90 sobre 4). Por el contrario, añadir costes y beneficios (2,57 sobre 4), así como enfocarse solo en la parte manejable del proyecto (resultados y actividades) (2,26 sobre 4), son las propuestas menos aceptadas.

La última afirmación que establece que el Marco Lógico necesita ser mejorado, obtiene un grado de conformidad muy alto (3,21 sobre 4). Aunque la propuesta de integrar la $G R$ es la más valorada para tratar de mejorar la metodología, alguna sugerencia relacionada, como cambiar la columna de hipótesis por riesgos, aunque bien puntuada, ha recibido el mayor número de respuestas NS/NC (19,5\%). Este hecho no hace nada más que demostrar que, aunque los profesionales perciben la necesidad de incluir los riesgos para mejorar la metodología, no lo ven como algo tan sencillo a resolver con ese simple cambio, sino que es necesaria una transformación a mayor escala. Esto no hace nada más que reforzar la necesidad de integrar la GR a lo largo de toda la metodología. 
Se ha realizado también el análisis de las correlaciones entre las 15 variables, para ver si, además de las ya previsibles relaciones entre las debilidades, fortalezas y propuestas, había alguna más no tan evidente en el planteamiento. La Tabla 6.9 confirma las relaciones positivas entre muchas de las variables dentro de un mismo bloque de afirmaciones relacionadas con debilidades o con fortalezas, e igualmente, las relaciones negativas entre ambos bloques. Destacan entre ellas, por ser muy significativas $(p<0,01$, esto es, la posibilidad de que esta correlación no exista es menor a un 1\%; marcado en verde oscuro), las relaciones entre metodología rígida y, ambas, metodología confusa y no relacionada con el éxito del proyecto. Asimismo, entre no relacionada con el éxito del proyecto y no integrada con otras herramientas de DP. Esto hace pensar que, para los encuestados, una mejora que haga más flexible el ML permitiría además hacer más sencillo su uso y podrían encontrarse vínculos más claros con el éxito del proyecto. Igualmente, se podría interpretar que, con una mejor integración entre el ML y otras herramientas de DP, habría una mejor vinculación entre el uso de esta metodología y el éxito del proyecto. En verde claro, también significativas, pero para una $p<0,05$ (la posibilidad de que esta correlación no exista es menor a un 5\%), puede observarse que el resto de las debilidades están correlacionadas.

Destaca también la correlación muy significativa $(p<0,01)$ que hay entre la identificación de que el ML es útil en todas las fases del ciclo de vida del proyecto y la afirmación de que considera bien los riesgos en la columna de supuestos. Se podría interpretar en la detección de la importancia de considerar bien los riesgos para que verdaderamente fuera una metodología con validez en todas las fases del ciclo de vida.

Entre las correlaciones negativas dadas entre estos dos bloques, destacan por muy significativas ( $p<0,01$, en rojo), las vinculaciones entre metodología rígida y confusa, con idea visual de todo el proyecto, mostrando que para que esta metodología realmente represente una idea visual completa del proyecto, debería mejorar y hacerse tan clara como sea posible y más flexible, representando la evolución del proyecto a lo largo de sus fases, tal vez con actualizaciones periódicas. Esto está ligado también con la relación negativa significativa que existe entre la propuesta de añadir la dimensión del tiempo y ambas debilidades, rígida y confusa.

La correlación negativa más fuerte se da entre considera bien los riesgos en la columna de supuestos y no guarda relación con el éxito del proyecto, lo cual no hace nada más que destacar lo que otros autores habían señalado ya sobre las relaciones que existen entre la buena consideración de los riesgos en un proyecto y el éxito del mismo (De Bakker, Boonstra y Wortmann, 2010; Carvalho y Rabechini, 2013; Banco Mundial, 2018).

Entre las correlaciones con las propuestas de mejora, destaca la correlación muy significativa $(<0,01)$ entre integrar la $G R$ en todo el proceso y el considerar esta metodología como imprescindible para obtener financiación, esto puede deberse 
precisamente al creciente interés que tienen los organismos financiadores en demostrar eficacia en sus acciones a través de proyectos factibles donde la gestión de riesgos se tenga en consideración. Destacan también las correlaciones muy significativas $(p<0,01)$ entre enfocarse en la parte manejable del proyecto y metodología rígida y confusa, pudiendo entenderse que, si la metodología solo se fijase en las actividades y resultados, disminuiría su rigidez y sería menos confusa. Por último, destaca con el valor más alto, la correlación existente entre añadir costes y beneficios y añadir la dimensión del tiempo, que podrían vincularse dentro del ámbito de mejorar el control y monitorización del proyecto. Ambas propuestas están también correlacionadas significativamente $(p<0,05)$ con la integración de la GR en todo el proceso, estando así las tres propuestas de mejora innovadoras, con mejor aceptación, vinculadas entre sí.

La última afirmación, el $M L$ necesita ser mejorada, aparece correlacionada significativamente $(p<0,05)$ con la rigidez y que la metodología sea confusa. Así una vez más se demuestra la importancia de hacer del ML una metodología más clara y flexible.

Tabla 6.9. Análisis de las correlaciones entre las variables del cuestionario del ML. Fuente: elaboración propia a partir de tratamiento de datos con SPSS.

\begin{tabular}{|c|c|c|c|c|c|c|c|c|c|c|c|c|c|c|c|}
\hline & 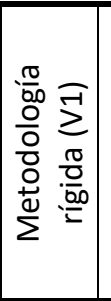 & 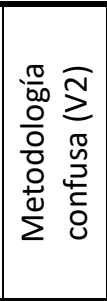 & 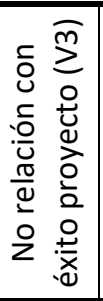 & 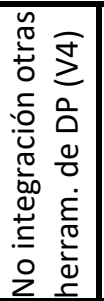 & 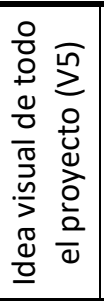 & 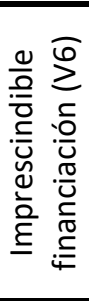 & 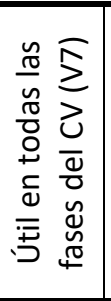 & 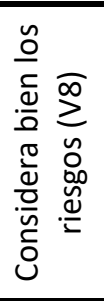 & 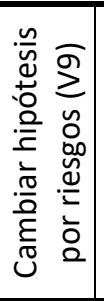 & 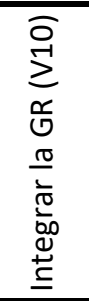 & 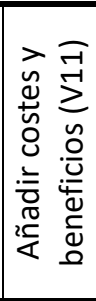 & 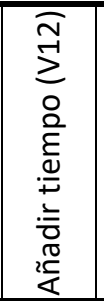 & 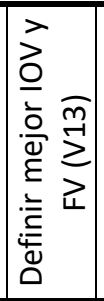 & 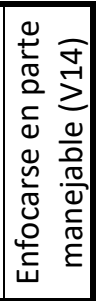 & 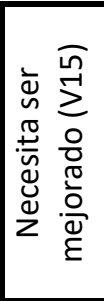 \\
\hline V1 & 1 &, $558^{* *}$ & $485^{* *}$ & $318^{*}$ &,$- 417^{* *}$ &,- 045 &,$- 291^{*}$ &,$- 309^{*}$ &,- 172 &,- 018 &,- 200 &,$- 333^{*}$ &,- 139 & $495^{* *}$ & ,304 \\
\hline V2 & & 1 & , 375 & ,371* &,$- 413^{* *}$ &,- 002 &,$- 349^{*}$ &,- 059 & -031 & ,046 & -117 &,$- 374^{*}$ &,- 268 & $497^{* *}$ & ,349* \\
\hline V3 & & & 1 &, $435^{* *}$ &,- 170 &,- 124 &,$- 318^{*}$ &,$- 564^{* *}$ & ,190 & ,083 &,- 036 &,- 113 &,- 094 & ,151 & ,271 \\
\hline V4 & & & & 1 & ,052 &,- 113 &,- 247 &,- 214 & ,020 & 174 & \begin{tabular}{|l|}
-198 \\
\end{tabular} & \begin{tabular}{|l|}
,- 064 \\
\end{tabular} &,- 161 & ,294* & 151 \\
\hline V5 & & & & & 1 & ,268 & ,369* & ,092 & ,186 & ,223 & \begin{tabular}{|l|}
, 068 \\
\end{tabular} & ,149 &,- 083 &,- 237 &,- 267 \\
\hline V6 & & & & & & 1 & ,361* & , 326* & ,135 &, $500^{* *}$ & , 328* & ,244 & -123 &,- 181 & 169 \\
\hline V7 & & & & & & & 1 & ,411** &,- 195 & , 336* & , 127 & 175 & $293^{*}$ &,- 171 &,- 045 \\
\hline V8 & & & & & & & & 1 &,- 290 & ,250 & , 105 & 0,000 & 0,000 & , 063 &,- 025 \\
\hline V9 & & & & & & & & & 1 & ,267 & , $315^{*}$ & \begin{tabular}{|l|}
, 279 \\
\end{tabular} & , 281 & , 085 & ,233 \\
\hline V10 & & & & & & & & & & 1 & , 372* & , 338* & 0,000 &,- 070 & ,208 \\
\hline V11 & & & & & & & & & & & 1 & ,622** & 189 & -109 & 117 \\
\hline V12 & & & & & & & & & & & & 1 & $299^{*}$ &,- 227 & 137 \\
\hline V13 & & & & & & & & & & & & & 1 & , 048 & ,229 \\
\hline V14 & & & & & & & & & & & & & & 1 & ,221 \\
\hline V15 & & & & & & & & & & & & & & & 1 \\
\hline & \multicolumn{4}{|c|}{ Debilidades } & \multicolumn{4}{|c|}{ Fortalezas } & \multicolumn{6}{|c|}{ Propuestas de mejora } & \\
\hline
\end{tabular}


El mismo análisis de correlaciones se llevó a cabo previamente exclusivamente para las personas pertenecientes a organizaciones españolas (ver apartado 7.6 de aportaciones), con resultados muy similares, lo que da mayor consistencia a la investigación.

Con la intención de explorar con mayor profundidad los resultados del cuestionario, se realizó la comparación de medias, a través del análisis de la varianza (ADEVA). Para ello, se han agrupado las respuestas al grado de conformidad, atendiendo a diferentes grupos establecidos atendiendo a las características propias de la muestra, como el país en el que trabajan o el tipo de organización y sus características, o las características de la persona que responde en relación con la dirección de $P C D$, o al uso que se hace del $M L$ y de todos sus pasos, entre otras que se irán viendo a continuación.

El primer análisis parte de la hipótesis nula de que las medias obtenidas con el grado de conformidad con las 15 afirmaciones sobre el $\mathrm{ML}$ es igual para las personas que respondían desde España que para las de Colombia. Al existir solo dos grupos de variables, este análisis se realizó a través de la Prueba $t$ (t-test) para muestras independientes, siendo las muestras independientes la de España (1) y la de Colombia (2). Para ello, en la Tabla 6.10 se pueden ver las medias, desviación estándar y media del error estándar para cada una de las afirmaciones o variables. En negrita aparecen marcados los valores de las medias significativamente diferentes.

La Tabla 6.11 muestra el resultado de la prueba de igualdad de medias para muestras independientes. Para ello se asumió la igualdad de varianzas entre los grupos, comprobada a través de la prueba de Levene (Field, 2003). Para todos aquellos donde esta prueba fue no significativa ( $p>0,05)$, se validó la hipótesis de que las varianzas son iguales. En aquellos casos donde esta prueba fue significativa, marcados en rojo, se incluyen los valores para las dos hipótesis: igualdad de varianzas (fila superior) y no igualdad de varianzas (fila inferior). 
Tabla 6.10. Medias para los grupos de España y Colombia.

Fuente: elaboración propia a partir de tratamiento de datos con SPSS.

\begin{tabular}{|c|c|c|c|c|c|}
\hline Afirmación sobre el ML & País & $\mathbf{N}$ & Media* & $\begin{array}{l}\text { Desviación } \\
\text { estándar }\end{array}$ & $\begin{array}{c}\text { Media de } \\
\text { error } \\
\text { estándar }\end{array}$ \\
\hline \multirow{2}{*}{ Metodología rígida } & España & 56 & 2,86 & ,699 & ,093 \\
\hline & Colombia & 20 & 2,35 & ,745 & ,167 \\
\hline \multirow{2}{*}{ Metodología confusa } & España & 56 & 2,21 & 780 & 104 \\
\hline & Colombia & 20 & 2,05 & ,686 & 153 \\
\hline \multirow{2}{*}{ No relacionado con el éxito del proyecto } & España & 57 & 2,40 & 753 & 100 \\
\hline & Colombia & 20 & 1,75 &, 550 & ,123 \\
\hline \multirow{2}{*}{ No integrada con otras herramientas de DP } & España & 54 & 2,39 & ,656 & 089 \\
\hline & Colombia & 20 & 1,95 & ,510 & 114 \\
\hline \multirow{2}{*}{ Idea visual de todo el proyecto } & España & 57 & 3,07 & 776 & 103 \\
\hline & Colombia & 19 & 3,00 & ,943 & ,216 \\
\hline \multirow{2}{*}{ Imprescindible para financiación } & España & 53 & 3,15 & 864 & 119 \\
\hline & Colombia & 18 & 3,11 & ,758 & ,179 \\
\hline \multirow{2}{*}{ Útil en todas las fases del CV } & España & 55 & 3,09 & ,617 & 083 \\
\hline & Colombia & 19 & 3,05 & ,780 & ,179 \\
\hline \multirow{2}{*}{ Considera bien los riesgos } & España & 55 & 2,29 & 762 & 103 \\
\hline & Colombia & 19 & 2,79 & ,631 & ,145 \\
\hline \multirow{2}{*}{ Cambiar hipótesis por riesgos } & España & 45 & 2,84 & ,706 & 105 \\
\hline & Colombia & 17 & 2,94 & ,748 & ,181 \\
\hline \multirow{2}{*}{ Integrar la GR en todo el proceso } & España & 51 & 3,06 & ,614 & ,086 \\
\hline & Colombia & 20 & 3,15 &, 587 & 131 \\
\hline \multirow{2}{*}{ Añadir costes y beneficios } & España & 48 & 2,44 & ,848 & 122 \\
\hline & Colombia & 20 & 2,90 & ,641 & ,143 \\
\hline \multirow{2}{*}{ Añadir tiempo } & España & 53 & 2,85 & ,662 & 091 \\
\hline & Colombia & 18 & 3,06 & ,539 & ,127 \\
\hline \multirow{2}{*}{ Definir mejor indicadores y FV } & España & 51 & 2,94 & ,732 & 103 \\
\hline & Colombia & 20 & 3,00 & ,725 & ,162 \\
\hline \multirow{2}{*}{ Enfocarse solo en parte manejable } & España & 53 & 2,30 & 799 & 110 \\
\hline & Colombia & 20 & 2,15 & ,745 & ,167 \\
\hline \multirow{2}{*}{ Necesita ser mejorado } & España & 49 & 3,22 & ,715 & 102 \\
\hline & Colombia & 19 & 3,16 & ,501 & 115 \\
\hline
\end{tabular}

*Valores de las medias sobre 4 
Tabla 6.11. Prueba t de igualdad de medias para muestras independientes.

Fuente: elaboración propia a partir de tratamiento de datos con SPSS.

\begin{tabular}{|c|c|c|c|c|c|c|c|c|c|}
\hline \multirow[t]{2}{*}{ Afirmación } & \multicolumn{2}{|c|}{ Test Levene } & \multirow[t]{2}{*}{$\mathbf{t}$} & \multirow[t]{2}{*}{ gl } & \multirow[t]{2}{*}{$\begin{array}{c}\text { Sig. } \\
\text { (bilat.) }\end{array}$} & \multirow[t]{2}{*}{$\begin{array}{l}\text { Dif. de } \\
\text { medias }\end{array}$} & \multirow{2}{*}{$\begin{array}{c}\text { Dif. de } \\
\text { error } \\
\text { estánd. }\end{array}$} & \multicolumn{2}{|c|}{$\begin{array}{c}95 \% \text { de } \\
\text { intervalo de } \\
\text { confianza }\end{array}$} \\
\hline & $\mathbf{F}$ & Sig. & & & & & & Inf. & Sup. \\
\hline Metodología rígida & ,68 & ,411 & 2,738 & 74 &, $008 * *$ & ,507 & ,185 & ,138 & ,876 \\
\hline $\begin{array}{l}\text { Metodología } \\
\text { confusa }\end{array}$ & 3,05 & ,085 & ,833 & 74 & ,407 & 164 & 197 &,- 229 & ,557 \\
\hline $\begin{array}{l}\text { No relacionado } \\
\text { con el éxito }\end{array}$ & 3,70 & ,058 & 3,55 & 75 &, $001 * *$ & 654 & 184 & ,288 & 1,019 \\
\hline \multirow{2}{*}{$\begin{array}{l}\text { No integrada con } \\
\text { otras herram. DP }\end{array}$} & \multirow[t]{2}{*}{10,19} & \multirow[t]{2}{*}{,002 } & 2,69 & 72 &, $009 * *$ & 439 & 163 & 115 & 763 \\
\hline & & & 3,02 & 43,54 &, $004^{* *}$ & ,439 & ,145 & ,147 & ,731 \\
\hline $\begin{array}{l}\text { Idea visual de todo } \\
\text { el proyecto }\end{array}$ & ,007 & ,933 & ,323 & 74 & ,747 & ,070 & ,217 &,- 362 & ,503 \\
\hline $\begin{array}{l}\text { Imprescindible } \\
\text { para financiación }\end{array}$ & 1,43 & ,235 & 174 & 69 & ,862 & ,040 & ,229 &,- 417 & ,496 \\
\hline $\begin{array}{l}\text { Útil en todas las } \\
\text { fases del CV }\end{array}$ & 1,98 & 163 & 217 & 72 & ,828 & ,038 & 176 &,- 313 & ,389 \\
\hline $\begin{array}{l}\text { Considera bien los } \\
\text { riesgos }\end{array}$ & ,650 & 423 & $-2,56$ & 72 &, $012^{*}$ &,- 499 & 195 &,- 886 &,- 111 \\
\hline $\begin{array}{l}\text { Cambiar hipótesis } \\
\text { por riesgos }\end{array}$ & ,344 &, 560 &,- 47 & 60 & ,637 &,- 097 & ,204 &,- 505 & ,312 \\
\hline $\begin{array}{l}\text { Integrar la GR en } \\
\text { todo el proceso }\end{array}$ &, 027 & 870 &,- 57 & 69 & ,571 &,- 091 & 160 &,- 410 & ,228 \\
\hline Añadir costes y & 5,63 & ,020 & $-2,18$ & 66 &, $032 *$ &,- 462 & ,211 &,- 884 &,- 041 \\
\hline beneficios & & & $-2,454$ & 46,79 &, $018 *$ &,- 462 & ,188 &,- 842 &,- 083 \\
\hline $\begin{array}{l}\text { Añadir dimensión } \\
\text { del tiempo }\end{array}$ & 3,01 & ,087 & $-1,19$ & 69 & 237 &,- 206 & 173 &,- 552 & 139 \\
\hline $\begin{array}{l}\text { Definir mejor } \\
\text { indicadores y FV }\end{array}$ & ,70 & ,404 &,- 30 & 69 & ,761 &,- 059 & 193 &,- 443 & ,326 \\
\hline $\begin{array}{l}\text { Enfocarse solo en } \\
\text { parte manejable }\end{array}$ & 1,40 & 240 & ,73 & 71 & ,463 & 152 & ,206 &,- 259 & ,562 \\
\hline Necesita ser & 6,15 & ,016 & 37 & 66 & ,712 & ,067 & 179 &,- 291 & ,425 \\
\hline mejorado & & & ,433 & 46,67 & ,667 & ,067 & ,154 &,- 243 & ,376 \\
\hline
\end{tabular}

*Significativo para $\mathrm{p}$-valor $<0,05 . * *$ Significativo para $\mathrm{p}$-valor $<0,01$

Al fijarse ahora en el nivel de significación bilateral $(p<0,05)$, se puede comprobar que existen pocas afirmaciones en las que haya diferencias entre las medias, pero destacan por ser muy significativas aquellas que tienen que ver con los puntos débiles de la metodología (rígida, no relacionada con el éxito y no integrada con otras herramientas de $D P$ ). Atendiendo a las medias expresadas en la Tabla 6.10., se puede ver que, para todas ellas, las personas que respondían de España eran más críticas con la metodología que las que lo hicieron desde Colombia. Con menor nivel, pero también significativas, están las diferencias sobre la Correcta consideración de los riesgos en la columna de 
supuestos y la propuesta de Añadir costes y beneficios, ambas mejor valoradas en el caso de Colombia.

Atendiendo ahora al tipo de organización al que pertenecen, se comprueba que la hipótesis nula de igualdad de medias es válida en la mayoría de los casos, con la excepción de considerar la metodología como rígida, que es apreciado por todos los grupos, excepto por la administración pública (media de 2,00 sobre 4). Y añadir costes y beneficios, que está muy bien valorado especialmente para las empresas privadas $(3,33)$ y la administración pública $(3,14)$, no siendo tan relevante para las ONGDs $(2,36)$.

Agrupando por el tamaño de la organización, en relación con su número de empleados, se cumple la hipótesis nula de igualdad de medias. No en cambio, si se agrupa atendiendo al número de proyectos realizados por la organización, donde existen diferencias significativas para la afirmación de que el $\mathrm{ML}$ sea una metodología rígida. Entre las organizaciones que llevan o muy pocos $(2,58)$ o muchos proyectos $(2,39)$, se reconoce peor la falta de flexibilidad con respecto a las que llevan un número intermedio de ellos, que la encuentran más rígida (entorno al 3).

Estas diferencias no se aprecian si se analiza en cambio el número de proyectos que dirige el profesional, ni la duración de estos proyectos, pero sí para el presupuesto de estos proyectos, destacando que los proyectos con un presupuesto elevado, pero no el más alto, encuentran significativamente menos importante que los demás, definir mejor los indicadores y las FV.

Tampoco existen diferencias entre medias atendiendo al lugar donde se desarrollan esos proyectos. Esto se comprobó primero agrupando en si trabajaban solo en un continente o en todo el mundo, sin diferencias significativas. Y luego analizando si trabajaban en cada uno de los continentes o no. Tras esta última agrupación, sólo para el caso de las personas que trabajan con proyectos en África, se encontraron opiniones significativamente distintas al resto, apreciando más algunas de las debilidades del ML, como su rigidez, su escasa relación con el éxito del proyecto y su falta de integración con otras herramientas de DP.

Respecto al uso del $\mathrm{ML}$, no se ha encontrado ninguna diferencia entre medias significativa en la Prueba $t$ de muestras independientes, con respecto al hecho de utilizar o no la casilla de precondiciones. Para la influencia de los pasos utilizados del ML se estudió primero si había diferencia entre utilizar todos los pasos o solo alguno/s, y posteriormente si el uso de cada uno de los pasos aportaba alguna diferencia frente a su no utilización. El resultado de este análisis es que no hay ninguna desigualdad de medias significativa.

En la Tabla 6.12 se muestran los grupos estudiados que han dado significativa su desigualdad de medias. 
Tabla 6.12. p-valor del análisis de igualdad de medias.

Fuente: elaboración propia a partir de tratamiento de datos con SPSS.

\begin{tabular}{|c|c|c|c|c|c|}
\hline & $\frac{n}{\sigma \pi}$ & 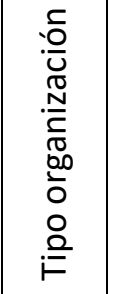 & 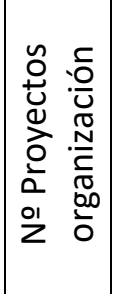 & 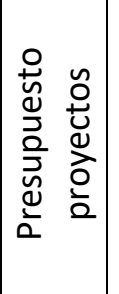 & 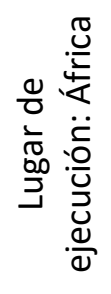 \\
\hline Metodología rígida &, $008 * *$ &, $047 *$ &, $038 *$ &, 574 & ,038* \\
\hline Metodología confusa & ,407 & ,672 & ,485 & ,443 & ,345 \\
\hline No relacionado con el éxito &, $001 * *$ & 084 & ,823 & ,672, & $005 * *$ \\
\hline No integrada con otras herramientas de DP &, $004 * *$ & ,625 & 120 & ,107 & ,016* \\
\hline Idea visual de todo el proyecto & ,747 & 602 & ,229 & 917 & ,477 \\
\hline Imprescindible para financiación & ,862 & 365 & ,531 & ,226 & ,327 \\
\hline Útil en todas las fases del CV & , 828 & 323 & ,569 & 792 & ,792 \\
\hline Considera bien los riesgos & ,012* & 680 & ,964 & ,790 & ,963 \\
\hline Cambiar hipótesis por riesgos & ,637 & 679 & ,483 & ,442 & ,524 \\
\hline Integrar la GR en todo el proceso &, 571 & ,792 & ,701 & ,748 & ,466 \\
\hline Añadir costes y beneficios &, $018^{*}$ & ,018* & ,885 & ,099 & ,563 \\
\hline Añadir dimensión del tiempo & ,237 & ,145 & 250 & 757 &, 527 \\
\hline Definir mejor indicadores y FV & ,761 & ,766 & ,448 &, $011^{*}$ & ,346 \\
\hline Enfocarse solo en parte manejable &, 463 & ,135 & 208 & ,630 & ,545 \\
\hline Necesita ser mejorado & ,667 & ,408 & ,807 & ,720 & 207 \\
\hline
\end{tabular}

A continuación, la Tabla 6.13 incluye las medias para cada uno de los grupos y subgrupos.

Este análisis ha permitido identificar que mientras que algunas afirmaciones tienen la misma aceptación por parte de todos los grupos, otras en cambio dependen del grupo definido.

El resultado obtenido es de gran valor a la hora de buscar una mejora que pueda cubrir las necesidades de todas las personas que trabajan con la metodología, dado que aporta información de las debilidades detectadas globalmente, como el uso de una terminología confusa, y de las propuestas, no solo mejor valoradas (Figura 6.7), sino aceptadas por todos los colectivos, como la inclusión de la GR y de la dimensión del tiempo. 
Tabla 6.13. Medias para los subgrupos significativamente diferentes. Fuente: elaboración propia a partir de tratamiento de datos con SPSS.

\begin{tabular}{|c|c|c|c|}
\hline Afirmación (variable) & Grupo & Subgrupo & Medias* \\
\hline \multirow{12}{*}{ Metodología rígida } & \multirow{2}{*}{ País } & España & 2,86 \\
\hline & & Colombia & 2,35 \\
\hline & \multirow{4}{*}{$\begin{array}{l}\text { Tipo de } \\
\text { organización }\end{array}$} & ONGD & 2,83 \\
\hline & & Empresa & 2,83 \\
\hline & & Universidad & 2,69 \\
\hline & & Admon. pública & 2,00 \\
\hline & \multirow{4}{*}{$\begin{array}{l}\text { № proyectos } \\
\text { organizacion }\end{array}$} & $<5$ & 2,58 \\
\hline & & $5-10$ & 2,88 \\
\hline & & $10-50$ & 3,00 \\
\hline & & $>50$ & 2,39 \\
\hline & Lugar de & Sí & 2,96 \\
\hline & ejecución: África & No & 2,58 \\
\hline \multirow{4}{*}{ No relacionada con el éxito } & \multirow{2}{*}{ País } & España & 2,40 \\
\hline & & Colombia & 1,75 \\
\hline & \multirow{2}{*}{$\begin{array}{l}\text { Lugar de } \\
\text { ejecución: África }\end{array}$} & Sí & 2,55 \\
\hline & & No & 2,04 \\
\hline \multirow{4}{*}{$\begin{array}{l}\text { No integrada con otras herramientas de } \\
\text { Dirección de Proyectos }\end{array}$} & \multirow{2}{*}{ País } & España & 2,39 \\
\hline & & Colombia & 1,95 \\
\hline & \multirow{2}{*}{$\begin{array}{l}\text { Lugar de } \\
\text { ejecución: África }\end{array}$} & Sí & 2,50 \\
\hline & & No & 2,13 \\
\hline \multirow{2}{*}{$\begin{array}{l}\text { Considera bien los riesgos en la columna } \\
\text { de supuestos }\end{array}$} & \multirow{2}{*}{ País } & España & 2,29 \\
\hline & & Colombia & 2,79 \\
\hline \multirow{6}{*}{ Añadir costes y beneficios } & \multirow{2}{*}{ País } & España & 2,44 \\
\hline & & Colombia & 2,90 \\
\hline & \multirow{4}{*}{$\begin{array}{l}\text { Tipo de } \\
\text { organización }\end{array}$} & ONGD & 2,36 \\
\hline & & Empresa & 3,33 \\
\hline & & Universidad & 2,75 \\
\hline & & Admon. pública & 3,14 \\
\hline \multirow{5}{*}{ Definir mejor indicadores y FV } & \multirow{5}{*}{$\begin{array}{l}\text { Presupuesto } \\
\text { proyectos }\end{array}$} & $<100.000 €$ & 3,10 \\
\hline & & $100.000-200.000 €$ & 3,17 \\
\hline & & $200.000-500.000 €$ & 2,44 \\
\hline & & $>500.000 €$ & 3,08 \\
\hline & & $<100.000 €$ & 3,10 \\
\hline
\end{tabular}

*Valores de las medias sobre 4

Previo al análisis aquí presentado, se estudió por separado la muestra española (ver Apartado 7.6 de aportaciones), con respecto al cual, aunque son muchas las semejanzas, se encuentran también algunas diferencias. En relación con el tamaño de la organización, las que contaban con más empleados veían más interesante que las que contaban con menos la inclusión de la dimensión del tiempo. En cuanto al número de proyectos que llevaban las organizaciones, en España, aquellas que llevaban a cabo un mayor número de proyectos, identificaban al ML como esencial a la hora de obtener 
fondos y aceptaban mejor la propuesta de cambiar hipótesis por riesgos, mientras que, al ampliar la muestra con Colombia, las diferencias se vinculan a la rigidez de la metodología. En la muestra española, el presupuesto de los proyectos no contaba con ninguna diferencia, mientras que sí su duración. Así, para proyectos más largos, se identificaba la metodología como útil en todas las fases y se consideraba mejor el tratamiento que se hacía de los riesgos en la columna de supuestos. Destaca también la diferencia encontrada en la muestra española con respecto al uso de todos los pasos de la metodología, dado que esto hacía que fuera valorada como menos confusa, y la integración de la GR en todos los pasos cobraba más valor, frente a los participantes que solo trabajaban con la MML.

El importante punto de vista de la metodología que la muestra colombiana añade, partiendo de la hipótesis de que trabajan más con el ML y, por tanto, tienen un mayor conocimiento, es que cuanto más se conoce la metodología son menores las dificultades a la hora de gestionar proyectos con ella, y con ello, las debilidades que muestra son menos apreciadas.

Esta observación está muy en la línea de las respuestas obtenidas en la última pregunta abierta del cuestionario sobre cómo mejorarían el ML. En ella, además de destacar la importancia de identificar acciones para combatir los riesgos y eliminar el estatismo de la matriz con actualizaciones periódicas, destacaba el hecho del inapropiado uso que a veces se hace de esta metodología, recurriendo a utilizarla solo como un medio inevitable para obtener la financiación, pero sin profundizar en su uso. Así, muchas de las personas encuestadas reclamaban una mayor formación en su uso.

Otra de las sugerencias más comentadas fue la necesidad de introducir nuevos enfoques, como el de género o el de derechos humanos, y tratar de adaptar mejor la metodología a procesos de cambio, a través, por ejemplo, de la Teoría del Cambio. También, ligado con lo anterior, los profesionales demandan una mayor inclusión e implicación de los beneficiarios en todas las fases del proyecto, tratando de hacer la metodología más participativa. Estos enfoques más propios de Cooperación al Desarrollo son mencionados junto con la necesidad de combinarlos con otras herramientas de Dirección de Proyectos, principalmente la gestión de riesgos y la gestión del tiempo.

\subsection{Caso de estudio Cauca}

Como se ha explicado en el Capítulo 5 de Metodología, se han realizado talleres de trabajo con los participantes de ocho PCD para identificar y evaluar los riesgos que sufrieron los proyectos ya realizados, con la excepción de uno de ellos que está actualmente en desarrollo. En esas mismas reuniones se definió en qué consistía el éxito del proyecto y se identificó el nivel de éxito alcanzado por el proyecto en cada una de 
las categorías definidas. También se plantearon preguntas abiertas para conocer las dificultades con las que habían tenido que hacer frente a lo largo del proyecto. En estos grupos de trabajo participaron las personas encargadas de la identificación, formulación, ejecución y control de los PCD.

En todos los PCD estudiados se siguió la misma metodología, incluyendo además una entrevista con la persona que dirigió el proyecto. Para todos se trabajó con la misma Estructura de Descomposición del Riesgo (EDR, más conocida por sus siglas en inglés, RBS), presentada al inicio de las sesiones y validada por todos los equipos como la más adecuada para el estudio. Esta RBS se puede ver en la Figura 6.8.

Cada una de las categorías de riesgo quedaba definida de manera simplificaba de la siguiente manera:

- Ambiental: riesgos asociados a climatología adversa o catástrofes en el medio ambiente debidos a fenómenos naturales o a una acción humana.

- Cultural: riesgos asociados a las diferencias culturales y al desconocimiento de la cultura local.

- De dirección de proyectos: riesgos asociados con la propia gestión del proyecto y el modo de trabajar del equipo de proyecto.

- Económica: riesgos asociados a la financiación y a la gestión económica del proyecto.

- Organizativa: riesgos asociados a las características de las actividades diseñadas y a su organización.

- Política: riesgos asociados al modo de ejercer el poder y a los cambios en las instituciones públicas.

- De seguridad: riesgos asociados a las características generales del lugar donde se desarrolla el proyecto y a las propias actividades a realizar que pudieran causar accidentes o poner en peligro la vida de las personas.

- Tecnológica: riesgos asociados a los equipos utilizados y a la infraestructura tecnológica disponible.

EDR

\begin{tabular}{|l|c|c|c|c|c|}
\hline Ambiental & Cultural & $\begin{array}{c}\text { De dirección } \\
\text { de } \\
\text { Proyectos }\end{array}$ & Económica & Organizativa & Política \\
\hline
\end{tabular}

Figura 6.8. Estructura de Descomposición del Riesgo utilizada.

Fuente: elaboración propia. 
Para la evaluación de los riesgos, se trabajó con las escalas que se muestran en las Tablas 6.14 y 6.15 , definidas previamente y validadas con los participantes antes del comienzo de cada sesión de trabajo. El impacto de los riesgos se valoró sobre los tres objetivos más relevantes de todo proyecto (triángulo de oro de la dirección de proyectos), añadiendo también el criterio de seguridad por ser el Cauca una zona de trabajo especialmente delicada tras 50 años de conflicto armado con mucha incidencia en la zona y por la alta actividad relacionada con la producción de cultivos ilícitos.

Tabla 6.14. Escala de probabilidad utilizada.

Fuente: elaboración propia.

\begin{tabular}{ll}
\hline & \multicolumn{1}{c}{ Probabilidad } \\
\hline Muy alta (MA) & Frecuentemente $(>50 \%)$ \\
Alta (A) & Una vez cada 4 proyectos $(>25 \%)$ \\
Media (M) & Una vez cada 10 proyectos $(>10 \%)$ \\
Baja (B) & Una vez cada 20 proyectos $(>5 \%)$ \\
Muy baja (MB) & Menos de 1 vez cada 20 proy. $(<5 \%)$ \\
\hline
\end{tabular}

Tabla 6.15. Escala de impacto utilizada. Fuente: elaboración propia.

\begin{tabular}{|c|c|c|c|c|}
\hline \multicolumn{5}{|c|}{ Impacto } \\
\hline & Tiempo & Coste & Alcance & Seguridad \\
\hline Muy alto (MA) & $>3$ meses & $>100.000 \$$ & $>10 \%$ & Fatalidad \\
\hline Alto (A) & 2-3 meses & $50.000-100.000 \$$ & $5-10 \%$ & Daños graves \\
\hline Medio (M) & 1-2 meses & $20.000-50.00 \$$ & $3-5 \%$ & Tratamiento médico \\
\hline Bajo (B) & 2-4 semanas & $10.000-20.000 \$$ & $1-3 \%$ & Primeros auxilios \\
\hline Muy bajo (MB) & $<2$ semanas & $<10.000 \$$ & $<1 \%$ & Sin daños \\
\hline
\end{tabular}

* Se incluyeron los rangos de coste en dólares americanos por ser más común en Colombia que en euros.

Con estas escalas se obtuvieron valores de la importancia del riesgo, para cada uno de los cuatro criterios y de manera global. Para identificar la importancia total de cada riesgo se recurrió a pedir a la persona encargada de dirigirlo que ponderara cada uno de los criterios, otorgando así un peso a cada uno de ellos, de acuerdo con la Ecuación 6.1.

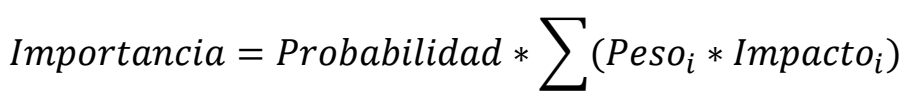

[Ecuación 6.1. Importancia del riesgo]

Donde $i$ representa cada uno de los criterios, y se debe cumplir que $\sum\left(\operatorname{Peso}_{i}\right)=0$. 
Además, se incluyó también en el análisis la identificación por parte de los participantes en los talleres de la fase del ciclo de vida del proyecto en la que sería más probable que apareciera el riesgo, siendo éstas las que muestra la Tabla 6.16.

Tabla 6.16. Fases del ciclo de vida del proyecto utilizadas en el análisis.

Fuente: elaboración propia.

\begin{tabular}{cl}
\hline $\begin{array}{c}\text { Codificación } \\
\text { de la fase }\end{array}$ & $\begin{array}{l}\text { Fase del ciclo de } \\
\text { vida del proyecto }\end{array}$ \\
\hline 1 & Identificación \\
2 & Formulación \\
3 & Ejecución \\
4 & Evaluación \\
\hline
\end{tabular}

El análisis cualitativo se muestra a continuación para cada uno de los proyectos, incluyéndose después en el Apartado 6.3.1.6 una reflexión conjunta para todos los proyectos. Posteriormente, los resultados son analizados cuantitativamente en el Apartado 6.3.2 a través de la metodología fuzzy o difusa.

\subsubsection{Análisis cualitativo de los proyectos}

Previo a realizar el análisis cualitativo de los riesgos, para cada uno de los proyectos, se incluye la identificación y categorización de los riesgos encontrados. Aunque se hizo hincapié en que los riesgos podían ser también oportunidades, la identificación de éstas fue más complicada para los participantes, demostrando el escaso uso que en la práctica se hace de éstas. Muchos de los riesgos incluidos fueron previamente identificados por la autora en el estudio de la información recibida de los proyectos, estos se presentaron a modo de ejemplo y, la gran mayoría fueron aceptados e incluidos en el análisis, añadiendo algunos más los participantes.

El análisis cualitativo de los PCD en Cauca se realizó a través de la matriz probabilidadimpacto que se muestra en la Figura 6.9, en la que se asignaron números del 1 al 5 a cada uno de los valores de las respectivas escalas para poder realizar la multiplicación y obtener así el valor de la importancia del riesgo. El código de colores seguido en la matriz es el que se ha utilizado para presentar los resultados a través de un formato tabular ordenado, en esta ocasión por el orden de importancia del riesgo, pero que permitiría la opción de ordenarse atendiendo a la categoría del riesgo, la etapa, la probabilidad o cada uno de los impactos o importancia parcial asignada a dichos impactos. 


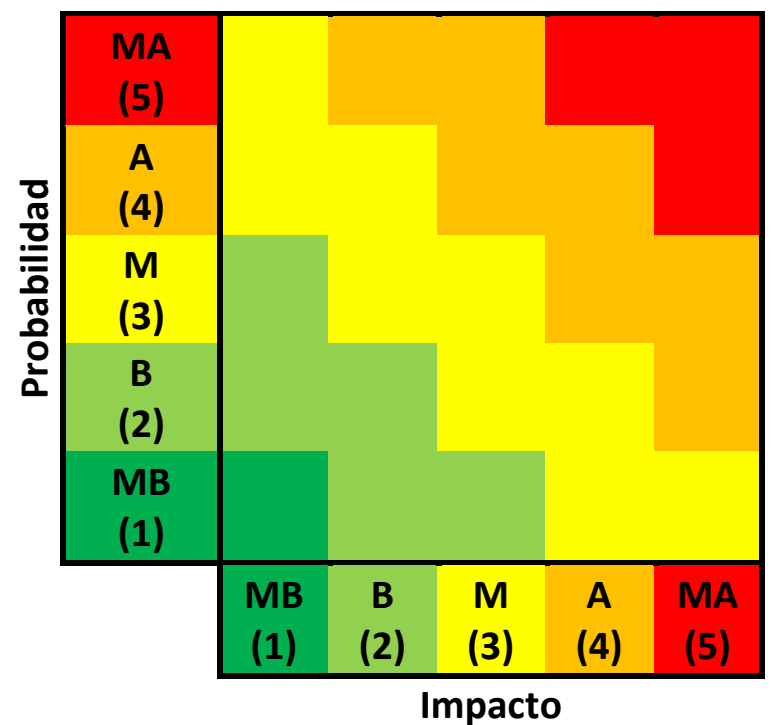

Figura 6.9. Matriz probabilidad impacto utilizada para el caso de estudio. Fuente: elaboración propia.

Los valores de importancia, representados con colores, como ya se comentó en el Apartado 4.3.3, se eligen de acuerdo con el nivel de tolerancia al riesgo por parte de la organización. En esta ocasión se ha optado por estos valores, en los que a partir de la posición central de la matriz (importancia=9), se consideraran riesgos de alta (o muy alta) importancia, y sería necesario priorizar su respuesta. Igualmente, para pasar de un nivel de importancia a otro, siempre se ha recurrido al valor correspondiente a la diagonal principal, en la que coinciden probabilidad e impacto, siendo éste el valor máximo para dicho nivel.

A la hora de incluir los resultados de las fases identificadas para la aparición de los riesgos por parte de los participantes, se incluyen, en la casilla correspondiente, las fases en las que puede aparecer, según los participantes, siendo de izquierda a derecha el grado de inclusión en cada una de las fases (vinculado a una escala de color de azules, de más oscuro a más claro).

Todos los resultados obtenidos en los talleres fueron después valorados en una entrevista personal con la persona que dirigió el proyecto.

\subsubsection{Proyecto de Educación Superior}

Fue un proyecto de larga duración, tres años, financiado a través de la convocatoria nacional de Regalías $^{26}$, del que cabe destacar que era la primera vez que se desarrollaba

${ }^{26}$ El Sistema General de Regalías (SGR) se encarga de distribuir los ingresos obtenidos a través de la minería hacia la población más vulnerable, generando mayor equidad social, y promoviendo el desarrollo y la competitividad regional. Los recursos son utilizados a través de proyectos que, tras la presentación 
un proyecto de estas características en el Departamento del Cauca, y que era también el primero dirigido por la entidad universitaria Unicomfacauca, siendo su director igualmente novel en esta tarea. Pese a ello, los valores de éxito alcanzados son los más altos de los PCD estudiados. Quizá esto es debido precisamente a las ganas de hacerlo bien por parte del equipo que intervino y de la propia institución, y que el proyecto pudiera ser un caso de éxito replicable en otras zonas.

El taller para la identificación y evaluación de riesgos se llevó a cabo en la sede de Unicomfacauca en Santander de Quilichao y contó con siete participantes. Fue el taller con mayor duración, casi cinco horas, gracias a la altísima participación de las personas asistentes. En este proyecto se trabajó con técnicas de prospectiva y de diseño de escenarios durante su planificación y estaban muy acostumbrados a talleres participativos como éste. Estuvo a punto de tener que ser suspendido, pese a haber podido cuadrar agendas con los participantes, debido a los cortes en la vía que comunica Popayán con Santander de Quilichao por protestas de campesinos en época electoral, viviendo así de primera mano uno de los riesgos que, curiosamente, no fue identificado directamente en este taller.

En la identificación de riesgos (ver Tabla 6.17), destaca el haber encontrado oportunidades, asociadas todas ellas a la cultura local. También se encuentra significativo el gran número de riesgos encontrados asociados a la categoría Organizativa. El total de riesgos encontrados fue de 33.

Una vez identificados y categorizados los riesgos, se procede a evaluarlos. Para ello se utliza la Ecuación 6.2, de acuerdo a la ponderación acordada con el director del proyecto, que daba más importancia al Alcance.

$$
\mathrm{I}=\mathrm{P} *\left(0,2 * \text { Impacto }_{\text {tiempo }}+0,2 * \mathrm{Impacto}_{\text {coste }}+0,4 * \mathrm{Impacto}_{\text {alcance }}+0,2 * \mathrm{Impacto}_{\text {seguridad }}\right)
$$

[Ecuación 6.2. Importancia del riesgo con prioridad impacto en alcance]

Donde I es la importancia total del riesgo, y $P$ la probabilidad de ocurrencia.

por las entidades territoriales, son evaluados y aprobados por los Órganos Colegiados de Administración y Decisión (OCAD). 
Tabla 6.17. Riesgos identificados y categorizados para proyecto de Educación Superior. Fuente: elaboración propia.

\begin{tabular}{|c|c|c|}
\hline Categoría & Id. & Riesgo \\
\hline Ambiental & AMB_1 & $\begin{array}{l}\text { Imposibilidad de desplazamiento de los estudiantes debido a las } \\
\text { inclemencias meteorológicas }\end{array}$ \\
\hline \multirow{5}{*}{ Cultural } & CUL_1 & $\begin{array}{l}\text { Dificultades para preguntar las dudas que surjan por parte de los } \\
\text { beneficiarios }\end{array}$ \\
\hline & CUL_2 & $\begin{array}{l}\text { Mayor participación en el proyecto por la afición a las actividades } \\
\text { deportivas (Oportunidad) }\end{array}$ \\
\hline & CUL_3 & $\begin{array}{l}\text { Mejor aceptación del proyecto por el gran arraigo cultural } \\
\text { (Oportunidad) }\end{array}$ \\
\hline & CUL_4 & $\begin{array}{l}\text { Aumento de la complejidad por la necesidad de introducir el enfoque } \\
\text { diferencial étnico }\end{array}$ \\
\hline & CUL_5 & $\begin{array}{l}\text { Dificultades en la comunicación de los beneficiarios con el equipo del } \\
\text { proyecto }\end{array}$ \\
\hline \multirow{3}{*}{$\begin{array}{l}\text { De Dirección } \\
\text { de Proyectos }\end{array}$} & DPR_1 & Inexperiencia del director del proyecto en proyectos similares \\
\hline & DPR_2 & Falta de comunicación con las instituciones educativas \\
\hline & DPR_3 & Falta de coordinación en el equipo \\
\hline \multirow[t]{2}{*}{ Económica } & ECO_1 & $\begin{array}{l}\text { Incapacidad para hacer frente a los gastos de transporte para acudir a } \\
\text { las formaciones }\end{array}$ \\
\hline & ECO_2 & Retrasos en la financiación por parte de la entidad financiadora \\
\hline \multirow{14}{*}{ Organizativa } & ORG_1 & Dependencia de las capacidades de los orientadores \\
\hline & ORG_2 & $\begin{array}{l}\text { Incapacidad para comprender el lenguaje técnico por parte de los } \\
\text { beneficiarios }\end{array}$ \\
\hline & ORG_3 & Dificultades con la lectura/escritura por parte de los beneficiarios \\
\hline & ORG_4 & Inapropiada selección de las instituciones educativas \\
\hline & ORG_5 & Abandono del proyecto por parte de los orientadores \\
\hline & ORG_6 & Abandono del proyecto por parte de los beneficiarios \\
\hline & ORG_7 & Abandono del proyecto por parte de las instituciones educativas \\
\hline & ORG_8 & $\begin{array}{l}\text { Inapropiada selección de las materias a impartir (matemáticas, } \\
\text { lectoescritura, computación) }\end{array}$ \\
\hline & ORG_9 & $\begin{array}{l}\text { Falta de interés hacia las capacitaciones de docentes por parte de los } \\
\text { docentes de las instituciones }\end{array}$ \\
\hline & ORG_10 & Falta de propuestas de empleo \\
\hline & ORG_11 & Falta de compromiso de los beneficiarios con el proceso educativo \\
\hline & ORG_12 & Diferentes niveles de educación de los participantes \\
\hline & ORG_13 & Escasa difusión del proyecto \\
\hline & ORG_14 & Inapropiada selección de los estudios superiores \\
\hline \multirow{3}{*}{ Política } & POL_1 & Cancelación del apoyo al proyecto por cambio de gobierno \\
\hline & POL_2 & Cierre de las vías \\
\hline & POL_3 & Influencia política a la hora de elegir municipios \\
\hline \multirow{2}{*}{ De seguridad } & SEG_1 & Desplazamientos por zonas conflictivas \\
\hline & SEG_2 & Alteración del orden público (levantamientos) \\
\hline \multirow{3}{*}{ Tecnológica } & TEC_1 & Pérdida de la corriente eléctrica en las instituciones educativas \\
\hline & TEC_2 & Falta de computadoras en las instituciones educativas \\
\hline & TEC_3 & $\begin{array}{l}\text { Uso de teléfonos muy antiguos por parte de los beneficiarios para } \\
\text { uso de App o realizar gestiones }\end{array}$ \\
\hline
\end{tabular}


La Tabla 6.18. muestra los riesgos evaluados, pudiendo apreciar que entre los primeros riesgos, los que predominan son los económicos, políticos, culturales y organizativos, teniendo una importancia Muy Alta en tiempo, coste y alcance, viéndose los valores de importancia total rebajados por el menor valor que se dio al impacto de acuerdo con el criterio de seguridad para casi todos los riesgos. Resulta muy clara la normalización que hay de la inseguridad a la hora de trabajar en esta zona de post conflicto, al identificarse la probabilidad del riesgo SEG_1, desplazamientos por zonas conflictivas, con una probabilidad muy alta y, sin embargo, impactos medios o bajos.

Hay que destacar que sólo se habían identificado dos riesgos económicos, y que aparecen los dos entre los tres riesgos más importantes. El otro en esta lista es el riesgo político asociado a la dependencia del apoyo de un gobierno local (la Gobernación del Cauca, en este caso) que cambia cada cuatro años.

Resulta relevante que el único riesgo en el que la totalidad de los participantes coincidieron otorgándole el máximo valor a su probabilidad de ocurrencia fue el cultural asociado a las dificultades para preguntar las dudas por parte de los beneficiarios (CUL_1). Este riesgo, posee además el valor más alto por su importancia en el Alcance del proyecto. Es un riesgo con el que pocas veces se cuenta, pero ha quedado demostrado que es el que más aparece y previsiblemente esté presente en todas las culturas jerárquicas, donde la distancia al poder está muy marcada y es aceptada socialmente.

En cuanto a las etapas en las que se podrían encontrar los riesgos, destaca que todos los participantes encontraban que todos los riesgos aparecían en la ejecución.

En la entrevista con el director del proyecto, se mostraron los resultados. En su opinión, los riesgos más importantes fueron el incumplimiento y retrasos de algunos pagos por parte de la entidad financiadora (ECO_2), que afectó directamente a la imposibilidad del pago del subsidio de transporte (ECO_1), y que sale el tercero en la clasificación general; el riesgo asociado a las diferencias en el nivel académico previo de los estudiantes (ORG_12), que aparece como noveno; y el riesgo ligado a su propia inexperiencia dirigiendo proyectos de este tipo (DPR_1), que sin embargo, ocupa un puesto medio en la tabla. 
Tabla 6.18. Evaluación de riesgos para el proyecto de Educación Superior.

Fuente: elaboración propia.

\begin{tabular}{|c|c|c|c|c|c|c|c|c|c|c|c|c|c|}
\hline \multirow{3}{*}{ Id } & \multirow{3}{*}{\multicolumn{3}{|c|}{ Etapa }} & \multirow{3}{*}{ Prob. } & \multirow{2}{*}{\multicolumn{4}{|c|}{ Impacto }} & \multicolumn{5}{|c|}{ Importancia (Probabilidad x Impacto) } \\
\hline & & & & & & & & & \multirow{2}{*}{$\begin{array}{l}\text { Imp. } \\
\text { Total }\end{array}$} & \multirow{2}{*}{$\begin{array}{c}\text { Imp. } \\
\text { Tiempo }\end{array}$} & \multirow{2}{*}{$\begin{array}{l}\text { Imp. } \\
\text { Coste }\end{array}$} & \multirow{2}{*}{$\begin{array}{c}\text { Imp. } \\
\text { Alcance }\end{array}$} & \multirow{2}{*}{$\begin{array}{l}\text { Imp. } \\
\text { Seg. }\end{array}$} \\
\hline & & & & & Tiempo & Coste & Alcance & Seg. & & & & & \\
\hline ECO_1 & $3:$ & 1 & & 4,71 & 4,43 & 4,29 & 4,29 & 1 & 18,18 & & 20,21 & & 9,42 \\
\hline POL_1 & $2:$ & 13 & 3 & 4 & 4,71 & 4,29 & 4,43 & 1,86 & 15,78 & 18,84 & 17,16 & & 7,44 \\
\hline ECO_2 & $3 \mid$ & 4 & & 3,86 & 4,57 & 4,43 & 4,57 & 2,29 & 15,77 & 17,64 & 17,1 & 17,64 & 8,84 \\
\hline CUL_1 & 3 & & & 5 & 3,86 & 1,57 & 4,57 & $\perp$ & 15,57 & 19,3 & 7,85 & 22,85 & 5 \\
\hline CUL_2 & $3:$ & 1 & & 4,71 & 4,14 & 1,86 & 3,86 & 2 & 14,81 & 19,5 & 8,76 & 8,18 & 9,42 \\
\hline ORG_1 & 3 & & & 4,57 & 3,71 & 3,29 & 3,43 & 2 & 14,5 & 16,95 & 15,04 & 5,68 & 9,14 \\
\hline ORG_10 & 3 & 4 & & 4,29 & 3,86 & 3,57 & 3,29 & 2,14 & 13,86 & 16,56 & 15,32 & 4,11 & 9,18 \\
\hline ORG_11 & 3 & 4 & & 1,29 & 86 & 2,71 & 3,43 & 2 & 13,24 & 16,56 & 11,63 & 4,71 & 8,58 \\
\hline ORG_12 & 3 & 41 & 1 & 3,86 & & & 3,29 & 1,57 & & 13,24 & & 2,7 & 6,06 \\
\hline SEG_1 & 3 & & & 4,17 & 86 & 2,29 & 3 & 2 & 10,97 & ,93 & 9,55 &, 51 & 8,34 \\
\hline ORG_13 & 2 & 3 & & 3,71 & 3 & 2,86 & 3 & 2 & 10,28 & 1,13 & 10,61 & 1,13 & 7,42 \\
\hline CUL_3 & 1 & 3 & & 29 & 14 & 2,57 & 4,14 & 1,29 & 10,05 & & 8,46 & 3,62 & 4,24 \\
\hline ORG_14 & 3 & & & 86 & & & 2,86 & & 9,71 & & 84 & & 6,6 \\
\hline CUL_4 & 3 & 12 & 2 & 43 & 3 & 1,71 & 4,14 & & 9,6 & 0,29 & 5,87 & 14,2 & 3,43 \\
\hline TEC_3 & 3 & 4 & & 29 & 71 & 3,29 & 3,29 & 1,14 & 9,03 & 8,92 & 10,82 &, 82 & 3,75 \\
\hline DPR_1 & 2 & 43 & 3 & 3 & 3 & & 3,14 & & & 0 & 7,71 & 42 & 5,13 \\
\hline ORG_2 & 3 & & & 71 & 43 & 2,29 & 2,86 & 1,86 & 7,21 & 9,3 & 6,21 & 75 & 5,04 \\
\hline DPR_2 & 3 & 2 & & 2,83 & & 2 & 2,83 & 1 & 79 & 9,42 & 5,66 & 01 & 2,83 \\
\hline POL_2 & 3 & & & 3 & & & 1,86 & & & & 7,71 & & 6,87 \\
\hline ORG_3 & 3 & 4 & & 71 & & 2,43 & 2,57 & & 6,58 & 7,75 & 6,59 & 6,96 & 4,63 \\
\hline ORG_4 & 3 & 1 & & 2,86 & 2,86 & 2 & 2,43 & 1,57 & 6,46 & 8,18 & 5,72 & 95 & 4,49 \\
\hline POL_3 & 3 & & & 3,33 & $\angle$ & & 2,5 & \pm & 6,33 & 6,66 & 3 & 33 & 3,33 \\
\hline ORG_5 & 3 & 4 & & 2,29 & & 3,14 & 2,71 & & 5,82 & 5,56 & 7,19 & 5,21 & 3,92 \\
\hline SEG_2 & 3 & & & 3 & 2,33 & 1,83 & 2 & 1,5 & 5,8 & 6,99 & 5,49 & 6 & 4,5 \\
\hline ORG_6 & 3 & & & 2,5 & 2 & 2,33 & 2,67 & 1,67 & 5,67 & 5 & 5,83 & 6,68 & 4,18 \\
\hline & 3 & 4 & & & & 1,43 & 2,29 & & 5,37 & 6,6 & 3,68 & 5,89 & 4,78 \\
\hline ORG_7 & 3 & 1 & & 2,43 & 2,57 & 2 & 2 & 1,71 & 5 & 6,25 & 4,86 & 4,86 & 4,16 \\
\hline TEC_2 & 3 & & & 2,29 & 2 & 2,29 & 2,29 & 2 & 4,98 & 4,58 & 5,24 & 5,24 & 4,58 \\
\hline AMB_1 & 3 & & & 2,29 & & 2 & 1,86 & & 4,52 & 3,92 & 4,58 & 4,26 & 5,56 \\
\hline DPR_3 & 3 & & & 2 & 2,67 & 1,67 & 2,33 & 1,33 & 4,13 & 5,34 & 3,34 & 4,66 & 2,66 \\
\hline TEC_1 & 3 & & & 2 & & 1,86 & 2 & 2 & 3,72 & 2,86 & 3,72 & 4 & 4 \\
\hline ORG_8 & 3 & 2 & & 2 & & & 1,71 & 1,86 & 3,31 & 3,42 & 2,58 & 3,42 & 3,72 \\
\hline ORG_9 & 3 & & & 1,43 & 1,43 & 1,57 & 1,43 & 1,14 & 2 & 2,04 & 2,25 & 2,04 & 1,63 \\
\hline
\end{tabular}

En esta entrevista también se obtuvo información sobre la evaluación previa que se hizo de los riesgos del proyecto, que fue durante la formulación, en el $\mathrm{ML}$, identificando y evaluando un riesgo por actividad/resultado/objetivo. Muchos de los riesgos no se 
identificaron inicialmente, y cuando se fueron identificando con el avance del proyecto, se les fue dando la mejor respuesta posible con los recursos disponibles, consiguiendo, al final y gracias al esfuerzo de todas las personas implicadas, unos valores de éxito muy altos.

El éxito de este proyecto se definió en el taller por parte de los participantes de acuerdo con tres criterios, que se componían a su vez de subcriterios que permiten explicar el significado de los correspondientes niveles, como muestra la Tabla 6.19.

Tabla 6.19. Criterios de éxito para el proyecto de Educación Superior. Fuente: elaboración propia.

\begin{tabular}{|c|c|}
\hline Criterio & Subcriterio \\
\hline & $\begin{array}{l}\text { Beneficiar a los jóvenes del norte del Cauca para acceder a la } \\
\text { Educación Técnica y Tecnológica (ETyT) }\end{array}$ \\
\hline $\begin{array}{l}\text { Mejora en la } \\
\text { calidad } \\
\text { de vida }\end{array}$ & $\begin{array}{l}\text { Educar a jóvenes de bajos recursos económicos en ETyT } \\
\text { Contribuir en el desarrollo humano y profesional de jóvenes } \\
\text { soñadores de nuestra región } \\
\text { Generar un cambio de vida de personas que sin este proyecto } \\
\text { nunca hubieran salido de la montaña }\end{array}$ \\
\hline \multirow{2}{*}{$\begin{array}{l}\text { Equidad } \\
\text { (acceso para } \\
\text { todos) }\end{array}$} & $\begin{array}{l}\text { Educación con pertinencia y acceso } \\
\text { Acceso a educación superior de calidad subsidiada para proyecto } \\
\text { de vida profesional }\end{array}$ \\
\hline & $\begin{array}{l}\text { Respaldo económico } \\
\text { Cobertura educativa, formación de bajo costo con currículo } \\
\text { pertinente }\end{array}$ \\
\hline Responsabilidad & Cumplimiento de objetivos y metas \\
\hline
\end{tabular}

El nivel de éxito se evaluó del 1 al 10, y los resultados, agrupados en Éxito en el impacto del proyecto y Éxito en la dirección del Proyecto, se pueden ver en la Tabla 6.20.

Tabla 6.20. Éxito obtenido para el proyecto de Educación Superior.

Fuente: elaboración propia.

\begin{tabular}{lclc}
\hline \multicolumn{4}{c}{ Nivel de éxito } \\
\hline Mejora en la calidad de vida & 8,29 & Impacto del proyecto & \multirow{2}{*}{8,5} \\
Equidad (acceso para todos) & 8,71 & & \\
\hline Responsabilidad & 9,14 & Dirección del proyecto & 9,14 \\
\hline
\end{tabular}

Destaca que, aunque en todo momento se persiguió en este proyecto el éxito en el Impacto del Proyecto, y pese a ser un equipo y un director de proyectos sin experiencia, los valores del éxito en la Dirección del Proyecto son más altos que en el impacto, siendo estos también muy altos. El esfuerzo por hacer las cosas bien y ser un ejemplo de 
proyecto replicable a lo largo de los tres años de duración del proyecto, se ve así reconocido. Los valores no tan altos en el impacto se deben, precisamente, al alto nivel de exigencia del equipo y a su compromiso y vinculación con el proyecto, que los llevó a fijarse metas personales más altas que las marcadas por el propio proyecto, según reconoce su propio director.

\subsubsection{Proyecto de creación y fortalecimiento de industrias culturales}

Este proyecto, de larga duración (tres años), fue solicitado por la Caja de Compensación Familiar del Cauca, COMFACAUCA, una empresa privada sin ánimo de lucro que, a través del aporte de las empresas afiliadas, se encarga de la elaboración de programas sociales y servicios relacionados con deporte, cultura y recreación. Cuenta con gran experiencia en la gestión de PCD y, para el caso concreto de este proyecto, escogió un director de proyecto, con 21 años dedicados a la gestión de este tipo de proyectos.

El taller para la identificación y evaluación de riesgos se realizó en la oficina de la Secretaría de Deporte y Cultura del Ayuntamiento de Popayán, por ser el lugar de trabajo de la supervisora del proyecto por parte de esta institución. Tuvo una duración de tres horas y se llevó a cabo con los cuatro miembros del equipo encargado de la gestión del proyecto.

Se identificaron 35 riesgos en el taller (ver Tabla 6.21), estando especialmente relacionados con las categorías de DP, económica y organizativa.

Tabla 6.21. Identificación de riesgos para el proyecto de Industrias Culturales.

Fuente: elaboración propia.

\begin{tabular}{|c|c|c|}
\hline Categoría & Id. & Riesgo \\
\hline \multirow{2}{*}{ Ambiental } & AMB_1 & $\begin{array}{l}\text { Imposibilidad de trasladarse para realizar las actividades de formación } \\
\text { debido a inclemencias meteorológicas }\end{array}$ \\
\hline & AMB_2 & Deslizamiento de terreno en la vía \\
\hline \multirow{4}{*}{ Cultural } & CUL_1 & $\begin{array}{l}\text { Recelos entre los grupos étnicos a la hora de seleccionar las empresas } \\
\text { y las alianzas empresariales }\end{array}$ \\
\hline & CUL_2 & No realizar preguntas en las formaciones \\
\hline & CUL_3 & Falta de motivación de los emprendedores \\
\hline & CUL_- 4 & Dificultades de comunicación entre beneficiarios y equipo de proyecto \\
\hline \multirow{7}{*}{$\begin{array}{l}\text { De Dirección } \\
\text { de Proyectos }\end{array}$} & DPR_1 & No consideración de una partida económica para imprevistos \\
\hline & DPR_2 & Falta de coordinación del equipo del proyecto \\
\hline & DPR_3 & Difícil acceso al patrimonio histórico cultural del Cauca \\
\hline & DPR_4 & $\begin{array}{l}\text { Inapropiada identificación y priorización de áreas de desarrollo } \\
\text { económico }\end{array}$ \\
\hline & DPR_5 & Mala promoción de eventos realizados \\
\hline & DPR_6 & Escasa identificación de los afectados negativamente por el proyecto \\
\hline & DPR_7 & Inexperiencia del director del proyecto en proyectos similares \\
\hline
\end{tabular}




\begin{tabular}{|c|c|c|}
\hline \multirow{6}{*}{ Económica } & ECO_1 & Suspensión de la ayuda \\
\hline & ECO_2 & Retrasos en la recepción de partidas económicas \\
\hline & ECO_3 & $\begin{array}{l}\text { Alto coste de inversión en ordenadores e internet para poder trabajar } \\
\text { con la plataforma web }\end{array}$ \\
\hline & ECO_4 & $\begin{array}{l}\text { Pérdidas asociadas a la falta de dedicación en la actual actividad } \\
\text { empresarial, por formaciones }\end{array}$ \\
\hline & ECO_5 & $\begin{array}{l}\text { Incapacidad de hacer frente al coste de transporte para recibir la } \\
\text { formación }\end{array}$ \\
\hline & ECO_6 & $\begin{array}{l}\text { Falta de interés por los inversores para cofinanciar planes de negocio } \\
\text { de los emprendedores }\end{array}$ \\
\hline \multirow{6}{*}{ Organizativa } & ORG_1 & Estudios de mercado poco reales por miedo a no recibir la ayuda \\
\hline & ORG_2 & Dificultades en el uso de la plataforma web por los beneficiarios \\
\hline & ORG_3 & $\begin{array}{l}\text { Mala selección de las empresas sin considerar las capacidades de los } \\
\text { beneficiarios }\end{array}$ \\
\hline & ORG_4 & Falta de interés de los beneficiarios en temas de Gestión Cultural \\
\hline & ORG_5 & $\begin{array}{l}\text { Inapropiada transferencia de conocimiento por parte de instituciones } \\
\text { capacitadores }\end{array}$ \\
\hline & ORG_6 & Abandono del proyecto por parte de los beneficiarios \\
\hline \multirow{5}{*}{ Política } & POL_1 & Cambio de la legislación vigente para la constitución de empresas \\
\hline & POL_2 & $\begin{array}{l}\text { Falta de colaboración de las instituciones públicas a la hora de facilitar } \\
\text { el legado cultural de los municipios }\end{array}$ \\
\hline & POL_3 & $\begin{array}{l}\text { Inadecuada priorización de áreas potenciales de desarrollo debido a } \\
\text { preferencias políticas }\end{array}$ \\
\hline & POL_4 & Falta de apoyo en la difusión de las actividades \\
\hline & POL_5 & $\begin{array}{l}\text { Falta de interés del gobierno local para medir los impactos de las } \\
\text { industrias culturales }\end{array}$ \\
\hline \multirow{2}{*}{ De seguridad } & SEG_1 & Desplazamientos por zonas conflictivas \\
\hline & SEG_2 & Cierre de vías \\
\hline \multirow{3}{*}{ Tecnológica } & TEC_1 & Pérdida de la corriente eléctrica \\
\hline & TEC_2 & $\begin{array}{l}\text { Imposibilidad de utilizar la plataforma web por falta de } \\
\text { medios/conocimiento en las empresas beneficiarias }\end{array}$ \\
\hline & TEC_3 & Falta mantenimiento de la plataforma on-line \\
\hline
\end{tabular}

Identificados y categorizados los riesgos, se procede a evaluarlos. Para calcular la importancia total de los riesgos, de acuerdo a lo establecido por el director del proyecto, se utiliza la misma ecuación que para el proyecto de Educación Superior (Ecuación 6.2), en la que se da más importancia al Alcance.

La Tabla 6.22 muestra la evaluación de los riesgos, donde se puede ver que de nuevo entre los más importantes destacan los económicos, políticos y culturales. Resalta que algún riesgo relacionado con la seguridad está entre los primeros, bien directamente, como SEG_1, desplazamiento por zonas conflictivas, o indirectamente como AMB_2, deslizamientos del terreno en la vía. Destaca también, como en el proyecto anterior, que el riesgo cultural con mayor importancia (CUL_4) está relacionado con las dificultades de comunicación entre los beneficiarios y el equipo del proyecto. 
Entre los riesgos económicos más importantes están el de retrasos en la recepción de la financiación (ECO_1) y el de falta de interés por cofinanciar los planes de negocio que definieran los emprendendores (ECO_6). Esto está muy ligado con la principal dificultad que encontró este proyecto, que estaba ligada con los compromisos de las instituciones públicas a través de cartas de intención, pero al no haber una partida reservada, previa a la concesión del proyecto, no existe la posibilidad de disponer de ese dinero. Este es un problema muy frecuente en proyectos de grandes convocatorias internacionales, como en este caso era la del BID, que tardan tiempo en resolverse, y pueden coincidir además con cambios en la administración.

En relación a las etapas del ciclo de vida, de nuevo casi todos los riesgos son asociados a la etapa de ejecución (3).

Al entrevistar al director del proyecto, contrastando estos resultados, coincidía en que el más importante, desde su punto de vista, fue la gestión de las contrapartidas (ECO_2); la inadecuada selección de las zonas beneficiarias ( $\mathrm{POL} 3$ ), que aparece en sexto lugar, ya que se dio prioridad a intereses políticos, en lugar de priorizar un área temática o una zona territorial, que hubiera logrado un mayor impacto; $y$, la falta de articulación institucional, relacionada con el riesgo DPR_2, falta de coordinación del equipo del proyecto, dado que en este proyecto participaban muchas instituciones, como el Ministerio de cultura, Comfacauca, la Gobernación del Cauca, varias alcaldías municipales, la Cámara de Comercio, etc., cada uno con sus agendas y con intereses a veces distintos, entonces poder reunirse y tomar decisiones fue algo muy complicado. Este último riesgo, en cambio, aparece a la mitad del ranking, no habiendo sido reconocido como tan importante por el equipo del proyecto.

Al entrevistar al director del proyecto, contrastando estos resultados, coincidía en que el más importante, desde su punto de vista, fue la gestión de las contrapartidas (ECO_2); la inadecuada selección de las zonas beneficiarias (POL_3), que aparece en sexto lugar, ya que se dio prioridad a intereses políticos, en lugar de priorizar un área temática o una zona territorial, que hubiera logrado un mayor impacto; y, la falta de articulación institucional, relacionada con el riesgo DPR_2, falta de coordinación del equipo del proyecto, dado que en este proyecto participaban muchas instituciones, como el Ministerio de cultura, Comfacauca, la Gobernación del Cauca, varias alcaldías municipales, la Cámara de Comercio, etc., cada uno con sus agendas y con intereses a veces distintos, entonces poder reunirse y tomar decisiones fue algo muy complicado. Este último riesgo, en cambio, aparece a la mitad del ranking, no habiendo sido reconocido como tan importante por el equipo del proyecto. 
Tabla 6.22. Evaluación de riesgos para el proyecto de Industrias Culturales.

Fuente: elaboración propia.

\begin{tabular}{|c|c|c|c|c|c|c|c|c|c|c|c|c|}
\hline \multirow{2}{*}{ Id. } & \multirow{2}{*}{\multicolumn{2}{|c|}{ Etapa }} & \multirow{2}{*}{ Prob. } & \multicolumn{4}{|c|}{ Impacto } & \multirow{2}{*}{$\begin{array}{l}\text { Imp. } \\
\text { Riesgo }\end{array}$} & \multirow{2}{*}{$\begin{array}{c}\text { Imp. } \\
\text { Tiempo }\end{array}$} & \multirow{2}{*}{$\begin{array}{l}\text { Imp. } \\
\text { Coste }\end{array}$} & \multirow{2}{*}{$\begin{array}{c}\text { Imp. } \\
\text { Alcance }\end{array}$} & \multirow{2}{*}{$\begin{array}{l}\text { Imp. } \\
\text { Seg. }\end{array}$} \\
\hline & & & & Tiempo & Coste & Alcance & Seg. & & & & & \\
\hline ECO_2 & 3 & & 4,5 & 4 & 4,5 & 4 & 2 & 16,65 & 18 & 20,25 & 18 & 9 \\
\hline ECO_6 & 3 & & 4,25 & 4 & 3,75 & 4,25 & 1,33 & 14,94 & 17 & 15,94 & 18,06 & 5,65 \\
\hline POL_5 & 3 & 1 & 4 & 4 & 4 & 3,75 & 1,33 & 13,46 & 16 & 16 & 15 & 5,32 \\
\hline POL_2 & 3 & & 4 & 3,5 & 4 & 3,75 & 1,33 & 13,06 & 14 & 16 & 15 & 5,32 \\
\hline CUL_4 & 3 & & 3,75 & 4,25 & 3,5 & 4 & 1,33 & 12,81 & 15,94 & 13,13 & 15 & 4,99 \\
\hline POL_3 & 4 & 3 & 4 & 3,25 & 3,25 & 3,5 & 1,67 & 12,14 & 13 & 13 & 14 & 6,68 \\
\hline SEG_1 & 1 & 23 & 3,5 & 3,75 & 3,75 & 3,25 & 3,33 & 12,13 & 13,13 & 13,13 & 11,38 & 11,66 \\
\hline CUL_3 & 3 & 2 & 3,5 & 3,75 & 4 & 4 & 1,33 & 11,96 & 13,13 & 14 & 14 & 4,66 \\
\hline AMB_2 & 3 & 4 & 4 & 3 & 4 & 1 & 5 & 11,2 & 12 & 16 & 4 & 20 \\
\hline SEG_2 & 3 & 4 & 3,25 & 3,75 & 3,75 & 3,5 & 2,67 & 11,16 & 12,19 & 12,19 & 11,38 & 8,68 \\
\hline ECO_4 & 1 & & 3,75 & 3,5 & 3 & 3,5 & 1,33 & 11,12 & 13,13 & 11,25 & 13,13 & 4,99 \\
\hline CUL_2 & 3 & 4 & 3,75 & 3,75 & 3,5 & 3 & 1,33 & 10,94 & 14,06 & 13,13 & 11,25 & 4,99 \\
\hline POL_4 & 4 & & 3,75 & 3 & 3,25 & 3,5 & 1,33 & 10,94 & 11,25 & 12,19 & & 4,99 \\
\hline DPR_1 & 3 & & 3 & 3,75 & 4,5 & 4,25 & 1,33 & 10,85 & 11,25 & 13,5 & 12,75 & 3,99 \\
\hline TEC_3 & 3 & & 3,75 & 3,25 & 3 & 3,25 & 1,33 & 10,56 & 12,19 & 11,25 & 12,19 & 4,99 \\
\hline DPR_5 & 3 & & 3,75 & 3 & 3,5 & 3 & 1,33 & 10,37 & 11,25 & 13,13 & 1,25 & 4,99 \\
\hline DPR_7 & 3 & & 2,75 & 3,25 & 4,5 & 4 & 2,67 & 10,13 & 8,94 & 12,38 & 11 & 7,34 \\
\hline DPR_2 & 3 & & 3 & 3,25 & 3,75 & 4,25 & 1,33 & 10,1 & 9,75 & 11,25 & 12,75 & 3,99 \\
\hline CUL_1 & 3 & & 3,5 & 4,25 & 2,5 & 3 & 1,33 & 9,86 & 14,88 & 8,75 & 10,5 & 4,66 \\
\hline DPR_4 & 3 & & 3,5 & 3 & 3 & 3,25 & 1,33 & 9,68 & 10,5 & 10,5 & 11,38 & 4,66 \\
\hline ECO_5 & 3 & & 3,25 & 3,25 & 3 & 3,5 & 1,33 & 9,48 & 10,56 & 9,75 & 11,38 & 4,32 \\
\hline POL_1 & 1 & 3 & 2,75 & 3 & 3,75 & 3,75 & 1,33 & 8,57 & 8,25 & 10,31 & 10,31 & 3,66 \\
\hline ECO_1 & 3 & & 2,5 & 3 & 3,75 & 3 & & 8,13 & 7,5 & 9,38 & 7,5 & 8,75 \\
\hline TEC_2 & 3 & 4 & 2,75 & 2,75 & 3,75 & 3,25 & 1,33 & 7,88 & 7,56 & 10,31 & 8,94 & 3,66 \\
\hline DPR_6 & 3 & & 2,5 & 3 & 3,25 & 3,5 & 1,33 & 7,29 & 7,5 & 8,13 & 8,75 & 3,33 \\
\hline AMB_1 & 3 & 4 & 3 & 2,75 & 2,25 & 2,25 & 1,67 & 6,7 & 8,25 & 6,75 & 6,75 & 5,01 \\
\hline ORG_3 & 3 & 4 & 3 & 3 & 2,67 & 2 & 1,33 & 6,6 & 9 & 8,01 & 6 & 3,99 \\
\hline ORG_2 & 2 & 3 & 3 & 2,75 & 2 & 2,33 & 1,33 & 6,44 & 8,25 & 6 & 6,99 & 3,99 \\
\hline ORG_4 & 3 & 4 & 3,5 & 2 & 1,75 & 2 & 1,33 & 6,36 & 7 & 6,13 & 7 & 4,66 \\
\hline ECO_3 & 4 & & 2,25 & 2,25 & 3 & 3,75 & 1,33 & 6,34 & 5,06 & 6,75 & 8,44 & 2,99 \\
\hline ORG_6 & 3 & & 3 & 2,75 & 2 & 2 & 1,33 & 6,05 & 8,25 & 6 & 6 & 3,99 \\
\hline ORG_5 & 3 & & 3,25 & 2,75 & 1,75 & 1,67 & 1,33 & 5,96 & 8,94 & 5,69 & 5,43 & 4,32 \\
\hline ORG_1 & 3 & & 2,75 & 2,25 & 2,33 & 1,75 & 1,67 & 5,36 & 6,19 & 6,41 & 4,81 & 4,59 \\
\hline TEC_1 & 3 & & 2,25 & 2,25 & 2,75 & 2,5 & 1,67 & 5,25 & 5,06 & 6,19 & 5,63 & 3,76 \\
\hline DPR_3 & 3 & & 1,75 & 2,25 & 2,5 & 3,25 & 1,33 & 4,4 & 3,94 & 4,38 & 5,69 & 2,33 \\
\hline
\end{tabular}

Según el director de este proyecto, lo que más le llamó la atención del ejercicio de evaluar los riesgos fue la inclusión de la categoría de riesgos asociados a las diferencias 
culturales, dado que, aunque los considera imprescindibles, en su dilatada experiencia como director de proyectos, nunca los había considerado expresamente.

Este proyecto contó una partida de imprevistos (menos del 3\% del presupuesto total), que no fue suficiente para atender los retrasos e impagos de algunas de las contrapartidas. También contó con una identificación y evaluación previa de riesgos muy generales, solo en la formulación, solicitada por el BID.

De cara al éxito, aunque no se consiguieron los niveles de crecimiento económico fijados como metas por el BID en un 3\%, sí que hubo un impacto directo muy importante en la generación de ingresos para los emprendedores. Los criterios de éxito establecidos durante los talleres se pueden ver en la Tabla 6.23, con sus correspondientes subcriterios

Tabla 6.23. Criterios de éxito para el proyecto de Industrias Culturales.

Fuente: elaboración propia.

\begin{tabular}{|c|c|}
\hline Criterio & Subcriterio \\
\hline \multirow{2}{*}{ Economía } & Impacto económico \\
\hline & Generar condiciones para el desarrollo económico de los beneficiarios \\
\hline \multirow{3}{*}{ Cultura } & Dignidad del sector cultural \\
\hline & Articulación institucional y visibilización de los sectores \\
\hline & Fortalecimiento sector cultural \\
\hline \multirow{3}{*}{ Entregables } & Metodología de entregables \\
\hline & Formulación: identificación de necesidades sentidas del sector \\
\hline & Gestión y ejecución \\
\hline
\end{tabular}

El nivel de éxito fue evaluado del 1 al 10, y los resultados se presentan en la Tabla 6.24 agrupados en Éxito en el impacto del proyecto y Éxito en la dirección del Proyecto.

Tabla 6.24. Éxito obtenido para el proyecto de Industrias Culturales. Fuente: elaboración propia.

\begin{tabular}{llll}
\hline \multicolumn{3}{c}{ Nivel de éxito } \\
\hline Economía & 6,25 & Impacto del proyecto & 6,88 \\
Cultura & 7,50 & & \\
\hline Entregables & 7,25 & Dirección del proyecto & 7,25 \\
\hline
\end{tabular}

Los niveles de éxito evaluados, como ya se ha comentado, para el nivel de desarrollo económico de la región, no fueron los esperados, y por eso recibe esa nota media. De cara al fomento de la cultura, parece que se podía haber conseguido más si no se hubiera 
querido abarcar a regiones culturalmente tan diferentes como Popayán y los municipios del norte del Cauca. Pese a todo el fomento de la cultura, recibe la nota más alta, quizá, como bien dice el director del proyecto, debido a que las personas que se dedican a industrias culturales lo hacen por vocación, y son emprendedores que sienten pasión por lo que hacen y logran transmitirlo, contribuyendo así al éxito en este nivel. En cuanto al cumplimiento con los entregables, debido a las dificultades sufridas con la financiación, no fue posible realizar todo lo esperado. Pese a ello, el proyecto se puede considerar exitoso, dado que todos los emprendimientos que surgieron con el proyecto continúan vivos y están muy activos, liderando movimientos y redes en la zona.

\subsubsection{Proyecto de emprendimiento con población desplazada}

El proyecto de creación de microempresas con población desplazada, fue de menor duración (un año) y presupuesto que los anteriores, y fue solicitado y dirigido, de nuevo, por COMFACAUCA, a través de una convocatoria de la OIM. La persona encargada de dirigirlo es la responsable del departamento de servicios sociales de esta institución, con más de 20 años de experiencia en la dirección de proyectos.

El trabajo de identificación y evaluación de riesgos se realizó en las instalaciones de COMFACAUCA, en Popayán, y se contó con tres participantes. Acabada la sesión, se pudo mantener también una entrevista con uno de los beneficiarios del proyecto, que actualmente se encarga de realizar labores de jardinería con el emprendimiento creado en este proyecto.

De la identificación, mostrada en la Tabla 6.25, destaca el número de riegos culturales identificados frente al resto. El total de riesgos identificados fue de 28 , siendo el proyecto para el cual menos riesgos se encontraron.

Tabla 6.25. Identificación de riesgos para el proyecto de Emprendimiento con Desplazados. Fuente: elaboración propia.

\begin{tabular}{lll}
\hline Categoría & Id. & Riesgo \\
\hline Ambiental & AMB_1 & $\begin{array}{l}\text { Imposibilidad de desarrollar actividades de formación agropecuarias en } \\
\text { parcelas demostrativas debido a inclemencias meteorológicas }\end{array}$ \\
& AMB_2 & $\begin{array}{l}\text { Dificultades en el transporte a las formaciones debido a las inclemencias } \\
\text { meteorológicas }\end{array}$ \\
\hline & CUL_1 & Miedos a enfrentarse a nuevos retos de producción \\
& CUL_2 & $\begin{array}{l}\text { Dificultades de comunicación de los beneficiarios con el equipo del } \\
\text { proyecto }\end{array}$ \\
& CUL_3 & $\begin{array}{l}\text { Realización de tareas agropecuarias en zonas diferentes a las autóctonas } \\
\text { de los desplazados }\end{array}$ \\
& CUL_4 & Falta de motivación de los emprendedores \\
& CUL_5 & No realizar preguntas en las formaciones \\
& CUL_6 & Recelos entre grupos étnicos en la selección de empresas participantes \\
\hline
\end{tabular}




\begin{tabular}{|c|c|c|}
\hline \multirow{4}{*}{$\begin{array}{l}\text { De Dirección } \\
\text { de Proyectos }\end{array}$} & DPR_1 & Falta de disponibilidad de tiempo del director del proyecto \\
\hline & DPR_2 & Inexperiencia del director del proyecto en proyectos similares \\
\hline & DPR_3 & Escasa identificación de los afectados negativamente por el proyecto \\
\hline & DPR_4 & Falta de coordinación del equipo \\
\hline \multirow{3}{*}{ Económica } & ECO_1 & Retrasos en la financiación por parte de la entidad financiadora \\
\hline & ECO_2 & $\begin{array}{l}\text { Incapacidad para hacer frente a los gastos de transporte para acudir a } \\
\text { las formaciones }\end{array}$ \\
\hline & ECO_3 & Mala gestión del dinero ganado por los emprendedores \\
\hline \multirow{6}{*}{ Organizativa } & ORG_1 & Abandono del proyecto por parte de los beneficiarios \\
\hline & ORG_2 & $\begin{array}{l}\text { Incapacidad para comprender el lenguaje técnico por parte de los } \\
\text { beneficiarios }\end{array}$ \\
\hline & ORG_3 & Dificultades con la lectura/escritura por parte de los beneficiarios \\
\hline & ORG_4 & Dependencia de las capacidades de los orientadores \\
\hline & ORG_5 & $\begin{array}{l}\text { Mala selección de las MIPYMES sin considerar las capacidades de los } \\
\text { beneficiarios }\end{array}$ \\
\hline & ORG_6 & Abandono del proyecto por parte de los orientadores \\
\hline \multirow[t]{3}{*}{ Política } & POL_1 & $\begin{array}{l}\text { Falta de interés del gobierno local para medir los impactos de las } \\
\text { empresas creadas }\end{array}$ \\
\hline & POL_2 & Falta de apoyo del gobierno local \\
\hline & POL_3 & Cambio de la legislación vigente para la constitución de empresas \\
\hline De seguridad & SEG_1 & Desplazamientos por zonas conflictivas para realizar las formaciones \\
\hline \multirow{3}{*}{ Tecnológica } & TEC_1 & $\begin{array}{l}\text { Imposibilidad de reproducir el material de apoyo electrónico por falta } \\
\text { de medios en las casas de los beneficiarios }\end{array}$ \\
\hline & TEC_2 & Difícil acceso al equipo de trabajo por alto costo \\
\hline & TEC_3 & Pérdida de la corriente eléctrica \\
\hline
\end{tabular}

En este proyecto también se da prioridad al criterio de Alcance frente a los demás, trabajando de nuevo con la Ecuación 6.2 para el cálculo de la importancia total de los riesgos.

Como se puede ver en la Tabla 6.26, el riesgo más importante, con bastante diferencia frente a los demás, es miedos a enfrentarse a nuevos retos de producción, correspondiente la categoría cultural, que obtuvo consenso además a la hora de ser puntuado. En proyectos como éste, en los que se trabaja con población muy vulnerable, que ha sufrido mucha violencia y que ha tenido que abandonar sus hogares, aunque se cuente con apoyo de psicólogos, como en este caso, hay que tener en cuenta que las inseguridades de las personas beneficiarias son muy altas.

Entre los siguientes riesgos más importanes, de nuevo tienen mucha importancia los políticos, ligados principalmente con el apoyo y el interés en el proyecto (POL_1 y POL_2). Junto a ellos los relacionados con el tiempo disponible y la experiencia de la directora del proyecto (DPR_1 y DPR_2), y, aparece también entre los primeros, el único riesgo relacionado con la Seguridad, debido a los desplazamientos por zonas de conflicto. 
De nuevo en este proyecto, los riesgos más identificados corresponden a la etapa de ejecución (3).

Tabla 6.26. Evaluación de riesgos para el proyecto de Emprendimiento con Desplazados. Fuente: elaboración propia.

\begin{tabular}{|c|c|c|c|c|c|c|c|c|c|c|c|c|c|}
\hline \multirow{2}{*}{ Id. } & \multirow{2}{*}{\multicolumn{2}{|c|}{ Etapa }} & \multirow{2}{*}{\multicolumn{2}{|c|}{ Prob. }} & \multicolumn{4}{|c|}{ Impacto } & \multirow{2}{*}{$\begin{array}{l}\text { Imp. } \\
\text { Riesgo }\end{array}$} & \multirow{2}{*}{$\begin{array}{l}\text { Imp. } \\
\text { Tiempo }\end{array}$} & \multirow{2}{*}{$\begin{array}{l}\text { Imp. } \\
\text { Coste }\end{array}$} & \multirow{2}{*}{$\begin{array}{c}\text { Imp. } \\
\text { Alcance }\end{array}$} & \multirow{2}{*}{$\begin{array}{l}\text { Imp. } \\
\text { Seg. }\end{array}$} \\
\hline & & & & & Tiempo & Coste & Alcance & Seg. & & & & & \\
\hline CUL_1 & 3 & & & 5 & 5 & 5 & 5 & 4 & 24 & 25 & 25 & 25 & 20 \\
\hline POL_1 & 2 & 3 & & 4,33 & 4,33 & 4 & 3,67 & 1,33 & 14,72 & 18,75 & 17,32 & 15,89 & 5,76 \\
\hline POL_2 & 1 & 3 & & 4 & 4 & 3,33 & 3,67 & 1,67 & 13,07 & 16 & 13,32 & 4,68 & 6,68 \\
\hline DPR_1 & 2 & 3 & & 4 & 4 & 3 & 3 & 2 & 12 & 16 & 12 & 12 & 8 \\
\hline SEG_1 & 3 & & & 4 & 3,67 & 2,67 & 3,67 & 2,67 & 12 & 14,68 & 10,68 & 14,68 & 10,68 \\
\hline DPR_2 & 2 & 3 & & 3,67 & 3,33 & 4 & 3,67 & 3 & 11,77 & 2,22 & 14,68 & 3,47 & 11,01 \\
\hline ORG_1 & 3 & & & 3,33 & 3,33 & 3,67 & 3,67 & 3 & & 1,09 &, 22 & 22 & 9,99 \\
\hline ECO_1 & 2 & & & 3,5 & 3,5 & 3,5 & 3,5 & 1,5 & 10,85 & 2,25 & 12,25 & 12,25 & 5,25 \\
\hline CUL_2 & 2 & 3 & & 3,67 & 3 & 3,67 & 4 & 2,67 & 0,4 & 1,01 & 13,47 & 4,68 & 9,8 \\
\hline CUL_3 & 3 & & & 33 & 3,33 & 3,33 & 3 & 2,33 & 9,98 & 1,09 & & ,99 & 7,76 \\
\hline CUL_4 & 3 & & & 67 & 3 & 2,67 & 4 & 2,33 & 9,6 & 01 & 9,8 & 4,68 & 8,55 \\
\hline ORG_2 & 3 & & & 4 & 3,33 & 3 & 3 & 2 &, 54 & 3,32 & 12 & 12 & 8 \\
\hline POL_3 & 2 & 3 & & 3 & 3 & & 3,67 & 2,67 & 9,41 & 9 & 01 & 1,01 & 8,01 \\
\hline DPR_3 & 3 & 4 & & 3 & 3 & 2,67 & 3,33 & 3,33 & 9,4 & 9 & 01 & 9,99 & 9,99 \\
\hline AMB_1 & 3 & & & 3 & 3,33 & 2,67 & 2,67 & 2,67 & 9,33 & 9,99 & 8,01 & 8,01 & 8,01 \\
\hline CUL_5 & 3 & & & 3,67 & 3,33 & 3 & 2,67 & 2 & 9,1 & 12,22 & 11,01 & 9,8 & 7,34 \\
\hline AMB_2 & 3 & & & 5 & 3 & 3 & 3 & 2,67 & 8,8 & 9 & 9 & 9 & 8,01 \\
\hline ORG_3 & 3 & & & ,33 & 3,33 & 3,33 & 2,33 & 1 & 8,21 & 11,09 & 11,09 & ,76 & 3,33 \\
\hline ORG_4 & 3 & & & 2,67 & 2,67 & 2,67 & 2,67 & 2,67 & 7,13 & 7,13 & 7,13 & 7,13 & 7,13 \\
\hline ORG_5 & 3 & & & 3 & 2,67 & 2,67 & 3,33 & 1,33 & 7,12 & 8,01 & 8,01 & 9,99 & 3,99 \\
\hline TEC_1 & 3 & & & 67 & 2,67 & & 3,33 & 1,33 & 7,12 & 7,13 & & 8,89 & 3,55 \\
\hline CUL_6 & 3 & & & 2,67 & 2,67 & 2,33 & 3 & 1,33 & 6,58 & 7,13 & 6,22 & 8,01 & 3,55 \\
\hline ORG_6 & 3 & & & 2,5 & 2,5 & 2,5 & 3 & 1,5 & 6,25 & 6,25 & 6,25 & 7,5 & 3,75 \\
\hline TEC_2 & 3 & & & 2 & 2,33 & 3 & 3 & 2 & 6,21 & 4,66 & 6 & 6 & 4 \\
\hline ECO_2 & 3 & 4 & & 2 & 2 & 1,67 & 2,33 & 2,67 & 4,4 & 4 & 3,34 & 4,66 & 5,34 \\
\hline DPR_4 & 2 & 3 & & 2 & 2 & 2,33 & 2,33 & 1,67 & 4,26 & 4 & 4,66 & 4,66 & 3,34 \\
\hline ECO_3 & 3 & 4 & & 2 & 2 & 2 & 2,33 & 1,67 & 4,13 & 4 & 4 & 4,66 & 3,34 \\
\hline TEC_3 & 3 & & & 1,67 & 1,67 & 1,67 & 1,67 & 1,33 & 2,68 & 2,79 & 2,79 & 2,79 & 2,22 \\
\hline
\end{tabular}

La entrevista mantenida con la directora del proyecto permite conocer que la única identificación de riesgos previa a la realización del proyecto consistió en la realizada a la hora de considerar los supuestos en el ML. A partir de ahí, los riesgos que fueron surgiendo, muchos más de los identificados inicialmente, se fueron solucionando con la intención de que causaran el menor efecto en los beneficiarios y que el aprendizaje 
sirviera para futuros proyectos. La convocatoria no permitía la inclusión de una partida de imprevistos. Entre los riesgos más importantes para ella, se encontraron, la desconfianza hacia la asociatividad, muy ligado con CUL_1; la falta de motivación y de responsabilidad hacia el cumplimiento de las obligaciones de formalización de la empresa, también en la categoría Cultural (CUL_4); y aquellos relacionados con deseo de aprender, por parte de los beneficiarios, nuevas líneas productivas en las que no tenían ninguna práctica (relacionado con CUL_3).

La entrevista mantenida con uno de los beneficiarios permitió confirmar el último punto mencionado por la directora del proyecto, ya que destacaba que su microempresa sigue adelante principalmente porque el tema de la jardinería era algo que él ya conocía, pero que otros emprendedores que decidieron empezar con otro tipo de negocios, están teniendo muchas dificultades, principalmente debidas a la competencia y al incremento de precios de los insumos. Actualmente, la microempresa de este beneficiario mantiene a cinco empleados, formados por él mismo. Preguntado por el éxito, confirma que, aunque algunas cosas se podían haber hecho de otra manera, por ejemplo, implementando algún servicio más, el proyecto le permitió aprender a trabajar en temas de reforestación, talas y podas y diseños de jardines, y a gestionar su propia empresa y a sus empleados, con lo cual está muy agradecido y lo califica con un diez.

En los talleres, el éxito solo se definió a través de criterios, dado que los participantes consideraron que ya estaban suficientemente definidos. La Tabla 6.27 recoge estos criterios, junto con los valores que obtuvieron, calificados del 1 al 10 y agrupados en Éxito en el impacto del proyecto y Éxito en la dirección del Proyecto.

Tabla 6.27. Criterios y niveles de éxito para el proyecto de Emprendimientos con Desplazados. Fuente: elaboración propia.

\begin{tabular}{lccc}
\hline \multicolumn{3}{c}{ Nivel de éxito } \\
\hline Mejora de ingresos & 7,33 & Impacto del proyecto & 7,56 \\
Adaptación social & 8,67 & & \\
\hline Formalización de actividades & 6,67 & Dirección del proyecto & 6,67 \\
\hline
\end{tabular}

Aunque la dirección del proyecto cumplió de cara a todos los informes y control establecido por OIM, que es un financiador muy exigente, se encontró con muchas dificultades debidas al cambio legislativo sobre la formación de empresas y la declaración de impuestos de éstas, que se incluyó entre las labores propias del equipo ejecutor del proyecto, y a ello se debe su puntuación media. Sin embargo, de cara a no solo utilizar las formaciones y la creación de empresas como medio de crecimiento económico, sino también de integración social, el proyecto recibe una valoración alta. 


\subsubsection{Proyecto de empoderamiento de las mujeres rurales}

El proyecto de empoderamiento de mujeres rurales es el único de los estudiados que continúa en desarrollo. Su duración es de dos años, y está financiado a través de una convocatoria europea (Europeaid). La institución que lo ejecuta es la Fundación Alpina, la obra social correspondiente a la empresa dedicada a la industria láctea más importante de Colombia, comprometida principalmente con la mejora de las condiciones de vida en zonas rurales. La persona encargada de dirigirlo contaba con nueve años de experiencia en la dirección de PCD, y previamente había estado también trabajando como técnica en ellos.

El taller se realizó en la sede de la Fundación Alpina, en Popayán, con una duración de casi cuatro horas. Fue el taller más numeroso, en el que participaron, no solo el equipo encargado de dirigirlo, sino también algunos de los técnicos participando en el proyecto en cada uno de los municipios, esto es debido, principalmente, a estar el proyecto en desarrollo. El total de participantes fue de 13 personas, y el número de riesgos identificados de 45 . Con este grupo tan masivo, tanto en la identificación, como en la categorización, se generaron debates muy interesantes, en los que, por ejemplo, se decidió colocar el riesgo temor a asumir nuevas responsabilidades en la categoría Organizativa, mientras que uno muy parecido, en el proyecto de Emprendimiento con Desplazados, fue incluido en la categoría Cultural. Pese a ello, la categoría Cultural fue la que más riesgos incorporó. Estos riesgos se pueden ver en la Tabla 6.28.

Tabla 6.28. Identificación de riesgos para el proyecto de Empoderamiento de Mujeres Rurales.

Fuente: elaboración propia.

\begin{tabular}{|c|c|c|}
\hline Categoría & Id. & Riesgos \\
\hline Ambiental & $\begin{array}{l}\text { AMB_1 } \\
\text { AMB_2 } \\
\text { AMB_3 }\end{array}$ & $\begin{array}{l}\text { Imposibilidad de trabajar las zonas por inclemencias meteorológicas } \\
\text { Escaso estudio normativo ambiental } \\
\text { Imposibilidad de acceder a la zona para ofrecer capacitaciones y } \\
\text { mantener reuniones debido a inclemencias meteorológicas }\end{array}$ \\
\hline Cultural & $\begin{array}{l}\text { CUL_1 } \\
\text { CUL_2 } \\
\text { CUL_3 } \\
\text { CUL_4 } \\
\text { CUL_5 } \\
\text { CUL_6 } \\
\text { CUL_7 } \\
\text { CUL_8 } \\
\text { CUL_9 } \\
\text { CUL_10 } \\
\text { CUL_11 }\end{array}$ & $\begin{array}{l}\text { Dificultades comunicación entre las mujeres beneficiarias } \\
\text { Resistencia al trabajo asociativo colaborativo } \\
\text { Dependencia del permiso de sus esposos o padres para participar } \\
\text { Dependencia del liderazgo de personas concretas } \\
\text { Desconfianza en los beneficios del proyecto } \\
\text { Falta de apoyo familiar en el proceso de empoderamiento } \\
\text { Escasa orientación a largo plazo } \\
\text { Rechazo social por la apropiación de roles masculinos tradicionales } \\
\text { Distinta concepción del tiempo } \\
\text { Dificultades en la comunicación de beneficiarias con equipo proyecto } \\
\text { Dificultades en el trabajo con diferentes grupos étnicos }\end{array}$ \\
\hline
\end{tabular}




\begin{tabular}{|c|c|c|}
\hline \multirow{5}{*}{$\begin{array}{l}\text { De Dirección } \\
\text { de Proyectos }\end{array}$} & DPR_1 & Falta de coordinación entre las personas participantes del proyecto \\
\hline & DPR_2 & No consideración de una partida económica para imprevistos \\
\hline & DPR_3 & Diferencia de intereses entre las diferentes instituciones participantes \\
\hline & DPR_4 & Inexperiencia del director del proyecto en proyectos similares \\
\hline & DPR_5 & Falta de seguimiento programado del proyecto \\
\hline \multirow{8}{*}{ Económica } & ECO_1 & Fluctuación del precio de venta \\
\hline & ECO_2 & No seguimiento de las recomendaciones de los técnicos \\
\hline & ECO_3 & Aumento precio de los insumos necesarios para la actividad productiva \\
\hline & ECO_4 & $\begin{array}{l}\text { Abandono de la nueva actividad productiva por menores rendimientos } \\
\text { económicos que los cultivos ilícitos }\end{array}$ \\
\hline & ECO_5 & $\begin{array}{l}\text { Imposibilidad de consolidar las actividades productivas por la situación } \\
\text { económica del país }\end{array}$ \\
\hline & ECO_6 & Problemas de inseguridad por el manejo de dinero de la act. productiva \\
\hline & ECO_7 & Retrasos en la recepción de partidas económicas \\
\hline & ECO_8 & Suspensión de la ayuda \\
\hline \multirow{8}{*}{ Organizativa } & ORG_1 & Mala selección de los participantes \\
\hline & ORG_2 & Escaso análisis previo de las zonas afectadas por el proyecto \\
\hline & ORG_3 & Temor a asumir nuevas responsabilidades \\
\hline & ORG_4 & Falta de confianza en las capacidades de las personas beneficiarias \\
\hline & ORG_5 & Falta de confianza para informar sobre viviendas y unidades productivas \\
\hline & ORG_6 & Escaso conocimiento en la admón. agropecuaria por las beneficiarias \\
\hline & ORG_7 & Falta de motivación de las personas beneficiarias del proyecto \\
\hline & ORG_8 & Deficiente identificación de los posibles perjudicados por el proyecto \\
\hline \multirow{4}{*}{ Política } & POL_1 & Existencia de intereses políticos al elegir las actividades productivas \\
\hline & POL_2 & Falta de interés por las alcaldías futuras en dar continuidad al proyecto \\
\hline & POL_3 & Falta de colaboración de las instituciones públicas \\
\hline & $\mathrm{POL} 44$ & Corrupción en entidades públicas \\
\hline \multirow{3}{*}{ Seguridad } & SEG_1 & Presencia de actores armados en la zona de influencia del proyecto \\
\hline & SEG_2 & Inseguridad para realizar el acompañamiento y formaciones \\
\hline & SEG_3 & Cierre de las vías por protestas \\
\hline \multirow{3}{*}{ Tecnológica } & TEC_1 & Falta herramientas adecuadas para construcción y mto. zonas product. \\
\hline & TEC_2 & Escasa cobertura en la zona \\
\hline & TEC_3 & Mal acceso a la electricidad para funcionamiento equipos de trabajo \\
\hline
\end{tabular}

Este proyecto de nuevo, según su directora, da prioridad al criterio de Alcance frente a los demás, por tanto, se trabaja con la Ecuación 6.2 para el cálculo de la importancia total de los riesgos. En la Tabla 6.29. se pueden ver los valores obtenidos. Destaca, con respecto a los anteriores proyectos, que en éste no aparece ningún riesgo calificado como Muy Importante y que, sin embargo, son muchos los riesgos considerados Importantes. Llama la atención también que son muy pocos los riesgos para los cuales se haya determinado una probabilidad media o baja, siendo la más común la alta probabilidad de ocurrencia.

De nuevo, entre los riesgos más destacados se encuentran los económicos, políticos y culturales, con una gran abundancia de estos últimos entre los más importantes. Hay que destacar también que entre los primeros seis riesgos apenas hay una diferencia de 
un punto para sus valores de importancia, estando, por tanto, muy igualados. Esta semejanza es compartida también entre los diversos criterios para el impacto del riesgo, y destaca frente al resto de proyectos.

El riesgo que ha obtenido la puntuación más alta en su importancia está ligado al carácter productivo de este proyecto, ligándose con la fluctuación de los precios de venta. Hay que mencionar también que quizá la alta influencia de los riesgos culturales en este proyecto sea debido al hecho de que es el único que trabaja exclusivamente con mujeres y que éstas son las más vulnerables en las culturas tradicionales. El riesgo político existencia de intereses políticos al elegir las actividades productivas (POL_1), que aparece en tercer lugar, fue muy importante en los comienzos del proyecto, descubriéndose estas influencias no solo en la elección de las tareas productivas, sino también en la selección de las mujeres beneficiarias por parte de las autoridades locales, suponiendo como consecuencia que al poco del proyecto, el 33\% de las mujeres seleccionadas inicialmente abandonaron el proyecto, teniéndose que incorporar a otras personas (ORG_1).

La desconfianza en la zona hacia el proyecto fue palpable desde el principio, las mujeres participantes no estaban acostumbradas a trabajar con la metodología de desarrollo de capacidades ligadas a la necesidad de asistir a unas formaciones, e inicialmente demandaban recibir bienes. Esto se demostró en riesgos como CUL_2, CUL_5, ECO_2 u ORG_5. Esta desconfianza inicial estaba también fundamentada en el escaso apoyo que las mujeres recibían por parte de sus familiares y de la comunidad (CUL_6 y CUL_8) para participar en el proyecto.

En cuanto a las etapas, llama la atención que en este taller casi todos los riesgos se asignaron a varias etapas, muchos de ellos, incluso fueron asignados a todas las etapas por un buen número de participantes. Aunque la etapa de ejecución (etapa 3 ) sigue siendo en la que más riesgos se identifican, destacan los que son asignados también a la etapa de diseño (etapa 2) en primer lugar. 
INDUSTRIALES

Tabla 6.29. Evaluación de riesgos para el proyecto de Empoderamiento de Mujeres Rurales.

Fuente: elaboración propia.

\begin{tabular}{|c|c|c|c|c|c|c|c|c|c|c|c|c|c|}
\hline \multirow{2}{*}{ Id } & \multirow{2}{*}{\multicolumn{3}{|c|}{ Etapa }} & \multirow{2}{*}{ Prob. } & \multicolumn{4}{|c|}{ Impacto } & \multirow{2}{*}{$\begin{array}{l}\text { Imp. } \\
\text { Riesgo }\end{array}$} & \multirow{2}{*}{\begin{tabular}{|c|} 
Imp. \\
Tiempo
\end{tabular}} & \multirow{2}{*}{$\begin{array}{l}\text { Imp. } \\
\text { Coste }\end{array}$} & \multirow{2}{*}{$\begin{array}{c}\text { Imp. } \\
\text { Alcance }\end{array}$} & \multirow{2}{*}{$\begin{array}{l}\text { Imp. } \\
\text { Seg. }\end{array}$} \\
\hline & & & & & Tiempo & Coste & Alcance & Seg. & & & & & \\
\hline ECO_1 & 3 & 4 & & 4 & 3,9 & 3,88 & 3,6 & 2 & 13,58 & 15,6 & 15,52 & 14,4 & 8 \\
\hline CUL_1 & 1 & 2 & 3 & 4 & 3,9 & 3,5 & 3,5 & 2,5 & 13,52 & 15,6 & 14 & 14 & 10 \\
\hline POL_1 & 3 & 2 & 1 & 4,15 & 3,27 & 3,15 & 3,58 & 2,62 & 13,45 & 13,57 & 13,07 & 14,86 & 10,87 \\
\hline CUL_2 & 3 & 2 & 4 & 4,23 & 3,62 & 3,08 & 3,08 & 2,31 & 12,83 & 15,31 & 13,03 & 13,03 & 9,77 \\
\hline CUL_3 & 3 & 4 & & 4,15 & 3,69 & 3 & 3,46 & 1,58 & 12,61 & 15,31 & 12,45 & 14,36 & 6,56 \\
\hline CUL_4 & 3 & 4 & & 4,08 & 3,46 & 3,23 & 3,31 & 2,08 & 12,56 & 14,12 & 13,18 & 13,5 & 8,49 \\
\hline ORG_1 & 3 & 4 & 2 & 4 & 3,64 & 3,58 & 3,08 & 1,77 & 12,12 & 14,56 & 14,32 & 12,32 & 7,08 \\
\hline CUL_5 & 3 & 4 & 2 & 4,23 & 3,38 & 2,85 & 3 & 2 & 12,04 & 14,3 & 12,06 & 12,69 & 8,46 \\
\hline POL_2 & 3 & 4 & & 3,77 & 3,85 & 3,22 & 3,17 & 2,42 & 11,94 & 14,51 & 12,14 & 11,95 & 9,12 \\
\hline ECO_2 & 3 & 2 & 1 & 3,75 & 3,58 & 3,83 & 3,25 & 2 & 11,93 & 13,43 & 14,36 & 12,19 & 7,5 \\
\hline CUL_6 & 3 & 4 & & 3,85 & 3,73 & 3,23 & 3 & 2,31 & 11,76 & 14,36 & 12,44 & 11,55 & 8,89 \\
\hline ECO_3 & 3 & 2 & 4 & 3,92 & 3,15 & 3,33 & 3,08 & 2,08 & 11,54 & 12,35 & 13,05 & 12,07 & 8,15 \\
\hline TEC_1 & 3 & 2 & 4 & 3,83 & 3,46 & 3,08 & 3,15 & 1,85 & 11,25 & 13,25 & 11,8 & 12,06 & 7,09 \\
\hline CUL_7 & 2 & 3 & 1 & 3,5 & 3,75 & 2,91 & 3,64 & 2,08 & 11,21 & 13,13 & 10,19 & 12,74 & 7,28 \\
\hline DPR_1 & 2 & 3 & 1 & 3,62 & 3,42 & 3,69 & 3,23 & 1,92 & 11,21 & 12,38 & 13,36 & 11,69 & 6,95 \\
\hline SEG_1 & 4 & 3 & 1 & 3,69 & 3 & 3,33 & 3,5 & 1,83 & 11,19 & 11,07 & 12,29 & 12,92 & 6,75 \\
\hline AMB_1 & 1 & 3 & 4 & 3,77 & 3,31 & 3 & 3,08 & 2,23 & 11,08 & 12,48 & 11,31 & 11,61 & 8,41 \\
\hline ORG_2 & 3 & 1 & 4 & 3,83 & 3,42 & 3,17 & 3,08 & 1,67 & 11,05 & 13,1 & 12,14 & 11,8 & 6,4 \\
\hline POL_3 & 3 & 4 & 2 & 3,46 & 3,5 & 3,38 & 3,23 & 2,31 & 10,83 & 12,11 & 11,69 & 11,18 & 7,99 \\
\hline TEC_2 & 3 & 2 & 4 & 3,73 & 3,27 & 3 & 3,18 & 1,55 & 10,58 & 12,2 & 11,19 & 11,86 & 5,78 \\
\hline ORG_3 & 3 & 4 & & 3,54 & 3,09 & 3,54 & 3,08 & 2,08 & 10,53 & 10,94 & 12,53 & 10,9 & 7,36 \\
\hline AMB_2 & 3 & 2 & 4 & 3,7 & 3,1 & 2,7 & 3 & 2,4 & 10,51 & 11,47 & 9,99 & 11,1 & 8,88 \\
\hline ECO_4 & 3 & 2 & 4 & 3,62 & 3,08 & 3,46 & 2,92 & 1,83 & 10,29 & 11,15 & 12,53 & 10,57 & 6,62 \\
\hline ORG_4 & 3 & 1 & 4 & 3,58 & 3,18 & 3,08 & 3,08 & 1,5 & 9,97 & 11,38 & 11,03 & 11,03 & 5,37 \\
\hline ORG_5 & 3 & & & 3,38 & 3,08 & 3,5 & 3,08 & 1,92 & 9,91 & 10,41 & 11,83 & 10,41 & 6,49 \\
\hline ORG_6 & 3 & 4 & & 3,42 & 3,08 & 2,91 & 3,08 & 2 & 9,68 & 10,53 & 9,95 & 10,53 & 6,84 \\
\hline DPR_2 & 2 & 1 & 3 & 3,15 & 3,15 & 3,69 & 3,17 & 2,08 & 9,61 & 9,92 & 11,62 & 9,99 & 6,55 \\
\hline CUL_8 & 2 & 1 & & 3,5 & 3,08 & 2,67 & 2,91 & 2,08 & 9,56 & 10,78 & 9,35 & 10,19 & 7,28 \\
\hline ORG_7 & 3 & 2 & & 3,64 & 2,82 & 2,7 & 2,82 & 1,91 & 9,51 & 10,26 & 9,83 & 10,26 & 6,95 \\
\hline SEG_2 & 3 & 4 & 2 & 3,33 & 3,09 & 3 & 3,17 & 1,77 & 9,46 & 10,29 & 9,99 & 10,56 & 5,89 \\
\hline ECO_5 & 3 & 4 & 2 & 3,31 & 3 & 3,5 & 2,83 & 2 & 9,37 & 9,93 & 11,59 & 9,37 & 6,62 \\
\hline ECO_6 & 3 & 4 & 2 & 3,25 & 2,64 & 3,5 & 2,83 & 2,42 & 9,24 & 8,58 & 11,38 & 9,2 & 7,87 \\
\hline ORG_8 & 3 & 2 & 4 & 3,38 & 3,17 & 2,92 & 2,83 & 1,92 & 9,24 & 10,71 & 9,87 & 9,57 & 6,49 \\
\hline ECO_7 & 3 & 2 & 4 & 3,08 & 2,67 & 3,3 & 3,31 & 2,15 & 9,08 & 8,22 & 10,16 & 10,19 & 6,62 \\
\hline CUL_9 & 1 & 2 & 3 & 3,08 & 3,25 & 2,67 & 3,42 & 1,75 & 8,94 & 10,01 & 8,22 & 10,53 & 5,39 \\
\hline POL_4 & 2 & 1 & 3 & 3,42 & 2,9 & 2,8 & 2,36 & 2 & 8,5 & 9,92 & 9,58 & 8,07 & 6,84 \\
\hline DPR_3 & 2 & 1 & 3 & 3,08 & 3 & 3,42 & 2,75 & 1,85 & 8,48 & 9,24 & 10,53 & 8,47 & 5,7 \\
\hline CUL_10 & 3 & 4 & 2 & 2,92 & 3,54 & 2,77 & 3,15 & 1,85 & 8,44 & 10,34 & 8,09 & 9,2 & 5,4 \\
\hline AMB_3 & 3 & 4 & 1 & 3,15 & 2,92 & 2,82 & 2,69 & 2,08 & 8,32 & 9,2 & 8,88 & 8,47 & 6,55 \\
\hline CUL_11 & 3 & 2 & 4 & 3,15 & 2,85 & 2,62 & 3 & 1,62 & 8,25 & 8,98 & 8,25 & 9,45 & 5,1 \\
\hline ECO_8 & 3 & 1 & 4 & 2,92 & 2,45 & 3,5 & 3 & 2,08 & 8,19 & 7,15 & 10,22 & 8,76 & 6,07 \\
\hline SEG_3 & 3 & 2 & 4 & 2,83 & 3 & 2,92 & 2,83 & 1,75 & 7,54 & 8,49 & 8,26 & 8,01 & 4,95 \\
\hline TEC_3 & 3 & 2 & 1 & 2,85 & 2,38 & 2,69 & 2,92 & 1,69 & 7,18 & 6,78 & 7,67 & 8,32 & 4,82 \\
\hline DPR_4 & 3 & 2 & 4 & 2,54 & 3,09 & 3,25 & 2,67 & 1,5 & 6,7 & 7,85 & 8,26 & 6,78 & 3,81 \\
\hline DPR_5 & 3 & 4 & 2 & 2,62 & 2,5 & 3 & 2,67 & 1,38 & 6,4 & 6,55 & 7,86 & 7 & 3,62 \\
\hline
\end{tabular}


Para la directora de este proyecto, el principal riesgo fue la mala selección inicial de las mujeres beneficiarias (ORG_1, aparece en 70 lugar en la evaluación), que ocasionó incluso abandonos y la consecuente necesidad de incorporar a más mujeres con el proceso iniciado, dado que el compromiso era trabajar con 400 mujeres rurales. Los siguientes riesgos más importantes para ella estaban relacionados con la falta de organización de las mujeres y su rechazo a trabajar colaborativamente (CUL_2), dado que nunca lo habían hecho así antes; y con las diferencias culturales y la inseguridad propia de los territorios elegidos, tradicionalmente dedicados a cultivos ilícitos. La directora resaltaba lo normalizada que está esa labor, así como la violencia, en unos territorios además muy pequeños donde todo el mundo se conoce, lo que limita mucho a la hora de denunciar. Estos hechos no se habían contemplado inicialmente.

En relación con la gestión de riesgos, en la formulación del proyecto se habían identificado factores de riesgo, pero no había definido ningún procedimiento para tratarlos, ni tampoco se contaba con una partida de imprevistos, dado que la convocatoria no lo permitía.

Sobre el éxito, con el proyecto a mitad de camino, su directora lo considera un éxito en el empoderamiento de las mujeres, que han pasado de ser temerosas, oprimidas y violentas, a valorarse y ser capaces de expresarse. En cambio, de cara al fortalecimiento organizativo, plantea ciertas dudas hasta el momento, por su rechazo a asociarse.

Los criterios de éxito definidos en el taller (Tabla 6.30.) siguen estas líneas de empoderamiento y mejora de la calidad de vida, relacionados con el Impacto, así como el cumplimiento de objetivos, relacionado con la propia DP.

Tabla 6.30. Criterios de éxito para el proyecto de Empoderamiento de las Mujeres Rurales. Fuente: elaboración propia.

\begin{tabular}{ll}
\hline \multicolumn{1}{c}{ Criterio } & \multicolumn{1}{c}{ Subcriterio } \\
\hline Empoderamiento & $\begin{array}{l}\text { Mujeres empoderadas con capacidad de decisión } \\
\text { Mujeres empoderadas social y económicamente }\end{array}$ \\
\hline & $\begin{array}{l}\text { Mujeres fortalecidas y asociadas } \\
\text { Mujeres con microempresas sostenibles }\end{array}$ \\
$\begin{array}{l}\text { Mejora de la calidad } \\
\text { de vida }\end{array}$ & $\begin{array}{l}\text { Mejora de la calidad de vida de las mujeres beneficiarias } \\
\text { Aprendizaje continuo de las participantes } \\
\text { Independencia económica y social de las mujeres del sur del Cauca }\end{array}$ \\
\hline $\begin{array}{l}\text { Cumplimiento de } \\
\text { objetivos } \\
\text { productivos }\end{array}$ & $\begin{array}{l}\text { Alcanzar los objetivos de producción fijados, así como los } \\
\text { resultados económicos }\end{array}$ \\
\hline
\end{tabular}


Los resultados para estos criterios se muestran en la Tabla 6.31., donde puede verse que, a criterio de las personas que están actualmente trabajando en él, los niveles de éxito están siendo medios. Esto puede deberse a que el proyecto aún no había terminado en el momento que se realizó el taller y existe aún capacidad de mejora, como se ha apreciado en otros aspectos, como la apertura de las mujeres a ser más participativas. Sería muy interesante volver a realizar esta pregunta a las mismas personas pasado un año de que el proyecto acabara.

Tabla 6.31. Éxito obtenido para el proyecto de Empoderamiento de Mujeres Rurales. Fuente: elaboración propia.

\begin{tabular}{lclc}
\hline \multicolumn{4}{c}{ Nivel de éxito } \\
\hline Empoderamiento & 6,42 & Impacto del proyecto & 6,3 \\
Mejora de la calidad de vida & 6,17 & & \\
\hline Cumplimiento de objetivos & 6,58 & Dirección del proyecto & 6,58 \\
\hline
\end{tabular}

Pese a los valores medios, destacan los logros alcanzados en unos territorios que son los más empobrecidos del Departamento del Cauca, en los que, en los primeros trabajos en terreno, la palabra más pronunciada por las mujeres fue miedo, mientras que ahora es felicidad, en palabras de la directora del proyecto.

\subsubsection{Proyectos en Espacios Territoriales de Capacitación y Reinserción (ETCR)}

En este apartado se van a tratar los cuatro proyectos llevados a cabos en los ETCRs, dado que, sus principales diferencias han sido comentadas en el Apartado 5.4.5 de este documento, y los cuatro proyectos fueron dirigidos y realizados por el mismo equipo. La principal particularidad de los cuatro, con respecto al resto de proyectos estudiados, es que su tiempo de desarrollo era muy breve, apenas nueve meses, de hecho, fueron denominados por el PNUD, como entidad ejecutante, como de proyectos de implementación rápida. Además, contaban con un presupuesto muy reducido (12.000€ para los cuatro). Al contrario que el resto de los proyectos analizados, éstos no estuvieron sujetos a ninguna convocatoria, sino que fue deseo expreso del gobierno de Suecia dedicar esa partida económica al desarrollo productivo de estos cuatro ETCR. Estas particularidades, además del hecho de trabajar con excombatientes en un momento delicado para la Paz en Colombia, hacían de estos proyectos una posible fuente de riesgos.

En el taller, realizado en las oficinas de la ONU en Popayán, participaron cuatro de las cinco personas que se encargaron de los cuatro proyectos. Tras una primera fase en la que se identificaron y categorizaron los riesgos comunes a los cuatro ETCR, después, cada uno de ellos, se enfocó en uno de los ETCR, para aportar algún riesgo destacado 
que quizá solo se hubiera dado en alguno de los espacios. El taller tuvo una duración aproximada de tres horas y fue muy dinámico.

La Tabla 6.32 muestra los resultados de la identificación. En ella, los riesgos que solo sucedían en alguno de los espacios están marcados expresamente con el código $\mathrm{E}$ seguido del número asignado (del 1 al 4) en el Identificador (ID). Destacan los riesgos que se encontraron especialmente en el ETCR 4, dado que en este espacio hubo mucha itinerancia y no contaba ni con agua, ni con luz. El total de riesgos encontrados fue de 47 , siendo 39 de ellos comunes a los cuatro espacios.

En esta ocasión, y de acuerdo a la directora de los proyectos, dado que lo más prioritario era cumplir con el tiempo de ejecución, y además el presupuesto era muy reducido, el reparto de pesos entre los criterios de impacto fue distinto al resto de proyectos, como puede verse en la Ecuación 6.3.

$$
\mathrm{I}=\mathrm{P} *\left(0,4 * \text { Impacto }_{\text {tiempo }}+0,3 * \text { Impacto }_{\text {coste }}+0,2 * \text { Impacto }_{\text {alcance }}+0,1 * \text { Impacto }_{\text {seguridad }}\right)
$$

[Ecuación 6.3. Importancia del riesgo con prioridad impacto en el tiempo]

Siendo / la importancia total del riesgo, y $P$ la probabilidad de ocurrencia.

Tabla 6.32. Identificación de riesgos para los proyectos productivos en los ETCR.

Fuente: elaboración propia.

\begin{tabular}{|c|c|c|}
\hline Categoría & ID & Riesgos \\
\hline \multirow[b]{2}{*}{ Ambiental } & AMB_1 & Imposibilidad de acceso por inclemencias meteorológicas. \\
\hline & AMB_2 & Imposibilidad de trabajo por inclemencias meteorológicas. \\
\hline \multirow{6}{*}{ Cultural } & CUL_1 & $\begin{array}{l}\text { Dificultades en la comunicación de los beneficiarios con el equipo } \\
\text { del proyecto }\end{array}$ \\
\hline & CUL_2 & Falta de participación sin orden de superiores \\
\hline & CUL_3 & Dependencia del liderazgo de personas concretas \\
\hline & CUL_4 & Dificultades en el trabajo con diferentes grupos étnicos \\
\hline & CUL_5 & Distinta concepción del tiempo \\
\hline & CUL_6 & Escasa orientación a largo plazo \\
\hline \multirow{7}{*}{$\begin{array}{l}\text { De Dirección } \\
\text { de Proyectos }\end{array}$} & DPR_1 & Falta de comunicación entre PNUD Bogotá y equipo en terreno \\
\hline & DPR_2 & Diferencia de intereses entre las diferentes instituciones \\
\hline & DPR_3 & Falta de seguimiento programado del proyecto \\
\hline & DPR_4 & Falta de coordinación entre participantes del proyecto \\
\hline & DPR_5 & No consideración de una partida económica para imprevistos \\
\hline & DPR_6 & Inexperiencia del director del proyecto en proyectos similares \\
\hline & DPR_E4 & $\begin{array}{l}\text { Descoordinación con los tiempos planificados (no hay agua/luz } \\
\text { para recibir los pollos) }\end{array}$ \\
\hline
\end{tabular}




\begin{tabular}{|c|c|c|}
\hline \multirow{6}{*}{ Económica } & ECO_1 & Dificultades en la gestión administrativa de compras \\
\hline & ECO_2 & Retrasos en la recepción de partidas económicas \\
\hline & ECO_3 & Escaso conocimiento de administración económica \\
\hline & ECO_4 & Suspensión de la ayuda \\
\hline & ECO_5 & Problemas de inseguridad por manejo de dinero en el ETCR \\
\hline & ECO_6 & Aumento precio de los animales o en el coste de su transporte \\
\hline \multirow{14}{*}{ Organizativa } & ORG_1 & Escaso análisis previo del espacio \\
\hline & ORG_2 & Falta de confianza en capacidades de personas beneficiarias \\
\hline & ORG_3 & Desconocimiento de los trámites administrativos \\
\hline & ORG_4 & Mala identificación de perjudicados por el proyecto \\
\hline & ORG_5 & No consideración de la falta de humanidad en el ETCR \\
\hline & ORG_6 & Mala selección de los participantes \\
\hline & ORG_7 & Falta de motivación de los beneficiarios del proyecto \\
\hline & ORG_8 & $\begin{array}{l}\text { Escaso conocimiento en la administración agropecuaria por los } \\
\text { beneficiarios }\end{array}$ \\
\hline & ORG_E1 & Dificultades para conseguir registro ICA para tener cerdos \\
\hline & ORG_E1_E3 & Falta de asistencia a las formaciones del SENA \\
\hline & ORG_E2 & Dificultades para trabajar en el espacio por ser arrendado \\
\hline & ORG_E4_1 & Distintas prioridades de los beneficiarios \\
\hline & ORG_E4_2 & Falta de $n$ o de asistentes para capacitación del SENA (mín. 25) \\
\hline & ORG_E4_3 & Malas condiciones de habitabilidad en el espacio \\
\hline \multirow{5}{*}{ Política } & POL_1 & Falta de colaboración de las instituciones públicas \\
\hline & POL_2 & Alta itinerancia de los excombatientes \\
\hline & POL_3 & Intereses políticos por la rápida ejecución del proyecto \\
\hline & POL_4 & $\begin{array}{l}\text { Inadecuada identificación de las personas para la entrega de } \\
\text { subsidios por parte del gobierno }\end{array}$ \\
\hline & POL_5 & Corrupción \\
\hline \multirow{3}{*}{ Seguridad } & SEG_1 & Cierre de las vías por protestas \\
\hline & SEG_2 & Inseguridad para realizar el acompañamiento \\
\hline & SEG_3 & $\begin{array}{l}\text { Escasa documentación y evaluación del proyecto por miedo a } \\
\text { posibles consecuencias }\end{array}$ \\
\hline \multirow{4}{*}{ Tecnológica } & TEC_1 & Escasa cobertura en la zona \\
\hline & TEC_2 & $\begin{array}{l}\text { Falta de herramientas adecuadas para la construcción y } \\
\text { mantenimiento del galpón }\end{array}$ \\
\hline & TEC_3 & Pérdida de la corriente eléctrica \\
\hline & TEC_E & Falta de suministro de agua en el espacio \\
\hline
\end{tabular}

La Tabla 6.33 muestra la evaluación de los riesgos. En ella se puede apreciar, en primer lugar, los altos valores de los riesgos en el ETCR 4, relacionados principalmente con la categoría Organizativa, y debido a los problemas comentados anteriormente en el espacio, en el cual la mayoría de los excombatientes no contaban todavía con una vivienda en la que instalarse. Entre los riesgos generales a todos los ETCR, los más importantes son los relacionados con las categorías organizativa, económica y cultural, siendo el primero, el escaso análisis previo de los campos, debido al carácter de 
implementación rápida del proyecto. Debido también a este reducido tiempo de maniobra, los riesgos asociados a las dificultades administrativas para la compra de insumos (ECO_1), así como los retrasos en la recepción de partidas económicas (ECO_2), fueron muy destacados. Entre los riesgos culturales, destacan las dificultades en la comunicación y en la participación (CUL_1 y CUL_2), que tuvieron mucha importancia, en primer lugar por lo característico de estos beneficiarios, muy militarizados y desconfiados, y, en segundo lugar, por la urgencia de la implementación, en la que no se dedicaba tiempo suficiente a la realización de trabajo psicosocial, muy necesario en los espacios.

Sobre las etapas en las que se pueden incluir los riesgos, destaca la cantidad de riesgos que se asocian a la etapa de identificación, que se puede explicar por la rapidez con la que tuvo que realizarse. Pese a ello, de nuevo, la etapa en la que más riesgos aparecen, de acuerdo a los participantes, es la de ejecución.

Al contrastar estos resultados con la directora del proyecto, con más de diez años de experiencia en la dirección de PCD y casi veinte trabajando en este tipo de proyectos, comenta que trabajar con tiempos tan cortos es problemático sobre todo porque los procesos administrativos son lentos y esto es poco compatible con implementaciones rápidas y con proyectos productivos, en los que se trabaja con especies vivas (plantas o animales) que requieren en la mayoría de las ocasiones, mecanismos más ágiles.

De cara a la gestión previa de riesgos, se centró en identificar los riesgos de seguridad para el personal técnico en terreno. Viendo los resultados, le ha sorprendido los valores medios precisamente de los riesgos de seguridad, que puede deberse, según ella, a que en el día a día no se perciben como tal. En su opinión, el riesgo más importante era el de inseguridad del personal desplazado allí para hacer los acompañamientos (SEG_2), seguido de las dificultades derivadas de los tiempos administrativos (DPR_PAT) y de las dificultades en la comunicación (CUL_1), dado que, ante la situación de desconfianza inicial, cualquier mensaje errado podía poner en peligro el desarrollo del proyecto. 
Tabla 6.33. Evaluación de riesgos para los proyectos productivos en los ETCR.

Fuente: elaboración propia.

\begin{tabular}{|c|c|c|c|c|c|c|c|c|c|c|c|c|c|}
\hline \multirow{2}{*}{ ID } & \multirow{2}{*}{\multicolumn{3}{|c|}{ Etapa }} & \multirow{2}{*}{ Prob. } & \multicolumn{4}{|c|}{ Impacto } & \multirow{2}{*}{$\begin{array}{l}\text { Imp. } \\
\text { Riesgo }\end{array}$} & \multirow{2}{*}{$\begin{array}{c}\text { Imp. } \\
\text { Tiempo }\end{array}$} & \multirow{2}{*}{$\begin{array}{l}\text { Imp. } \\
\text { Coste }\end{array}$} & \multirow{2}{*}{$\begin{array}{l}\text { Imp. } \\
\text { Alcance }\end{array}$} & \multirow{2}{*}{$\begin{array}{l}\text { Imp. } \\
\text { Seg. }\end{array}$} \\
\hline & & & & & Tiempo & Coste & Alcance & Seg. & & & & & \\
\hline ORG_E1_1 & 1 & 2 & 3 & 5 & 5 & 1 & 5 & 4 & 22 & 25 & 5 & 25 & 20 \\
\hline DPR_E1 & 1 & 2 & 3 & 5 & 5 & 5 & 5 & 1 & 21 & 25 & 25 & 25 & 5 \\
\hline TEC_E1 & 1 & 2 & 3 & 5 & 5 & 5 & 5 & 1 & 21 & 25 & 25 & 25 & 5 \\
\hline ORG_E1_2 & 3 & 2 & & 5 & 5 & 1 & 5 & 1 & 19 & 25 & 5 & 25 & 5 \\
\hline ORG_E1_4 & 1 & 2 & 3 & 5 & 5 & 1 & 5 & 1 & 19 & 25 & 5 & 25 & 5 \\
\hline ORG_1 & 1 & 2 & 3 & 3,75 & 4,5 & 2,25 & 4,25 & 3,5 & 15 & 16,88 & 8,44 & 15,94 & 13,13 \\
\hline ECO_1 & 3 & 1 & 2 & 4,33 & 4,33 & 3 & 3 & 2 & 14,43 & 18,75 & 12,99 & 12,99 & 8,66 \\
\hline CUL_1 & 3 & 1 & 2 & 4,25 & 5 & 1,75 & 1,75 & 3,25 & 14,24 & 21,25 & 7,44 & 7,44 & 13,81 \\
\hline CUL_2 & 2 & 1 & 3 & 4,5 & 3,75 & 1,25 & 3 & 3 & 14,06 & 16,88 & 5,63 & 13,5 & 13,5 \\
\hline ECO_2 & 1 & 2 & 3 & 4,25 & 3,75 & 2,25 & 3,75 & 1,75 & 13,6 & 15,94 & 9,56 & 15,94 & 7,44 \\
\hline CUL_3 & 1 & 2 & 3 & 4 & 4 & 1,25 & 3,5 & 3 & 13,5 & 16 & 5 & 14 & 12 \\
\hline POL_1 & 1 & 2 & 3 & 3,75 & 4,25 & 2,5 & 4,5 & 1,25 & 13,31 & 15,94 & 9,38 & 16,88 & 4,69 \\
\hline ORG_2 & 3 & 1 & 2 & 3,5 & 4,25 & 2,25 & 4 & 3,25 & 13,21 & 14,88 & 7,88 & 14 & 11,38 \\
\hline ORG_3 & 3 & 2 & 1 & 4,5 & 4,25 & 2,75 & 2 & 1,5 & 12,94 & 19,13 & 12,38 & 9 & 6,75 \\
\hline ORG_8 & 3 & & & 4,25 & 4 & 1,75 & 3,5 & 1 & 12,86 & 17 & 7,44 & 14,88 & 4,25 \\
\hline TEC_1 & 3 & & & 3,5 & 3,75 & 2,25 & 4 & 2,5 & 11,99 & 13,13 & 7,88 & 14 & 8,75 \\
\hline DPR_1 & 3 & & & 3,5 & 3,5 & 3,75 & 3,5 & 2,5 & 11,64 & 12,25 & 13,13 & 12,25 & 8,75 \\
\hline SEG_1 & 3 & & & 4 & 2,5 & 1,25 & 3,25 & 3,5 & 11,2 & 10 & 5 & 13 & 14 \\
\hline SEG_2 & 3 & & & 3,75 & 2,5 & 1,5 & 3,5 & 3,5 & 10,88 & 9,38 & 5,63 & 13,13 & 13,13 \\
\hline CUL_4 & 1 & 2 & 3 & 3,75 & 3,75 & 1,5 & 1,75 & 2,75 & 10,22 & 14,06 & 5,63 & 6,56 & 10,31 \\
\hline CUL_5 & 2 & 3 & & 3,75 & 3,5 & 1,5 & 3 & 1 & 9,94 & 13,13 & 5,63 & 11,25 & 3,75 \\
\hline CUL_6 & 2 & 3 & 1 & 4 & 3,5 & 1,25 & 2,25 & 1,25 & 9,8 & 14 & 5 & 9 & 5 \\
\hline ECO_3 & 2 & 3 & 1 & 3,33 & 4,33 & 2 & 2,67 & 1 & 9,77 & 14,42 & 6,66 & 8,89 & 3,33 \\
\hline ECO_4 & 3 & 1 & 2 & 4 & 2,5 & 2,5 & 2,5 & 1,75 & 9,4 & 10 & 10 & 10 & 7 \\
\hline TEC_2 & 3 & & & 3,5 & 2,5 & 2,25 & 3,75 & 1,25 & 9,1 & 8,75 & 7,88 & 13,13 & 4,38 \\
\hline ORG_4 & 3 & & & 3,5 & 1,75 & 2 & 3,75 & 2,5 & 8,84 & 6,13 & 7 & 13,13 & 8,75 \\
\hline DPR_2 & 3 & & & 3,75 & 1,75 & 1,5 & 2,5 & 2,5 & 7,88 & 6,56 & 5,63 & 9,38 & 9,38 \\
\hline ORG_E1 & 3 & 2 & 1 & 3 & 3 & 3 & 3 & 1 & 7,8 & 9 & 9 & 9 & 3 \\
\hline SEG_3 & 3 & 2 & 1 & 3,25 & 2 & 1,5 & 3,5 & 1,5 & 7,48 & 6,5 & 4,88 & 11,38 & 4,88 \\
\hline ORG_5 & 3 & & & 3,25 & 1,5 & 1,25 & 3 & 3 & 7,23 & 4,88 & 4,06 & 9,75 & 9,75 \\
\hline TEC_3 & 3 & 2 & 1 & 3 & 2,5 & 2,5 & 2 & 1,25 & 6,3 & 7,5 & 7,5 & 6 & 3,75 \\
\hline ECO_5 & 3 & 2 & 1 & 2,25 & 1,25 & 1,75 & 2,75 & 2,75 & 4,61 & 2,81 & 3,94 & 6,19 & 6,19 \\
\hline ORG_E1_E2 & 3 & 2 & 1 & 2 & 2 & 2,5 & 3,5 & 1 & 4,6 & 4 & 5 & 7 & 2 \\
\hline POL_2 & 2 & 3 & 1 & 2,25 & 2 & 1,75 & 2 & 1,25 & 4,11 & 4,5 & 3,94 & 4,5 & 2,81 \\
\hline ORG_E3 & 2 & 3 & 1 & 2 & 2 & 2 & 2 & 2 & 4 & 4 & 4 & 4 & 4 \\
\hline DPR_3 & 3 & 1 & 2 & 2 & 2 & 1,75 & 1,75 & 2 & 3,8 & 4 & 3,5 & 3,5 & 4 \\
\hline ORG_6 & 2 & 3 & & 1,75 & 2,5 & 1,75 & 2 & 1,5 & 3,63 & 4,38 & 3,06 & 3,5 & 2,63 \\
\hline POL_3 & 3 & & & 2 & 1,75 & 2 & 2 & 1,5 & 3,6 & 3,5 & 4 & 4 & 3 \\
\hline ORG_7 & 3 & & & 1,75 & 2,5 & 2 & 2 & 1,25 & 3,59 & 4,38 & 3,5 & 3,5 & 2,19 \\
\hline ECO_6 & 3 & & & 2,25 & 1,25 & 1,75 & 1,75 & 1,25 & 3,26 & 2,81 & 3,94 & 3,94 & 2,81 \\
\hline AMB_1 & 3 & & & 2 & 1,5 & 1,5 & 2 & 1,25 & 3,2 & 3 & 3 & 4 & 2,5 \\
\hline AMB_2 & 3 & & & 2 & 1,5 & 1,5 & 1,5 & 1,25 & 2,9 & 3 & 3 & 3 & 2,5 \\
\hline POL_4 & 3 & & & 2 & 1,25 & 1,5 & 1,5 & 1,75 & 2,9 & 2,5 & 3 & 3 & 3,5 \\
\hline POL_5 & 3 & & & 2 & 1 & 1,5 & 1,5 & 2 & 2,8 & 2 & 3 & 3 & 4 \\
\hline DPR_4 & 3 & 4 & 2 & 1,25 & 1,5 & 1,75 & 1,5 & 1 & 1,78 & 1,88 & 2,19 & 1,88 & 1,25 \\
\hline DPR_5 & 3 & 4 & & 1 & 1,5 & 1,75 & 1,5 & 1,5 & 1,53 & 1,5 & 1,75 & 1,5 & 1,5 \\
\hline DPR_6 & $3 \mid$ & & & 1 & 1,25 & 2 & 1,75 & 1,5 & 1,53 & 1,25 & 2 & 1,75 & 1,5 \\
\hline
\end{tabular}


En relación con el éxito, los criterios y subcriterios pueden verse en la Tabla 6.34.

Tabla 6.34. Criterios de éxito para los proyectos productivos en los ETCR.

Fuente: elaboración propia.

\begin{tabular}{|c|c|}
\hline Criterio & Subcriterio \\
\hline \multirow{5}{*}{$\begin{array}{l}\text { Compromiso y } \\
\text { apertura al cambio }\end{array}$} & Reevaluación de las estructuras militares \\
\hline & Actividades económicas definidas y que aportan valor económico \\
\hline & Motivación por la capacitación y formación \\
\hline & $\begin{array}{l}\text { Compromiso con la reincorporación y con sacar sus iniciativas } \\
\text { adelante }\end{array}$ \\
\hline & Apertura hacia un cambio positivo de vida \\
\hline $\begin{array}{l}\text { Integración con la } \\
\text { comunidad civil }\end{array}$ & Vinculación con la comunidad vecina \\
\hline \multirow{2}{*}{$\begin{array}{l}\text { Generación de } \\
\text { confianza }\end{array}$} & Generación de confianza en la cooperación internacional \\
\hline & Acompañamiento permanente \\
\hline
\end{tabular}

La Tabla 6.35 muestra los resultados obtenidos para estos criterios. En ella, la generación de confianza se ha alineado con el éxito en la DP, dado que, según los participantes, se debía al buen trabajo y a la transparencia en la gestión del proyecto.

Tabla 6.35. Éxito obtenido para para los proyectos productivos en los ETCR. Fuente: elaboración propia.

\begin{tabular}{lclc}
\hline \multicolumn{4}{c}{ Nivel de éxito } \\
\hline Compromiso y apertura al cambio & 7,25 & Impacto del proyecto & 7,25 \\
Integración con la comunidad civil & 7,25 & & \\
\hline Generación de confianza & 8 & Dirección del proyecto & 8 \\
\hline
\end{tabular}

La valoración general del proyecto es que ha sido un éxito como piloto, y que se sigue necesitando mucho trabajo para que estas personas canalicen su potencial y disciplina hacia otras tareas y no vuelvan a las armas. En la implementación de estos proyectos se ha descubierto la buena organización y la disciplina de este colectivo, que lo sitúa en muy acto para este tipo de proyectos productivos.

\subsubsection{Reflexiones conjuntas}

Se presentan a continuación en la Tabla 6.36 los datos más relevantes de los talleres sobre los ocho ${ }^{27}$ proyectos. En ella se puede observar que el número de riesgos identificados oscila entre 30 y 40 mayoritariamente. Se comprueba con este estudio que

\footnotetext{
${ }^{27}$ Ya se ha visto que aunque eran ocho proyectos, los cuatro realizados en los ETCR se presentan en este estudio como uno.
} 
contar con más personas para la identificación de riesgos no siempre es la mejor manera de identificar más, sino que lo importante es que esas personas tengan conocimiento del proyecto así como de las técnicas de identificación y se sientan en confianza en el equipo para hablar libremente. Se descubre que, en aquellos talleres donde los equipos tenían más experiencia en este tipo de dinámicas participativas, la identificación de riesgos y los debates generados fueron más enriquecedores. Igualmente, cuanto más cercano está el proyecto en el tiempo, más fácil resulta identificar los riesgos.

Tabla 6.36. Comparativa resultados talleres PCD Cauca.

Fuente: elaboración propia.

\begin{tabular}{|c|c|c|c|c|}
\hline \multicolumn{5}{|c|}{ Proyecto } \\
\hline $\begin{array}{l}\text { Educación } \\
\text { superior (P1) }\end{array}$ & $\begin{array}{l}\text { Industrias } \\
\text { culturales (P2) }\end{array}$ & $\begin{array}{l}\text { Emprendimiento } \\
\text { desplazados (P3) }\end{array}$ & $\begin{array}{l}\text { Empoderamiento } \\
\text { mujer rural (P4) }\end{array}$ & $\mathrm{ETCR}^{* *}(\mathrm{P} 5)$ \\
\hline \multicolumn{5}{|c|}{ Duración proyecto } \\
\hline 3 años & 3 años & 1 año & 2 años* & 9 meses \\
\hline \multicolumn{5}{|c|}{ Participantes en el taller } \\
\hline 7 participantes & 4 participantes & 3 participantes & 13 participantes & 4 participantes \\
\hline \multicolumn{5}{|c|}{ N.o de riesgos encontrados, identificación e importancia de los cinco primeros } \\
\hline 33 riesgos $* * *$ & 35 riesgos & 28 riesgos & 45 riesgos & 51 riesgos \\
\hline P1_ECO_1 18,18 & P2_ECO_2 16,65 & P3_CUL_1 24 & P4_ECO_1 13,58 & P5_ORG_1 15 \\
\hline P1_POL_1 15,78 & P2_ECO_6 14,94 & P3_POL_1 14,72 & P4_CUL_1 13,52 & P5_ECO_1 14,43 \\
\hline P1_ECO_2 15,77 & P2_POL_5 13,46 & P3_POL_2 13,07 & P4_POL_1 13,45 & P5_CUL_1 14,24 \\
\hline P1_CUL_1 15,57 & P2_POL_2 13,06 & P3_DPR_1 12 & P4_CUL_2 12,83 & P5_CUL_2 14,06 \\
\hline P1_CUL_2 14,81 & P2_CUL_4 12,81 & P3_SEG_1 12 & P4_CUL_3 12,61 & P5_ECO_2 13,6 \\
\hline \multicolumn{5}{|c|}{ Prioridad en sus objetivos y nivel de éxito del proyecto en impacto y DP } \\
\hline Alcance & Alcance & Alcance & Alcance & Tiempo \\
\hline Impacto DP & Impacto DP & Impacto DP & Impacto DP & Impacto DP \\
\hline 9,14 & 6,88 & 7,56 & 6,58 & 7,25 \\
\hline
\end{tabular}

*Aún en desarrollo cuando se llevó a cabo el taller

**Se incluyen solo los riesgos comunes a los cuatro ETCR

***Se incluye en la identificación el código $\mathrm{Pi}$, donde i es el número de proyecto, del 1 al 5

Entre los riesgos más importantes, destacan los asociados con las categorías Económica, Cultural y Política, siendo algunos riesgos, entre los más importantes, comunes a casi todos los proyectos. Entre estos riesgos comunes y muy importantes, se encuentran, aunque a veces expresados de diferentes formas, la falta de apoyo y/o de interés del gobierno local (político: P1_POL_1; P2_POL_5; P3_POL_1_2; P4_POL_1), los retrasos en la financiación (económico: P1_ECO_2; P2_ECO_6; P5_ECO_1_2) y las dificultades en la comunicación entre la comunidad beneficiaria y el equipo que ejecuta el proyecto (cultural: P1_CUL_1; P2_CUL_4; P4_CUL_1; P5_CUL_1_2).

Conviene destacar que las dificultades en la comunicación no proceden en la mayoría de los casos de hablar una lengua distinta, sino que responden a patrones culturales 
ligados a estructuras jerárquicas en las que la comunicación solo fluye entre personas situadas en la misma jerarquía. Es una información muy valiosa a tener en cuenta en las metodologías participativas que se realizan en este tipo de proyectos. Sobre los retrasos en la financiación, conviene tener en cuenta que es un riesgo muy común, al que sería conveniente darle respuesta. En relación con la falta de apoyo del gobierno local, dado que es ampliamente reconocido que una intervención sostenible debe contar con el apoyo de las instituciones locales, los gobiernos locales deben ser aliados de toda propuesta, más allá de intereses partidistas.

Destaca también, que dependiendo del tipo de proyectos que sean y de las comunidades beneficiarias correspondientes, hay que prestar más atención a unos riesgos u otros. Por ejemplo, en el único caso de proyecto con mujeres, aparece entre los cinco primeros riesgos más importantes la Dependencia del permiso de sus esposos o padres para participar. Se requiere pues de especial atención cuando se trata de colectivos vulnerables.

Los riesgos relacionados con los aspectos tecnológicos, atendiendo a los resultados obtenidos, no son prioritarios en ninguno de los proyectos. Es cierto que entre los PCD estudiados no existía ninguno de componente marcadamente tecnológico, aunque en los procesos productivos y en algunos de los emprendimientos sí que se requerían aspectos tecnológicos. Queda claro que es más complejo lidiar con las relaciones entre personas e instituciones, que con equipos y tecnología. Del mismo modo, y aunque el Departamento del Cauca se encuentra en una zona montañosa sujeta a fuertes lluvias y desprendimientos del terreno, los riesgos relacionados con los fenómenos medioambientales no son los que más afectan a los PCD, pese a tener que ver muchos de ellos con temas de producción agrícola. Igualmente, pese a la inseguridad presente en el Cauca, y al reconocimiento de ésta por los equipos que trabajan en la zona, se han convertido en riesgos tan asumidos que cuesta verlos como importantes.

En cuanto a las prioridades, cumplir con el Alcance se convierte en lo primordial para casi todos los proyectos, que quieren cubrir el total de las actividades planificadas y llegar al mayor número de personas posibles.

En relación con las etapas en las que se identifican los riesgos, en el estudio de estos PCD se han asociado mayoritariamente a la etapa de ejecución, esto es debido, seguramente, a que no contaron con una buena gestión de riesgos en las etapas previas de identificación y diseño, y fue durante la ejecución donde fueron surgiendo la gran mayoría de los riesgos.

Por último, valorando los niveles de éxito alcanzados, destaca que, aunque todos los equipos priorizan el éxito en el impacto, sin embargo, los valores de éxito en la dirección del proyecto obtienen valores más altos, con la excepción del proyecto de 
emprendimientos con población desplazada, donde además existe la mayor diferencia entre sendos niveles de éxito. Los valores de éxito más altos, tanto en impacto como en DP, los alcanza el proyecto de Educación superior, pese a ser un equipo novel.

\subsubsection{Análisis a través de la metodología fuzzy}

Se va a estudiar la relación que existe entre el éxito de los PCD llevados a cabo en el Cauca y los tipos o categorías de riesgos a los que se enfrentaron.

\subsubsection{Representatividad de la muestra}

Definida la muestra de las 31 personas entrevistadas correspondientes a ocho proyectos de cooperación en el Cauca, se comprueba que la muestra es significativa dentro de la población. Para ello se buscan los proyectos de cooperación internacional desarrollados o previstos para los próximos años en la zona.

La verificación de la representatividad de los proyectos de cooperación para la zona del Cauca se realiza a través de varias etapas. En primer lugar, consultando a los profesionales de las organizaciones internacionales que trabajan en terreno. En segundo lugar, con un minucioso estudio de las financiaciones de instituciones internacionales otorgadas a proyectos en el Cauca. Y, por último, los proyectos encontrados se validan con el Director de Cooperación de la Gobernación del Cauca, en una entrevista mantenida telefónicamente el 10 de diciembre de 2018. Aunque la Gobernación del Cauca no exige a las organizaciones registrar los proyectos, las organizaciones suelen tramitar en esta institución la certificación de sus proyectos para obtener los beneficios correspondientes en el pago de impuestos, es por eso que se considera una fuente válida para comprobar los proyectos realizados o previstos en el Cauca entre esos años. En la Tabla 5.2. se pueden ver los PCD en ejecución o previstos en el Cauca.

El número de estos proyectos de cooperación internacional realizados, en ejecución o previstos para el intervalo de años considerado, ronda los 30, con lo cual, la muestra de ocho se considera representativa para poder realizar el análisis con la metodología difusa y extraer conclusiones válidas entre las relaciones de las categorías de riesgo y el éxito de los proyectos en la zona del Cauca.

\subsubsection{Elección de las variables}

Para comenzar con el estudio, es necesario definir las variables que se van a tomar, que son, por un lado, las categorías de riesgo (variables entradas o condiciones) y el nivel de éxito del proyecto, tanto en impacto, como en la DP (variables salidas o resultados). Estas variables y resultados se estudian para el total de 31 personas o casos.

Las variables entrada o condiciones se obtienen tomando los valores totales dados por cada persona o caso para cada categoría. Esto es, la puntuación total de cada persona 
para cada categoría será la suma de todas las puntuaciones obtenidas para la importancia de cada riesgo dentro de esa categoría. La importancia de cada riesgo viene dada del producto entre la probabilidad de ocurrencia y el impacto de éste. Como el impacto se había dividido previamente en los correspondientes impactos sobre tiempo, coste, alcance y seguridad, el valor final del impacto se obtiene dando los pesos estimados por el director de cada proyecto a cada uno de los mismos.

Como en cada proyecto se identificaron distinto número de riesgos, dependiendo de en qué proyecto trabaje cada persona, el valor obtenido para cada categoría de riesgos varía, no solo por las puntuaciones otorgadas (su percepción del riesgo), sino por el número de riesgos identificados. Esta variación se soluciona gracias a la calibración que se hace con ellas, como se explicará posteriormente.

Se dispone en total de los valores de importancia de ocho categorías de riesgo correspondientes a 31 personas que participaron en ocho proyectos. Son las variables entrada o condiciones.

Se cuenta además con la puntuación del 1 al 10 de cada una de las personas con respecto al nivel de éxito alcanzado con el proyecto en dos sentidos, el impacto en la población beneficiaria y la dirección de proyectos. Éstas son las variables salida o resultado. La definición de los casos, condiciones y resultados puede observarse en la Figura 6.10.

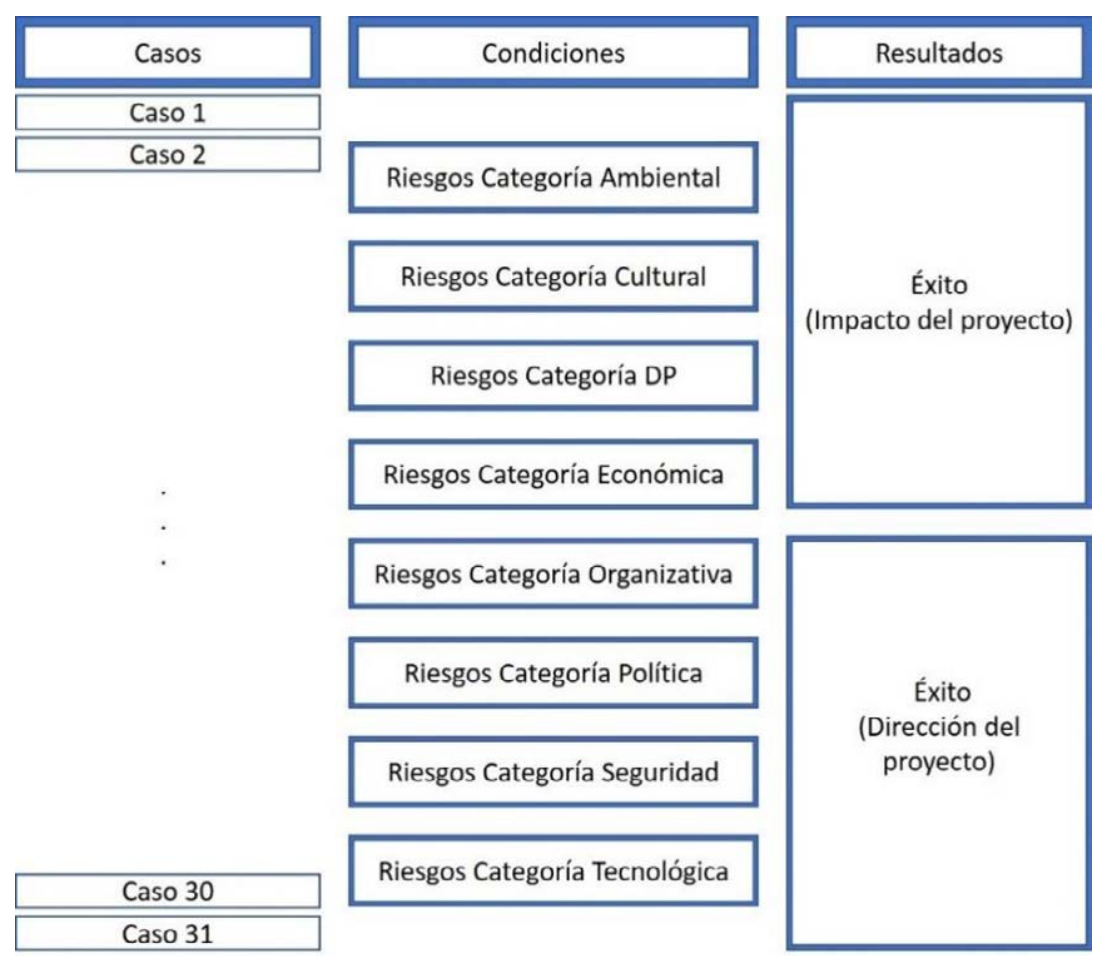

Figura 6.10. Casos, condiciones y resultados utilizados en el estudio Fuzzy. Fuente: elaboración propia. 
Los valores dados para las categorías de riesgo, así como para los resultados, por cada una de las personas con las que se ha trabajado se pueden ver en la Tabla 6.37.

Tabla 6.37. Datos disponibles para el análisis.

Fuente: elaboración propia.

\begin{tabular}{l|cccccccc|cc}
\hline Casos & \multicolumn{7}{|c}{ Categorías } \\
\hline & AMB & CUL & DPR & ECO & ORG & POL & SEG & TEC & Impacto & DP \\
\cline { 2 - 11 } P1 & 6 & 49,4 & 5,6 & 36 & 119,2 & 27,8 & 19 & 21,6 & 8,5 & 9 \\
P2 & 7,2 & 64,4 & 10,2 & 30,8 & 79,6 & 24,2 & 16,8 & 33 & 7,5 & 8 \\
P3 & 1,8 & 40 & 14,6 & 29,4 & 87,2 & 32,4 & 8,8 & 9,8 & 9,5 & 9 \\
P4 & 1,2 & 62,4 & 16,6 & 32,4 & 135,4 & 28,8 & 10,8 & 12,2 & 7,5 & 10 \\
P5 & 1,4 & 52,4 & 17,6 & 30 & 116,8 & 32,4 & 7,8 & 13,2 & 8,5 & 10 \\
P6 & 11,2 & 62 & 24,8 & 42 & 115,6 & 30,6 & 0 & 15 & 9,5 & 9 \\
P7 & 6,6 & 70,4 & 42,4 & 41,2 & 181 & 21,6 & 28,6 & 32,6 & 8,5 & 9 \\
P8 & 4 & 41,8 & 77,4 & 68,4 & 25,8 & 69,8 & 13,6 & 13,2 & 6 & 6 \\
P9 & 12 & 47,2 & 59 & 96,8 & 42 & 88,8 & 41,4 & 39,2 & 6,5 & 8 \\
P10 & 4,8 & 51,8 & 41,6 & 46,2 & 21,4 & 47,4 & 20,4 & 14,8 & 7,5 & 8 \\
P11 & 9 & 52,2 & 85,8 & 88,2 & 74,6 & 47,6 & 24,4 & 43,4 & 7,5 & 7 \\
P12 & 12,4 & 59,4 & 28 & 20 & 68,2 & 43,6 & 9 & 16,4 & 6 & 5 \\
P13 & 6,4 & 27,2 & 12 & 22,6 & 33 & 26,4 & 14,4 & 12,2 & 6,7 & 5 \\
P14 & 41,8 & 77,2 & 51 & 4,8 & 69,8 & 48,6 & 16 & 26 & 10 & 10 \\
P15 & 52,4 & 159,2 & 97,6 & 122,4 & 150,4 & 40,2 & 51,6 & 58,8 & 5,5 & 6 \\
P16 & 17,6 & 86,6 & 33,4 & 86,4 & 71,8 & 45,2 & 60 & 25,2 & 6,5 & 6 \\
P17 & 28,4 & 113,4 & 35,2 & 51,4 & 84 & 52,6 & 28,8 & 35,4 & 5 & 5 \\
P18 & 32 & 116 & 56,8 & 103,4 & 118,4 & 54,4 & 32 & 31,2 & 7,5 & 6 \\
P19 & 23 & 181,2 & 57,2 & 155 & 70,3 & 66 & 8 & 24 & 5,5 & 7 \\
P20 & 26 & 128,8 & 36,6 & 83,4 & 71,2 & 14,4 & 35,2 & 52,4 & 7 & 8 \\
P21 & 32,4 & 151,4 & 35,6 & 53,6 & 81,6 & 54 & 27,6 & 28,2 & 7 & 7 \\
P22 & 57,2 & 119,2 & 96 & 93,6 & 80 & 61 & 34,4 & 55 & 6 & 6 \\
P23 & 6,2 & 62,8 & 21,8 & 41,6 & 47 & 7,6 & 5,2 & 7 & 6,3 & 6,5 \\
P24 & 15,8 & 78 & 19 & 31,6 & 24,8 & 19,4 & 3 & 6 & 6 & 7 \\
P25 & 30 & 59,4 & 9,2 & 43,2 & 57 & 35 & 4,8 & 10 & 6,5 & 6 \\
P26 & 30,8 & 128 & 75,6 & 92 & 130,6 & 61,8 & 61 & 19,6 & 6,5 & 6 \\
P27 & 23,8 & 131,8 & 26 & 73,4 & 77,2 & 49,4 & 12,4 & 17,6 & 6,5 & 9 \\
P28 & 12 & 26,8 & 6,8 & 56,6 & 62,55 & 26,8 & 8,6 & 6,8 & 8 & 9 \\
P29 & 2,3 & 104,8 & 42,4 & 50 & 99,5 & 19,2 & 48,5 & 42 & 6 & 8 \\
P30 & 2,3 & 104,8 & 42,4 & 50 & 96,75 & 19,2 & 48,5 & 42 & 7,5 & 9 \\
P31 & 10,8 & 75,6 & 37,5 & 51,8 & 85,5 & 58,5 & 22 & 23,4 & 7,5 & 6 \\
\hline
\end{tabular}

* Las condiciones muestran las categorías de riesgo de la Figura 6.10 con sus nombres codificados. 


\subsubsection{Preparación de las variables}

En el caso concreto que vamos a estudiar, se utiliza la metodología difusa a través del programa FsQCA 3.0 (Fuzzy set Qualitative Comparative Analysis). Este software utiliza lógica combinatoria, la teoría de conjuntos de la lógica difusa y la minimización booleana para averiguar qué combinación de características pueden ser necesarias o suficientes para dar un resultado (Kent y Olsen, 2008). Así, el FsQCA aplicado al estudio de los casos permite identificar cuáles son las condiciones necesarias y cómo influyen a la hora de alcanzar el resultado o variable salida. Este método permite también identificar la condición suficiente (combinación a su vez de condiciones) para alcanzar el resultado (Ragin, 2008).

Así, una vez se tiene la muestra de las 31 personas (o casos), con las ocho variables de entrada (las categorías de riesgo) y las dos variables salidas (éxito del proyecto y de la dirección del proyecto), se procede a calibrarlas. La calibración es el paso de transformar las variables convencionales a variables difusas, pasando así a denominarse condiciones (entrada) y resultado (salida). La calibración determina el grado de pertenencia de los casos en cada uno de los conjuntos, con puntuaciones que van del 0 al 1 . Entre las calibraciones propuestas por Ragin (2009), se opta por la de tres valores $(0,3 ; 0,6 ; 0,9)$, tras consultar con un experto en el uso de esta metodología. Así, en la Tabla 6.38 se puede ver cuál sería la interpretación de estas calibraciones.

Tabla 6.38. Calibración con cuatro conjuntos.

Fuente: Romero Ruíz, 2017.

\begin{tabular}{cl}
\hline Valor del caso calibrado & \multicolumn{1}{c}{ Interpretación } \\
\hline$<0,3$ & El caso tiene una pertenencia mínima a la condición \\
$0,3-0,6$ & El caso tiene una pertenencia media-baja a la condición \\
$0,6-0,9$ & El caso tiene una pertenencia media-alta a la condición \\
$>0,9$ & El caso tiene una pertenencia máxima a la condición \\
\hline
\end{tabular}

De acuerdo con esta calibración, en la Tabla 6.39, se pueden ver los datos del estudio, calibrados para el análisis con el programa FsQCA 3.0. 
Tabla 6.39. Datos calibrados para el análisis.

Fuente: elaboración propia.

\begin{tabular}{l|cccccccc|cc}
\hline Casos & \multicolumn{10}{|c}{ Categorías } \\
\hline & AMB & CUL & DPR & ECO & ORG & POL & SEG & TEC & Impacto & DP \\
P1 & 0,3 & 0,3 & 0,3 & 0,3 & 0,9 & 0,6 & 0,6 & 0,6 & 0,9 & 0,9 \\
P2 & 0,3 & 0,6 & 0,3 & 0,3 & 0,6 & 0,3 & 0,6 & 0,9 & 0,6 & 0,6 \\
P3 & 0,3 & 0,3 & 0,3 & 0,3 & 0,6 & 0,6 & 0,3 & 0,3 & 0,9 & 0,9 \\
P4 & 0,3 & 0,6 & 0,3 & 0,3 & 0,9 & 0,6 & 0,6 & 0,3 & 0,6 & 0,9 \\
P5 & 0,3 & 0,6 & 0,3 & 0,3 & 0,9 & 0,6 & 0,3 & 0,3 & 0,9 & 0,9 \\
P6 & 0,6 & 0,6 & 0,6 & 0,6 & 0,9 & 0,6 & 0,3 & 0,6 & 0,9 & 0,9 \\
P7 & 0,3 & 0,6 & 0,6 & 0,6 & 0,9 & 0,3 & 0,6 & 0,9 & 0,9 & 0,9 \\
P8 & 0,3 & 0,3 & 0,9 & 0,6 & 0,3 & 0,9 & 0,6 & 0,3 & 0,3 & 0,3 \\
P9 & 0,6 & 0,3 & 0,9 & 0,9 & 0,3 & 0,9 & 0,9 & 0,9 & 0,3 & 0,6 \\
P10 & 0,3 & 0,6 & 0,6 & 0,6 & 0,3 & 0,6 & 0,6 & 0,3 & 0,6 & 0,6 \\
P11 & 0,3 & 0,6 & 0,9 & 0,9 & 0,6 & 0,6 & 0,6 & 0,9 & 0,6 & 0,6 \\
P12 & 0,6 & 0,6 & 0,6 & 0,3 & 0,6 & 0,6 & 0,3 & 0,6 & 0,3 & 0,3 \\
P13 & 0,3 & 0,3 & 0,3 & 0,3 & 0,3 & 0,6 & 0,6 & 0,3 & 0,3 & 0,3 \\
P14 & 0,9 & 0,6 & 0,9 & 0,3 & 0,6 & 0,6 & 0,6 & 0,6 & 0,9 & 0,9 \\
P15 & 0,9 & 0,9 & 0,9 & 0,9 & 0,9 & 0,6 & 0,9 & 0,9 & 0,3 & 0,3 \\
P16 & 0,6 & 0,6 & 0,6 & 0,9 & 0,6 & 0,6 & 0,9 & 0,6 & 0,3 & 0,3 \\
P17 & 0,6 & 0,9 & 0,6 & 0,6 & 0,6 & 0,9 & 0,6 & 0,9 & 0,3 & 0,3 \\
P18 & 0,9 & 0,9 & 0,9 & 0,9 & 0,9 & 0,9 & 0,9 & 0,9 & 0,6 & 0,3 \\
P19 & 0,6 & 0,9 & 0,9 & 0,9 & 0,6 & 0,9 & 0,3 & 0,6 & 0,3 & 0,6 \\
P20 & 0,6 & 0,9 & 0,6 & 0,9 & 0,6 & 0,3 & 0,9 & 0,9 & 0,6 & 0,6 \\
P21 & 0,9 & 0,9 & 0,6 & 0,6 & 0,6 & 0,9 & 0,6 & 0,6 & 0,6 & 0,6 \\
P22 & 0,9 & 0,9 & 0,9 & 0,9 & 0,6 & 0,9 & 0,9 & 0,9 & 0,3 & 0,3 \\
P23 & 0,3 & 0,6 & 0,6 & 0,6 & 0,3 & 0,3 & 0,3 & 0,3 & 0,3 & 0,3 \\
P24 & 0,6 & 0,6 & 0,3 & 0,3 & 0,3 & 0,3 & 0,3 & 0,3 & 0,3 & 0,6 \\
P25 & 0,9 & 0,6 & 0,3 & 0,6 & 0,6 & 0,6 & 0,3 & 0,3 & 0,3 & 0,3 \\
P26 & 0,9 & 0,9 & 0,9 & 0,9 & 0,9 & 0,9 & 0,9 & 0,6 & 0,3 & 0,3 \\
P27 & 0,6 & 0,9 & 0,6 & 0,6 & 0,6 & 0,6 & 0,6 & 0,6 & 0,3 & 0,9 \\
P28 & 0,6 & 0,3 & 0,3 & 0,6 & 0,6 & 0,6 & 0,3 & 0,3 & 0,9 & 0,9 \\
P29 & 0,3 & 0,9 & 0,6 & 0,6 & 0,6 & 0,3 & 0,9 & 0,9 & 0,3 & 0,6 \\
P30 & 0,3 & 0,9 & 0,6 & 0,6 & 0,6 & 0,3 & 0,9 & 0,9 & 0,6 & 0,9 \\
P31 & 0,6 & 0,6 & 0,6 & 0,6 & 0,6 & 0,9 & 0,6 & 0,6 & 0,6 & 0,3 \\
\hline & & & & & & & & & &
\end{tabular}

\subsubsection{Análisis de las condiciones necesarias}

Haciendo uso del software FqSCA se analizan las condiciones necesarias. La necesidad de una condición se demuestra comprobando que el resultado es un subconjunto de la condición, es decir, el valor de la pertenencia del resultado debe ser menor o igual que el de la condición (Ragin, 2008; Romero Ruiz, 2017). Para ello, se analizan los valores obtenidos para cada resultado (impacto y $D P$ ) y su versión negada ( impacto, $\sim D P$ ) todas las posibles opciones con las condiciones ( $A M B, C U L, D P R, E C O, O R G, P O L, S E G$, y $T E C$ ) y 
sus negadas ( $\sim A M B, \sim C U L, \sim D P R, \sim E C O, \sim O R G, \sim P O L, \sim S E G, y \sim T E C)$. Los valores negados representan la ausencia de la condición o resultado. La Figura 6.11 muestra un ejemplo en el que todas las condiciones serían necesarias para cada uno de los resultados buscados.

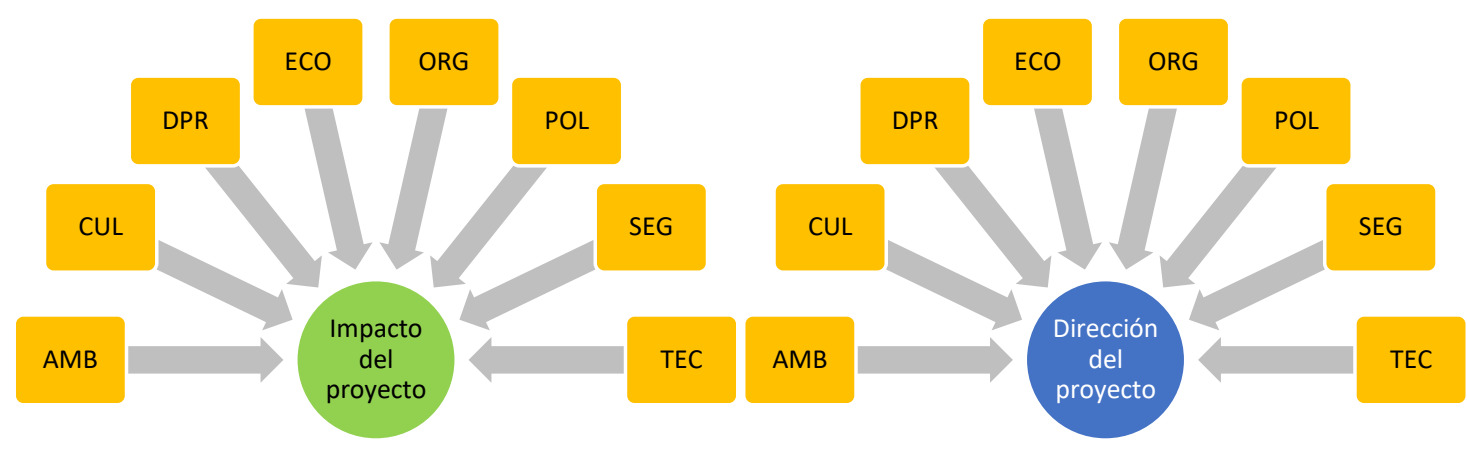

Figura 6.11. Posibles condiciones necesarias para alcanzar los resultados. Fuente: elaboración propia.

De acuerdo con Ragin (2008), se puede decir que una condición es necesaria cuando tiene un valor del índice de consistencia mayor a 0,9. En la Tabla 6.40 se pueden ver los valores obtenidos con FsQCA 3.0. Atendiendo a los números que salen, se toman los valores de consistencia con mayor relevancia, aunque en algunos casos no son superiores al valor orientativo de 0,9 .

Antes de interpretar estos resultados, conviene recordar que el hecho de que una categoría tenga un valor más alto, quiere decir que se les ha dado más importancia a sus riesgos. Esto puede ser porque se hayan identificado más riesgos en esa categoría, o porque los que se han identificado tienen altos valores de importancia. Para este estudio, tanto si se han identificado más, como si los identificados tienen puntuaciones más altas, es solo síntoma de que a los participantes de cada uno de los proyectos les preocupaba especialmente atender esa categoría y sus riesgos, y, por tanto, esa condición debe ser destacada.

Observando los resultados de la Tabla 6.40 se puede apreciar que para que un proyecto tenga alto impacto necesita considerar los riesgos organizativos, es decir, que ha requerido una buena y supervisada organización. Destaca también la importancia dada a los riesgos culturales, esto es, que un proyecto tenga alto impacto implica además que preste especial atención a los riesgos asociados a las diferencias culturales.

Analizando ahora el caso negado, es decir, la ausencia de impacto se puede apreciar que cuando un proyecto tiene poco impacto sobre los beneficiarios, la condición que tiene 
más influencia es la cultura. El hecho de que los riesgos asociados a las diferencias culturales aparezcan tanto en el resultado de impacto como de no impacto, no hace nada más que demostrar la fuerte relación que existe entre los riesgos de esta categoría y las posibilidades de que el proyecto consiga mejorar las vidas de los beneficiarios. La interpretación que puede hacerse de este hecho es que, demostrada la importancia de los riesgos asociados a las diferencias culturales, dependiendo de cómo se traten estos riesgos, se podrá hablar de impacto del proyecto o ausencia del mismo.

Como condiciones también importantes para la ausencia de impacto, aparecen la economía y la dirección de proyectos. Lo cual puede interpretarse como que la presencia no controlada de riesgos asociados a estas categorías, provocarían que el proyecto no tuviera impacto sobre la comunidad beneficiaria.

En cuanto a las condiciones necesarias para considerar que el proyecto ha tenido éxito de cara a su dirección del proyecto, curiosamente coinciden las condiciones de organización y cultura, aunque con valores menos relevantes. La lectura que puede hacerse de este resultado es que ambas condiciones son necesarias para el éxito del proyecto en toda su definición, tanto de impacto, como de dirección de proyecto, aunque con mayor importancia para el impacto. Esto puede ser porque los participantes de estos proyectos dieran más importancia al impacto del proyecto que a la parte de gestión del mismo.

Analizando ahora la ausencia de éxito en la dirección del proyecto, las condiciones varían ligeramente, y aunque la cultura, la economía y la propia dirección del proyecto están también presentes, domina la condición política. La interpretación que puede hacerse es que cuando un proyecto no alcanza el éxito en la dirección de proyectos, los riesgos que tienen más importancia son los políticos, acompañados de los culturales, de los económicos y de los relacionados con la propia dirección del proyecto.

La Tabla 6.40 muestra el resumen de los resultados obtenidos para las condiciones necesarias. 
Tabla 6.40. Condiciones necesarias para los cuatro resultados.

Fuente: elaboración propia a partir de los datos obtenidos con FsQCA 3.0.

\begin{tabular}{ccccccccc}
\hline \multirow{2}{*}{ Condición } & \multicolumn{2}{c}{ Impacto } & \multicolumn{2}{c}{$\sim$ Impacto } & \multicolumn{2}{c}{ DP } & \multicolumn{2}{c}{$\sim$ DP } \\
\cline { 2 - 8 } & Consist. & Cobert. & Consist. & Cobert. & Consist. & Cobert. & Consist. & Cobert. \\
\hline AMB & 0.7222 & 0.6964 & 0.8108 & 0.7142 & 0.6833 & 0.7321 & 0.8461 & 0.6547 \\
$\sim$ AMB & 0.7037 & 0.8028 & 0.6554 & 0.6830 & 0.6777 & 0.8591 & 0.6538 & 0.5985 \\
CUL & $\mathbf{0 . 8 1 4 8}$ & 0.6567 & 0.8851 & 0.6517 & 0.8000 & 0.7164 & 0.8923 & 0.5771 \\
$\sim$ CUL & 0.5679 & 0.8440 & 0.5337 & 0.7247 & 0.5277 & 0.8715 & 0.5615 & 0.6697 \\
DPR & 0.7777 & 0.6774 & 0.8648 & 0.6881 & 0.7333 & 0.7096 & 0.8846 & 0.6182 \\
$\sim$ DPR & 0.6419 & 0.8387 & 0.5945 & 0.7096 & 0.6055 & 0.8790 & 0.5846 & 0.6129 \\
ECO & 0.7592 & 0.6612 & 0.8648 & 0.6881 & 0.7166 & 0.6935 & 0.8846 & 0.6182 \\
$\sim$ ECO & 0.6419 & 0.8387 & 0.5743 & 0.6854 & 0.6055 & 0.8790 & 0.5615 & 0.5887 \\
ORG & 0.9259 & 0.7812 & 0.8040 & 0.6197 & 0.8666 & 0.8125 & 0.8384 & 0.5677 \\
$\sim$ ORG & 0.5493 & 0.7542 & 0.7162 & 0.8983 & 0.5388 & 0.8220 & 0.7230 & 0.7966 \\
POL & 0.7962 & 0.6718 & 0.8581 & 0.6614 & 0.7333 & 0.6875 & 0.9000 & 0.6093 \\
$\sim$ POL & 0.5987 & 0.8220 & 0.5743 & 0.7203 & 0.5833 & 0.8898 & 0.5384 & 0.5932 \\
SEG & 0.7962 & 0.6935 & 0.8378 & 0.6666 & 0.7500 & 0.7258 & 0.8615 & 0.6021 \\
$\sim$ SEG & 0.6172 & 0.8064 & 0.6148 & 0.7338 & 0.5888 & 0.8548 & 0.6076 & 0.6370 \\
TEC & 0.7962 & 0.6825 & 0.8175 & 0.6402 & 0.7666 & 0.7301 & 0.8307 & 0.5714 \\
$\sim$ TEC & 0.5802 & 0.7768 & 0.5945 & 0.7272 & 0.5500 & 0.8181 & 0.6076 & 0.6528 \\
\hline
\end{tabular}

\subsubsection{Análisis de las condiciones suficientes}

Igualmente, las condiciones suficientes o, mejor dicho, la combinación de condiciones suficientes para obtener el resultado buscado del éxito del proyecto en su doble vertiente, se analizan a través del software FqSCA. Estas combinaciones de condiciones se denominan también combinaciones causales. Se puede decir que una combinación de condiciones o combinación causal es suficiente cuando es un subconjunto del resultado. La relación entre los conjuntos y subconjuntos entre condiciones necesarias, suficientes y resultados, se puede apreciar en la Figura 6.12.
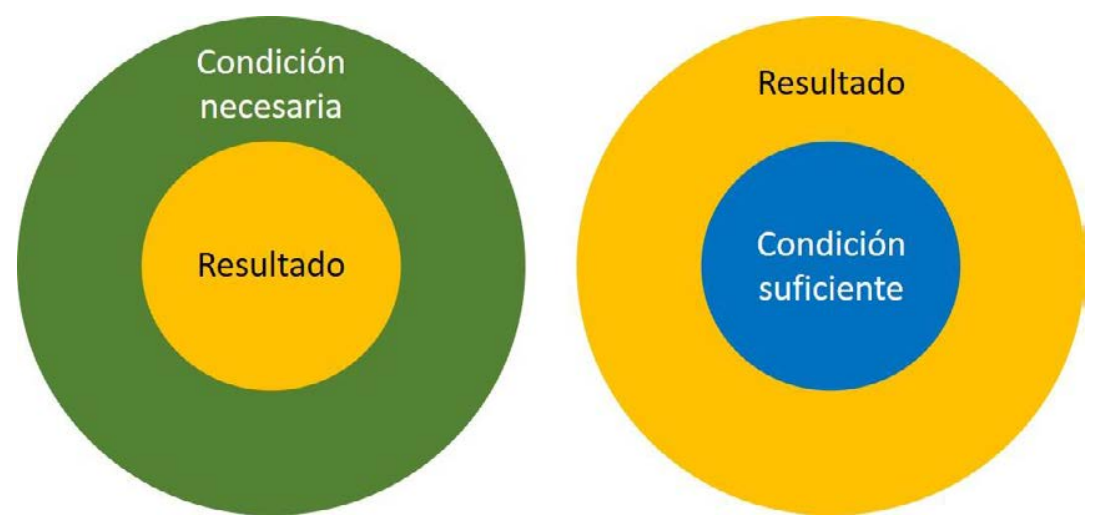

Figura 6.12. Relación entre las condiciones necesarias, suficientes y resultados.

Fuente: elaboración propia. 
Según Ragin (2008), para cumplir la condición de suficiencia el valor de consistencia debe ser superior a 0,8 .

El primer paso para obtener la combinación de condiciones causales es trabajar con la tabla de verdad. La tabla de verdad dispone de $2^{k}$ filas o configuraciones, donde $k$ representa el número de variables independientes o condiciones causales. En el caso estudiado, k es igual a ocho, por ser ocho las categorías de riesgos estudiadas. Así, se dispone de tablas de verdad de 256 filas. Lo cierto es que, de todas estas 256 configuraciones posibles, FsQCA 3.0 solo muestra los resultados que han sido elegidos por los casos estudiados, es decir, la tabla de verdad solo muestra las combinaciones que tienen casos. Las tablas de verdad correspondientes al estudio de los cuatro resultados a analizar (impacto y dirección de proyectos, y sus correspondientes negados) pueden verse en el Anexo VI.

Partiendo de la tabla de verdad, FsQCA 3.0 realiza la minimización booleana a través de dos análisis posibles: el específico y el estándar. La principal diferencia entre ambos es que, mientras que en el específico es necesario definir cómo se desea hacer la minimización y hasta qué nivel llegar, el análisis estándar permite al programa realizar automáticamente la minimización. En cualquier caso, ambos análisis permiten llegar a tres tipos de soluciones diferentes: la simplificada, la intermedia y la compleja. El análisis estándar es el más recomendado (Ragin, 2008; Ragin y Davey, 2017) y es el que se va a utilizar para el estudio de las soluciones suficientes de los proyectos tratados.

Los supuestos que utiliza la lógica fuzzy para realizar las simplificaciones booleanas se basan en lo que la lógica denomina contrafactual o contra fáctica, que hace referencia a todo aquello que no ha sucedido en el universo actualmente observable por el ser humano y sus investigaciones, pero que podría haber ocurrido. Aplicado al programa, son aquellos supuestos cuya combinación de condiciones es falsa, es decir, que no existen casos presentes en el resultado.

El algoritmo que utiliza FsQCA 3.0 para realizar la minimización es el de QuineMcCluskey (Schneider y Wagemann, 2012). Este algoritmo se basa en el análisis de los contra fácticos de las condiciones causales para obtener soluciones más simplificadas. Los contra fácticos, a su vez, pueden ser fáciles o difíciles. Los contra fácticos fáciles hacen referencia a situaciones en las cuales una condición causal redundante es añadida al conjunto de condiciones causales que ya por sí mismas conducían al resultado (Fiss, 2011). La simplificación que se realiza teniendo en cuenta solo estos contra fácticos fáciles da lugar a la solución intermedia, que es la más recomendada y la que debe utilizarse como punto de referencia, dado que la minimización se apoya en los casos de los que se posee información (Ragin, 2008; Romero Ruiz, 2017). 
Los contra fácticos difíciles, por otro lado, aluden a las situaciones en las cuales una condición es eliminada del conjunto de condiciones causales bajo la hipótesis de que esta condición era redundante (Fiss, 2011). La solución simplificada (parsimonious, en inglés), incluye la simplificación de ambos contra fácticos, los fáciles y los difíciles.

La solución compleja, por el contrario, es aquella en la que no se realiza ninguna simplificación, siendo la solución más completa pero también la más difícil de interpretar y escasamente recomendada, dado que proporciona muy poca comprensión de las condiciones causales (Fiss, 2011).

Basándose en el tipo de soluciones en el que aparecen, las condiciones causales pueden dividirse a su vez en condiciones principales (aparecen en la solución simplificada y en la intermedia), y contribuyentes (aparecen solo en la solución intermedia). En este estudio, y con el fin de encontrar las condiciones suficientes principales y contribuyentes, solo se presentan las soluciones simplificada e intermedia para cada uno de los cuatro resultados, pudiéndose encontrar las soluciones complejas en el Anexo VII.

\section{A) Combinación de condiciones suficientes para el resultado de Impacto del proyecto}

Antes de llegar a las soluciones, desde la tabla de verdad correspondiente a este análisis, se preparan los datos, tomando sólo aquellos con una consistencia mayor al 0,95. Esto se hace así tras la observación de los valores correspondientes a la columna de impacto y ver dónde se produce un salto mayor. De esta manera, de las 29 soluciones observadas de entre las 256 soluciones contra fácticas, al filtrar por una consistencia de 0,95, el programa trabaja solo con 10 configuraciones. Al realizar el análisis estándar con estas configuraciones, y habiéndole pedido que muestre tanto las condiciones causales presentes, como las ausentes, (ver Figura 6.13) el programa nos muestra los resultados que aparecen en la Tabla 6.41 para la solución intermedia, elegida para iniciar el estudio, como recomiendan los expertos (Ragin, 2008; Romero Ruiz, 2017). Esta solución intermedia tiene una cobertura de 0,75 y una consistencia de 0,94, lo cual indica que tiene una buena representatividad de las condiciones en la variable resultado, es decir, en el Impacto del proyecto. 


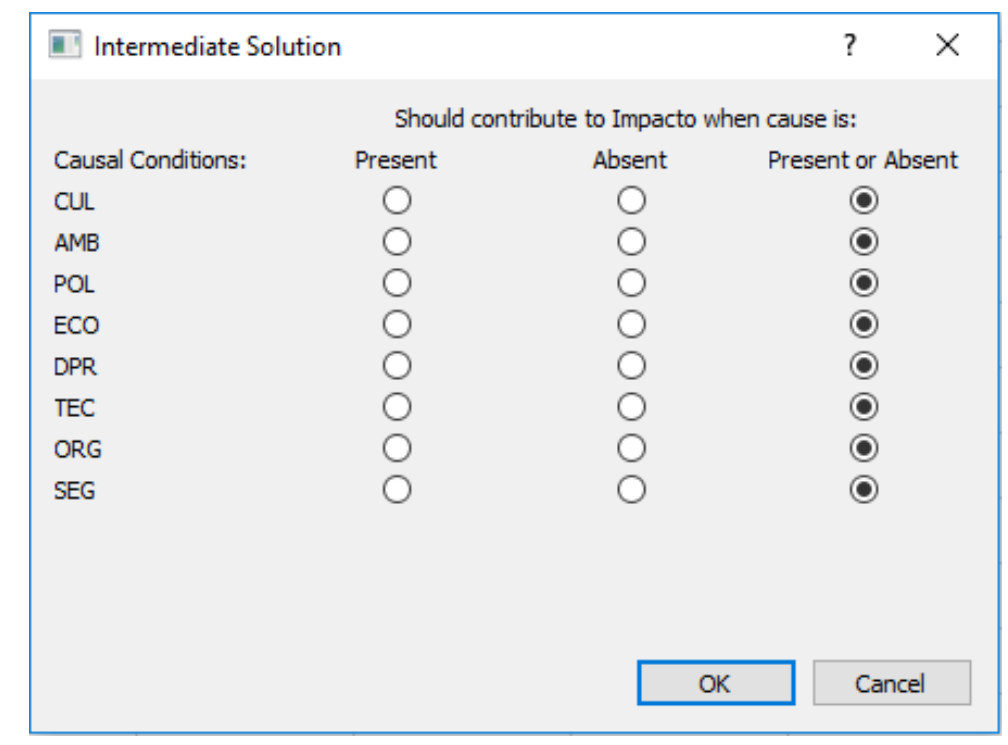

Figura 6.13. Selección de las condiciones causales para contribuir al resultado de Impacto.

Fuente: FsQCA 3.0.

Tabla 6.41. Solución intermedia para el resultado Impacto.

Fuente: elaboración propia a partir de los datos obtenidos con FsQCA 3.0.

\begin{tabular}{|c|c|c|c|c|}
\hline Cód. & Combinación & $\begin{array}{c}\text { Cobertura } \\
\text { propia }\end{array}$ & $\begin{array}{c}\text { Cobertura } \\
\text { única }\end{array}$ & Consistencia \\
\hline C.1.I & $\sim \mathrm{AMB}^{*} \mathrm{POL}^{* \sim} \mathrm{ECO}^{* \sim} \mathrm{DPR}^{* \sim} \mathrm{TEC} * \mathrm{ORG} * \sim \mathrm{SEG}$ & 0.4197 & 0.0185 & 0.9714 \\
\hline C.1.II & $\mathrm{CUL}^{* \sim} \mathrm{AMB}^{*} \mathrm{POL}^{* \sim} \mathrm{ECO} * \sim \mathrm{DPR}^{* \sim} \mathrm{TEC} * \mathrm{ORG}$ & 0.4012 & 0.0123 & 0.9701 \\
\hline C.1.III & $\sim$ CUL*AMB*POL*ECO* DPR* TEC*ORG* SEG & 0.3827 & 0.0123 & 0.9841 \\
\hline C.1.IV & CUL* ${ }^{*} \mathrm{AB}^{* \sim} \mathrm{POL}^{* \sim}$ ECO* DPR*TEC*ORG*SEG & 0.4197 & 0.0308 & 0.9714 \\
\hline C.1.V & $\sim \mathrm{CUL}^{* \sim} \mathrm{AMB}^{*} \mathrm{POL}^{* \sim}$ ECO* DPR*TEC*ORG*SEG & 0.3888 & 0.0123 & 1 \\
\hline C.1.VI & CUL* AMB*POL*ECO*DPR* TEC* ORG*SEG & 0.3641 & 0.0185 & 0.9672 \\
\hline C.1.VII & CUL*AMB*POL* ECO*DPR*TEC*ORG*SEG & 0.4938 & 0.0370 & 0.9756 \\
\hline C.1.VIII & CUL*AMB* POL*ECO*DPR*TEC*ORG*SEG & 0.4814 & 0.0308 & 0.9629 \\
\hline C.1.IX & CUL* AMB*POL*ECO*DPR*TEC*ORG*SEG & 0.5123 & 0.0308 & 0.9651 \\
\hline
\end{tabular}

Cobertura de la solución: 0.7530

Consistencia de la solución: 0.9457

De todas las combinaciones de condiciones posibles en esta solución, la más representativa es la que tiene mayor cobertura propia. La diferencia entre cobertura propia y única, es que la propia tiene en cuenta también la participación en otras condiciones, mientras que la única sólo tiene en cuenta la cobertura de esa condición. Es decir, la cobertura propia representa la intersección de todas las pertenencias de cada una de las condiciones. Por ejemplo, en este caso, con una cobertura propia de 0.51 se explica un $51 \%$ de pertenencia en el resultado, siendo además una solución bastante consistente, con un valor de consistencia superior al 90\%. Los valores tan bajos 
obtenidos para las coberturas únicas se deben a que existe mucho solapamiento de los casos en las diferentes combinaciones (Romero Ruíz, 2017).

Así, la configuración con mayor cobertura propia $(0,51)$, que tiene además una consistencia de 0,96, es: CUL* AMB*POL*ECO*DPR*TEC*ORG*SEG, es decir, tiene a todas las categorías presentes menos al medio ambiente, que está ausente. En una primera interpretación, se puede entender que los riesgos de todas las categorías son igual de importantes siempre que no haya riesgos de tipo medioambiental, de cara a que sea más probable el éxito del proyecto a través del impacto en la comunidad beneficiaria.

Por ser muy escasa la diferencia entre las coberturas propias de esta combinación y sus dos más cercanas $(0,49$ y 0,48$)$, se van a estudiar estas dos también. La segunda combinación en relevancia es así: CUL*AMB*POL* ECO*DPR*TEC*ORG*SEG, (con una consistencia de 0,97) mientras que la tercera (con una consistencia de 0,96) es: CUL*AMB* POL*ECO*DPR*TEC*ORG*SEG.

Se puede observar que estas tres soluciones tienen valores muy similares de cobertura única y consistencia. Además, están formadas por prácticamente las mismas componentes, con la diferencia de que en el primer caso hay ausencia de la categoría ambiental, en el segundo de la categoría económica y en el tercero, de la categoría política. Así, se podría decir inicialmente que la ausencia de los riesgos de estas tres categorías podría compensar la presencia de los demás riesgos para tener impacto en la comunidad beneficiaria.

Observando ahora la información que aporta la solución simplificada (Tabla 6.42), con una cobertura del 0,76 y una consistencia de 0,98, que indican su buena representatividad, se toma de nuevo la combinación con mayor cobertura propia, por tener más relevancia. Ésta es: $C U L^{*} \sim A M B * P O L$, con una cobertura propia de 0,57 , y una consistencia de 0,95.

Tabla 6.42. Solución simplificada para el resultado Impacto. Fuente: elaboración propia a partir de los datos obtenidos con FsQCA 3.0.

\begin{tabular}{llll}
\hline \multicolumn{1}{c}{ Combinación } & $\begin{array}{c}\text { Cobertura } \\
\text { propia }\end{array}$ & $\begin{array}{c}\text { Cobertura } \\
\text { única }\end{array}$ & Consistencia \\
\hline$\sim \mathrm{CUL}^{*} \mathrm{ORG}$ & 0.5493 & 0.03703 & 0.9673 \\
$\mathrm{CUL}^{*} \sim \mathrm{AMB}{ }^{*} \mathrm{POL}$ & $\mathbf{0 . 5 7 4 0}$ & 0.05555 & 0.9489 \\
$\sim \mathrm{ECO}^{*} \mathrm{ORG} \mathrm{*} \mathrm{SG}$ & 0.5617 & 0.04938 & 0.9680 \\
$\mathrm{AMB}^{*} \sim \mathrm{POL}{ }^{*} \mathrm{ORG}$ & 0.5 & 0.03086 & 0.9418 \\
\hline Cobertura de la solución: 0.7592 & & \\
Consistencia de la solución: 0.9389 & & \\
\hline
\end{tabular}


El hecho de que vuelvan a aparecer la presencia de las categorías cultural y política, y la ausencia de ambiental, pone de relevancia el especial valor de estas tres categorías como condiciones suficientes para que se dé el éxito a nivel de impacto del proyecto, y da más peso a la combinación que incluía la ausencia de la categoría ambiental en la solución intermedia.

Su interpretación es que una cuidada gestión de riesgos asociados tanto a la cultura como a la política, junto con evitar todos los riesgos que puedan poner en peligro el medio ambiente, aumenta mucho la probabilidad de éxito en el impacto de un proyecto en la zona del Cauca.

La Figura 6.14 muestra las condiciones principales y contribuyentes para generar el éxito en el Impacto de un proyecto en el Cauca. En rojo las condiciones principales (CUL* AMB*POL) y en naranja las contribuyentes (ECO*DPR*TEC*ORG*SEG).

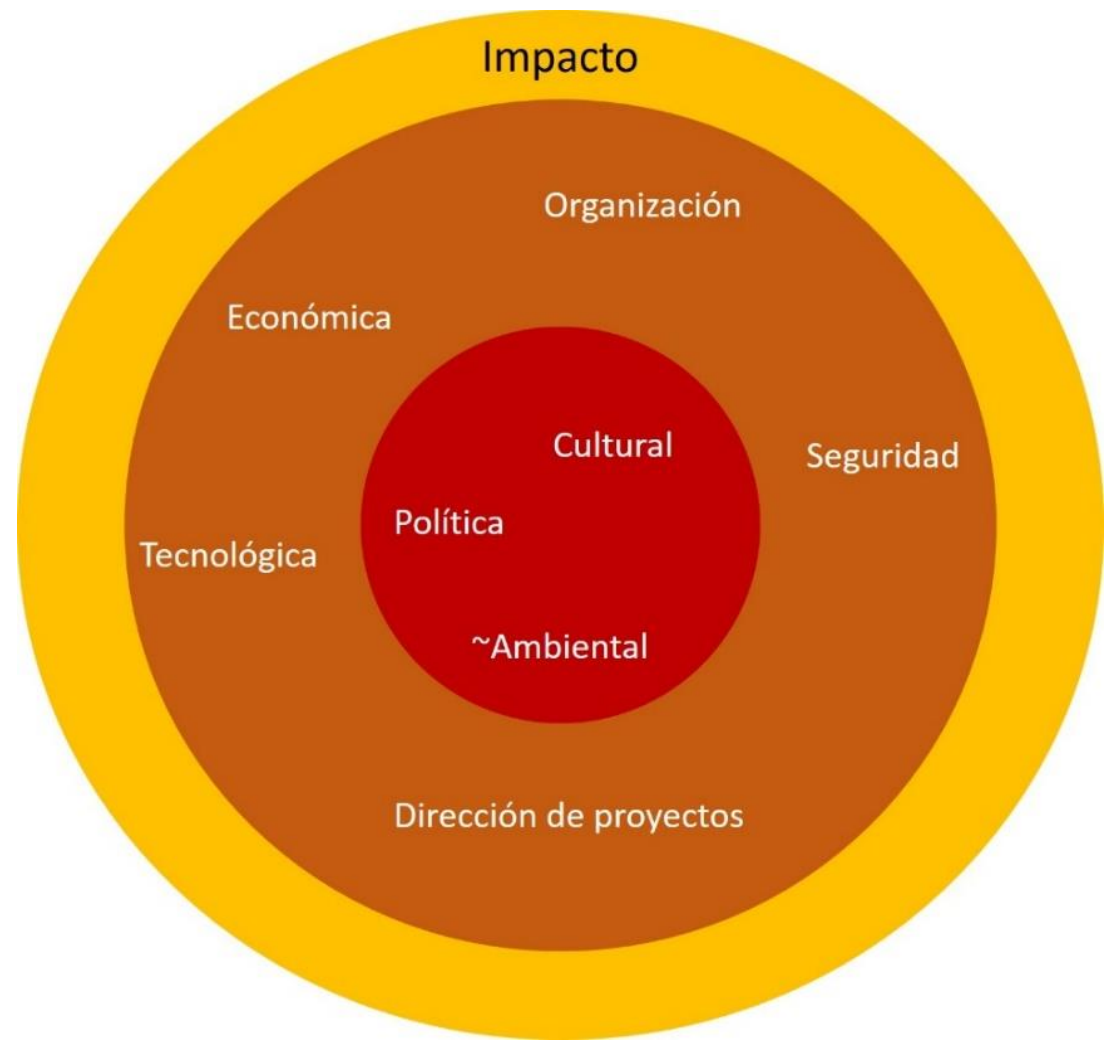

Figura 6.14. Condiciones suficientes, principales y contribuyentes: impacto. Fuente: elaboración propia a partir de los datos obtenidos con FsQCA 3.0.

La presencia de la categoría cultural tanto en las condiciones necesarias, como en las suficientes demuestra que el éxito en el impacto de un PCD en la zona del Cauca está muy vinculado a la buena gestión de estos riesgos, dado que son muy importantes. 


\section{B) Combinación de condiciones suficientes para el resultado de Impacto del proyecto}

Para obtener la combinación de condiciones suficientes para que un proyecto tenga ausencia de impacto en la comunidad beneficiaria, se parte desde la tabla de verdad correspondiente, que puede verse en el Anexo V.

Observando los datos, se filtra inicialmente por una consistencia mayor a 0,9, por ser en este valor donde se produce el salto mayor en los resultados, trabajando así con seis configuraciones posibles. Una vez realizado en el análisis estándar con estas configuraciones, y habiéndole pedido de nuevo que muestre tanto las condiciones causales presentes, como las ausentes, el programa presenta los resultados para la solución intermedia, con una cobertura de 0,54 y una consistencia de 0,91. Dado que esta solución tiene una representatividad media, se considera necesario volver a realizar el análisis, filtrando ahora por 0,83, incluyendo entonces dos configuraciones más. Esta solución intermedia sigue teniendo una cobertura media-alta, en principio no satisfactoria para el análisis, y una consistencia media-baja, atendiendo a los criterios de Ragin (2008) de superar el 0,8 para condiciones de suficiencia.

Se realiza otro filtro más por 0,81 para incluir nueve casos más. Esta última opción tiene una cobertura de 0,82 con una consistencia de 0,81 , con lo cual ya sí tiene una muy buena representatividad de las condiciones en el resultado de ausencia de impacto, y, pese a tener una baja consistencia, se considera la opción más representativa, dado que además la cobertura propia de su combinación más representativa es considerablemente más alta que la de las restantes.

La tabla 6.43 recoge el análisis de las tres soluciones intermedias, incluyendo también la combinación con cobertura propia más alta para cada una de las soluciones.

Tabla 6.43. Análisis opciones de la solución intermedia más representativa para el Impacto. Fuente: elaboración propia a partir de los datos obtenidos con FsQCA 3.0.

\begin{tabular}{cccccc}
\hline Filtro & $\begin{array}{c}\text { N.o de } \\
\text { casos } \\
\text { incluidos }\end{array}$ & $\begin{array}{c}\text { Cobertura de } \\
\text { la solución }\end{array}$ & $\begin{array}{c}\text { Consistencia } \\
\text { de la } \\
\text { solución }\end{array}$ & $\begin{array}{c}\text { Cobertura } \\
\text { propia }\end{array}$ & Combinación de soluciones \\
\hline 0,90 & 6 & 0,5405 & 0,9090 & 0,4054 & $\sim$ CUL*AMB*POL*ECO*DPR*TEC* ORG*SEG \\
0,83 & 8 & 0,6554 & 0,8362 & 0,4864 & CUL* AMB*POL*ECO*DPR*TEC*ORG*SEG \\
0,81 & 17 & 0,8175 & 0,8120 & $\mathbf{0 , 6 8 2 4}$ & CUL*POL*ECO*DPR*TEC*ORG*SEG \\
\hline
\end{tabular}

La Tabla 6.44 muestra las posibles combinaciones de la solución intermedia escogida, donde puede verse que la combinación más representativa es: CUL*POL*ECO*DPR*TEC*ORG*SEG. Esta combinación tiene una cobertura propia de 0,68 , y una cobertura única de 0,23 , siendo ambas coberturas muy superiores al resto 
de las combinaciones, por lo tanto, se la considera la combinación más acertada. Como se puede apreciar, en esta combinación aparecen presentes todas las categorías, salvo el medio ambiente, que al contrario de lo que pasaba al estudiar el resultado impacto, aparecía como ausente, en esta ocasión no aparece.

Tabla 6.44. Solución intermedia para el resultado de ausencia de impacto. Fuente: elaboración propia a partir de los datos obtenidos con FsQCA 3.0.

\begin{tabular}{|c|c|c|c|c|}
\hline Cód. & Combinación & $\begin{array}{c}\text { Cobertura } \\
\text { propia }\end{array}$ & $\begin{array}{c}\text { Cobertura } \\
\text { única }\end{array}$ & Consistencia \\
\hline C.2.I. & $\sim \mathrm{AMB}^{*} \mathrm{POL} * \mathrm{ECO} * \mathrm{DPR}{ }^{* \sim T E C}$ T ORG*SEG & 0.3918 & 0.4054 & 0.9062 \\
\hline C.2.II & CUL*POL*ECO*DPR*TEC*ORG*SEG & 0.6824 & 0.2297 & 0.8015 \\
\hline C.2.III & CUL*AMB* ${ }^{*} \mathrm{POL}^{* \sim} \mathrm{ECO}^{* \sim} \mathrm{DPR}^{* \sim}$ TEC ${ }^{*} \sim \mathrm{ORG}{ }^{*} \sim \mathrm{SEG}$ & 0.3445 & 0.0270 & 0.9272 \\
\hline C.2.IV & $\sim \mathrm{CUL}^{*} \sim \mathrm{AMB}^{*} \mathrm{POL}^{* \sim}$ ECO* DPR ${ }^{* \sim T E C}{ }^{*}$ ORG*SEG & 0.3243 & 0.0202 & 0.9230 \\
\hline C.2.V & CUL* AMB* POL*ECO*DPR ${ }^{* \sim T E C}{ }^{* \sim O R G}{ }^{* \sim}$ SEG & 0.3243 & 0.0202 & 0.9230 \\
\hline C.2.VI & CUL*AMB*POL*ECO* DPR* TEC*ORG* SEG & 0.3851 & 0.0135 & 0.8382 \\
\hline C.2.VII & $\sim$ CUL*AMB*POL*ECO*DPR*TEC* ORG*SEG & 0.4054 & 0.0202 & 0.9090 \\
\hline
\end{tabular}

Cobertura de la solución: 0.8175

Consistencia de la solución: 0.8120

Se comprueba a continuación qué combinación nos ofrece la solución simplificada, que puede verse en la Tabla 6.45

Tabla 6.45. Solución simplificada para el resultado ausencia de impacto. Fuente: elaboración propia a partir de FsQCA 3.0.

\begin{tabular}{lccc}
\hline \multicolumn{1}{c}{ Combinación } & $\begin{array}{c}\text { Cobertura } \\
\text { propia }\end{array}$ & $\begin{array}{c}\text { Cobertura } \\
\text { única }\end{array}$ & Consistencia \\
\hline$\sim$ ORG & 0.7162 & 0.0675 & 0.8983 \\
POL*ECO*SEG & 0.75 & 0.1351 & 0.7708 \\
CUL*AMB* TEC & 0.4864 & 0 & 0.8372 \\
CUL*AMB* DPR & 0.5135 & 0 & 0.8539 \\
CUL*ECO* TEC & 0.4864 & 0 & 0.8275 \\
\hline Cobertura de la solución: 0.8986 & & \\
Consistencia de la solución: 0.7777 & & \\
\hline
\end{tabular}

La combinación con una cobertura propia mayor, y, por tanto, la combinación más representativa es POL*ECO*SEG, con una cobertura propia de 0,75 , y una cobertura única también considerablemente alta, de 0,13 y una consistencia de 0,77.

La interpretación que se puede dar de ambas soluciones, intermedia y simplificada, es que la presencia de altos riesgos principalmente políticos, económicos y de seguridad, 
pero sin descuidar todos los demás, a excepción de los relacionados con el medio ambiente, que no entra en la ecuación, trae consigo la ausencia de impacto en la comunidad beneficiaria de un PCD en la zona del Cauca. Las condiciones principales (en rojo) y las condiciones contribuyentes (en naranja) se muestran en la Figura 6.15.

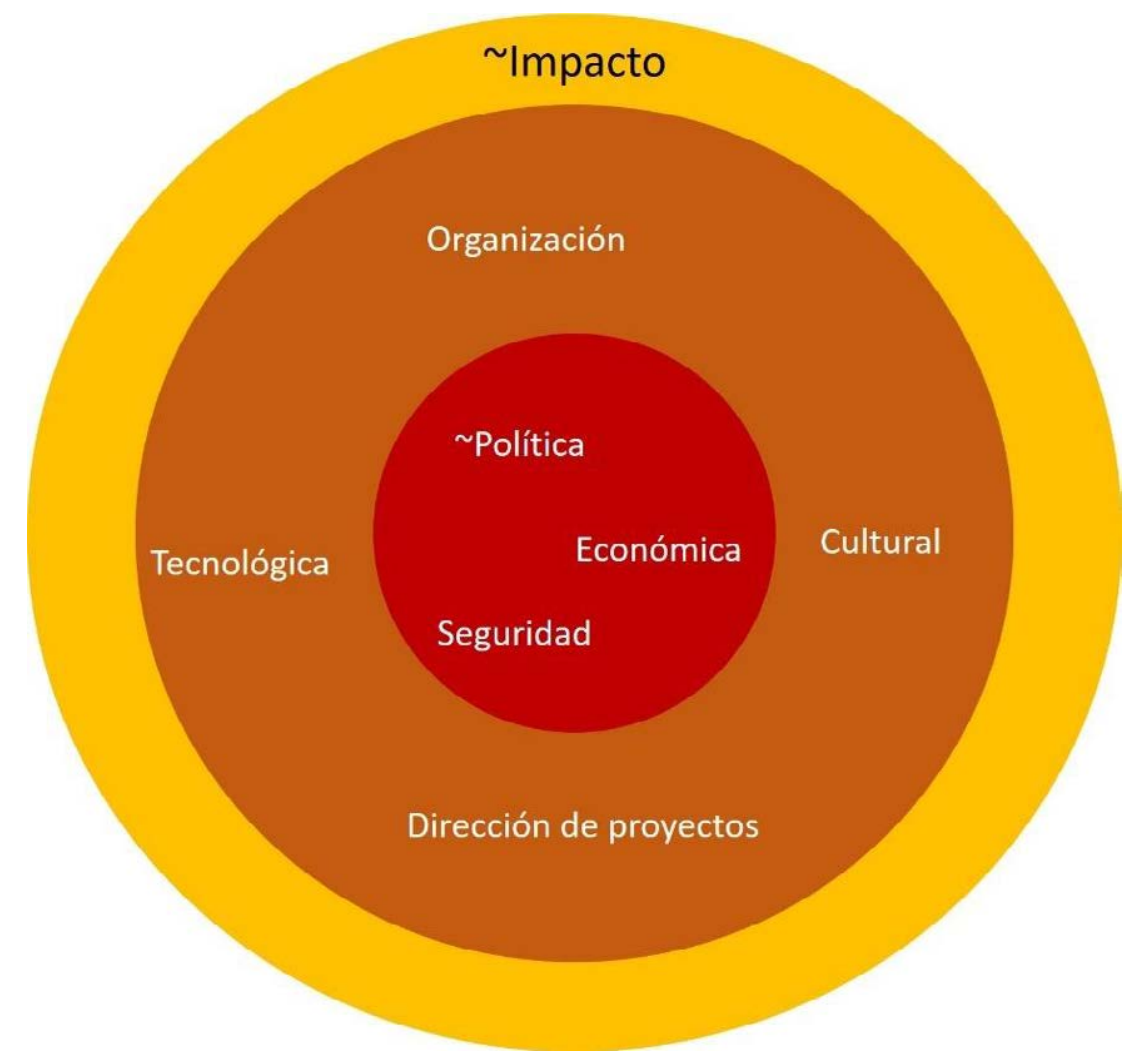

Figura 6.15. Condiciones suficientes, principales y contribuyentes: ausencia de impacto.

Fuente: elaboración propia a partir de los datos obtenidos con FsQCA 3.0.

La presencia de la categoría de Economía tanto en las condiciones necesarias como en las suficientes para que un proyecto no tenga impacto se puede interpretar como que habría que prestar especial atención a los riesgos económicos, dado que su presencia sin control contribuiría notablemente a la falta de impacto de un PCD en la zona tratada.

\section{C) Combinación de condiciones suficientes para el resultado de Dirección de proyectos}

Analizando ahora el éxito de un PCD en su vertiente de dirección de proyectos, se procede como en los análisis anteriores, partiendo desde la tabla de verdad correspondiente (ver Anexo V), y aplicando tras una previa observación, el filtro de consistencia en 0,95 , lo que nos deja en 14 configuraciones posibles. Realizado el análisis estándar, incluyendo las condiciones presentes, como las ausentes, la solución 
intermedia que se obtiene posee una cobertura de 0,78 y una consistencia de 0,88 , considerándose muy representativa. La Tabla 6.46 muestra las distintas combinaciones de esta solución intermedia.

Tabla 6.46. Solución intermedia para el resultado de dirección de proyectos.

Fuente: elaboración propia a partir de los datos obtenidos con FsQCA 3.0.

\begin{tabular}{|c|c|c|c|c|}
\hline Cód. & Combinación & $\begin{array}{c}\text { Cobertura } \\
\text { propia }\end{array}$ & $\begin{array}{c}\text { Cobertura } \\
\text { única }\end{array}$ & Consistencia \\
\hline C.3.I & $\mathrm{POL}^{* \sim} \mathrm{AMB}^{* \sim} \mathrm{DPR}^{* \sim} \mathrm{ECO}^{*} \mathrm{ORG} * \sim \mathrm{TEC} * \sim \mathrm{SEG}$ & 0.3777 & 0.0166 & 0.9714 \\
\hline C.3.II & CUL*POL* AMB* DPR* ECO*ORG* TEC & 0.3611 & 0.0111 & 0.9701 \\
\hline C.3.III & CUL* AMB*DPR*ECO*ORG*TEC*SEG & 0.5166 & 0.0111 & 0.9687 \\
\hline C.3.IV & CUL* POL*DPR*ECO*ORG*TEC*SEG & 0.4944 & 0.0222 & 0.9780 \\
\hline C.3.V & CUL* POL*AMB* DPR* ECO* ORG ${ }^{*} \sim$ TEC ${ }^{*} \sim$ SEG & 0.2944 & 0.0166 & 0.9636 \\
\hline C.3. $\mathrm{VI}$ & $\sim \mathrm{CUL}^{*} \mathrm{POL}{ }^{*} \mathrm{AMB}{ }^{*} \sim \mathrm{DPR}{ }^{*} \mathrm{ECO}{ }^{*} \mathrm{ORG}{ }^{*} \sim \mathrm{TEC} *$ SEG & 0.3388 & 0.0111 & 0.9682 \\
\hline C.3.VII & $\mathrm{CUL}^{* \sim} \mathrm{POL}^{* \sim} \mathrm{AMB}^{* \sim} \mathrm{DPR}^{* \sim}$ ECO*ORG*TEC*SEG & 0.3888 & 0.0166 & 1 \\
\hline C.3.VIII & $\sim \mathrm{CUL}^{*} \mathrm{POL}{ }^{*}$ AMB* DPR $* \sim$ ECO*ORG*TEC*SEG & 0.3444 & 0.0111 & 0.9841 \\
\hline C.3.IX & CUL*POL* ${ }^{*}{ }^{*} B^{*}$ DPR $^{*} E C O * \sim O R G * \sim T E C * S E G$ & 0.3277 & 0.0166 & 0.9672 \\
\hline C.3.X & $\sim \mathrm{CUL} * \mathrm{POL} * \mathrm{AMB} * \mathrm{DPR} * \mathrm{ECO} * \sim \mathrm{ORG} * \mathrm{TEC} * \mathrm{SEG}$ & 0.3555 & 0.0166 & 0.9696 \\
\hline C.3.XI & CUL*POL*AMB*DPR*ECO*ORG*TEC* SEG & 0.4611 & 0.0277 & 0.9764 \\
\hline C.3.XII & CUL*POL*AMB*DPR* ECO*ORG*TEC*SEG & 0.4444 & 0.0166 & 0.9756 \\
\hline
\end{tabular}

Cobertura de la solución: 0.7530

Consistencia de la solución: 0.9457

De las combinaciones posibles, la que tiene mayor cobertura propia $(0,52)$, está muy igualada con la siguiente $(0,49)$, que tiene incluso el doble de representatividad en términos de cobertura única. Por eso se considerarán ambas combinaciones, que comparten, además, muchas semejanzas.

Por un lado, la combinación con más representatividad es la formada por CUL* AMB*ECO*DPR*TEC*ORG*SEG, que difiere de la segunda más representativa (CUL* POL*ECO*DPR*TEC*ORG*SEG) solo en dos categorías, manteniendo las seis restantes iguales. Una de las combinaciones incluye la ausencia de la categoría medioambiental, dejando fuera de la combinación a la categoría política, mientras que la otra incluye la ausencia de la categoría política, dejando fuera a la categoría medioambiental. La primera interpretación que puede hacerse de ello, previa a ver los resultados de la solución simplificada, es que la ausencia de riesgos medioambientales puede compensar la presencia de los demás riesgos, excepto los políticos, de cara al éxito de la dirección del proyecto. Y que, del mismo modo, la ausencia de riesgos políticos puede compensar la existencia del resto de riesgos, salvo los medioambientales. Esto da una gran importancia al cuidado de los riesgos relacionados con estas dos categorías. 
Observando la solución simplificada (Tabla 6.47), la combinación con mayor cobertura propia $(0,64)$ destaca sobre las demás y es la formada por la siguiente combinación: $\sim \mathrm{AMB}^{*} \mathrm{ORG}$, donde aparece la presencia de la categoría organizativa, y la ausencia de la categoría ambiental. Dado que la categoría organizativa aparecía presente en ambas combinaciones de la solución intermedia, cobra valor la que incluía la ausencia de los riesgos medioambientales.

Tabla 6.47. Solución simplificada para el resultado de dirección de proyectos. Fuente: elaboración propia a partir de los datos obtenidos con FsQCA 3.0.

\begin{tabular}{lccc}
\hline \multicolumn{1}{c}{ Combinación } & $\begin{array}{c}\text { Cobertura } \\
\text { propia }\end{array}$ & $\begin{array}{c}\text { Cobertura } \\
\text { única }\end{array}$ & Consistencia \\
\hline$\sim$ ECO*ORG*SEG & 0.5111 & 0.0111 & 0.9787 \\
AMB* ORG & 0.4944 & 0.0111 & 0.9368 \\
$\sim$ POL*AMB & 0.4722 & 0 & 0.9550 \\
$\sim$ CUL*AMB & 0.4444 & 0 & 0.9523 \\
$\sim$ AMB*ORG & 0.6388 & 0.0055 & 0.9663 \\
$\sim$ POL*ORG & 0.5555 & 0 & 0.9615 \\
$\sim$ CUL*ORG & 0.4888 & 0 & 0.9565 \\
$\sim$ POL*TEC & 0.5388 & 0 & 0.9417 \\
$\sim$ POL*SEG & 0.5388 & 0 & 0.9509 \\
$\sim$ ECO* TEC ${ }^{*}$ SEG & 0.4666 & 0 & 0.9230 \\
$\sim$ DPR* ECO* SEG & 0.4833 & 0 & 0.9255 \\
CUL*POL* AMB & 0.5222 & 0 & 0.9591 \\
ECO*TEC* SEG & 0.4722 & 0 & 0.9770 \\
CUL* AMB*SEG & 0.5722 & 0 & 0.9626 \\
POL*DPR*ECO* SEG & 0.4722 & 0 & 0.9550 \\
AMB*DPR*ECO* SEG & 0.4611 & 0 & 0.9764 \\
DPR*ECO*ORG* SEG & 0.4722 & 0 & 0.9770 \\
\hline Cobertura de la solución: 0.8222 & & \\
Consistencia de la solución: 0.9079 & & \\
\hline
\end{tabular}

Así, se podría decir que, minimizando principalmente los riesgos relacionados con el medio ambiente, y con una buena gestión de todos los demás, especialmente los organizativos, sería posible conseguir el éxito en la dirección de un PCD en la zona del Cauca. La Figura 6.16 muestra en rojo las condiciones principales, y en naranja las contribuyentes para obtener como resultado el éxito en la dirección de proyectos de este tipo y en esta zona determinada.

El hecho de que la categoría de Organización aparezca tanto en las condiciones necesarias, como en las principales de las suficientes, le da a los riesgos relacionados con ella un valor muy significativo, esto es, habría que prestarles especial atención para alcanzar el éxito en la DP. 


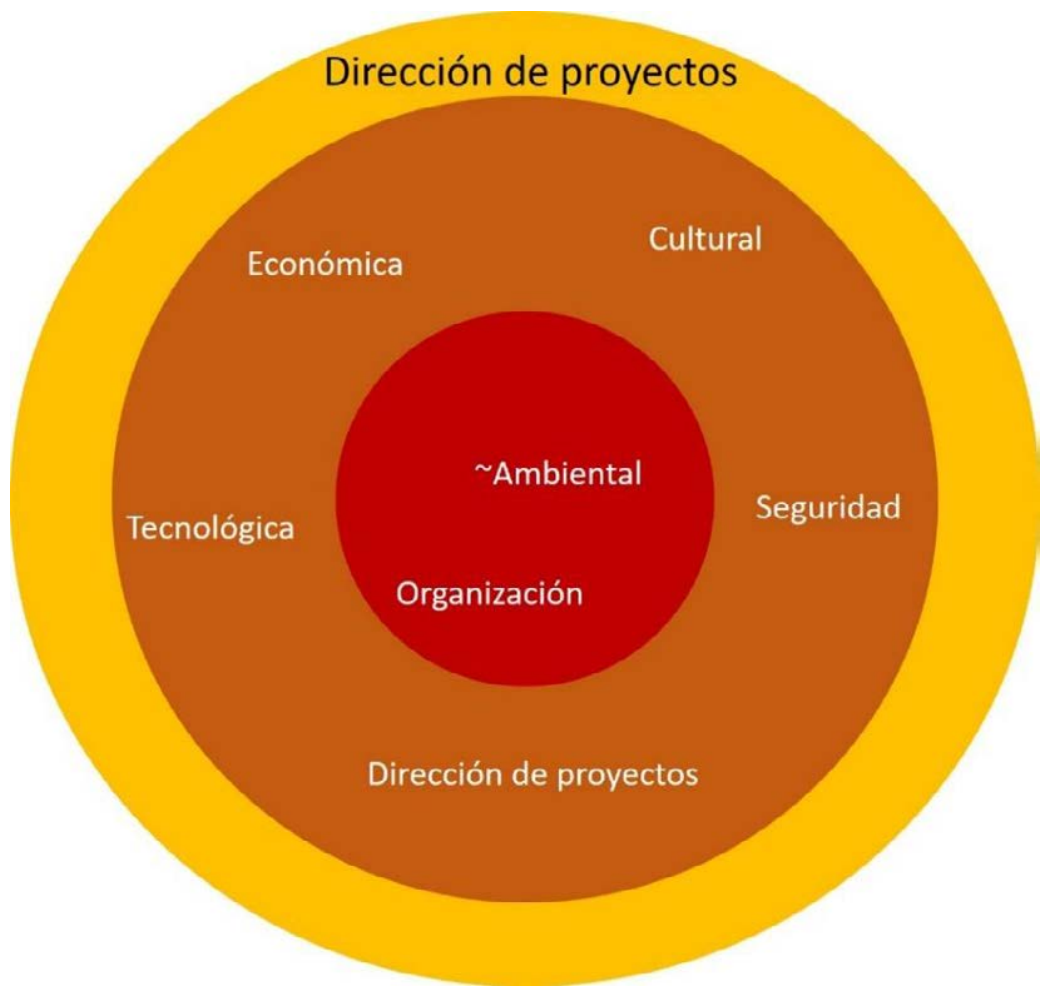

Figura 6.16. Condiciones suficientes, principales y contribuyentes: dirección de proyectos. Fuente: elaboración propia a partir de los datos obtenidos con FsQCA 3.0.

\section{D) Combinación de condiciones suficientes para el resultado de Dirección de proyectos}

Para obtener la combinación de condiciones suficientes para que un proyecto tenga ausencia de éxito en la dirección del proyecto, se parte desde la tabla de verdad correspondiente (Anexo VI) y, tras la observación de los valores, se filtra por el valor de 0,8 por ser la consistencia mínima que permite realizar un estudio fiable (Ragin, 2008). Las consistencias en esta tabla de verdad son todas muy bajas, y esto hace que con ese filtro tan apurado solo se consideren seis configuraciones posibles. Tras el análisis estándar con estas configuraciones, y pidiendo que muestre tanto las condiciones causales presentes, como las ausentes, el programa muestra los resultados para la solución intermedia, con una cobertura de 0,56 y una consistencia de 0,84 . Es cierto que esta solución tiene una representatividad media, pero es la mejor opción dentro de los márgenes válidos de trabajo para obtener una solución fiable. La Tabla 6.48 muestra las posibles combinaciones de esta solución intermedia.

De las combinaciones posibles que aparecen en la Tabla 6.48, la que tiene mayor cobertura propia $(0,45)$, está muy igualada con la siguiente $(0,42)$. Por eso se considerarán ambas combinaciones. Estas combinaciones comparten, además, muchas semejanzas. Al centrarse en sus diferencias, se puede apreciar que en la más relevante 
aparecen todas las categorías presentes, menos la cultural y la de organización, que aparecen ausentes. En cambio, en la otra combinación, la cultura no aparece, y, junto a la ausencia de la categoría de organización, están ausentes también la ambiental y la tecnológica.

Tabla 6.48. Solución intermedia para el resultado de ausencia de éxito en la DP.

Fuente: elaboración propia a partir de los datos obtenidos con FsQCA 3.0.

\begin{tabular}{|c|c|c|c|c|}
\hline Cód. & Combinación & $\begin{array}{c}\text { Cobertura } \\
\text { propia }\end{array}$ & $\begin{array}{c}\text { Cobertura } \\
\text { única }\end{array}$ & Consistencia \\
\hline C.4.I & $\sim$ AMB*POL*ECO*DPR* TEC $* \sim O R G * S E G$ & 0.4230 & 0.0384 & 0.8593 \\
\hline C.4.II & CUL*AMB* ${ }^{*} \mathrm{POL}^{* \sim} \mathrm{ECO}^{* \sim} \mathrm{DPR}^{* \sim}$ TEC* ORG* SEG & 0.3538 & 0.0230 & 0.8363 \\
\hline C.4.III & $\sim \mathrm{CUL}^{* \sim} \mathrm{AMB}^{*} \mathrm{POL}^{* \sim} \mathrm{ECO} * \sim \mathrm{DPR}^{*} \sim \mathrm{TEC} * \sim \mathrm{ORG} * \mathrm{SEG}$ & 0.3692 & 0.0230 & 0.9230 \\
\hline C.4.IV & $\mathrm{CUL}^{* \sim} \mathrm{AMB}^{* \sim}$ POL*ECO*DPR* TEC $* \sim \mathrm{ORG} * \sim \mathrm{SEG}$ & 0.3461 & 0.0230 & 0.8653 \\
\hline C.4.V & CUL*AMB*POL*ECO*DPR*TEC* ORG*SEG & 0.4461 & 0.0538 & 0.8787 \\
\hline
\end{tabular}

Cobertura de la solución: 0.5615

Consistencia de la solución: 0.8295

Antes de interpretar estos resultados, se observa también la solución simplificada que aparece en la Tabla 6.49 En ella puede verse que la ausencia de la categoría organización es la combinación única, con una buena cobertura propia $(0,72)$ es una solución principal para que no exista éxito en la dirección de proyectos.

Tabla 6.49. Solución simplificada para el resultado de ausencia de éxito en la DP. Fuente: elaboración propia a partir de los datos obtenidos con FsQCA 3.0.

\begin{tabular}{lccc}
\hline \multicolumn{1}{c}{ Combinación } & $\begin{array}{c}\text { Cobertura } \\
\text { propia }\end{array}$ & $\begin{array}{c}\text { Cobertura } \\
\text { única }\end{array}$ & Consistencia \\
\hline$\sim$ ORG & $\mathbf{0 . 7 2 3 1}$ & 0.7231 & 0.7966 \\
\hline Cobertura de la solución: 0.7231 & & \\
Consistencia de la solución: 0.7966 & & \\
\hline
\end{tabular}

Una primera interpretación que puede hacerse atendiendo a estas dos soluciones es que la presencia de riesgos importantes de todas las categorías, aún con la ausencia de riesgos organizativos y culturales, conllevaría a la ausencia de éxito en la dirección del proyecto. Otra interpretación podría ser que, sin asumir riesgos organizativos, no se alcanza el éxito en la DP.

En esta ocasión no se representa la solución con sus contribuciones principales y contribuyentes dado que no se podría establecer como única, debido a las semejanzas entre C.4.I y C.4.V. 


\subsubsection{Resumen de resultados y validación}

En este apartado se presenta un resumen de los resultados encontrados, mostrando además el contraste que se ha hecho de los mismos con la persona responsable de los PCD de la gobernación del Cauca. Se tratan también de presentar las conclusiones extraídas.

La Figura 6.17 resume las condiciones necesarias y suficientes para cada uno de los resultados, mostrando además las coberturas y consistencias de cada una de las soluciones y combinaciones.

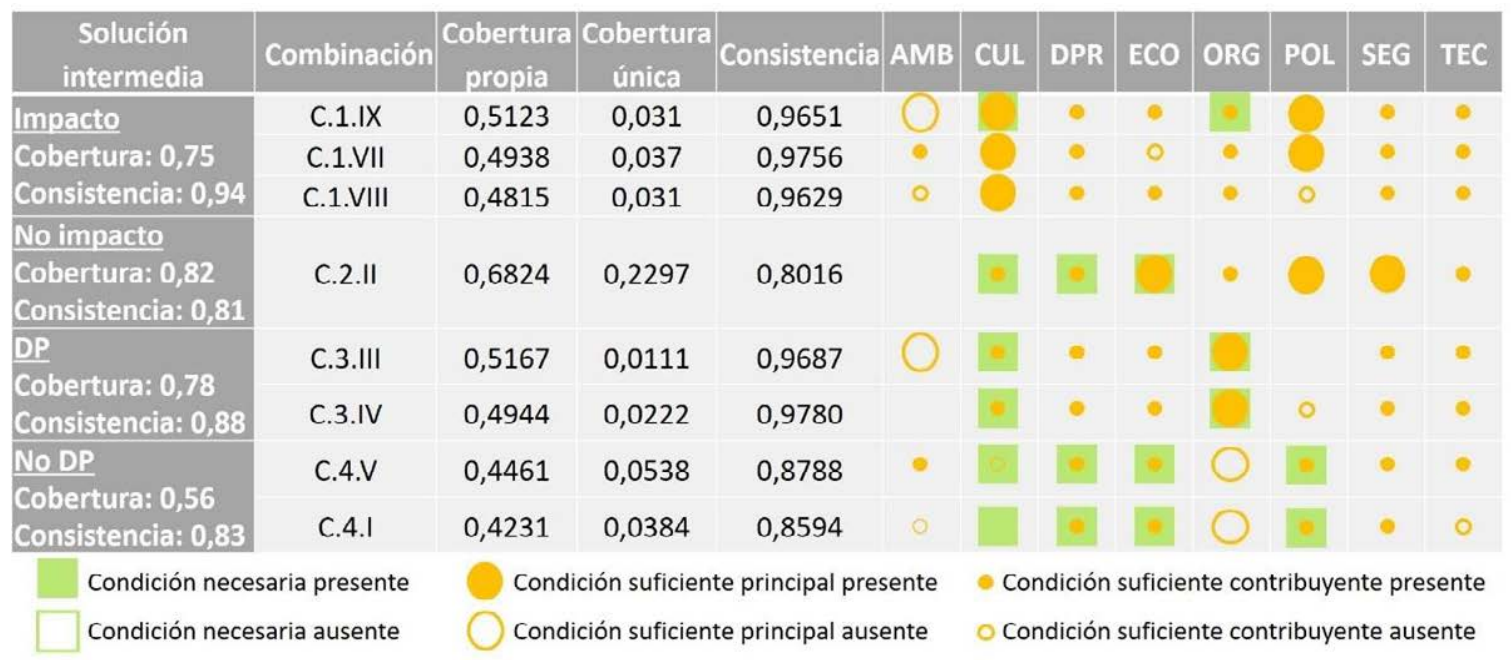

Figura 6.17. Resumen condiciones.

Fuente: elaboración propia a partir de los datos obtenidos con FsQCA 3.0.

La fuerza de la unión de las condiciones necesarias y suficientes establece como significativas las siguientes relaciones biunívocas:

\section{Éxito en el impacto del proyecto $\leftrightarrow$ Riesgos culturales}

\section{Ausencia de éxito en el impacto del proyecto $\leftrightarrow$ Riesgos económicos}

\section{Éxito en la dirección del proyecto $\leftrightarrow$ Riesgos organizativos}

Estas relaciones muestran quizá los resultados más valiosos de esta Tesis Doctoral, estableciendo, que se podrá obtener éxito en el impacto en la comunidad beneficiaria con un PCD en el Cauca si y solo si se presta especial atención a los riesgos asociados 
con las diferencias culturales, identificándolos y controlándolos desde el principio. En la misma línea, un PCD en la zona estudiada, no tendrá impacto en la comunidad beneficiaria si y solo si los riesgos económicos no son tratados adecuadamente. En torno al impacto del proyecto y a su ausencia, están muy presentes también los riesgos políticos, por lo que se recomienda prestarles también mucha atención. Estos primeros resultados han sido contrastados con el Director de Cooperación de la Gobernación del Cauca para su validación, a través de una entrevista realizada en diciembre de 2018 por vía telefónica, con una duración de 1,5 horas y de la cual se extraen las consideraciones más relevantes.

Lo primero que se contrastó con él fue la importancia de los riesgos asociados a las diferencias culturales para que el PCD tenga impacto en la comunidad, que además de tener que ver directamente con el impacto, aparece presente como condición necesaria en casi todos los resultados. El representante de cooperación manifestó estar de acuerdo y confirma la importancia de considerar la cultura y los saberes ancestrales de la zona, dado que como dice "la parte cultural es imprescindible. Si un proyecto no encaja con la cultura, no funciona". Además, resalta, "lo cultural en esta zona del Cauca es muy importante, hay muchas etnias, y a veces se cuida una sola etnia y se descuidan las otras y se crean rivalidades que ponen el peligro el desarrollo del proyecto". Se debe tener en cuenta también, indica, que "algunas comunidades indígenas son autoridad ambiental, a través del CRIC ${ }^{28}, \mathrm{y}$, por lo tanto, se debe contar con su apoyo para poder realizar cualquier proyecto".

En relación a la ausencia de impacto de un proyecto y su relación con los riesgos económicos, el técnico de cooperación establece que este riesgo es especialmente crítico "cuando el proyecto se ejecuta entre varias entidades", para lo cual recomienda que se "independicen responsabilidades y fondos, para no retrasar a los demás", dado que muchas veces, este retraso de fondos implica que no se puedan realizar algunas actividades, con el consecuente impacto sobre el alcance del proyecto, que puede acabar suponiendo que el PCD no tenga el impacto inicialmente planeado en la comunidad beneficiaria (falta de impacto).

Igualmente, la influencia de los riesgos políticos es reconocida, dado que, en sus propias palabras, "si un proyecto no está en el plan de desarrollo, es muy difícil de articular. Los proyectos tienen que estar articulados con las políticas de desarrollo regional", y, además, "se tienen que considerar los riesgos asociados a los cambios de gobierno".

La tercera relación biunívoca obtenida establece que un PCD en el Cauca tendrá éxito en la dirección del mismo si y solo si los riesgos organizativos son bien identificados y

\footnotetext{
${ }^{28}$ CRIC: Consejo Regional Indígena del Cauca, fundado en 1971 e integrado por siete Cabildos y siete resguardos indígenas, busca defender los territorios ancestrales y los espacios de vida de las comunidades indígenas.
} 
controlados a lo largo del proyecto. Esta conclusión también ha sido contrastada con el director de cooperación, quien la valida y opina que "los riesgos que más afectan a los proyectos de cooperación son los que afectan a la propia sostenibilidad del proyecto, basados en la escasa organización y falta de alianzas entre las diversas organizaciones ejecutantes, riesgos que incluiría en la categoría de organización".

Con menor fuerza, y sin ser en ningún caso una relación biunívoca, está la relación entre la ausencia de éxito en la dirección del proyecto y los riesgos políticos, económicos y de la propia dirección del proyecto. Además, este resultado cuenta con una solución con una cobertura media que hace que las interpretaciones que se establezcan tengan que hacerse con la debida precaución. Es por eso que en esta Tesis Doctoral no se van a tratar de extraer más conclusiones sobre estas relaciones de las ya presentadas previamente en el punto $D$ de este mismo apartado.

Las que sí se consideran muy valiosas son las otras tres relaciones y la posterior validación que se hace de ellas con el responsable de cooperación de la Gobernación del Cauca, por tratarse de la máxima autoridad local en el asunto y por contar además con una amplia experiencia en el conocimiento de los PCD en el Cauca.

Por último, para una validación general de la tabla resumen presentada en la Figura 6.17, se preguntó al responsable de cooperación de la Gobernación del Cauca por qué creía que los riesgos técnicos y de seguridad no parecían ser tan representativos, así como su opinión sobre los riesgos ambientales y la condición de su ausencia. Su respuesta fue que "la parte técnica la puedes corregir, y la parte de seguridad es muy importante y puede impedir que se desarrollen muchas actividades, de ahí su influencia para que un proyecto no tenga impacto, pero podría arreglarse en la mayoría de los casos con el ejército". En cuanto al medio ambiente, considera que "hoy en día tiene que ser transversal a todos los proyectos, al igual que el género, porque el respeto a la tierra es esencial. Casi todos los PCD que se desarrollan en el Cauca cuidan ese aspecto ya, por eso tal vez, aun siendo muy importante, no salga nunca como una condición necesaria".

\subsection{Registro de riesgos}

Tras haber realizado la identificación de los principales riesgos en los proyectos estudiados en el caso del Cauca, se presenta como resultado de esta Tesis Doctoral un Registro de 99 Riesgos para PCD en el Cauca. Éste será la base sobre la cual se podrán ir añadiendo nuevos riesgos según se estudien nuevos proyectos, de tal manera que se genere un registro disponible y accesible para todas las organizaciones que trabajen en la zona. En el Capítulo 7 se podrán ver las propuestas que se realizan para futuros trabajos.

La Tabla 6.50. muestra el registro de los riesgos agrupados por las mismas ocho categorías con las que se ha trabajado en el documento. Aunque está basado en los PCD del Cauca, muchos de los riesgos incluidos podrían ser extrapolables a otros territorios. 
Tabla 6.50. Registro de riesgos por categorías para PCD en Cauca (Colombia).

Fuente: elaboración propia.

\section{AMBIENTAL}

- Imposibilidad de trasladarse para recibir formación debido a inclemencias meteorológica

- Imposibilidad de desarrollar las actividades debido a inclemencias meteorológicas

- Inclemencias meteorológicas que imposibiliten acudir a reuniones

- Deslizamientos del terreno en la vía

\section{CULTURAL}

- Dificultades para preguntar las dudas que surjan por parte de los beneficiarios

- Dificultades en la comunicación de los beneficiarios con el equipo del proyecto

- Dificultades en la comunicación entre las propias personas beneficiarias

- Mayor participación en el proyecto por afición a las actividades deportivas (Oportunidad)

- Mejor aceptación del proyecto por el gran arraigo cultural (Oportunidad)

- Aumento de la complejidad por la necesidad de introducir el enfoque diferencial étnico

- Dificultades en el trabajo con diferentes grupos étnicos

- Recelos entre los grupos étnicos

- Falta de motivación de los beneficiarios

- Desconfianza en los beneficios del proyecto

- Miedos a enfrentar nuevos retos

- Dependencia de la participación de las mujeres del permiso de sus esposos o padres

- Rechazo social a la mujer por la apropiación de roles tradicionalmente masculinos

- Falta de apoyo familiar en el proceso de empoderamiento de la mujer

- Distinta concepción del tiempo

- Escasa orientación a largo plazo

- Dependencia del liderazgo de personas concretas

- Falta de participación sin orden de superiores

- Resistencia al trabajo asociativo colaborativo

\section{DE DIRECCIÓN DE PROYECTOS}

- Inexperiencia del director/a del proyecto en proyectos similares

- Falta de disponibilidad de tiempo del director/a del proyecto

- No consideración de una partida económica para imprevistos

- Falta de coordinación entre las personas participantes del proyecto

- Falta de comunicación de la organización con los actores del proyecto en terreno

- Falta de comunicación con las instituciones implicadas

- Diferencia de intereses entre las diferentes instituciones

- Falta de seguimiento programado del proyecto

- Descoordinación con los tiempos planificados

- Escasa identificación de los afectados negativamente por el proyecto

- Difícil acceso a información necesaria para el proyecto

- Inapropiada identificación de la comunidad beneficiaria

- Inapropiada priorización de las actividades a realizar

- Mala promoción de los eventos relacionados con el proyecto 


\section{ECONÓMICA}

- Suspensión de la ayuda por parte de la entidad financiadora

- Retrasos en la recepción de partidas económicas

- Alto coste de inversión en equipos

- Ausencias a formaciones debido a necesidad de mantener otras actividades económicas

- Incapacidad de hacer frente al coste de transporte para recibir la formación

- Falta de interés de los inversores para cofinanciar futuros emprendimientos a medio plazo

- Mala gestión del dinero ganado en las actividades productivas generadas con el proyecto

- Problemas de inseguridad derivados del manejo de dinero fruto de la actividad productiva

- Aumento del precio de los insumos necesarios para la actividad productiva

- Imposibilidad de consolidar las actividades productivas por la situación económica del país

- Abandono de la nueva actividad productiva por menor rendimiento que los cultivos ilícitos

- No seguimiento de las recomendaciones de los técnicos en materia económica

- Fluctuación del precio de compra-venta de insumos

- Variación en el precio de transporte de los insumos/equipos

- Fluctuación en el cambio de divisa

\section{ORGANIZATIVA}

- Escaso análisis previo de la comunidad en la que se va a realizar la intervención

- Mala selección de los participantes

- Mala identificación de los posibles perjudicados por el proyecto

- Falta de confianza en las capacidades de las personas beneficiarias

- No consideración de la falta de humanidad que puede existir en algunos terrenos

- Desconocimiento de los trámites administrativos

- Dificultades para trabajar en el terreno por parte del equipo de proyecto

- Falta de asistencia a las formaciones

- Distintas prioridades de los beneficiarios

- Falta de confianza para suministrar información veraz

- Temor a asumir nuevas responsabilidades por parte de las organizaciones

- Dependencia de las capacidades de los orientadores

- Incapacidad para comprender el lenguaje técnico por parte de los beneficiarios

- Dificultades con la lectura/escritura por parte de los beneficiarios

- Mala selección de las actividades sin considerar las capacidades de los beneficiarios

- Abandono del proyecto por parte de los orientadores

- Abandono del proyecto por parte de los beneficiarios

- Abandono del proyecto por parte de las instituciones que integran el proyecto

- Estudios de mercado poco reales por miedo a no recibir la ayuda

- Dificultades en el uso de nuevas tecnologías por parte de los beneficiarios

- Falta de interés por parte de los beneficiarios en los temas elegidos de formación

- Falta de compromiso por parte de los beneficiarios para atender a las formaciones

- Inapropiada transferencia de conocimiento por parte de instituciones capacitadores

- Diferentes niveles de formación entre los beneficiarios participantes en el proyecto 


\section{POLÍTICA}

- Cancelación del apoyo al proyecto por cambio de gobierno

- Falta de apoyo del gobierno local

- Corrupción e intereses políticos

- Cambio de la legislación vigente

- Falta de colaboración de las instituciones públicas

- Inadecuada priorización de áreas potenciales de desarrollo debido a preferencias políticas

- Falta de apoyo en la difusión de las actividades

- Falta de interés del gobierno local para medir los impactos de los proyectos

- Falta de interés por las alcaldías futuras en dar continuidad al proyecto

\section{SEGURIDAD}

- Escasa documentación y evaluación del proyecto por ser en territorio armado

- Inseguridad para realizar el acompañamiento

- Cierre de las vías por protestas

- Presencia de actores armados en terreno

- Desplazamientos por zonas conflictivas para realizar las formaciones

- Alteración del orden público (levantamientos, manifestaciones,...)

\section{TECNOLÓGICA}

- Pérdida de la corriente eléctrica

- Falta de ordenadores en las casas para continuar con lo aprendido en las formaciones

- Uso de teléfonos muy antiguos por los beneficiarios para usar App requeridas

- Imposibilidad de utilizar plataformas web

- Difícil acceso al equipo por alto costo

- Escasa cobertura en la zona

- Falta de herramientas adecuadas para construcción y mantenimiento de zona productiva

- Falta de suministro de agua en el terreno

\subsection{Diseño de la Metodología del Marco Lógico con Enfoque de Gestión de}

\section{Riesgos}

La metodología del Marco Lógico con Enfoque de Gestión de Riesgos (MLEGR) responde a la necesidad contrastada con los profesionales, a través del cuestionario del $\mathrm{ML}$, de introducir elementos de la GR en la metodología por excelencia en las intervenciones de cooperación al desarrollo, el ML. Esta necesidad surge del hecho de que las personas y organizaciones que trabajan para el desarrollo quieren mejorar la situación actual en lo local y hacia lo global, y esta mejora supone un cambio y todo cambio implica tomar riesgos, entonces, hay que gestionarlos.

La metodología MLEGR consta de dos ámbitos de aplicación, el primero a nivel organización, y el segundo a nivel de la propia metodología. 


\subsubsection{La metodología del MLEGR en el ámbito de la propia organización}

Al ser la metodología del MLEGR una metodología integral, cada organización que la utilice deberá a su vez establecer una cultura de GR interna propia, que empezará con la elaboración de un Plan de Gestión de Riesgos, en el que se establezcan las metodologías de GR, estableciendo roles y responsabilidades, definiendo las escalas con las que se va a trabajar para evaluar la probabilidad de ocurrencia y el impacto de un riesgo, y su significado, así como la tolerancia al riesgo. También se establecerán las categorías de riesgo que se van a considerar y los formatos documentales con los que se va a trabajar. Este plan igualmente debe de abordar las estrategias de respuesta al riesgo, así como las herramientas de control. Esto permitiría a la organización no solo considerar la GR a nivel proyecto, sino también a nivel estratégico (porfolio).

Previo al propio planteamiento del proyecto y debido a este carácter integral, se deberían analizar también los riesgos asociados al propio equipo participante en el proyecto y al tipo de proyecto que se pretende diseñar, así como a la zona geográfica en la que se desee ejecutar. Para ello se proponen tres niveles: Equipo, Tipología y Terreno. Este análisis (TTT., por sus siglas en inglés) está esquemáticamente representado en la Figura 6.18.

El análisis TTT debería realizarse previo a la formulación de cualquier Proyecto de Cooperación al Desarrollo (PCD). Este análisis quiere ayudar, desde el principio, a mejorar la gestión de riesgos, para garantizar que las intervenciones propuestas sean más eficaces. También podría ayudar a decidir la pertinencia de no seguir adelante con la iniciativa si el nivel de riesgo fuera muy elevado.

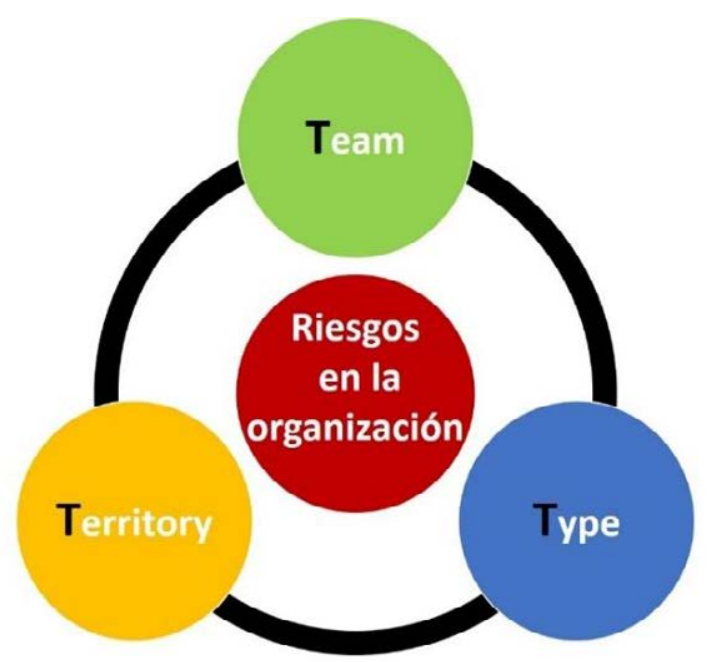

Figura 6.18. Análisis TTT para riesgos en la organización. Fuente: elaboración propia. 
Dentro del análisis de riegos asociado al propio equipo de proyecto, se incluye no solo al equipo ejecutante del proyecto, sino a otros grupos de interés como pueden ser sus socios locales, a la entidad financiadora, y a todas aquellas organizaciones que, aunque con diferentes puntos de vista, van a participar en la intervención. En él se deberían considerar las experiencias previas de cada uno de los participantes por separado y también las experiencias en alianzas previas, identificando los riesgos que de ellas puedan surgir, evaluándolos y dándoles respuesta.

En relación con el análisis del tipo de proyecto, tiene que ver con el sector en el que se encuadra (energía, educación, salud, TICs, infraestructuras, etc.). No solo influye la experiencia de la organización en ese sector determinado, sino también el propio sector, su madurez, su tecnología, su legislación, etc. De nuevo estos riesgos se deben identificar y evaluar, y deben ser gestionados.

El análisis territorial hace referencia al contexto geográfico para el cual se va a definir el proyecto. Tiene asociados los riesgos propios del país ${ }^{29}$, dependientes de la estabilidad política, de la existencia de conflictos armados, de la escasez de infraestructuras para el transporte, de las diferencias en la lengua y cultura, etc. Pero también exige que se analicen los Marcos de Asociación País, así como las políticas y planes de desarrollo locales. Por supuesto, al igual que en los casos anteriores, las experiencias previas en terreno y conocimiento del país por parte del equipo dan lugar a la identificación tanto de riesgos, como de lecciones aprendidas. Los riesgos que de este análisis territorial se deriven, deben ser gestionados.

El control de todos los riesgos tratados en esos tres niveles debe realizarse periódicamente a lo largo de todo el proyecto, como el resto de los riesgos.

\subsubsection{La metodología MLEGR en el ámbito de la dirección de PCD}

Una vez analizados estos riesgos por la organización que diseña el proyecto, la metodología MLEGR propone sistematizar los procesos de GR de manera participativa en cada uno de los pasos del Marco Lógico (ver Figura 6.19). Su uso se puede integrar con otros enfoques actuales como el de Derechos Humanos o el de Género, a la vez que es perfectamente aplicable con las Teorías del Cambio.

\footnotetext{
${ }^{29}$ CESCE, Compañía Española de Seguros de Crédito a la Exportación, es una empresa de gestión de riesgo que presenta los riesgos comerciales y políticos de cada país.
} 


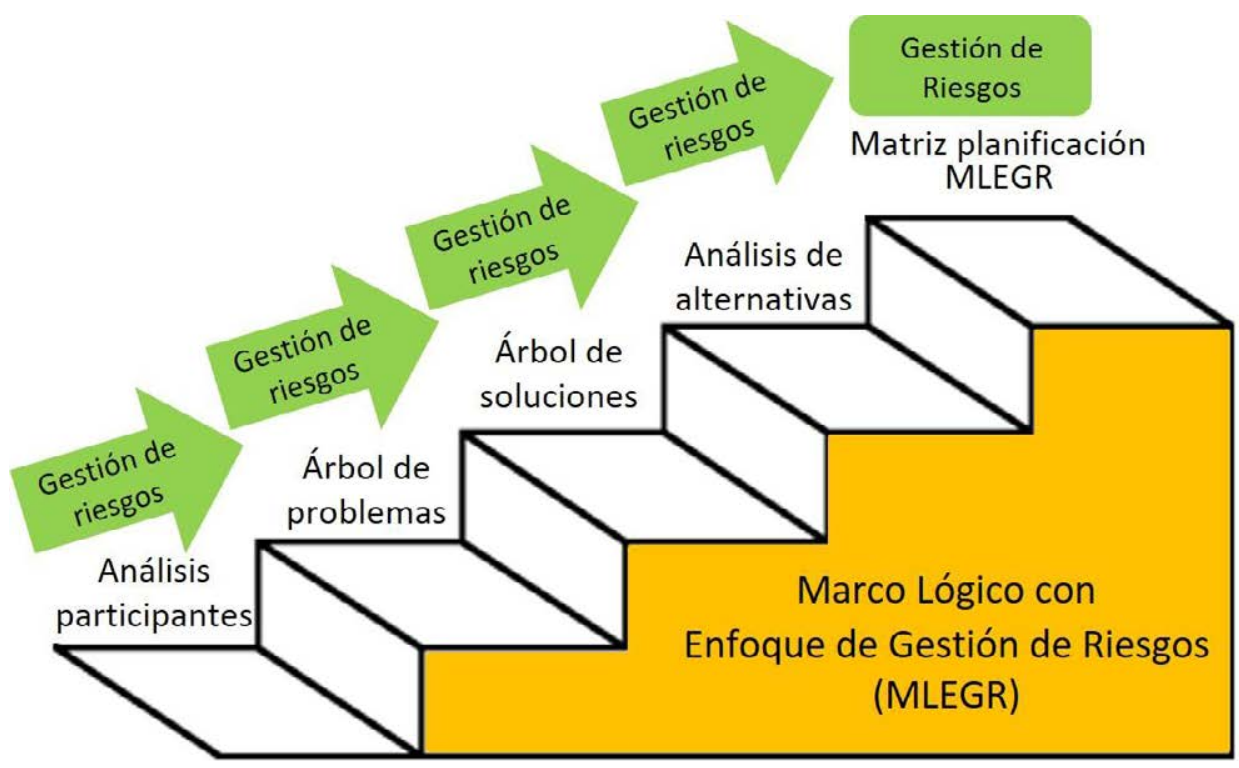

Figura 6.19. Metodología del MLEGR aplicada a los pasos del ML. Fuente: elaboración propia.

\subsubsection{Gestión de Riesgos en los pasos del Marco Lógico}

En el primer paso del ML se identifican tanto beneficiarios directos e indirectos, como excluidos y neutrales y perjudicados por la intervención. Este primer paso supone una de las tareas más importantes dentro de la etapa de identificación del proyecto.

Para todos ellos se sugiere estudiar sus características concretas y los riesgos derivados de las diferencias culturales que puedan afectar al buen desarrollo del proyecto. Para ello se recomienda conocer el terreno y haber pasado tiempo en él conviviendo con la comunidad beneficiaria, así como contactar con líderes y lideresas locales y personas desplazadas en terreno.

Asimismo, el posicionamiento de todos los participantes con respecto a la intervención y su interrelación es muy importante, dado que, al existir siempre participantes neutrales y perjudicados, hay que considerar a estos grupos especialmente para identificar los riesgos que puedan surgir de esta situación y establecer las estrategias necesarias para conocerlos y tenerles informados, pudiendo así intervenir en la mediación de conflictos en caso de que surjan.

Resulta importante también identificar a los agentes de cambio, definiendo los actores que pueden jugar un rol promotor, neutro o bloqueador, así como su nivel de poder. Del cruce entre su situación o no de poder y su disposición en favor o en contra del cambio permitirá identificar riesgos en la manera de amenazas, pero también de oportunidades.

Entre las herramientas que se pueden utilizar, se describen a continuación las más recomendadas. 
- Matriz de interrelación: prestando especial atención a si la intervención cambiaría en algo las interrelaciones previas. Como todo cambio es en sí una fuente de riesgos, realizar el estudio en dos escenarios, antes y después del proyecto, se convierte en una fuente de información de posibles riesgos. Por ejemplo, en el proyecto de estudiado de empoderamiento de la mujer rural, el cambio en las mujeres beneficiarias va a suponer cambios en las interrelaciones de éstas dentro de su ambiente familiar, así como en la comunidad, dado que pasan de ser económicamente dependientes a tener una autonomía, e incluso suponer la competencia para otros negocios de la zona. Estas situaciones son fuentes de riesgo, generando, como se ha podido comprobar, riesgos como el de rechazo social (CUL_8 del proyecto de Empoderamiento de la mujer rural).

La Figura 6.20 representa las matrices en las que se podrían incluir con texto en cada casilla cual es la interrelación previa a la intervención entre las personas afectadas por el proyecto (en este caso A, B y C), y cómo sería previsiblemente tras ella.

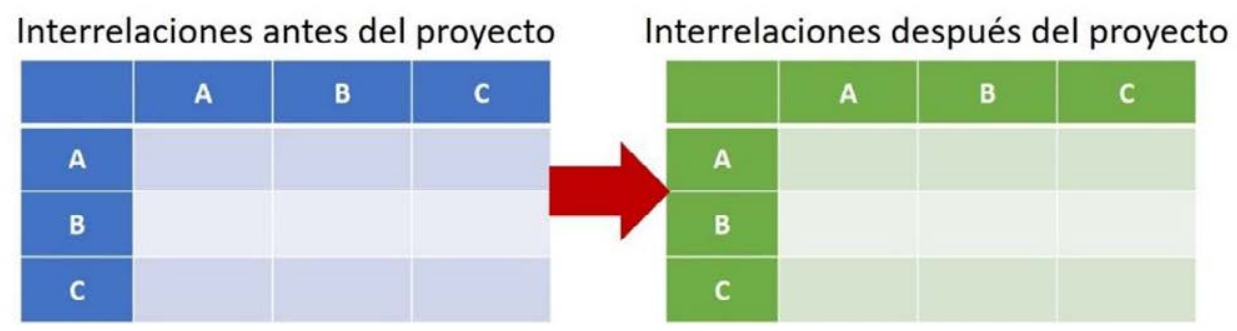

Figura 6.20. Ejemplo de cambios en la interrelación de las personas con la intervención.

Fuente: elaboración propia.

- Matriz de poder-interés: identificando a los participantes con mayor poder e interés en la intervención se pueden identificar riesgos ligados con las dependencias de apoyo o con la mala comunicación con participantes estratégicos que puedan afectar al proyecto. La Figura 6.21 representa un ejemplo de esta matriz.

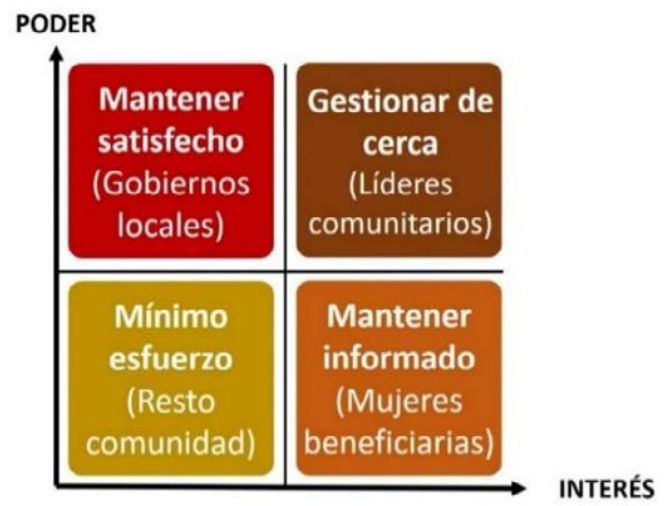

Figura 6.21. Ejemplo de matriz poder-interés.

Fuente: basado en PMBOK (PMI, 2017). 
- Análisis multiactor: para contemplar los diferentes enfoques de cada grupo participante y los riesgos que podrían afectarle especialmente a cada uno, así como los riesgos debidos a su interactuación. En el ejemplo propuesto en la Figura 6.21, la ONGD ejecutaría el proyecto en la Comunidad, implicando a la municipalidad local para buscar la sostenibilidad y apropiación del proyecto y con equipos de la empresa privada.

La Gestión de Riesgos en los dos pasos siguientes, Árbol de Problemas y Árbol de Objetivos, debe enfocarse en identificar el mayor número de riesgos posibles en los procesos participativos. Disponer de la oportunidad de trabajar conjuntamente con la comunidad en la búsqueda de los problemas y de las soluciones más adecuadas permite, además de conocer los intereses de la comunidad, identificar de primera mano una serie de riesgos basados en la observación de los comportamientos y las decisiones de los participantes, de gran valor para la GR. También, a través de sencillas preguntas, se podría tener idea de la probabilidad de ocurrencia de esos riesgos y de su impacto, o incluso sobre las posibles estrategias de respuestas a los riesgos.

Estos trabajos permiten identificar los elementos clave del contexto en el que se va a realizar la intervención, por tanto, prestar atención a los riesgos asociados a este contexto ayudará a identificar los riesgos que podrían afectar a las actividades en la zona.

Entre las herramientas que se pueden utilizar, se recomienda el uso de preguntas relacionadas con los riesgos en el proceso de realización de estas dinámicas. Ejemplos: ¿qué pasaría si...? ¿qué cambio se estaría produciendo en la comunidad si...? ¿a qué/quién afectaría...? ¿qué haría falta para evitar...?

Para el paso del Análisis de las Alternativas, incluir el criterio de riesgos es determinante para ayudar a conseguir que las intervenciones que se llevan a cabo cuenten con una GR desde su concepción, apostando por los proyectos con riesgos más asumibles por la organización, para así mejorar sus niveles de eficacia.

Entre las herramientas que se pueden utilizar, se recomienda el análisis multicriterio, incluyendo como un criterio más los riesgos. En el sencillo ejemplo que se expone en la Tabla 6.51, se van a utilizar como criterios el tiempo, el coste, el número de beneficiarios y el nivel de riesgos de cada una de las alternativas. A cada criterio se le otorga un peso. Estos pesos suelen depender de las prioridades de la organización o de los requisitos de la convocatoria. Los valores se dan, en esta ocasión, del 1 al 10, y cuanto más alto quiere decir que más adecuada es esa alternativa al criterio correspondiente. 
Tabla 6.51. Ejemplo de análisis multicriterio.

Fuente: elaboración propia.

\begin{tabular}{lllllll}
\hline \multirow{2}{*}{ Criterio (Peso) } & \multicolumn{2}{l}{ Alternativa A } & \multicolumn{2}{l}{ Alternativa B } & \multicolumn{2}{l}{ Alternativa C } \\
\cline { 2 - 7 } & Valor & Ponderado & Valor & Ponderado & Valor & Ponderado \\
\hline Tiempo $(0,1)$ & 6 & 0,6 & 3 & 0,3 & 9 & 0,9 \\
Coste $(0,2)$ & 5 & 1 & 6 & 1,2 & 3 & 0,6 \\
№ Beneficiarios $(0,5)$ & 8 & 4 & 5 & 2,5 & 7 & 3,5 \\
Riesgos $(0,2)$ & 3 & 0,6 & 6 & 1,2 & 9 & 1,8 \\
\hline Total & & 6,2 & & 5,2 & & 6,8 \\
\hline
\end{tabular}

Es importante disponer de este análisis de alternativas durante el desarrollo del proyecto, dado que según avance éste por su ciclo de vida y, atendiendo al proceso de la GR, una iniciativa descartada inicialmente, puede merecer la pena ser retomada.

A la hora de realizar la MML, se propone añadir la columna de riesgos y analizar la columna de supuestos como fuente de riesgos.

Los riesgos detectados para cada actividad/resultado/objetivo, se mostrarán así en esa columna. Adicionalmente, la MML debe ir acompañada del registro de estos riesgos, en el que se incluirán, al menos, su importancia (fruto del producto de su probabilidad de ocurrencia por su impacto) y su respuesta, en caso de considerarse necesaria porque el riesgo no sea aceptable ${ }^{30}$. (Ver Figura 6.22) Se pretende así lograr un uso de la columna de supuestos más adecuado, útil y realista, al igual que dejar constancia documentada de la existencia de riesgos para asegurar su gestión. De hecho, estos riesgos se deberían incluir luego en el Registro de Riesgos que se propone en la Figura 4.4 para control interno en la organización a lo largo del proyecto.

30 Entre las estrategias de respuesta más comunes, se encuentran: escalar, evitar/explotar, mitigar/mejorar, transferir/compartir y aceptar, algunas de ellas dependen de si el riesgo es negativo (amenaza) o positivo (oportunidad). 


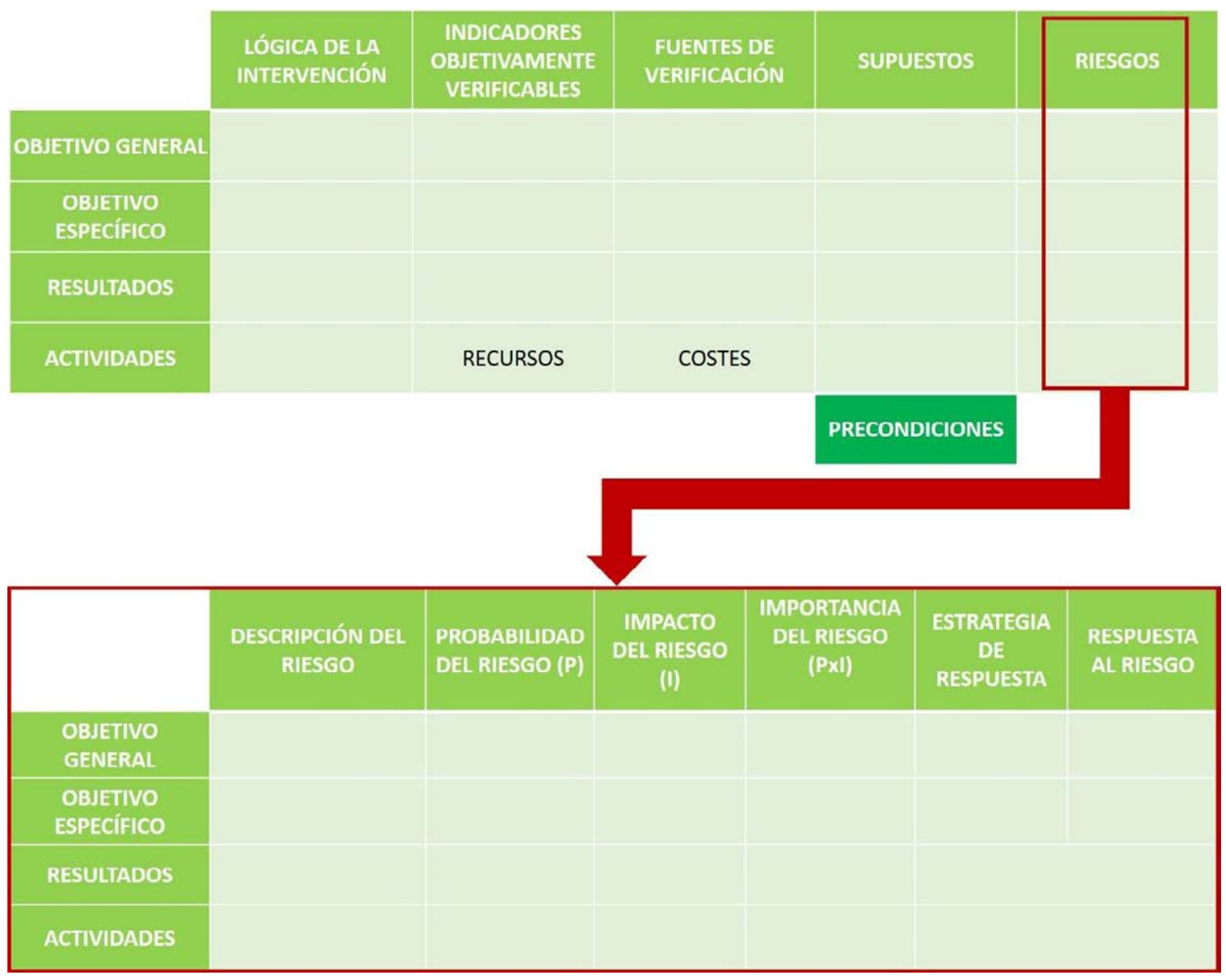

Figura 6.22. Matriz del MLEGR.

Fuente: elaboración propia.

\subsubsection{EI MLEGR como proceso participativo}

La identificación, evaluación y búsqueda de respuestas para los riesgos asociados a cada una de estas etapas se propone participativa, como la propia metodología del ML se supone que es. Como todo proceso participativo, se recomienda realizarlo en varias fases, primero de manera segregada y concluyendo con una búsqueda de consenso conjunta. Los diferentes grupos de interés con los que se propone trabajar serían, por ejemplo, el equipo de proyecto; la comunidad beneficiaria segregada inicialmente por género y luego de manera conjunta; los líderes y lideresas locales. Tras este primer trabajo por grupos, se recomienda una última sesión conjunta en la que se busque el consenso a través de un diálogo multiactor, puede contar con todos los participantes con los que se ha trabajado previamente por separado, o con las personas designadas en esos procesos como sus representantes.

Para que los procesos participativos puedan ser provechosos, se recomienda utilizar técnicas de GR muy sencillas e introducir previamente los conceptos con los que se va a trabajar. 
Las herramientas que pueden facilitar este proceso son:

- La Estructura de Descomposición de Riesgos, para ayudar en la identificación de riesgos, así como en el establecimiento de estrategias conjuntas de respuesta a los riesgos (ver ejemplos en Tabla 4.2 y en Figura 6.8)

- La matriz Probabilidad-Impacto, simplificada de acuerdo con las necesidades de los participantes, para la evaluación de los riesgos (ver ejemplos en Figuras 4.5 y 6.9).

Es muy recomendable, además, contar con el juicio de personas expertas en la zona y con documentación relativa a proyectos previos realizados y sus lecciones aprendidas.

\subsubsection{Definir e implementar la respuesta a los riesgos}

La definición de las respuestas con las que trabajará la organización debe haber sido definida en el Plan de Gestión de Riesgos, como se ha comentado en el apartado 6.5.1. Así, en el registro de riesgos se irá complementando para cada riesgo no aceptado su respuesta. El nivel de aceptación de los riesgos debe igualmente quedar definido en el Plan de Gestión de Riesgos de la organización.

A la hora de implementar las respuestas a los riesgos no aceptados, se recomienda hacer uso de la matriz Riesgo-Respuesta, que viene a representar la importancia del riesgo frente a la dificultad de su respuesta, y que determina qué respuestas se deben priorizar y cuáles se pueden postponer o repensar. La Figura 6.23 muestra este diagrama. Se ha buscado una formulación fácil de recordar para que su uso pueda extenderse (RR-PPPP).

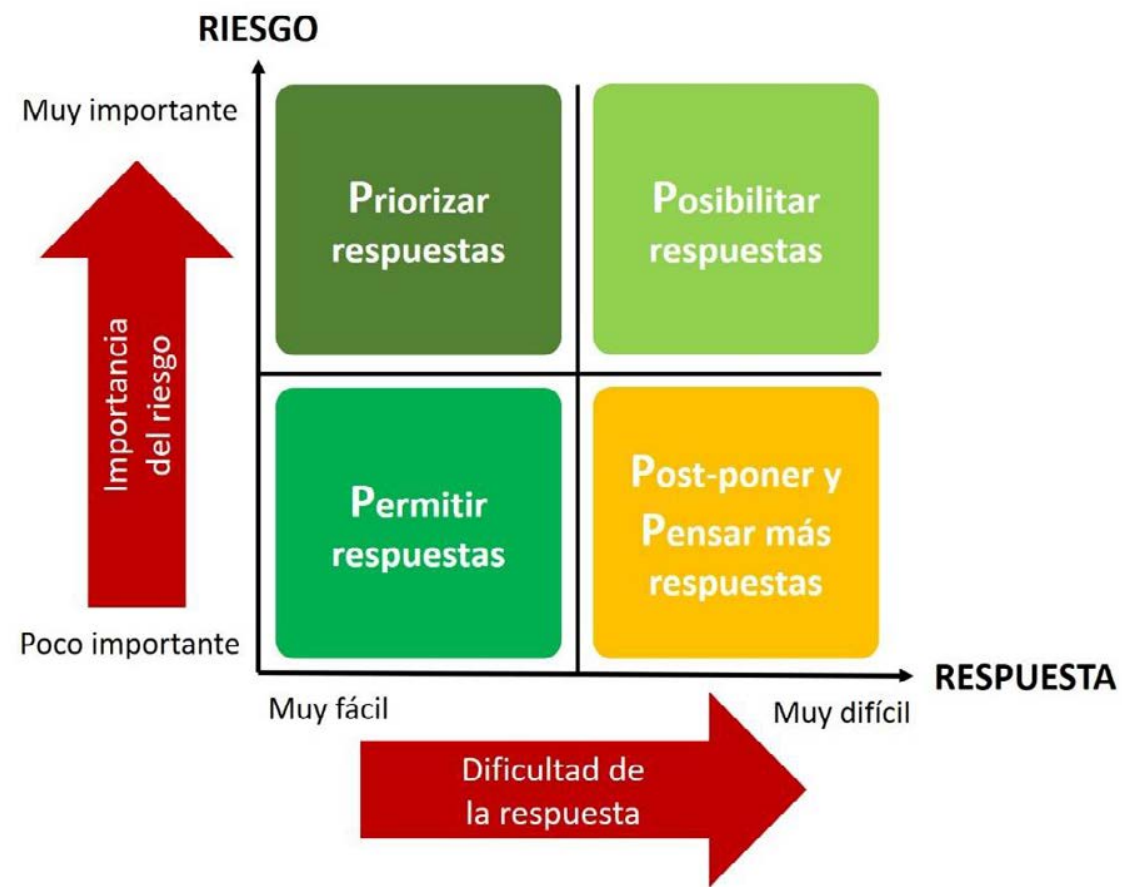

Figura 6.23. Matriz Riesgo-Respuesta.

Fuente: elaboración propia. 
Entre las respuestas a priorizar estarían aquellas que dependen de la propia organización ejecutante y que no requieren demasiados recursos. Por ejemplo, ante el riesgo de que las personas participantes no acudan a las formaciones previstas por necesitar atender sus actuales tareas que son su fuente de ingresos, las formaciones se podrían poner al caer el sol. Entre las respuestas a posibilitar, están aquellas que la propia organización no puede quizá atender, pero para las que podría buscar aliados, como, por ejemplo, ante riesgos de falta de confianza en el equipo de proyecto o dificultades de comunicación, se podría contratar a personal local que pudiera mediar entre ambas partes, o entablar alianzas con ONGDs con experiencia previa en terreno. Aquellas respuestas que requieren de grandes recursos para riesgos o menos importantes o no inminentes, es conveniente pensarlas y considerar otras opciones, para lo cual resulta útil entablar diálogos multiactor con los que conocer diferentes puntos de vista, por si alguno de ellos pudiera plantear una nueva y más asequible respuesta. Todas aquellas respuestas que sean fáciles de atender por parte de la organización deben permitirse, por pequeño que sea el riesgo.

El coste de todas las respuestas a los riesgos debe integrarse en el presupuesto total del proyecto.

\subsubsection{El control y la monitorización del registro de riesgos}

A lo largo del proyecto nuevos riesgos pueden ir apareciendo y los existentes pueden variar en alguna de sus componentes (probabilidad o impacto) o desaparecer, por eso es importante controlar su evolución a lo largo del proyecto.

Contar con un registro documental de los riesgos no solo ayudará en este proceso, sino que también permitirá a cada organización disponer de una valiosa información para nuevos proyectos. Aunque cada proyecto es único, apoyarse en los registros de riesgos previos puede facilitar mucho la GR en nuevos proyectos. Un ejemplo de Registro de Riesgos se puede ver en la Figura 4.4.

La periodicidad para el control de los riesgos y la persona responsable de controlarlos, así como el formato del registro de riesgos utilizado deben definirse en el Plan de Gestión de Riesgos de cada organización.

\subsubsection{La asociación de los riesgos a las etapas del ciclo de vida del proyecto}

Resulta muy útil de cara a tener una base documental que ayude a la ejecución de nuevos proyectos, asociar qué tipo de riesgos se dan en cada etapa del ciclo de vida de un PCD. Para ello se propone colocar sobre el diagrama del ciclo de vida seleccionado por la organización las categorías de riesgos que contienen los riesgos de mayor importancia. 
En la Figura 6.24 se propone un ejemplo, en el que se pueden ver representadas en cada etapa las tres categorías con riesgos más importantes. Esto se obtiene sumando las puntuaciones de importancia obtenidas para cada riesgo dentro de cada categoría, y permite conocer de un simple vistazo qué tipo de riesgos afectan más al PCD en cada una de sus fases. Se incluye además una capa transversal dedicada a la propia dirección del proyecto, en la que se deben incluir también los riesgos.

De nuevo la información obtenida con esta sencilla herramienta permite a la organización tener una información muy útil de cara a la elaboración de nuevos proyectos.

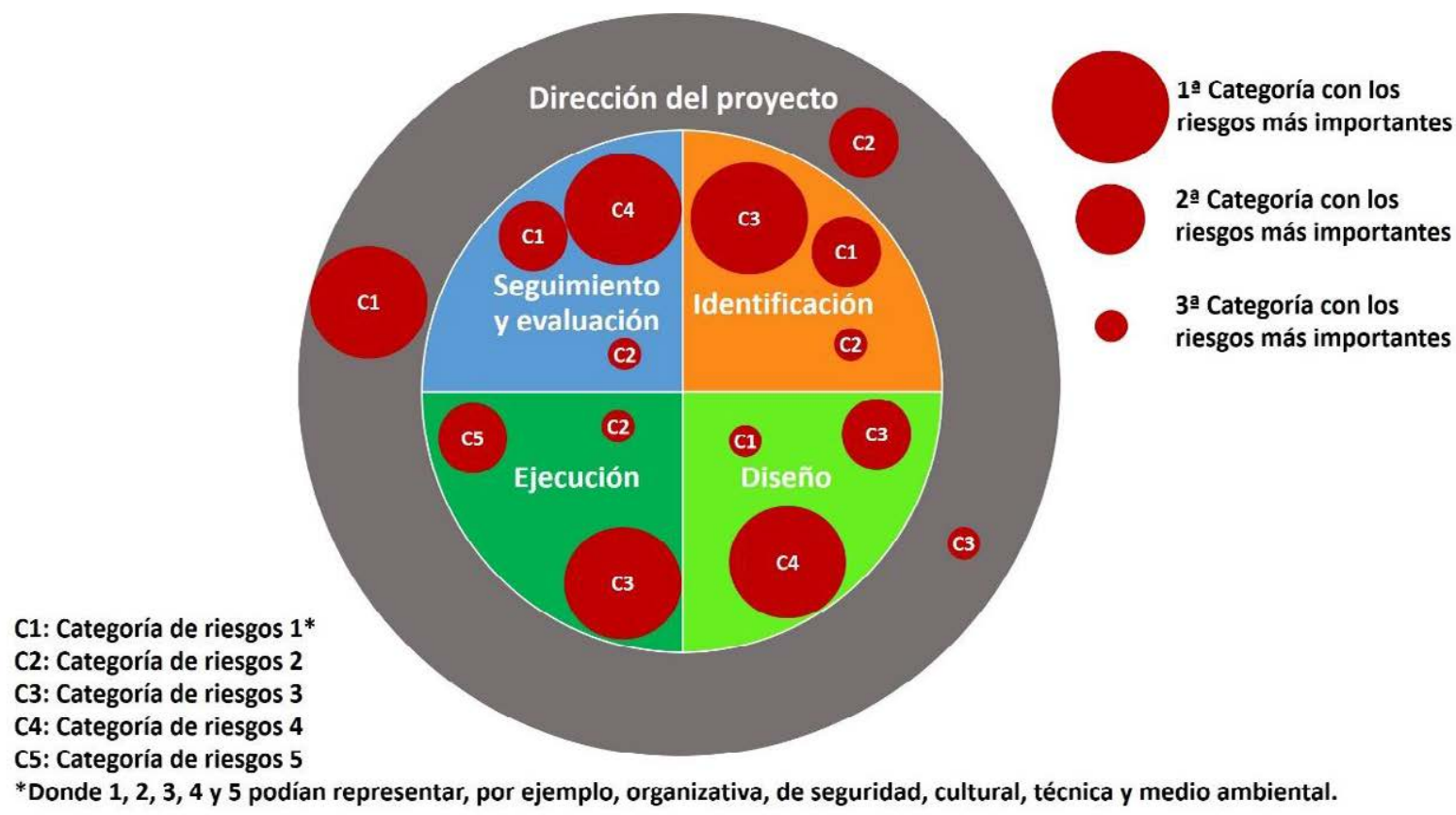

Figura 6.24. Asociación de riesgos a cada fase del ciclo de vida del PCD.

Fuente: elaboración propia.

\subsubsection{Contraste de la Metodología del MLEGR}

Se realiza un contraste con ocho profesionales que previamente habían contestado el cuestionario sobre el ML y habían comunicado su interés en seguir participando en la investigación. Estos expertos se eligieron entre los treinta que habían manifestado su interés en futuras consultas, tratando de conseguir la representatividad de todos los actores e incluyendo tanto a profesionales españoles (5) como colombianos (3). Todos ellos fueron consultados previamente sobre su disponibilidad para la lectura y posteriores comentarios de la metodología, aceptando todos, el compromiso de realizarlo además en el tiempo establecido de una semana. 
El panel de expertos y expertas (E) con el que se realizó la consulta estaba compuesto por:

- (E1): responsable Departamento de Cooperación Internacional de IntermónOxfam.

- (E2): profesora de proyectos de la Universidad Politécnica de Madrid y evaluadora independiente de Proyectos de Cooperación al Desarrollo.

- (E3): coordinador de proyectos de energía en ONGD ONGAWA.

- (E4): técnico responsable de cooperación al desarrollo de la Gobernación del Cauca (Colombia).

- (E5): director de la fundación Acciona.org.

- (E6): investigador universitario del Centro de Innovación y Tecnologías para el Desarrollo Humano de la Universidad Politécnica de Madrid.

- (E7): Coordinadora de la Oficina Territorial de Nariño, Cauca y Putumayo del Programa de Naciones Unidas para el Desarrollo (PNUD).

- (E8): Coordinador del Banco de Proyectos de la Corporación Autónoma Regional de Santander (Colombia).

La Figura 6.25 representa el panel multiactor con el que se realizó el contraste.

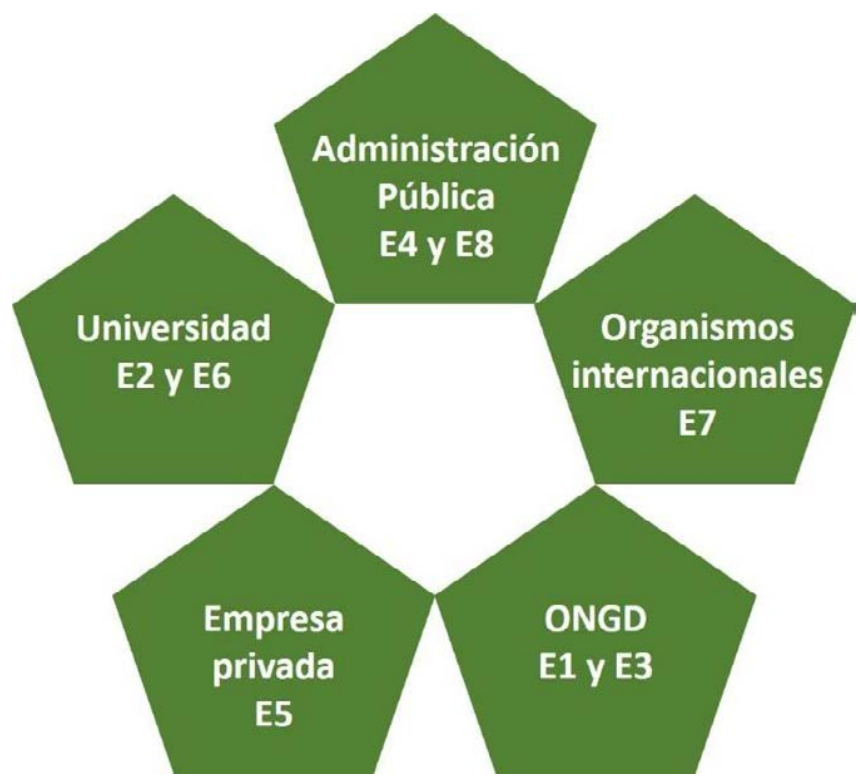

Figura 6.25. Panel multiactor seleccionado para el contraste de la metodología. Fuente: elaboración propia.

Todas las personas participantes fueron preguntadas separadamente sobre las cuatro cuestiones de respuesta abierta que se exponen a continuación de manera sintetizada. 
Pregunta 1: ¿Crees que esta metodología puede ayudar a mejorar la eficacia de los Proyectos de Cooperación al Desarrollo y por ende el impacto en la comunidad beneficiaria? ¿Por qué?

Todas las personas preguntadas estuvieron de acuerdo en que esta metodología ayudará a mejorar los niveles de éxito de los proyectos, reconociendo que muchos de los actuales proyectos no tienen en cuenta los riesgos, pero, sobre todo, que no existe un aprendizaje efectivo de un proyecto a otro.

Con el registro de riesgos se puede dar, en primer lugar, una "continuidad a la evolución de los riesgos, más allá de la identificación inicial y, sobre todo, una identificación de riesgos de gran valor para futuros proyectos" [E1 y E2]. Destaca el "gran potencial que tiene al poder sistematizarse a través de programas informáticos que permitan monitorizar los riesgos a través del registro de riesgos presentado" [E8].

Además, "permitiría elegir y definir mejor las intervenciones durante la fase de identificación y diseño" [E3], y "ayudaría a lidiar mejor con los riesgos durante la fase de implementación al contar con un plan de contingencia estructurado" [E3 y E4], lo que "supondría una reducción de costes y retrasos en las intervenciones" [E3], y "a mejorar los resultados de los proyectos, impactando directamente sobre la comunidad beneficiaria" [E5]. Aporta además la "novedad de contar con la comunidad para la identificación de riesgos, lo cual es muy valioso dado que las personas de los territorios son las que tienen una mejor visión y conocimiento del territorio y esto permitirá identificar mejor algunos riesgos que no suelen percibirse por los equipos que diseñan el proyecto" [E4].

Solo por "el hecho de introducir una GR mejora per se la planificación de los proyectos, al permitir tener un conocimiento más profundo de las intervenciones" [E6]. "La GR debería ser imprescindible en cualquier proyecto de cooperación, como lo es en otros sectores, y la mejor manera para interiorizarlo es hacerlo a través de una herramienta muy habitual en este sector como el ML" [E5].

"En Colombia, particularmente, no prestar la atención debida a los riesgos ha causado que PCD de gran envergadura hayan pasado al olvido sin causar ningún impacto favorable" [E7]. Esta metodología, "puede complementarse, además, para el caso de Colombia con los Mapas de Riesgos de Corrupción" (Función pública, 2018), recientemente editada a nivel nacional [E8].

Pregunta 2: ¿Qué es lo que más te gusta de ella? ¿Por qué?

Todas las personas encuestadas destacaron la sencillez de la metodología y la facilidad de integración con otros enfoques, valorando especialmente la 
incorporación de analizar los riesgos de manera interna en la organización y, concretamente, el modelo TTT presentado.

La "integración en los propios pasos del ML" [E5] y su "compatibilidad con otros enfoques y con las teorías del cambio" [E1] y el "carácter participativo de la metodología, incluyendo a la comunidad beneficiaria" [E1 y E4].

Destaca entre las herramientas presentadas el análisis TTT, "especialmente por incluir aspectos multiactor" [E6], pero también se valora muy positivamente "el diagrama de asociación de los riesgos a cada fase del ciclo de vida del proyecto" [E1 y E3]. En relación también con la pregunta anterior, cobra un gran valor el "disponer de un registro de riesgos que permita además consolidar lecciones aprendidas para futuros proyectos" [E4 y E7].

El hecho además de que sea una metodología "marcadamente visual" [E3] consolida su "facilidad de entendimiento" [E8], "a través de sencillos pasos que conectan muy bien con la lógica de los proyectos" [E7], destacando "la manera pragmática de integrar la GR en la matriz del ML" [E5].

Pero, sobre todo, el hecho de que con muy poco esfuerzo adicional y sin necesitar muchos más recursos, va a mejorar mucho la herramienta de planificación del ML [E2, E5 y E7].

Pregunta 3: ¿Qué es lo que menos te gusta de ella? ¿Por qué?

La principal preocupación manifestada por cuatro de los participantes estaba relacionada con el esfuerzo necesario para realizar un análisis tan exhaustivo de riesgos en algunas de las etapas iniciales del proyecto donde aún ni si quiera está clara que vaya a realizarse la intervención. Atendiendo a esta preocupación y a los valiosos comentarios aportados por algunos de los participantes, se eliminaron algunos pasos aconsejados en la propuesta inicial y se simplificó su uso en los pasos del marco lógico disminuyendo la incidencia de la integración de la GR en algunos pasos del ML, como en el árbol de problemas y de objetivos. Esto consiguió dar el "equilibrio" solicitado "entre el protagonismo a la GR y la propia gestión del proyecto" [E2].

Otra de las debilidades de la propuesta inicial era la "falta de ejemplos" [E1, E7 y E8], que se mejoró con la inclusión de algunos sencillos ejemplos.

A parte de eso, resultó muy interesante uno de los comentarios dados sobre la necesidad de "hacer hincapié en las comunidades beneficiarias que la búsqueda de riesgos es para hacer más eficaz la intervención, pero que el proyecto se va a hacer, dado que, si esto no queda claro, las personas pueden situarse en una posición 
defensiva y no colaborar en la identificación de riesgos por temor a que el descubrimiento de los mismos haga que el proyecto no se realice" [E4].

Otro de los puntos negativos tiene que ver con la dificultad de resolver, a través de una sola mejora, las "limitaciones de rigidez del ML" [E6]. Aunque la metodología del MLEGR propone atender a la evolución de los riesgos y responderles oportunamente, lo que conlleva la necesaria replanificación de algunas actividades y el consecuente acercamiento a flexibilizar el ML, es cierto que es solo la mejora más aceptada, pero el ML podría admitir más.

Pregunta 4: ¿La aplicarías o recomendarías su aplicación? ¿Por qué?

La totalidad de las personas preguntadas aplicaría y recomendaría la aplicación de esta metodología, considerando que "el tercer caso de fracaso de un proyecto es la mala consideración de los riesgos", siendo los otros dos posibles la mala formulación o la deficiente implementación [E2].

La mayoría destacan sobre todo la necesidad de aplicarla en las etapas iniciales del proyecto (identificación y diseño), dado que "cualquier cambio no considerado en la planificación inicial, generalmente significa desperdicio en tiempo y recursos" [E4], dado que "los marcos rígidos de la cooperación, así como la propia capacidad de muchas ONGDs, hacen más difícil gestionar los riesgos durante la ejecución del proyecto" [E3].

Algunas personas hacen también distinción a su aplicación parcial en intervenciones de corta duración o con muy poco alcance [E3, E5 y E6].

Resulta muy sugerente también la propuesta de "demostrar las virtudes de la aplicación poniendo casos reales de lo que pasa cuando no la aplicas" [E1]. Aunque la metodología es nueva y, por tanto, no se dispone de resultados de su aplicación para permitir comparativas, sí que son muchos y conocidos los PCD que han fracasado por no contar con una buena GR, pudiendo utilizarse estos ejemplos a la hora de difundir el uso de la metodología.

Tras la consulta con los profesionales, se ha realizado más hincapié en la separación entre las distintas aplicaciones de la metodología, por un lado, para la organización y, por otro lado, para la propia gestión del proyecto, dado que además la parte dedicada a la organización es una de la que más ha gustado. Con esto, se facilita su comprensión y se potencia la necesidad de integrar la cultura de la GR en el mundo de la cooperación al desarrollo. Igualmente, se han añadido más ejemplos para la buena comprensión de las herramientas propuestas. 


\section{CAPÍTULO 7. CONCLUSIONES Y DESARROLLOS FUTUROS}

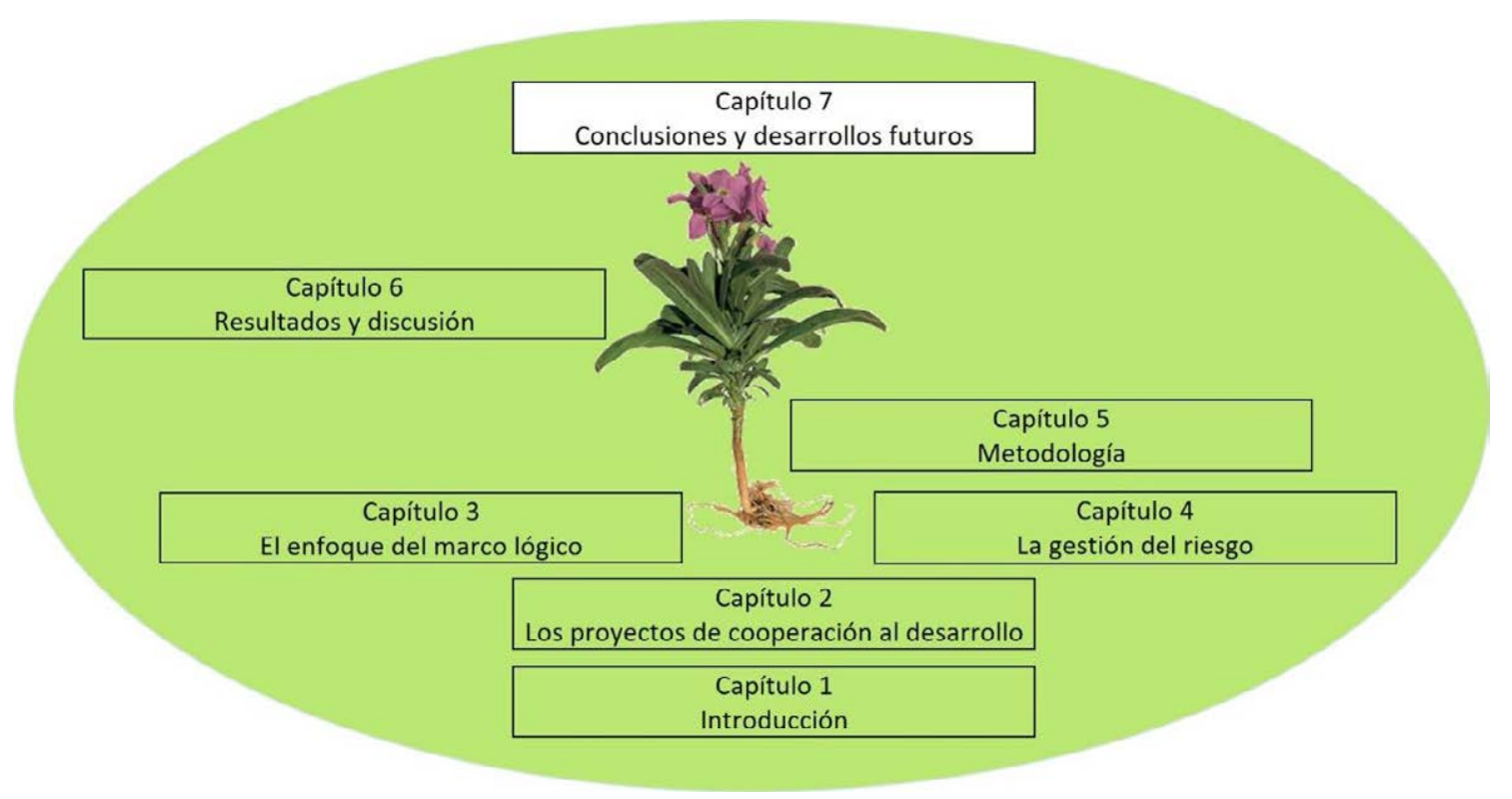

Figura 7.1. Conclusiones y desarrollos futuros.

Fuente: elaboración propia.

"En un mundo en rápida y profunda transformación todos somos diseñadores"

(Ezio Manzini, 2015. Design, when everybody designs: an introduction to design for social innovation. Cambridge: MIT Press) 


\subsection{Introducción}

El objetivo principal de esta Tesis Doctoral, definido en el Capítulo 1, es desarrollar una metodología para la gestión de los PCD con una gestión de riesgos integrada, con el fin de mejorar su eficacia, y contribuir a un mayor impacto en la comunidad beneficiaria. Esta metodología toma los puntos fuertes del Marco Lógico, incorporando la gestión de riesgos en cada una de sus etapas, por ello, se propone el nombre de Metodología del Marco Lógico con Enfoque en Gestión de Riesgos (MLEGR).

Para contribuir a este objetivo principal, se plantearon asimismo los siguientes objetivos específicos (OE):

OE1. Conocer cómo son los PCD de la Universidad Politécnica de Madrid, cuáles son sus lecciones aprendidas y a qué riesgos se enfrentan.

OE2. Analizar las fortalezas y debilidades de la metodología del Marco Lógico para proponer las mejoras más convenientes.

OE3. Identificar y evaluar los riesgos de los proyectos caso de estudio para proponer un registro y categorización de riesgos en el contexto analizado que pudiera servir de modelo para otros contextos.

OE4. Descubrir la relación existente entre los riesgos evaluados y la percepción de éxito de los proyectos caso de estudio para encontrar posibles vinculaciones entre los riesgos y el éxito del proyecto.

OE5. Contrastar con profesionales del ámbito de la cooperación el diseño de la metodología del MLEGR para que sea una metodología que tenga aplicación en el sector.

El cumplimiento de estos objetivos se apoyó en una extensa revisión de la literatura. Entre las principales referencias destacan las de Lavagnon Ika, con sus teorías críticas, su acercamiento al post-desarrollo y su revalorización de los trabajos previos de Albert Hirschman. Destacan también los trabajos de Ruggero Golini por otorgar la visibilidad que merecen los profesionales de las ONGDs, y darles voz en el mundo académico. Muy inspiradores han resultado también los estudios de Marly Monteiro de Carvalho por conceder a la gestión de riesgos un puesto de importancia en el éxito de los proyectos. $Y$, por último, la estancia realizada en la universidad de Sussex con Andrew Stirling ha permitido reconocer la dificultad de trabajar en entornos de incertidumbre y el protagonismo que eso concede a los análisis cualitativos.

Estos trabajos, junto con los de otros muchos autores, han dado lugar a aportaciones interesantes que se presentan a continuación ligadas con el objetivo principal y los objetivos específicos propuestos. 
Este último capítulo revisa así la consecución de los objetivos y las aportaciones más relevantes de esta Tesis Doctoral, mostrando también cómo se han ido respondiendo a cada una de las hipótesis de investigación planteadas.

Se incluyen además en este capítulo las principales dificultades y limitaciones surgidas en la investigación, así como las futuras líneas de trabajo relacionadas.

\subsection{Sobre la Metodología del Marco Lógico con Enfoque de Gestión Riesgos}

La gran aportación de este trabajo de investigación ha sido el diseño de la Metodología del Marco Lógico con Enfoque en Gestión de Riesgos (MLEGR), cuyo resumen a modo de esquema visual se presenta en la Figura 7.2. El diseño de esta metodología, co-creada gracias a todas las personas que han colaborado con sus aportaciones, tanto en terreno, como a través de sus respuestas a cuestionarios y entrevistas, responde al objetivo principal de esta Tesis Doctoral.

La metodología del MLEGR tiene un carácter integral y va más allá de la mera aplicación a los proyectos, implicando a la organización a través del análisis TTT. Además, gracias a introducirse en la cultura organizativa, la metodología es capaz de generar un registro documental vivo, tanto de riesgos, como de lecciones aprendidas, que garantiza disponer de unos datos de entrada valiosos para futuros proyectos.

El uso de esta metodología establece un puente práctico entre la dirección de proyectos y la cooperación al desarrollo, al integrar la gestión de riesgos en los pasos del Marco Lógico y en todas las etapas del ciclo de vida del proyecto. La construcción de este puente sigue los pasos previos dados por guías teórico-didácticas, como la guía PMD Pro (PM4NGOS, 2013), y responde a la necesidad detectada en el transcurso de esta investigación.

A través de sencillas herramientas y haciendo uso de muy pocos recursos adicionales, esta metodología participativa se integra y complementa los pasos del Marco Lógico, lenguaje común en la cooperación al desarrollo, disminuyendo así alguna de sus debilidades y asegurando sus fortalezas. Es a la vez compatible con otros enfoques actuales, como el de género, o el de derechos humanos, así como con las teorías del cambio. 


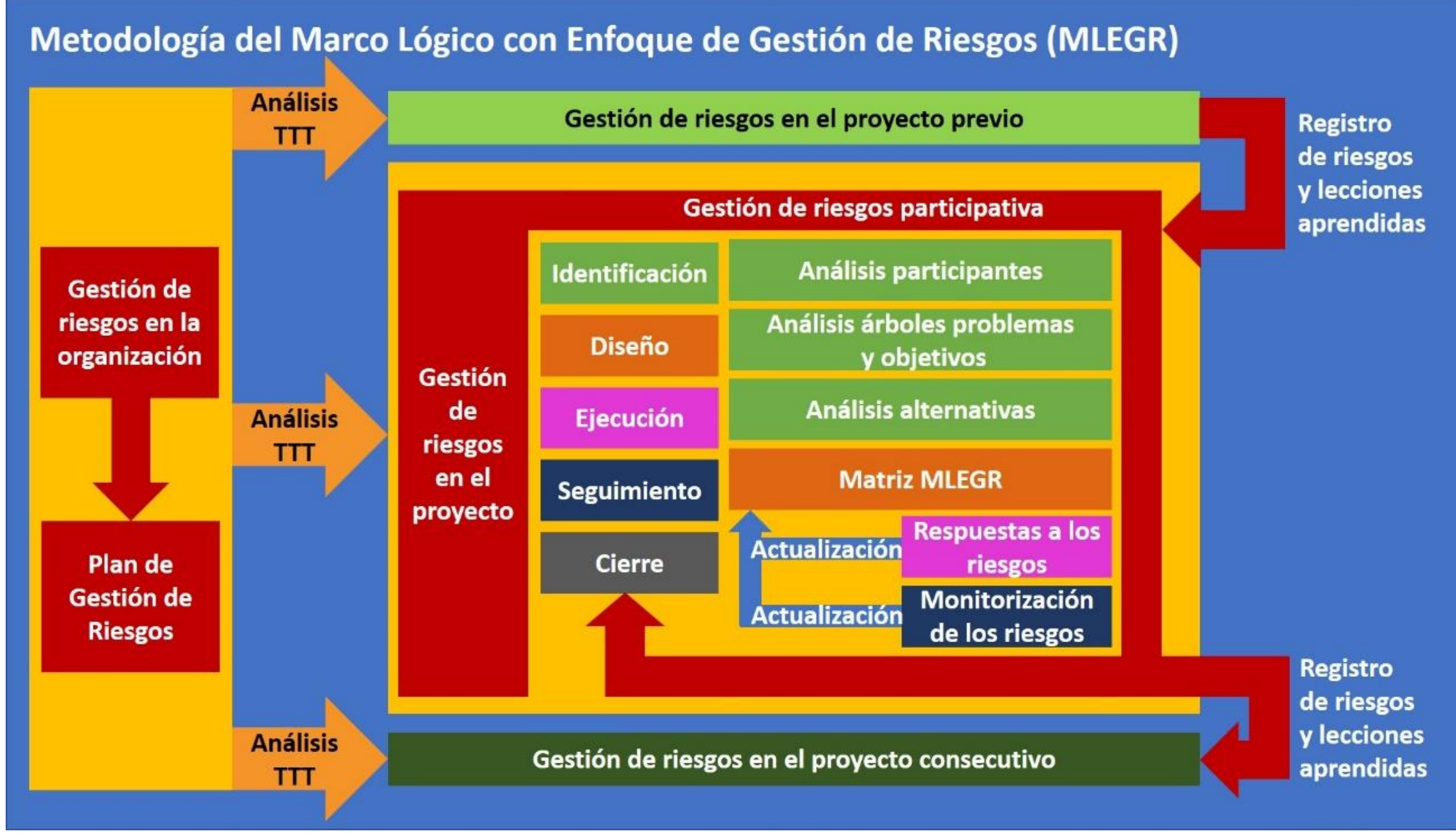

Figura 7.2. Metodología del MLEGR.

Fuente: elaboración propia. 


\subsection{Sobre la actualidad de la cooperación al desarrollo y la necesidad de eficacia}

La profundidad con la que se ha abordado el marco teórico ha permitido conocer el momento actual de transición en el que se encuentra la cooperación al desarrollo, en el que la inclusión de nuevos participantes y la búsqueda de soluciones sostenibles y adecuadas a los territorios están abriendo paso a enfoques bottom-up donde la participación ciudadana y los movimientos locales tienen un gran protagonismo, no siendo ya una cuestión exclusiva de gobiernos o instituciones internacionales.

En este momento de transición, debe primar la responsabilidad de las intervenciones, no solo para combatir las desigualdades y sus problemas derivados, sino para establecer la confianza necesaria entre los múltiples actores que intervienen en los proyectos de cooperación al desarrollo, principalmente, con las comunidades beneficiarias. La eficacia de estos proyectos es vital para generar confianza a partir de la cual co-crear el cambio hacia el desarrollo deseado.

El concepto de desarrollo ligado hasta ahora con crecimiento está incorporando nuevas fórmulas que aumentan el respeto hacia el ser humano y la naturaleza en la que vive. Nociones como el pluriverso (Escobar, 2016), muy ligado con el Buen Vivir (Radcliffe, 2018), comienzan a plantearse como alternativas a los enfoques más tradicionales, como ya adelantaban las teorías del post-desarrollo (Sachs, 1992), buscando el desarrollo de capacidades de acuerdo al entorno en el que vive la comunidad. Las comunidades beneficiarias deben ser las protagonistas a la hora de elegir ese desarrollo $y$, el equipo de proyecto, como mediador con el resto de los actores implicados, tiene que saber cómo permitirles que lo expresen. Las metodologías participativas, con su base en la Evaluación Rural Participativa, ayudan a conocer las demandas emergentes que surgen en el evolutivo concepto de desarrollo, como ya anticipaba Rober Chambers. Precisamente Chambers (2017) anima a la interacción entre las comunidades para transformar mutuamente la manera de ver las cosas, de comportarse, de aprender y de hacer.

El mundo de la cooperación está compuesto por personas con pasión por cambiar las cosas. Esas ganas de cambio, junto con una altísima capacidad de adaptación les dan la creatividad para traspasar sus propios límites y superar adversidades que no se podían ni haber imaginado, como decía Hirschman (1967).

En la búsqueda de la eficacia de la cooperación, hay que ver en cada PCD una oportunidad única de impactar en la mejora de la calidad de vida de los habitantes de una comunidad y, desde ahí, trabajar para no desaprovecharla y ser eficaces en la respuesta. Desde esta concepción, que responde a la pregunta para qué, las 
metodologías y herramientas son solo los instrumentos al servicio de los profesionales $y$, por lo tanto, debe consensuarse con ellos su mejora.

\subsubsection{Las lecciones aprendidas y los riesgos de los PCD de la UPM (OE1)}

En estos momentos de cambio, donde la comunidad internacional y los países "desarrollados" y "en desarrollo" se han dado la mano en la búsqueda de unos objetivos de desarrollo comunes materializados en los 17 ODS y sus 169 metas, todos los estamentos de la sociedad están llamados a contribuir al cambio. Entre ellos, también la universidad.

El estudio de los 152 PCD desarrollados por la UPM fue el primero de los objetivos marcados en esta investigación, para conocer en qué medida, hasta ahora, la ejecución de esos proyectos estaba alineada con los grandes retos marcados por la agenda internacional, así como documentar las lecciones aprendidas e identificar y evaluar los riesgos a los que se enfrentaron. Su conocimiento ha permitido identificar como lección aprendida principal la importancia de conocer previamente y en profundidad la comunidad en la que se va a trabajar, así como su contexto político, legal, sociocultural y climatológico. Con un mayor conocimiento del territorio en el que se va a actuar, así como de la comunidad particular, algunos riesgos comunes a casi todos los proyectos, como la falta de orientación a largo plazo de las comunidades beneficiarias, la falta de formación de sus habitantes y la falta de conocimiento sobre los temas de interés para formación en la comunidad, podían haberse visto disminuidos.

Las lecciones aprendidas, de gran valor en contextos de incertidumbre (Stirling, 2010), son quizá el método más efectivo para avanzar hacia el cambio más demandado por las comunidades, pues supone, en definitiva, aprender con ellas.

\subsection{Sobre la metodología del Marco Lógico}

En su cincuenta aniversario (1969-2019), el ML sigue siendo reconocido como el lenguaje común en las intervenciones de cooperación al desarrollo (Banco Mundial, 2005; Hummelbrunner, 2010). Esto supone una ventaja que no se puede desperdiciar, en estos momentos, además, en los que la sostenibilidad propone apostar por el modelo de las " $R$ ", Repensar el ML, fomentando sus fortalezas y disminuyendo sus debilidades, para Reutilizarlo de una manera más eficaz, aprovechando el reconocimiento del que goza, es el objetivo específico número dos que se planteó con esta Tesis, respondiendo además a la pregunta qué se quiere mejorar.

\subsubsection{Fortalezas y debilidades de la metodología del Marco Lógico (OE2)}

El estudio teórico inicial de esta metodología dio lugar al diseño de un cuestionario que, gracias a la colaboración de los profesionales del sector, ha permitido descubrir que los profesionales de la cooperación valoran más las fortalezas de esta metodología que sus 
debilidades y que no resulta confusa, sino que, al contrario, facilita el trabajo al estar extendido su uso en todo el mundo. Los resultados obtenidos confirman los estudios previos de Golini, Landoni y Kalchschmidt (2017), donde comprobaba el nivel de adopción del ML en las ONGDs con algunos indicadores de desempeño como el tiempocoste y la estrategia en los proyectos, y concluía que el ML es una metodología muy útil para las ONGDs.

También, ha conseguido confirmar la hipótesis de investigación uno, concluyendo que el ML necesita ser mejorado, y que, entre las propuestas de mejora, la más aceptada es la introducción de la Gestión de Riesgos en todo el proceso.

Esta revelación es de gran valor, dado que, entre todas las propuestas de mejora señaladas en trabajos anteriores, como la integración de la dimensión del tiempo de Crawford y Bryce (2003), o la inclusión de costes y beneficios (Ika y Lytvynov, 2011), pone el foco en la GR, como también proponían Yamaswari et al. (2016) y Couillard, Garon y Riznic (2009). La aportación frente a estos dos últimos trabajos es que, mientras que en el caso de Yamaswari et al. (2016) se trabajó con un solo proyecto y en el caso de Couillard, Garon y Riznic (2009) fue una valoración teórica, en esta investigación se ha contado con la opinión de 77 profesionales, la mayoría con más de 10 años de experiencia en la dirección de proyectos en el sector de la cooperación.

A través de los resultados del cuestionario se ha detectado, además, que la debilidad más marcada de esta metodología es su rigidez, como ya manifestaban previamente otros autores (Crawford y Bryce, 2003; Gasper, 2000; Hummelbrunner, 2010). Para romper esta falta de flexibilidad, es necesario reconocer que los proyectos se realizan en sistemas abiertos en los que se producen cambios y que las relaciones no pueden ser tan lineales como define el ML, sino más dinámicas, como defienden las TC.

El ML necesita adaptarse, lo mismo que a las personas trabajando en los PCD se les exige adaptación, las metodologías deberían poder flexibilizarse y para ello la opción más sencilla es mantener la matriz viva, no congelarla, sino darle dinamismo a lo largo del desarrollo del proyecto, confirmando de nuevo lo que otros autores habían sugerido (Crawford y Bryce, 2003; Golini, Landoni y Kalchscmidt, 2017; Khang y Moe, 2008; Yamaswari et al., 2016). Esto podría hacerse, por ejemplo, de una manera muy sencilla a través de actualizaciones periódicas de la matriz, aprovechando la actualización de la evolución de los riesgos. Estas actualizaciones se podrían hacer, al menos, antes de iniciar cada una de las etapas del ciclo de vida del proyecto.

La inclusión en el análisis del ML de profesionales colombianos, donde la metodología es más utilizada, ha permitido confirmar que cuanto más y mejor se conoce el ML, las dificultades a la hora de gestionar los PCD se reducen. Por lo tanto, y aunque se ha demostrado necesario incluir herramientas de DP participativas y anticipativas, en las 
que se tenga en cuenta la cultura local, como puede ser la GR, cobra también un papel importante la mejora en el uso actual que se está haciendo del ML que, en sí mismo, es una metodología participativa y, sin embargo, ha resultado que apenas utiliza el análisis de participantes. Así, se convierte en imprescindible para su mejora, devolverle el carácter participativo que tenía en su origen, haciéndolo además compatible con otros enfoques actuales, como el de género y el de derechos humanos, y con el que aquí se propone de gestión de riesgos.

En cuanto a la introducción de la GR, ha quedado demostrado que se requiere un cambio más profundo en la metodología que sustituir la columna de supuestos por la de riesgos. EI MLEGR es la propuesta integral resultado de la investigación de esta Tesis Doctoral para introducirla.

\subsection{Sobre la necesidad de incluir la gestión de riesgos}

Como ya se ha visto, los PCD conllevan procesos de cambio, y todo cambio implica incertidumbre, por lo tanto, los riesgos son inevitables. Conviene resaltar que la mejor arma para combatir la incertidumbre es la información, y que la mejor fuente de información habita en la comunidad beneficiaria. Tampoco hay que olvidar que los riesgos también constan de una componente positiva que, al descubrirse puede dar lugar a oportunidades muy convenientes.

En este trabajo de investigación se ha demostrado el escaso uso que se hace de la gestión de los riesgos en los PCD a través de sus casos de estudio de la UPM y del Cauca, confirmando lo que estudios previos ya denunciaban (Enyinda, 2017).

Así, en esta Tesis Doctoral, el cómo mejorar, tanto la metodología del ML como la eficacia de los $P C D$, se propone a través de la integración de la $G R$, que permite conocer los riesgos, así como las fuentes de riesgo, que rodean a estas intervenciones. A vista de los profesionales consultados, es la propuesta mejor valorada.

\subsubsection{Riesgos en el caso de estudio y vínculos con el éxito del proyecto (OE3 y OE4)}

Como ya adelantaban otros estudios en relación con los vínculos entre la GR y el éxito del proyecto (Banco Mundial, 2018; Carvalho y Rabechini, 2015), el análisis de los proyectos del Cauca planteado en los objetivos específicos tercero y cuarto de esta Tesis Doctoral, ha permitido establecer relaciones biunívocas entre el éxito en el impacto del proyecto y los riesgos culturales, así como entre el éxito en la dirección del proyecto y los riesgos organizativos. Confirmándose, con ello, la hipótesis de investigación dos: el éxito de los proyectos de cooperación al desarrollo depende de la buena gestión de riesgos.

El caso de estudio del Cauca ha permitido, en primer lugar, y tras el análisis cualitativo, descubrir que los riesgos más importantes, y comunes a todos los proyectos estudiados, 
corresponden a las categorías Económica, Cultural y Política, destacando entre ellos, y para cada categoría, los riesgos de retrasos en la financiación, dificultades en la comunicación y la falta de apoyo del gobierno local.

En segundo lugar, el posterior análisis a través de la Lógica Fuzzy también destacaba la importancia que tenía la identificación y buena gestión de las diferencias culturales al inicio del proyecto como condición necesaria y suficiente para alcanzar el éxito en el impacto del proyecto. De la misma manera, el estudio determina que una intervención no podrá tener impacto si los riesgos económicos no son gestionados de manera apropiada. La categoría política, aunque no alcanza la condición de necesaria, se presenta como condición suficiente, estando presente tanto en el impacto, como en la ausencia de impacto, lo que le da una tremenda importancia a la hora de producirse el cambio buscado en la comunidad.

Se podría decir así, que el estudio cualitativo ha permitido descubrir qué categorías, e incluso qué riesgos concretos, son más importantes para el impacto del proyecto. Esta conclusión está muy en la línea con lo manifestado por los directores y directoras de los proyectos en las entrevistas, donde priorizaban el cumplimiento de actividades (alcance) frente a otros criterios.

En tercer lugar, de nuevo la metodología Fuzzy ha permitido descubrir una relación biunívoca entre los riesgos organizativos y el éxito en la dirección del proyecto, que podría tener su base en la necesidad de alianzas entre las diferentes comunidades y actores que rodean la intervención.

La última, y no menos valiosa, aportación del estudio del Cauca es el registro detallado de riesgos categorizados que se presenta para la ejecución de futuros proyectos en el Cauca y que podría tener aplicación también en otros proyectos ejecutados en otros lugares.

Destaca del caso de estudio la importancia de los factores culturales, dado que como se ha demostrado, gestionar adecuadamente los riesgos relacionados con las diferencias culturales va a tener una fuerte repercusión en el impacto de la intervención. El hecho de que el riesgo de no hacer preguntas y no participar, asociado a culturas jerárquicas, haya aparecido de manera general en casi todos los proyectos estudiados, debe tenerse en cuenta de cara al lanzamiento de procesos participativos, donde será necesario previamente establecer un ambiente de confianza y contar con sesiones entre iguales.

Otro de los riesgos más presentes ha sido el de la falta de apoyo de gobiernos locales, hecho que cobra especial importancia para proyectos de larga duración, en los que la legislatura cambia. El apoyo de los gobiernos e instituciones locales resulta imprescindible para estos proyectos, pero resultaría muy conveniente independizar estas intervenciones de la política, garantizando el apoyo, amparado, tal vez, en la 
Agenda 2030, o en organizaciones independientes que velen por su buen desarrollo. Ejemplos piloto de estas organizaciones pueden encontrarse en las denominadas Oficinas para las Futuras Generaciones, que velan por el desarrollo sostenible de las políticas y proyectos llevados a cabo por los gobiernos. Los más conocidos son los casos de Gales (Future Generations Commissioner for Wales), en Reino Unido y Hungría (The Hungarian Parliamentary Commissioner for Future Generations).

De esta manera, el caso de estudio del Cauca ha demostrado la vinculación de la gestión de riesgos con el éxito del proyecto en el ámbito de la cooperación al desarrollo, sector en el cual esta relación, hasta ahora, solo había sido estudiada de manera exploratoria por el Banco Mundial.

El estudio ha permitido también conocer cómo la aplicación de la prospectiva, con su análisis de escenarios, en el caso del proyecto de educación de Unicomfacauca, ha logrado alcanzar unos resultados extraordinarios, pese a la inexperiencia del equipo del proyecto. La prospectiva emerge así como una buena aliada en la dirección de proyectos en contextos de incertidumbre (Stirling, 1999), aportando anticipación para generar apropiación (Godet, 1986).

Además, los PCD del Cauca, han demostrado cómo los riesgos aumentan cuando se trabaja con poblaciones vulnerables, como desplazados, mujeres, o excombatientes. $Y$ ha confirmado que, pese a que los riesgos pueden verse como oportunidades, queda mucho por hacer en este sentido, dado que apenas se identificaron un par de oportunidades en el proyecto de educación, quizá, precisamente, debido al apoyo del análisis prospectivo.

\subsection{Sobre la contribución de la metodología a la eficacia}

La metodología MLEGR es una aportación original y contrastada con profesionales que permitirá mejorar la eficacia de los proyectos de cooperación al desarrollo incrementando su tasa de éxito. Su ámbito de aplicación no solo se ciñe a la gestión de los proyectos, sino también a la propia organización, dado que, sin el compromiso de ésta con la gestión de riesgos, cualquier cambio introducido tendría menor repercusión. Esta dualidad dota a la metodología de un valioso carácter integral, como así reconocen los profesionales con los que se ha contrastado.

\subsubsection{Contraste de la metodología con profesionales del sector (OE5)}

Desde la consciencia de que el problema de la eficacia es un problema difícil y retorcido (wicked problem), cuya complejidad no puede disponer de una solución única, la GR contribuye a su mejora en el sentido de estructurar el saber cotidiano de la existencia de riesgos y permitir una toma de decisiones de acuerdo con ellos. En la búsqueda 
también de la eficacia en la contribución a la mejora, se ha perseguido la co-creación de la solución propuesta.

Así, la metodología del MLEGR está contrastada con profesionales del sector para mejorar la eficacia de los PCD, tal y como se definía en el objetivo específico cinco.

La valoración positiva recibida tras el contraste confirma las posibilidades que tiene para contribuir a la eficacia de los PCD, validando la hipótesis de investigación tres: el MLEGR puede mejorar la eficacia de los PCD.

\subsection{Principales aportaciones}

La principal aportación de esta Tesis Doctoral es el diseño de una metodología contrastada con ocho profesionales de la cooperación internacional, provenientes de diversos ámbitos, y positivamente valorada como capaz de mejorar la eficacia de los PCD. El consenso alcanzado ha permitido demostrar la coherencia de este trabajo, en el que se aboga por una metodología participativa desde su propio diseño.

La metodología del MLEGR destaca por su sencillez y por su carácter integral, abarcando no solo al proyecto, si no a la propia organización, aspecto muy valorado por los profesionales consultados. Su uso permitirá dar continuidad a las organizaciones en la identificación, evaluación y evolución de los riesgos, de gran valor para proyectos presentes y futuros, contribuyendo a la mejora de los actuales niveles de éxito de los proyectos de cooperación al desarrollo y cumpliendo así el objetivo general con el que nació esta Tesis Doctoral.

El diseño del MLEGR está apoyado en otras contribuciones previas necesarias para la consecución de este resultado. Estas aportaciones se detallan a continuación:

- Presentación de las lecciones aprendidas de los PCD realizados en la UPM, así como de sus riesgos.

El análisis realizado se ha presentado como comunicación en el VII Congreso de Universidad y Cooperación al Desarrollo (Madrid, marzo, 2017), donde fue seleccionado para publicación en la Revista Española de Desarrollo y Cooperación.

- Análisis de la trayectoria y obtención de lecciones aprendidas en los proyectos de cooperación internacional de la UPM. Rocío Rodríguez-Rivero, Isabel OrtizMarcos y Manuel Sierra-Castañer. Revista Española de Desarrollo y Cooperación 41, 109-119. (Diciembre, 2017).

- Diseño de un modelo de Estructura de Descomposición de Riesgos que incluyera la categoría cultural. 
La Cultural Risk Breakdown Structure fue presentada en el $7^{\text {th }}$ Global Innovation and Knowledge Academy (GIKA) (Lisboa, junio de 2017), bajo el título Psychological competences of project managers working in an international context, donde fue premiado como mejor comunicación y seleccionado para su publicación en la revista indexada Psychology and Marketing.

- The opportunity to improve psychological competences of project managers in international business. Rocío Rodríguez-Rivero, Isabel Ortiz-Marcos, Luis Ballesteros-Sánchez y Javier Romero. Psychology \& Marketing 35, 150-159. (Marzo, 2018).

Previamente, se presentó un póster en el II Industriales Research Meeting (Madrid, abril de 2017) bajo el título Cultural risks in projects developed in South East countries. A closeness to identify risks in international development projects (Rocío Rodríguez-Rivero e Isabel Ortiz-Marcos).

- Conocimiento de la evolución del ML, de sus fortalezas y debilidades y de la opinión de los profesionales que trabajan con esta metodología.

El análisis del cuestionario sobre el ML con profesionales españoles se presentó como comunicación al $22^{\text {nd }}$ International Congress on Project Management and Engineering (Madrid, julio de 2018), donde fue seleccionado para su publicación como capítulo del libro Project Management and Engineering Research, parte de la serie Lecture Notes in Management and Industrial Engineering (Springer).

- The Logical Framework Approach, does its history guarantee its future? Rocío Rodríguez-Rivero, Isabel Ortiz-Marcos, Luis Ballesteros-Sánchez, Javier Mazorra y María Jesús Sánchez-Naranjo. En: Ayuso Muñoz J., Yagüe Blanco J., Capuz-Rizo S. (eds) Project Management and Engineering Research. Lecture Notes in Management and Industrial Engineering. Springer, Cham. (En prensa, edición impresa prevista para septiembre de 2019).

Un posterior análisis con una estadística más desarrollada se encuentra en revisión en la revista indexada International Journal of Managing Projects in Business.

- Improving the management of International Development Projects. Rocío Rodríguez-Rivero, Isabel Ortiz-Marcos, Luis Ballesteros-Sánchez y María Jesús Sánchez-Naranjo. International Journal of Managing Projects in Business. (En revisión desde febrero de 2019).

Además, un estudio preliminar se presentó como póster en la II Edición del Simposio "cuéntanos tu tesis" (Madrid, marzo de 2018), bajo el título de 
Introduction of Risk Management in International Development Projects. An innovative approach of the Logical Framework. (Rocío Rodríguez-Rivero e Isabel Ortiz-Marcos).

- Registro de riesgos para los proyectos de cooperación al desarrollo en el Cauca y definición de los riesgos más importantes.

El caso de estudio del Cauca y de sus proyectos ha resultado muy revelador, dado que, además, ha contado con el apoyo de los equipos de proyecto, de sus directores y de la gobernación del Cauca. Fruto de este estudio se ha podido obtener un registro de riesgos que servirá de base para futuros proyectos en éste y en otros contextos.

El análisis en profundidad del proyecto de educación superior para jóvenes sin recursos ha permitido conocer la aplicación de la prospectiva a la dirección de proyectos y está siendo revisado tras su aceptación con comentarios en la revista indexada International Journal of Project Management.

- The Strategic Prospective Approach Applied to Project Management in a Development Project in Colombia. Rocío Rodríguez-Rivero, Isabel OrtizMarcos, Virginia Díaz-Barcos y Sergio A. Lozano.

- Difusión de la gestión de riesgos en el ámbito de la cooperación al desarrollo.

Demostrada la influencia de la gestión de riesgos en el éxito de los proyectos, en el seno de la Plataforma de la UPM para Latinoamérica y el Caribe, se ha elaborado una guía didáctica para su introducción y uso a través de herramientas y técnicas participativas.

- Manual de Gestión de Riesgos para Proyectos de Cooperación al Desarrollo. Rocío Rodríguez-Rivero y Jessica García del Águila. (En prensa, pendiente de ISBN).

Se ha participado en la III Edición del Simposio "cuéntanos tu tesis" (Madrid, mayo de 2019), con la ponencia titulada The Logical Framework with a Risk Management Approach. (Rocío Rodríguez-Rivero e Isabel Ortiz-Marcos) que ha obtenido el premio de finalista del Simposio.

Por último, para darle continuidad a la investigación, se ha presentado un proyecto a la convocatoria pública de subvenciones 2019 del Ayuntamiento de Madrid para la realización de proyectos de investigación en materia de ciudadanía global y cooperación internacional para el desarrollo. El proyecto ha 
sido solicitado por la Fundación General de la Universidad Politécnica de Madrid tras haber sido seleccionado entre los presentados por la UPM.

- Estudio de la influencia de la mejora de la gestión de riesgos en los proyectos de cooperación al desarrollo sobre el impacto de los resultados del proyecto en la comunidad beneficiaria. IP: Rocío Rodríguez-Rivero. Presupuesto: 44.266€. (Presentado en febrero de 2019, pendiente de resolución de financiación).

\subsection{Principales dificultades y limitaciones}

Las principales dificultades a las que se ha enfrentado esta Tesis Doctoral guardan mucha relación con los desafíos planteados en el Capítulo 1. Así, encontrar el equilibrio entre la búsqueda de eficacia en las acciones y la sensibilidad para entender la dificultad de trabajar en muchos de los terrenos ha sido una de las principales dificultades. Otra ha sido el tiempo limitado para realizar la investigación, en el que no resulta posible ejecutar la metodología diseñada y ver sus resultados, dejándose esto para futuros trabajos.

Entre las limitaciones se encuentra que el sector de la cooperación al desarrollo es muy pequeño y cuenta con un número reducido de profesionales, los cuales, en su mayoría, pasan grandes periodos en terreno, por lo tanto, el acceso y comunicación con ellos ha sido en algunas ocasiones muy complicado y ha limitado la muestra del cuestionario a 77 profesionales que, aunque es representativo del sector, no deja de ser reducido a la hora de generalizar resultados. En la misma línea, en la muestra solo están profesionales españoles y colombianos que, pese a representar una interesante combinación de los puntos de vista de un país "desarrollado" y uno de "renta media", está delimitada a los contextos, principalmente políticos y socioculturales de cada país.

Igualmente, el contraste de la metodología con ocho profesionales españoles y colombianos está sometida al mismo sesgo.

A la hora de elegir el caso de estudio del Cauca, también se ha limitado la investigación a un contexto determinado en el que la diversidad cultural está muy presente, por tanto, algunos de los resultados obtenidos podrían variar al estudiarse otro contexto. De la misma manera, los ocho proyectos elegidos, aunque son muy variados, representan solo a determinados sectores dentro de la cooperación. Probablemente de haberse elegido otros proyectos con componentes más técnicas, los riesgos y su importancia variarían. El estudio realizado en ningún caso presenta una identificación de riesgos únicos y extrapolables a otros proyectos, puesto que cada proyecto es único. Lo que sí presenta es un registro de riesgos para ayudar a la identificación de los mismos en futuros proyectos, así como una metodología de aplicación en cualquier PCD. 


\subsection{Desarrollos futuros}

Atendiendo a las limitaciones comentadas, algunos desarrollos futuros se plantean en la línea de expandir el estudio del marco lógico a profesionales de la cooperación de otros países. Igualmente, se propone ampliar a otras zonas geográficas y sectores el análisis de PCD y sus riesgos, para ver si los riesgos y su evaluación varía. En la identificación de riesgos sería muy interesante también aplicar el método DELPHI para completar el registro de riesgos presentado en el Capítulo 6.

Para ampliar estudio realizado con los datos de los proyectos del Cauca, se propone realizar su estudio estadístico y compararlo con los resultados obtenidos a través de la metodología Fuzzy. Igualmente, se podría incorporar a este análisis el uso de la metodología multicriteria mapping (Stirling, 1997) que aportaría nuevas perspectivas a los resultados obtenidos. En esta labor se contaría con el apoyo y supervisión de su diseñador, el profesor Andrew Stirling.

En relación con los riesgos encontrados, la búsqueda de respuestas para los mismos se plantea también como un futuro trabajo de investigación, dado que existe muy poco realizado en materia de respuestas a los riesgos, con excepción de algún trabajo, como el de Wang, Dulami y Aguria (2004) aplicado al ámbito de la construcción.

Es de interés también conocer qué opinan las comunidades beneficiarias de esta metodología y empezar a trabajar con ella en estas comunidades, de tal manera que se puedan obtener resultados para valorar los beneficios de su uso. Actualmente, y como se ha indicado en el Apartado 7.6, se ha presentado ya un proyecto de estas características a la convocatoria de Proyectos de investigación en materia de ciudadanía global y cooperación internacional para el desarrollo del Ayuntamiento de Madrid, para desarrollar esta línea en el Cauca, lo que permitiría comparar resultados.

Debido también al compromiso demostrado de la Gobernación del Departamento del Cauca y a su apertura a seguir trabajando con esta línea, se propone ofrecer el registro de riesgos en abierto a los directores de proyecto que trabajen en la zona, de tal manera que puedan disponer de él y actualizarlo con nuevos riesgos encontrados. Este registro se podría mantener así siempre vivo y accesible a las organizaciones que registraran en esta administración sus proyectos.

Igualmente, en el ámbito de la UPM debido a los vínculos con esta universidad, se propone, en primer lugar, el análisis de los PCD fruto de las plataformas de trabajo surgidas alrededor de la Convocatoria UPM para acciones para contribuir al cumplimiento de los Objetivos de Desarrollo Sostenible y comparar su alineamiento con Ios ODS con respecto al obtenido en el estudio realizado con los 152 proyectos. $Y$, en segundo lugar, la aplicación de la metodología MLEGR, empezando para ello con su 
difusión y su inclusión a nivel organización, así como hacer accesible y actualizable el registro de riesgos.

En relación con la metodología diseñada, y con el fin de que pueda ser aplicada al mayor número de PCD posible, contribuyendo así a la mejora de su efectividad, como futuros pasos se propone el diseño de una herramienta informática acompañada de aplicación para dispositivo móvil, en el que cada organización pueda ir utilizando las herramientas presentadas y guardando un registro de los PCD ejecutados. Conforme más organizaciones la utilicen, mayor será el registro de riesgos disponible para cada zona y tipo de proyecto, pudiendo establecer así un registro colaborativo de riesgos que pudiera ser compartido entre las distintas organizaciones.

Además, con la idea de difundir la metodología y hacerla lo más sencilla posible en su uso, resulta muy pertinente el diseño de una guía para su utilización dotada de sencillos ejemplos.

Por último y no por ello menos importante, esta Tesis Doctoral es solo un paso más para aprovechar la oportunidad abierta con la Agenda 2030 de generar cambios más sostenibles y plurales hacia el desarrollo de millones de personas en todo el mundo, pero quedan muchos pasos que dar en el futuro próximo. En estos pasos, la vinculación de los gobiernos y de las políticas de desarrollo se plantea imprescindible, por lo tanto, buscar su implicación y exigir su compromiso es responsabilidad de todos. Esta Tesis Doctoral buscará esta implicación en todos sus futuros desarrollos. 


\section{CHAPTER 7. CONCLUSIONS AND FUTURE WORKS}

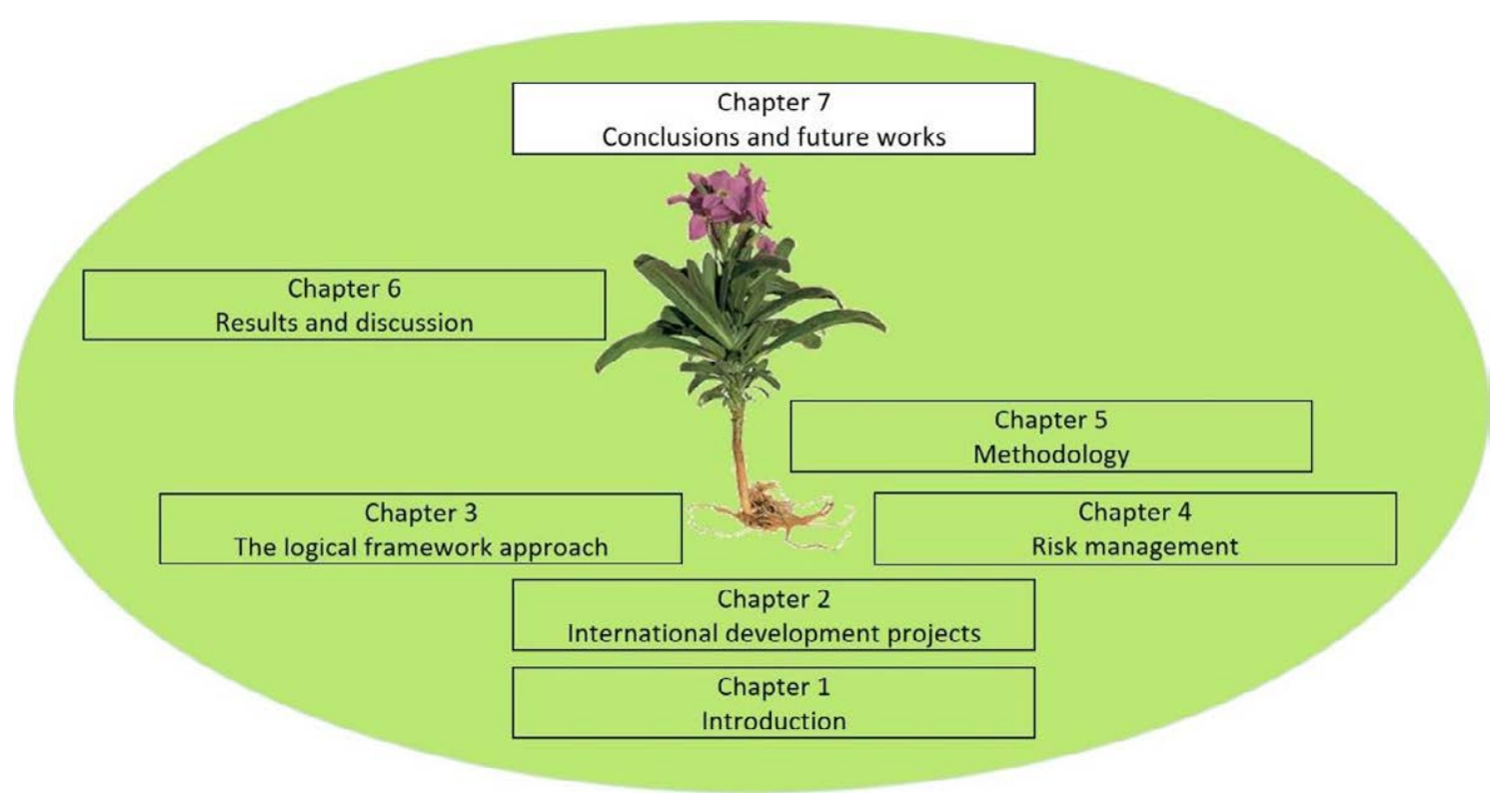

Figure 7.1. Conclusions and future works.

Source: prepared by the author.

"In a world in rapid and profound transformation we are all designers"

(Ezio Manzini, 2015. Design, when everybody designs: an introduction to design for social innovation. Cambridge: MIT Press) 


\subsection{Introduction}

The main objective of this Doctoral Thesis, defined in Chapter 1, is to develop a methodology for the management of International Development Projects (IDP) with integrated Risk Management (RM), to improve their effectiveness, and contribute to a greater impact on the beneficiary community. This methodology takes the strengths of the Logical Framework Approach (LFA), incorporating risk management in each of its stages. Therefore, it is named the Logical Framework with a Risk Management Approach (LFRMA).

To contribute to this main objective, the following Specific Objectives (SO) are also raised:

SO1: to know how the IDP of the Universidad Politécnica de Madrid (UPM) are, what their lessons learned are and what risks they face.

SO2: to analyze the strengths and weaknesses of the LFA to propose the most convenient improvements.

SO3: to identify and evaluate the risks of the case study's projects to propose a register and categorization of risks in that context that could serve as a model for other contexts.

SO4: to discover the relationship between the evaluated risks and the perception of success of the case study's projects to find possible links between risks and success.

SO5: to contrast with professionals in the field of international development the design of the LFRMA to do it suitable to the sector.

The fulfillment of these objectives was supported by an extensive review of the literature. Among the main references stand out those of Lavagnon Ika, with its critical theories, its approach to post-development and its re-evaluation of the previous works of Albert Hirschman. Samely, it stands out the work of Ruggero Golini for ensuring visibility to the professionals of the Non-Governmental Development Organizations (NGDO). The studies of Marly Monteiro de Carvalho have also been very inspiring to grant risk management an important position in the success of the projects. And finally, the stay at the University of Sussex with Andrew Stirling has allowed to recognize the difficulty of working in environments of uncertainty and the prominence that this gives to qualitative analysis.

These works, along with those of many other authors, have led to interesting contributions that are presented below, linked with the main and the specific objectives. 
This last chapter reviews the achievement of the objectives and presents the most relevant contributions of this Doctoral Thesis. It also shows how the research hypotheses have been responded.

This chapter also includes the main difficulties and limitations arising in the research, as well as future works.

\subsection{About the Logical Framework with a Risk Management Approach}

The great contribution of this research is the design of the LFRMA. Its visual scheme is presented in Figure 7.2. The design of this methodology is co-created thanks to all the people who have collaborated with their contributions, both in the field, and through their answers to questionnaires and interviews, and it responds to the main objective of the Doctoral Thesis.

The MLEGR has a holistic nature and goes beyond mere application to projects, involving the organization through the Team-Type-Territory (TTT) analysis. In addition, thanks to its introduction into the organizational culture, the methodology is capable of generating a living documentary record, both of risks and lessons learned, which guarantees to have valuable input data for future projects.

The use of this methodology establishes a practical bridge between Project Management (PM) and international development, by integrating risk management in the LFA steps and in all stages of the project's life cycle. The construction of this bridge follows the previous steps given by theoretical-didactic guides, such as the PMD Pro (PM4NGOS, 2013), and responds to the need detected in this investigation.

Through simple tools and using very few additional resources, this participatory methodology integrates and complements the steps of the LFA, since it represents a common language in international development. Thus, reducing some of its weaknesses whilst reinforcing its strengths. The LFRMA is at the same time compatible with other current approaches of the LFA, such as gender, or human rights, as well as with theories of change (TC). 

INDUSTRIALES Metodología del Marco Lógico con Enfoque de Gestión de Riesgos para mejorar la eficacia de los proyectos de cooperación al desarrollo

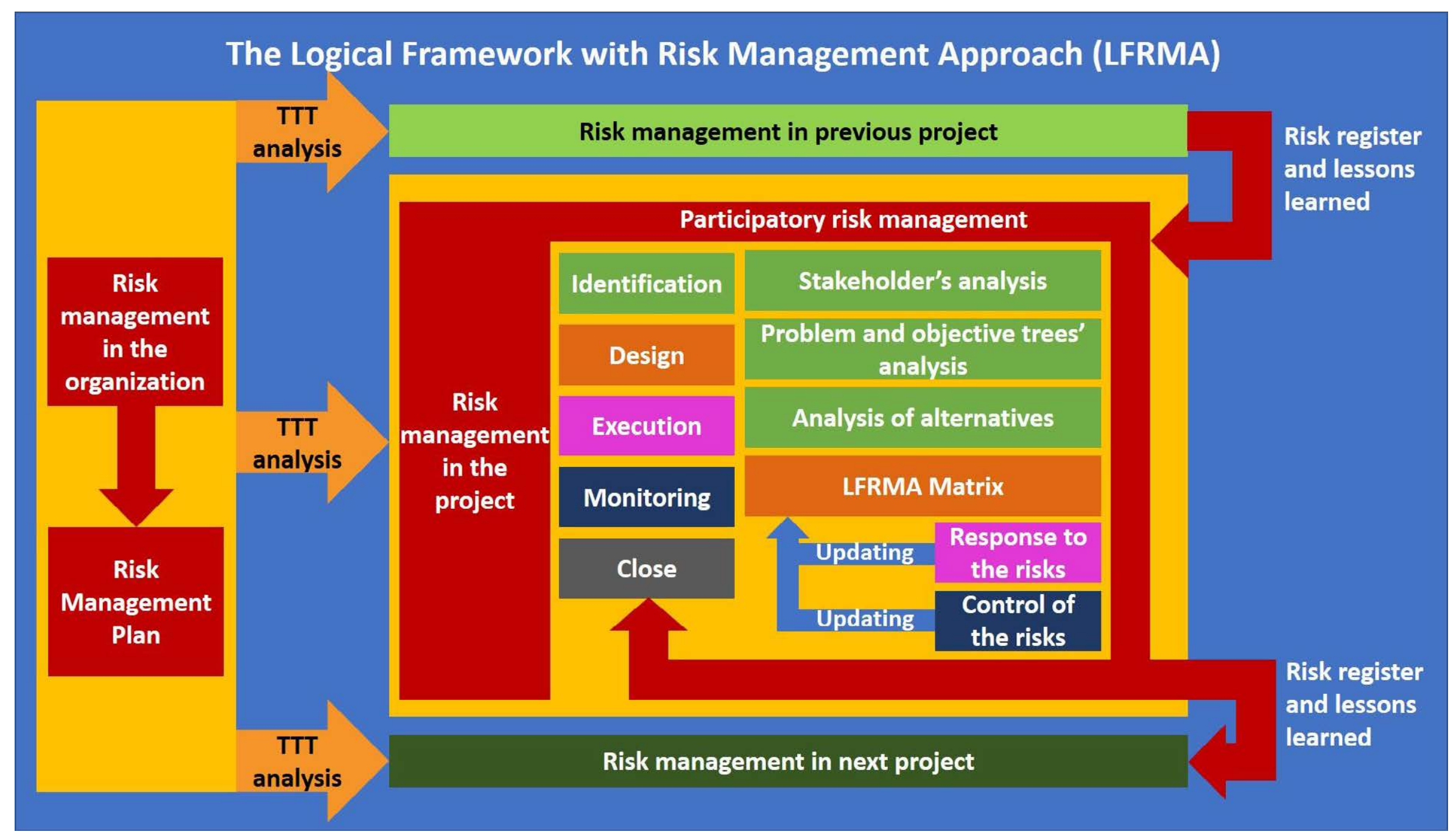

Figure 7.2. LFRMA.

Source: prepared by the author. 


\subsection{About the current situation of international development and the need for effectiveness}

The depth in the research in the theoretical framework has made possible to know the current transition moment in which international development cooperation is. The inclusion of new participants and the search for sustainable and adequate solutions to the territories, are opening up a step to bottom-up approaches where citizen participation and local movements have a major role, and international development is not being a matter exclusively for governments or international institutions.

In this moment of transition, the responsibility of interventions should prevail, not only to combat inequalities and their related problems, but also to establish the necessary trust among the multiple actors involved in IDP and the beneficiary communities. The effectiveness of these projects is vital to generate trust from which to co-create the change towards the desired development.

The concept of development linked so far with growth is now incorporating new formulas that increase respect towards human beings and their nature. Notions such as Pluriverso (Escobar, 2016), closely linked to the Buen Vivir (Radcliffe, 2018), begin to be considered as alternatives to more traditional approaches, as the post-development theories were already advancing (Sachs, 1992). These new approaches seek to develop capacities according to the environment in which the community lives. The beneficiary communities must be the protagonists in choosing the type of development desired, and, the project team, as a mediator with the rest of the actors involved, must know how to allow them to express it. The participatory methodologies, based on the Participatory Rural Appraisal, help to understand the emerging demands that arise in the evolutionary concept of development, as Rober Chambers already anticipated. Precisely Chambers (2017) encourages interaction between communities to mutually transform the way of seeing things, behaving, learning and doing.

The cooperation community is made up of people with a passion for changing things. This desire for change, along with a very high capacity for adaptation, give them the creativity to go beyond their own limits and overcome adversities that could not have been imagined, as Hirschman (1967) said.

In the search of the effectiveness of the international development, it is necessary to see in each IDP a unique opportunity to impact in the improvement of the quality of life of the inhabitants of a community. From there, is necessary to work hard to not waste this opportunity and be effective in the response. From this conception, which answers the question of what, the methodologies and tools are only the instruments at the service of the professionals and, therefore, their improvement must be agreed with them. 


\subsubsection{Lessons learned and risks in the IDP of the UPM (SO1)}

In these moments of change, the international community, and the "developed" and "developing" countries have joined hands in the pursuit of common development objectives materialized in the 17 Sustainable Development Goals (SDG) and their 169 goals. In the 2030 Agenda, all the sectors of the society are called to contribute to change. Among them, also the Academia.

The study of the 152 IDP executed by the UPM was the first of the objectives set out in this research, to know to what extent, until now, the development of these projects was aligned with the great challenges set by the international agenda, as well as to document the lessons learned, and to identify and to evaluate the risks they faced. Their knowledge has made possible to identify as a lesson learned the importance of knowing in advance and in-depth the target community, as well as their political, legal, sociocultural, and climatological context. With a greater knowledge of the territory in which it is going to act, as well as of the particular community, some risks common to almost all projects, such as the lack of long-term orientation of the beneficiary communities, the lack of training of its inhabitants and the lack of knowledge about the topics of interest for formation in the community, could have been diminished.

The lessons learned, of great value in contexts of uncertainty (Stirling, 2010), are perhaps the most effective method to move towards the change most demanded by the communities, since it supposes, in short, learning from them.

\subsection{About the Logical Framework Approach}

In its fiftieth anniversary (1969-2019), the LFA continues to be recognized as the common language in development cooperation interventions (Banco Mundial, 2005; Hummelbrunner, 2010). This is an advantage that cannot be wasted. In these moments, when sustainability proposes to bet on the model of the "R", Rethink the LFA, fostering its strengths and diminishing its weaknesses, to Reuse it in a more effective methodology, taking advantage of the recognition that enjoys, is the $\mathrm{SO} 2$ that was raised with this Thesis, answering in addition to the question what to improve.

\subsubsection{Strengths and weaknesses of the Logical Framework Approach (SO2)}

The initial theoretical study of this methodology led to the design of a questionnaire that, thanks to the collaboration of professionals in the sector, has revealed that professionals value the strengths of this methodology more than their weaknesses. Also, they think that the LFA is not confusing, but facilitates their work as its use is extended throughout the world. The results obtained confirm the previous studies of Golini, Landoni, and Kalchschmidt (2017), which verified the level of the adoption of the LFA in 
the NGDOs with some performance indicators such as time-cost and strategy in the projects, and concluded that the LFA is a very useful methodology for NGDOs.

This study confirms also the research hypothesis one, concluding that the LFA needs to be improved, and that, among the proposals for improvement, the most accepted is the introduction of Risk Management throughout the process.

This revelation is of great value, since among all the improvement proposals mentioned in previous works, such as the integration of the time dimension (Crawford and Bryce, 2003), or the inclusion of costs and benefits (Ika and Lytvynov, 2011), focuses on the GR, as also proposed by Yamaswari et al. (2016) and Couillard, Garon and Riznic (2009). The contribution to these two works is that, while the case of Yamaswari et al. (2016) was working with a single project, and the case of Couillard, Garon and Riznic (2009) was a theoretical assessment, this research has been based on the opinion of 77 professionals, most of them with more than ten years of experience in PM in the international development sector.

Through the results of the questionnaire, it has been detected that the most marked weakness of this methodology is its rigidity, as previously stated by other authors (Crawford and Bryce, 2003; Gasper, 2000; Hummelbrunner, 2010). To break this lack of flexibility, it is necessary to recognize that projects are carried out in open systems in which changes occur, and that the relationships cannot be as linear as the LFA defines, but more dynamic, as TC defend.

The LFA needs to adapt, just as people working in IDPs are required to do so. The methodology should be flexible and the simplest option for that is to keep the matrix alive, not to freeze it, but to give it dynamism throughout the development of the project, confirming what other authors had suggested (Crawford and Bryce, 2003; Golini, Landoni and Kalchscmidt, 2017; Khang and Moe, 2008; Yamaswari et al., 2016). This could be done, for example, through periodic updates of the LFA matrix, taking advantage of the revision of the evolution of the risks. These updates could be made, at least, before starting each of the stages of the project's life cycle.

The inclusion in the LFA' analysis of the Colombian professionals, where the methodology is most used, has confirmed that the more and better the LFA is known, the difficulties in managing IDP are fewer. Therefore, and although it has been shown necessary to include participatory and proactive PM tools, where the local culture is taken into account, such as the RM, an improvement in the current use of the LFA also plays an important role. The LFA is, in itself, a participatory methodology and, nevertheless, it has turned out that it hardly uses the analysis of participants. Thus, it becomes essential for its improvement, returning the participatory nature that it had in 
its origin, making it also compatible with other current approaches, such as gender and human rights, and with the one proposed here for RM.

Regarding the introduction of the RM, it has been demonstrated that a more profound change in the methodology is required, rather than replacing the column of assumptions by the risks. The LFRMA is the integral proposal resulting from the research of this Doctoral Thesis to introduce it.

\subsection{On the need to include Risk Management}

As it has seen, IDP involve processes of change, and any change implies uncertainty, therefore, risks are inevitable. It should be noted that the best weapon to combat uncertainty is information, and that the best source of information lives in the beneficiary community. Nor should be forgotten that the risks also consist of a positive component that, when discovered, can lead to very convenient opportunities.

In this research, the scarce use of RM in IDP has been demonstrated through their case studies from UPM and Cauca, confirming what previous studies have already reported (Enyinda, 2017).

Thus, in this Doctoral Thesis, how to improve, both the LFA and the effectiveness of the IDP, is proposed through the integration of the RM. The RM allows knowing the risks, as well as the sources of risk, that surround these interventions. In view of the professionals consulted, it is the best-valued proposal.

\subsubsection{Risks in the case study and their links with the sucess of the project (SO3 \& SO4)}

As other studies carried out in relation to the links between the RM and the success of the project (Banco Mundial, 2018; Carvalho and Rabechini, 2015), the analysis of the Cauca projects, set out in the third and fourth specific objectives of this Doctoral Thesis, has allowed to establish direct relationships between the success in the impact of the project and the cultural risks, as well as between the success in the PM and the organizational risks. It confirms the research hypothesis two: the success of development cooperation projects depends on good risk management.

The case study of Cauca has allowed, first of all, and through the qualitative analysis, to discover that the most important risks, common to all the projects studied, correspond to the Economic, Cultural and Political categories, standing out among them, and for each category, the risks of delays in financing, difficulties in communication and lack of support from the local government.

Second, the subsequent analysis through the fuzzy logic also highlighted the importance of identifying and managing cultural differences at the beginning of the project, as a necessary and sufficient condition to achieve success in the impact of the project. In the 
same way, the study determines that an intervention cannot have an impact if the economic risks are not managed appropriately. The political category, although it does not reach the necessary condition, appears as a sufficient condition, being present both in the impact, and in the absence of impact. This gives great importance to this category in the seeking of the improvement in the impact in the community.

It could be said that the qualitative study has made possible to discover which categories, and even which specific risks, are more important for the impact of the project. This conclusion is aligned with the statements made by the project managers in the interviews since they prioritized the fulfillment of activities (scope) against other criteria.

In the third place, the fuzzy logic has also revealed a direct relationship between organizational risks and success in project management, which could be based on the need for alliances between the different communities and actors surrounding the intervention.

The last, and no less valuable, contribution of the Cauca study is the detailed risk register that is presented for the execution of future projects in Cauca, and that could have application also in other projects executed in other places.

The importance of cultural factors is highlighted in the case study, showing that the proper managing of the risks related to cultural differences will have a strong implication on the impact of the intervention. The fact that the risk of not asking questions and not participating, associated with hierarchical cultures, has appeared in a general way in almost all the projects studied, should be taken into account when launching participatory processes. According to this, it will be necessary previously to establish an environment of trust with sessions between equals.

Another of the most present risks has been the lack of support from local governments, which is particularly important for long-term projects, in which the legislature changes. The support of local governments and institutions is essential for these projects, but it would be very convenient to separate these interventions from political changes. The support should be guaranteed better by the 2030 Agenda, or independent organizations that ensure the good development of the projects. Pilot examples of these organizations can be found in the so-called Offices for Future Generations, which ensure the sustainable development of policies and projects carried out by governments. The best known are the cases of Wales (Future Generations Commissioner for Wales), in the United Kingdom and Hungary (The Hungarian Parliamentary Commissioner for Future Generations).

In this way, the case study of Cauca has demonstrated the link between risk management and the success of the project in the field of international development, a 
sector in which this relationship, until now, had only been studied in an exploratory way by the World Bank.

The study has also allowed knowing how the application of the strategic prospective and its analysis of scenarios, in the case of the education project of Unicomfacauca, has managed to achieve extraordinary results, despite the inexperience of the project team. The prospective emerges as a good ally in the management of projects executed in contexts of uncertainty (Stirling, 1999), providing anticipation to generate ownership (Godet, 1986).

In addition, the IDP of Cauca have demonstrated how risks increase when working with vulnerable populations, such as displaced persons, women, or ex-combatants. Also, it has confirmed that, although risks can be seen as opportunities, there is still much to be done in this regard. In this study, only a couple of opportunities were identified in the Education project, perhaps precisely because of the support of the prospective analysis.

\subsection{About the contribution of the methodology to the effectiveness}

The MLEGR methodology is an original contribution, also contrasted with professionals, that will make it possible to improve the effectiveness of IDP by increasing their success rate. Its scope of application is not limited to the management of projects, but also to the organization itself. It is due to the idea of without the organization's commitment to risk management, any change introduced would have less impact. This duality gives the methodology a highly valued integral character, as recognized by the professionals with whom it has been contrasted.

\subsubsection{The contrast of the methodology with professionals of the sector (SO5)}

From the awareness that the problem of effectiveness is a wicked problem, whose complexity cannot have a single solution, the RM contributes to its improvement in the sense of structuring the daily knowledge of the existence of risks and allowing decision making according to them. Searching also for the effectiveness in the contribution to the improvement, this research has pursued the co-creation of the proposed solution.

Thus, the LFRMA is contrasted with professionals of the sector to improve the effectiveness of the PCD, as defined in the SO5.

The positive assessment received after the contrast confirms the possibilities of this methodology to contribute to the effectiveness of the IDP, validating the research hypothesis three: the LFRMA can improve the effectiveness of the IDP. 


\subsection{Main contributions}

The main contribution of this Doctoral Thesis is the design of a methodology contrasted with eight professionals from international development, and positively valued as able to improve the effectiveness of the IDP. The consensus reached allows demonstrating the coherence of this work, which calls for a participatory methodology from its own design.

The LFRMA stands out for its simplicity and for its integral nature, encompassing not only the project but the organization itself, an aspect highly valued by the professionals consulted. Its use will allow continuity to organizations in the identification, evaluation, and evolution of the risks. It will be of great value for present and future projects and will contribute to the improvement of the current levels of success of the IDP. The fulfillment of the general objective of this Doctoral Thesis is then achieved.

The design of the LFRMA is supported by other previous and necessary contributions to achieving this result. These contributions are detailed below:

- Presentation of the lessons learned and risks from the IDP executed by the UPM.

The analysis has been presented as communication in the VII Congress of University and Development Cooperation (Madrid, March 2017) and it was selected for publication in the Revista Española de Desarrollo y Cooperación [Spanish Journal of Development and Cooperation].

- An evaluation of the pathway, culmination and lessons learned of International Development Projects lead by Universidad Politécnica de Madrid. Rocío Rodríguez-Rivero, Isabel Ortiz-Marcos, and Manuel SierraCastañer. Revista Española de Desarrollo y Cooperación 41, 109-119. (December 2017).

- Design of a Risk Breakdown Structure that includes the cultural category.

The Cultural Risk Breakdown Structure was presented in the $7^{\text {th }}$ Global Innovation and Knowledge Academy (GIKA) (Lisboa, June 2017), entitled Psychological competences of project managers working in an international context. It was awarded as best communication in the Congress and it was also selected for publication in the indexed journal Psychology and Marketing.

- The opportunity to improve psychological competences of project managers in international business. Rocío Rodríguez-Rivero, Isabel Ortiz-Marcos, Luis Ballesteros-Sánchez, and Javier Romero. Psychology \& Marketing 35, 150159. (March 2018). 
Previously, a poster was presented to the II Industriales Research Meeting (Madrid, April 2017) entitled Cultural risks in projects developed in South East countries. A closeness to identify risks in international development projects (Rocío Rodríguez-Rivero, and Isabel Ortiz-Marcos).

- Knowledge of the evolution of the LFA, its strengths and weaknesses and the opinion of professionals working with this methodology.

The analysis of the Spanish professionals' opinion about the LFA was presented as communication to the $22^{\text {nd }}$ International Congress on Project Management and Engineering (Madrid, July 2018). It was selected for publication as a chapter of the book Project Management and Engineering Research, part of the series Lecture Notes in Management and Industrial Engineering (Springer).

- The Logical Framework Approach, does its history guarantee its future? Rocío Rodríguez-Rivero, Isabel Ortiz-Marcos, Luis Ballesteros-Sánchez, Javier Mazorra, and María Jesús Sánchez-Naranjo. In: Ayuso Muñoz J., Yagüe Blanco J., Capuz-Rizo S. (eds) Project Management and Engineering Research. Lecture Notes in Management and Industrial Engineering. Springer, Cham. (In press, printed edition in September 2019).

Further analysis with a more detailed statistical analysis is under review in the indexed journal, International Journal of Managing Projects in Business.

- Improving the management of International Development Projects. Rocío Rodríguez-Rivero, Isabel Ortiz-Marcos, Luis Ballesteros-Sánchez, and María Jesús Sánchez-Naranjo. International Journal of Managing Projects in Business. (Under review from February 2019).

In addition, a preliminary study was presented as a poster in the /I Edición del Symposium "cuéntanos tu tesis" (Madrid, March 2018), entitled Introduction of Risk Management in International Development Projects. An innovative approach of the Logical Framework. (Rocío Rodríguez-Rivero, and Isabel OrtizMarcos).

- A risk register for IDP in Cauca and definition of the most important risks.

The case study of Cauca and its projects has been very revealing thanks to the support of the project teams, their directors and the government of Cauca. As a result of this study, it has been possible to obtain a risk register that will serve as a basis for future projects in this and other contexts. 
The in-depth analysis of the Higher education project (project 1) made possible to know the application of strategic prospective to project management. The corresponding paper is being reviewed after its acceptance with major revision in the International Journal of Project Management.

- The Strategic Prospective Approach Applied to Project Management in a Development Project in Colombia. Rocío Rodríguez-Rivero, Isabel OrtizMarcos, Virginia Díaz-Barcos, and Sergio A. Lozano.

- Dissemination of risk management in the field of international development.

Demonstrated the influence of RM on the success of the IDP, within the UPM Platform for Latin America and the Caribbean, a didactic guide has been prepared for its introduction and uses through participatory tools and techniques.

- Manual de Gestión de Riesgos para Proyectos de Cooperación al Desarrollo. [Risk Management Guide for International Development Projects]. Rocío Rodríguez-Rivero, and Jessica García del Águila. (In press, ISBN pending).

The methodology has been also presented as communication in the III Edition of the Symposium "Your thesis in a nutshell" (Madrid, May 2019), under the tittle The Logical Framework with a Risk Management Approach (Rocío RodríguezRivero, and Isabel Ortiz-Marcos). This communication has been a finalist at the Best Communication Award during the Symposium.

Finally, to continue with the research, a project has been presented to the public calls 2019 of the Madrid's City Council for the implementation of research projects in the field of global citizenship and international cooperation for development. The project was requested by the General Foundation of the Universidad Politécnica de Madrid after having been selected among those presented by the UPM.

- Estudio de la influencia de la mejora de la gestión de riesgos en los proyectos de cooperación al desarrollo sobre el impacto de los resultados del proyecto en la comunidad beneficiaria. [Study of the influence of risk management improvement in international development projects on the impact of project results on the beneficiary community]. PI: Rocío Rodríguez-Rivero. Budget: 44.266€. (Submitted on February 2019, pending funding resolution). 


\subsection{Main difficulties and limitations}

The main difficulties faced by this Doctoral Thesis are closely related to the challenges presented in Chapter 1. Thus, finding the balance between the search for effectiveness in actions and sensitivity to understand the difficulty of working in most of the contexts has been one of the main difficulties. Another has been the limited time to carry out the research, in which it is not possible to execute the designed methodology and see its results, leaving this for future work.

Among the limitations, it is necessary to mention that the sector of international development is very small and has a small number of professionals, who, in addition, spend large periods in the field. Therefore, access and communication with them have been sometimes very complicated and limited the sample of the questionnaire to 77 professionals. The sample is representative of the sector, but still reduced when it comes to generalizing results. Likewise, the sample includes only Spanish and Colombian professionals who, despite representing an interesting combination of the points of view of a "developed" country and one of "average income", are limited to contexts, mainly socio-political and of each country.

On a similar way, the contrast of the methodology with eight Spanish and Colombian professionals is subject to the same bias.

At the time of choosing the case study of Cauca, research has also been limited to a specific context in which cultural diversity is a major factor. Therefore, some of the results obtained could vary when studying another context. In the same way, the eight selected projects, although they are very varied, represent only certain sectors within the cooperation. Probably having chosen other projects with more technical components, the risks, and their importance would vary. The study conducted in no case presents identification of unique and extrapolated risks to other projects since each project is unique. Here is a risk register to help identify risks in future projects, and a methodology applicable on any IDP.

\subsection{Future works}

In view of the limitations mentioned, some future works are proposed to broaden the research of the LFA to cooperation professionals from other countries. Likewise, it is proposed to expand the analysis of the IDP and their risks to other geographical areas and sectors, to see if the risks and their evaluation vary. In the identification of risks, it would be very interesting to apply the DELPHI method to complete the risk register presented in Chapter 6.

To enlarge the analysis carried out with the data of the Cauca projects, it is proposed to conduct a statistical study and compare it with the results obtained through the Fuzzy 
Logic. Likewise, the use of the Multicriteria Mapping Methodology (Stirling, 1997) could be incorporated into this analysis, which would bring new perspectives to the results obtained. This work would have the support and supervision of its designer, Professor Andrew Stirling.

Regarding the risks encountered, the search for their responses is also considered as future work, due to very little has been done in terms of responses to risks, with the exception of some work, such as that of Wang, Dulami, and Aguria (2004), applied to the field of construction.

It is also interesting to know what the beneficiary communities think about the LFRMA and start working with it in these communities to obtain some results and to assess the benefits of its use. Currently, and as indicated in Section 7.6, a project of this nature has already been submitted to the public call for research projects on global citizenship and international cooperation for the development of the Madrid's City Council. This project aims to develop this line in the Cauca Department since it would allow comparing results.

Due to the demonstrated commitment of the Government of the Department of Cauca and its openness to continue working with this line, it is proposed to offer the risk register as an open tool to project managers working in the area. Thus, they can update it adding the new risks found. This register could be kept alive and accessible to the organizations that register their projects in this administration.

Likewise, in the area of the UPM, due to the links of the author with this university, it is proposed, firstly, the analysis of the IDP from the work platforms arising around the UPM call for actions to contribute to the fulfillment of the SDG, and the subsequent comparison of their SDGs alignment with respect to that obtained in the study of the 152 projects. And, secondly, the application of the LFRMA, beginning with its dissemination and inclusion at the organization level, as well as making an updated and accessible risk register.

In relation to the methodology designed, to be applied to the largest number of IDP possible and contributing to the improvement of its effectiveness, the design of software and a phone's application is proposed. Each organization could use this application and keep a record of the executed IDP. As more organizations use it, the wider the risk register available for each zone and type of project. Thus, it would be possible to establish a collaborative risk register that could be shared between the different organizations.

In addition, with the idea of disseminating the methodology and making it as simple as possible in its use, it is very pertinent to design a guide for its use with simple examples. 
Last but not least, this Doctoral Thesis is just one more step to take advantage of the open opportunity with the 2030 Agenda to generate more sustainable and plural changes towards the development of millions of people around the world, but there are still many steps that give in the near future. In these steps, the linking of governments and development policies is essential, therefore, seek their involvement and demand their commitment is everyone's responsibility. This Doctoral Thesis will seek this implication in all its future works. 


\section{REFERENCIAS}

Agencia Española de Cooperación Internacional (AECID) (2018). V Plan Director de la Cooperación Española 2018/2021. Ministerio de Asuntos Exteriores, Unión Europea y Cooperación.

Agencia Española de Cooperación Internacional al Desarrollo (AECID) (2015). Marco Asociación País (MAP) Colombia 2015-2019. Secretaría General de Cooperación Internacional para el Desarrollo (SGCID), Madrid.

Agencia Estatal de Evaluación y Calidad (AEVAL) (2014). Guía para la Realización de Estudios de Análisis de la Demanda y de Evaluación de la Satisfacción de los Usuarios, 2a Edición. Agencia Estatal de Evaluación y Calidad, Madrid.

Agheneza, Z. (2009). Why development projects fail in Cameroon: Evidence from Ngie in the NW Province of Cameroon. International Journal of Rural Management 5(I), 73-90. https://doi.org/10.1177/097300520900500104.

Ahmad, S., Ng, C. y McManus, L. A. (2014). Entreprise Risk Management (ERM) Implementation: Some empirical evidence from large Australian companies. Procedia-Social and Behavioral Sciences 164(31), 541-547. https://doi.org/10.1016/j.sbspro.2014.11.144.

Ahsan, K. y Gunawan, I. (2010). Analysis of cost and Schedule performance of international development projects. International Journal of Project Management 28, 68-78. https://doi.org/10.1016/j.ijproman.2009.03.005.

Ale, B., Burnap, P. y Slater, D. (2015). On the origin of PCDS - (Probability Consequence Diagrams). Safety Science 72, 229-239. https://doi.org/10.1016/j.ssci.2014.09.003.

Alvesson, M. y Sköldberg, K. (2009). Reflexive Methodology. New vistas for qualitative research. SAGE, Londres.

Arasaratnam, L. A. y Doerfel, M. L. (2005). Intercultural communication competence: Identifying key components from multicultural perspectives. International Journal of Intercultural Relations 29(2), 137-163. https://doi.org/10.1016/j.ijintrel.2004.04.001.

Arndt, C., Jones, S. y Tarp, F. (2015). Assessing foreign aid's long-run contribution to growth and development. World Development 69, 6-18. https://doi.org/10.1016/j.worlddev.2013.12.016.

AS/NZS 4360:1999 (1999). Risk Management, Standards Australia/Standards New Zealand. Standards Australia, Sydney. 
Ashley, P. A. (2014). Towards a Territorial, Multi-Actor and Multi-Level Approach for Sustainable Development Cooperation and Social Responsability Policies. En capítulo 6: Development and Equity: An Interdisciplinary Exploration by Ten Scholars from Africa, Asia and Latin America, 105-118. Brill, Leiden.

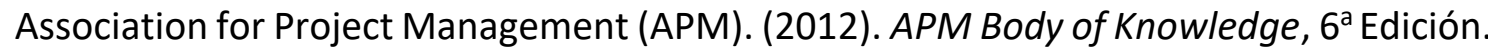
APM Publishing, Londres.

Association for Project Management (APM). (2004). Project Risk Analysis \& Management (PRAM) Guide, 2a Edición. APM Publishing, Londres.

Australian Agency for International Development (AusAID) (2003). AusGUIDE: The Logical Framework Approach. AusAID, Barton.

Baccarini, D. (1999). The Logical Framework Method for Defining Project Success. Project Management Journal 30(4), 25-32.

Bakewell, O. y Garbutt, A. (2005). The use and abuse of the Logical Framework Approach. A Review of International Development NGOs' Experiences. Swedish International Development Agency (SIDA), Stockholm.

Banco Mundial (2018). Results and Performance of the World Bank Group 2017: An Independent Evaluation. World Bank, Washington, DC.

Banco Mundial (2005). The Logframe Handbook. A Logical Framework Approach to Project Cycle Management. World Bank, Washington, D. C.

Bao, C., Li, J. y Wu, D. (2016). A fuzzy mapping framework for risk aggregation based on risk matrices. Journal of Risk Research 21(5), 539-561. https://doi.org/10.1080/13669877.2016.1223161.

Baum, W. C. (1970). The project cycle. Finance and Development 15(4), 10-18.

Bebbington, J. y Unerman, J. (2018). Achieving the United Nations Sustainable Development Goals: An enabling role for accounting research. Accounting, Auditing \& Accountability Journal 31(1), 2-24. https://doi.org/10.1108/AAAJ-05-2017-2929.

Berger, G. (1957). Human Science and Forecasting. La Revue des Deux Mondes 3.

Bernoulli, D. (1954). Exposition of a new theory on the measurement of risk. Econometrica 22, 23-36. [Traducción de: Bernoulli, D. (1738) Specimen theoriae novae de mensura sortis. Commentarii Academiae Scientiarum Imperialis Petropolitanae, Tomus V, 175-192]. 
Berssaneti, F. T. y Carvalho, M. M. (2015). Identification of variables that impact project success in Brazilian companies. International Journal of Project Management 33(3), 638-649. https://doi.org/10.1016/j.ijproman.2014.07.002.

Biggs, S. y Smith, S. (2003). A paradox of learning in project cycle management and the role of organizational culture. World Development 31 (10), 1743-1757. https://doi.org/10.1016/S0305-750X(03)00143-8.

Bigsten, A. y Tengstam, S. (2015). International Coordination and the Effectiveness of Aid. World Development 69, 75-85. https://doi.org/10.1016/j.worlddev.2013.12.021.

Blanco-Mesa, F., Merigó, J. M. y Gil-Lafuente, A. M. (2016). A bibliometric analysis of fuzzy decision making research. En: Annual Conference of the North American Fuzzy Information Processing Society (NAFIPS). IEEE, 1-4. El Paso, Texas, USA. https://doi.org/10.1109/NAFIPS.2016.7851585.

Blunt, P. y Jones, M. L. (1992). Managing organisations in Africa. Walter de Gruyter, Berlin.

Boni, A. (2010). El sistema de la cooperación internacional al desarrollo. Evolución histórica y retos actuales. En Capítulo I: La cooperación internacional para el desarrollo, 7-23. Universidad Politécnica de Valencia.

Boni, A. y Cerezo, S. (2008). La Educación para el Desarrollo (EpD) como motor de cambio transformador en los actores de la cooperación para el desarrollo. Cuadernos internacionales de tecnología para el desarrollo humano, 7.

Bourguignon, F. y Platteau, J. P. (2017). Does Aid availability affect effectiveness in reducing poverty? A review article. World Development 90, 6-16. https://doi.org/10.1016/j.worlddev.2015.06.003.

Box, G. E. P., Hunter, W. G. y Hunter, J. S. (1978). Statistics for Experimenters. An Introduction to Design, Data Analysis and Model Building. John Wiley \& Sons, Nueva York.

Brady, T. y Davies, A. (2014). Managing structural and dynamic complexity: a tale of two projects. Project Management Journal 45(4), 21-38. https://doi.org/10.1002/pmj.21434.

Bredillet, C., Yatim, F. y Ruiz, P. (2010). Project management deployment: The role of cultural factors. International Journal of Project Management 28, 183-193. https://doi.org/10.1016/j.ijproman.2009.10.007.

Brinkmann, S. (2013). Qualitative interviewing. Oxford University Press, Oxford. 
British Standards Institution (BSI). (2008). BS 31100: Risk management - Code of practice. British Standards Institution, Londres.

Brooks, A. (2017). The end of development. A global history of poverty and development. Zed Books, Londres.

Buttigieg, S. C., Gauci, D. y Dey, P. (2016). Continuous quality improvement in a Maltese hospital using logical framework análisis. Journal of Health Organization and Management 30(7), 1026-1046. https://doi.org/10.1108/JHOM-11-2015-0185.

Cahlikova, J. y Cingl, L. (2017). Risk preferences under acute stress. Experimental Economics 20(1), 209-236. https://doi.org/10.1007/s10683-016-9482-3.

Camacho, H., Cámara, L., Cascante, R. y Sainz, H. (2001). El enfoque del Marco Lógico: 10 casos prácticos. Cuaderno para la identificación y diseño de proyectos de desarrollo. Fundación CIDEAL, Madrid.

Canadian International Development Agency (CIDA). (1997). The logical framework: Making it results-oriented. CIDA, Gatineau.

Cappelen, A. W., Konow, J., Sorensen, E. y Tungodden, B. (2013). Just luck: An experimental study of risk taking and fairness. American Economic Review 103(4), 1398-1413. https://doi.org/10.1257/aer.103.4.1398.

Carey, R. y Li, X. (2016). The BRICS in International Development: The New Landscape. IDS Evidence Report 189. Institute of Development Studies, Brighton.

Carmody, P. (2012). Another BRIC in the Wall? South Africa's Developmental Impact and Contradictory Rise in Africa and Beyond. The European Journal of Development Research 24(2), 223-241.

Carter, B., Hancock, T., Morin, J. M. y Robins, N. (1996). Introducing RISKMAN: the European project risk management methodology. The Stationary Office, Londres.

Carvalho, M. M. y Rabechini, R. (2015). Impact of risk management on project performance: the importance of soft skills. International Journal of Production Research 53(2), 321-340. https://doi.org/10.1080/00207543.2014.919423.

Cassen, R. (1986). Does Aid Work? Clarendon, Oxford.

Cavaye, A. L. M. (1996). Case study research: A multi-faceted research approach for IS. Information Systems Journal 6(3), 227-242. https://doi.org/10.1111/j.13652575.1996.tb00015.x. 
Chambers, R. (2017). Can we know better? Reflections for Development. Practical Action Publishing, Rugby.

Chambers, R. (2005). Ideas for Development. Routledge, Londres.

Chan, D. W., Chan, A. P., Lam, P. T., Yeung, J. F. y Chan, J. H. (2011). Risk ranking and analysis in target cost contracts: empirical evidence from the construction industry. International Journal of Project Management 29(6), 751-763. https://doi.org/10.1016/j.ijproman.2010.08.003.

Chapman, C. y Ward, S. (2004). Why risk efficiency is a key aspect of best practice projects. International Journal of Project Management 22(8), 619-632. https://doi.org/10.1016/j.ijproman.2004.05.001.

Checker, M. (2007). "But I Know It's True": Environmental Risk Assessment, Justice, and Anthropology. Human Organization 66(2), 112-124. https://doi.org/10.17730/humo.66.2.1582262175731728.

Cettolin, E., Riedl, A. y Tran, G. (2018). Giving in the Face of Risk. Journal of Risk and Uncertainty 55, 95-118. https://doi.org/10.1007/s11166-017-9270-2.

Cobo, J. R. (2010). Diseño de un modelo basado en competencias para la dirección de programas y proyectos en el nuevo marco de la cooperación internacional para el desarrollo. Tesis Doctoral.

Cohen, E. y Franco, R. (2006). Evaluación de proyectos sociales. 7ạ edición en español. Siglo veintiuno editores, Madrid.

Cohen, L., Manion, L. K. y Morrison, K. (2011). Research Methods in Education, 7a Edición. Routledge, Londres.

Coleman, G. (1987). Logical framework approach to monitoring and evaluation of agricultural and rural development projects. Project Appraisal 2, 251-259.

Comisión de Medio Ambiente y Desarrollo (CMAD) (1987). Report of the World Commission on Envirnment and Development: Our Common Future.

Concord (2018). Aidwatch 2018 Report. EU Aid: A broken Ladder? Concord Europe, Brussels.

Convención Marco de Naciones Unidas sobre el Cambio Climático (CMNUCC). (2015). Adoption of the Paris Agreement FCCC CP/2015/L.9. United Nations Framework Convention on Climate Change. [Extraído en octubre de 2018 de: https://unfccc.int/resource/docs/2015/cop21/eng/l09.pdf]. 
Cooke-Davies, T. (2002). The "Real" Success Factors on Projects. International Journal of Project Management 20, 185-190. https://doi.org/10.1016/S02637863(01)00067-9.

Cooke-Davies, T., Cicmil, S., Crawford, L. y Richardson, K. (2007). We're not in Kansas anymore, Toto: Mapping the strange landscape of complexity theory, and its relationship to project management. Project Management Journal 38(2), 50-61. https://doi.org/10.1177/875697280703800206.

Cornwall, A. (2006). Historical perspectives on participation in development.

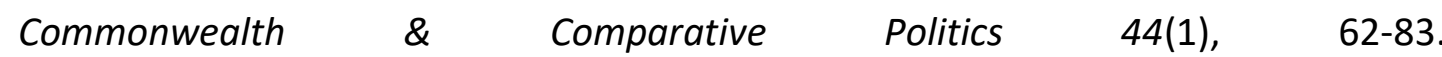
https://doi.org/10.1080/14662040600624460.

Cotton, M. (2009). Ethical assessment in radioactive waste management: a proposed reflective equilibrium based deliberative approach. Journal of Risk Research 12(5), 603-618. https://doi.org/10.1080/13669870802519455.

Couillard, J., Garon, S. y Riznic, J. (2009). The Logical Framework Approach-Millennium. Project Management Journal 40(4), 31-44. https://doi.org/10.1002/pmj.20117.

Cox, L. A. (2008). What's wrong with Risk Matrices? Risk Analysis 28(2), 497-512. https://doi.org/10.1111/j.1539-6924.2008.01030.x.

Crawford, L. y Bryce, P. (2003). Project monitoring and evaluation: a method for enhancing the efficiency and effectiveness of aid project implementation. International Journal of Project Management, 21, 363-373. https://doi.org/10.1016/S0263-7863(02)00060-1.

Cuesta, I., y Calabuig, C. (2010). La Cooperación No Gubernamental. En Capítulo IV: La cooperación internacional para el desarrollo, 91-116. Universidad Politécnica de Valencia.

Darke, P. y Shanks, G. (2002) Case study research. En Capítulo 6: Research Methods for Students, Academics and Professionals, 2a Edición, Williamson, K., Elsevier.

De Bakker, K., Boonstra, A. y Wortmann, H. (2012). Risk Managements' Communicative Effects Influencing IT Project Success. International Journal of Project Management 30, 444-457. https://doi.org/10.1016/j.ijproman.2011.09.003.

De Bakker, K., Boonstra, A. y Wortmann, H. (2010). Does Risk Management Contribute to IT Project Success? A Meta-analysis of Empirical Evidence. International Journal of Project Management 28, 493-503. https://doi.org/10.1016/j.ijproman.2009.07.002. 
Denizer, C., Kaufmann, D. y Kraay, A. (2013). Good countries or good projects? Macro and micro correlates of World Bank project performance. Journal of Development Economics 105, 288-302. https://doi.org/10.1016/j.jdeveco.2013.06.003.

Denzin, N. K. y Lincoln, Y. S. (2011). The Sage handbook of qualitative research. Sage, Londres.

Departamento Administrativo Nacional de Estadística (DANE). (2017). Boletín técnico: Pobreza Monetaria Cauca 2017. DANE, Bogotá.

Diallo, A. y Thuillier, D. (2005). The success of international development projects, trust and communication: an African perspective. International Journal of Project Management 23, 237-252. https://doi.org/10.1016/j.ijproman.2004.10.002.

Duijm, N. J. (2015). Recommendations on the Use and Design of Risk Matrices. Safety Science 76, 21-31. https://doi.org/10.1016/j.ssci.2015.02.014.

Dul, J. y Hak, T. (2008). Case study methodology in business research. Elsevier, Oxford.

Dvir, D. y Lechler, T. (2004). Plans are Nothing, Changing Plans is Everything: The Impact of Changes on Project Success. Research Policy 33(1), 1-15. https://doi.org/10.1016/j.respol.2003.04.001.

Easterly, W. (2006). The White Man's Burden: Why the West's efforts to aid the rest have done so much ill and so little good. The Penguin Press, Nueva York.

Eden, C. y Ackermann, F. (2018). Theory into practice, practice to theory: Action research in method development. European Journal of Operational Research 271(3), 11451155. https://doi.org/10.1016/j.ejor.2018.05.061.

El-Karim, M. S. B. A., Nawawy, O. A. M. E. y Abdel-Alim, A. M. (2015). Identification and assessment of risk factors affecting construction projects. Housing and Building National Research Center Journal 13, 202-216. https://doi.org/10.1016/j.hbrcj.2015.05.001.

El-Sabaa, S. (2001). The skills and career path of an effective project manager. International Journal of Project Management 19(1), 1-7. https://doi.org/10.1016/S0263-7863(99)00034-4.

Engwall, M. (2003). No Project is an island: linking projects to history and context. Research Policy 32(5), 789-808. https://doi.org/10.1016/S0048-7333(02)00088-4.

Enyinda, C. I. (2017). Quantitative Risk Analysis for International Project Management and Programs in an Emerging Economy. En Capítulo 69: Leadership, Innovation and Entrepreneurship as Driving Forces of the Global Economy. Benlamri R. y Sparer M. 
(Eds.) Springer Proceedings in Business and Economics. Springer. https://doi.org/10.1007/978-3-319-43434-6_69.

Escobar, A. (2016). Autonomía y diseño. La realización de lo comunal. Editorial Universidad del Cauca.

Escobar, A. (1995). Encountering Development: The making and unmaking of the Third World. Princeton University Press, Princeton, Nueva Jersey.

Essinger, J. y Rosen, J. (1991). Using Technology for Risk Management. Pearson Education Ltd., Reino Unido.

EuropeAid (2018). Convocatorias de propuestas y anuncios de licitación para proyectos de cooperación internacional y desarrollo. Comisión Europea. [Online: consultado en diciembre de 2018 de https://webgate.ec.europa.eu/europeaid/onlineservices/index.cfm?ADSSChck=1544033641221\&do=publi.welcome\&searchtype=AS $\& P g m=7573839 \&$ zgeo $=11879810$ \&aoet $=36538 \% 2$ C36539\& ccnt $=7573876 \% 2 C 75738$ 77\&debpub=\&nbPubliList=15\&orderby=upd\&orderbyad=Desc].

Farooq, M. U., Thaheem, M. J. y Arshad, H. (2018) Improving the risk quantification under behavioural tendencies: A tale of construction projects. International Journal of Project Management 36, 414-428. https://doi.org/10.1016/j.ijproman.2017.12.004.

Farquhar, J. D. (2012). Case study research for business. Sage, Londres.

Farrell, M. y Gallagher, R. (2019). Moderating influences on the ERM maturityperformance relationship. Research in International Business and Finance 47, 616628. https://doi.org/10.1016/j.ribaf.2018.10.005.

Field, A. (2003). Discovering Statistics. Using SPSS for Windows. SAGE Publications, Londres.

Fine, G. A. (2015). Participant observation. En: International encyclopedia of the social \& behavioral sciences, 2a Edición, 530-534. Elsevier, Orlando.

Fiss, P. C. (2011). Building better causal theories: A fuzzy set approach to typologies in organization research. Academy of Management Journal 54(2), 393-420. https://doi.org/10.5465/amj.2011.60263120.

Flyvjberg, B. (2005). Policy and Planning for Large Infrastructure Projects: Problems, Causes, Cures. World Bank, Washington DC. 
Función Pública (2018). Guía para la administración del riesgo y el diseño de controles en entidades públicas. Riesgos de gestión, corrupción y seguridad digital. Departamento Administrativo de la Función Pública, Bogotá.

Gasper, D. (2000). Evaluating the "Logical Framework Approach" towards LearningOriented development evaluation. Public Administration and Development 20(1), 1728.

Gesellschaft für Technische Zusammenarbeit (GTZ). (1997). ZOPP: A planning guide for new and ongoing projects and programs. GTZ, Eschborn.

Gil-Lafuente, A. M. y Paula, L. B. (2013). Algorithm applied in the identification of stakeholders. Kybernetes 42(5), 674-685. https://doi.org/10.1108/K-04-2013-0073.

Godet, M. (1986). Introduction to la Prospective: Seven key ideas and one scenario method. Futures 18(2), 134-157. https://doi.org/10.1016/0016-3287(86)90094-7.

Golini, R., Kalchschmidt, M. y Landoni, P. (2015). Adoption of project management practices: The impact on international development projects of non-governmental organizations. International Journal of Project Management 33, 650-663. https://doi.org/10.1016/j.ijproman.2014.09.006.

Golini, R. y Landoni, P. (2014). International Development Projects by NonGovernmental Organizations: an evaluation of the need for specific project management and appraisal tools. Impact Assessment and Project Appraisal 32(2), 121-135. https://doi.org/10.1080/14615517.2014.894088.

Golini, R., Landoni, P. y Kalchscmidt, M. (2017). The adoption of the logical framework in international development projects: a survey of non-governmental organizations. Impact Assessment and Project Appraisal 36(2), 145-154. https://doi.org/10.1080/14615517.2017.1354643.

Gómez, M., Ayllón, B. y Albarrán, M. (2011). Reflexiones prácticas sobre cooperación triangular. Fundación CIDEAL, Madrid.

Gómez, M. L., y Monzó, J. M. (2010). Universidad y Cooperación para el Desarrollo. En Capítulo V: La cooperación internacional para el desarrollo, 117-131. Universidad Politécnica de Valencia.

Gómez, M. y Sainz, H. (1999). El ciclo de gestión del proyecto de cooperación al desarrollo: aplicación del marco lógico. CIDEAL, Madrid.

Green, P. E. J. (2015). Entreprise Risk Management. A Common Framework for the Entire Organization. Butterworth-Heinemann, Tokio. 
Grisham, W. T. (2010). International Project Management: Leadership in Complex Environments. John Wiley \& Sons Publishing, Hoboken.

Gu, J., Shankland, A. y Chenoy, A. (2018). The BRICS in International Development. Springer, Londres.

Guntzburger, Y., Johnson, K. J., Martineau, J. T. y Pauchant, T. C. (2018). Professional ethnocentrism and ethical risk management efficacy: How engineer's emotional openness mediates this complex relationship. Safety Science 109, 27-35. https://doi.org/10.1016/j.ssci.2018.05.004.

Hailey, J. y Sorgenfrei, M. (2004). Measuring Success: Issues in Performance Management. Occasional Paper Series 44. INTRAC, Oxford.

Hajer, M., Nilsson, M., Raworth, K., Bakker, P., Berkhout, F., de Boer, Y., Rockström, J., Ludwig, K. y Kok, M. (2015). Beyond cockpit-ism: four insights to enhance the transformative potential of the Sustainable Development Goals. Sustainability 7(2), 1651-1660. https://doi.org/10.3390/su7021651.

Hall, E. T. (1976). Beyond culture. Garden City, Nueva York.

Harris, D. y Vittorini, S. (2018). Taking "development cooperation" and South-South discourse seriously: Indian claims and Ghanaian responses. Commonwealth \& Comparative Politics 56(3), 360-378. https://doi.org/10.1080/14662043.2017.1368152.

Hartono, B., Sulistyo, S. R., Praftiwi, P. P. y Hasmoro, D. (2014). Project Risk: Theoretical concepts and stakeholders' perspectives. International Journal of Project Management 32(3), 400-411. https://doi.org/10.1016/j.ijproman.2013.05.011.

Hekala, W. (2012). Why donors should care more about project management. [Online: consultado en septiembre de 2018 en https://www.devex.com/news/why-donorsshould-care-more-about-project-management-77595].

Hermano, V., López-Paredes, A., Martín-Cruz, N. y Pajares, J. (2013). How to manage international development (ID) projects successfully. Is the PMD Pro1 Guide going to the right direction? International Journal of Project Management 31, 22-30. https://doi.org/10.1016/j.ijproman.2012.07.004.

Hermano, V. y Martín-Cruz, N. (2013). How to deliver Foreign Aid? The case of projects governed by the Spanish International Agency. World Development 43, 298-314. https://doi.org/10.1016/j.worlddev.2012.10.017.

Hillson, D. (2002a). When is a Risk not a Risk? [Online: consultado en febrero de 2019 en https://www.who.int/management/general/risk]. 
Hillson, D. (2002b). Extending the risk process to manage opportunities. International Journal of Project Management 20, 235-240. https://doi.org/10.1016/S02637863(01)00074-6.

Hillson, D. (2002c). Extending the risk process to manage opportunities. Proceedings of the Project Management Institute Annual Seminars \& Symposium, October 3-10, San Antonio, Texas.

Hillson, D. (2012). How much risk is too much risk? Understanding risk appetite. $\mathrm{PMI}^{\circledR}$ Global Congress 2012-North America, Vancouver, British Columbia, Canada. Newtown Square, PA: Project Management Institute.

Hillson, D. (2018). What is a Risk? Identifying real risks is critical for effective risk management. [Online: consultado en enero de 2019 en https://infoworks.com/whatis-a-risk/].

Hillson, D. (2019). About David Hillson. [Online: consultado en febrero de 2019 en http://www.risk-doctor.com/about_david_hillson/awards].

Hirschman, A. O. (1967). Development Projects Observed. Brookings Institution, Washington, DC.

Hofstede, G. (1984). Cultural dimensions in management and planning. Asia Pacific Journal of Management 1(2), 81-99. https://doi.org/10.1007/BF01733682.

Hofstede, G. y Bond, M. H. (1988). The Confucius connection: from cultural roots to economic growth. Organizational Dynamics 16, 4-21. https://doi.org/10.1016/00902616(88)90009-5.

Hofstede, G. (2001). Culture's Consequences, 2a Edición. Sage, Thousand Oaks.

Hofstede, G., Hofstede, G. J. y Minkov, M. (2010). Cultures and Organizations: Software of the Mind. $3^{\text {era }}$ Edición. McGraw-Hill, Nueva York.

House, R., Javidan, M., Hanges, P. y Dorfman, P. (2002). Understanding cultures and implicit leadership theories across the globe: an introduction to project GLOBE. Journal of World Business 37(1), 3-10. https://doi.org/10.1016/S10909516(01)00069-4.

Huarng, K. H., Rey-Martí, A. y Miquel-Romero, M. J. (2018). Quantitative and qualitative comparative analysis in business. Journal of Business Research 89, 171-174. https://doi.org/10.1016/j.jbusres.2018.02.032. 
Hummelbrunner, R. (2010). Beyond Logframe: Critique, Variations and Alternatives. En Capítulo I: Beyond Logframe; Using Systems Concepts in Evaluation, 1-34. Foundation for Advanced Studies on International Development (FASID), Japón.

Ika, L. A. (2012). Project Management for Development in Africa: Why Projects Are Failing and What Can Be Done About It. Project Management Journal 43(4), 27-41. https://doi.org/10.1002/pmj.21281.

Ika, L. A., Diallo, A. y Thuillier, D. (2012). Critical success factors for World Bank projects: An empirical investigation. International Journal of Project Management 30, 105-116. https://doi.org/10.1016/j.ijproman.2011.03.005.

Ika, L. A., Diallo, A. y Thuillier, D. (2010). Project management in the international industry: the project coordinator's perspective. International Journal of Managing Projects in Business 3(1), 61-93. https://doi.org/10.1108/17538371011014035.

Ika, L. A. y Donnelly, J. (2017). Success conditions for international development capacity building projects. International Journal of Project Management 35, 44-63. https://doi.org/10.1016/j.ijproman.2016.10.005.

Ika, L. A. y Hodgson, D. (2014). Learning from international development projects: Blending Critical Project Studies and Critical Development Studies. International Journal of Project Management 32, 1182-1196. https://doi.org/10.1016/j.ijproman.2014.01.004.

Ika, L. A. y Lytvynov, V. (2011). The "Management-Per-Result" Approach to International Development Project Design. Project Management Journal 42(4), 87-104. https://doi.org/10.1002/pmj.20248.

Ika, L. A. y Saint-Macary, J. (2012). The project planning myth in international development. International Journal of Managing Projects in Business 5(3), 420-439. https://doi.org/10.1108/17538371211235308.

INMUJERES (2014). Hacia una metodología de marco lógico con perspectiva de género. Instituto Nacional de las Mujeres (INMUJERES), ONU Mujeres, México D. F.

International Organization for Standardization (ISO) (2018). ISO 31000: Risk management guidelines. [Online: Consultado en enero de 2019 en https://www.iso.org/obp/ui\#iso:std:iso:31000:ed-2:v1:en].

International Organization for Standardization (ISO). (2009). ISO 31000: Risk management - Principles and guidelines. International Organization for Standardization, Ginebra. 
International Project Management Association (IPMA). (2015). Individual Competence Baseline for Project, Programme, \& Portfolio Management, $4^{\text {a }}$ Edición. IPMA, The Netherdlands.

ISI Argonauta (2010). Guía para la incorporación del enfoque basado en derechos humanos en las intervenciones de cooperación para el desarrollo. ISI Argonauta, Madrid.

Jones, M. C. y Cheung, W. W. L. (2017). Using fuzzy logic to determine the vulnerability of marine species to climate change. Global Change Biology 24(2), 719-731. https://doi.org/10.1111/gcb.13869.

Julian, R. (2016). Is it for donors or locals? The relationship between stakeholder interests and demonstrating results in international development. International Journal of Managing Projects in Business 9(3), 505-527. https://doi.org/10.1108/IJMPB-09-2015-0091.

Juselius, K., Møller, N. F. y Tarp, F. (2014). The long-run impact of foreign aid in 36 African countries: Insights from multivariate time series analysis. Oxford Bulletin of Economics and Statistics 76(2), 153-184. https://doi.org/10.1111/obes.12012.

Kahneman, D. y Tversky, A. (2013). Prospect Theory: An analysis of decision under risk. En Capítulo 6 de Handbook of the Fundamentals of Financial Decision Making, 99127. https://doi.org/10.1142/9789814417358_0006.

Kamphof, R. y Melissen, J. (2018). SDGs, Foreign Ministries and the Art of Partnering with the Private Sector. Global Policy 9(3), 327-335. https://doi.org/10.1111/17585899.12563.

Kates, R. W. (2011). What kind of science is sustainability science? Proceedings of the National Academy of Sciences of the United States of America 108(49), 19449-19450.

Kealey, D. J., Protheroe, D. R., MacDonald, D. y Vulpe, T. (2005). Re-examining the role of training in contributing to international project success: A literature review and an outline of a new model training program. International Journal of Intercultural Relations 29, 289-316. https://doi.org/10.1016/j.ijintrel.2005.05.011.

Kent, R. y Olsen, W. (2008). Using fsQCA. A Brief Guide and Workshop for Fuzzy-Set Qualitative Comparative Analysis. University of Stirling, Stirling.

Kerzner, H. (2017). Project Management: A Systems Approach to Planning, Scheduling, and Controlling, 12ª Edición. John Wiley \& Sons, Inc., Hoboken.

Khan Mohmand, S. y Loureiro, K. M. (2017). Interrogating Decentralisation in Africa. IDS Bulletin 48(2), 1-14. http://dx.doi.org/10.19088/1968-2017.113. 
Khang, D. B. y Moe, T. L. (2008). Success criteria and factors for international development projects: a lifecycle-based framework. Project Management Journal 39(1), 72-84. https://doi.org/10.1002/pmj.20034.

Kirchler, M., Andersson, D., Bonn, C., Johannesson, M., Sørensen, E., Stefan, M., Tinghög, G. y Västfjäll, D. (2017). The effect of fast and slow decisions on risk taking. Journal of Risk and Uncertainty 54(1), 37-59. https://link.springer.com/article/10.1007/s11166017-9252-4.

Kirkman, B. L., Lowe, K. B. y Gibson, C. B. (2006). A quarter century of Culture's Consequences: A review of empirical research incorporating Hofstede's cultural values framework. Journal of International Business Studies 37, 285-320. https://doi.org/10.1057/palgrave.jibs.8400202.

Kluckhohn, C. (1953). Universal categories of culture. En: Anthropology today, 507-523. Ed. Kroeber, University of Chicago Press, Chicago.

Kluckhohn, C. y Strodtbeck, F. L. (1961). Variations in value orientations. Row Peterson, Evanston.

Kutsch, E. y Hall, M. (2010). Deliberate ignorance in project risk management. International Journal of Project Management 28, 245-255. https://doi:10.1016/j.ijproman.2009.05.003.

Kutsch, E. y Hall, M. (2009). The rational choice of not applying project risk management in Information Technology projects. Project Management Journal 40(3), 72-81. https://doi.org/10.1002/pmj.20112.

Landoni, P. y Corti, B. (2011). The management of international development projects: moving toward a standard approach or differentiation? Project Management Journal 42(3), 45-61. https://doi.org/10.1002/pmj.20231.

Leal Filho, W., Azeiteiro, U., Alves, F, Pace, P., Mifsud, M., Brandli, L., Caeiro, S. S. y Disterheft, S. (2017). Reinventing the sustainable development research agenda: the role of sustainable development goals (SDG). International Journal of Sustainable Development $\& \quad$ World Ecology 25(2), 131-142. https://doi.org/10.1080/13504509.2018.1460632.

LenCD. (2018). Learning Network on Capacity Development [Online: consultado en octubre de 2018 de www.lencd.org/learning].

Lewin, K. (1946). Action Research and minority problems. Journal of Social Issues 2, 3446. 
Lewis, R. D. (2010). When cultures collide. Leading successfully across cultures, $3^{\text {era }}$ Edición. Nicholas Brealey Publishing.

Lewis, D. y Kanji, N. (2009). Non-Governmental Organizations and Development. Routledge, Londres.

Liu, J., Meng, F. y Fellows, R. (2015). An exploratory study of understanding project risk management from the perspective of national culture. International Journal of Project $\quad$ Management 33(3), 564-575. https://doi.org/10.1016/j.ijproman.2014.08.004.

Lovegrove, N., Gebre, B., Lee, T. y Kumar, R. (2011). McKinsey-Devex Survey Results: Practitioners See Need for New Approaches to System-wide Reform. McKinsey-Devex.

Lynn, R. y Hampson, S. L. (1975). National differences in extraversion and neuroticism. British Journal of Social and Clinical Psychology 14, 223-240. https://doi.org/10.1111/j.2044-8260.1975.tb00175.x.

Mairal Buil, G. (2013). La Década del riesgo. Situaciones y narrativas de riesgo en España a comienzos de siglo. Ediciones Catarata, Madrid.

Martin, B. R. (1996). Technology Foresight: capturing the benefits from science-related technologies. Research Evaluation 6(2), 158-168. https://doi.org/10.1093/rev/6.2.158.

Mataix, C., Rojo, A., Pastor, M., Gurmu, D., Stott, L. y Mazorra, J. (2017). Alianzas Multiactor para la innovación social en la consecución de los ODS: La Universidad y su gran potencial como facilitador y promotor. Revista Española de Desarrollo y Cooperación 41, 27-38.

Mawdsley, E. (2015). DFID, the Private Sector and the Re-centring of an Economic Growth Agenda in International Development. Global Society 29(3), 339-358. https://doi.org/10.1080/13600826.2015.1031092.

Mawdsley, E. (2012). From Recipients to Donors: Emerging Powers and the Changing Development Landscape. Zed Books, Londres.

McArthur, J. (2014). The origins of the Millenium Development Goals. SAIS Review XXXIV(2), 5-24. https://doi.org/10.1353/sais.2014.0033.

McEvoy, P., Brady, M. y Munck R. (2016). Capacity development through international projects: a complex adaptive systems perspective. International Journal of Managing Projects in Business 9(3), 528-545. https://doi.org/10.1108/IJMPB-08-2015-0072.

Meyer, E. (2015). The culture map. Affairs, Nueva York. 
Mikes, A. (2011). From counting risk to making risk count: Boundary-work in risk management. Accounting, Organizations and Society 36(4), 226-245. https://doi.org/10.1016/j.aos.2011.03.002.

Ministerio de Educación de Colombia (2018). Datos de matriculación. [Online: consultado en junio de 2018 de https://www.mineducacion.gov.co].

Mishra, A., Das, S. R. y Murray, J. J. (2016). Risk, process maturity, and project performance: An empirical analysis of US federal government technology projects. Production and Operations Management 25(2), 210-232. https://doi.org/10.1111/poms.12513.

Morris, P. W. G. (2013). Reconstructing project management reprised: a knowledge perspective. Project Management Journal 44 (5), 6-23. https://doi.org/10.1002/pmj.21369.

Morvaridi, B. y Hughes, C. (2018). South-South Cooperation and Neoliberal Hegemony in a Post-aid World. Developent and Change 49(3), 867-892. https://doi.org/10.1111/dech.12405.

Moyo, D. (2009). Dead Aid: Why aid is not working and how there is a better way for Africa. D\&M Publishers Inc., Vancouver.

Müller, R. y Turner, R. (2010). Leadership competency profiles of successful project managers. International Journal of Project Manager 28, 437-448. https://doi.org/10.1016/j.ijproman.2009.09.003.

Müller, R. y Turner, J. R. (2004). Cultural differences in project owner manager communication. Project Management Institute Conference Proceedings, Londres.

Munns, A. K. Aloquili, O. y Ramsay, B. (2000). Joint venture negotiations and managerial practices in the new countries of former soviet union. International Journal of Project Management 18(6), 403-413. https://doi.org/10.1016/S0263-7863(99)00071-X.

Muriithi, N. y Crawford, L. (2003). Approaches to project management in Africa: implications for international development projects. International Journal of Project Management 21, 309-319. https://doi.org/10.1016/S0263-7863(02)00048-0.

Nelson, T. y Cropper, J. (2016). PMD Pro forward: making the world better one project at a time. Procedia - Social and Behavioral Sciences 226, 20-26. https://doi.org/10.1016/j.sbspro.2016.06.157.

Norwegian Agency for Development Cooperation (NORAD). (1999). The Logical Framework Approach. NORAD, Oslo. 
Novales, B. y Freres, C. (2016). 10 años de la agenda de eficacia de la ayuda. ¿Qué queda de París? [Online: consultado en octubre de 2018 de https://elpais.com/elpais/2016/04/08/planeta_futuro/1460121449_027457.html].

Oficina de las Naciones Unidas para la Cooperación Sur-Sur (UNOSSC, por sus siglas en inglés). (2016). About South-Shout and Triangular Cooperation. United Nations Office for South-South Cooperation. [Extraído en octubre de 2018 de: https://www.unsouthsouth.org/about/about-sstc/].

Ojeda, T. (2016). Relaciones Internacionales y Cooperación con Enfoque Sur-Sur. La Catarata, Madrid.

Olechowski, A., Oehmen, J., Seering, W. y Ben-Daya, M. (2016). The professionalization of risk management: What role can the ISO 31000 risk management principles play? International Journal of Project Management 34(8), 1568-1578. https://doi.org/10.1016/j.ijproman.2016.08.002.

Olivier, C., Hunt, M. R. y Ridde, V. (2016). NGO-researcher parterships in global health research: benefits, challenges, and approaches that promote success. Development in Practice 26(4), 444-455. https://doi.org/10.1080/09614524.2016.1164122.

O’Neill, J. (2001). Building Better Global Economic BRICs. Global Economics Paper 66, Goldman Sachs, Nueva York.

Organización para la Cooperación y el Desarrollo Económico (OCDE) (2018). Official Development Assistance 2017. [Online: consultado en junio de 2018 en http://www2.compareyourcountry.org].

Organización para la Cooperación y el Desarrollo Económico (OCDE) (2005). Paris declaration on aid effectiveness. [Extraído en septiembre de 2018 de www.oecd.org/dac/effectiveness/34428351].

Organización para la Cooperación y el Desarrollo Económico. Comité de Ayuda al Desarrollo (OCDE-CAD) (2011). Busan Partnership for Effective Development Cooperation. 40 Foro de Alto Nivel sobre la Eficacia de la Ayuda, Busan.

Organización para la Cooperación y el Desarrollo Económico. Programa de Naciones Unidas. (OCDE-PNUD) (2014). Hacia una cooperación al desarrollo más eficaz: Informe de avances 2014. OECD Publishing.

Organización de las Naciones Unidas (ONU). (2016). The Sustainable Development Goals Report. Organización de las Naciones Unidas, Nueva York. 
Organización de las Naciones Unidas (ONU). (2015a). Transforming our World: Agenda 2030 for sustainable development. LXX Asamblea General de las Naciones Unidas, Nueva York.

Organización de las Naciones Unidas (ONU). (2015b). The Millennium Development Goals Report 2015. Organización de las Naciones Unidas, Nueva York.

Organización de las Naciones Unidas (ONU). (2015c). Addis Ababa Action Agenda on the Third International Conference on Financing for Development. Organización de las Naciones Unidas, Nueva York.

Organización de las Naciones Unidas (ONU). (2000). United Nations Millennium Declaration. United Nations General Assembly (A/55/L.2). Organización de las Naciones Unidas, Nueva York.

Organización de las Naciones Unidas para la Alimentación y la Agricultura (FAO, por sus siglas en inglés) (2018). The state of food security and nutrition in the world. FAO.

Ortega, M. L. (2007). Estrategia de Educación para el Desarrollo de la Cooperación Española. Ministerio de Asuntos Exteriores y de Cooperación.

Ortega-San Martín, F. (2017). Prospectiva empresarial: Manual de corporate foresight para América Latina. Fondo Editorial Universidad de Lima, Lima.

Ortegón, E., Pacheco, J. F. y Prieto, A. (2015). Metodología del marco lógico para la planificación, el seguimiento y la evaluación de proyectos y programas (Vol. 42). CEPAL, United Nations Publications.

Ortengren, K. (2004). The Logical Framework Approach. A summary of the theory behind the LFA method. Swedish International Development Agency (SIDA), Stockholm.

Ortiz, A. y Rivero, G. (2007). Desmitificando la Teoría del cambio. PACT Capacity Building Brief, Washington D. C.

Ortiz-Marcos, I. y Cobo, J. R. (2011). Gestión para Resultados de Desarrollo. AECID, Madrid.

Ortiz-Marcos, I., Cobo Benita, J. R., Aldeanueva, C. M. y Colsa, A. U. (2013). Competency training for managing international cooperation engineering projects. Project Management Journal 44(2), 88-97. https://doi.org/10.1002/pmj.21328.

Osipova, E. y Eriksson, P. E. (2013). Balancing control and flexibility in joint risk management: Lesson learned from two construction projects. International Journal of Project Management 31(3), 391-399. https://doi.org/10.1016/j.ijproman.2012.09.007. 
Otway, H. J. (1975). Risk Assessment and Social Choices. IIASA Research Memorandum. International Institute of Applied Systems Analysis, Austria.

Padalkar, M. y Gopinath, S. (2016). Are complexity and uncertainty distinct concepts in project management? A taxonomical examination from literature. International Journal of Project Management 34(4), 688-700. https://doi.org/10.1016/j.ijproman.2016.02.009.

Papke-Shields, K. E., Beise, C. y Quan, J. (2010). Do project managers practice what they preach, and does it matter to project success? International Journal of Project Management 28, 650-662. https://doi.org/10.1016/j.sbspro.2013.03.035.

Parry, S. B. (1998). Just what is a competency? (and why should you care?). Training 35(6), 58-64.

Paula, L. B. y Silva Marins, F. A. (2018). Algorithms applied in decision-making for sustainable transport. Journal of Cleaner Production 176, 1133-1143. https://doi.org/10.1016/j.jclepro.2017.11.216.

Perea, C. (2017). Análisis de riesgos por áreas geográficas en proyectos de cooperación financiados por la Universidad Politécnica de Madrid. Trabajo Fin de Grado, E.T.S.I. Industriales (UPM). http://oa.upm.es/48877/.

Perminova, O., Gustafsson, M. y Wikström, K. (2008). Defining uncertainty in projects a new perspective. International Journal of Project Management 26(1), 73-79. https://doi.org/10.1016/j.ijproman.2007.08.005.

Petit, Y. (2009). Project portfolios in dynamic environments: Organizing for uncertainty. (Tesis Doctoral). Universidad de Quebec, Montreal.

Pfeiffer, P. (2015). El Nuevo Marco Lógico. Una herramienta para el diseño eficaz de proyectos de desarrollo. Espacios, Sociedad y Territorio (EST) 2(4), 123-137.

Pinto, J. K. y Slevin, D. P. (1988). Project Success: Definitions and Measurement Techniques. Project Management Journal 19, 67-73.

Power, M. (2004). The risk management of everything. Rethinking the politics of uncertainty. Demos, Londres.

Practical Concepts Incorporated (1979). The Logical Framework: A Manager's Guide to a Scientific Approach to Design and Evaluation. Practical Concepts Incorporated, Washington, D. C.

Practical Concepts Incorporated (1972). Guidelines for Teaching Logical Framework Concepts. Practical Concepts Incorporated, Washington, D. C. 
Programa de Naciones Unidas para el Desarrollo (PNUD). (2018). South-South and Triangular Cooperation. [Extraído en octubre de 2018 de: http://www.undp.org/content/dam/undp/library/Poverty\%20Reduction/Developm ent\%20Cooperation\%20and\%20Finance/SSC_FAQ\%20v1.pdf].

Programa de Naciones Unidas para el Desarrollo (PNUD). (2009). Desarrollo de capacidades: Texto básico del PNUD. PNUD, Nueva York.

Project Management for Development Organizations (PM4DEV). (2015). Development Project Management. A methodology to manage development projects for international humanitarian assistance and relief organizations. PM4DEV.

Project Management for NGOs (PM4NGOS). (2013). A Guide to the PMD Pro. Project Management for Development Professionals, 6a Edición. PM4NGOS Working Group.

Project Management Institute (PMI). (2017). A Guide to the Project Management Body of Knowledge (PMBOK ${ }^{\oplus}$ Guide), 6a Edición. Project Management Institute Inc., Pennsylvania.

Project Management Institute (PMI). (2007). Project manager competency development

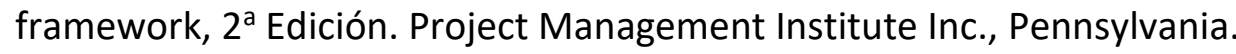

Project Management Institute (PMI). (2005). Project management for post disaster reconstruction. Project Management Institute Inc., Pennsylvania.

Proulx, D. y Brière, S. (2014). Characteristics and success of international development projects: what can we learn from NGO managers? Canadian Journal of Development Studies - Revue Canadienne d'Études du Développement 35(2), 249-264. https://doi.org/10.1080/02255189.2014.900478.

Quereda, B. (2018). Comparativa y análisis de las herramientas de gestión utilizadas en los proyectos de cooperación al desarrollo. Trabajo Fin de Grado, E.T.S.I. Industriales (UPM).

Radcliffe, S. A. (2018). Tackling Complex Inequalities and Ecuador's Buen Vivir: Leaving No-one Behind and Equality in Diversity. Bulletin of Latin American Research 37(4), 417-433. https://doi.org/10.1111/blar.12706.

Rafindadi, A. D., Mikic, M., Kovacic, I. y Cekic, Z. (2014). Global perception of sustainable construction project risks. Procedia-Social and Behavioral Sciences 119, 456-465. https://doi.org/10.1016/j.sbspro.2014.03.051.

Ragin, C. C. (2009). Qualitative Comparative Analysis Using Fuzzy Sets (fsQCA). En Capítulo 5: Configurational Comparative Methods, 87-122. Sage, Thousand Oaks. 
Ragin, C. C. (2008). Redesigning Social Inquiry: Fuzzy sets and beyond. University of Chicago Press, Chicago.

Ragin, C. C. y Davey, S. (2017). User's guide to Fuzzy-Set Qualitative Comparative Analysis. University of California, Irvine.

Rees-Caldwell, K. y Pinnington, A. H. (2013). National culture differences in project management: Comparing British and Arab project managers' perceptions of different planning areas. International Journal of Project Management 31, 212-227. https://doi.org/10.1016/j.ijproman.2012.04.003.

Reeves, J. D., Eveleigh, T., Holzer, T. H. y Sarkani, S. (2013). Identification Biases and Their Impact to Space System Development Project Performance. Engineering Management Journal 25(2), 3-12. https://doi.org/10.1080/10429247.2018.1450030.

Rein, M. y Stott, L. (2009). Working Together: Critical Perspectives on Six Cross-Sector Partnerships in Southern Africa. Journal of Business Ethics 90, 79-89. https://doi.org/10.1007/s10551-008-9915-9.

Retolaza (2010). Teoría del Cambio. Un enfoque de pensamiento-acción para navegar en la complejidad de los procesos de cambio social. Programa de Naciones Unidas para el Desarrollo (PNUD) e Instituto Humanista de Cooperación al Desarrollo (HIVOS), Guatemala.

Rist, G. (2008). The History of Development. From Western Origins to Global Faith. Zed Books, Londres.

Robson, C. y McCartan, K. (2016). Real World Research. A resource for users of social research methods in applied settings, 4a Edición. John Wiley \& Sons Ltd., Chichester.

Rodríguez-Rivero, R., Ortiz-Marcos, I., Ballesteros-Sánchez, L. y Romero, J. (2018). The opportunity to improve psychological competences of project managers in international business. Pyschology and Marketing 35, 150-159. https://doi.org/10.1002/mar.21076.

Rodríguez-Rivero, R., Ortiz-Marcos, I. y Sierra-Castañer, M. (2017). Análisis de la trayectoria y obtención de lecciones aprendidas en los proyectos de cooperación internacional de la Universidad Politécnica de Madrid. Revista Española de Desarrollo y Cooperación 41, 109-119.

Romero Ruiz, J. J. (2017). Identificación de los elementos clave de la estrategia competitiva en el modelo de negocio aeroportuario en un contexto liberalizado de competencia internacional: aplicación al caso del Reino Unido. Tesis (Doctoral), E.T.S.I. Industriales (UPM). https://doi.org/10.20868/UPM.thesis.48224. 
Sachs, J. D. (2005). The end of poverty: Economic possibilities for our time. Penguin Books, Nueva York.

Sachs, W. (1992). The development dictionary: A guide to knowledge as power. Zed Books, Londres.

Sartorius, R. (1996). The third generation logical framework approach: Dynamic management for agricultural research projects. Journal of Agricultural Education and Extension 2(4), 49-62. https://doi.org/10.1080/13892249685300071.

Saunders, M. N. K. y Bezzina, F. (2015). Reflections on conceptions of research methodology among management academics. European Management Journal 33, 297-304. https://doi.org/10.1016/j.emj.2015.06.002.

Saunders, M., Lewis, P. y Thornhill, A. (2016). Research methods for business students, 7ạ Edición. Pearson, Harlow.

Schumaker, L., Brooks, A., Msiska, E., Pollard, E. y Potts, D. (2017). Situating the BRICS Phenomenon within the Histories and Cultures of Southern Africa. Journal of Southern African Studies 43(5), 853-861. https://doi.org/10.1080/03057070.2017.1365478.

Schwartz, S. H. (2014). National Culture as Value Orientations: Consequences of Value Differences and Cultural Distance. En: Capítulo 20 de Handbook of the Economics Art and Culture Vol. 2. https://doi.org/10.1016/B978-0-444-53776-8.00020-9.

Schneider, C. Q. y Wagemann, C. (2012). Set-theoretic methods for the social sciences: A guide to qualitative comparative analysis. Cambridge University Press, Cambridge.

Sekaran, U. y Bougie, R. (2016). Research methods for business: A skill building approach, 7ạ Edición. John Wiley \& Sons, Chichester.

Shaw, T. M., Cooper, A. F. y Chin, G. (2009). Emerging Powers in Africa: Implications for/from global governance. Politikon: South African Journal of Political Studies 36(1), 27-44. https://doi.org/10.1080/02589340903155385.

Shenhar, A. J. y Dvir, D. (2007). Reinventing Project Management: The Diamond Approach to Successful Growth and Innovation. Harvard Business School Press, Boston.

Shore, B. y Cross, B. J. (2005). Exploring the role of national culture in the management of large-scale international science projects. International Journal of Project Management 23(1), 55-64. https://doi.org/10.1016/j.ijproman.2004.05.009. 
Sluyts, K., Matthyssens, P., Martens, R. y Streukens, S. (2011). Building capabilities to manage strategic alliances. Industrial Marketing Management 40(6), 875-886. https://doi.org/10.1016/j.indmarman.2011.06.022.

Smith, S. M. y Albaum, G. S. (2005). Fundamentals of Marketing Research. SAGE, Thousand Oaks.

Soares de Lima, M. R., Milani, C. R. S. y Muñoz, E. E. (2016). Cooperación Sur-Sur, política exterior y modelos de desarrollo en América Latina. CLACSO, Buenos Aires.

Starmer, C. (2000). Developments in non-expected utility theory: The hunt for a descriptive theory of choice under risk. Journal of Economic Literature 38, 332-382. https//doi.org/10.1257/jel.38.2.332.

Steinford, P. y Walker, D.H.T. (2007). Critical success factors in project management globally and how they may be applied to aid projects. Proceedings of the PMOZ Achieving Excellence-4 ${ }^{\text {th }}$ Annual Project Management Australia Conference.

Sterling, M. (2008). Project management methodology for a post disaster reconstruction. PMI Global Congress 2008. Project Management Institute, Newtown Square, Pennsylvania.

Stirling, A. (2010). Keep It Complex. Nature 468, 1029-1031. https://doi.org/10.1038/4681029a.

Stirling, A. (2008). "Opening Up" and "Closing Down" Power, Participation, and Pluralism in the Social Appraisal Technology. Science, Technology \& Human Values 33(2), 262 294. https://doi.org/10.1177/0162243907311265.

Stirling, A. (1999). The appraisal of sustainability: some problems and possible responses. Local Environment 4(2), 111-135. https://doi.org/10.1080/13549839908725588.

Stirling, A. (1997). Muticriteria Mapping. [Online: consultado en abril de 2019 en https://www.multicriteriamapping.com/].

Svensson, J. (2003). Why conditional aid does not work and what can be done about it? Journal of Development Economies 70(2), 381-402. https://doi.org/10.1016/S03043878(02)00102-5.

Sword-Daniels, V., Eriksen, C., Hudson-Doyle, E. E., Alaniz, R., Adler, C., Schenk, T. y Vallance, S. (2018). Embodied uncertainty: living with complexity and natural hazards. Journal of Risk Research 21(3), 290-307. https://doi.org/10.1080/13669877.2016.1200659. 
Syrett, M. y Devine, M. (2012). Managing Uncertainty. Strategies for surviving and thriving in turbulent times. Profile Books Ltd., Londres.

Trompenaars, F. y Hampden-Turner, C. (2011). Riding the waves of culture: Understanding diversity in global business, $3^{\text {era }}$ Edición. Nicholas Brealey International.

Vidal, L. A. y Marle, F. (2008). Understanding project complexity: implications on project $\begin{array}{lll}\text { management. Kybernetes } & \text { 37(8), }\end{array}$ https://doi.org/10.1108/03684920810884928.

Vogel, I. (2012). Review of the use of "Theory of Change" in international development. United Kingdom Department for International Development (DFID), Londres.

Wakker, P. P. (2010). Prospect theory for risk and ambiguity. Cambridge University Press, Cambridge.

Walliman, N. (2017). Research Methods: The basis, 2a Edición. Routledge, Londres.

Wang, S. Q., Dulaimi, M. F. y Aguria, M. Y. (2004). Risk management framework for construction projects in developing countries. Construction Management and Economics 22(3), 237-252. https://doi.org/10.1080/0144619032000124689.

Ward, S. y Chapman, C. (2003). Transforming Project Risk Management into Project Uncertainty Management. International Journal of Project Management 21, 97-105. https://doi.org/10.1016/S0263-7863(01)00080-1.

Ward, S. y Chapman, C. (2008). Stakeholders and uncertainty management in projects. Construction Management and Economics 26, 563-577. https://doi.org/10.1080/01446190801998708.

Wendling, C. (2014). Incorporating Social Sciences in Public Risk Assessment and Risk Management Organisations. European Journal of Risk Regulation 5(1), 7-13. https://doi.org/10.1017/S1867299X00002907.

Westerveld, E. (2003). The Project Excellence Model ${ }^{\circledR}$ : linking succes criteria and critical sucess factors. International Journal of Project Management 21, 411-418. https://doi.org/10.1016/S0263-7863(02)00112-6.

Wherry, R. J. (1984). Contributions to Correlational Analysis. Academic Press, Columbus.

Wirick, D. (2009). Public-Sector Project Management: Meeting the Challenges and Achieving Results. John Wiley \& Sons Publishing, Hboken. 
Yalegama, S., Chileshe, N. y Ma, T. (2016). Critical success factors for community-driven development projects: A Sri Lankan community perspective. International Journal of Project Management 34, 643-659. https://doi.org/10.1016/j.ijproman.2016.02.006.

Yamaswari, I. A. C., Kazbekov, J., Lautze, J. y Wegerich, K. (2016). Sleeping with the enemy? Capturing internal risks in the logical framework of a water management project. International Journal of Water Resources Development 32(1), 116-134. https://doi.org/10.1080/07900627.2015.1058766.

Yin, R. K. (2014). Case study research: Design and methods, 5a Edición. SAGE, Thousand Oaks.

Youker, R. (2003). The nature of international development projects. In PMI Conference, Baltimore, September 21, 2003.

Youker, R. (1999). Managing international development projects-lessons learned. Project Management Journal 30(2), 6-7.

Yu, H. K., Huang, M. C. y Huarng, K. H. (2016). Causal complexity of economic development by energy consumption. Journal of Business Research 69(6), 2271-2276. https://doi.org/10.1016/j.jbusres.2015.12.041.

Zadeh, L. A. (1965). Fuzzy sets. Information and Control 8(3), 338-353.

Zelenev, S. (2017). Translating the 2030 Agenda for Sustainable Development into local circumstances: principles and trade-offs. International Social Work 60(6), 1652-1655. https://doi.org/10.1177/0020872817739541.

Ziai, A. (2017). 'I am not a Post-Developmentalist, but...'The influence of PostDevelopment on development studies. Third World Quarterly 38(12), 2719-2734. https://doi.org/10.1080/01436597.2017.1328981.

Zou, P. X. W., Zhang, G. y Wang, J. (2007). Understanding the Key Risks in Construction Projects in China. International Journal of Project Management 25(6), 601-614. https://doi.org/10.1016/j.ijproman.2007.03.001.

Zwikael, O. y Ahn, M. (2011). The Effectiveness of Risk Management: An Analysis of Project Risk Planning across Industries and Countries. Risk Analysis 31(1), 25-37. https://doi.org/10.1111/j.1539-6924.2010.01470.x. 


\section{ANEXOS}

- Anexo I: Plantilla de la Matriz del Marco Lógico para solicitud de financiación de proyectos por parte de la Comisión Europea.

- Anexo II: Cuestionario de evaluación de riesgos PCD en la UPM.

- Anexo III: Cuestionario Marco Lógico.

- Anexo IV: Cuestionario Riesgos y Éxito.

- Anexo V: Estructura entrevista directores/as PCD caso de estudio.

- Anexo VI: Tablas de verdad proporcionadas por el programa FsQCA 3.0.

- Anexo VII: Soluciones complejas proporcionadas por el programa FsQCA 3.0. 


\section{Anexo I: Plantilla de la Matriz del Marco Lógico para solicitud de proyectos europeos}

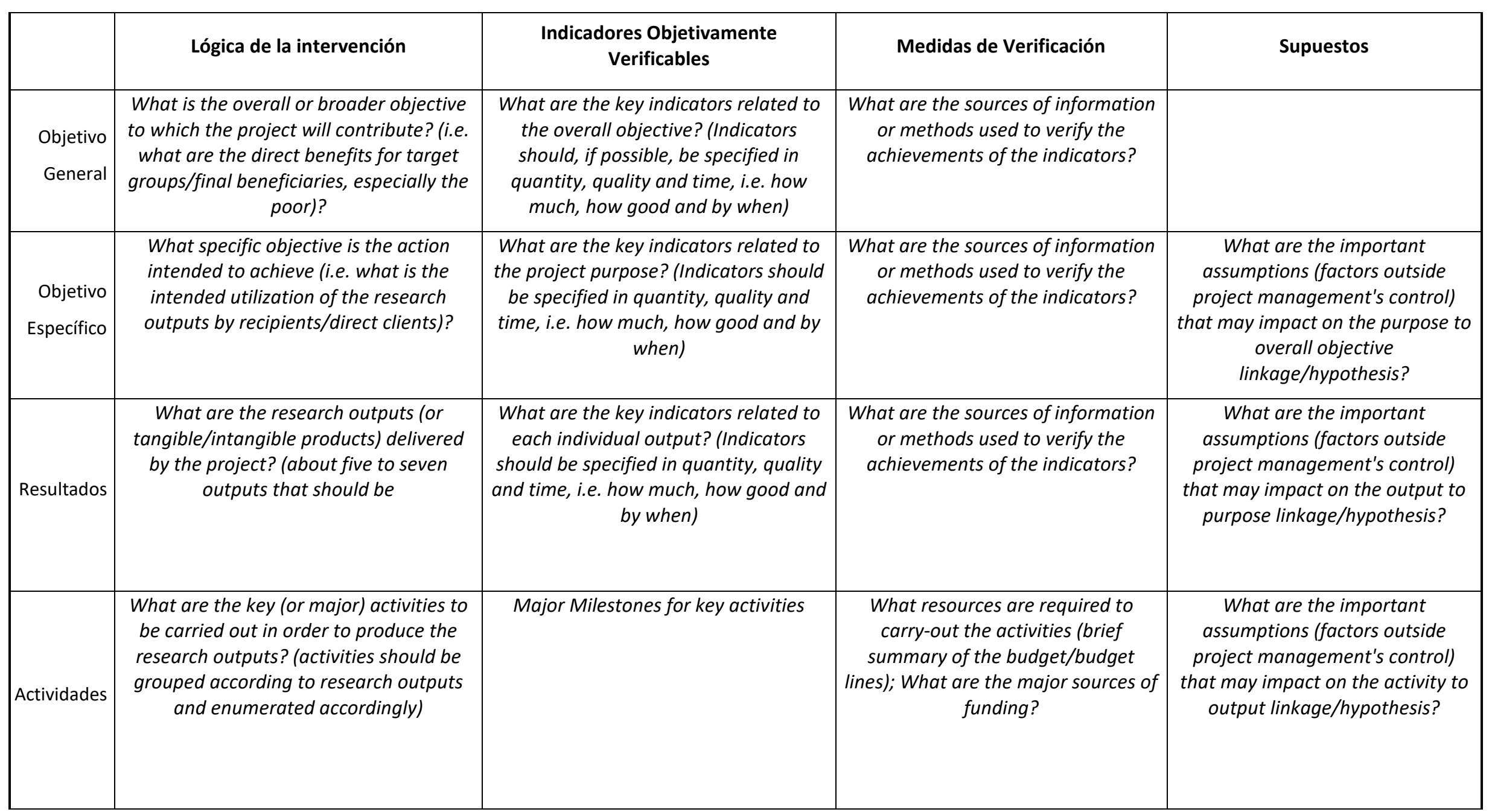


Anexo II: Cuestionario de evaluación de riesgos en los PCD de la UPM

Información General

Nombre:

Género:

Número de proyectos de cooperación al desarrollo en los que ha colaborado en esta convocatoria:

Número de proyectos de cooperación al desarrollo que ha dirigido en esta convocatoria:

Escoja el proyecto que ha dirigido de entre los presentados en el desplegable

En el caso de que haya dirigido más de un proyecto, por favor, rellene esta encuesta tatas veces como proyectos haya dirigido.

En el proyecto que dirigió, ¿̇se realizó un análisis previo de riesgos?

Sí $\square \quad$ No $\square$

¿Cuál fue la duración del proyecto?

0-12 meses $\square \quad 12-18$ meses $\square \quad$ Más de 18 meses

¿En qué zona geográfica se ha desarrollado el proyecto?

África del Norte $\square \quad$ África Subsahariana $\square \quad$ América del Sur

América Central, México y el Caribe $\square \quad$ Asia $\square \quad$ España

Evalúa el impacto y la frecuencia de los siguientes riesgos según la zona geográfica

Siendo 1 ningún impacto (en términos de impacto) y nada frecuente (en términos de probabilidad). Siendo 5 muy alto impacto y muy frecuente, en términos de impacto y probabilidad, respectivamente.

- Las personas beneficiarias del proyecto no expresan su opinión al equipo del proyecto

Probabilidad $1 \square 2 \square 3 \square 4 \square 5 \square \quad$ Impacto $1 \square 2 \square 3 \square 4 \square 5 \square$

- Falta de entendimiento por no hablar el mismo idioma

Probabilidad $\quad 1 \square 2 \square 3 \square 4 \square 5 \square \quad$ Impacto $1 \square 2 \square 3 \square 4 \square 5 \square$

- Corrupción del estado y falta de implicación de los líderes locales

Probabilidad $\quad 1 \square 2 \square 3 \square 4 \square 5 \square \quad$ Impacto $\quad 1 \square \quad 2 \square \quad 3 \square \quad 4 \square 5 \square$ 
- Inestabilidad política y existencia de revueltas sociales

Probabilidad $1 \square 2 \square 3 \square 4 \square 5 \square \quad$ Impacto $1 \square 2 \square 3 \square 4 \square 5 \square$

- Desastres naturales y climatología adversa

Probabilidad $1 \square 2 \square 3 \square 4 \square 5 \square \quad$ Impacto $\quad 1 \square \quad 2 \square 3 \square 4 \square 5 \square$

- Conflictos entre grupos de interés o con las indefiniciones de alcance del proyecto

Probabilidad $\quad 1 \square 2 \square 3 \square 4 \square 5 \square \quad$ Impacto $1 \square 2 \square 3 \square 4 \square 5 \square$

- Falta de orientación a largo plazo por la comunidad beneficiaria

Probabilidad $\quad 1 \square 2 \square 3 \square 4 \square 5 \square \quad$ Impacto $\quad 1 \square 2 \square 3 \square 4 \square 5 \square$

- Falta de formación por parte de la mano de obra local o de las personas enviadas para la ejecución del proyecto

Probabilidad $1 \square 2 \square 3 \square 4 \square 5 \square \quad$ Impacto $\quad 1 \square 2 \square 3 \square 4 \square 5 \square$

- Escasez de mano de obra local joven

Probabilidad $\quad 1 \square 2 \square 3 \square 4 \square 5 \square \quad$ Impacto $\quad 1 \square 2 \square \quad 3 \square 4 \square 5 \square$

- Problemas de suministro eléctrico o de conexión a internet

Probabilidad $1 \square 2 \square 3 \square 4 \square 5 \square \quad$ Impacto $1 \square 2 \square 3 \square 4 \square 5 \square$

- Dificultades en el transporte por bloqueo o mal estado de las vías de comunicación

Probabilidad $\quad 1 \square 2 \square 3 \square 4 \square 5 \square \quad$ Impacto $\quad 1 \square \quad 2 \square \quad 3 \square 4 \square \quad 5 \square$

- Variaciones en el coste total del proyecto por fluctuaciones en la moneda

Probabilidad $\quad 1 \square 2 \square 3 \square 4 \square 5 \square \quad$ Impacto $\quad 1 \square 2 \square 3 \square 4 \square 5 \square$

- Escepticismo ante el proyecto por parte de la comunidad beneficiaria

Probabilidad $1 \square 2 \square 3 \square 4 \square 5 \square \quad$ Impacto $\quad 1 \square 2 \square 3 \square 4 \square 5 \square$

¿A qué sector pertenece el proyecto que ha desarrollado?

Agricultura $\square$ Agua y saneamiento $\square \quad$ Construcción $\square \quad$ Energía $\square \quad$ Formación $\square$

Ganadería $\square \quad$ Integración $\otimes \quad$ Medio Ambiente $\square \quad$ Salud $\square \quad$ TICs

Evalúa el impacto y la frecuencia de los siguientes riesgos según el sector

Siendo 1 ningún impacto (en términos de impacto) y nada frecuente (en términos de probabilidad). Siendo 5 muy alto impacto y muy frecuente, en términos de impacto y probabilidad, respectivamente. 
- Falta de infraestructura, equipamiento o manuales de operación necesarios

Probabilidad $\quad 1 \square 2 \square 3 \square 4 \square 5 \square \quad$ Impacto $\quad 1 \square \quad 2 \square \quad 3 \square 4 \square 5 \square$

- Mala programación de las etapas del proyecto y falta de capacidad de reacción

Probabilidad $\quad 1 \square 2 \square 3 \square 4 \square 5 \square \quad$ Impacto $\quad 1 \square 2 \square 3 \square 4 \square 5 \square$

- Incidencia de plagas y enfermedades

Probabilidad $1 \square 2 \square 3 \square 4 \square 5 \square \quad$ Impacto $1 \square \quad 2 \square \quad 3 \square 4 \square 5 \square$

- Mala calidad del servicio del agua o mala disponibilidad del agua

Probabilidad $1 \square 2 \square 3 \square 4 \square 5 \square \quad$ Impacto $\quad 1 \square 2 \square \quad 3 \square 4 \square 5 \square$

- Falta de conocimiento sobre los temas de interés de la Comunidad para programas de formación

Probabilidad $\quad 1 \square 2 \square 3 \square 4 \square 5 \square \quad$ Impacto $\quad 1 \square 2 \square 3 \square 4 \square 5 \square$

- Falta de indicadores para evaluar la conducta y el progreso durante el proceso formativo Probabilidad $\quad 1 \square 2 \square 3 \square 4 \square 5 \square \quad$ Impacto $\quad 1 \square \quad 2 \square \quad 3 \square \quad 4 \square 5 \square$

- Inclemencias meteorológicas

Probabilidad $\quad 1 \square 2 \square 3 \square 4 \square 5 \square \quad$ Impacto $1 \square 2 \square 3 \square 4 \square 5 \square$

- Cambios legislativos y falta de apoyo de las instituciones locales

Probabilidad $\quad 1 \square 2 \square 3 \square 4 \square 5 \square \quad$ Impacto $\quad 1 \square 2 \square 3 \square 4 \square 5 \square$

- Mal acceso a la comunidad beneficiaria

Probabilidad $\quad 1 \square 2 \square 3 \square 4 \square 5 \square \quad$ Impacto $\quad 1 \square 2 \square \quad 3 \square 4 \square 5 \square$

- Alto coste de mantenimiento y operación de la nueva tecnología

Probabilidad $1 \square 2 \square 3 \square 4 \square 5 \square \quad$ Impacto $1 \square 2 \square \quad 3 \square 4 \square 5 \square$

- Dificultades en el aprendizaje sin la guía de una persona física y dificultades con la lengua inglesa de manuales y programas

Probabilidad $\quad 1 \square 2 \square 3 \square 4 \square 5 \square \quad$ Impacto $\quad 1 \square 2 \square 3 \square 4 \square 5 \square$ 


\section{Anexo III: Cuestionario Marco Lógico}

\section{Cuestionario sobre cómo mejorar el Marco Lógico}

Esta investigación está hecha en el contexto de una tesis doctoral sobre la gestión de riesgos en los proyectos de cooperación al desarrollo. El objetivo principal de la tesis es contribuir a la mejora de la eficiencia de estos proyectos tan particulares, para que tengan el mayor impacto positivo posible en las comunidades más vulnerables. Atendiendo a que el Marco Lógico es la herramienta más utilizada en los proyectos de cooperación desde hace décadas, esta encuesta busca identificar sus fortalezas y sus debilidades. La encuesta va dirigida a profesionales del área de la cooperación al desarrollo que traten con la búsqueda de financiación, la planificación o la ejecución de los proyectos de cooperación al desarrollo.

Se agradece de antemano la colaboración.

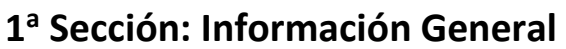

Las siguientes cuatro preguntas tienen el objetivo de ofrecer una información general sobre su organización

País:

España Colombia

Tipo de organización:

ONGD $\square$ Universidad $\square \quad$ Agencia de Coop. $\square \quad$ Admon. Pública $\square$ Otra:

Número de empleados:

Menos de $10 \square \quad$ Entre 10 y $50 \square \quad$ Entre 50 y $100 \square \quad$ Entre 100 y $200 \square \quad$ Más de 200

Número de proyectos al año:

Menos de $5 \square \quad$ Entre 5 y $10 \square \quad$ Entre 10 y $500 \square \quad$ Más de 50

\section{$2^{\text {a }}$ Sección: Información sobre su experiencia profesional}

Las siguientes cuatro cuestiones ofrecen información sobre su experiencia profesional en el ámbito de los proyectos de cooperación al desarrollo

№ de proyectos en los que ha participado en los últimos cinco años:
Menos de 5
Entre 5 y 10
Más de 10 
Lugar donde se ejecutaron esos proyectos:

$\begin{array}{lll}\text { Europa } \square & \text { Norte de África } \square & \text { África sub-sahariana } \\ \text { América del Sur } \square & \text { América Central y Caribe } \square & \text { Asia } \square\end{array}$

Duración media de esos proyectos:

Menos de 6 meses $\square \quad$ Entre 6 meses y 1 año $\square \quad$ Entre 1 año y 3 años $\square \quad$ Más de 3 años

Presupuesto medio de esos proyectos:

Menos de $100.000 € \square$ Entre 100.000 y $200.000 € \square$ Entre 200.000 y $500.000 € \square$ Más $500.000 € \square$

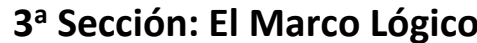

La siguiente sección comprende el bloque principal de preguntas de esta investigación y está dirigida a conocer el uso del Marco Lógico

Preguntas generales sobre el uso del Marco Lógico:

A continuación, puede ver la versión tradicional de la matriz del marco lógico o matriz de planificación, con la casilla adicional de precondiciones.
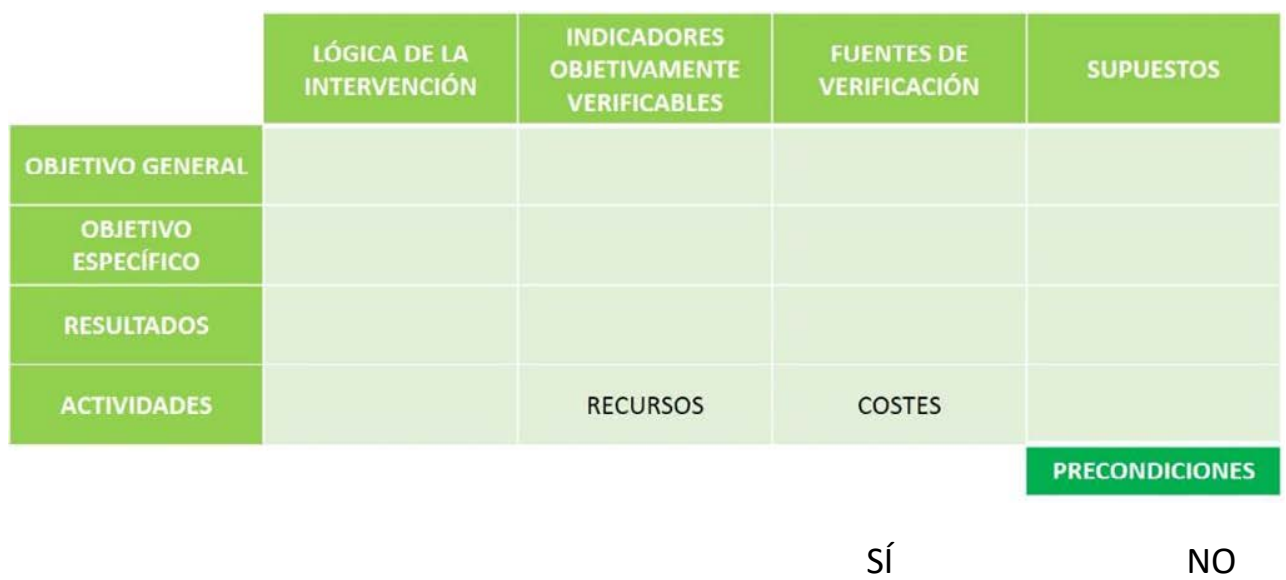

Utiliza el ML en sus proyectos

Utiliza la Matriz tradicional del ML

Utiliza la casilla adicional de precondiciones

Si no utiliza la matriz tradicional ¿qué fila o columna añade o elimina? 
Cuáles de los siguientes pasos del proceso del Marco Lógico utiliza:

Análisis de los participantes

Análisis de los problemas

Análisis de las soluciones

Análisis de las alternativas

Matriz del Marco Lógico

Ninguno

Indique su grado de conformidad con las siguientes afirmaciones sobre el Marco Lógico:

1: Totalmente en desacuerdo

2: En desacuerdo

3: De acuerdo

4: Completamente de acuerdo

5: NS/ NC

\section{El Maro Lógico es...}

...una metodología rígida

...usa una terminología confusa

...tiene escasa relación con el éxito del proyecto

...no tiene integración con otras herramientas de DP

...proporciona una visión completa del proyecto

...es imprescindible a la hora de solicitar subvenciones

...no es solo útil en las fases de planificación y ejecución, sino también en las fases de monitorización y evaluación

...considera la incertidumbre y los riesgos de una manera adecuada en la columna de Supuestos

\begin{tabular}{lcc}
\hline ...debería cambiar la columna de Supuestos por la de Riesgos & $1 \square \quad 2 \square \quad 3 \square$ \\
\hline ...debería integrar la gestión de riesgos en todo el proceso & $1 \square$ & $5 \square$ \\
\hline ...debería añadir la columna de Costes y Beneficios, para & $1 \square \quad 3 \square$ \\
rellenarla según se vaya disponiendo de la información
\end{tabular}

Grado de conformidad

$1 \square 2 \square 3 \square 4 \square 5 \square$

$1 \square 2 \square 3 \square 4 \square 5 \square$

$1 \square 2 \square 3 \square 4 \square 5 \square$

\begin{tabular}{ll}
\hline ...debería incluir la dimensión del tiempo & $1 \square 2 \square \quad 3 \square 4 \square 5 \square$ \\
\hline ...debería definir mejor los Indicadores y las Fuentes de & $1 \square \quad 2 \square \quad 3 \square \quad 4 \square 5 \square$
\end{tabular}
Verificación

...debería enfocarse únicamente en la parte manejable del $\quad 1 \square 2 \square \quad 3 \square 4 \square 5 \square$ proyecto (actividades y resultados)

...necesita ser mejorado

$1 \square 2 \square \quad 3 \square 4 \square \quad 5 \square$

En su opinión ¿qué podría ser mejorado en el Marco Lógico?

Si está interesado/a en participar en futuras reuniones sobre el Marco Lógico, añada su correo electrónico: 


\section{Anexo IV: Cuestionario Riesgos y Éxito para los proyectos del Cauca}

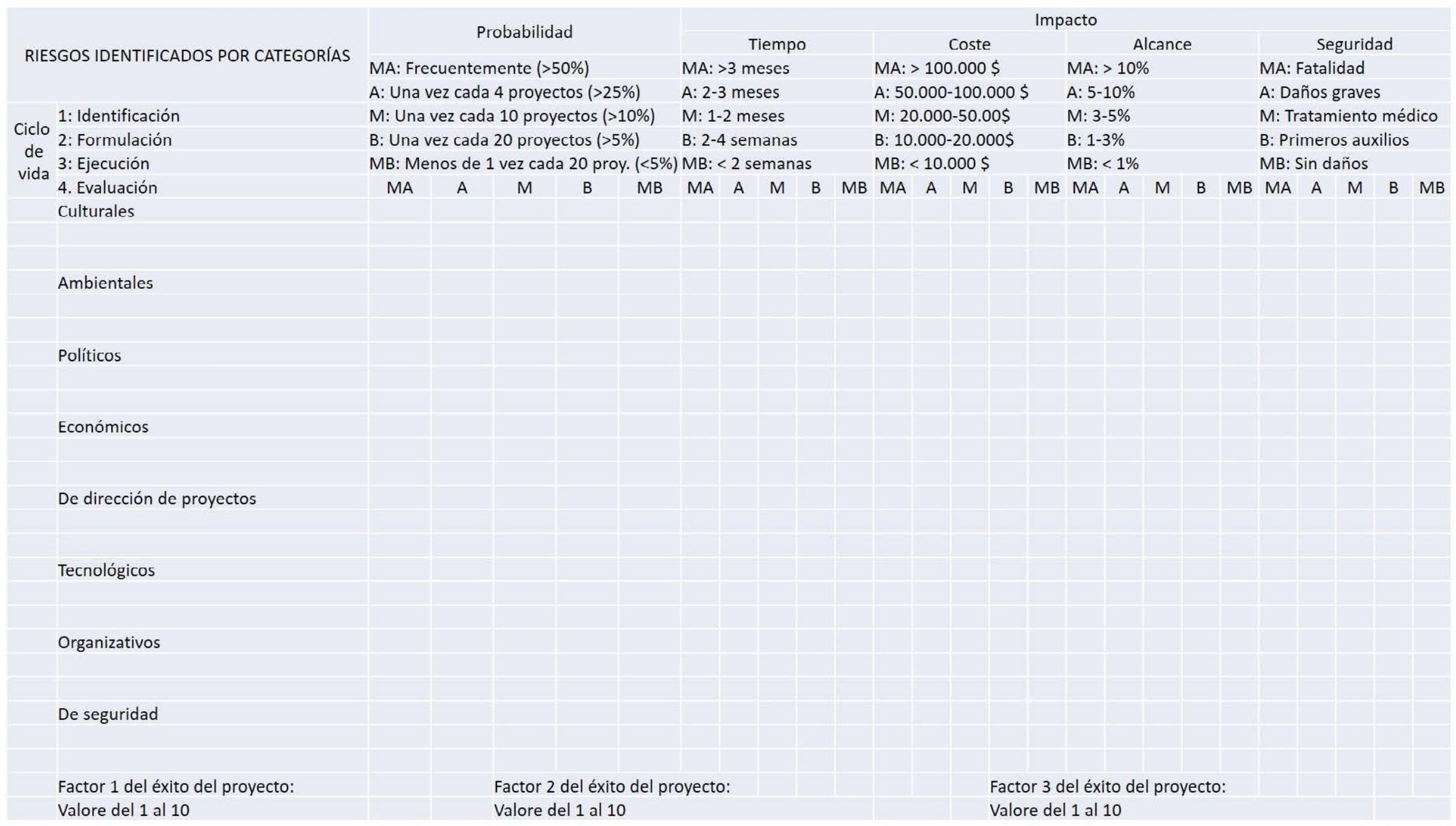




\section{Anexo V: Estructura entrevista directores/as PCD Cauca}

\section{Caracterización}

Nombre:

Institución y cargo:

Años de experiencia en proyectos de cooperación al desarrollo:

Años de experiencia en la dirección de proyectos:

Números de proyectos dirigidos hasta la fecha:

Número de personas que integraban el equipo del proyecto:

Durante la etapa de formulación y ejecución del proyecto

- ¿Cuál fue el objetivo prioritario en este proyecto: alcance, coste, cronograma o seguridad?

- ¿Cuáles fueron las principales dificultades que se encontró en la dirección del proyecto? ¿cómo las afrontó?

- ¿Había metodología establecida de gestión de riesgos? En caso afirmativo ¿en qué consistía?

- ¿Se encontró con más riesgos de los identificados previamente? ¿cómo respondieron ante ellos?

- ¿Está de acuerdo con los resultados obtenidos tras el taller de riesgos? ¿le ha sorprendido algo?

- ¿Cuáles fueron en su opinión los tres riesgos que más afectaron al proyecto y en qué medida? (retrasos, aumento de coste...) ¿cómo los priorizaría? ¿en qué categoría incluiría estos riesgos?

- ¿El proyecto contaba con una partida para imprevistos?

- ¿Los factores asociados a la cultura han sido importantes en este proyecto? ¿se consideraron?

Una vez puesto en marcha el proyecto

- Si hoy tuviera que volver a iniciar el proyecto ¿qué haría diferente y por qué? ¿cambiaría alguna de las herramientas/métodos utilizados? ¿por qué?

- ¿Qué ha aprendido con este proyecto?

- ¿Considera que se han alcanzado los niveles de éxito deseados del proyecto? ¿en qué sentido? (dirección del proyecto/impacto)

- ¿Se han cumplido los objetivos del proyecto? ¿cuáles? 
- ¿Cuánto tiempo ha pasado desde que el proyecto terminó? Y hoy, ¿cree que ha impactado en la población objetivo de la manera esperada?

- ¿Desearía volver a dirigir otro proyecto parecido? ¿por qué? 
INDUSTRIALES

ETSII IUPM

\section{Anexo VI: Tablas de verdad proporcionadas por el programa FsQCA 3.0}

\section{Impacto:}

\begin{tabular}{|c|c|c|c|c|c|c|c|c|c|c|c|c|c|c|}
\hline \multicolumn{15}{|c|}{$\begin{array}{l}\text { II Edit Truth Table } \\
\text { File Edit }\end{array}$} \\
\hline CUL & AMB & POL & ECO & \multirow[t]{2}{*}{ DPR } & \multirow[t]{2}{*}{ TEC } & \multirow[t]{2}{*}{ ORG } & \multirow[t]{2}{*}{ SEG } & \multirow[t]{2}{*}{ number } & \multirow[t]{2}{*}{ Impacto } & cases & \multirow{2}{*}{$\begin{array}{l}\text { raw consist. } \\
1\end{array}$} & \multirow{2}{*}{$\begin{array}{l}\text { PRI consist. } \\
\\
\\
\end{array}$} & \multirow{2}{*}{\multicolumn{2}{|c|}{$\begin{array}{l}\text { SYM consist }_{1} \\
1\end{array}$}} \\
\hline 0 & 0 & 1 & 0 & & & & & & & cases & & & & \\
\hline 0 & 0 & 1 & 0 & 0 & 0 & 1 & 0 & 1 & & cases & 0.984615 & 0.944444 & 0.944445 & \\
\hline 0 & 1 & 1 & 1 & 0 & 0 & 1 & 0 & 1 & & cases & 0.984127 & 0.933333 & 0.933333 & \\
\hline 1 & 0 & 1 & 0 & 0 & 0 & 1 & 1 & 1 & & cases & 0.983871 & 0.923077 & 0.923077 & \\
\hline 1 & 1 & 1 & 0 & 1 & 1 & 1 & 1 & 1 & & cases & 0.97561 & 0.894737 & 0.894737 & \\
\hline 1 & 0 & 0 & 0 & 0 & 1 & 1 & 1 & 1 & & cases & 0.971429 & 0.882353 & 0.882353 & \\
\hline 1 & 0 & 1 & 0 & 0 & 0 & 1 & 0 & 1 & & cases & 0.969231 & 0.875 & 0.875 & \\
\hline 1 & 0 & 1 & 1 & 1 & 0 & 0 & 1 & 1 & & cases & 0.967213 & 0.75 & 0.75 & \\
\hline 1 & 0 & 1 & 1 & 1 & 1 & 1 & 1 & 1 & & cases & 0.965116 & 0.82353 & 0.823529 & \\
\hline 1 & 1 & 0 & 1 & 1 & 1 & 1 & 1 & 1 & & cases & 0.962963 & 0.842105 & 0.842105 & \\
\hline 0 & 0 & 1 & 0 & 0 & 0 & 0 & 1 & 1 & & cases & 0.942308 & 0.571429 & 0.571429 & \\
\hline 1 & 1 & 1 & 1 & 0 & 0 & 1 & 0 & 1 & & cases & 0.941177 & 0.733334 & 0.733334 & \\
\hline 1 & 1 & 1 & 1 & 1 & 1 & 1 & 0 & 2 & & cases & 0.941176 & 0.772727 & 0.772727 & \\
\hline 0 & 1 & 1 & 1 & 1 & 1 & 0 & 1 & 1 & & cases & 0.939394 & 0.6 & 0.6 & \\
\hline 1 & 0 & 0 & 1 & 1 & 1 & 1 & 1 & 3 & & cases & 0.939024 & 0.772727 & 0.772727 & \\
\hline 1 & 1 & 1 & 0 & 1 & 1 & 1 & 0 & 1 & & cases & 0.9375 & 0.761905 & 0.761905 & \\
\hline 0 & 0 & 1 & 1 & 1 & 0 & 0 & 1 & 1 & & cases & 0.929824 & 0.5 & 0.5 & \\
\hline 1 & 0 & 0 & 1 & 1 & 0 & 0 & 0 & 1 & & cases & 0.923077 & 0.5 & 0.5 & \\
\hline 1 & 1 & 0 & 0 & 0 & 0 & 0 & 0 & 1 & & cases & 0.890909 & 0.4 & 0.4 & \\
\hline 1 & 1 & 1 & 1 & 1 & 1 & 1 & 1 & 9 & & cases & 0.829268 & 0.487805 & 0.526316 & \\
\hline \multicolumn{4}{|c|}{ Reset } & \multicolumn{4}{|c|}{ Cancel } & \multicolumn{3}{|c|}{ Specify Analysis } & \multicolumn{4}{|c|}{ Standard Analyses } \\
\hline
\end{tabular}




\section{Impacto:}

\begin{tabular}{|c|c|c|c|c|c|c|c|c|c|c|c|c|c|c|}
\hline \multicolumn{15}{|c|}{$\begin{array}{l}\text { Edit Truth Table } \\
\text { File Edit }\end{array}$} \\
\hline CUL & AMB & POL & ECO & DPR & TEC & ORG & SEG & \multirow[t]{2}{*}{ number } & \multirow[t]{2}{*}{$\sim$ Impacto } & cases & \multirow{2}{*}{$\begin{array}{l}\text { raw consist. } \\
0.929824\end{array}$} & \multirow{2}{*}{$\begin{array}{r}\text { PRI consist. } \\
0.5\end{array}$} & \multirow{2}{*}{\multicolumn{2}{|c|}{$\begin{array}{r}\text { SYM consist } \\
0.5\end{array}$}} \\
\hline 0 & 0 & 1 & 1 & 1 & 0 & 0 & 1 & & & cases & & & & \\
\hline 1 & 1 & 0 & 0 & 0 & 0 & 0 & 0 & 1 & & cases & 0.927273 & 0.6 & 0.6 & \\
\hline 1 & 0 & 0 & 1 & 1 & 0 & 0 & 0 & 1 & & cases & 0.923077 & 0.5 & 0.5 & \\
\hline 0 & 0 & 1 & 0 & 0 & 0 & 0 & 1 & 1 & & cases & 0.923077 & 0.428571 & 0.428571 & \\
\hline 0 & 1 & 1 & 1 & 1 & 1 & 0 & 1 & 1 & & cases & 0.909091 & 0.4 & 0.4 & \\
\hline 1 & 0 & 1 & 1 & 1 & 0 & 0 & 1 & 1 & & cases & 0.901639 & 0.25 & 0.25 & \\
\hline 1 & 1 & 1 & 1 & 0 & 0 & 1 & 0 & 1 & & cases & 0.838235 & 0.266667 & 0.266667 & \\
\hline 1 & 0 & 1 & 1 & 1 & 1 & 1 & 1 & 1 & & cases & 0.837209 & 0.176471 & 0.176471 & \\
\hline 1 & 1 & 1 & 1 & 1 & 1 & 1 & 1 & 9 & & cases & 0.813008 & 0.439024 & 0.473684 & \\
\hline 1 & 0 & 1 & 0 & 0 & 0 & 1 & 1 & 1 & & cases & 0.806452 & 0.076923 & 0.076923 & \\
\hline 1 & 1 & 0 & 1 & 1 & 1 & 1 & 1 & 1 & & cases & 0.802469 & 0.157895 & 0.157895 & \\
\hline 1 & 1 & 1 & 1 & 1 & 1 & 1 & 0 & 2 & & cases & 0.8 & 0.227273 & 0.227273 & \\
\hline 1 & 1 & 1 & 0 & 1 & 1 & 1 & 0 & 1 & & cases & 0.8 & 0.238095 & 0.238095 & \\
\hline 1 & 0 & 0 & 1 & 1 & 1 & 1 & 1 & 3 & & cases & 0.792683 & 0.227273 & 0.227273 & \\
\hline 1 & 1 & 1 & 0 & 1 & 1 & 1 & 1 & 1 & & cases & 0.792683 & 0.105263 & 0.105263 & \\
\hline 1 & 0 & 0 & 0 & 0 & 1 & 1 & 1 & 1 & & cases & 0.785714 & 0.117647 & 0.117647 & \\
\hline 1 & 0 & 1 & 0 & 0 & 0 & 1 & 0 & 1 & & cases & 0.784615 & 0.125 & 0.125 & \\
\hline 0 & 1 & 1 & 1 & 0 & 0 & 1 & 0 & 1 & & cases & 0.777778 & 0.0666666 & 0.0666666 & \\
\hline 0 & 0 & 1 & 0 & 0 & 1 & 1 & 1 & 1 & & cases & 0.761905 & 0 & 0 & \\
\hline 0 & 0 & 1 & 0 & 0 & 0 & 1 & 0 & 1 & & cases & 0.738461 & 0.0555553 & 0.0555553 & r \\
\hline \multicolumn{4}{|c|}{ Reset } & \multicolumn{4}{|c|}{ Cancel } & \multicolumn{3}{|c|}{ Specify Analysis } & \multicolumn{4}{|c|}{ Standard Analyses } \\
\hline
\end{tabular}


$\underset{\text { ETSII | UPM }}{\text { INDUSTRIALS }}$

\section{Dirección de proyectos:}

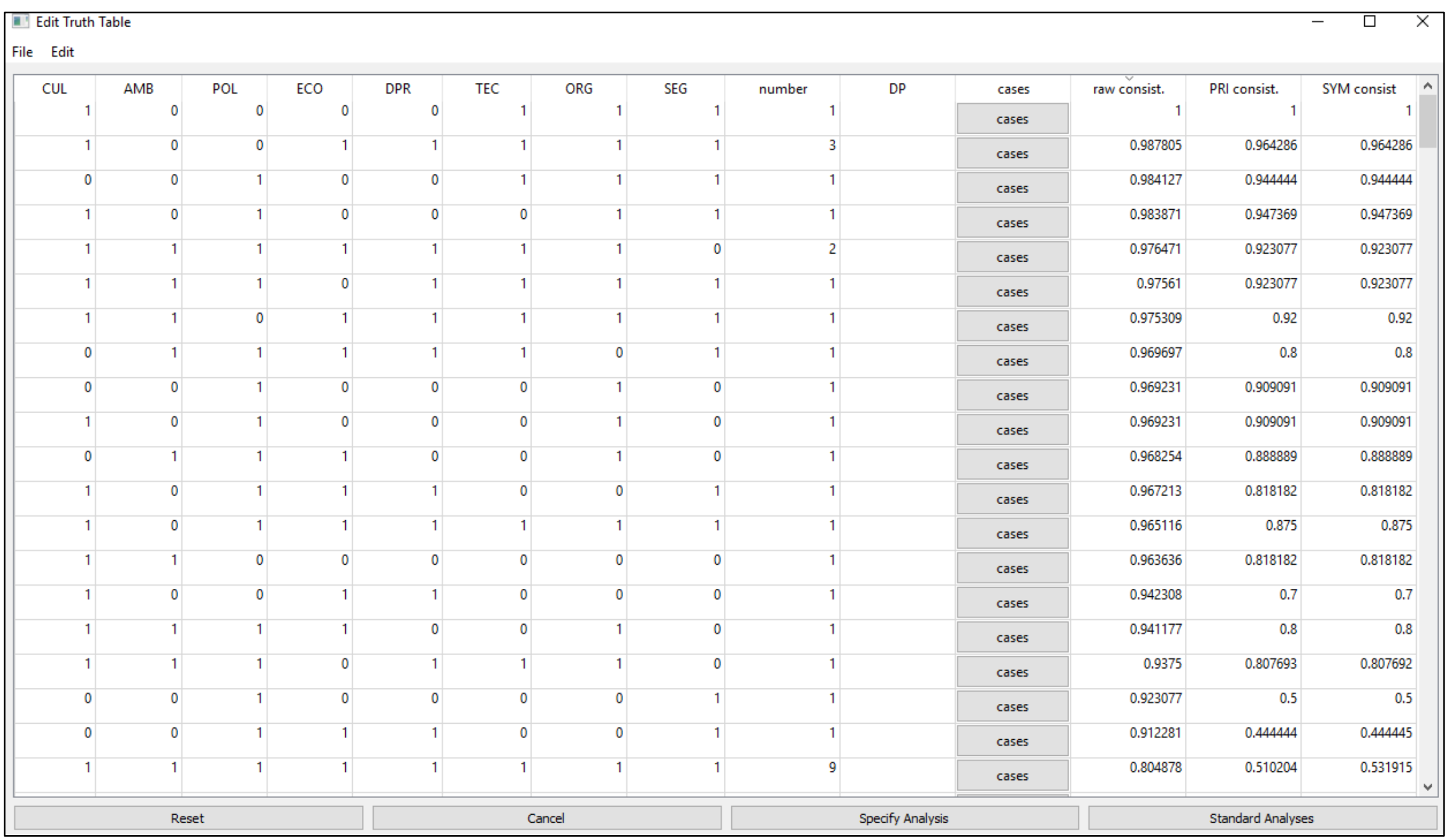




\section{〜Dirección de proyectos:}

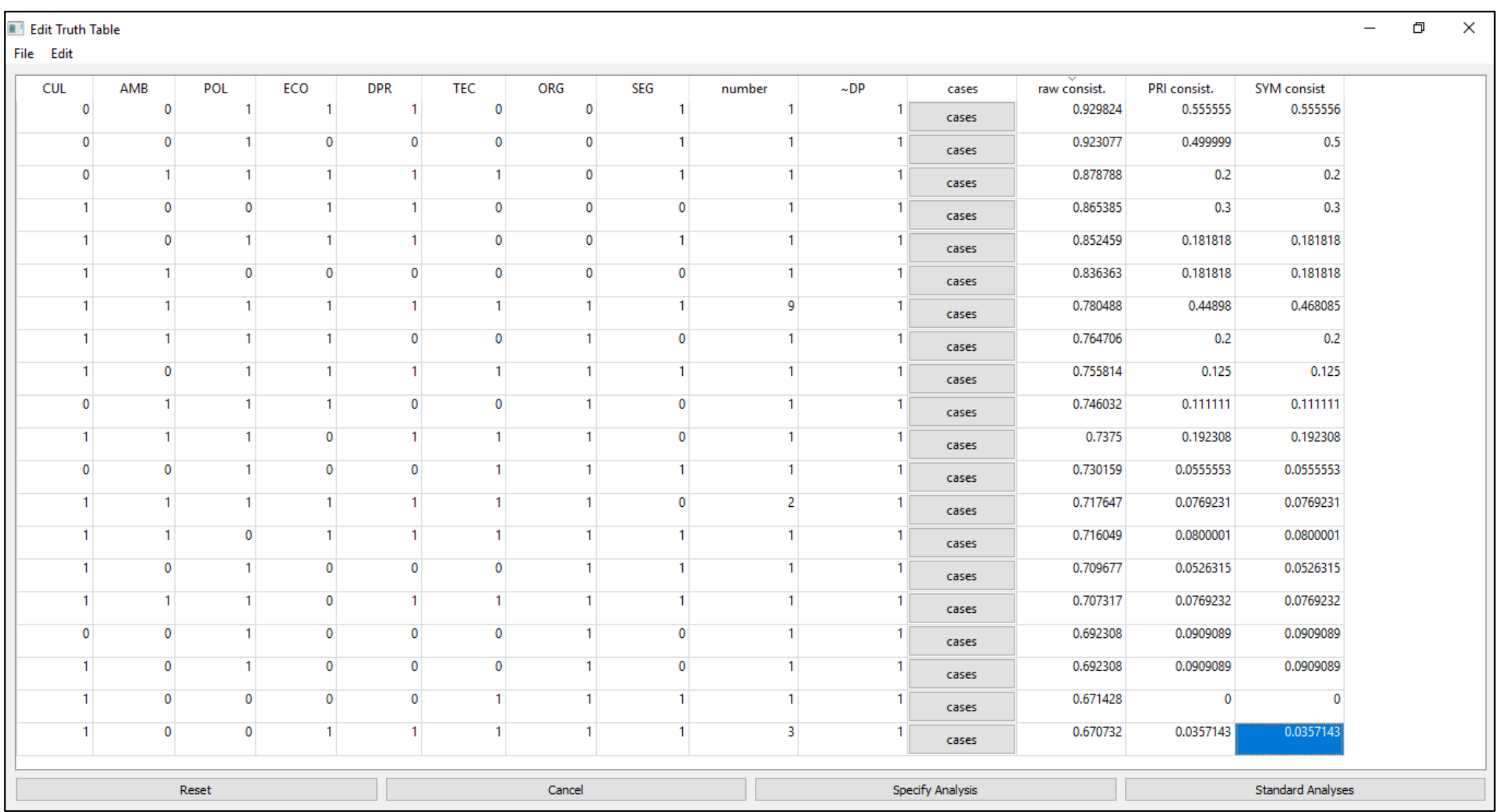


Anexo VII: Soluciones complejas proporcionadas por el programa FsQCA3.0

1. Solución compleja para el resultado Impacto:

\begin{tabular}{|c|c|c|c|}
\hline Solución & $\begin{array}{l}\text { Cobertur } \\
\text { a propia }\end{array}$ & $\begin{array}{l}\text { Cobertura } \\
\text { única }\end{array}$ & Consistencia \\
\hline$\sim \mathrm{AMB}^{*} \mathrm{POL}^{* \sim} \mathrm{ECO}^{* \sim} \mathrm{DPR}^{* \sim}$ TEC*ORG ${ }^{*}$ SEG & 0.419753 & 0.01851 & .971429 \\
\hline CUL* AMB*POL* ECO* DPR* TEC*ORG & 0.401234 & 0.012345 & 0.970149 \\
\hline$\sim \mathrm{CUL}^{*} \mathrm{AMB}^{*} \mathrm{POL}^{*} \mathrm{ECO} * \sim \mathrm{DPR}^{*} \sim \mathrm{TEC} * \mathrm{ORG} * \sim \mathrm{SEG}$ & 0.382716 & 0.01234 & 0.98412 \\
\hline CUL* AMB $^{* \sim P O L}{ }^{* \sim}$ ECO* DPR*TEC*ORG*SEG & 0.419753 & 0.030864 & 0.971429 \\
\hline$\sim \mathrm{CUL}^{* \sim}$ AMB*POL ${ }^{* \sim}$ ECO* DPR*TEC*ORG*SEG & 0.388889 & 0.012345 & 1 \\
\hline CUL* AMB*POL*ECO*DPR* TEC* ORG*SEG & 0.364197 & 0.018518 & 850.967 \\
\hline CUL*AMB*POL* ECO*DPR*TEC*ORG*SEG & 0.493827 & 0.037037 & 0.97561 \\
\hline CUL*AMB* POL*ECO*DPR*TEC*ORG*SEG & 0.481481 & 0.0308642 & 0.96296 \\
\hline CUL* AMB*POL*ECO*DPR*TEC*ORG*SEG & 0.512346 & 0.0308642 & 0.96511 \\
\hline $\begin{array}{l}\text { Cobertura: } 0.753086 \\
\text { Consistencia: } 0.945737\end{array}$ & & & \\
\hline
\end{tabular}

2. Solución compleja para el resultado Impacto:

\begin{tabular}{|c|c|c|c|}
\hline Solución & $\begin{array}{c}\text { Cobertura } \\
\text { propia }\end{array}$ & $\begin{array}{l}\text { Cobertura } \\
\text { única }\end{array}$ & Consistencia \\
\hline$\sim{ }^{\prime}$ AMB*POL*ECO*DPR* TEC* ORG*SEG & 0.391892 & 0.033783 & 0.90625 \\
\hline CUL*AMB* ${ }^{*} \mathrm{PL}^{* \sim} \mathrm{ECO}^{* \sim} \mathrm{DPR}^{* \sim}$ TEC ${ }^{*}$ ORG ${ }^{*}$ SEG & 0.344595 & 0.033783 & 0.927273 \\
\hline$\sim \mathrm{CUL}^{* \sim} \mathrm{AMB}^{*} \mathrm{POL}^{* \sim}$ ECO* DPR $* \sim$ TEC $* \sim O R G * S E G$ & 0.324324 & 0.020270 & 0.923077 \\
\hline $\mathrm{CUL}^{* \sim} \mathrm{AMB}^{* \sim} \mathrm{POL}^{*} \mathrm{ECO}^{*} \mathrm{DPR}{ }^{* \sim T E C}{ }^{*} \sim \mathrm{ORG}{ }^{*} \sim \mathrm{SEG}$ & 0.324324 & 0.020270 & 0.923077 \\
\hline CUL*AMB*POL*ECO*DPR*TEC* ORG*SEG & 0.405405 & 0.060810 & 0.909091 \\
\hline $\begin{array}{l}\text { Cobertura: } 0.540541 \\
\text { Consistencia: } 0.909091\end{array}$ & & & \\
\hline
\end{tabular}


3. Solución compleja para el resultado Dirección de proyectos:

\begin{tabular}{|c|c|c|c|}
\hline Solución & $\begin{array}{c}\text { Cobertura } \\
\text { propia }\end{array}$ & $\begin{array}{l}\text { Cobertura } \\
\text { única }\end{array}$ & Consistencia \\
\hline $\mathrm{POL}^{* \sim} \mathrm{AMB}^{* \sim} \mathrm{DPR}^{* \sim}$ ECO*ORG ${ }^{* \sim T E C} * \sim \mathrm{SEG}$ & 0.377778 & 0.0166667 & 0.971429 \\
\hline CUL*POL* AMB* DPR* ECO*ORG* TEC & 0.36111 & 0.0111111 & 0.970149 \\
\hline CUL* AMB*DPR*ECO*ORG*TEC*SEG & 0.516667 & 0.96875 & 0.96875 \\
\hline CUL* POL*DPR*ECO*ORG*TEC*SEG & 0.494444 & 0.978022 & 0.978022 \\
\hline CUL* POL ${ }^{*} \mathrm{AMB}^{* \sim} \mathrm{DPR}^{* \sim} \mathrm{ECO} * \sim \mathrm{ORG} \mathrm{F}^{* \sim}$ TEC $*$ SEG & 0.294444 & 0.016666 & 0.963636 \\
\hline$\sim$ CUL*POL*AMB* DPR*ECO*ORG* TEC ${ }^{*} \sim$ SEG & 0.33888 & 0.011111 & 0.968254 \\
\hline CUL* POL ${ }^{*} \sim \mathrm{AMB}^{*} \sim \mathrm{DPR}^{*} \sim \mathrm{ECO} * \mathrm{ORG}{ }^{*} \mathrm{TEC} * \mathrm{SEG}$ & 0.38888 & 0.016666 & 1 \\
\hline$\sim \mathrm{CUL}^{*} \mathrm{POL}{ }^{*} \sim \mathrm{AMB}^{*} \sim \mathrm{DPR}^{*}$ ECO*ORG*TEC*SEG & 0.34444 & 0.011111 & 0.984127 \\
\hline CUL*POL* AMB*DPR*ECO* ORG* TEC*SEG & 0.32777 & 0.016666 & 0.967213 \\
\hline CUL*POL*AMB*DPR*ECO* ORG*TEC*SEG & 0.355556 & 0.0166667 & 0.969697 \\
\hline CUL*POL*AMB*DPR*ECO*ORG*TEC* SEG & 0.461111 & 0.0277778 & 0.976471 \\
\hline CUL*POL*AMB*DPR* ECO*ORG*TEC*SEG & 0.444444 & 0.0166667 & 0.97561 \\
\hline
\end{tabular}

Cobertura: 0.777778

Consistencia: 0.958904

4. Solución compleja para el resultado Dirección de proyectos:

\begin{tabular}{|c|c|c|c|}
\hline Solución & $\begin{array}{c}\text { Cobertura } \\
\text { propia }\end{array}$ & $\begin{array}{c}\text { Cobertura } \\
\text { única }\end{array}$ & Consistencia \\
\hline AMB*POL*ECO*DPR* TEC* ORG*SEG & 0.423077 & 0.0384616 & 0.859375 \\
\hline CUL*AMB* POL ${ }^{* \sim}$ ECO* DPR ${ }^{* \sim}$ TEC ${ }^{*} \sim \mathrm{ORG}^{*} \sim \mathrm{SEG}$ & 0.353846 & 0.0230769 & 0.836363 \\
\hline 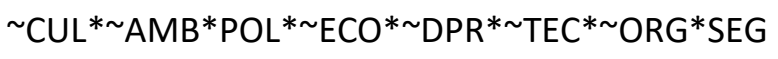 & 0.369231 & 0.0230769 & 0.923077 \\
\hline $\mathrm{CUL}^{* \sim} \mathrm{AMB}^{* \sim} \mathrm{POL}^{*} \mathrm{ECO}{ }^{*} \mathrm{DPR}^{* \sim}$ TEC $* \sim O R G * \sim S E G$ & 0.346154 & 0.023076 & 0.865385 \\
\hline CUL*AMB*POL*ECO*DPR*TEC* ORG*SEG & 0.446154 & 0.0538462 & 0.878788 \\
\hline
\end{tabular}

Cobertura: 0.561538

Consistencia: 0.829545 

